TESIS DOCTORAL

\title{
SÍNTESIS, CARACTERIZACIÓN Y PROPIEDADES CATALÍTICAS PARA LA OXIDACIÓN SELECTIVA DE PROPANO DE ÓXIDOS MIXTOS DE METALES DE TRANSICIÓN TIPO BRONCES
}

Realizada en:

INSTITUTO DE TECNOLOGÍA QUÍMICA (UPV-CSIC)

Presentada por:

SELENE HERNÁNDEZ MOREJUDO

Dirigida por:

Prof. JOSÉ MANUEL LÓPEZ NIETO

VALENCIA, JULIO 2012 



\section{Agradecimientos}

Con estas líneas quiero dar las gracias a todas las personas que me han acompañado durante estos cinco años, y que han colaborado en el desarrollo de esta tesis doctoral de un modo $\mathrm{u}$ otro.

En primer lugar, quiero expresar mi agradecimiento al director de este trabajo, Pof. José Manuel López Nieto, por la confianza depositada en mí desde el primer día, por sus enseñanzas y consejos, y por transmitirme la ilusión por la investigación.

A su vez, quiero agradecer a todas las personas que con su trabajo han colaborado en la consecución de esta tesis: Patricia Concepción, Benjamin Solsona, Esther García González, Teresa Blasco, Fernando Rey, José Luís Jordá.

Gracias al Instituto de Tecnología Química (UPV-CSIC) por permitirme llevar a cabo mi formación en el centro. A todo el personal investigador por tener siempre las puertas abiertas, en especial a Ximo y Cristina por su ayuda descubriendo el mundo de la cromatografía. A todo el personal de caracterización, al personal de informática y de taller, y al personal del departamento de microscopía de la UPV, por su inestimable ayuda sin la cual nada de esto habría sido posible.

Gracias a Jim Anderson por brindarme la oportunidad de realizar la estancia con su grupo de investigación en la University of Aberdeen (UK) y mostrarme el gran valor de las técnicas de caracterización. A todas las personas con las que trabajé y conocí en esos tres meses.

Además, quiero dar las gracias a mis compañeros y amigos del ITQ con los que he compartido momentos inolvidables, tanto dentro como fuera del ITQ. Gracias por hacer de cada día un día diferente.

A los miembros del grupo JM por todos los ratos pasados en el laboratorio, por su apoyo, consejo y crítica, y por su amistad. A Fran, gracias por enseñarme y por tus consejos. A Dolo, compañera desde la carrera hasta ahora con la que he compartido tantos momentos. A Amada, gracias por ayudarme en todo y estar ahí siempre que lo he necesitado. A Segundo, la última incorporación. A Stefania, Katerina y Souhila, con las que compartí poco tiempo, gracias por vuestra paciencia. Mención especial a Dolo y Amada sin cuya agilidad para los trámites administrativos esta tesis no hubiera salido adelante, imuchas gracias!

A les floretes del ITQ, que siempre están para lo bueno y para lo malo: Belén (Belénix) por ser tan buena amiga y confidente, Cris F. por las charlas y momentos compartidos, Elena por sus risas y despistes, Teresa G., por tantas cosas compartidas, Rebe por su risa contagiosa, Carlos (Carlinhos Brown) por las míticas barbacoas, Aarón por ser una más de las Maris, Estefanía por hacerme reír siempre, Ángel por sus consejos, Inés por ser la más xunga, Amparo M. (Amparito), Amparo F. por su paciencia con mis despistes. 
A Raquel (Rachel, la organizadora de viajes), Diego (Don Diego de Almagro), Yannick (el francés que sí es persona), Teresa P. (Rubia 0.0), David (Sr. Recalde), Santi, Tati (la internacional), Noemí, Yolanda, con los que he compartido tantos almuerzos, jueves de cañas, cenas, viajes y tantas risas que han alegrado mi estancia en el ITQ. ¡Siempre nos quedará el Jamón!

A mis compañeros de reacción: Eva Briz (Evita), Cris I., Aroa, Salva, Javi D. (es lo que hay), Imma, Rut (la responsable de broncas), Víctor (el maestro de los cromas), Roberto, Eva Y. (la dueña de Dali), Olga, Susi, María, Andrés, Johnny, Isi, Natalia, Gonzalo, Raúl. A la gente de la primera planta: Tania, Javi N., Victoria, Saray. Gracias por los ratos compartidos.

A mis compañeros del Máster de Química Sostenible (my sustainable friends): Xelo (nuestra madre), Sergio y Miguel (los contadores de chistes), Anita, Anna Mona, Héctor (nano, nano) y Karen, por todos los buenos momentos pasados en Castellón y Almagro.

A mis amigas, por estar ahí siempre que las necesito y por su interés por esta tesis aunque no entiendan nada. A Javi, por ser un buen amigo, por saber escuchar, y por venir a tantas cenas que ha llegado a ser uno más del ITQ.

A mi familia, por su esfuerzo y dedicación, sin vosotros nada de esto hubiera sido posible. A mi madre, por su apoyo incondicional. A mis tíos, Alfonso y Ernesto. A Manuel, por la confianza depositada en mí. A mis abuelos, a los que he perdido en estos años. Primero mi abuela, antes de empezar la tesis, $y$, hace poco más de un mes, mi abuelo (mi Lolo). Siempre os llevaré en mis pensamientos. 
A mis abuelos 



\section{Resumen}

La presente tesis doctoral muestra un estudio sobre la síntesis y caracterización de bronces basados en óxidos metálicos de Mo y $\mathrm{V}$, para ser empleados como catalizadores en la reacción de oxidación parcial de propano a ácido acrílico. La preparación de sólidos basados en óxidos mixtos MoVSb, MoVTe y MoVTeNb, se ha llevado a cabo mediante síntesis hidrotermal. Los materiales fueron finalmente activados térmicamente, en atmósfera inerte, para obtener catalizadores activos y selectivos en la oxidación parcial de propano. El estudio de las propiedades físicoquímicas de estos materiales (antes y después de la etapa de activación térmica) se ha llevado a cabo mediante el empleo combinado de diversas técnicas de caracterización: adsorción de $\mathrm{N}_{2}$, DRX, FTIR, Raman, microscopía electrónica (SEM/HREM), así como con la determinación de las características redox y/o ácidas superficiales (XPS, TPD- $\mathrm{NH}_{3}$, o la adsorción de moléculas sonda mediante espectroscopia infrarroja).

En primer lugar, se ha estudiado la incorporación de un metal promotor en la síntesis de óxidos mixtos MoVTeO. La incorporación de promotores en el gel de síntesis afecta a la distribución de fases cristalinas y al comportamiento catalítico de los materiales dependiendo de la naturaleza del metal incorporado. Únicamente en el caso de la incorporación de $\mathrm{Ca}$, Ga o $\mathrm{Nb}$ se ha observado una mejora en las propiedades catalíticas de los materiales. Especialmente, cabe destacar que, además del niobio (elemento promotor ya conocido), la incorporación de galio mejora sustancialmente la selectividad a ácido acrílico durante la oxidación de propano con estos materiales. Así, se han conseguido obtener catalizadores promovidos con galio con rendimientos catalíticos superiores a los obtenidos con los catalizadores ternarios de partida.

Posteriormente, se ha estudiado la influencia de los dos parámetros importantes en la síntesis de óxidos mixtos (MoVSbO, MoVTeO y MoVTeNbO): i) la temperatura de síntesis hidrotermal y ii) la temperatura de activación térmica de los materiales. La temperatura de síntesis hidrotermal afecta principalmente a la formación de las fases cristalinas presentes en los catalizadores activos y selectivos, mientras que la temperatura de activación térmica influye en las características redox y/o ácidas de la superficie del catalizador lo que tiene una gran influencia en las propiedades catalíticas de los materiales.

Finalmente, se ha realizado un estudio comparativo de la oxidación parcial de propano, propileno y metanol de materiales MoVSbO, MoVTeO y MoVTeNbO activados térmicamente a 500 (en general materiales muy activos pero poco selectivos) y $600^{\circ} \mathrm{C}$ (en general materiales activos y muy selectivos). Además, el estudio de caracterización superficial de los catalizadores activados térmicamente (a 500 ó $600^{\circ} \mathrm{C}$ ), ha permitido conocer la naturaleza de los centros activos y selectivos presentes en la superficie de los materiales más interesantes catalíticamente. Así, de la comparación de los resultados catalíticos y de caracterización se ha establecido una relación entre la modificación de las propiedades superficiales y las propiedades catalíticas en la oxidación parcial de propano a ácido acrílico de estos materiales. 



\section{Resum}

La present tesi doctoral mostra un estudi sobre la síntesi i caracterització de bronzes basats en òxids metàl-lics de Mo i V, per ser empleats com a catalitzadors en la reacció d'oxidació parcial de propà a àcid acrílic. La preparació de sòlids basats en òxids mixtes MoVSb, MoVTe i MoVTeNb, s'ha portat a terme per mitjà de la síntesi hidrotermal. Els materials van ser finalment activats tèrmicament, en atmosfera inert, per a obtenir catalitzadors actius i selectius per l'oxidació parcial de propà. L'estudi de les propietats fisico-químiques d'aquests materials (abans i després de l'etapa d'activació tèrmica) s'ha portat a terme per mitjà de l'ús combinat de diverses tècniques de caracterització: adsorció de N2, DRX, FTIR, Raman, microscòpia electrònica (SEM/HREM), així com amb la determinació de les característiques redox i/o àcides superficials (XPS, TPD-NH3, o l'adsorció de molècules sonda per mitjà de espectroscòpia infraroja).

En primer lloc, s'ha estudiat la incorporació d'un metall promotor en la síntesi d'òxids mixtos MoVTeO. La incorporació de promotors en el gel de síntesi afecta la distribució de fases cristal-lines i al comportament catalític dels materials depenent de la naturalesa del metall incorporat. Únicament en el cas de la incorporació de $\mathrm{Ca}, \mathrm{Ga}$ o Nb s'ha observat una millora en les propietats catalítiques dels materials. Especialment, cal destacar que, a més del niobi (element promotor ja conegut), la incorporació de gal-li millora substancialment la selectivitat a àcid acrílic durant l'oxidació de propà amb aquests materials. Així, s'ha aconseguit obtenir catalitzadors promoguts amb gal-li amb rendiments catalítics superiors als obtesos amb els catalitzadors ternaris de partida.

Posteriorment, s'ha estudiat la influència dels dos paràmetres importants en la síntesi d'òxids mixtos (MoVSbO, MoVTeO i MoVTeNbO): i) la temperatura de síntesi hidrotermal i ii) la temperatura d'activació tèrmica dels materials. La temperatura de síntesi hidrotermal afecta principalment a la formació de les fases cristal-lines presents en els catalitzadors actius i selectius, mentre que la temperatura d'activació tèrmica influeix en les característiques redox i/o àcides de la superfície del catalitzador, que té una gran influència en les propietats catalítiques dels materials.

Finalment, s'ha realitzat un estudi comparatiu de l'oxidació parcial de propà, propilè i metanol de materials MoVSbO, MoVTeO i MoVTeNbO activats tèrmicament a 500 (en general materials molt actius però poc selectius) i 600 ㄷ (en general materials actius i molt selectius). A més, l'estudi de caracterització superficial dels catalitzadors activats tèrmicament (a 500 ó $600^{\circ} \mathrm{C}$ ), ha permès conèixer la naturalesa dels centres actius i selectius presents en la superfície dels materials més interessants catalíticament. Així, de la comparació dels resultats catalítics i de caracterització s'ha establert una relació entre la modificació de les propietats superficials i les propietats catalítiques en l'oxidació parcial de propà a àcid acrílic d'aquests materials. 



\section{Abstract}

The present doctoral thesis presents a study on the synthesis and characterization of $\mathrm{V}$ - and Mo-containing mixed metal oxide bronzes to be used as catalysts in the partial oxidation of propane to acrylic acid. MoVSb, MoVTe and MoVTeNb mixed oxides have been prepared hydrothermally and, finally, heat-treated (in inert atmosphere) to obtain active and selective catalysts for the selective oxidation of propane. The physical and chemical characteristics of catalysts have been determined by using several spectroscopic techniques ( $\mathrm{N}_{2}$ adsorption, XRD, FTIR, Raman, electro microscopy (SEM/HREM), as well as the determination of surface redox and/or acid properties (XPS, $\mathrm{NH}_{3}$-TPD, or the adsorption of probe molecules by infrared spectroscopy).

First, the incorporation of a promoter metal in the synthesis of MoVTeO mixed oxides has been studied. In general, the incorporation of a promoter in the synthesis gel affects both the distribution of the crystalline phases and the catalytic properties of the materials depending on the metal incorporated. Only in the case of $\mathrm{Ca}-$, Ga- or Nb-promoted catalysts, an improvement in the catalytic properties of the materials has been observed. Especially, it should be noted that, in addition to niobium (promoter element already known), the incorporation of gallium improves the selectivity to acrylic acid during the oxidation of propane over these catalysts. Thus, yields of acrylic acid higher than those achieved over ternary metal oxides have been achieved with Ga-promoted catalysts.

Two important parameters on the preparation of these metal mixed oxides have been studied: i) the hydrothermal synthesis temperature; and ii) the catalysts activation temperature. The hydrothermal synthesis temperature mainly affects the M1 phase formation, while the catalysts activation temperature has an influence in the catalysts redox and/or acid surface properties and, thus, on the catalytic behavior of the materials.

Finally, a comparative study on the partial oxidation of propane, propylene and methanol over MoVSbO, MoVTeO and MoVTeNbO catalysts heat-treated at 500 (very active but less selective) and $600^{\circ} \mathrm{C}$ (active and very selective) is presented. In addition, the study of the surface characterization of heat-treated (at 500 or $600^{\circ} \mathrm{C}$ ) catalysts, allowed us to know the nature of the active and selective sites on the catalyst surface. Thus, the comparison of catalytic and characterization results has allowed us to establish the relationship between the modification of the surface properties and the catalytic properties in the partial oxidation of propane to acrylic acid over these materials. 



\section{Índice}

1. Introducción ................................................................................. 1

1.1. Oxidación catalítica selectiva ............................................................. 5

1.2. Las olefinas ligeras en la industria petroquímica ................................ 6

1.2.1. Procesos de obtención de olefinas ligeras ..................................... 8

1.2.2. Problemática del uso de olefinas ................................................... 9

1.3. Amoxidación y oxidación selectiva de propileno .............................. 11

1.3.1. Acrilonitrilo y ácido acrílico. Aplicaciones y producción. ................. 11

1.3.2. Catalizadores para la amoxidación/oxidación de propileno a

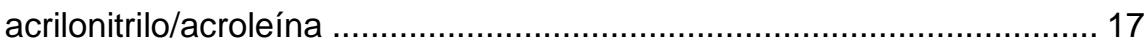

1.3.2.1. Catalizadores basados en molibdatos metálicos................. 20

1.3.2.2. Catalizadores basados en antimoniatos metálicos.............. 22

1.3.3. Catalizadores para la oxidación de acroleína a ácido acrílico ....... 24

1.3.4. Catalizadores para la oxidación de propileno a ácido acrílico en una

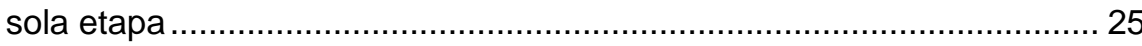

1.4. Hidrocarburos saturados como alternativa al empleo de olefinas .. 26

1.4.1. Obtención de olefinas a partir de alcanos ..................................... 27

1.4.2. Obtención de compuestos oxigenados a partir de alcanos ........... 29

1.5. Oxidación y amoxidación selectiva de propano ................................ 31

1.5.1. Aspectos clave de los catalizadores para la oxidación parcial de

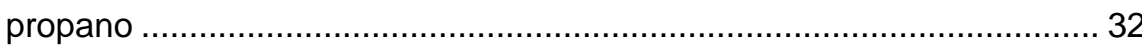

1.5.2. Sistemas catalíticos para la oxidación y amoxidación selectiva de propano

1.6. Catalizadores multicomponentes $\mathrm{MoVTe}(\mathrm{Sb}) \mathrm{Nb}$ para la oxidación parcial de propano a ácido acrílico........................................................... 36

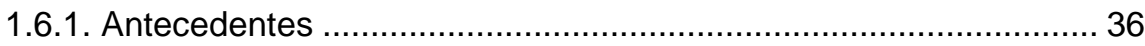

1.6.2. Características de los catalizadores multicomponentes

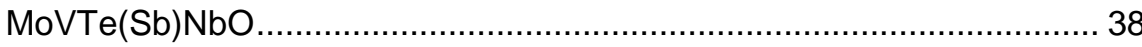

1.6.3. Propiedades catalíticas de los catalizadores MoVTe(Sb)NbO ...... 40

1.6.4. Estructuras de las fases cristalinas M1 y M2 ............................... 42

1.6.5. Centros activos de las fases cristalinas M1 y M2 ......................... 44

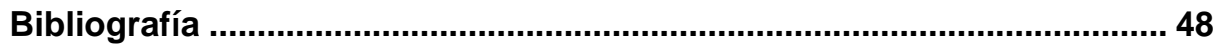

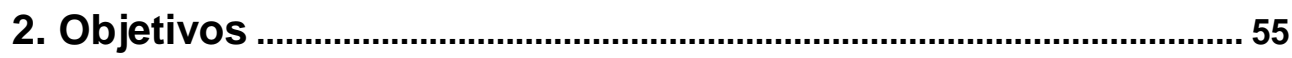




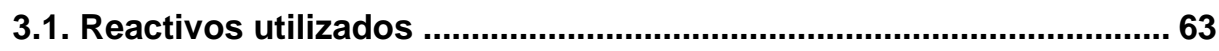

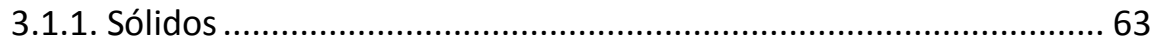

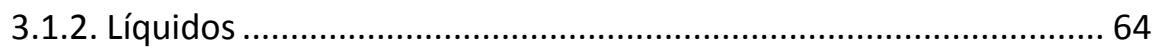

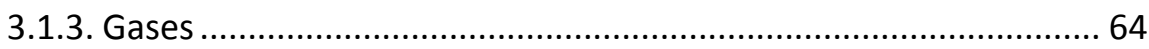

3.2. Preparación de óxidos mixtos MoVTe(Sb)Nb por el método

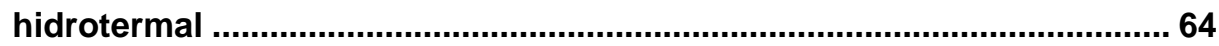

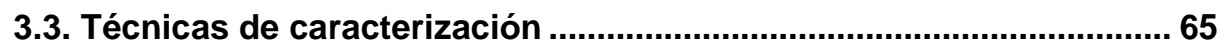

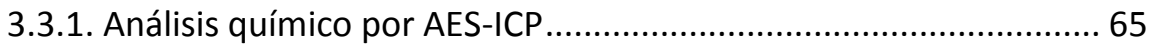

3.3.2. Determinación de la superficie específica (BET) ............................6 66

3.3.3. Análisis térmico gravimétrico y diferencial (TG-DTA) ..................... 67

3.3.4. Difracción de rayos $X$ en polvo (DRX)........................................... 68

3.3.5. Espectroscopia de reflectancia difusa en la región ultravioleta-

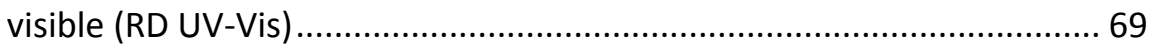

3.3.6. Espectroscopia de absorción infrarroja (FT-IR) ............................. 70

3.3.6.1. Procedimiento IR transmisión.............................................. 72

3.3.6.2. Procedimiento FT-IR con adsorción de metanol................... 72

3.3.6.3. Procedimiento DRIFT con moléculas sonda........................ 72

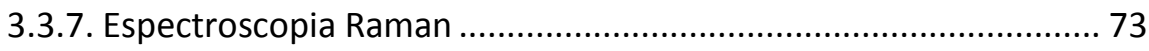

3.3.8. Espectroscopia Fotoelectrónica de rayos X (XPS) ......................... 74

3.3.9. Microscopía electrónica de barrido (SEM) y microanálisis de rayos

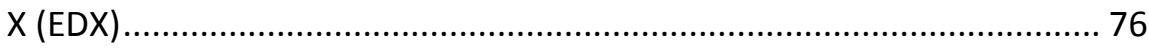

3.3.10. Técnicas de temperatura programada........................................ 78

3.3.10.1. Reducción a temperatura programada $\left(T P R-H_{2}\right) \ldots \ldots \ldots \ldots . . . . .78$

3.3.10.2. Desorción de amoníaco a temperatura programada (TPD-

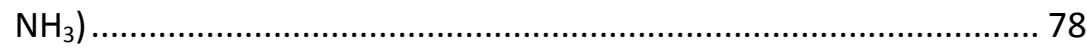

3.3.10.3. Intercambio isotópico de oxígeno .................................... 80

\subsection{Ensayos catalíticos en la oxidación parcial de propano a ácido} acrílico

3.4.1. Sistema de reacción 81

3.4.2. Descripción de un experimento 82 
3.4.3. Análisis de los productos de reacción 83

3.4.4. Cálculo de conversión, selectividad y rendimiento. .84

3.5. Ensayos catalíticos en la oxidación parcial de propileno a ácido acrílico 85

3.6. Ensayos catalíticos en la oxidación de metanol 86

Bibliografía .87

4. Óxidos mixtos Mo-V-Te promovidos con metales 89

4.1. Antecedentes .93

4.2. Estudio preliminar sobre la incorporación de un metal en catalizadores Mo-V-Te-O 96

4.2.1. Caracterización físico-química de los materiales. .96

4.2.2. Resultados catalíticos para la Oxidación parcial de Propano. 99

4.2.3. Discusión de los resultados 101

4.3. Efecto de la incorporación de $\mathrm{Ca}$, Ga y Nb en catalizadores MoVTeO

4.3.1. Caracterización físico-química de los materiales promovidos con

$\mathrm{Ca}, \mathrm{Ga}$ o $\mathrm{Nb}$ 104

4.3.2. Resultados catalíticos para la Oxidación de Propano con catalizadores promovidos con $\mathrm{Ca}, \mathrm{Ga} \circ \mathrm{Nb}$

4.3.3. Estudio mediante microscopía de alta resolución (HREM) de los catalizadores promovidos con $\mathrm{Ca} \circ \mathrm{Ga}$ 117

4.3.4. Discusión de los resultados 119

4.3.4.1. Efecto de Ca como promotor 119

4.3.4.2. Efecto de $\mathrm{Nb}$ como promotor 120

4.3.4.3. Efecto de Ga como promotor 122

4.4. Catalizadores MoVTeGaO con diferente relación $\mathrm{Ga} /(\mathrm{Ga}+\mathrm{V})$ 125

4.4.1. Resultados catalíticos de los catalizadores MoVTeGaO y MoVGaO

4.4.2. Caracterización físico-química de los catalizadores MoVTeGaO y MoVGaO. 127

4.4.3. Discusión de los resultados 131

4.5. Conclusiones 132

Bibliografía 136 
5. Estudio sobre la preparación de óxidos mixtos MoVSbO, MoVTeO y MoVTeNbO

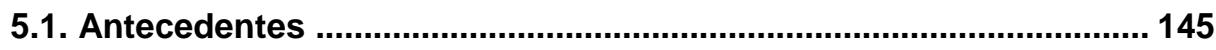

5.2. Influencia de la temperatura de síntesis ........................................ 148

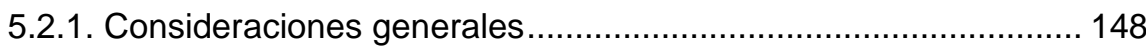

5.2.2. Caracterización de los precursores de síntesis .......................... 148

5.2.3. Caracterización de los materiales activados térmicamente......... 153

5.2.4. Resultados catalíticos para la oxidación de propano.................... 159

5.3. Influencia de la temperatura de activación .................................... 160

5.3.1. Consideraciones generales.................................................... 160

5.3.2. Resultados catalíticos para la oxidación parcial de propano........ 161

3.5.3. Caracterización de los catalizadores ........................................ 163

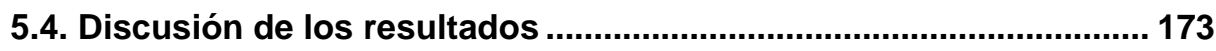

5.4.1. Influencia de la temperatura de síntesis hidrotermal ................... 173

5.4.2. Influencia de la temperatura de activación térmica...................... 176

5.4. Conclusiones ........................................................................ 179

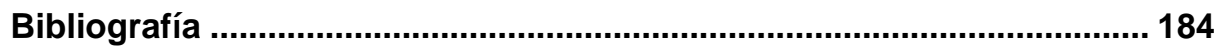

6. Óxidos mixtos MoVSbO, MoVTeO Y MoVTeNb activados a 500

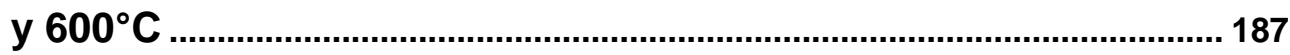

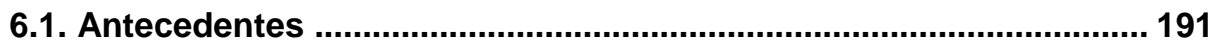

6.2. Estudio comparativo de la oxidación selectiva de propano, propeno

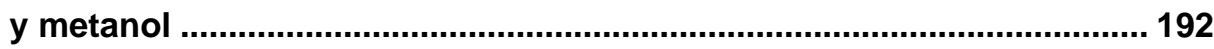

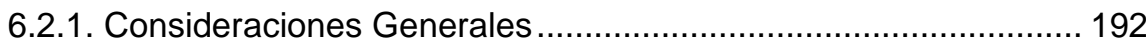

6.2.2. Resultados catalíticos para la oxidación selectiva de propano a

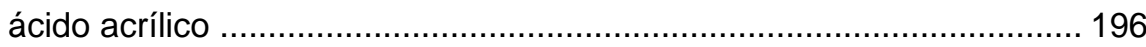

6.2.3. Resultados catalíticos para la oxidación selectiva de propileno a

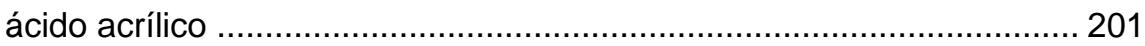

6.2.4. Resultados catalíticos para la oxidación de metanol ................... 206

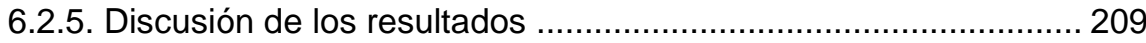

6.3. Técnicas de caracterización superficiales ...................................... 212

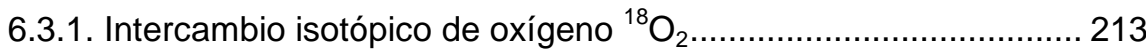

6.3.2. Adsorción de metanol por espectroscopia FTIR .......................... 214 
6.3.3. Adsorción de moléculas sonda $\left(\mathrm{NH}_{3}\right.$ y acroleína) por

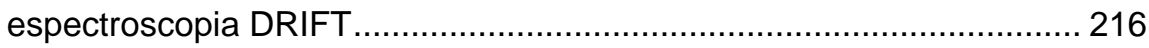

6.3.3.1. Adsorción de amoníaco ................................................. 216

6.3.3.2. Adsorción de acroleína .................................................... 218

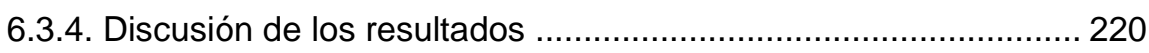

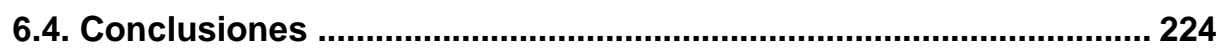

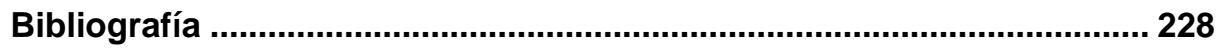

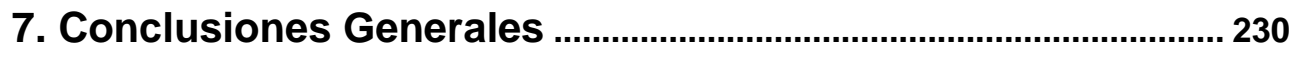

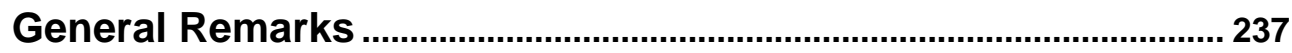

Anexo I: Índice de Tablas, Esquemas y Figuras .......................... 243

Anexo II: Curriculum obtenido durante el período de tesis

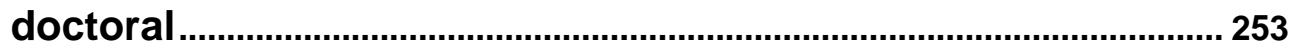




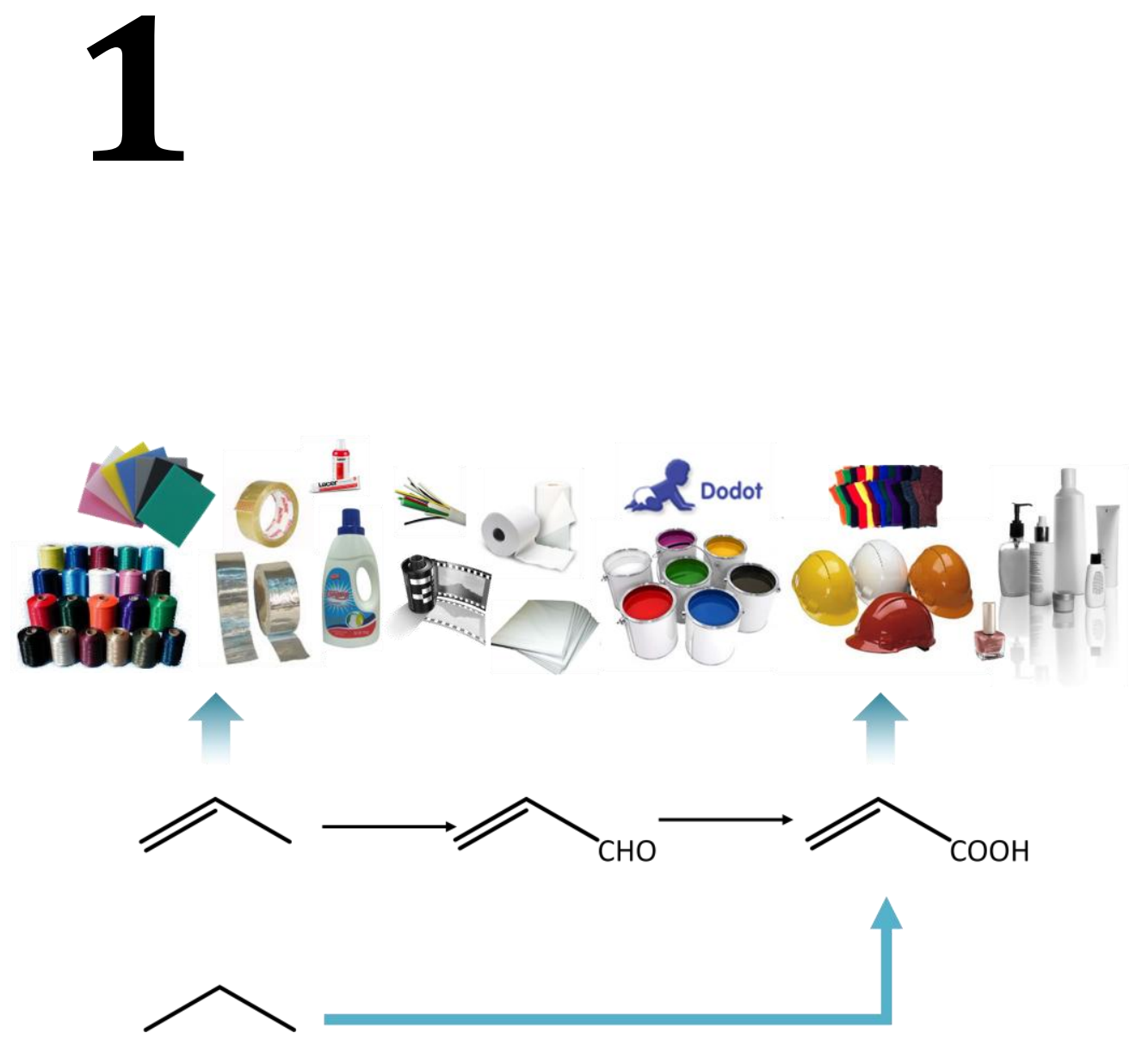

Introducción 



\section{Abstract}

The substitution of an expensive olefin by less expensive alkanes as feedstock in selective oxidation processes has had increasing interest from the chemical industry. In the last two decades, a research effort has been devoted to the development of efficient processes for the partial oxidation of light alkanes. This research has been directed to both the oxidative dehydrogenation of light alkanes (C2-C4) to the corresponding olefins and to the substitution of olefins by paraffins in well known industrial processes, i.e. selective (amm)oxidation of propane to acrylonitrile and acrylic acid, respectively. Industrially, acrylonitrile and acolein are obtained by (amm)oxidation of propylene over multicomponent Bi-Fe-Mo and $\mathrm{Fe}$ $S b$ based catalysts. The oxidation of acrolein over Mo-V-W mixed oxides produces acrylic acid.

Propane (amm)oxidation to acrylonitrile and acrylic acid is a one-step process. It is necessary in the development of a catalytic system that it is able to active propane and to selectively oxidize it to acrylic acid. At this moment, $\mathrm{MoVTe}(\mathrm{Sb}) \mathrm{NbO}$ multicomponent metal oxides are the most effective catalysts in the (amm)oxidation of propane to acrylonitrile and acrylic acid. These mixed metal oxides were initially reported by Mitsubishi. After that, many groups have worked in the last years on the synthesis and characterization of these catalytic systems.

MoVTeNb-based catalysts present as two main crystalline phases: i) orthorhombic $\mathrm{Te}_{2} \mathrm{M}_{20} \mathrm{O}_{57}(\mathrm{M}=\mathrm{Mo}, \mathrm{V}, \mathrm{Nb})$, also called $\mathrm{M1}$ phase; and ii) orthorhombically distorted HTB-type phase $T_{0.33} M_{3} O_{3.33}(M=M o, V, N b)$, also called M2 phase. The M1 phase is active and selective by itself in the selective oxidation of propane, while the M2 phase is not able to activate propane (but it is active and selective for propene oxidation). A synergetic effect for propane oxidation between the M1 and M2 phases has been proposed for the MoVTeNbO catalysts. Although the presence of the M1 phase in the catalysts composition seems be crucial in active and selective catalysts, the lower or higher presence of M1 phase depends on the synthesis method and chemical composition. Thus, the presence of $\mathrm{Nb}$ ions favors an improvement in the selective oxidation reactions. This effect has been clearly explained by an increased stability of acrylic acid on $\mathrm{Nb}$-containing catalysts, as a consequence of the low number/strength of the acid sites in these catalysts. On the other hand, it has been proposed that the catalytic behaviour for the selective oxidation of propane to acrylic acid on MoVTeNbO catalysts could be explained by the presence of three moieties: (i) the activation of propane in V-sites; (ii) the oxidation of propylene in Mo/Te sites; and (iii) the oxidation of acrolein to acrylic acid in Mo/Nb sites. 


\section{Resumen}

En los últimos años ha aumentado el interés de la intustria petroquímica en la sustitución de olefinas por alcanos, más viables económicamente, como materias primas en procesos de oxidación selectiva. En las últimas dos décadas, se ha investigado el desarrollo de procesos eficientes para la oxidación parcial de alcanos ligeros. El estudio se ha dirigido tanto a la obtención de olefinas por dehidrogenación oxidativa de alcanos ligeros (C2-C4), como a la sustitución de las olefinas por parafinas en procesos industriales conocidos, como es el caso de la amoxidación/oxidación de propano a acrilonitrilo y ácido acrílico, respectivamente. Industrialmente, el acrilonitrilo y la acroleína se obtienen por oxidación de propileno sobre catalizadores multicomponentes basados en Bi-Fe-Mo y Fe-Sb. El ácido acrílico se produce por sucesiva oxidación de acroleína con óxidos mixtos Mo-V-W.

La amoxidación/oxidación de propano a acrilonitrilo y ácido acrílico, respectivamente, es un proceso en una sola etapa. Por ello, es necesario el desarrollo de un sistema catalítico capaz de activar el propano y oxidarlo selectivamente a ácido acrílico. Hasta el momento, los óxidos mixtos multicomponentes $\mathrm{MoVTe}(\mathrm{Sb}) \mathrm{NbO}$ son los catalizadores más efectivos en la amoxidación/oxidación de propano. Estos óxidos mixtos metálicos fueron desarrollados inicialmente por Mitsubishi. Después de eso, muchos grupos de investigación han trabajado en los últimos años en la síntesis y caracterización de este sistema catalítico.

Los catalizadores MoVTeNb presentan principalmente dos fases cristalinas: i) una fase ortorrómbica $T e_{2} M_{20} \mathrm{O}_{57}(M=M o, V, N b)$, denominada fase $M 1$; y ii) una fase hexagonal tipo HTB $T e_{0.33} M O_{3.33}(M=M o, V, N b)$, también denominada fase M2. La fase M1 es activa y selectiva por si sola en la oxidación selectiva de propano, mientras que la fase M2 no es capaz de activar el propano (pero es activa y selectiva en la oxidación de propeno). Únicamente en el caso de catalizadores MoVTeNbO se ha propuesto un efecto de colaboración entre las fases M1 y M2. Si bien la presencia de la fase M1 parece ser clave en los catalizadores activos y selectivos, la mayor o menor presencia de esta fase depende del método de síntesis y de la composición química. Así, la presencia de $\mathrm{Nb}$ favorece una mayor selectividad a ácido acrílico (o acrilonitrilo). Este efecto se ha explicado por una mayor estabilidad del ácido acrílico en catalizadores con $\mathrm{Nb}$ como consecuencia de un menor número y fortaleza de los centros ácidos en estos catalizadores. Por otro lado, se ha propuesto que el comportamiento catalítico para la oxidación selectiva de propano a ácido acrílico con catalizadores MoVTeNbO podría ser explicada por la presencia de tres centros: i) la activación de propano en los centros de $\mathrm{V}$; ii) la oxidación de propileno en los centros $\mathrm{Mo} / \mathrm{Te}$; y iii) la oxidación de acroleína a ácido acrílico en los centros Mo/Nb. 


\subsection{Oxidación catalítica selectiva}

Los procesos catalíticos han desempeñado un papel vital en el desarrollo económico de la industria química en el siglo XX. Se estima que el $90 \%$ de los productos químicos utilizados actualmente han estado, en alguna etapa de su producción, en contacto con un catalizador, desde productos químicos como ácido acético y amoníaco a productos de consumo como detergentes y vitaminas.

Al comienzo del siglo XXI, la catálisis es una pieza clave para el desarrollo de una nueva industria química sostenible basada en tecnologías más limpias. En este sentido, se ha introducido el concepto de Química Sostenible que engloba la utilización de doce principios a fin de reducir o eliminar el uso y generación de sustancias peligrosas en el diseño, manufactura y aplicación de productos químicos [1]. En este sentido, existe una estrecha relación entre la catálisis y la Química Sostenible, pues el empleo de catalizadores puede ayudar al desarrollo de procesos más selectivos (eliminación de subproductos y número de pasos del proceso), menos tóxicos y menos contaminantes (al sustituir catalizadores homogéneos por catalizadores heterogéneos), así como fomentar el empleo de nuevas materias primas (más complejas) al facilitar la realización de varias etapas mecanísticas en una sola etapa de reacción (reacciones en cascada) [2]. Además, el empleo de catalizadores puede facilitar una reducción drástica del consumo energético del proceso global.

En la industria petroquímica a gran escala, el empleo de procesos catalíticos está ampliamente desarrollado. Entre estos procesos, se pueden encontrar reacciones de polimerización, hidrogenación, deshidrogenación u oxidación selectiva (también denominada oxidación parcial). Ahora bien, si la polimerización es el proceso catalítico con mayor volumen de producción, los procesos de oxidación selectiva, también han ido adquiriendo una mayor importancia y, en la actualidad, suponen el $25 \%$ de la producción total de la industria petroquímica.

Durante las últimas seis décadas, una de las aplicaciones más importantes de la oxidación selectiva ha sido la funcionalización de olefinas e hidrocarburos aromáticos para su transformación en monómeros de gran interés en la industria de polímeros. Estos procesos son imprescindibles en la sociedad actual, ya que a partir de ellos se producen algunos de los compuestos orgánicos más relevantes usados en la producción industrial de bienes de consumo [3]: óxido de etileno, óxido de propileno, acrilonitrilo, ácido acrílico, acroleína, ácido metacrílico, anhídrido maleico, anhídrido ftálico, 1,2-dicloroetano, ciclohexanol, ciclohexanona, fenol, o MTBE (metil tert-butil éter). En la mayoría de los casos, los procesos se llevan a cabo en fase heterogénea, aunque todavía existe un número considerable de procesos que se realizan mediante procesos de catálisis homogénea. 
A pesar de que estos procesos están muy optimizados, las reacciones de oxidación tienen importantes limitaciones. En algunos casos porque no se obtienen rendimientos altos. En efecto, en las reacciones de oxidación selectiva, la formación de óxidos de carbono y agua está muy favorecida termodinámicamente. Sólo controlando la cinética de las reacciones implicadas se puede favorecer la formación de productos parcialmente oxigenados e inhibir las reacciones de combustión u oxidación total.

En otros casos, se obtienen subproductos de escaso interés económico, son necesarios agentes oxidantes de alto precio o se emplean reactivos tóxicos, como los hidrocarburos aromáticos (en especial el benceno). Por todo ello, los procesos de oxidación selectiva tienen grandes posibilidades de mejora. Parte de las mejoras están encaminadas al empleo de materias primas más baratas y menos contaminantes, o a la heterogeneización de reacciones que hasta la fecha se llevan a cabo en fase homogénea.

Las nuevas líneas de investigación de la industria petroquímica tienen como principal objetivo la disminución del coste global del proceso lo que conlleva a una reducción del precio y, en algunos casos, de la toxicidad de la materia prima. Pero también, las nuevas líneas de investigación se están dirigiendo hacia el empleo de materias primas de baja demanda y/o materias primas sostenibles. En este sentido, los hidrocarburos saturados (en especial alcanos ligeros) presentan una mayor disponibilidad y un precio inferior al de las olefinas e hidrocarburos aromáticos, puesto que se pueden obtener directamente a partir de petróleo o del gas natural. Además la toxicidad de los alcanos es muy inferior a la de los compuestos aromáticos. Sin embargo, el principal problema que presenta el empleo de alcanos es su baja reactividad.

Es por esto que, en los últimos veinte años, se ha estudiado intensamente, tanto desde un punto de vista fundamental como aplicado, la síntesis de nuevos materiales sólidos para ser empleados como catalizadores en procesos de oxidación parcial de alcanos ligeros (C2-C6). Pero, para ello, se requieren materiales capaces de incorporar, al mismo tiempo, diferentes tipos de centros activos, en entornos adecuados, con los que se pueda llevar a cabo las diferentes etapas de reacción en un proceso de una etapa.

\subsection{Las olefinas ligeras en la industria petroquímica}

Las olefinas son consideradas unos de los pilares de la industria petroquímica actual, empleadas principalmente como materiales de partida. En un principio, las olefinas, subproducto del craqueo de hidrocarburos, se emplearon únicamente para la mejora de la calidad de la gasolina. Sin embargo, a partir de la Segunda Guerra Mundial, se produjo un desarrollo en la producción de monómeros a partir 
de olefinas y en los métodos de polimerización para la producción de plásticos y fibras sintéticas, lo que supuso un auge en la industria petroquímica.

Las olefinas más empleadas son etileno y propileno. El etileno es la materia prima para aproximadamente el $30 \%$ de todos los productos petroquímicos. En 2009, la capacidad mundial para su producción fue de 126.7 millones de toneladas/año, con un crecimiento anual del 3.5\% [4]. El propileno es la segunda olefina más importante, con una producción anual próxima a los 65 millones de toneladas/año, con un crecimiento anual estimado entre $4.5-5.0 \%$.

El etileno se utiliza en la fabricación de polímeros como el polietileno, cloruro de polivinilo y poliestireno, así como fibras y otros productos químicos orgánicos. Estos productos se emplean en una amplia variedad de aplicaciones tanto industriales como de consumo: embalaje, transporte, industrial textil, revestimientos y adhesivos.

El propileno, por su parte, es usado en los procesos de alquilación para una mejora en el octanaje de las gasolinas en las refinerías. Además, a partir del propileno, se sintetiza un buen número de compuestos químicos, como se muestran en la Figura 1.1. El producto más importante derivado del propileno es el polipropileno, obtenido por polimerización, empleado para la obtención de distintos materiales plásticos. Se trata de un polímero versátil, con buenas propiedades mecánicas y químicas, además de ser barato, por lo que ocupa el tercer lugar en ventas de plásticos. Las principales aplicaciones se encuentran en la industria de la automoción, productos para el hogar, electrodomésticos, embalajes, utensilios de laboratorio, botellas, etc.

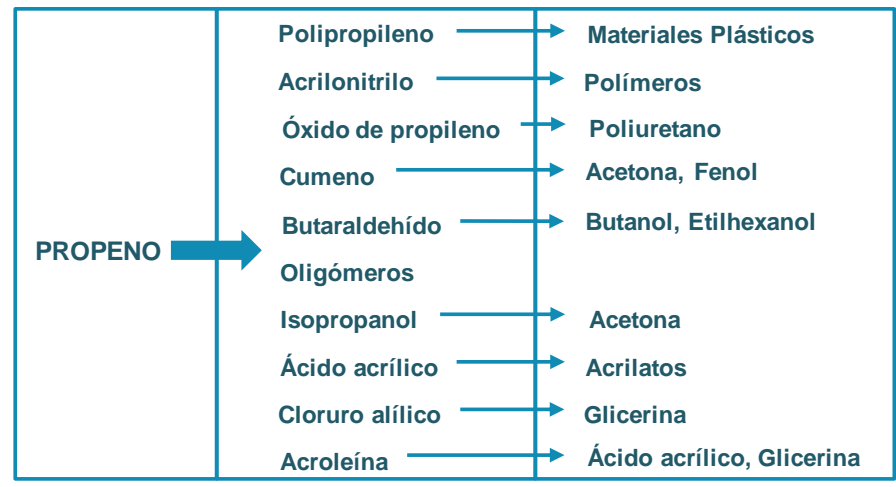

Figura 1.1. Empleo de propeno como materia prima.

Después del polipropileno, el producto de mayor interés industrial obtenido a partir de propileno es el acrilonitrilo. El acrilonitrilo se emplea en la fabricación de una gran variedad de polímeros con diversos usos: plásticos, textiles, etc.; y como intermediario en la síntesis de otros compuestos químicos. Así mismo, el ácido 
acrílico y la acroleína son productos importantes obtenidos a partir de propileno para la fabricación de acrilatos. En el siguiente apartado veremos con mayor detalle las aplicaciones de estos compuestos y su producción industrial.

El óxido de propileno ocupa un $11 \%$ del consumo mundial de propeno. El óxido de propileno se utiliza para la fabricación de polioles de poliéteres, que reaccionan con isocianato para formar poliuretanos. Entre las aplicaciones del poliuretano se incluyen espumas flexibles para la industria del mueble y del automóvil, y espumas rígidas para el aislamiento de edificios. El óxido de propileno también se emplea en la fabricación de glicoles de propileno (como materias primas para resinas no-saturadas de poliéster y anticongelantes); y los éteres de glicol de propileno, con aplicaciones en pinturas, revestimientos, tintas, resinas y productos de limpieza.

Además, a partir de propeno se obtiene cumeno, para su uso en la síntesis de algunos detergentes, acetona y fenol; butiraldehído, materia prima para la producción de aromas sintéticos; e isopropanol, utilizado como disolvente en los productos cosméticos y de higiene personal, pinturas y resinas, productos farmacéuticos, colorantes alimentarios y adhesivos.

\subsubsection{Procesos de obtención de olefinas ligeras}

Debido a su reactividad, las olefinas ligeras se encuentran en cantidades muy limitadas en el gas natural y el petróleo. Por este motivo, hasta el momento, las olefinas se han producido industrialmente a partir del petróleo mediante procesos de craqueo de hidrocarburos de mayor peso molecular. El etileno se produce mayoritariamente por craqueo con vapor de la fracción nafta (hidrocarburos C5C11), del LPG (Liquefied Petroleum Gas) del petróleo o de etano, mientras que el propileno se obtiene como subproducto en el craqueo con vapor $(70 \%$ de la producción mundial) y en el craqueo catalítico (28\%).

El craqueo con vapor está optimizado para la producción de etileno, y la cantidad de propileno obtenida depende de la composición del alimento y de la severidad del proceso. En este proceso, los hidrocarburos se craquean en presencia de vapor de agua a una temperatura de reacción entorno a $800^{\circ} \mathrm{C}$. El tiempo de residencia es de sólo unos milisegundos para mejorar el rendimiento. Para evitar reacciones indeseadas, que pueden disminuir la selectividad a olefinas en el proceso, los reactantes deben enfriarse rápidamente. Esta etapa se realiza en intercambiadores en línea inmediatamente después de la zona de craqueo. Los productos son enfriados y separados para dar olefinas y otros subproductos. Así, los productos obtenidos en el craqueo dependen de la composición de la alimentación, la proporción hidrocarburo/vapor de agua, la temperatura y el tiempo de residencia. Una temperatura de craqueo alta favorece la producción de etileno, 
mientras que procesos menos severos (de menor temperatura) produce una mayor cantidad de propileno, hidrocarburos C4 y productos líquidos.

Además, alimentos ligeros como la fracción LPG, nafta ligero o etano da lugar a corrientes de producto ricos en alquenos ligeros, incluyendo etileno, propileno y butadieno. Los hidrocarburos más pesados (naftas pesadas y otros productos de refinerías) dan productos ricos en hidrocarburos aromáticos. La materia prima empleada en los procesos de craqueo con vapor depende de los recursos naturales disponibles en cada país, lo que determina la distribución final de olefinas. En Europa y Asia, el etileno se produce mayoritariamente mediante craqueo de nafta, gasóleo y condensados, con la coproducción de propileno, olefinas-C4 y aromáticos (craqueo de gasolina). En USA, Canadá y Oriente Medio, el etileno se obtiene mayoritariamente mediante craqueo con vapor de etano y propano, con la ventaja de que prácticamente sólo se obtiene etileno y propileno [5].

En refinería, el propileno se obtiene principalmente como subproducto del craqueo catalítico en lecho fluidizado (FCC) de gasóleos. De nuevo, la producción depende del destino al que se orienta la refinería (por ejemplo, las refinerías de Estados Unidos, más orientadas a maximizar la producción de gasolina, producen más propileno que las de Europa).

La creciente necesidad mundial de olefinas ligeras ha hecho que se comiencen a desarrollar nuevos procesos de producción de olefinas. En el caso de la obtención de propileno, cabe destacar el proceso de deshidrogenación catalítica de propano (materia prima más abundante y viable económicamente), que supone, actualmente, cerca del $2 \%$ de la producción mundial. Sin embargo, en el caso de etileno, la deshidrogenación catalítica de etano no es económicamente viable pues requiere temperaturas mayores, más de $800^{\circ} \mathrm{C}$ [6]. En cambio, la deshidrogenación oxidativa de etano parece un camino viable en la obtención de etileno [7-8], aunque no parece ser un proceso adecuado para la obtención de olefinas de mayor longitud de cadena. Por otro lado, se ha desarrollado el proceso MTO (Methanol To Olefins) que convierte metanol en olefinas ligeras como etileno y propileno [9].

\subsubsection{Problemática del uso de olefinas}

Sin embargo, el empleo de olefinas en la industria petroquímica lleva asociado una serie de problemas económicos y medioambientales, derivados de los procesos industriales empleados para su obtención. Así, el craqueo con vapor es un proceso endotérmico que requiere operar a elevadas temperaturas (700$850^{\circ} \mathrm{C}$ ), seguido de un enfriamiento rápido de los productos de salida y generan subproductos que es necesario separar de las olefinas mediante procesos 
complicados y costosos. Cuanto más pesada es la carga mayor será el número de subproductos. Esto significa que el etano produce mayoritariamente etileno y menos subproductos, mientras que el gasóleo da menos etileno y más subproductos (que deben ser separados del producto de interés empleando principalmente columnas de destilación, mediante procesos complicados y costosos). Por estos motivos, el craqueo con vapor es el proceso químico con mayor demanda de energía, mayor incluso que la destilación atmosférica de crudo o el reformado catalítico, cuyo coste energético corresponde al $70 \%$ del coste de producción [10].

El proceso también produce una lenta deposición de coque en las paredes del reactor. La cantidad de coque producido y depositado depende del tipo de combustible empleado, las condiciones de operación y la naturaleza metalúrgica de las conducciones [11]. Aunque, las condiciones de operación están diseñadas para minimizar la formación de coque, finalmente se terminan formando unos depósitos de coque de unos pocos milímetros, dificultando la transferencia de calor, por lo que se debe elevar la temperatura generando aún más coque. Esto obliga a parar la unidad para eliminar el coque (decoquización o decoking), que consiste en pasar una mezcla de vapor de agua y aire a través de las bobinas del horno, quemando el coque a óxidos de carbono $\left(\mathrm{CO}\right.$ y $\left.\mathrm{CO}_{2}\right)$. En el caso de la deshidrogenación catalítica y del craqueo catalítico, la formación de depósitos de carbono (coque) en el catalizador hace que sea necesaria además la regeneración del catalizador para eliminar el coque.

Además, también se deben tener en cuenta los factores medioambientales relacionados con las elevadas tasas de $\mathrm{CO}_{2}$ asociadas a estos procesos de producción de olefinas. Por un lado, están las emisiones de dióxido de carbono debido a las reacciones químicas que tienen lugar en el proceso en sí, y durante la decoquización del sistema. Y por otro, las que derivan de la necesidad de consumir una elevada cantidad de energía. En este sentido, las emisiones de $\mathrm{CO}_{2}$ asociadas con la producción de etileno en un proceso de craqueo con vapor son de $1200 \mathrm{~g} \mathrm{CO}_{2} / \mathrm{kg}_{\text {etileno }}$ [12]. Esto significa que en 2004, la emisión total de $\mathrm{CO}_{2}$ en el mundo asociada a la producción de etileno fue de 180-200 millones de toneladas (53-55 millones de toneladas en Europa) [10, 13].

A esto hay que sumar la creciente demanda de etileno y propileno debido al aumento en la demanda de los productos derivados, mientras que no se prevé que se produzca un aumento proporcional en la producción. Todos estos factores llevan a pensar que es necesario un cambio de estrategia respecto a la producción y/o empleo de olefinas, siendo dos las alternativas más interesantes: i) un cambio en el proceso de obtención de las olefinas, siendo la deshidrogenación oxidativa del correspondiente alcano, la alternativa más atractiva (en especial para la producción de etileno); y ii) la sustitución de la olefina por su correspondiente 
alcano en procesos industriales de oxidación o amoxidación selectiva, siendo de especial interés la oxidación parcial de propano o de isobutano.

\subsection{Amoxidación y oxidación selectiva de propileno}

Como hemos visto, el propileno es uno de los compuestos químicos de mayor producción industrial debido principalmente a su empleo en la industria como materia prima para la producción de diversos compuestos químicos. Después del polipropileno, los productos de mayor interés industrial son los obtenidos por procesos de oxidación y amoxidación de propileno para la obtención de acrilonitrilo, acroleína y ácido acrílico. De acuerdo con datos del 2005, la producción anual de acrilonitrilo se cifra en unas $5.24 \times 10^{6} \mathrm{Tm} /$ año mientras que la producción anual de ácido acrílico está en torno a las $3.20 \times 10^{6} \mathrm{Tm} /$ año [14]. Ambos son empleados en la producción de fibras acrílicas con diversos usos. A continuación, se detallan los diferentes usos de cada uno, además de los métodos de producción en la industria y los catalizadores más empleados.

\subsubsection{Acrilonitrilo y ácido acrílico. Aplicaciones y producción.}

El acrilonitrilo (propenonitrilo, $\mathrm{CH}_{2}=\mathrm{CHCN}$ ) es un líquido incoloro, volátil e inflamable, de olor penetrante. Se emplea principalmente en la industria petroquímica como monómero o co-monómero en la producción de plásticos, elastómeros o fibras sintéticas. Además, es un importante intermediario en la obtención de otros productos químicos, como la acrilamida. Antiguamente, el acrilonitrilo, en combinación con tetracloruro de carbono, se utilizaba como pesticida, aunque, su uso se ha limitado debido a sus efectos perjudiciales para la salud.

Sin embargo, las fibras acrílicas, son los productos derivados del acrilonitrilo con mayor demanda; aproximadamente el $50 \%$ de la producción mundial de acrilonitrilo está destinada a la fabricación de fibras acrílicas [14-15]. Estas fibras se emplean en prendas de vestir como suéteres, jerséis, calcetines o ropa deportiva; en muebles para el hogar y ropa de cama, tales como alfombras, tapicerías y mantas. Otro tipo de fibras, mediante copolimerizión de acrilonitrilo con cloruro de vinilo o vinilideno, son resistentes al fuego o se emplean en cortinas y pelucas.

Actualmente, el sector de mayor crecimiento es la producción de plásticos, como el acrilonitrilo-butadieno-estireno (ABS) o el estireno-acrilonitrilo (SAN). El ABS es un plástico muy resistente al impacto, por lo que es muy usado en la industria del automóvil, ordenadores, radios, televisores y teléfonos móviles. A su vez, el SAN es un plástico con mayor facilidad de procesamiento que es empleado en componentes para el automóvil, utensilios de cocina y artículos para el hogar. 
El poliacrilonitrilo (PAN) es también el precursor de la fibra de carbono en aplicaciones de alta resistencia, desde piezas de aviones hasta equipos deportivos.

Entre los productos químicos producidos a partir de acrilonitrilo se encuentra el adiponitrilo, dímero del acrilonitrilo obtenido por electrohidrodimerización. Es un intermedio importante en la industria, ya que su hidrogenación produce el 1,6diaminohexano, materia prima para la elaboración de nylon 6-6 [16].

Otro producto derivado es la acrilamida, que se emplea en la industria petroquímica como monómero para la fabricación de homopolímeros y copolímeros. La poliacrilamida se utiliza como floculante en el agua y tratamiento de residuos, fabricación de papel y de telas.

El acrilonitrilo se sintetizó por primera vez en 1893, por Charles Moureu [17], a partir de la deshidratación de la cianhidrina de etileno con pentóxido de fósforo. Aunque ya en los años 1930 se conocía la utilidad de las fibras acrílicas, no fue hasta poco antes de la Segunda Guerra mundial cuando se desarrolló el uso de copolímeros resistentes al calor, aumentando la demanda de acrilonitrilo. Sin embargo, los métodos de fabricación empleados eran costosos, con varias etapas y/o con materias primas caras. Un ejemplo es el proceso DuPont, que producía acrilonitrilo a partir de acetileno y acido cianhídrico, catalizada por cloruro cuproso a $80^{\circ} \mathrm{C}$ en acido clorhídrico diluido [16].

En 1960, la Standard Oil de Ohio (Sohio) desarrolló un catalizador comercialmente viable para la fabricación de acrilonitrilo a través de un proceso más sencillo: la amoxidación de propileno en presencia de oxígeno y amoníaco [18]. Este proceso permitió la reducción del coste en la fabricación de acrilonitrilo, aumentando la demanda de acrilonitrilo y derivados. Hoy en día, más del $90 \%$ de la producción mundial de acrilonitrilo se obtiene por el proceso Sohio.

El proceso Sohio se basa en la amoxidación catalítica de propeno con amoníaco en fase vapor. Cantidades estequiométricas aproximadas de propeno y amoníaco reaccionan con presencia de aire y vapor de agua:

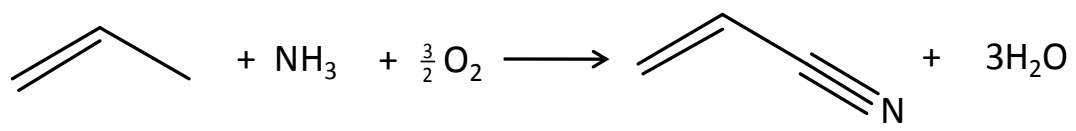

La reacción tiene lugar en una sola etapa y es altamente exotérmica. El calor de reacción se utiliza para conseguir vapor de agua a alta presión, empleado en los procesos de separación y purificación.

En la Figura 1.2 se muestra el esquema simplificado del proceso Sohio. Durante el proceso, se alcanza una conversión de 98\% de propileno, produciendo 
$1 \mathrm{~kg}$ de acrilonitrilo por $1.1 \mathrm{~kg}$ de propileno alimentado [14, 19]. Los principales subproductos de la reacción son HCN (unos $0.1 \mathrm{~kg} / \mathrm{Kg}$ de acrilonitrilo), el cual se usa en la producción de metil metacrilato; y acetonitrilo ( $0.03 \mathrm{~kg} / \mathrm{kg}$ de acrilonitrilo), un disolvente industrial muy común. También se obtienen pequeñas cantidades de óxidos de carbono y nitrógeno (de la combustión del amoníaco). El amoníaco sin reaccionar se neutraliza con acido sulfúrico, resultando sulfato amónico que se emplea como fertilizante.

\section{Reactor Columna de} adsorción

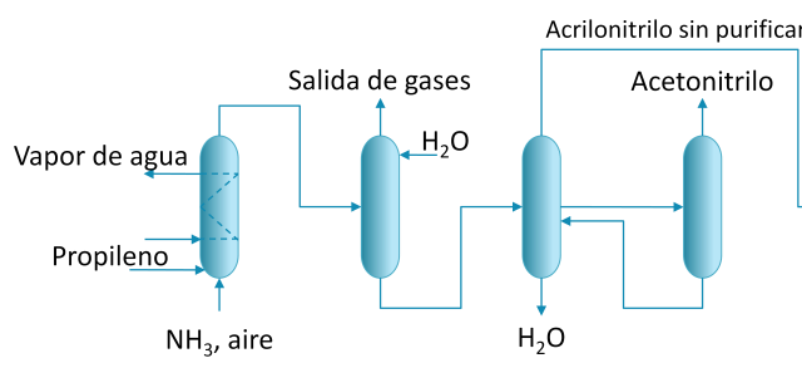

Columna de purificación

Columnas de recuperación de Acrilonitrilo

\section{Columna de purificación}

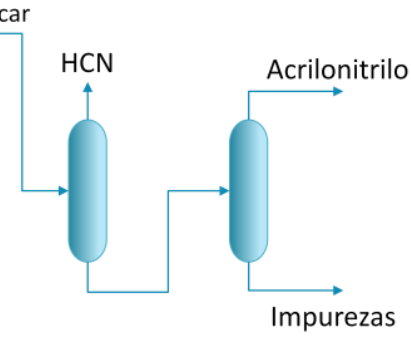

Figura 1.2. Esquema del proceso Sohio para la amoxidación de propileno a acrilonitrilo [19]

El proceso se lleva a cabo en un reactor de lecho fluidizado donde los reactivos en fase gas (propileno, amoníaco y oxígeno) se ponen en contacto con el catalizador en forma sólida. Un reactor de escala industrial puede contener unas 70-80 toneladas de catalizador, el cual tiene forma esférica $(<40 \mu \mathrm{m}$ de diámetro) para resistir la tracción mecánica. Los reactivos se encuentran en alta pureza, siendo la relación amoníaco/propileno del orden de 1.05-1.2 y la relación oxígeno/propileno entre 1.9 y 2.1. En general, en la industria se emplea aire enriquecido en oxígeno. El lecho del reactor se mantiene a una temperatura constante entre $420-450^{\circ} \mathrm{C}$ y a presión entre 1.5 y $3.0 \mathrm{~atm}$, necesaria para mantener la características del reactor pero lo suficientemente baja para obtener la mayor selectividad a acrilonitrilo, pues si se aumenta la presión se favorecen los subproductos.

La alimentación entra en el reactor de forma separada, a fin de minimizar la combustión homogénea en fase gas y prevenir la posibilidad de explosión. La salida de gases está compuesto por $\mathrm{N}_{2}$, óxidos de carbono e hidrocarburo sin reaccionar, que son incinerados obteniendo $\mathrm{CO}_{2}$ y agua. El acrilonitrilo obtenido sale de la columna de adsorción y se hace pasar por las columnas de recuperación a fin de separar en un primer paso, el agua y acetonitrilo. El acetonitrilo se purifica para su uso como disolvente. En segundo lugar, se separa el HCN producido durante la reacción. Finalmente, el acrilonitrilo se dirige a una 
columna de purificación donde se separan las impurezas (acetona, acetaldehído, propionaldehído, acroleína) y se purifica bajo vacío.

El proceso Sohio utiliza una serie de complejos catalizadores basados en óxidos metálicos, que se describirán mejor en el apartado siguiente. El primero de los catalizadores empleados en la amoxidación de propileno fue un fosfomolibdato de bismuto $\left(\mathrm{Bi}_{9} \mathrm{PMo}_{12} \mathrm{O}_{52}\right)$ [18]. Actualmente, los catalizadores comerciales están hechos de molibdatos multicomponentes $\mathrm{Bi}-\mathrm{Fe}-\mathrm{Ni}-\mathrm{Co}$, que pueden contener numerosos aditivos: $\mathrm{Cr}, \mathrm{Mg}, \mathrm{Rb}, \mathrm{K}, \mathrm{Cs}, \mathrm{P}, \mathrm{B}, \mathrm{Ce}, \mathrm{Sb}$ y $\mathrm{Mn}$. La introducción de nuevos catalizadores en el proceso de amoxidación ha aumentado la producción de acrilonitrilo, aumentando el rendimiento a acrilonitrilo de 50 a $80 \%$.

La acroleína (propenal, $\mathrm{CH}_{2}=\mathrm{CH}-\mathrm{CHO}$ ) es un aldehído insaturado líquido, incoloro, de olor penetrante y desagradable. La principal aplicación de la acroleína es la producción de ácido acrílico y sus ésteres. Además, se emplea como plaguicida en los canales de riego y suministro de aguas a plantas industriales para controlar el crecimiento de algas y mohos.

El ácido acrílico (ácido propanoico, $\mathrm{CH}_{2}=\mathrm{CHCOOH}$ ) es un ácido carboxílico líquido, incoloro, corrosivo, de olor penetrante. La presencia del grupo carboxílico y el doble enlace le confiere gran versatilidad, lo que le permite una amplia gama de reacciones. En consecuencia, el ácido acrílico es un importante intermediario en la fabricación de muchos productos químicos.

El ácido acrílico y sus ésteres se emplean, sobre todo, como monómeros combinados entre sí o con otros en la obtención de acrilatos. Los acrilatos tienen diferentes aplicaciones comerciales, usándose en detergentes, tejidos, aditivos para el papel, adhesivos, plásticos y materiales protectores.

Tradicionalmente, los ésteres de acrílico (acrilato de metilo, acrilato de etilo, acrilato de butilo y acrilato de 2-etilhexil) se producen por reacción de ácido acrílico con sus respectivos alcoholes. Estos ésteres de acrílico polimerizan para formar resinas termoplásticas de cadena larga (acrilatos). En general, estos polímeros son incoloros, insolubles en hidrocarburos alifáticos, resistentes a álcalis, aceites minerales y agua, con lo que son muy resistentes a la degradación. Los polímeros de metacrilato de metilo y otros ésteres de alquilo con cadenas laterales son sólidos duros y quebradizos, mientras que los esteres de cadena lineal son suaves y flexibles. Así, por copolimeración de ésteres acrílicos se pueden obtener polímeros con la flexibilidad y dureza deseada. Además, si estos ésteres son copolimerizados con otros compuestos (por ejemplo, amidas, acrilonitrilo, vinilo, estireno, butadieno, cloruro de vinilo) se aportan nuevas propiedades a los polímeros de forma que puedan ser modificados para aplicaciones específicas. 
Las principales aplicaciones del ácido acrílico y su porcentaje correspondiente en la demanda mundial anual se muestran en la Figura 1.3. Dos tercios de la producción mundial de ácido acrílico se utiliza para producir esteres acrílicos (acrilatos), principalmente para su uso en revestimientos de superficies, como pinturas acrílicas y lacas; adhesivos y compuestos de sellado; industria textil; plásticos; tratamientos de papel; floculantes; y otras aplicaciones, como modificadores de resinas sintéticas, emulsiones para el acabo del cuero y aglutinantes.

Otro uso importante del acido acrílico es la fabricación de ácido poliacrílico, destinado a la producción de polímeros superabsorbentes y polímeros de detergente. El ácido acrílico también se emplea como co-monómero con la acrilamida en la poliacrilamida aniónica para su uso en formulaciones de revestimiento industrial.

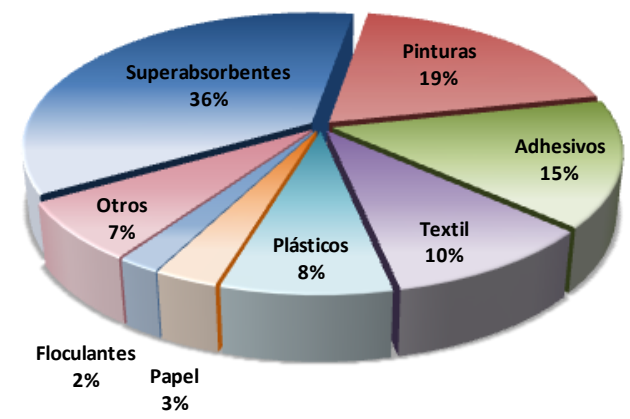

Figura 1.3. Demanda mundial de Ácido Acrílico. Datos 2007.

Los polímeros superabsorbentes son poliacrilatos entrecruzados con la capacidad de absorber y retener más de cien veces su propio peso en líquido. Consisten en una mezcla acuosa con un 30 a $40 \%$ de monómeros de acrilato de sodio y ácido acrílico, con iniciadores y aditivos. Se emplean principalmente en la fabricación de pañales para bebes, productos de higiene femenina y absorbente en cables de transmisión. Han experimentado un fuerte crecimiento, representando el $36 \%$ del consumo mundial de ácido acrílico (Figura 1.3).

La forma soluble del ácido poliacrílico también se usa como reemplazo de los fosfatos en la preparación de tensoactivos, especialmente en forma líquida, a veces en combinación de zeolitas. Además, el ácido poliacrílico se puede emplear como agente floculante en el tratamiento de aguas.

El primer método de obtención industrial de ácido acrílico fue desarrollado por Rohm \& Haas en 1901, basado en la clorohidrina etilénica (a partir de $\mathrm{C}_{2} \mathrm{H}_{4}$ y 
$\mathrm{HOCl}$ ) e hidroxipropionitrilo. En los siguientes años se desarrollaron otros procesos para la producción de ácido acrílico. El primero, basado también en hidroxipropionitrilo (obtenido por catálisis básica de óxido de etileno y $\mathrm{HCN}$ ), que reacciona con un alcohol o agua en presencia estequiométrica de $\mathrm{H}_{2} \mathrm{SO}_{4}$ formando el ácido o éster correspondiente [16].

El proceso Reppe empleaba la reacción catalítica de carbonilación de acetileno en presencia de agua o alcoholes. Otro proceso fue la reacción de cetena con formaldehido para dar $\beta$-propiolactona cuya hidrólisis con $\mathrm{H}_{3} \mathrm{PO}_{4}$ da lugar al ácido acrílico. Finalmente, también se desarrollo la hidrólisis de acrilonitrilo con intermedio de acrilamida. Sin embargo, a partir de los años 60-70, la obtención de ácido acrílico se ha llevado a cabo principalmente por oxidación catalítica de propileno a través de la acroleína.

Actualmente, casi toda la producción mundial de ácido acrílico se obtiene por oxidación catalítica de propileno, en fase gas, en un proceso en dos etapas [16, 20]. En la primera etapa, el propeno se transforma selectivamente en acroleína (en un proceso similar al empleado en la obtención de acrilonitrilo), mientras que en la segunda etapa, la acroleína se oxida selectivamente a ácido acrílico:

Etapa 1:

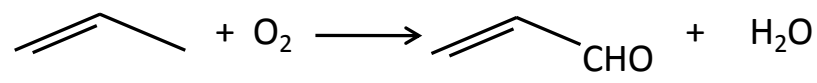

Etapa 2:<smiles>C=C[C+][O+2]C=CC(=O)O</smiles>

Las condiciones óptimas de ambos procesos son diferentes. La temperatura de reacción es mayor en la primera etapa que en la segunda, ya que la activación de propeno requiere mayores temperaturas que la activación de la acroleína. Generalmente, en la primera etapa el propileno se oxida a acroleína en presencia de aire y vapor de agua a $320-330^{\circ} \mathrm{C}$ y $1-2$ bar. La reacción exotérmica se lleva a cabo en un reactor tubular de lecho fijo. Los productos de reacción se alimentan directamente a un segundo reactor donde la acroleína es oxidada a ácido acrílico a $200-260^{\circ} \mathrm{C}$. Cada etapa se lleva a cabo con buenos rendimientos, siendo mayores del $90 \%$ para la obtención de acroleína y del $97 \%$ para el ácido acrílico en la segunda etapa, lo que supone un rendimiento global de ácido acrílico en torno al 87\%. Los subproductos obtenidos (ácido acético, ácido propiónico, ácido maléico, acetaldehído y acetona) se separan del ácido acrílico por destilación.

Las dos etapas de reacción se llevan a cabo con catalizadores multicomponentes, aunque los sistemas catalíticos son diferentes para cada una 
de ellas. En la primera etapa, son catalizadores multicomponentes basados en óxidos mixtos de MoBiO o FeSbO [20-21], similares a los empleados en la amoxidación de propileno a acrilonitrilo. En el caso de la oxidación de acroleína a ácido acrílico se emplean catalizadores basados en óxidos mixtos de molibdeno y vanadio (Mo-V-O) [22].

Alternativamente, el ácido acrílico se puede producir también a partir de la oxidación de propeno en una sola etapa:

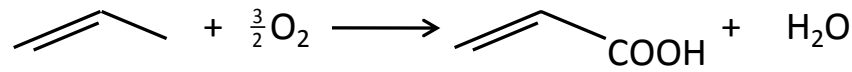

En este caso, el rendimiento por etapa (73\%) es inferior al obtenido en el proceso de dos etapas [20]. La temperatura de reacción utilizada está en el rango $325-350^{\circ} \mathrm{C}$, necesario para obtener la suficiente conversión de propileno. Sin embargo, a esta temperatura no solo se produce la reacción deseada sino que también puede dar lugar la transformación de acroleína o ácido acrílico para producir compuestos $\mathrm{C} 1-\mathrm{C} 2$, como el ácido acético y productos de la oxidación completa.

\subsubsection{Catalizadores para la amoxidación/oxidación de propileno a acrilonitrilo/acroleína}

La obtención de acrilonitrilo y acroleína se llevan a cabo por amoxidación/oxidación de propileno, respectivamente. En ambos casos, la reacción tiene lugar por un mecanismo de oxidación alílico [23-25]. Así, en la primera etapa la olefina se activa mediante la abstracción de un hidrógeno a para dar lugar a un intermedio m-alílico. La abstracción del hidrogeno es la etapa determinante en la velocidad de reacción. A continuación, se produce la adición de oxígeno al intermedio m-alílico para la formación de acroleína o, en presencia de amoníaco, la inserción de nitrógeno en el caso del acrilonitrilo.

Debido a la similitud de ambos mecanismos de reacción, era de esperar que se pudiera emplear el mismo tipo de catalizadores en ambas reacciones. De hecho, se han desarrollado sistemas de catalizadores capaces de actuar en ambas reacciones, bien para la formación de acroleína, bien para la obtención de acrilonitrilo. Aunque, la presencia de amoníaco y el uso de mayores temperaturas de reacción hacen que la amoxidación sea una reacción de mayor complejidad que la oxidación parcial de propeno a acroleina. Por este motivo, los catalizadores industriales empleados en la actualidad en la amoxidación de propileno son más complejos y sofisticados. Aun así, un catalizador de amoxidación es generalmente activo y muy selectivo en ambas reacciones. 
Todos los sistemas catalíticos estudiados para la amoxidación/oxidación de propileno son de naturaleza similar: óxidos metálicos que actúan de acuerdo con un mecanismo redox o de reducción-oxidación, propuesto inicialmente por Mars y Van Krevelen en 1954 [26], mecanismo que se muestra simplificado en el Esquema 1.1. Según este mecanismo, una molécula de hidrocarburo se adsorbe sobre un centro activo del catalizador. Un oxígeno de la red unido a un catión metálico $M_{1}^{n+}$, es el responsable de la abstracción del primer hidrógeno, mientras que la incorporación posterior de un átomo de oxígeno del catalizador a la molécula de hidrocarburo da lugar a la formación de un producto de oxidación parcial y $\mathrm{H}_{2} \mathrm{O}[23,27]$. El oxígeno de la red de un centro metálico próximo $\mathrm{M}_{\|}{ }^{\mathrm{n}}$ difunde hacia el centro activo que se ha reducido por el alcano, para reemplazar el oxígeno perdido durante la reacción. Finalmente, el oxígeno molecular en fase gas se incorpora al centro $\mathrm{M}_{\|}{ }^{\mathrm{m}+}$ (adsorción y disociación del $\mathrm{O}_{2}$ ) y lo reoxida a $\mathrm{M}_{\|}{ }^{\mathrm{n}+}$, convirtiéndose en oxígeno de red y entrando a formar parte de la estructura del catalizador. De acuerdo con este modelo, la oxidación catalítica de un hidrocarburo conlleva la reducción de un centro del catalizador por el hidrocarburo, y la reoxidación del catalizador a través de otro centro por el oxígeno molecular alimentado. El ciclo redox se completa con el oxígeno de red y por la transferencia de electrones entre los dos centros del catalizador involucrados.

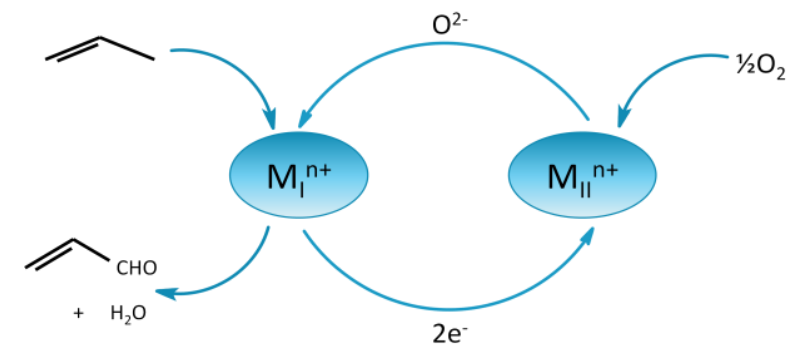

Esquema 1.1. Mecanismo Mars-Van Krevelen simplificado. Adaptado de [25].

De esta forma, el oxígeno de red del óxido es capaz de actuar como agente oxidante de forma más selectiva que el oxígeno molecular. Así, el óxido metálico se emplea como reactante, donde el oxígeno de red del catalizador participa en la inserción de oxígeno para la obtención de acroleína [28-29]. El papel del oxígeno de red del catalizador se ha demostrado mediante intercambio isotópico de oxígeno, usando ${ }^{18} \mathrm{O}_{2}$ en lugar de ${ }^{16} \mathrm{O}_{2}$ [30-32]. Los resultados muestran que el oxígeno de red es incorporado a los productos de oxidación selectiva, siendo los primeros productos formados ricos en ${ }^{16} \mathrm{O}_{2}$, seguidos de productos formados posteriormente ricos en ${ }^{18} \mathrm{O}_{2}$ debido a la reoxidación del catalizador por el oxígeno en estado gaseoso. 
Así, los catalizadores efectivos en la amoxidación/oxidación de propileno deben tener dos centros activos diferentes involucrados en la reacción. En primer lugar, deben tener centros activos capaces de adsorber el propileno y transformarlo en el intermedio alílico, por abstracción de un protón, y posterior adición de oxígeno para la formación del producto de oxidación selectiva. Además, se encuentran los centros capaces de disociar el oxígeno e incorporarlo en la red del catalizador, para su reoxidacíon. Estos dos tipos de centros (activos y reoxidación) deben estar próximos para que se produzca rápidamente la migración de electrones y oxígeno de red $\left(\mathrm{O}^{2-}\right)$. Este hecho se ve fuertemente influenciado por la energía del enlace metal-oxígeno, que debe estar en un rango intermedio en condiciones de reacción, para que se dé rápidamente la eliminación durante la oxidación de la olefina y la adición durante la reoxidación. Si el enlace metaloxígeno es demasiado fuerte no se producirá la reacción. Si por el contrario, es demasiado débil se puede dar sobreoxidación obteniendo productos no deseados [33]. Este requisito lo cumplen óxidos de metales de naturaleza covalente y anfótera, como por ejemplo, molibdatos, antimoniatos y vanadatos.

Los óxidos metálicos deben ser multifuncionales y poseer una serie de características redox, no sólo para reducirse durante la formación de acroleína sino también por la consecuente reoxidación del catalizador, en el cual el oxígeno gaseoso se incorpora a la red del catalizador como $\mathrm{O}^{2-}$ para reemplazar las vacantes en el catalizador [19, 25]. Además, los centros activos tienen que realizar diversas funciones en el ciclo catalítico, como la absorción química del propileno, la abstracción de hidrógeno de la olefina, la inserción de oxígeno o de nitrógeno en el intermedio alílico activo y adsorbido en la superficie del catalizador y la desorción del producto de oxidación selectiva. Normalmente, el tipo de óxidos estudiados en la oxidación de propileno son multimetálicos para poder llevar a cabo todas las etapas del proceso catalítico.

Las funciones de los centros activos en la superficie del catalizador están asociadas con las propiedades de los metales que componen el catalizador: (1) la abstracción de un hidrogeno $\alpha$, que viene dada por metales como $\mathrm{Bi}^{3+}, \mathrm{Sb}^{3+} \circ \mathrm{Te}^{4+}$; (2) adsorción de la olefina e inserción de oxígeno o nitrógeno, en metales como $\mathrm{Mo}^{6+} \circ \mathrm{Sb}^{5+}$; y (3) un par redox para aumentar la transferencia de oxígeno desde la red a la superficie del catalizador, como $\mathrm{Fe}^{2+} / \mathrm{Fe}^{3+}, \mathrm{Ce}^{3+} / \mathrm{Ce}^{4+} \circ \mathrm{U}^{5+} / \mathrm{U}^{6+}$. Además de la multifuncionalidad de los centros activos, la selectividad de este tipo de catalizadores también dependerá de su estructura, del oxígeno de red, de la fuerza del enlace metal-oxígeno, de la actividad redox y de la cooperación de fases, si existe más de una fase presente en el catalizador [33].

Debido al estudio de estas propiedades catalíticas se han desarrollado diversos tipo de catalizadores para el aumento de la producción de acroleína/acrilonitrilo desde el primer catalizador empleado en la oxidación de 
propileno basado en fosfomolibdato de bismuto [18]. Entre estos catalizadores podemos encontrar gran número de catalizadores multicomponentes basados en óxidos metálicos, diferenciando claramente dos grandes grupos: los basados en óxidos de antimonio, con uranio o hierro; o aquellos basados en óxidos multicomponentes de molibdeno y bismuto, los más empleados comercialmente.

\subsubsection{Catalizadores basados en molibdatos metálicos.}

En la literatura se pueden encontrar numerosos estudios sobre la estructura, propiedades fisicoquímicas y reactividad en la amoxidación/oxidación de propileno de los molibdatos de bismuto. El óxido de bismuto $\left(\mathrm{Bi}_{2} \mathrm{O}_{3}\right)$ por sí solo presenta una baja conversión y da como resultados los productos de oxidación completa $\left(\mathrm{CO}_{\mathrm{x}}\right)$, mientras que el óxido de molibdeno $\left(\mathrm{MoO}_{3}\right)$ da también una baja conversión pero ligera selectividad a los productos de oxidación parcial. Sin embargo, la combinación de ambos óxidos da un aumento considerable de la actividad y la selectividad en la oxidación de propileno [24], debido a que presenta una cooperación entre los centros de bismuto, capaces de activar a la olefina, y los centros de molibdeno dónde se produce la inserción de oxígeno o nitrógeno [19].

La actividad de estos molibdatos de bismuto está relacionada con la composición, siendo los más efectivos los que se encuentran en el rango de composiciones Bi:Mo entre 2:3 y 2:1. En este rango se encuentras tres tipos de fases cristalinas: $\alpha-\mathrm{Bi}_{2} \mathrm{Mo}_{3} \mathrm{O}_{12}, \beta-\mathrm{Bi}_{2} \mathrm{Mo}_{2} \mathrm{O}_{9}, \mathrm{y} \mathrm{y}-\mathrm{Bi}_{2} \mathrm{MoO}_{6}$. La fase $\alpha$ es isomorfa a $\mathrm{CaWO}_{4}$, donde los molibdenos se encuentran en coordinación tetraédrica. La fase y tiene una estructura laminar (capas sucesivas de $\mathrm{Bi}_{2} \mathrm{O}_{2}$ y $\mathrm{MoO}_{2}$ ), donde los átomos de molibdenos se coordinan octaédricamente. Por último, la fase $\beta$ es una mezcla entre las fases a y $\mathrm{\gamma}$, donde los átomos molibdeno se encuentra coordinado tetraédricamente. De las tres fases puras, la fase $\beta$ es la que representa un mayor rendimiento a acrilonitrilo, seguido de la fase $\alpha$. Sin embargo, composiciones intermedias, es decir, mezcla de fases, presentan un rendimiento mayor [19].

La primera generación de catalizadores comerciales para la amoxidación de propileno, desarrollados por Sohio en los años 60, fue el heteropoliácido de formula $\mathrm{Bi}_{9} \mathrm{PMo}_{12} \mathrm{O}_{52}$ soportado en $\mathrm{SiO}_{2}(50 \%$ en peso) [18]. Debido a la estabilidad del heteropoliácido y a la temperatura de reacción, $450-480^{\circ} \mathrm{C}$, el catalizador en condiciones de reacción se transformaba a $4 \mathrm{Bi}_{2} \mathrm{Mo}_{3} \mathrm{O}_{12}$ (fase $\alpha$ ) + $\mathrm{BiPO}_{4}$, con un rendimiento a acrilonitrilo de $55 \%$. Sin embargo, el rendimiento a acrilonitrilo o acroleína se ve incrementado si se adicionan otros elementos, con propiedades redox (como $\mathrm{Fe}, \mathrm{Cr} \circ \mathrm{Ce}$ ) a los molibdatos de bismuto. Entre los catalizadores estudiados destaca el sistema Bi-Fe-Mo, que es capaz de aumentar considerablemente la conversión en comparación con sus homólogos sin hierro. Así, la primera mejora dentro de los catalizadores comerciales para la amoxidación/oxidación de propileno fue la adición del Fe como elemento redox, 
siendo la composición final $\mathrm{Fe}_{4.5} \mathrm{Bi}_{4.5} \mathrm{PMo}_{12} \mathrm{O}_{52}$ [34], aumentando el rendimiento a acrilonitrilo hasta un $65 \%$. El hierro, en su estado de oxidación 3+ es capaz de transferir eficientemente el oxígeno de red a la fase activa Bi-O-Mo; y capaz de quimisorber el oxígeno molecular e incorporarlo a la red de oxigeno $\left(\mathrm{O}^{2-}\right)$ en su estado de oxidación 2+. La presencia de hierro hace que los óxidos mantengan su actividad y selectividad incluso bajo condiciones reductoras. Además de las mejoras catalíticas, el uso de hierro en lugar de bismuto abarató los costes en la producción del catalizador. Sin embargo, la presencia de hierro obliga a trabajar con un control muy riguroso de la composición de la alimentación, debido a que el exceso de hierro empleado da lugar a $\mathrm{Fe}_{2} \mathrm{Mo}_{3} \mathrm{O}_{12}$ que quema el hidrocarburo y el amoníaco. De hecho, los catalizadores comerciales para la (am)oxidación de propileno que actualmente se comercializan son óxidos multicomponentes que contienen bismuto, hierro y molibdeno, con adición de otros cationes como promotores.

El siguiente cambio producido en la composición de los catalizadores comerciales fue la introducción de un catalizador multifase. La fórmula de este catalizador es $\mathrm{K}_{2}(\mathrm{Ni}, \mathrm{Co})_{9} \mathrm{Fe}_{3} \mathrm{BiPMo}_{12} \mathrm{O}_{x}$ y da lugar a rendimientos a acrilonitrilo del orden de 75\% [35-36]. La concentración de hierro y bismuto se reduce, y se adicionan elementos como $\mathrm{Ni}$ y $\mathrm{Co}$ a la estructura. La presencia de $\mathrm{Ni}$ y Co da lugar a la formación de molibdatos isomorfos a $\beta$-FeMoO4, formando la estructura ( $\mathrm{Fe}, \mathrm{Ni}, \mathrm{Co}) \mathrm{MoO}_{4}$, con lo que se consigue la estabilización de $\mathrm{Fe}^{2+}$. También, se adiciona una pequeña cantidad de alcalino, como potasio, con el que se disminuye la acidez en la superficie del catalizador, además de influir en la topología de la fase activa. Las dos fases se componen por la fase activa a molibdato de bismuto que contiene $\mathrm{Fe}^{3+}$ y la fase $(\mathrm{Fe}, \mathrm{Ni}, \mathrm{Co}) \mathrm{MoO}_{4}$ con $\mathrm{Fe}^{2+}[37]$.

La siguiente generación de catalizadores comerciales son más complejos y refinados, con la formula empírica $(\mathrm{K}, \mathrm{Cs})_{\mathrm{a}}(\mathrm{Ni}, \mathrm{Co}, \mathrm{Mn})_{9.5}(\mathrm{Fe}, \mathrm{Cr})_{2.5} \mathrm{BiMo}_{12} \mathrm{O}_{\mathrm{x}}$ [38]. El rendimiento alcanzado con este tipo de catalizadores asciende a $80 \%$. La incorporación de $\mathrm{Mn}$ estabiliza la estructura de los molibdatos divalentes. La adición de $\mathrm{Cr}$ ayuda a la dilución de la concentración de $\mathrm{Fe}^{3+}$ en la fase activa $\mathrm{BiMo}_{3} \mathrm{O}_{12}$, además de actuar como par redox $\mathrm{Cr}^{3+} / \mathrm{Cr}^{2+}$ por sí mismo.

Por último, se refina aun más la composición del catalizador para la amoxidación de propileno, siendo $(\mathrm{K}, \mathrm{Cs})_{\mathrm{a}}(\mathrm{Ni}, \mathrm{Mg}, \mathrm{Mn})_{7.5}(\mathrm{Fe}, \mathrm{Cr})_{2.3} \mathrm{Bi}_{0.5} \mathrm{Mo}_{12} \mathrm{O}_{\mathrm{x}}$ [39], obteniendo un rendimiento a acrilonitrilo de $80 \%$. El cambio más significativo es la sustitución de Co por Mg. Este cambio estabiliza la estructura $\beta$ con la formación de la fase de reoxidación $(\mathrm{Fe}, \mathrm{Ni}, \mathrm{Mg}, \mathrm{Mn}) \mathrm{MoO}_{4}$, haciendo que el proceso de reoxidación sea más eficiente. Además, el Co es un elemento perjudicial para el medio ambiente. 
Los catalizadores también contienen un exceso de molibdeno con respecto a la estequiometria requerida para la formación de los molibdatos. El exceso de Mo es importante para la reacción porque actúa como puente entre los molibdatos. Además, bajo condiciones reductores se pierde molibdeno, bajo la forma $\mathrm{MoO}(\mathrm{OH})_{2}$ volátil, al reducirse $\mathrm{Fe}^{3+}$ a $\mathrm{Fe}^{2+}$. El exceso de $\mathrm{MoO}_{3}$ puede añadirse bien en la composición del catalizador, o bien puede ser añadido durante la misma reacción.

Otro tipo de molibdatos desarrollados como catalizadores son molibdatos basados en Te y no en Bi. Este tipo de molibdato fueron comercializados en Italia por Montedison Corporation [40].Sin embargo, este tipo de catalizadores no ha alcanzado una importancia industrial debido a los problemas de volatilidad de teluro (p. f. $450^{\circ} \mathrm{C}$ ), que durante la reacción se reduce a $\mathrm{Te}^{0}$ que volatiliza y destruye la fase activa del catalizador.

\subsubsection{Catalizadores basados en antimoniatos metálicos.}

Otro grupo de catalizadores empleados en la amoxidación/oxidación de propileno son los basados en antimoniatos que contienen al menos uno de los siguientes elementos: $\mathrm{U}, \mathrm{Fe}, \mathrm{Sn}, \mathrm{Mn} \circ \mathrm{Ce}$.

El primer catalizador de este tipo fue desarrollado por Sohio en los años 60 basado en antimoniato de uranio, $\mathrm{USb}_{4.6} \mathrm{O}_{x}$ (cuya fórmula molecular es $\mathrm{USb}_{3} \mathrm{O}_{10}$. $0.8 \mathrm{Sb}_{2} \mathrm{O}_{4}$ ) [41]. La fase activa, $\mathrm{USb}_{3} \mathrm{O}_{10}$, es una fase de estructura ortorrómbica donde el $\mathrm{Sb}$ en estado de oxidación 3+ activa tanto el propeno como el amoníaco, la adsorción de propileno y la inserción de oxígeno o nitrógeno se lleva a cabo en los centros de $\mathrm{Sb}^{5+}$, y donde la reoxidación del catalizador tiene lugar sobre el par redox $\mathrm{U}^{5+} / \mathrm{U}^{6+}$. Los rendimientos obtenidos con este catalizador eran mayores a los obtenidos con el fosfomolibdato de bismuto, por lo que fue llevado a escala comercial. Sin embargo, debido a las leyes medioambientales referentes al uso de uranio, este se dejó de comercializar y se sustituyó por antimoniatos basados en hierro o molibdatos de bismuto.

Los antimoniatos de hierro fueron desarrollados simultáneamente por Sohio, UCB en Bélgica y Nitto Corp en Japón. La primera versión de esta catalizador tiene como fórmula $\mathrm{FeSb}_{8.6} \mathrm{O}_{x}\left(1 / 2 \mathrm{Fe}_{2} \mathrm{Sb}_{2} \mathrm{O}_{7} \cdot 3.8 \mathrm{Sb}_{2} \mathrm{O}_{4}\right)$ [19]. La fase activa de estos catalizadores, $\mathrm{Fe}_{2} \mathrm{Sb}_{2} \mathrm{O}_{7}$, tiene una estructura de trirutilo, sin embargo, es necesaria la adición de óxido de antimonio para obtener la selectividad deseada a los productos de oxidación parcial. Este exceso de antimonio actúa de igual forma que el exceso de molibdeno en los molibdatos: para mantener la composición estequiometria debido a la pérdida de antimonio durante la reacción.

Como en los molibdatos de bismuto, el hierro tiene un papel primordial en la reoxidación del catalizador, la transferencia de oxígeno desde la red a la superficie 
del catalizador, dejando los centros activos $\mathrm{Sb}^{3+}-\mathrm{O}_{-} \mathrm{Sb}^{5+}$ en su estado de oxidación. El hierro es fundamental, ya que sin su presencia, los óxidos de $\mathrm{Sb}$ no pueden llevar a cabo la reacción. Aun así, la fase activa no es muy selectiva para la amoxidación por lo que requiere una cantidad adicional de óxidos de antimonio.

Desde su desarrollo, se han hecho muchas modificaciones a los antimoniatos de hierro, siendo las formulaciones catalíticas cada vez más complejas. Un ejemplo de estas modificaciones es el catalizador descrito por $\mathrm{Nitto}, \mathrm{Na}_{0-3}(\mathrm{Cu}, \mathrm{Mg}$, $\mathrm{Zn}, \mathrm{Ni})_{0-4}(\mathrm{~V}, \mathrm{~W})_{0.05-1} \mathrm{Mo}_{0.1-2.5} \mathrm{Te}_{0.2-5} \mathrm{Fe}_{10} \mathrm{Sb}_{13-20} \mathrm{O}_{x}$ [42], que presenta un rendimiento a acrilonitrilo del $81.5 \%$. La adición de Cu provee un nuevo par redox al catalizador. Sin embargo, la adición de Mo y W compite con la formación de antimoniatos de $\mathrm{Fe}$ y $\mathrm{Cu}$ para formar molibdatos y wolframatos de estos dos elementos que favorecen una mayor disociación de oxígeno, incorporación de oxígeno al catalizador y transferencia de oxígeno que las correspondientes fases de antimoniatos. La función del teluro parece estar relacionada con la disminución de los centros no selectivos, mejorando la selectividad a acrilonitrilo.

Otra clase de antimoniatos similares a los de hierro, y con estructuras similares, son lo que contienen elementos con propiedades redox, tales como $\mathrm{Mn}$, $\mathrm{V}$ o Ce. Sin embargo, todos estos catalizadores requieren un exceso de antimonio. Sin embargo, la incorporación de otros elementos químicos puede mejorar también sus propiedades catalíticas.

La última clase de antimoniatos efectivos en la amoxidación de propileno son los basados en óxidos mixtos de antimonio y estaño, en los que la estructura de la fase activa parece ser una mezcla íntima de ambos óxidos más que la formación de fases cristalinas únicas. En este caso, se han observado dos tipos de catalizadores óptimos: uno rico en antimonio y otro rico en estaño. El estaño provee el necesario par redox $\mathrm{Sn}^{4+} / \mathrm{Sn}^{2+}$, y estabiliza los centro de $\mathrm{Sb}^{5+}$ en la estructura $\mathrm{Sb}^{3+}-\mathrm{O}-\mathrm{Sb}^{5+}$. Este tipo de materiales fueron comercializados en los años 60 , aunque ya en la década de los 80 dejaron paso a los catalizadores basados en molibdatos de bismuto multicomponentes y antimoniatos de hierro.

Todos los catalizadores basados en antimoniatos tienen problemas en condiciones reductoras, con altos niveles de hidrocarburo, incluso los dopados con Mo y W. Por ello, hay que tener un especial cuidado en la condiciones de reacción y trabajar siempre con un exceso de aire. En algunos casos, se puede llegar a perder la estructura de los materiales de forma irreversible por alguna fuga o pérdida de aire. En comparación, los molibdatos de bismuto son más indestructibles y aguantan mejor ese tipo de condiciones. 


\subsubsection{Catalizadores para la oxidación de acroleína a ácido acrílico}

La oxidación de acroleína constituye la segunda etapa del proceso de obtención de ácido acrílico. Antiguamente, esta oxidación se llevaba a cabo en fase líquida con complejos de metales de transición [43]. Sin embargo, a partir de los años 60, con la comercialización del proceso de oxidación catalítica de acroleína, en fase gas, se comenzó a emplear el proceso de oxidación de propileno a ácido acrílico en dos etapas. Desde entonces, se han desarrollado un gran número de catalizadores basados en óxidos metálicos multicomponentes para ambas etapas.

En el caso de la oxidación de acroleína a ácido acrílico, los sistemas catalíticos también están basados principalmente en óxidos de molibdeno multicomponentes. En un principio, se emplearon óxidos de molibdeno y cobalto [44]. Sin embargo, este tipo de sistemas fue rápidamente reemplazado por los catalizadores basados en óxidos de molibdeno y vanadio. Actualmente, en la industria se emplean sistemas catalíticos de composición $\mathrm{Mo}_{12} \mathrm{~V}_{4.6} \mathrm{Cu}_{2.2} \mathrm{~W}_{2.4} \mathrm{Cr}_{0.6}$, $\mathrm{Mo}_{12} \mathrm{~V}_{2} \mathrm{~W}_{2} \mathrm{Fe}_{3}, \mathrm{y} \mathrm{Mo}_{12} \mathrm{~V}_{3} \mathrm{~W}_{1.2} \mathrm{Ce}_{3}$ [45] con un rendimiento a ácido acrílico del $90 \%$.

Los óxidos mixtos Mo-V-O constituyen la base para el sistema catalítico en la oxidación de acroleína. En la literatura se pueden encontrar estudios sobre la estructura, propiedades fisicoquímicas y reactividad de estos óxidos [44-48]. En general, el comportamiento catalítico de este tipo de materiales depende de la composición y de las condiciones de reacción. Hoy en día se sabe que la oxidación de acroleína se ve favorecida por un exceso estequiométrico de oxígeno, en presencia de vapor de agua, y con una temperatura de reacción no superior a $300^{\circ} \mathrm{C}$. A altas temperaturas, además de la oxidación catalítica se produce la reacción radicalaria en fase gas [47].

En relación con la composición, los óxidos mixtos con una relación Mo/V alrededor de 3 ó 4 han demostrado ser activos y selectivos en la oxidación de acroleína a ácido acrílico. Cantidades de vanadio superiores dan lugar a una reducción de la selectividad con un aumento de la actividad catalítica. Por el contrario, el óxido de molibdeno puro es prácticamente inactivo [48]. Sin embargo, la naturaleza de la fase activa se ve fuertemente influenciada por la composición. Así, en los sistemas binarios Mo-V se han realizado varias investigaciones, encontrando que la fase activa y selectiva es $\mathrm{MO}_{3} \mathrm{VO}_{11}$ [44] ó $\mathrm{Mo}_{4} \mathrm{VO}_{14}$ [46], con una relación Mo-oxígeno similar pero estructuras muy diferentes.

Por otro lado, en los catalizadores comerciales, además de óxidos de vanadio y molibdeno, se añaden distintos elementos, como por ejemplo W, $\mathrm{Cu}, \mathrm{Fe}, \mathrm{Mn}$ ó $\mathrm{Ni}$ [49-50], como promotores a fin de mejorar la selectividad de la reacción de oxidación de acroleína a ácido acrílico y la estabilidad a largo plazo del 
catalizador. Así, la presencia de tungsteno parece jugar un papel clave en las propiedades catalíticas, además de estabilizar las estructuras a altas temperaturas y modificar las propiedades ácidas de los materiales. La presencia de Cu también modifica la acidez de los materiales y, en algunas industrias, se sustituye el W por $\mathrm{Nb}$ obteniendo propiedades similares [51]. En los catalizadores basados en óxidos de molibdeno y vanadio modificado con cobre la fase activa parece ser $\mathrm{Mo}_{3} \mathrm{VO}_{11+\mathrm{x}}$ y $\mathrm{Mo}_{2} \mathrm{VO}_{8+\times}$, donde el vanadio está parcialmente sustituido por cobre.

En los catalizadores con tungsteno se sugiere que la fase activa es $\mathrm{Mo}_{5} \mathrm{O}_{14}$, con una sustitución parcial de molibdeno por vanadio y wolframio, (MoVW) ${ }_{5} \mathrm{O}_{14}$ [52-53]. El wolframio ejerce un papel importante como promotor estructural en la formación y estabilización de la fase activa. El vanadio es responsable de la actividad catalítica, sin embargo, al emplearlo en la cantidades necesarias para un comportamiento catalítico óptimo desestabiliza la fase activa y pierde selectividad. La actividad de los catalizadores MoVW depende considerablemente de la cantidad de óxido (MoVW) ${ }_{5} \mathrm{O}_{14}$ presente en el material [52].

\subsubsection{Catalizadores para la oxidación de propileno a ácido acrílico en una sola etapa}

Como se ha mencionado anteriormente, el ácido acrílico también se puede obtener por oxidación catalítica de propileno en una sola etapa. Sin embargo, los rendimientos alcanzados en la oxidación directa son menores a los obtenidos en el proceso con dos etapas. Por esta razón, la mayoría de industrias emplean el proceso en dos etapas con acroleína como intermediario. Aun así, se han realizado muchos estudios para desarrollar un sistema catalítico eficaz para la oxidación directa de propeno a ácido acrílico.

La oxidación de propileno a ácido acrílico en una sola etapa necesita un catalizador muy selectivo, en cuyos centros activos se pueda activar el propileno, favoreciendo la oxidación a ácido acrílico en lugar de acroleína, es decir, adsorbiendo la acroleína para oxidar la cetona a su correspondiente ácido. En este sentido, cabe esperar que el sistema catalítico contenga elementos en común a los catalizadores empleados en las dos etapas del proceso industrial. En general, en la literatura de patentes [54-56] se pueden encontrar catalizadores basados en óxidos de molibdeno multicomponentes, empleando promotores metálicos, generalmente teluro. Además del teluro, también se emplean metales como $\mathrm{Bi}, \mathrm{Fe}$, Co ó $\mathrm{Ni}$, elementos presentes en los catalizadores para la oxidación de propano a acroleína; o elementos como $\mathrm{V}$ o W, importantes en la oxidación de acroleína a ácido acrílico.

En 1970, la compañía Nippon Shokunbai abrió su primera planta para la producción de ácido acrílico basada en la oxidación de propileno en una sola 
etapa. El catalizador empleado contenía Mo-W-Te-Sn-Co [56], alcanzando un rendimiento a ácido acrílico de $65 \%$. Sin embargo, al cabo de un año, la planta puso fin al proceso en un solo paso para convertirse en un proceso en dos etapas. Esto se debió principalmente al corto tiempo de vida del catalizador debido a la pérdida de Te por sublimación que se produce a la temperatura de reacción.

Desde entonces, se han realizado muchos esfuerzos para estabilizar el catalizador. Así, se desarrollaron materiales para suprimir la sublimación de teluro, como Mo-W-Te-Fe-Mn [55], alcanzando un $38 \%$ de rendimiento a ácido acrílico. Otra forma, es el desarrollo de catalizadores $\sin \mathrm{Te}$, como los patentados por Nippon Hayaku [57], Mo-Bi-Fe-Ni-Co-As con un 60\% de rendimiento; o Mitsubishi [58], Mo-Bi-Ni-Co-Pd con un $50 \%$ de rendimiento; siendo menos efectivos que los catalizadores con Te y, por tanto nunca se comercializaron. Posteriormente, Nippon Shokubai desarrolló el catalizador sin Te más efectivo hasta el momento, $\mathrm{Nb}-\mathrm{W}-\mathrm{Co}-\mathrm{Ni}-\mathrm{Bi}-\mathrm{Fe}-\mathrm{Mn}-\mathrm{Si}-\mathrm{Z}$ [59], alcanzando un rendimiento a ácido acrílico del $73 \%$, pero se mantuvo en un nivel más bajo en comparación con los catalizadores de los procesos de dos etapas que se había comercializado.

\subsection{Hidrocarburos saturados como alternativa al empleo de olefinas}

Los hidrocarburos saturados (alcanos) de cadena corta, principalmente propano y butano, se encuentran en las fracciones ligeras del petróleo (fracción LPG) y, en menor medida, en el gas natural (LNG). En este último caso, el compuesto mayoritario es el metano, pero también se encuentran en él una cierta cantidad de otros hidrocarburos como etano (3-5\%) o propano (0.5-2\%). Sin embargo, hasta el momento, los excedentes de las fracciones LPG y LNG, exceptuando el etano, se han empleado mayoritariamente como combustible doméstico para la generación de calor.

La gran abundancia y disponibilidad de la fracción LPG como excedente en las refinerías y la existencia de grandes yacimientos de gas natural, determinan el bajo precio de cada uno de sus componentes, y ha despertado el interés sobre su posible aprovechamiento como materias primas en la industria petroquímica. En el caso particular del propano, su olefina correspondiente (propileno) es prácticamente inexistente en el petróleo y se debe recurrir a la transformación del crudo para su obtención. Esto hace que su disponibilidad sea inferior a la del alcano, lo que supone que su precio sea unas tres veces superior al precio del propano.

Además de la mayor disponibilidad y menor coste de los alcanos ligeros, hay que sumar el menor impacto ambiental asociado al uso de alcanos. Así, en el caso del propano, la tasa de $\mathrm{CO}_{2}$ asociada al proceso para su obtención a partir del gas 
natural, es de $230 \mathrm{~g}_{\mathrm{CO} 2} / \mathrm{Kg}_{\text {propano }}$, mientras que la tasa de $\mathrm{CO}_{2}$ asociada al proceso de obtención de propileno es unas 5 veces superior $\left(1200 \mathrm{~g}_{\mathrm{co} 2} / \mathrm{Kg}_{\text {propeno }}\right)$ [12].

El aumento de la demanda mundial de olefinas, lo que repercute en el alto precio de éstas, ha supuesto el desarrollo de procesos basados en alcanos para su transformación en olefinas y/o la sustitución de olefinas ligeras procesos conocidos. En este sentido, se ha propuesto la deshidrogenación oxidativa de propano como una alternativa para la obtención de propileno. Además, otra alternativa interesante es la sustitución de propileno por propano, en especial procesos de amoxidación/oxidación selectiva para la obtención de acrilonitrilo/ ácido acrílico.

Sin embargo, la menor reactividad de los alcanos ligeros presenta algunos inconvenientes importantes. Así, el empleo de alcanos conlleva un aumento del calor de reacción no sólo debido a la diferencia del calor de reacción asociada a la propia molécula sino también debido a un aumento en la formación de productos de combustión total, lo que supone una mayor inversión a nivel industrial. La mayoría de los procesos de conversión de alcanos implica mayor gasto de energía que las rutas competitivas basadas en una materia prima más cara pero más reactiva (olefina). Este es el caso de la producción de ácido acrílico a partir de la oxidación de propano (10.6 GJ/ton) o propileno (8.2 GJ/ton) [60]. No obstante, una vez hecha la inversión inicial en la infraestructura adecuada, el aprovechamiento del mayor calor de reacción de los alcanos supondría un mayor ahorro energético de la planta industrial, convirtiéndose en una ventaja adicional.

En los últimos años, se han intentado solventar algunos de estos problemas mediante el desarrollo de catalizadores miltifuncionales más activos para poder ser viables a nivel industrial, además de lo suficientemente selectivos como para evitar la formación de productos de oxidación total (combustión de los productos deseados).

\subsubsection{Obtención de olefinas a partir de alcanos}

Desde un punto de vista aplicado, el proceso catalítico más interesante para la obtención de olefinas a partir de su correspondiente alcano sería la deshidrogenación catalítica (DHC), dado que en esta reacción se produce también hidrógeno, de gran interés en las refinerías por su valor como fuente energética.

$$
\text { Alcano } \rightarrow \text { Olefina }+\mathrm{H}_{2}
$$

Actualmente, este tipo de reacciones de emplea para la producción de propeno (el $2 \%$ de la producción), butenos, butadieno, isobuteno y estireno, operando a altas temperaturas (entre 550 y $600^{\circ} \mathrm{C}$ ). Sin embargo, esta reacción presenta el inconveniente de ser un proceso endotérmico, por lo que la conversión 
máxima de alcano que se puede alcanzar, a una temperatura dada, está limitada por la constante de equilibrio. Además, se dan reacciones secundarias no deseadas, como el craqueo de parafinas y olefinas y, sobretodo, la formación de coque que obstruye los centros activos del catalizador y causa su desactivación.

Una alternativa al proceso de deshidrogenación catalítica es la deshidrogenación oxidativa $(\mathrm{DHO})$ del alcano:

$$
\text { Alcano }+\mathrm{O}_{2} \rightarrow \text { Olefina }+\mathrm{H}_{2} \mathrm{O}
$$

Esta reacción presenta la ventaja de ser exotérmica, permitiendo trabajar a temperaturas más bajas. Además, no existe el problema de la formación de coque, ya que al estar presente el oxígeno se obtiene en su lugar óxidos de carbono como subproductos de las reacciones secundarias, lo que supone una regeneración in-situ del catalizador.

Sin embargo, uno de los inconvenientes de la deshidrogenación oxidativa es la dificultad de obtener altos rendimientos a olefinas, dado que el aumento de la conversión de alcano produce generalmente un aumento considerable de la formación de óxidos de carbono y un descenso en la selectividad a olefina. Esto se debe a que la velocidad de combustión de la olefina es mucho mayor (entre $5 \mathrm{y}$ 10 veces) que la velocidad de formación de la olefina [61]. Además, para alcanzar mayor conversión de alcano, es necesario aumentar la proporción de oxígeno en la alimentación, lo que también puede favorecer los procesos de combustión. Así, los procesos de DHO sólo resultarían rentables si se alcanzaran rendimientos a olefina lo suficientemente altos como para compensar la obtención de hidrógeno (alto valor energético) que tiene lugar en los procesos DHC. En este sentido, se ha sugerido que aquellos procesos que sean capaces de obtener rendimientos a olefina en torno al $65 \%$ podrían ser competitivos, y resultarían interesantes para plantearse una implantación a nivel industrial [7].

Hasta el momento, los resultados de mayor selectividad a olefina se han encontrado durante procesos de DHO de etano a eteno [8,62-63], debido a la menor reactividad de la olefina, que le hacen menos susceptible a reacciones de degradación. En este sentido, este es el proceso que presenta mayores expectativas de una aplicación industrial. Entre los catalizadores estudiados para la DHO de etano destacan principalmente dos grupos: i) óxidos mixtos basados en $\mathrm{NiO}$ [64-65]; ii) catalizadores multicomponentes MoVTe(Sb)NbO (con los que se alcanzan rendimientos de etileno cercanos al 75\%) [66-67]. 


\subsubsection{Obtención de compuestos oxigenados a partir de alcanos}

En los últimos 20 años se está prestando una especial atención a la posible funcionalización de alcanos mediantes procesos de oxidación selectiva [3, 14, 19, 23-25, 33, 63, 68-70]. En la Tabla 1.1 se muestran algunos de los ejemplos de mayor interés industrial de procesos de oxidación selectiva de alcanos.

Tabla 1.1. Estado actual de posibles aplicaciones de oxidación selectiva de alcanos ligeros $\left(\mathrm{C}_{1}-\mathrm{C}_{5}\right)$ a procesos industriales [70].

\begin{tabular}{llll}
\hline Alcano & Catalizador & Producto & Estado del proceso \\
\hline Metano & $\mathrm{VO}_{\times} / \mathrm{SiO}_{2}$ & Formaldehído & Investigación \\
Metano & $\mathrm{REO} ;{\mathrm{MWMn} / \mathrm{SiO}_{2}}$ & Eteno & Investigación \\
Etano/HCl & $\mathrm{LaOCl} / \mathrm{LaCl}_{3}$ & Cloruro de vinilo & Investigación \\
Etano & $\mathrm{Mo}-\mathrm{V}-\mathrm{Nb}-\mathrm{O}$ & Ácido Acético & Investigación \\
Propano & $\mathrm{Mo}-\mathrm{V}-\mathrm{Te}-\mathrm{Nb}-\mathrm{O}$ & Ácido Acrílico & Investigación \\
Propano/ $\mathrm{NH}_{3}$ & $\mathrm{Mo}-\mathrm{V}-\mathrm{Te}-\mathrm{Nb}-\mathrm{O}$ & Acrilonitrilo & Planta Piloto \\
n-Butano & V-P-O & Anhídrido Maleico & Industrial \\
Isobutano & V-P-Mo-Cu-Cs-O & Ácido Metacrílico & Investigación \\
n-Pentano & V-P-O & Anhídrido Ftálico & Investigación \\
\hline
\end{tabular}

Aunque el posible número de productos de oxidación parcial de alcanos ligeros $\mathrm{C}_{2}-\mathrm{C}_{5}$ (con la posible formación de epóxidos, aldehídos, ácidos 0 anhídridos) es relativamente alto, sólo unas pocas reacciones parecen ser viables por el momento. Esto sugiere que se debería tener en cuenta las características de los reactivos y productos en el diseño de posibles procesos químicos. En el caso de la oxidación de alcanos, la activación de los enlaces $\mathrm{C}$-H es el paso determinante en la reacción de oxidación, ya que al carecer de electrones $\pi$ dificulta la adsorción y, por tanto, la activación. Además, los productos de oxidación de alcanos son más susceptibles a reacciones adicionales que el reactivo de partida. Así, si un catalizador es capaz de activar un alcano de bajo peso molecular (muy estable), en principio podría ser capaz de descomponer más fácilmente el producto si éste es más reactivo. Por ello, la reactividad del reactante y la estabilidad de los productos de oxidación parcial determinan la viabilidad de un proceso de oxidación selectiva. Teniendo en cuenta estas consideraciones, la síntesis de anhídrido maleico a partir de n-butano, etileno a partir de etano, y ácido acrílico o acrilonitrilo a partir de propano son las que poseen mejores expectativas para los próximos años [71].

De hecho, el único proceso de oxidación selectiva en fase gas de un alcano ligero que está plenamente desarrollado a nivel industrial es la oxidación selectiva de n-butano a anhídrido maleico empleando como catalizadores materiales del tipo V-P-O [3, 72-73] (Esquema 1.2), proceso que ha sustituido a los procesos 
anteriores en los que se empleaba benceno o butenos. La sustitución de benceno por n-butano evita la toxicidad asociada al empleo de una materia prima tóxica (benceno, un compuesto cancerígeno), pero, además, supone un ahorro en el coste de la materia prima de un $64 \%$ y un ahorro en el coste final del anhídrido maleico superior al 40\%, con una reducción importante del número de subproductos [73].
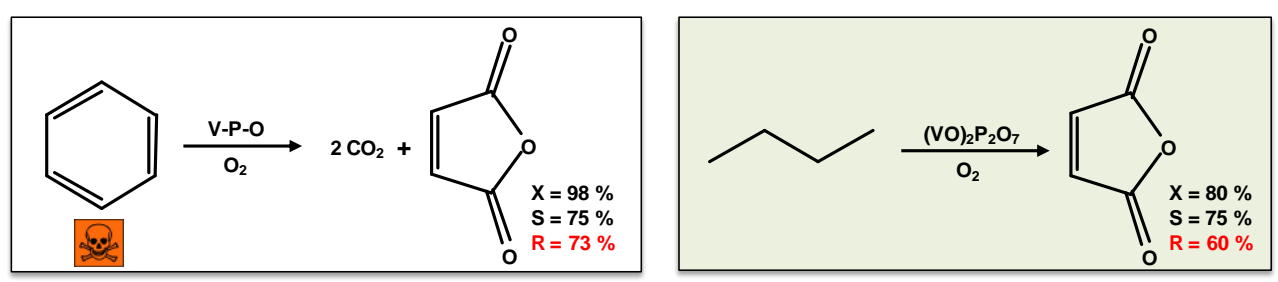

Esquema 1.2. Proceso de obtención del anhídrido maleico (AM) a partir de n-butano en comparación con el antiguo proceso que empleaba benceno como materia prima. Conversión $(X)$ del alcano, selectividad (S) y rendimiento $(R)$ a $A M$.

Por otro lado, es importante destacar que el proceso de oxidación selectiva de n-butano favorece un mayor rendimiento atómico, disminuyendo drásticamente la formación de óxidos de carbono. Así, la oxidación de benceno (con 6 átomos de carbono) para obtener anhídrido maleico (con 4 átomos de carbono) lleva asociada la formación estequiométrica de dos moléculas de $\mathrm{CO}_{2}$ por cada molécula de anhídrido maleico. En condiciones óptimas, $100 \mathrm{Kg}$ de benceno producen $129 \mathrm{Kg}$ de anhídrido maleico y $113 \mathrm{Kg}$ de $\mathrm{CO}_{2}$, mientras que en proceso a partir de n-butano, $100 \mathrm{Kg}$ de butano darán lugar sólo a la formación de anhídrido maleico (unos $170 \mathrm{Kg}$ de anhídrido maleico).

La obtención de anhídrido maleico también se ha llevado a cabo a partir de la olefina (1-buteno). Sin embargo, la oxidación de 1-buteno conlleva la formación de pequeñas cantidades de furano, acetaldehído, crotonaldehído o metil-vinil-cetona, lo que encarece el proceso, ya que es necesaria una etapa de purificación [73]. Sin embargo, estos subproductos no se observan durante la oxidación selectiva de n-butano [72-73].

Actualmente, este proceso a partir de n-butano se lleva a cabo en presencia de catalizadores basados en pirofosfato de vanadilo, $(\mathrm{VO}){ }_{2} \mathrm{P}_{2} \mathrm{O}_{7}$ (denominados genéricamente VPO), lo que permite alcanzar rendimientos a anhídrido maleico alrededor del $60 \%[3,72-73]$. Estos resultados son superiores a los que se obtendrían a partir de n-buteno, y aumentan las expectativas de una posible sustitución de las olefinas por alcanos en otros procesos de oxidación selectiva [72]. 


\subsection{Oxidación y amoxidación selectiva de propano}

En el caso particular de la oxidación de propano, esta se puede desarrollar por diferentes vías (Figura 1.4) [20]. En todos los casos, la reacción de oxidación de propano se inicia con la abstracción de un hidrógeno de la molécula de alcano. Esta etapa puede dar lugar a la formación de diferentes intermedios de reacción, dependiendo de la naturaleza de los centros activos y/o del entorno de los mismos. La abstracción de un segundo hidrógeno puede dar lugar a la formación de la olefina, la cual, dependiendo del medio de reacción y del catalizador empleado, puede dar lugar a la formación de compuestos parcialmente oxigenados y/o óxidos de carbono.

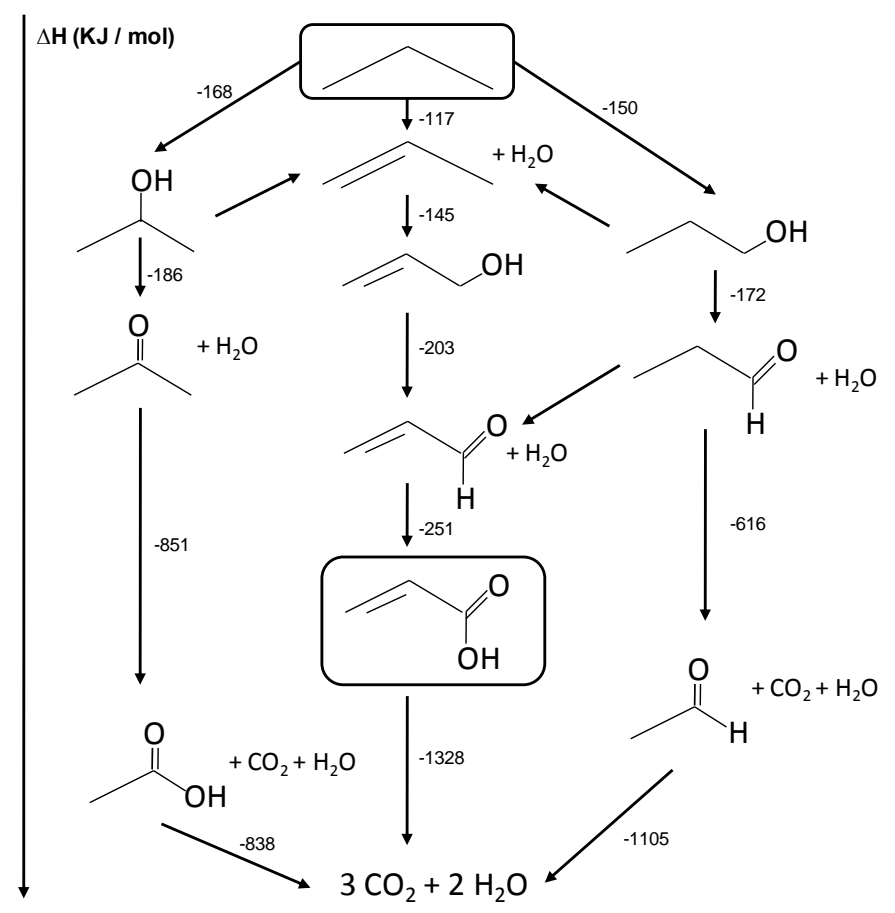

Figura 1.4. Esquema de la oxidación de propano y entalpías estándar de reacción (KJ/mol), adaptado de [20].

El propano, como hidrocarburo saturado, es menos reactivo que sus productos de oxidación parcial, debido a la fuerza de los enlaces $\mathrm{C}-\mathrm{H}$. Como resultado, se necesita una gran cantidad de energía para activar selectivamente los enlaces $\mathrm{C}-\mathrm{H}$ secundarios (aún mayor tratándose de enlaces $\mathrm{C}-\mathrm{H}$ primarios), esta energía es más que suficiente para que se produzca la rotura de enlaces C-C de los productos de oxidación parcial, dando productos $\mathrm{C} 1$ o C2 de escaso valor. 
Otra dificultad que presenta el proceso es la mayor o menor afinidad para la formación de productos de oxidación parcial. Algunos de estos productos, como el propileno o la acroleína, son intermedios para la obtención final de ácido acrílico mientras que otros, como la acetona, dan como resultados productos no deseados como el ácido acético. Por ello, para que se produzca la reacción de oxidación selectiva a los productos deseados, es necesario un sistema catalítico que active el propano mientras que, al mismo tiempo, suprima las reacciones de oxidación a productos no deseados y minimice la posibilidad de rotura del enlace C-C para dar $\mathrm{CO}_{x}[74]$.

La mayor estabilidad del ácido acrílico respecto a otros productos de oxidación parcial, sugiere mayores posibilidades a la hora de encontrar un catalizador selectivo en la reacción de oxidación parcial de propano. En cualquier caso, la estabilidad del ácido acrílico es inferior al acrilonitrilo, producto también deseado y que se obtiene en el proceso de amoxidación de propano.

\subsubsection{Aspectos clave de los catalizadores para la oxidación parcial de propano}

El sistema catalítico que se vaya a emplear en la oxidación de propano debe cumplir una serie de características para que la transformación de una molécula simple y poco reactiva (propano) se transforme en un compuesto más complejo y más reactivo. En primer lugar, debe ser capaz de activar el propano pero evitando la sobreoxidación de los productos deseados, formación de óxidos de carbono. Además, debe ser selectivo e inhibir la formación de otros productos como el ácido acético.

Hasta el momento, los catalizadores que presentan los resultados más prometedores en las reacciones de oxidación parcial de alcanos ligeros son aquellos basados en óxidos mixtos de metales de transición con propiedades redox, que actúan de acuerdo con un mecanismo de oxidación-reducción MarsVan Krevelen (Esquema 1.1). La capacidad de la superficie de los catalizadores para llevar a cabo este ciclo de oxidación-reducción dependerá de las propiedades redox de los átomos metálicos que formen el catalizador. En este sentido, los óxidos de metales de transición que resultan de interés como catalizadores de oxidación parcial son aquellos que presentan [23]: i) la posibilidad de tener dobles enlaces Metal=O; ii) un carácter ácido débil; iii) diferentes estados de oxidación; iv) la posibilidad de formar óxidos no estequiométricos en los que se puede cambiar el estado de oxidación con modificaciones mínimas en la estructura cristalina. Este es el caso de los óxidos de molibdeno $\left(\mathrm{MoO}_{3}, \mathrm{Mo}_{8} \mathrm{O}_{23}, \mathrm{Mo}_{5} \mathrm{O}_{14}, \mathrm{Mo}_{14} \mathrm{O}_{47}, \mathrm{Mo}_{4} \mathrm{O}_{11}\right.$, $\left.\mathrm{MoO}_{2}\right)$ o los óxidos de vanadio $\left(\mathrm{V}_{2} \mathrm{O}_{5}, \mathrm{~V}_{3} \mathrm{O}_{7}, \mathrm{~V}_{4} \mathrm{O}_{9}, \mathrm{~V}_{6} \mathrm{O}_{13}, \mathrm{VO}_{2}\right)$. Por otro lado, la presencia de promotores puede modificar las características de estos óxidos metálicos, variando el carácter de doble enlace Metal=O, las propiedades ácido- 
base, las propiedades redox o la estabilidad de la estructura cristalina $[3,14,19$, 23-25, 33, 63, 68-69].

Si bien los catalizadores basados en óxidos de molibdeno han resultado ser los más efectivos en procesos de oxidación parcial de olefinas [3, 19, 23-25, 33], los catalizadores basados en óxidos de vanadio parecen presentar las propiedades más adecuadas para los procesos de oxidación parcial de alcanos ligeros [14, 23, 33, 63, 68-69, 75-76]. Así, los resultados obtenidos con catalizadores en los que el vanadio aparece como elemento fundamental se han relacionado con la capacidad de los grupos $\mathrm{V}=\mathrm{O}$ y/o $\mathrm{V}-\mathrm{O}-\mathrm{V}$ para activar enlaces $\mathrm{C}$ $\mathrm{H}$ de los alcanos [23].

Por otro lado, la oxidación de propano a ácido acrílico requiere la cooperación de varios centros activos en la superficie del catalizador. Cada uno de estos centros formaría parte del mecanismo de reacción para la obtención del producto de oxidación parcial. Así, además de los centros para la activación de propano, son necesarios centros capaces de adsorber los productos intermedios (como propeno), en los que pueda seguir reaccionando. La naturaleza de la interacción con los compuestos intermedios de reacción en el mecanismo global de reacción es una pieza clave del control de la selectividad de la reacción [69]. Si la interacción entre los intermedios de reacción y el catalizador es muy fuerte, estos compuestos pueden ser sobreoxidados, formándose productos de reacción no deseados. Pero, si por el contrario, la interacción es débil puede causar la desorción los intermedios de reacción y/o la readsorción en centros no selectivos, disminuyendo la selectividad de los productos deseados.

Por tanto, un catalizador efectivo para llevar a cabo este proceso debería ser capaz de realizar al menos cuatro funciones:

1. Activar el propano, rompiendo un enlace $\mathrm{C}-\mathrm{H}$, el cual es extremadamente estable.

2. Insertar oxígenos selectivamente, bloqueando la oxidación de intermedios a productos no deseados

3. Bloquear o minimizar la ruptura del enlace C-C de los productos de oxidación parcial, que dirige a la formación de productos de combustión total, $\mathrm{CO}$ y $\mathrm{CO}_{2}$.

4. Favorecer la desorción del ácido acrílico para evitar su sobreoxidación.

Es decir, se necesitan catalizadores multifuncionales y con estructuras cristalinas que permitan completar los ciclos de oxidación-reducción a las temperaturas de reacción (entre 300 y $420^{\circ} \mathrm{C}$, temperaturas en las que los productos deseados son relativamente estables) sin sufrir alteraciones que favorezcan la desactivación y/o modificación de sus propiedades catalíticas y estructurales. 


\subsubsection{Sistemas catalíticos para la oxidación y amoxidación selectiva de propano}

Hasta el momento, los sistemas catalíticos estudiados en la reacción de oxidación selectiva de propano a ácido acrílico se pueden dividir en tres grandes grupos:

i) Sistemas catalíticos basados en pirofosfatos de vanadilo (sistema VPO);

ii) Sistemas basados en heteropoliácidos o sus sales correspondientes (HPA), en especial aquellos que contienen oxoaniones de Mo y V;

iii) Sistemas multicomponentes basados en óxidos metálicos mixtos (OMM), basados en óxidos de Mo y $\vee$ (que han demostrado una mayor eficiencia).

La Tabla 1.2 muestra los resultados catalíticos de algunos de los catalizadores estudiados en la oxidación selectiva de propano a ácido acrílico.

Tabla 1.2. Catalizadores más representativos de los tres sistemas catalíticos estudiados en para la oxidación selectiva de propano a ácido acrílico.

\begin{tabular}{|c|c|c|c|c|c|c|}
\hline & Catalizador & $\begin{array}{c}\mathrm{T} \\
\left({ }^{\circ} \mathrm{C}\right)\end{array}$ & $\begin{array}{c}\text { Conv. }^{a} \\
(\%)\end{array}$ & $\begin{array}{l}S_{A A}^{b} \\
(\%)\end{array}$ & $\begin{array}{l}\mathbf{R}_{\mathrm{AA}}{ }^{\mathrm{b}} \\
(\%)\end{array}$ & Ref. \\
\hline \multirow{3}{*}{ 웅 } & VPO & 420 & 46 & 32 & 15 & [77] \\
\hline & $\mathrm{VPZr}_{0.5} \mathrm{O}$ & 340 & 18 & 81 & 15 & [78] \\
\hline & $\mathrm{Ce} / \mathrm{VPO}$ & 390 & 28 & 68 & 19 & [79] \\
\hline \multirow{3}{*}{ 吕 } & $\mathrm{H}_{1.26} \mathrm{Cs}_{2.5} \mathrm{Fe}_{0.08} \mathrm{PVMo}_{11} \mathrm{O}_{40}$ & 380 & 47 & 28 & 13 & [80] \\
\hline & $\mathrm{H}_{3+\mathrm{n}} \mathrm{PV}_{\mathrm{n}} \mathrm{Mo}_{12} \mathrm{O}_{40} / \mathrm{Cs}_{3} \mathrm{PMo}_{12} \mathrm{O}_{40}$ & 400 & 50 & 22 & 11 & [81] \\
\hline & H-Sb-P-Mo-O & 340 & 10 & 20 & 2 & [82] \\
\hline \multirow{11}{*}{$\sum_{0}^{\Sigma}$} & $\mathrm{MoV}_{0.30} \mathrm{Te}_{0.23} \mathrm{Nb}_{0.12}$ & 380 & 84 & 63 & 53 & [83] \\
\hline & $\mathrm{MoV}_{0.30} \mathrm{Te}_{0.23} \mathrm{Nb}_{0.12}$ & 380 & 80 & 60 & 48 & [84] \\
\hline & $\mathrm{MoV}_{0.26} \mathrm{Te}_{0.14} \mathrm{Nb}_{0.16}$ & 380 & 63 & 76 & 48 & [85] \\
\hline & $\mathrm{MoV}_{0.30} \mathrm{Sb}_{0.17} \mathrm{Nb}_{0.07}$ & 430 & 55 & 62 & 34 & [86] \\
\hline & $\mathrm{MoV}_{0.30} \mathrm{Sb}_{0.25} \mathrm{Nb}_{0.12} \mathrm{~K}_{0.013}$ & 420 & 49 & 69 & 34 & [84] \\
\hline & $\mathrm{MoV}_{0.50} \mathrm{Te}_{0.17}$ & 380 & 34 & 46 & 16 & [87] \\
\hline & $\mathrm{MoV}_{0.50} \mathrm{Te}_{0.17}$ & 380 & 29 & 48 & 14 & [88] \\
\hline & $\mathrm{MoV}_{0.33} \mathrm{Sb}_{0.17}$ & 380 & 29 & 20 & 6 & [87] \\
\hline & $\mathrm{MoV}_{0.33} \mathrm{Sb}_{0.17}$ & 380 & 29 & 26 & 8 & [88] \\
\hline & $\mathrm{MoV}_{0.18} \mathrm{Sb}_{0.15} \mathrm{~K}_{0.01}$ & 380 & 27 & 39 & 11 & [89] \\
\hline & $\mathrm{MoV}_{0.33} \mathrm{Sb}_{0.17} \mathrm{~K}_{0.13}$ & 380 & 29 & 58 & 12 & [90] \\
\hline
\end{tabular}

a conversión de propano; ${ }^{\mathrm{b}}$ selectividad $\left(\mathrm{S}_{\mathrm{AA}}\right)$ y rendimiento $\left(\mathrm{R}_{\mathrm{AA}}\right)$ a ácido acrílico 
Debido a las similitudes que presentan las reacciones de oxidación de propano y de n-butano, se pensó en la posibilidad de emplear catalizadores del tipo VPO selectivos en la oxidación de n-butano a anhídrido maleico. Sin embargo, en el caso de la oxidación selectiva de propano el rendimiento a ácido acrílico obtenido con estos sistemas son menores al 15\% en comparación con el rango de rendimientos del 45-61\% para anhídrido maleico [77]. La razón de este comportamiento de los catalizadores VPO puede ser debida a una especificidad estructural para n-butano. También, se han estudiado el efecto de la adición de promotores al sistema VPO, obteniéndose en la mayoría de los casos una mejoría respecto del catalizador sin dopar aunque sin llegar a ser efectivos para la oxidación de propano a ácido acrílico. De hecho, el mayor rendimiento de ácido acrílico observado es $18.8 \%$ para el sistema V-P-O dopado con Ce [79].

El segundo tipo de catalizadores estudiado para la obtención de ácido acrílico es el formado por heteropoliácidos inorgánicos y sus correspondientes sales. La estructura de estos compuestos tiene forma de jaula con un catión central ( $P, A s$, $\mathrm{Si}, \mathrm{Ge}, \mathrm{B}$, etc.) que está rodeado por diversos polianiones de Mo o W. Entre sus propiedades más importantes para su aplicación a las reacciones de oxidación de propano se encuentran el control de los iones que pueden incorporarse a la red $y$ las propiedades redox de estos materiales. Así, este tipo de materiales ha resultado ser efectivo en reacciones de dehidrogenación oxidativa de etano y propano [91-92]. Sin embargo, los rendimientos de ácido acrílico son bajos (13\%) [80] y, además, presentan una baja estabilidad térmica (en muchos casos a temperaturas inferiores a $380^{\circ} \mathrm{C}$ ).

Más recientemente, Davis y col. [93-96] obtuvieron una alta actividad y selectividad para la oxidación de n-butano a ácido maleico empleando como catalizadores heteropoliácidos basados en ácido molibdovanado-fosfórico con metales y/o piridina intercambiados. Estos catalizadores deben ser pretratados a $420^{\circ} \mathrm{C}$ en una atmósfera inerte con el fin de obtener materiales activos y selectivos. Esta activación a $420^{\circ} \mathrm{C}$ elimina todas las especies orgánicas presentes en el sólido favoreciendo un reordenamiento estructural del heteropolianión de partida, formándose principalmente una fase amorfa de molibdeno, cuya formación final depende fuertemente de la con la composición del material de partida [95]. Estos materiales han resultado ser también activos y relativamente selectivos en la oxidación de propano a ácido acrílico y en la deshidrogenación oxidativa de etano.

Un tercer tipo de catalizadores que ha despertado grandes expectativas en los últimos años es el basado en mezclas de óxidos metálicos mixtos, entre ellos óxidos de molibdeno y vanadio. Estos materiales presentan la ventaja, respecto a los heteropoliácidos, de poseer una buena estabilidad térmica, debido especialmente a las altas temperaturas a las que son activados (típicamente 
$600^{\circ} \mathrm{C}$ ). Además, presentan una mayor actividad y selectividad para la oxidación de propano a ácido acrílico (Tabla 1.2 [83-86, 97-100]).

Las propiedades catalíticas de este sistema catalítico dependen de la composición de los materiales, siendo los más efectivos los sistemas Mo-V-Te-Nb$\mathrm{O}$, con un rendimiento a ácido acrílico aproximadamente del $50 \%$ (Tabla 1.2). También se han preparado catalizadores similares basados en óxidos mixtos de Mo y $\mathrm{V}$ con antimonio, rindiendo ácido acrílico aunque en menor proporción [84, 86].

La mayoría de los sistemas catalíticos estudiados para la oxidación parcial de propano a ácido acrílico no presentan rendimientos aceptables para la amoxidación de propano a acrilonitrilo, y viceversa. Así, los catalizadores basados en óxidos mixtos de $\mathrm{V}$ y Sb [101-103], desarrollados inicialmente por BP a finales de la década de los 80 para la amoxidación de propano no son efectivos para la oxidación de propano a ácido acrílico [102]. Sin embargo, los catalizadores Mo-VTe-Nb-O son también los más efectivos en la amoxidación de propano a acrilonitrilo, obteniendo rendimientos próximos al $60 \%$ [86, 104-105].

\subsection{Catalizadores multicomponentes MoVTe(Sb)Nb para la oxidación parcial de propano a ácido acrílico}

\subsubsection{Antecedentes}

El primer estudio con catalizadores basados en óxidos mixtos de Mo y $\mathrm{V}$ se llevó a cabo, a finales de los años 70, cuando Thorsteinson y col. [106] propusieron catalizadores $\mathrm{Mo}_{0.73} \mathrm{~V}_{0.18} \mathrm{Nb}_{0.09} \mathrm{O}_{\mathrm{x}}$, como materiales activos y selectivos en la oxidación de etano a etileno y ácido acético, a temperaturas relativamente moderadas (alrededor de $300^{\circ} \mathrm{C}$ ), obteniendo rendimientos del 40\% [106]. Sin embargo, estos catalizadores presentan una selectividad muy baja a productos de oxidación parcial durante la oxidación de propano u otros alcanos superiores [107].

A finales de los años 80, investigadores de British Petroleum (BP) [108] desarrollaron un sistema catalítico multicomponente, V-Sb-W-Mo-Al-O con estructura de rutilo, activo y selectivo en la amoxidación de propano a acrilonitrilo, obteniéndose un $39 \%$ de rendimiento a acrilonitrilo. Sin embargo, estos óxidos presentan una baja selectividad en el caso de la oxidación selectiva de propano, lo que sugiere que los centros activos son específicos para la amoxidación de propano y/o que la presencia de amoníaco modula su comportamiento catalítico.

Al inicio de los años 90, Mitsubishi presentó un nuevo sistema catalítico basado en óxidos mixtos de Mo-V-Te-Nb-O, que alcanzaba un rendimiento a acrilonitrilo de $60 \%$ a una temperatura de reacción de $400-450^{\circ} \mathrm{C}$ [84, 109-110], 
rendimiento mayor que el conseguido con los sistemas V-Sb-O. Este sistema también era activo y selectivo en la oxidación de propano a ácido acrílico, con rendimientos a ácido acrílico del 48\% [111], lo que podría ser una alternativa interesante al proceso en dos etapas a partir de propileno.

En los últimos años, se ha desarrollado un intenso estudio de estos catalizadores para la amoxidación/oxidación de propano a acrilonitrilo y ácido acrílico, respectivamente, por diversas empresas y grupos de investigación [8390]. De hecho, se ha informado de la creación de una planta de acrilonitrilo a partir de propano, de $70.000 \mathrm{Tm} / \mathrm{año}$, en Ulsan (Corea del Sur); basada en la tecnología de Asahi Kasei Chemicals, y que emplea catalizadores multicomponentes de $\mathrm{MoVTe}(\mathrm{Sb}) \mathrm{NbO}$. Así mismo, está en construcción una nueva planta en Malasia con una tecnología similar.

Al igual que con los catalizadores MoVTeNbO, es posible obtener catalizadores similares con la sustitución de teluro por antimonio (catalizadores MoVSbNbO) que también son activos y selectivos en la amoxidación / oxidación de propano. La sustitución de teluro por antimonio se pensó como solución a los problemas que podría ocasionar el teluro en una posible implantación del proceso a nivel industrial. El teluro puede llegar a reducirse a teluro metálico a lo largo de sucesivos ciclos redox de la reacción catalítica, y, debido a su bajo punto de fusión $(450 \stackrel{\circ}{\circ}$ ), próximo a las temperaturas a las que se lleva a cabo la reacción de oxidación parcial de propano, podría desprenderse provocando tanto la desactivación del catalizador, como la formación de depósitos de teluro metálico en las tuberías de conducción del sistema de producción, contaminando además el producto de reacción. En este sentido, se sugirió el Sb como principal candidato (p.f. para el $\mathrm{Sb}^{0}$ es de $630^{\circ} \mathrm{C}$ ) debido a sus propiedades similares, en cuanto a la capacidad de insertar oxígeno en hidrocarburos ligeros. Los catalizadores MoVSbNbO que se obtuvieron también eran activos y selectivos en la oxidación y amoxidación de propano a ácido acrílico o a acrilonitrilo [83, 86, 99], respectivamente; aunque los rendimientos eran inferiores a los obtenidos con los catalizadores de MoVTeNbO.

Recientemente, se ha demostrado que este tipo de catalizadores, tanto con Te como con $\mathrm{Sb}$, son activos y muy selectivos para la deshidrogenación oxidativa de etano a eteno [66-67, 112-113], pudiéndose alcanzar rendimientos de hasta el $75 \%$ dependiendo de la composición del catalizador. Estos resultados hacen que sea posible plantear el empleo de la deshidrogenación oxidativa de etano como alternativa real a los procesos actuales de obtención de etileno (craqueo con vapor). 


\subsubsection{Características de los catalizadores multicomponentes MoVTe(Sb)NbO}

Los catalizadores MoVTe(Sb)NbO se caracterizan por la presencia, en general, de dos fases cristalinas, a las que los investigadores de Mitsubishi denominaron como fases M1 y M2 [111]. En un principio, a la fase M1 se le asignó la capacidad de activar el propano para formar propileno, mientras que a la fase M2 se le atribuyó la transformación selectiva de propileno en ácido acrílico (oxidación) o en acrilonitrilo (amoxidación). Posteriormente se demostró que este comportamiento no era del todo exacto.

Millet y col. [114] mostraron que dichas fases cristalinas correspondía a: i) una fase hexagonal $\mathrm{Te}_{0,33} \mathrm{MO}_{3,33}(\mathrm{M}=\mathrm{Mo}, \mathrm{V}, \mathrm{Nb})$ isomorfa al bronce de tungsteno hexagonal $\mathrm{K}_{0,13-0,33} \mathrm{WO}_{3}$; y ii) una fase ortorrómbica $\mathrm{Te}_{2} \mathrm{M}_{20} \mathrm{O}_{57}(\mathrm{M}=\mathrm{Mo}, \mathrm{V}, \mathrm{Nb})$ isomorfa con $\mathrm{Cs}_{0,7}(\mathrm{Nb}, \mathrm{W})_{5} \mathrm{O}_{14}$. Estas dos estructuras han sido confirmadas por otros autores [74, 105, 115-118]. Así mismo, los sistemas que contienen antimonio en lugar de teluro, MoVSb(Nb)O, presentan fases similares a los sistemas con teluro: una ortorrómbica, $\left(\mathrm{SbO}_{2}\right) \mathrm{M}_{20} \mathrm{O}_{56}$, y otra hexagonal, $\left(\mathrm{Sb}_{2} \mathrm{O}\right) \mathrm{M}_{6} \mathrm{O}_{18}$ [119].

El papel que desempeñan estas dos fases cristalinas ha sido objeto de un profundo estudio a fin de comprender el comportamiento catalítico de estos catalizadores multicomponentes. La preparación de la fase $\mathrm{Te}_{0,33} \mathrm{MO}_{3,33}$ pura [116] muestra que esta fase es activa y selectiva para la oxidación de propileno a ácido acrílico pero es inactiva en la oxidación de propano. Por lo que se concluye que la fase cristalina $\mathrm{Te}_{0,33} \mathrm{MO}_{3,33}$ corresponde a la llamada fase $\mathrm{M} 2$ por Ushikubo.

Resultados posteriores han mostrado que la fase $\mathrm{Te}_{2} \mathrm{M}_{20} \mathrm{O}_{57}$, denominada como fase M1, es por sí sola activa y selectiva en la amoxidación y en la oxidación de propano a acrilonitrilo y ácido acrílico, respectivamente. De esta forma la presencia de la fase M1 parece ser clave para la obtención de catalizadores activos y selectivos en la oxidación parcial de propano a ácido acrílico. En algunos casos, se ha propuesto que la presencia de la fase $\mathrm{Te}_{0,33} \mathrm{MO}_{3,33}$ podría tener un efecto positivo en la actividad y selectividad, a altas conversiones de propano, existiendo un efecto sinérgico entre ambas fases [120-121].

La fase ortorrómbica $M 1$ se puede obtener selectivamente tanto en catalizadores sin teluro, Mo-V-O, o sin niobio, Mo-V-Te(Sb)-O. Sin embargo, los resultados catalíticos en la oxidación de propano con estos catalizadores no alcanzan los valores observados con catalizadores MoVTeNbO, lo que sugiere que la composición tiene una fuerte influencia en la naturaleza de las fases cristalinas, los estados de oxidación de cada elemento y, por tanto, en la propiedades catalíticas de los materiales. 
Los óxidos mixtos basados en Mo-V se pueden obtener mediante síntesis hidrotermal o mediante co-precipitación de una disolución acuosa conteniendo los diferentes elementos del catalizador. La síntesis hidrotermal se realiza en un sistema cerrado (autoclave) donde tienen lugar reacciones heterogéneas en medio acuoso a temperaturas $\left(100-200^{\circ} \mathrm{C}\right)$ y presiones ( 1 bar) moderadas. Aunque habitualmente, la síntesis se realice en hornos eléctricos, en los últimos años han aparecido procedimientos novedosos donde se emplean radiaciones de microondas para asistir este tipo de síntesis (HT) [122], que reducen los tiempos de preparación de varios días a horas. Sin embargo, todavía existen parámetros que no se controlan en la síntesis con microondas y de momento no se obtienen resultados reproducibles.

Por otro lado, en las síntesis de precipitación por evaporación, el sólido precursor se obtiene por co-precipitación de las especies que están presentes en el gel de síntesis, mediante evaporación del agua empleada como disolvente. Como técnica de evaporación se emplea un sistema rotatorio de evaporación a vacío, aunque existen otros métodos como el secado a vacío por pulverización (spray-drying) y la liofilización (secado a vacío por congelación o freeze-drying), desarrollados con la intención de aumentar el área y la homogeneidad de las partículas [123].

A parte de las fases M1 y M2, la preparación de ese tipo de materiales puede llevar a la aparición de otras fases cristalinas, debido a que los elementos que constituyen el sistema $\mathrm{MoVTe}(\mathrm{Sb}) \mathrm{Nb}$ son la base para la formación de diversas estructuras, como se muestra en la Figura 1.5.

De esta forma, se pueden observar otras fases cristalinas, tales como $\mathrm{Mo}_{5-\mathrm{x}}(\mathrm{V}, \mathrm{Nb})_{\mathrm{x}} \mathrm{O}_{14}$ y $\mathrm{TeMo}_{5} \mathrm{O}_{16}$ (o su equivalente con antimonio, $\mathrm{Sb}_{2} \mathrm{Mo}_{10} \mathrm{O}_{31}$ ). Estas fases cristalinas, así como otros bronces de Mo y $\mathrm{V}$ [124] presentan variaciones respecto a las estructuras de las fases M1 (ortorrómbica) y M2 (hexagonal), diferenciándose en la forma de ordenarse los octaedros en los planos (Figura 1.5). Además, en estos sistemas también puede observarse la presencia de $\mathrm{MoO}_{3}$, que puede obtenerse como molibdita ortorrómbica $\left(\mathrm{MoO}_{3}\right.$-orto) y/o hexagonal $\left(\mathrm{MoO}_{3}\right.$ hexa).

El tipo de proceso empleado y las condiciones de síntesis: $\mathrm{pH}$ del gel de síntesis [125], la naturaleza del precursor de teluro [126], presencia de oxoácidos y/o agentes reductores [104] y la activación del catalizador [127], condicionan la distribución de las fases cristalinas y la aparición o no de la fase M1, influyendo, de ese modo en los resultados catalíticos para la oxidación de propano. 


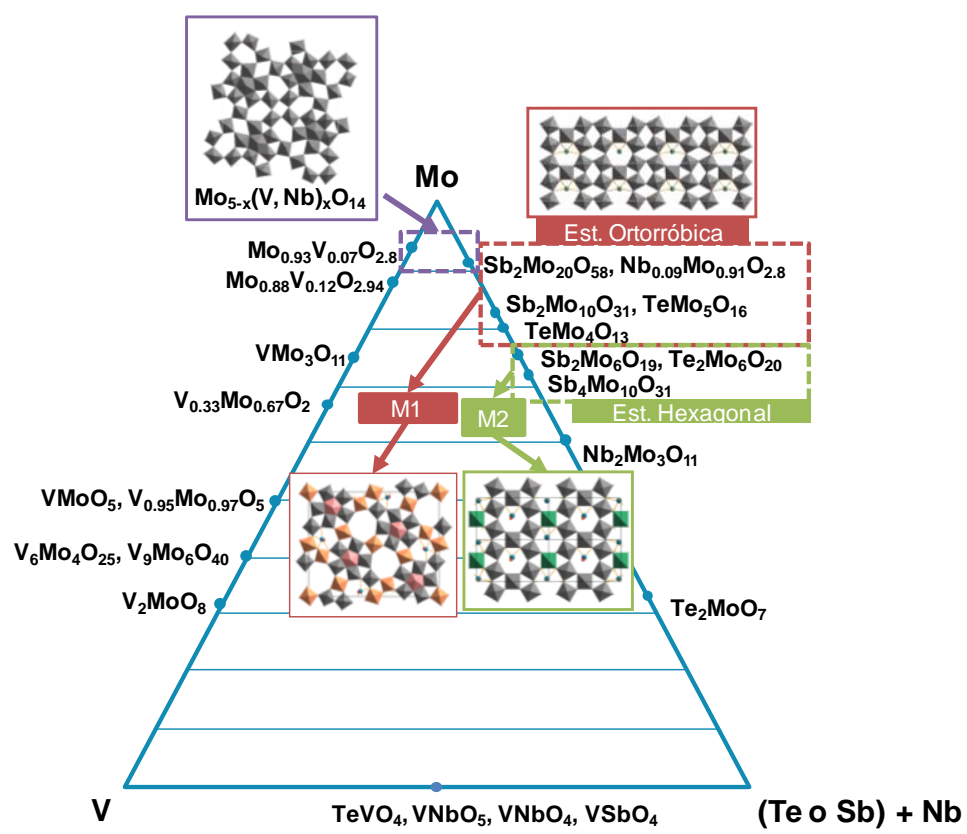

Figura 1.5. Diagrama de composición para el sistema $\mathrm{Mo} / \mathrm{V} / \mathrm{Nb}(+\mathrm{Te} \circ \mathrm{Sb})$, indicando la estequiometria de los compuestos que pueden formar [69].

\subsubsection{Propiedades catalíticas de los catalizadores MoVTe(Sb)NbO}

La fase $\mathrm{M} 1, \mathrm{Te}_{2} \mathrm{M}_{20} \mathrm{O}_{57}$, es capaz de activar el propano y formar selectivamente ácido acrílico [128-129], mientras que la fase $M 2, \mathrm{Te}_{0.33} \mathrm{MO}_{3.33}$, es inactiva para la oxidación de propano pero activa y selectiva en la oxidación parcial de propeno a acroleína y/o ácido acrílico [116]. En este sentido, se ha propuesto que la presencia conjunta de las fases M1 y M2 podría mejorar el comportamiento catalítico a altas conversiones de propano por un efecto de cooperación entre ambas fases [111, 120-121, 128]. Este efecto se ha atribuido principalmente a un mecanismo catalítico bifuncional adicional, mediante el cual, parte del propileno formado sobre la fase ortorrómbica M1, se podría también oxidar a ácido acrílico (o acrilonitrilo en caso de amoxidación) sobre la fase M2 [111, 116, 120-121, 128-129]. Aunque, también se ha sugerido que la fase M2 podría jugar un papel importante como reserva de teluro para la fase activa M1, evitando la desactivación de ésta por pérdida de teluro y permitiendo una regeneración in situ [128].

En este sentido, se ha observado un incremento considerable en la selectividad a ácido acrílico (o acrilonitrilo) de un catalizador MoVTeNbO (presentando sólo fase M1) al mezclarlo físicamente con un material con estructura tipo M2 [128, 130]. Sin embargo, en la mayoría de los estudios 
catalíticos se emplean catalizadores en los que la mezcla de fases (M1 y M2) se ha obtenido directamente de síntesis (presentando una mayor interacción), por lo que podría haber diferencias importantes en el papel de ambas fases cristalinas dependiendo de las características del método de síntesis empleado.

Por otro lado, la sustitución de teluro por antimonio, sistemas MoVSbO, da lugar a catalizadores activos y selectivos en la oxidación de propano a ácido acrílico. Sin embargo, los catalizadores con antimonio son menos selectivos a ácido acrílico y más selectivo a ácido acético que los correspondientes con teluro. Este hecho puede ser debido a una diferencia en número y fuerza de los centros ácidos. Así, se ha observado que la incorporación de potasio a los catalizadores con Sb aumenta la selectividad, probablemente a consecuencia de la desaparición de centros ácidos Brönsted de la superficie del catalizador. Este efecto se observa cuando el potasio es incorporado por impregnación en la superficie del catalizador activado [89, 131], o mediante su sal correspondiente en la composición del gel de síntesis en la síntesis hidrotermal [132].

Sin embargo, el efecto de cooperación entre ambas fases cristalinas sugerido para los materiales con teluro no es tan evidente en los catalizadores con antimonio [128]. Así, se ha sugerido que la presencia de fase M2 en catalizadores MoVSbO podría ejercer una influencia negativa sobre el rendimiento a ácido acrílico durante la oxidación parcial de propano [128, 133]. De hecho, el tratamiento post-síntesis de los catalizadores MoVSbO, para la obtención de la fase M1 pura, aumenta considerablemente la selectividad a ácido acrílico de estos materiales, alcanzado selectividades a ácido acrílico del 70\% [133-134].

La presencia de niobio en el catalizador también parece ser un factor clave en la obtención de catalizadores selectivos para la oxidación parcial de propano a ácido acrílico. Si bien, la incorporación de niobio en el catalizador no parece ser indispensable para la obtención de ácido acrílico (como se puede deducir de los resultados con catalizadores MoVTeO o MoVSbO), sí promueve de una manera muy importante su formación [129]. Además, la naturaleza de las fases cristalinas y la dificultad de obtención de la fase ortorrómbica en materiales sin niobio, preparados por co-precipitación, hacen pensar que el niobio puede tener un papel estructural. La presencia de niobio, podría estabilizar la estructura de los óxidos Mo-V-O, lo que la hace más estable a oxidaciones o reducciones del material.

Por otro lado, la incorporación de niobio en el sistema Mo-V-Te-O no tiene un efecto intrínseco en la actividad catalítica pero produce un aumento considerable en la selectividad a ácido acrílico, aproximadamente un 15-25\%, a expensas de la disminución de subproductos y óxidos de carbono. Estos resultados muestran que el niobio no sólo presenta una estabilización estructural sino que, además, el aumento de selectividad en presencia de niobio se atribuye a la supresión de 
oxidaciones adicionales del ácido acrílico. Así, el niobio tendría un papel esencial en la estabilización del ácido acrílico durante la reacción [129].

Este hecho podría estar estrechamente relacionado con la desaparición de centros ácidos Brönsted en la superficie de estos catalizadores [88, 135]. En efecto, parece existir una relación directa entre la incorporación de niobio en la estructura del catalizador y la disminución del número de centros ácidos Brönsted, lo que favorece un aumento de la selectividad a ácido acrílico disminuyendo la formación de ácido acético a partir de propileno mediante un mecanismo de hidratación [88, 135].

\subsubsection{Estructuras de las fases cristalinas $M 1$ y $M 2$}

En la Figura 1.6 se puede observar con mayor detalle las estructuras propuestas para las fases cristalinas M1 y M2. Ambas fases tienen en común una estructura laminar, que consiste en planos formados por octaedros $M_{6}(M=M o$, V) que comparten vértices (oxígenos) y a su vez, estos octaedros comparten un oxígeno entre planos consecutivos formando cadenas infinitas a lo largo del eje cristalográfico $c$. De hecho, ambas fases se caracterizan por tener un pico de difracción a $2 \theta=22^{\circ}$, que coincide exactamente con una distancia interlaminar $d=$ $4 \AA ̊$ (el parámetro de celda unidad del eje $c$ en este tipo de estructuras es aproximadamente 4 Å) [124].
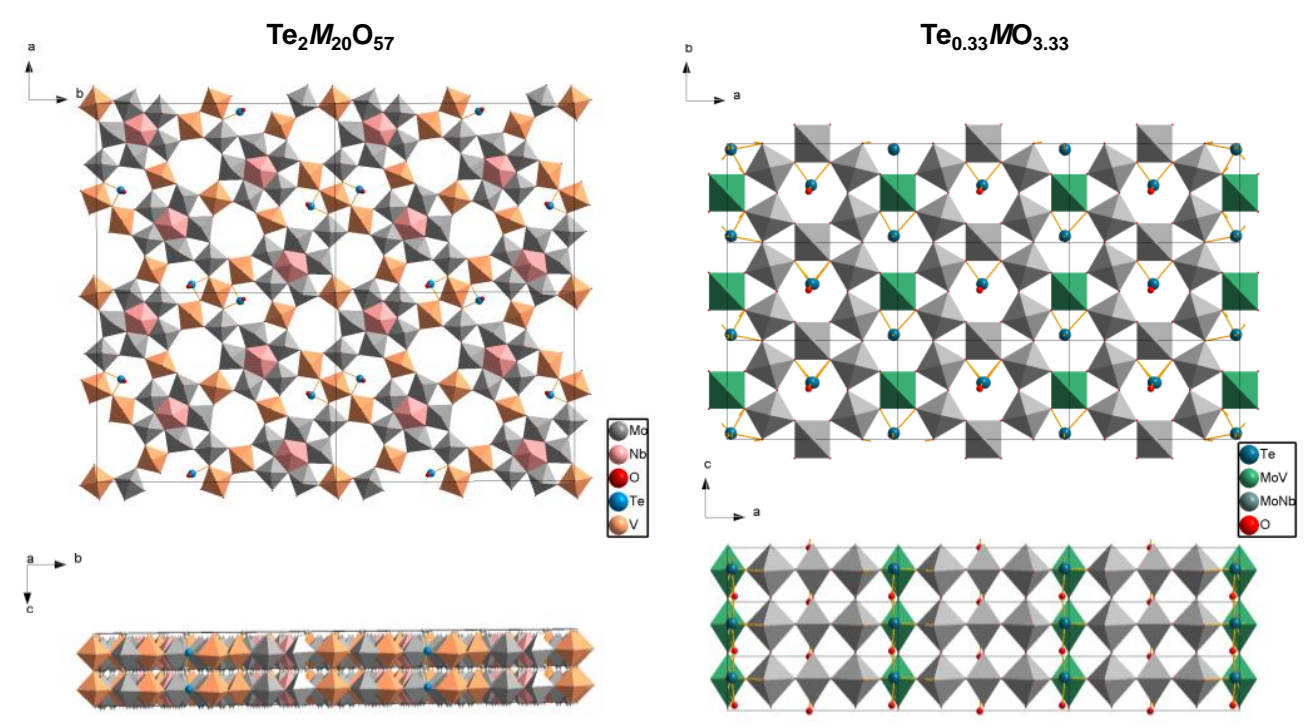

Figura 1.6. Estructuras propuestas para las fases $\mathrm{Te}_{2} \mathrm{M}_{20} \mathrm{O}_{57}(\mathrm{M} 1)$ y $\mathrm{Te}_{0.3} \mathrm{MO}_{3.33}(\mathrm{M} 2)$.

La fase M2 es una fase pseudo-ortorrómbica cuya estequiometria se describe en la bibliografía como $\mathrm{Te}_{0.33} \mathrm{MO}_{3.33}[117] \circ(\mathrm{TeO})_{2} \mathrm{M}_{6} \mathrm{O}_{18}[114,136]$ (para teluro) y 
$\left(\mathrm{Sb}_{2} \mathrm{O}\right) M_{6} \mathrm{O}_{18}$ (para antimonio) [136-137] $(M=\mathrm{Mo}, \mathrm{V}, \mathrm{Nb})$. La estructura de la fase $\mathrm{M} 2$ es isomorfa a la descrita para los bronces $\mathrm{Sb}_{0.4} \mathrm{MoO}_{31}$ [138] o $\mathrm{K}_{0.13-0.33} \mathrm{WO}_{3}$ [139], con estructura HTB (hexagonal tungsten bronze), [114, 117]. Estas estructuras se caracterizan por presentar canales hexagonales, que se ocupan o no dependiendo de la composición del material. En el caso de los catalizadores MoVTeNb, estos canales se encuentran ocupados por los cationes de teluro [114].

En el caso de la fase M1, la red estructural formada es más complicada. La fase $\mathrm{M} 1$ pertenece al sistema cristalino ortorrómbico, con estequiometria $\left(\mathrm{Te}_{2} \mathrm{O}\right) M_{20} \mathrm{O}_{56}$ para materiales con teluro [114, 136, 140-141] o $(\mathrm{SbO})_{2} \mathrm{M}_{20} \mathrm{O}_{56}$ para materiales con antimonio ( $\mathrm{M}=\mathrm{Mo}, \mathrm{V}, \mathrm{Nb})$ [136-137]. La estructura de la fase $\mathrm{M} 1$ es isomorfa a la estructura de la fase descrita como $\mathrm{Cs}_{0.7}(\mathrm{Nb}, \mathrm{W})_{5} \mathrm{O}_{14}$ [142], y se puede describir como un bronce con canales pentagonales, hexagonales y heptagonales (ocupados o no, dependiendo de la composición del material) [88, $114,129]$.

En la estructura de la fase M1, los anillos pentagonales pueden estar ocupados por átomos de Mo, $\mathrm{V}$ o Nb con una coordinación bipirámide pentagonal (átomo central). La presencia de átomos de niobio no es indispensable para la obtención de esta estructura [129, 143-144], pero si está presente, éste se sitúa preferentemente en el centro de los canales pentagonales [145]. Los átomos de teluro o el antimonio se ubican en el interior de los canales hexagonales, aunque tampoco resultan imprescindibles según se ha descrito en la bibliografía [143-144, 146]. No obstante, la presencia de teluro o antimonio parece favorecer la formación y estabilidad de la fase M1, aumentando la velocidad de cristalización. En general, los canales heptagonales permanecen vacíos, aunque existen estudios en los que se ha descrito que los átomos de teluro también puede ocupar parcialmente el interior de los canales heptagonales (dependiendo de la composición y método de preparación del catalizador) [124].

En ambas estructuras, los átomos de teluro se encuentran en el interior de los canales hexagonales se encuentra como especies $\mathrm{Te}^{4+}$, mientras que en la superficie se presenta mayoritariamente como $\mathrm{Te}^{6+}[114]$. En el interior de la fase $\mathrm{M} 1$, la coordinación que se observa para el $\mathrm{Te}^{4+}$ (config. electrónica: $4 d^{10} 5 s^{2} 5 p^{0}$ ) es de pirámide trigonal, con especies $\mathrm{TeO}_{3} \mathrm{E}$ formando dímeros $\left[\mathrm{EO}_{2} \mathrm{Te}-\mathrm{O}-\mathrm{TeO}_{2} \mathrm{E}\right]$ (donde $\mathrm{E}$ representa un par de electrones desapareados). En la fase $\mathrm{M} 2$ el teluro se presenta como entidades $\mathrm{TeO}_{4} \mathrm{E}$, con una coordinación de bipirámide trigonal, formando cadenas infinitas [-Te-O- $]_{\infty}$. En ambos casos dos oxígenos enlazados al Te pertenecen a octaedros que forman el anillo hexagonal, mientras que el tercer $y$ cuarto oxígeno están únicamente enlazados al Te en el interior del canal [114].

En el caso de los materiales con antimonio, éste se encuentra en el interior de ambas estructuras como $\mathrm{Sb}^{3+}$ y Sb${ }^{5+}$ [137]. La cantidad relativa de cada especie 
de antimonio depende de la estructura $\left(\mathrm{Sb}^{3+}\right.$ suele ser mayoritario en la fase $\mathrm{M} 2$, mientras que en la fase $\mathrm{M} 1 \mathrm{el} \mathrm{Sb}^{5+}$ suele ser más abundante), pero también depende fuertemente de las condiciones de síntesis y del tratamiento de activación al que ha sido sometido el catalizador [89, 136-137]. El Sb también se coordina de forma diferente en ambas fases, aunque en este caso la coordinación depende más bien del estado de oxidación en el que se encuentra el Sb en el interior de la estructura. Cuando el antimonio se presenta como $\mathrm{Sb}^{3+}$ (config. electrónica: $4 d^{10} 5 s^{2} 5 p^{0}$ ) forma entidades $\mathrm{SbO}_{3} \mathrm{E}$ donde dos oxígenos se comparten con octaedros del anillo, y el tercer oxígeno enlazado queda en el interior del canal, formando dímeros $\left[\mathrm{EO}_{2} \mathrm{Sb}-\mathrm{O}-\mathrm{SbO}_{2} \mathrm{E}\right]$ a lo largo de los canales hexagonales. Por otro lado, el $\mathrm{Sb}^{5+}$ (config. electrónica: $4 d^{10} 5 s^{0} 5 p^{0}$ ) se coordina con 4 oxígenos (dos oxígenos del canal hexagonal y dos en el interior del canal) como especies $\mathrm{SbO}_{4}$ con una configuración de bipirámide trigonal, formando cadenas infinitas [-O$\left.\mathrm{SbO}_{2}-\mathrm{O}-\right]_{\infty}$.

Por último, el contenido de oxígeno en ambas fases (M1 y M2) depende de: i) los niveles de sustitución de Mo por $\mathrm{V}$ y $\mathrm{Nb}$; y ii) la cantidad y el estado de oxidación de los átomos de $\mathrm{Te}$ o $\mathrm{Sb}$, que determinan el número de oxígenos coordinados únicamente a estos átomos y el estado de oxidación medio del resto de cationes metálicos que forman el esqueleto de la estructura. Por lo tanto, es muy importante tener en cuenta que el contenido de oxígeno puede variar dependiendo del procedimiento de preparación empleado, pero también durante la reacción catalítica de oxidación de propano en función de las condiciones de reacción [147].

\subsubsection{Centros activos de las fases cristalinas M1 y M2}

A partir de los resultados de los diversos estudios mecanísticos para la oxidación parcial de propano sobre catalizadores $\mathrm{MoVTe}(\mathrm{Sb}) \mathrm{NbO}$, se ha propuesto que la formación de ácido acrílico tiene lugar por la presencia de tres tipos de centros activos que explican el comportamiento catalítico de los catalizadores MoVTeNbO [148]. En la Figura 1.7 se puede observar el mecanismo propuesto para este tipo de catalizadores y los centros activos que intervienen en el mismo.

La primera etapa sería la activación de propano que se lleva a cabo en los centros de vanadio, Mo-O-V-O-(Mo o Nb). En la segunda etapa de reacción, la oxidación parcial de propeno a acroleína ocurre en los centros Mo/Te, Te-O-Mo(Te o V). Y, finalmente, la oxidación de acroleína a ácido acrílico que tiene lugar en los centros $\mathrm{Mo} / \mathrm{Nb}, \mathrm{Nb}-\mathrm{O}-\mathrm{Mo}-\mathrm{O}-(\mathrm{Nb} \circ \mathrm{V})$. 


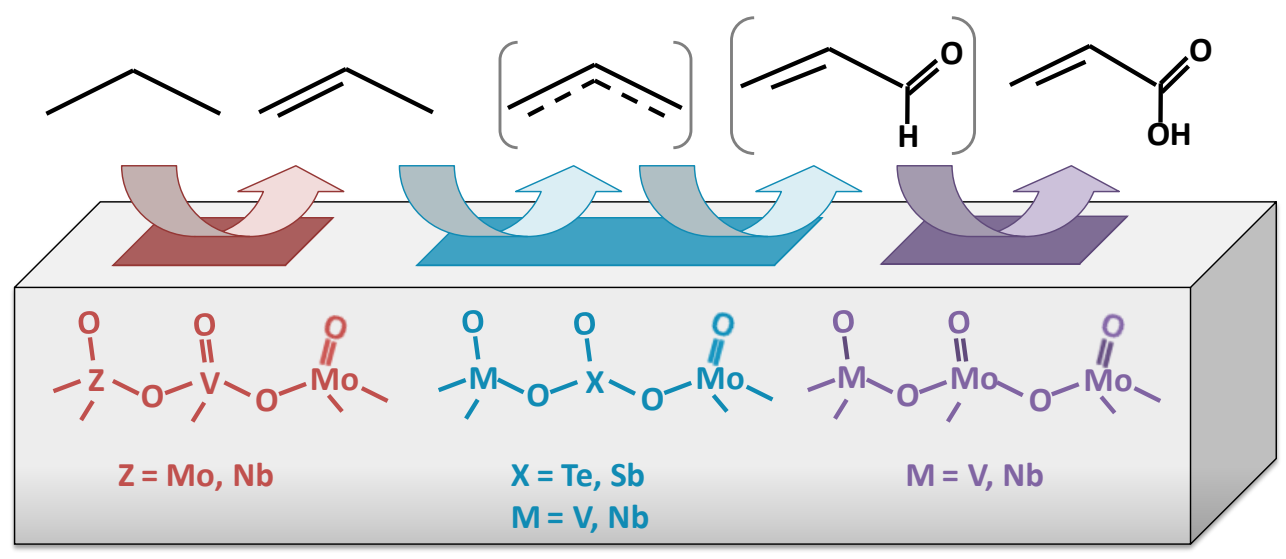

Figura 1.7. Esquema general de los centros activos y las etapas de reacción propuesto para la oxidación de propano a ácido acrílico sobre catalizadores basados en óxidos mixtos de MoV-X con o $\sin \mathrm{Nb}$ (X= Te ó Sb) [148].

El vanadio parece ser el elemento clave en la ruptura del enlace $\mathrm{C}-\mathrm{H}$ (activación) del propano $[87,105,148]$. Así, se ha atribuido a las especies $\mathrm{V}^{5+}=\mathrm{O}$, presentes en la superficie de la fase M1, la activación y la abstracción de un hidrógeno del grupo metileno de la parafina, debido a su forma resonante $\mathrm{V}^{5+}=\mathrm{O}$ $\leftrightarrow \mathrm{V}^{4+,} \cdot-\mathrm{O}^{\bullet}$. Concretamente, se ha sugerido que la activación del alcano se produce en los centros $\mathrm{V}^{5+}$ localizados en los canales heptagonales de la fase $\mathrm{Te}_{2} \mathrm{M}_{20} \mathrm{O}_{57}[130,135,149]$. La presencia de especies $\mathrm{V}^{5+}$ se ha descartado en la fase M2, lo que podría explicar la inactividad de esta fase en la oxidación de propano.

Por su parte, teluro y antimonio, según el caso, se asocian con la oxidación de propileno a acroleína [105, 150-152]. En efecto, es bien conocido que los centros de $\mathrm{Te}^{4+}$-O- son los responsables de la abstracción del protón situado en la posición $\alpha$ del propileno en la oxidación alílica de propileno. Además, los centros de $\mathrm{Mo}^{6+}$ se asocian con la adsorción del propileno y la inserción de oxígeno en el intermedio $\pi$-alílico $[130,135,148,153]$. Los canales hexagonales ocupados por los cationes de teluro (o antimonio) descritos en la fase $\mathrm{Te}_{2} \mathrm{M}_{20} \mathrm{O}_{57}$ son similares a los descritos para la fase $\mathrm{Te}_{0,33} \mathrm{MO}_{3,33}[114,153]$, de forma que la oxidación de propileno a ácido acrílico se produce tanto en presencia de la fase M1 como de la fase M2.

Por último, el papel del niobio en este tipo de catalizadores se ha relacionado con la estabilización y el aislamiento estructural de los centros catalíticamente activos de la superficie del catalizador, lo que favorece la desorción del ácido acrílico, evitando su oxidación y, por lo tanto, aumentando su selectividad [74, 105]. 
En este sentido, sería lógico pensar que todos los elementos necesarios para la transformación directa de propano a ácido acrílico deben estar estratégicamente organizados dentro de la distancia de enlace. Así, diversos autores han sugerido que la capacidad de la fase M1 para activar el propano se debe al plano ab ó [001] de dicha estructura [105, 149, 154-155], el cual contendría los centros activos y selectivos para la oxidación/amoxidación de propano a ácido acrílico/acrilonitrilo.

Grasselli y col. $[105,149,156]$ propone que el centro catalítico en el plano $a b$ está compuesto por $2 \mathrm{~V}_{0.32}{ }^{5+} / \mathrm{Mo}_{0.68}{ }^{6+}(\mathrm{M} 7), 1 \mathrm{~V}_{0.62}{ }^{4+} / \mathrm{Mo}_{0.38}{ }^{5+}(\mathrm{M} 2), 2 \mathrm{Mo}_{0.5}{ }^{6+} / \mathrm{Mo}_{0.5}{ }^{5+}$ (M4) y $2 \mathrm{Te}_{0.94}{ }^{4+}$ (M12) (Figura 1.8), los cuales están estabilizados por cuatro centros de $\mathrm{Nb}^{5+}$, cada uno rodeado de cinco octaedros molibdeno-oxígeno. El estudio de este centro catalítico mediante cálculos DFT (Density Functional Theory), muestra que las especies $\mathrm{C}_{3}$ radicales se adsorben fuertemente a las especies $\mathrm{V}=\mathrm{O}$ y $\mathrm{Te}=\mathrm{O}$, siendo las especies $\mathrm{Te}=\mathrm{O}$ más activas para la abstracción de un hidrógeno del grupo metilo que las especies $V=O$ [154].
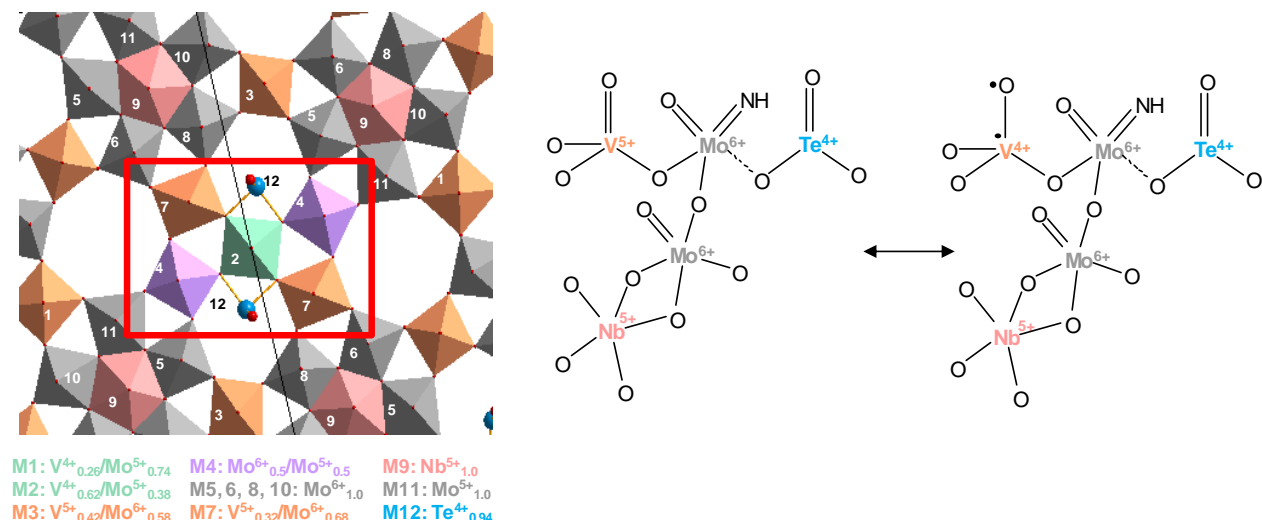

Figura 1.8. Esquema de la distribución de los centros activos [149]

Además, parece existir una relación entre la distorsión intrínseca de los octaedros que forman la fase M1 (necesaria para mantener el ordenamiento característico del plano ab), y la capacidad que posee dicha estructura para la activación oxidativa del propano $[150,157]$. En efecto, la distorsión de los octaedros en la superficie del catalizador podría favorecer la presencia de especies de oxígeno especialmente activas, proporcionando al catalizador una alta capacidad de oxidación. Por el contrario, la fase M2 presenta una estructura de mayor simetría donde los octaedros no necesitan estar tan distorsionados, dando como resultado oxígenos menos activos, lo que justificaría, en parte, la incapacidad de ésta y demás fases similares para oxidar el propano.

Sin embargo, la presencia de los centros activos exclusivamente en el plano basal ab todavía está bajo discusión. En este sentido, se han publicado estudios donde se observan evidencias acerca de una posible actividad catalítica también 
en planos cristalográficos paralelos al eje $c$ [158]. Por microscopía electrónica se ha observado que la periodicidad del plano ab se rompe en las secciones más delgadas, con lo que los canales de la fase M1 pueden quedar expuestos en los laterales de los cristales de la fase cristalina [159]. De esta forma, los centros activos también pueden estar localizados en la terminación de la fase M1 [160161]. 


\section{Bibliografía}

[1] P. T. Anastas, J. C. Warner, Green chemistry: theory and practice, Oxford University Press, 2000.

[2] G. Centi, S. Perathoner, Catalysis Today 77 (2003) 287-297.

[3] G. Centi, F. Cavani, F. Trifirò, Selective oxidation by heterogeneous catalysis, Kluwer Academic/Plenum Publishers, 2001.

[4] D. N. Nakamura, Oil Gas Journal 107 (2009) 43-54.

[5] D. Seddon, Petrochemical economics: technology selection in a carbon constrained world, Imperial College Press, 2010.

[6] M. M. Bhasin, Topics in Catalysis 23 (2003) 145-149.

[7] G. Grubert, E. Kondratenko, S. Kolf, M. Baerns, P. van Geem, R. Parton, Catalysis Today 81 (2003) 337-345.

[8] O. S.Ted, Journal of Catalysis 128 (1991) 210-217.

[9] P. T. Barger, B. V. Vora, US Patent 6534692 B1 (2003) UOP LLC

[10] T. Ren, M. Patel, K. Blok, Energy 31 (2006) 425-451.

[11] H. Cai, A. Krzywicki, M. C. Oballa, Chemical Engineering and Processing 41 (2002) 199-214.

[12] J. L. Dubois, Catalysis Today 99 (2005) 5-14.

[13] T. Ren, M. K. Patel, K. Blok, Energy 33 (2008) 817-833.

[14] Fabrizio Cavani, Gabriele Centi, P. Marion, in Metal Oxide Catalysis, Vol. 2 (Eds.: S. D. Jackson, J. S. J. Hargreaves), WILEY-VCH Verlag GmbH \& Co. KGaA, 2009, pp. 771-818.

[15] T. Ihara, A. Kayou, H. Kameo, H. Nakamura, C. J. Guo, in Studies in Surface Science and Catalysis, Vol. 121 (Eds.: H. Hideshi, O. Kiyoshi), Elsevier, 1999, pp. 347-350.

[16] K. Weissermel, H. J. Arpe, Industrial Organic Chemistry, Verlag Chemie $\mathrm{GmbH}, 1978$.

[17] C. Moureu, Annales de Chemie et de Physique 2 (1894) 187.

[18] J. D. Idol, S. Heights, US Patent 2904580 (1959)

[19] R. K. Grasselli, in Handbook of Heterogeneous Catalysis, Vol. 5 (Eds.: G. Ertl, H. Knözinger, J. Weitkamp), WILEY-VCH Verlag GmbH \& Co. KGaA, 1997, pp. 2302-2326.

[20] M. M. Lin, Applied Catalysis A: General 207 (2001) 1-16.

[21] N. Nojiri, Y. Sakai, Y. Watanabe, Catalysis Reviews: Science and Engineering 37 (1995) 145-178.

[22] M. Ogawa, JP 62-43742B (1987)

[23] M. M. Bettahar, G. Costentin, L. Savary, J. C. Lavalley, Applied Catalysis A: General 145 (1996) 1-48.

[24] G. W. Keulks, L. D. Krenzke, T. M. Notermann, in Advances in Catalysis, Vol. 27 (Eds.: H. P. D.D. Eley, B. W. Paul), Academic Press, 1979, pp. 183-225.

[25] R. K. Grasselli, J. D. Burrington, in Advances in Catalysis, Vol. 30 (Eds.: H. P. D.D. Eley, B. W. Paul), Academic Press, 1981, pp. 133-163.

[26] P. Mars, D. W. van Krevelen, Chemical Engineering Science 3 (1954) 4159.

[27] L. D. Krenzke, G. W. Keulks, Journal of Catalysis 64 (1980) 295-302.

[28] C. R. Adams, T. J. Jennings, Journal of Catalysis 2 (1963) 63-68. 
[29] C. R. Adams, T. J. Jennings, Journal of Catalysis 3 (1964) 549-558.

[30] G. W. Keulks, Journal of Catalysis 19 (1970) 232-235.

[31] R. D. Wragg, P. G. Ashmore, J. A. Hockey, Journal of Catalysis 22 (1971) 49-53.

[32] Y. Moro-oka, W. Ueda, K.-H. Lee, Journal of Molecular Catalysis A: Chemical 199 (2003) 139-148.

[33] R. K. Grasselli, Topics in Catalysis 21 (2002) 79-88.

[34] K. Sennewald, W. Vogt, J. Kamdler, R. Sommerfeld, G. Sorbe, US Patent 3226422 (1965)

[35] R. K. Grasselli, H. F. Hardman, US Patent 3642930 (1972)

[36] R. K. Grasselli, H. F. Hardman, US Patent 4503001 (1985)

[37] R. K. Grasselli, Catalysis Today 49 (1999) 141-153.

[38] R. K. Grasselli, D. D. Suresh, H. F. Hardman, US Patent 4139552 (1979)

[39] D. D. Suresh, M. S. Friedrich, M. J. Seely, US Patent 5212137 (1993)

[40] G. Caporali, N. Ferlazzo, N. Giordano, US Patent 3691224 (1972)

[41] J. L. Callahan, B. Gertisser, US Patent 3198750 (1965)

[42] Y. Sasaki, T. Nakamura, Y. Nakamura, K. Moriya, H. Utsumi, S. Saito, US Patent 4370279 (1983)

[43] A. Misono, T. Osa, Y. Ohkatsu, in Oxidation of Organic Compounds, Vol. 75, American Chemical Society, 1968, pp. 120-137.

[44] T. V. Andrushkevich, Catalysis Reviews: Science and Engineering 35 (1993) 213 - 259.

[45] M. M. Green, H. A. Wittcoff, Organic chemistry principles and industrial practice, Wiley-VCH, 2003.

[46] H. Werner, O. Timpe, D. Herein, Y. Uchida, N. Pfänder, U. Wild, R. Schlögl, H. Hibst, Catalysis Letters 44 (1997) 153-163.

[47] J. Tichý, Applied Catalysis A: General 157 (1997) 363-385.

[48] P. Kampe, L. Giebeler, D. Samuelis, J. Kunert, A. Drochner, Haa, A. H. Adams, J. Ott, S. Endres, G. Schimanke, T. Buhrmester, M. Martin, H. Fuess, H. Vogel, Physical Chemistry Chemical Physics 9 (2007) 35773589.

[49] D. L. Childress, W. V. Hayes, R. L. Poppe, US Patent 4035262 (1977)

[50] R. Krebetz, W. Herrmann, N. Scholz, H. Engelbach, G. J. Engert, C. H. Willersinn, G. Duembgen, F. Thiessen, US Patent 4259211 (1981)

[51] M. Dieterle, H. Hibst, W. J. Poepel, J. Petzoldt, K. J. Mueller-Engel, EU Patent 1633478 (2006)

[52] G. Mestl, Topics in Catalysis 38 (2006) 69-82.

[53] L. Giebeler, P. Kampe, A. Wirth, A. H. Adams, J. Kunert, H. Fuess, H. Vogel, Journal of Molecular Catalysis A: Chemical 259 (2006) 309-318.

[54] M. Croci, E. Cavaterra, US Patent 3736355 (1969) to Montecatini Edison

[55] R. Krabetz, H. Engelbach, US Patent 3527797 (1967) to BASF

[56] N. Kurata, T. Matsumoto, T. Ohara, K. Oda, JP 42-9805B (1967)

[57] S. Takenaka, G. Yamaguchi, Japan Patent 45-4970A (1970) to Nippon Kayaku

[58] T. Kita, H. Ishii, Japan Patent 47-6606B (1972) to Mitsubishi

[59] I. Nagai, I. Yanagisawa, M. Ninomiya, T. Ohara, Japan Patent 58-17172B (1983) to Nippon Shokubai 
[60] J. P. Lange, in Heterogeneous catalysis, Vol. 191 (Eds.: E. G. Derouane, V. Parmon, F. Lemos, F. Ramôa Ribeiro), Springer Netherlands, 2005, pp. 51-83.

[61] T. Blasco, J. M. López Nieto, Applied Catalysis A: General 157 (1997) 117142.

[62] F. Cavani, N. Ballarini, A. Cericola, Catalysis Today 127 (2007) 113-131.

[63] J. M. López Nieto, Topics in Catalysis 41 (2006) 3-15.

[64] E. Heracleous, A. A. Lemonidou, Journal of Catalysis 237 (2006) 175-189.

[65] B. Solsona, P. Concepción, S. Hernández, B. Demicol, J. M. López Nieto, Catalysis Today 180 (2012) 51-58.

[66] J. M. López Nieto, P. Botella, M. I. Vazquez, A. Dejoz, Chemical Communications (2002) 1906-1907.

[67] P. Botella, E. García-González, A. Dejoz, J. M. López Nieto, M. I. Vázquez, J. González-Calbet, Journal of Catalysis 225 (2004) 428-438.

[68] J. L. G. Fierro, Metal oxides: chemistry and applications, Taylor \& Francis, 2006.

[69] F. Cavani, J. H. Teles, ChemSusChem 2 (2009) 508-534.

[70] F. Ivars, Instituto de Tecnología Química (UPV-CSIC) 2010.

[71] A. Costine, B. K. Hodnett, Applied Catalysis A: General 290 (2005) 9-16.

[72] G. Centi, F. Trifiro, J. R. Ebner, V. M. Franchetti, Chemical Reviews 88 (1988) 55-80.

[73] L. Lloyd, Handbook of Industrial Catalysts, Springer, 2008.

[74] D. Vitry, J.-L. Dubois, W. Ueda, Journal of Molecular Catalysis A: Chemical 220 (2004) 67-76.

[75] F. Cavani, F. Trifirò, Catalysis Today 36 (1997) 431-439.

[76] C. Fabrizio, Catalysis Today 157 (2010) 8-15.

[77] C. B. Wang, W. Wei, G. Liu, G. Mao, D. Kuang, Acta petroleum Sinica 14 (1998) 21.

[78] Y. F. Han, H. M. Wang, H. Cheng, J. F. Deng, Chemical Communications (1999).

[79] H. Cheng, Y. F. Han, H. M. Wang, Shiyou Huagong 28 (1999) 803-807.

[80] N. Mizuno, M. Tateishi, M. Iwamoto, Applied Catalysis A: General 128 (1995) L165-L170.

[81] A. F. Volpe, J. E. Lyons, P. E. Ellis, S. Karmakar, US Patent 5990248 (1999)

[82] H. Krieger, L. S. Kirch, EP 10902 (1980) Rohm and Hass Co. USA

[83] T. Ushikubo, H. Kinoshita, A. Watanabe, JP 10057813 A (1998) Mitsubishi Chemical Industries Ltd., Japan

[84] T. Ushikubo, H. Nakamura, Y. Koyasu, S. Wajiki, US Patent 5380933 (1995) assigned to Mitsubushi

[85] X. Tu, N. Furuta, Y. Sumida, M. Takahashi, H. Niiduma, Catalysis Today 117 (2006) 259-264.

[86] H. Tsuji, Y. Koyasu, Journal of the American Chemical Society 124 (2002) 5608-5609.

[87] W. Ueda, K. Oshihara, Applied Catalysis A: General 200 (2000) 135-143.

[88] M. Baca, A. Pigamo, J. L. Dubois, J. M. M. Millet, Catalysis Communications 6 (2005) 215-220.

[89] T. Blasco, P. Botella, P. Concepción, J. M. López Nieto, A. Martinez-Arias, C. Prieto, Journal of Catalysis 228 (2004) 362-373. 
[90] W. Ueda, Y. Endo, N. Watanabe, Topics in Catalysis 38 (2006) 261-268.

[91] B. B. Bardin, R. J. Davis, Applied Catalysis A: General 185 (1999) 283292.

[92] F. Cavani, M. Koutyrev, F. Trifirò, Catalysis Today 24 (1995) 365-368.

[93] M. E. Davis, C. J. Dillon, J. H. Holles, J. Labinger, Angewandte Chemie International Edition 41 (2002) 858-860.

[94] J. H. Holles, C. J. Dillon, J. A. Labinger, M. E. Davis, Journal of Catalysis 218 (2003) 42-53.

[95] C. J. Dillon, J. H. Holles, R. J. Davis, J. A. Labinger, M. E. Davis, Journal of Catalysis 218 (2003) 54-66.

[96] C. J. Dillon, J. H. Holles, M. E. Davis, J. A. Labinger, Catalysis Today 81 (2003) 189-195.

[97] K. Oshihara, T. Hisano, W. Ueda, Topics in Catalysis 15 (2001) 153-160.

[98] M. Lin, M. W. Linsen, EP Patent 962253 A2 (1999) to Rohm and Haas Company, USA

[99] M. Takahashi, S. To, S. Hirose, JP Patent 98118491 (1998-A)

[100] M. Takahashi, S. To, S. Hirose, JP Patent 98120617 (1998-B)

[101] A. Andersson, S. L. T. Andersson, G. Centi, R. K. Grasselli, M. Sanati, F. Trifirò, Applied Catalysis A: General 113 (1994) 43-57.

[102] G. Centi, S. Perathoner, F. Trifirò, Applied Catalysis A: General 157 (1997) 143-172.

[103] R. Nilsson, T. Lindblad, A. Andersson, Journal of Catalysis 148 (1994) 501-513.

[104] H. Tsuji, K. Oshima, Y. Koyasu, Chemistry of Materials 15 (2003) 21122114.

[105] R. K. Grasselli, J. D. Burrington, D. J. Buttrey, P. DeSanto, C. G. Lugmair, A. F. Volpe, T. Weingand, Topics in Catalysis 23 (2003) 5-22.

[106] E. M. Thorsteinson, T. P. Wilson, F. G. Young, P. H. Kasai, Journal of Catalysis 52 (1978) 116-132.

[107] A. A. Adesina, N. W. Cant, A. Saberi-Moghaddam, C. H. L. Szeto, D. L. Trimm, Journal of Chemical Technology \& Biotechnology 72 (1998) 19-22.

[108] A. T. Gutterman, R. K. Graselli, J. F. Brazdil, US Patents 4788317 and 4746641 (1998)

[109] T. Ushikubo, I. Sawaki, K.Oshima, K. Inumaru, S. Kovayakawa, K. Kiyono, EP 0603836 (1993)

[110] T. Ushikubo, K. Oshima, A. Kayo, T. Umezawa, K. Kiyono, T. Sawaki, EP Patent 0529853 A2 (1992) assigned to Mitsubishi

[111] T. Ushikubo, K. Oshima, A. Kayou, M. Hatano, X. Can Li and Qin, in Studies in Surface Science and Catalysis, Vol. Volume 112, Elsevier, 1997, pp. 473-480.

[112] P. Botella, A. Dejoz, J. M. López Nieto, P. Concepción, M. I. Vázquez, Applied Catalysis A: General 298 (2006) 16-23.

[113] J. M. López Nieto, P. Botella, M. I. Vázquez, A. Dejoz, WO Patent 0346035 (2003)

[114] J. M. M. Millet, H. Roussel, A. Pigamo, J. L. Dubois, J. C. Jumas, Applied Catalysis A: General 232 (2002) 77-92.

[115] X. Li, D. Buttrey, D. Blom, T. Vogt, Topics in Catalysis 54 (2011) 614-626.

[116] P. Botella, J. M. López Nieto, B. Solsona, Catalysis Letters 78 (2002) 383387. 
[117] E. Garcia-Gonzalez, J. M. Lopez Nieto, P. Botella, J. M. Gonzalez-Calbet, Chemistry of Materials 14 (2002) 4416-4421.

[118] W. Goddard, L. Liu, J. Mueller, S. Pudar, R. Nielsen, Topics in Catalysis 54 (2011) 659-668.

[119] D. L. Nguyen, Y. B. Taarit, J. M. M. Millet, Catalysis Letters 90 (2003) 6570.

[120] M. Baca, A. Pigamo, J. L. Dubois, J. M. M. Millet, Topics in Catalysis 23 (2003) 39-46.

[121] J. Holmberg, R. K. Grasselli, A. Andersson, Applied Catalysis A: General 270 (2004) 121-134.

[122] L. Espinal, K. A. Malinger, A. E. Espinal, A. M. Gaffney, S. L. Suib, Advanced Functional Materials 17 (2007) 2572-2579.

[123] P. Beato, A. Blume, F. Girgsdies, R. E. Jentoft, R. Schlögl, O. Timpe, A. Trunschke, G. Weinberg, Q. Basher, F. A. Hamid, S. B. A. Hamid, E. Omar, L. Mohd Salim, Applied Catalysis A: General 307 (2006) 137-147.

[124] P. Botella, E. García-González, J. M. López Nieto, J. M. González-Calbet, Solid State Sciences 7 (2005) 507-519.

[125] J. M. Oliver, J. M. López Nieto, P. Botella, A. Mifsud, Applied Catalysis A: General 257 (2004) 67-76.

[126] P. Botella, P. Concepción, J. M. López Nieto, Y. Moreno, Catalysis Today 99 (2005) 51-57.

[127] P. Concepción, S. Hernández, J. M. López Nieto, Applied Catalysis A: General 391 (2011) 92-101.

[128] M. Baca, M. Aouine, J. L. Dubois, J. M. M. Millet, Journal of Catalysis 233 (2005) 234-241.

[129] D. Vitry, Y. Morikawa, J. L. Dubois, W. Ueda, Applied Catalysis A: General 251 (2003) 411-424.

[130] R. Grasselli, D. Buttrey, J. Burrington, A. Andersson, J. Holmberg, W. Ueda, J. Kubo, C. Lugmair, A. Volpe, Topics in Catalysis 38 (2006) 7-16.

[131] F. Ivars, B. Solsona, P. Botella, M. D. Soriano, J. M. López Nieto, Catalysis Today 141 (2009) 294-299.

[132] F. Ivars, B. Solsona, M. Soriano, J. M. López Nieto, Topics in Catalysis 50 (2008) 74-81.

[133] F. Ivars, B. Solsona, E. Rodríguez-Castellón, J. M. López Nieto, Journal of Catalysis 262 (2009) 35-43.

[134] B. Deniau, G. Bergeret, B. Jouguet, J. Dubois, J. Millet, Topics in Catalysis 50 (2008) 33-42.

[135] P. Concepción, P. Botella, J. M. López Nieto, Applied Catalysis A: General 278 (2004) 45-56.

[136] M. Baca, J. M. M. Millet, Applied Catalysis A: General 279 (2005) 67-77.

[137] J. M. M. Millet, M. Baca, A. Pigamo, D. Vitry, W. Ueda, J. L. Dubois, Applied Catalysis A: General 244 (2003) 359-370.

[138] M. Parmentier, C. Gleitzer, R. J. D. Tilley, Journal of Solid State Chemistry 31 (1980) 305-311.

[139] A. Magneli, Acta Chemica Scandinavica 7 (1953) 315-324.

[140] P. DeSanto, D. J. Buttrey, R. K. Grasselli, C. G. Lugmair, A. F. Volpe, B. H. Toby, T. Vogt, Zeitschrift Fur Kristallographie 219 (2004) 152-165.

[141] P. DeSanto, D. J. Buttrey, R. K. Grasselli, C. G. Lugmair, A. F. Volpe, B. H. Toby, T. Vogt, Topics in Catalysis 23 (2003) 23-38. 
[142] M. Lundberg, M. Sundberg, Ultramicroscopy 52 (1993) 429-435.

[143] N. Watanabe, W. Ueda, Industrial \& Engineering Chemistry Research 45 (2006) 607-614.

[144] Masahiro Sadakane, N. Watanabe, T. Katou, Y. Nodasaka, W. Ueda, Angewandte Chemie International Edition 46 (2007) 1493-1496.

[145] W. Ueda, D. Vitry, T. Kato, N. Watanabe, Y. Endo, Research on Chemical Intermediates 32 (2006) 217-233.

[146] W. Ueda, M. Sadakane, H. Ogihara, Catalysis Today 132 (2008) 2-8.

[147] O. V. Safonova, B. Deniau, J.-M. M. Millet, The Journal of Physical Chemistry B 110 (2006) 23962-23967.

[148] P. Botella, J. M. López Nieto, B. Solsona, A. Mifsud, F. Márquez, Journal of Catalysis 209 (2002) 445-455.

[149] R. Grasselli, C. Lugmair, A. Volpe, Topics in Catalysis 54 (2011) 595-604.

[150] D. Vitry, Y. Morikawa, J. L. Dubois, W. Ueda, Topics in Catalysis 23 (2003) 47-53.

[151] W. Ueda, K. Oshihara, D. Vitry, T. Hisano, Y. Kayashima, Catalysis Surveys from Japan 6 (2002) 33-44.

[152] W. Ueda, D. Vitry, T. Katou, Catalysis Today 96 (2004) 235-240.

[153] J. M. Oliver, J. M. López Nieto, P. Botella, Catalysis Today 96 (2004) 241 249.

[154] K. Muthukumar, J. Yu, Y. Xu, V. Guliants, Topics in Catalysis 54 (2011) 605-613.

[155] N. R. Shiju, X. Liang, A. W. Weimer, C. Liang, S. Dai, V. V. Guliants, Journal of the American Chemical Society 130 (2008) 5850-5851.

[156] R. K. Grasselli, Catalysis Today 99 (2005) 23-31.

[157] T. Katou, D. Vitry, W. Ueda, Catalysis Today 91-92 (2004) 237-240.

[158] A. Celaya Sanfiz, T. W. Hansen, A. Sakthivel, A. Trunschke, R. Schlögl, A. Knoester, H. H. Brongersma, M. H. Looi, S. B. A. Hamid, Journal of Catalysis 258 (2008) 35-43.

[159] W. Zhang, A. Trunschke, R. Schlögl, D. Su, Angewandte Chemie International Edition 49 (2010) 6084-6089.

[160] M. Hävecker, S. Wrabetz, J. Kröhnert, L. I. Csepei, R. Naumann d'Alnoncourt, Y. V. Kolen'ko, F. Girgsdies, R. Schlögl, A. Trunschke, Journal of Catalysis 285 (2012) 48-60.

[161] R. Schlögl, Topics in Catalysis 54 (2011) 627-638. 



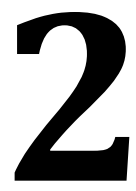

Objetivos 



\section{Objetivos}

El principal objetivo de la presente tesis doctoral consiste en el estudio de la influencia de algunos de los parámetros de síntesis de catalizadores basados en óxidos metálicos mixtos, no estequiométricos, con Mo y $\mathrm{V}$, para poder establecer posibles vías de optimización que dirijan a la formación de catalizadores más activos y selectivos para la oxidación de propano a ácido acrílico. A lo largo de esta tesis se ha estudiado la síntesis y modificación de este tipo de catalizadores, que presentan mayoritariamente las fases cristalinas M1 y M2, para la oxidación parcial de propano.

Se estudiará también la influencia de la incorporación al catalizador Mo-V-Te de diversos metales como promotores. Concretamente, se analizará la influencia de la naturaleza del metal incorporado en la distribución de las fases cristalinas presentes en los materiales promovidos y sus propiedades catalíticas en la oxidación selectiva de propano.

Además, se estudiará la influencia de la temperatura de síntesis en la preparación hidrotermal de los óxidos mixtos MoVSbO, MoVTeO y MoVTeNbO, así como la influencia de la temperatura de activación térmica de estos materiales. En este sentido, se analizarán las diferencias observadas según la composición de los materiales en las propiedades catalíticas del material durante la oxidación parcial de propano.

Por último, se han estudiado, comparativamente, las propiedades catalíticas en la oxidación selectiva de propileno a ácido acrílico y en la transformación de metanol en presencia de oxígeno de los materiales activados térmicamente a 500 y $600^{\circ} \mathrm{C}$ (en flujo de nitrógeno). Además, se ha llevado a cabo un estudio de caracterización de los materiales activados a 500 y $600^{\circ} \mathrm{C}$ (mediantes diferentes técnicas de caracterización superficial, tales como XPS, FTIR de metanol adsorbido o intercambio isotópico de $\mathrm{O}^{18}$ ) con el fin de comprender la naturaleza de los centros activos presentes en la superficie de estos materiales, concretamente en aquellos que presentan de forma mayoritaria la denominada fase M1. 


\section{Aims}

The main aim of this thesis is to study the influence of some of the synthesis parameters in catalysts based on Mo and V-containing metal mixed oxides, to determine how to optimize the formation of more active and selective catalysts for the selective oxidation of propane to acrylic acid. In this thesis, we studied the synthesis and modification of these catalysts, which present mainly the crystalline phases M1 and M2, for the partial oxidation of propane.

The incorporation of various metals as promoters on Mo-V-Te materials has been studied. In particular, the influence of the metal incorporated on the nature of the crystalline phases present in these materials and their catalytic properties in the selective oxidation of propane have been analyzed.

In addition, the influence of the hydrothermal synthesis temperature, as well as, the influence of catalysts activation temperature on the hydrothermal synthesis of MoVSb, MoVTe and MoVTeNb mixed oxides has been studied. The observed differences on the catalytic properties during partial propane oxidation have been analyzed according to the composition of materials studied.

Finally, a comparative study on the catalytic properties in the selective oxidation of propylene and the conversion of methanol in the presence of oxygen on these materials heat-treated at 500 and $600^{\circ} \mathrm{C}$ has been studied. In addition, a comparative study of the surface characteristics of the materials followed by XPS, FTIR studies with methanol adsorption as well as isotopic exchange reaction with $\mathrm{O}^{18}$ will be provided in order to understand the nature of the active sites present on the surface of the materials (specifically those with mainly pure M1 phase). 

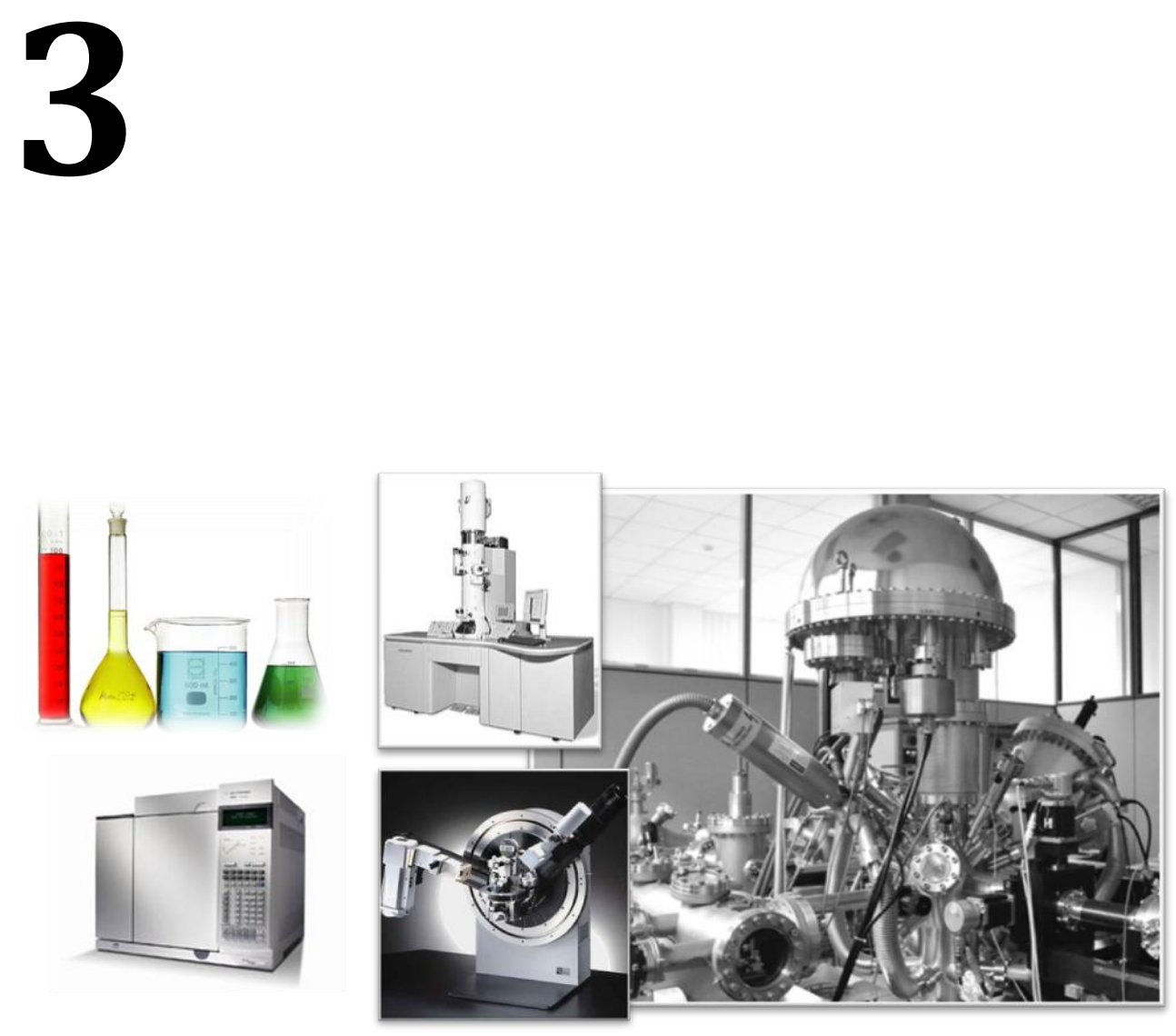

\section{Parte Experimental}





\section{Abstract}

$\operatorname{MoVTe}(\mathrm{Sb}) \mathrm{Nb}$ mixed oxides have been prepared hydrothermally from an aqueous solution of the corresponding salts. Ammonium heptamolybdate, vanadium sulfate, telluric acid or tellurium oxide, antimony sulfate and niobium oxalate were use as Mo-, $\mathrm{V}$-, $\mathrm{Te}$-, $\mathrm{Sb}$ - and $\mathrm{Nb}$-sources, respectively. The gels were autoclaved in teflon-lined stainless steel autoclaves at $175^{\circ} \mathrm{C}$ for $48 \mathrm{~h}$. In some cases, the synthesis temperature and/or residence time were varied. The resulting solids were filtered, washed and dried at $100^{\circ} \mathrm{C}$ for $16 \mathrm{~h}$. The catalyst precursors had been heat-treated at high temperature (generally $600{ }^{\circ} \mathrm{C}$ ) during $2 \mathrm{~h}$ in $\mathrm{N}_{2^{-}}$ stream.

The physical-chemical properties of the catalysts have been studied by several characterization techniques: inductively coupled plasma atomic emission spectroscopy (AES-ICP), adsorption of $N_{2}$ for surface area measurement $\left(S_{B E T}\right)$, thermogravimetric analysis (TGA), powder X-ray diffraction (XRD), diffuse UV-Vis reflectance spectroscopy (DR-UV-Vis), Fourier transform infrared spectroscopy (FT-IR); Raman spectroscopy; X-ray photoelectron spectroscopy (XPS), scanning electron microscopy with EDX microanalysis (SEM-EDX), temperature programmed reduction $\left(\mathrm{H}_{2}-\mathrm{TPR}\right)$, desorption $\left(\mathrm{NH}_{3}-\mathrm{TPD}\right)$ and oxygen isotopicexchange $\left({ }^{18} \mathrm{O}_{2}\right)$.

Selective propane oxidation was carried out in a fixed bed quartz tubular reactor, working at atmospheric pressure. Catalyst samples were introduced in the reactor and diluted with silicon carbide in order to keep a constant volume in the catalyst bed. The flow rate and the amount of catalyst were varied in order to achieve different propane conversion levels. The feed consisted of a mixture of propane/oxygen/water/helium in the ratio 4/8/30/58. Experiments were carried out in the 340-420 ${ }^{\circ} \mathrm{C}$ temperature range in order to achieve the highest selectivity to partial oxidation products. Reactants and reaction products were analyzed by on-line gas chromatography. 


\section{Resumen}

Los óxidos mixtos MoVTe(Sb)NbO se han preparado por el método hidrotermal a partir de una disolución acuosa de las sales conrrespondientes. Como sales de Mo, V, Te, Sb y $\mathrm{Nb}$ se han empleado heptamolibdato amónico, sulfato de vanadilo, ácido telúrico o óxido de teluro, sulfato de antimonio y oxalato de niobio. El gel obtenido se introdujo en un autoclave a $175^{\circ} \mathrm{C}$ durante $48 \mathrm{~h}$. En algunos casos, se ha variado la temperatura de síntesis y/o el tiempo de residencia. El sólido resultante se filtró, se lavó y se secó a 100C durante 16h. El precursor se ativó a alta temperature (generalmente $600^{\circ} \mathrm{C}$ ) durante $2 \mathrm{~h}$ en flujo de nitrógeno.

Las propiedades físico-químicas de los catalizadores se han estudiado por diferentes técnicas de caracterización: espectroscopia emisión atómica de plasma de acoplamiento inductivo (AES-ICP), adsorción de $N_{2}\left(S_{B E T}\right)$, termogravimetría (TGA), difracción de rayos $X$ en polvo (DRX), espectroscopia de reflectancia difusa en la región ultravioleta-visible (RD UV-Vis), espectroscopia de absorción infrarroja (FT-IR), espectroscopia Raman, espectroscopia fotoelectrónica de rayos X (XPS), microscopía electrónica de barrido (SEM) y microanálisis de rayos $X$ (EDX), reducción a temperatura programada $\left(T P R-H_{2}\right)$, desorción de amoníaco a temperatura programada (TPD-NH ) e intercambio isotópico de oxígeno.

La oxidación selectiva de propano se ha llevado acabo en un reactor tubular de lecho fijo, trabajando a presión atmosférica. Los catalizadores se diluyen con carburo de silicio para mantener constante el volumen del lecho catalítico. El flujo total y la cantidad de catalizador se han variado para obtener diferentes niveles de conversión de propano. La alimentación consiste en una mezcla propano/oxígeno/agua/helio de 4/8/30/58. Los experimentos se han llevado a cabo en el intervalo de temperaturas $340-420^{\circ} \mathrm{C}$ para obtener la mayor selectividad a productos de oxidación parcial. El análisis de reactivos y productos de reacción se ha realizado por cromatografía de gases on-line. 


\subsection{Reactivos utilizados}

Los reactivos comerciales empleados en el trabajo experimental de la presente tesis se detallan a continuación:

\subsubsection{Sólidos}

- Heptamolibdato amónico tetrahidrato $99 \%,\left(\mathrm{NH}_{4}\right)_{6} \mathrm{Mo}_{7} \mathrm{O}_{24} \cdot 4 \mathrm{H}_{2} \mathrm{O}$ (Merck)

- Sulfato de vanadilo hidrato $97 \%, \mathrm{VOSO}_{4} \cdot \mathrm{xH}_{2} \mathrm{O}$ (Sigma-Aldrich).

- Sulfato de antimonio (III) $95 \%, \mathrm{Sb}_{2}\left(\mathrm{SO}_{4}\right)_{3}$ (Fluka)

- Óxido de teluro (IV) $+99 \%, \mathrm{TeO}_{2}$ (Sigma-Aldrich)

- Ácido telúrico $98 \%, \mathrm{H}_{6} \mathrm{TeO}_{6}$ (Sigma-Aldrich)

- Oxalato de niobio hexahidrato, $\mathrm{C}_{10} \mathrm{H}_{5} \mathrm{NbO}_{20}$ (ABCR)

- Ácido oxálico $98 \%, \mathrm{HO}_{2} \mathrm{C}_{2} \mathrm{O}_{2} \mathrm{H}$ (Sigma-Aldrich)

- Bromuro de antimonio (III) $99 \%, \mathrm{SbBr}_{3}$ (Alfa Aesar)

- Bicarbonato potásico $99.7 \%, \mathrm{KHCO}_{3}$ (Sigma-Aldrich)

- Carbonato cálcico $\geq 99 \%, \mathrm{CaCO}_{3}$ (Sigma-Aldrich)

- Sulfato de bismuto (III) $99 \%, \mathrm{Bi}_{2}\left(\mathrm{SO}_{4}\right)_{3}$ (Avocado)

- Sulfato de cerio (III) $97 \%, \mathrm{Ce}_{2}\left(\mathrm{SO}_{4}\right)_{3}$ (Sigma-Aldrich)

- Sulfato de cobalto (II) heptahidrato $\geq 99 \%, \mathrm{CoSO}_{4} \cdot 7 \mathrm{H}_{2} \mathrm{O}$ (Sigma-Aldrich)

- Sulfato de cobre (II) $\geq 99 \%, \mathrm{CuSO}_{4}$ (Sigma-Aldrich)

- Sulfato de estroncio $99 \%, \mathrm{SrSO}_{4}$ (Sigma-Aldrich)

- Sulfato de galio hidrato $\geq 99.99 \%, \mathrm{Ga}_{2}\left(\mathrm{SO}_{4}\right)_{3} \cdot \mathrm{xH}_{2} \mathrm{O}$ (Sigma-Aldrich)

- Sulfato de hierro (II) heptahidrato, $\mathrm{FeSO}_{4} \cdot 7 \mathrm{H}_{2} \mathrm{O}$ (Merck)

- Sulfato de lantano $\geq 99.99 \%, \mathrm{La}_{2}\left(\mathrm{SO}_{4}\right)_{3}$ (Sigma-Aldrich)

- Sulfato de magnesio heptahidrato $98 \%, \mathrm{MgSO}_{4} \cdot 7 \mathrm{H}_{2} \mathrm{O}$ (Sigma-Aldrich)

- Sulfato de niquel (II) hexahidrato $98 \%, \mathrm{NiSO}_{4} \cdot 6 \mathrm{H}_{2} \mathrm{O}$ (Sigma-Aldrich)

- Sulfato de plata $99.999 \%, \mathrm{Ag}_{2} \mathrm{SO}_{4}$ (Sigma-Aldrich) 


\subsubsection{Líquidos}

- Agua ultrapura o milli Q (obtenida con un equipo MILLIPORE), sometida a un control de calidad diario.

- Agua desionizada (obtenida mediante filtros y resinas de intercambio), sometida a un control de calidad diario.

- Ácido nítrico $60 \%, \mathrm{HNO}_{3}$ (Scharlau)

- Amoníaco 25\%, $\mathrm{NH}_{3}$ (Panreac)

- Metanol, $\mathrm{CH}_{3} \mathrm{OH}$ (Scharlau)

- También se han empleado micro-volúmenes de los distintos compuestos orgánicos líquidos que se obtienen en los experimentos catalíticos para el cálculo de factores de respuesta y calibrado de diversos parámetros en los análisis por cromatografía de gases (ácido acético, ácido acrílico, acroleína, etc)

\subsubsection{Gases}

- Helio (Abelló-Linde)

- Oxígeno (Abelló-Linde)

- Propano (Abelló-Linde)

- Propeno (Abelló-Linde)

- Mezcla propeno/oxígeno/helio de relación molar 2/8/90 (Abelló-Linde)

- Nitrógeno (obtenido directamente mediante un generador de $\mathrm{N}_{2}$ )

- También se han empleado balas con varias mezclas de gases (reactivos y productos que se obtienen en nuestros experimentos catalíticos) para el cálculo de factores de respuesta y calibrado de los tiempos de retención en el análisis por cromatografía de gases ( $\mathrm{CO}, \mathrm{CO}_{2}$, propano, propeno, etc).

Todos los reactivos gaseosos utilizados llevan certificada una pureza $>99 \%$.

\subsection{Preparación de óxidos mixtos MoVTe(Sb)Nb por el método hidrotermal}

Los catalizadores basados en óxidos mixtos de Mo y $\mathrm{V}$ se han preparado mediante el método hidrotermal, tal y como se describe a continuación.

En primer lugar, se preparó una disolución acuosa de las sales de los distintos metales que se van a emplear en la síntesis con una composición determinada. Como sales de Mo y $\mathrm{V}$ se han empleado heptamolibdato amónico y 
sulfato de vanadilo, respectivamente. En el caso de los catalizadores con antimonio la sal utilizada normalmente es bromuro de antimonio (III), mientras que, en los materiales con teluro se ha empleado ácido telúrico u óxido de teluro (IV).

De esta forma se obtiene un gel de síntesis que se introduce en un teflón, que a su vez se introduce en un autoclave de acero inoxidable. El autoclave se purga con nitrógeno para eliminar el aire, y se introduce en la estufa a una temperatura de $175^{\circ} \mathrm{C}$ durante $48 \mathrm{~h}$. En algunos casos, se varió la temperatura de síntesis y/o el tiempo de síntesis. Transcurrido este tiempo, el autoclave se saca de la estufa y se deja enfriar a temperatura ambiente.

Una vez a temperatura ambiente, el autoclave se abre y el contenido del teflón se filtra para separar el sólido que ha cristalizado de la disolución que contiene los metales que no han reaccionado. El sólido, al que llamaremos precursor, se lava con agua destilada y se seca en la estufa a $100^{\circ} \mathrm{C}$ durante 16 horas.

Por último, el precursor obtenido se debe activar mediante un tratamiento térmico con nitrógeno. Este tratamiento térmico se lleva a cabo en un reactor tubular de cuarzo con una placa porosa en su interior, donde se sitúa el sólido. El reactor se introduce en un horno y se calienta a una velocidad de $3{ }^{\circ} \mathrm{C} / \mathrm{min}$ hasta alcanzar la temperatura deseada (normalmente $600^{\circ} \mathrm{C}$ ) a la cual se mantiene durante el tiempo programado (generalmente $2 \mathrm{~h}$ ) para posteriormente dejar enfriar a temperatura ambiente. Durante todo el proceso se mantiene un flujo constante de $\mathrm{N}_{2}$ con un caudal de $15 \mathrm{ml} \mathrm{g}_{\text {cat }}{ }^{-1} \mathrm{~min}^{-1}$ a través del interior del reactor.

\subsection{Técnicas de caracterización}

La caracterización físico-química de los catalizadores tiene como objetivo aportar información estructural, textural y del tipo de fases cristalinas y/o especies presentes en los catalizadores. A continuación se describen las técnicas empleadas a lo largo de la tesis.

\subsubsection{Análisis químico por AES-ICP}

Para determinar el contenido de los distintos elementos que conforman el catalizador, se recurrió a su análisis mediante espectrometría de emisión atómica (AES).

La AES es un tipo de espectrometría atómica óptica que se basa en la medición de radiación emitida por los átomos que han sido excitados mediante una fuente de energía a alta temperatura. A temperatura ambiente, esencialmente todos los átomos de una muestra de materia se encuentran en el estado fundamental. La excitación de un electrón a orbitales de mayor energía se puede 
conseguir por el calor de una llama, un plasma, una chispa o arco eléctrico. El tiempo de vida de un átomo excitado es breve y, sin embargo, su regreso al estado fundamental va acompañado de la emisión de un fotón de radiación. Los espectros de emisión obtenidos están constituidos por líneas o picos definidos por las longitudes de onda características de las radiaciones electromagnéticas (dentro del intervalo ultravioleta-visible) emitidas por los átomos elementales excitados. Estas líneas de emisión son características de cada elemento, lo que hace que sean útiles para el análisis elemental tanto cualitativo como cuantitativo [1].

La espectrometría de emisión atómica de plasma de acoplamiento inductivo (AES-ICP) se usa principalmente para el análisis cuantitativo de muestras disueltas $\mathrm{o}$ en suspensión en disolventes acuosos u orgánicos. En nuestro caso, una cantidad de la muestra a analizar (alrededor de $30 \mathrm{mg}$ ) se disgrega en medio ácido, generalmente una mezcla de ácido clorhídrico y fluorhídrico. Las medidas se realizaron en un aparato Varian 715-ES.

\subsubsection{Determinación de la superficie específica (BET)}

Las áreas superficiales de los catalizadores se determinaron mediante el método BET a partir de las isotermas de adsorción de nitrógeno.

El método de la isoterma BET fue desarrollado por Brunauer, Emmer y Teller a finales de los años 30 [2]. En el modelo, se asume que un gas, como por ejemplo el nitrógeno, a bajas temperaturas se adsorbe sobre la superficie sólida disponible formando varias capas moleculares, a cada una de las cuales se aplica la isoterma de Langmuir. La ecuación que describe este estado es la siguiente:

$$
\frac{\mathrm{P}}{\mathrm{V}\left(\mathrm{P}_{0}-\mathrm{P}\right)}=\frac{1}{\mathrm{~V}_{\mathrm{m}} \mathrm{C}}+\frac{\mathrm{C}-1}{\mathrm{~V}_{\mathrm{m}} \mathrm{C}} \cdot \frac{\mathrm{P}}{\mathrm{P}_{0}}
$$

En esta expresión, $V$ es el volumen de gas adsorbido a la presión $P, V_{m}$ es el volumen de gas que se requiere para cubrir la monocapa, $P_{0}$ es la presión de vapor saturado del gas y $C$ es una constante que refleja la diferencia entre los calores de adsorción de la primera y la segunda monocapa adsorbida. $V_{m}$ se calcula a partir de la isoterma.

Una vez que se ha determinado el volumen de la monocapa, el área superficial de la muestra $\left(\mathrm{S}_{\mathrm{BET}}\right.$, expresada en $\left.\mathrm{m}^{2} / \mathrm{g}_{\text {muestra }}\right)$ puede calcularse mediante la siguiente expresión, donde $N_{a}$ es el número de Avogadro y $\sigma$ la superficie que ocupa una molécula de nitrógeno. El valor generalmente aceptado para $\sigma$ es de $0.162 \mathrm{~nm}^{2}$. 


$$
\mathrm{S}_{\mathrm{BET}}=\left(\frac{\mathrm{V}_{\mathrm{m}}}{22414}\right) \mathrm{N}_{\mathrm{a}} \sigma
$$

Las medidas realizadas para este estudio se llevaron a cabo en un instrumento Micromeritics modelo TriStar 3000. En un primer paso, a la muestra se le realiza un pre-tratamiento a vacío a una temperatura de $400^{\circ} \mathrm{C}$ para limpiar la superficie del sólido de cualquier tipo de impurezas. Después del tratamiento de evacuación, se pesa el sólido en un tubo de muestra y se enfría a $77 \mathrm{~K}\left(-196{ }^{\circ} \mathrm{C}\right.$, temperatura del nitrógeno líquido), se introduce el gas nitrógeno y se registra el volumen de gas adsorbido frente a la variación de la presión.

\subsubsection{Análisis térmico gravimétrico y diferencial (TG-DTA)}

Un análisis térmico consiste en medir una propiedad física de una sustancia en función de la temperatura mientras la sustancia se somete a un programa de temperatura controlado [3].

En nuestro caso, se ha empleado el análisis termogravimétrico (TGA), que determina los cambios de masa, pérdida o ganancia, que sufre un material por calentamiento a temperatura programada, en una atmósfera determinada: reactiva (aire) o inerte $\left(\mathrm{N}_{2}\right)$. Así, se obtiene una curva que representa la variación de la masa en función de la temperatura que suministra información sobre la estabilidad térmica y composición de una muestra.

Además, se ha utilizado el análisis térmico diferencial (DTA), que mide los cambios de temperatura en una muestra, lo que permite estudiar la naturaleza del proceso asociado a estas pérdidas, indicando si es endotérmico o exotérmico, así como su magnitud. Además, mediante el análisis térmico diferencial se pueden observar fenómenos como transiciones de fases cristalinas (reacciones en estado sólido) que pueden no llevar asociadas variaciones de masa.

Fundamentalmente, toda la información obtenida mediante los análisis térmicos empleados nos puede ayudar a comprender mejor los fenómenos que tienen lugar durante las etapas de activación térmica de los catalizadores que se han preparado para este estudio.

Los análisis térmicos gravimétricos y diferenciales se llevaron a cabo simultáneamente (TG-DTA) sobre cada muestra. Las medidas se han efectuado entre 20 y $600^{\circ} \mathrm{C}$ en un equipo Mettler Toledo TGA/SDTA 851e, utilizando entre 10 y 20 miligramos de muestra. La velocidad de calentamiento es de $10^{\circ} \mathrm{C} / \mathrm{min}$ y los experimentos se realizaron en atmósfera controlada de aire (reactiva) o nitrógeno (inerte), con un flujo de $50 \mathrm{ml} / \mathrm{min}$. 


\subsubsection{Difracción de rayos $X$ en polvo (DRX)}

Para determinar las fases cristalinas presentes en el catalizador se recurre a la técnica de difracción de rayos $X$.

En la difracción de rayos $X$, se hace incidir un haz monocromático de rayos $X$ sobre la muestra sólida a analizar. Cuando este haz monocromático choca contra la superficie de un cristal formando un ángulo $\theta$, una porción del haz es dispersada por la primera capa de átomos, y la porción no dispersada penetra hasta la segunda capa de átomos donde, de nuevo, una fracción es dispersada y el resto pasa a la tercera capa y así sucesivamente con el resto de capas de átomos o planos cristalográficos característicos del cristal. La difracción se produce como consecuencia del efecto acumulativo de estas dispersiones (interferencias constructivas) debido al ordenamiento regular de los átomos del cristal y a que las distancias entre estos átomos (centros de dispersión) son del mismo orden de magnitud que la longitud de onda de la radiación de rayos $\mathrm{X}$. Cuando el ángulo de incidencia sobre los planos reticulares de la muestra satisface la ecuación de Bragg, se produce la difracción de rayos $\mathrm{X}$ :

$$
\mathrm{n} \lambda=2 \mathrm{~d}_{h k l} \cdot \operatorname{sen} \theta
$$

En esta expresión, $n$ es un número entero, $\lambda$ es la longitud de onda del haz de rayos $\mathrm{X}, d_{h k l}$ es la separación entre los planos del cristal y $\theta$ es el ángulo de incidencia de los rayos $X$.

En los aparatos de DRX, se emiten electrones hacia un objetivo de cobre con el fin de crear los rayos $X$. Estos se dirigen hacia la muestra en polvo con un ángulo variable, siendo detectados después de la difracción por un detector. El difractograma resultante contiene picos que corresponden a un plano de átomos en la muestra, que satisface la ecuación de Bragg. Es conveniente que la muestra se encuentre como polvo, pues de este modo se asegura que algunos cristales estén orientados cumpliéndose la ley de Bragg, produciéndose el fenómeno de difracción.

Los difractogramas de rayos $\mathrm{X}$ son característicos de cada material analizado, por lo que puede usarse para identificar la fase o fases presentes en la muestra por comparación con patrones de fases puras, que pueden estar almacenados en bases de datos o en archivos. Así pues, el uso de esta técnica permite, entre otras cosas, determinar la naturaleza amorfa o cristalina de una muestra en polvo, identificar las fases cristalinas presentes, estimar su abundancia relativa, y determinar sus parámetros de celda unidad. 
El equipo utilizado para la realización de las medidas fue un difractómetro $P A N a l y t i c a l$ CUBIX, equipado con un detector $X$ 'Celerator, usando radiación de un ánodo de $\mathrm{Cu} \mathrm{K}_{\alpha}\left(\mathrm{K}_{\alpha 1}=1.54056 \mathrm{~nm}, \mathrm{~K}_{\mathrm{a} 2}=1.54439 \mathrm{~nm}\right.$, relación de intensidades $\mathrm{K}_{\mathrm{a} 2} / \mathrm{K}_{\mathrm{\alpha} 1}=0.5$ ) que pasa a través de un filtro de níquel para eliminar $\mathrm{K}_{\beta}$. Las medidas se llevaron a cabo operando a $45 \mathrm{kV}$ de potencia y $40 \mathrm{~mA}$ de intensidad. Normalmente, las medidas se realizaron con el programa general: rendija de divergencia variable, con área irradiada $=3 \mathrm{~mm}$, en el rango $2 \theta$ de $2.0 \mathrm{a}$ $90.0^{\circ}$ con adquisiciones a $\Delta(2 \theta)=0.04^{\circ}$, tiempo por paso $35 \mathrm{~s}$.

La cuantificación de las fases cristalinas se ha llevado a cabo por el método Rietveld [4] con ayuda del software X'Pert High Score Plus. Para ello, las medidas de difracción de rayos $X$ se han realizado con un programa especial con la rendija de divergencia fija, con apertura angular de $1 / 16$, en el intervalo $2 \theta$ de 5.0 a $90.0^{\circ}$ con un incremento de $0.04^{\circ}$, tiempo por paso $500 \mathrm{~s}$. En algunos casos, para la determinación de la presencia de sólido amorfo en las muestras, se ha empleado $\mathrm{V}_{2} \mathrm{O}_{5}$ [JCPS: $77-2418$ ] como patrón interno (20\% en peso).

\subsubsection{Espectroscopia de reflectancia difusa en la región ultravioleta-visible (RD UV-Vis)}

La radiación ultravioleta-visible comprende la zona del espectro electromagnético de longitudes de onda desde 160 hasta $780 \mathrm{~nm}$, aproximadamente. Los fenómenos en los que se produce absorción de radiación UV-Vis generalmente están relacionados con la excitación de electrones de enlace [1].

La mayoría de los iones de metales de transición absorben energía en la región UV-Vis del espectro. En la región visible del espectro, se suelen producir las transiciones entre orbitales $\mathrm{d}$, que dependen del número de electrones $d$ y cuyas bandas no son muy intensas pero están muy influidas por el número de electrones $d$ y el entorno del centro metálico. Además, en la región UV, aparecen generalmente transiciones de transferencia de carga del metal al ligando o viceversa, cuyas bandas de adsorción suelen ser anchas y están enormemente influenciadas por los factores químicos del entorno del centro adsorbente. Así, el espectro de UV-Vis que presenta un compuesto de metales de transición depende de las energías de los orbitales $d$ de sus átomos metálicos, de su degeneración, y del número de electrones distribuidos en ellos; factores éstos que vienen determinados por parámetros tales como el estado de oxidación del metal, la clase de ligandos y la geometría del compuesto.

En este estudio, las muestras que se analizan son sólidos en polvo, opacos o poco transparentes, por lo que la luz se vería reflejada y no trasmite, siendo la técnica de adsorbancia o transmisión inapropiada. En su lugar, se emplea la 
reflexión o reflectancia no especular que tiene lugar en todas las direcciones del espacio como consecuencia de procesos de absorción y dispersión por parte de una muestra cuando es irradiada por un haz de radiación UV-Vis. A este tipo de reflexión se le conoce como reflectancia difusa, y la intensidad del haz difuso reflectado por las partículas de una muestra será menor que la del haz incidente. Midiendo esta diferencia para cada longitud de onda irradiada se puede obtener el mismo tipo de información que en un experimento de transmisión, con las limitaciones o particularidades intrínsecas del estado sólido de la muestra.

Esta técnica se ha empleado en la caracterización de los óxidos de Mo y $\mathrm{V}$ obtenidos en el presente trabajo. Tanto el Mo como el $V$ son metales de transición con configuraciones electrónicas $4 d^{5} 5 s^{1}$ y $3 d^{3} 4 s^{2}$, respectivamente. Así, el Mo (VI) y el $V(V)$ no tienen electrones $d$, y por tanto, no se producen transiciones $d$-d. Sin embargo, sí se producen transiciones de transferencia de carga ligando-metal dependiendo del entorno en el que se encuentren. Es sabido que las especies de vanadio tetraédrico aparecen a $270-280 \mathrm{~nm}$, mientras que las especies de vanadio octaédrico aparecen a mayor longitud de onda (sobre 400-500 nm) [5]. Por su parte, el molibdeno presenta transiciones de transferencia de carga $\mathrm{O}^{2-} \rightarrow \mathrm{Mo}^{6+}$ a 250-280 nm si se encuentra en coordinación tetraédrica, y 290-330 nm si está octaédrico [6]. Por otro lado, la presencia de iones $\mathrm{Mo}^{5+} \mathrm{y} / \mathrm{o} \mathrm{V}^{4+}$ en el material da lugar a transiciones $d-d$ en el espectro visible. Así, los iones $\mathrm{VO}^{2+}$ pueden ser observados entre 600 y $770 \mathrm{~nm}$, aunque su intensidad es 10-30 veces más débil que las transiciones de transferencia de carga [7]. En el caso del Mo, la presencia de bandas a 400 y $790 \mathrm{~nm}$ sugieren que el molibdeno se encuentra hexacoordinado $\left[\mathrm{Mo}^{5+} \mathrm{O}_{6}\right.$ ]; bandas a 500 y $600 \mathrm{~nm}$ aparecen si se encuentra pentacoordinado (una vacante de oxígeno), $\left[\mathrm{Mo}^{5+} \mathrm{O}_{5}\right]$ [8]; y si se encuentra en coordinación tetraédrica se observa una banda a $500 \mathrm{~nm}$.

Las medidas se realizaron con un espectrofotómetro UV-Vis-NIR marca Varian modelo Cary 5, en el rango de 200-800nm. Antes de medir la muestra se hace un barrido del espectro sobre un patrón inerte (no adsorbe) de sulfato de bario, en el rango donde se va a medir la muestra, que luego usará el equipo en el procesado del espectro de la muestra para corregir la línea base.

\subsubsection{Espectroscopia de absorción infrarroja (FT-IR)}

La región del infrarrojo se encuentra limitada entre las regiones del visible y de microondas, abarcando longitudes de onda desde 0.78 a $1000 \mu \mathrm{m}$. En ella se distinguen tres zonas: infrarrojo próximo $\left(12500-4000 \mathrm{~cm}^{-1}\right)$, infrarrojo medio $\left(4000-660 \mathrm{~cm}^{-1}\right)$ e infrarrojo lejano $\left(660-50 \mathrm{~cm}^{-1}\right)$.

El espectro infrarrojo se origina por una absorción de fotones con energía correspondiente a la región del infrarrojo, que genera una transición entre niveles 
vibracionales o rotacionales en una molécula, dentro del estado electrónico en que se encuentre esa especie [3]. Los átomos de una molécula presentan un movimiento de vibración que se produce como consecuencia del alargamiento o balanceo de los enlaces interatómicos sobre la posición de equilibrio, originando modificaciones en el momento dipolar de la molécula. Cuando la frecuencia de uno de estos movimientos vibracionales con cambio en la polarizabilidad molecular, coincide con la frecuencia de la radiación incidente, se produce un fenómeno de resonancia con absorción de energía por parte de la molécula. Este fenómeno constituye la base de la espectroscopia de absorción IR.

La espectroscopia infrarroja nos permite obtener información estructural, superficial y de las propiedades ácido-base de los materiales [9]. Su uso está muy generalizado en el estudio de materiales inorgánicos, ya que el número, la posición y la intensidad de las bandas están relacionados con la estructura, fortaleza del enlace y número de especies activas en el infrarrojo. La espectroscopia infrarroja con transformada de Fourier (FT-IR), utilizada en el presente trabajo, permite una mayor resolución que la espectroscopia infrarroja IR convencional.

En nuestro caso, la espectroscopia FT-IR se ha empleado fundamentalmente con dos objetivos. Por un lado, obtener información acerca de la naturaleza del catalizador, en cuanto a vibraciones de red (de las fases cristalinas) y tipos de enlaces metal-oxígeno presentes $(\mathrm{M}=\mathrm{O}$ y $\mathrm{M}-\mathrm{O}-\mathrm{M})$, cuyas bandas para las especies de molibdeno y vanadio estudiadas se encuentran en el intervalo comprendido entre 300 y $1100 \mathrm{~cm}^{-1}$ [10]. Además, se ha empleado la espectroscopía IR en sólidos después de la adsorción de diferentes moléculas a fin de estudiar la naturaleza de los centros activos presentes en la superficie del catalizador (tanto centros con características ácidas como centros con propidades redox). Para ello, se han empleado moléculas como metanol o $\mathrm{NH}_{3}$.

El estudio de la adsorción de moléculas sonda por espectroscopia infrarroja FTIR es un método bien establecido para extraer información sobre una superficie de un sólido [11]. La adsorción de moléculas sonda sobre la superficie de óxidos está dominada por la naturaleza iónica del sólido. La adsorción se puede dar en centros catiónicos ácidos Lewis que interaccionan con moléculas dadoras de electrones como agua o amoníaco, mientras que la presencia de aniones óxidos exhibe un carácter básico aceptando protones después de la disociación del adsorbato [11-12]. Además, la presencia de centros redox capaces de oxidar/reducir al adsorbato se ven reflejados en un cambio en el estado de oxidación del adsorbato. Por ejemplo, cuando la molécula sonda es una molécula orgánica como un alcohol o aldehído puede producirse una transferencia de oxígeno oxidando la molécula a su correspondiente aldehído o ácido [11, 13-15]. 


\subsubsection{Procedimiento IR transmisión}

Para el estudio de las características estructurales de los catalizadores estudiados se empleo la espectroscopia IR de transmisión. Los espectros de infrarrojo de transmisión fueron adquiridos a temperatura ambiente en la región de $300-3900 \mathrm{~cm}^{-1}$ en un modelo NICOLET 710 FTIR, con una resolución espectral de $1 \mathrm{~cm}^{-1}$ y 128 acumulaciones en cada espectro. Para ello, $20 \mathrm{mg}$ de muestra seca en polvo se mezclaron con $100 \mathrm{mg}$ de bromuro potásico $(\mathrm{KBr})$ y se prensaron para obtener una pequeña pastilla traslúcida.

\subsubsection{Procedimiento FTIR con adsorción de metanol}

El espectro IR de la adsorción de metanol se realiza a temperatura ambiente en un espectrómetro Nexus 8700 FTIR, empleando un detector DTGS y una resolución de adquisición de $4 \mathrm{~cm}^{-1}$. Antes de la adsorción de metanol, las muestras (una pastilla autoconsistente) se activan a $150^{\circ} \mathrm{C}$ a vacío $\left(1 \times 10^{-4} \mathrm{mbar}\right)$ durante 2 horas. Posteriormente, el metanol se adsorbe a temperatura ambiente incrementando progresivamente la presión (1-6 mbar).

\subsubsection{Procedimiento DRIFT con moléculas sonda}

La espectroscopia de reflectancia difusa en el infrarrojo de transformada de Fourier (DRIFTS) es una forma eficaz de obtener espectros en el infrarrojo directamente sobre muestras pulverizadas con un mínimo de preparación de la misma [16]. El principio de esta técnica se basa en el fenómeno de reflexión, que ocurre cuando la radiación incide sobre una muestra opaca y no absorbente. La reflexión difusa es un proceso complejo que tiene lugar cuando un haz de radiación choca con la superficie de un polvo finamente dividido. En este tipo de muestras tiene lugar una reflexión especular en cada superficie plana. Sin embargo, como hay muchas superficie de éstas y se encuentran aleatoriamente orientadas, la radiación se refleja en todas las direcciones. La radiación que ha sufrido la reflexión difusa en la muestra se recoge en un espejo esférico centrado en el detector.

La ventaja del empleo de la reflectancia difusa (DRIFTS) frente a la espectroscopia de adsorción normalmente utilizada reside en la preparación de la muestra, empleando la muestra directamente en polvo como alternativa a la preparación de pastillas (usadas en espectroscopia FTIR). En ambos casos, la posición de las bandas observadas es la misma pero la intensidad relativa de las bandas difiere considerablemente, siendo los picos secundarios más grandes en el espectro de reflexión [17].

En nuestro caso, la adsorción de moléculas sonda sobre catalizadores mediante espectroscopia DRIFTS se realizó durante la estancia realizada en la 
Universidad de Aberdeen (Escocia). Aproximadamente $80 \mathrm{mg}$ de muestra fue colocada en una celda DRIFTS con cristales de $\mathrm{CaF}_{2}$ esquipada con un sistema de calefacción que permite el funcionamiento en diferentes atmósferas hasta $600^{\circ} \mathrm{C}$. Los espectros se recogieron en un espectrómetro Perkin-Elmer Spectrum 100 equipado con un detector MCT, con 125 scans a una resolución de $4 \mathrm{~cm}^{-1}$. Los gases de la celda se controlaron mediante un Gas Blender y fueron analizados a la salida de la celda mediante un Baltzers Prisma Quadrupole mass spectrometer [18-19]. En todos los casos, las muestras se activaron en condiciones de reacción a $400^{\circ} \mathrm{C}$ durante $2 \mathrm{~h}$ antes de realizar la adsorción de moléculas. La mezcla empleada en la activación consta de $2 \%$ de propileno, $8 \%$ de oxígeno, equilibrado con nitrógeno para un flujo total de $50 \mathrm{ml} / \mathrm{min}$. Una vez activada la muestra, se enfría hasta temperatura ambiente o a la temperatura a la que se procederá a la adsorción de moléculas. En el caso de adsorción de amoníaco la temperatura utilizada fue $80^{\circ} \mathrm{C}$, mientras que en la adsorción de acroleína fue $100^{\circ} \mathrm{C}$. Las sustancias a adsorber fueron inyectadas en la celda mediante una válvula de inyección equipada con un loop de $1 \mathrm{~mL}$, cuando se empleó acroleína se inyectó ( $10 \mu \mathrm{L})$ con una jeringa.

\subsubsection{Espectroscopia Raman}

La espectroscopia Raman es, en muchos casos, complementaria a la espectroscopia infrarroja, obteniendo también información sobre los niveles de energía vibracional y rotacional de una molécula.

Cuando a una molécula se irradia una radiación electromagnética $h v$ puede ser transmitida, absorbida o dispersada. La espectroscopia Raman examina la frecuencia de la luz dispersada de las moléculas. Esta dispersión puede ser elástica 0 inelástica. La componente elástica se conoce como la dispersión Rayleigh y no contribuye al espectro Raman, siendo la componente inelástica la que da el espectro Raman.

Como resultado de la colisión, la energía vibracional o rotacional de la molécula se modifica en una cantidad $\Delta \mathrm{E}_{\mathrm{m}}$. La energía del fotón dispersado $\left(h v_{s}\right)$ debe ser diferente de la energía del fotón incidente $\left(h v_{i}\right)$, en una cantidad igual a $\Delta \mathrm{E}_{\mathrm{m}}$.

$$
\Delta \mathrm{E}_{\mathrm{m}}=\mathrm{h} v_{\mathrm{i}}-\mathrm{h} v_{\mathrm{s}}=\mathrm{h}\left(v_{\mathrm{i}}-v_{\mathrm{s}}\right)=\mathrm{h} v_{\mathrm{m}}
$$

Si la molécula gana energía, esto es $\Delta \mathrm{E}_{\mathrm{m}}$ positiva, da lugar a un aumento de la radiación Stokes. Si la molécula pierde energía, $\Delta \mathrm{E}_{\mathrm{m}}$ es negativa y da lugar a un aumento de radiación Anti-Stokes. En la dispersión Raman, la frecuencia del fotón incidente es normalmente mayor que $v_{\mathrm{m}}$. Cuanto el fotón incidente interacciona con una molécula en estado fundamental, la molécula absorbe la energía y 
aumenta de nivel momentáneamente a un nivel energético superior, pero inestable. La molécula inmediatamente pierde energía y cae a un nivel de menor energía, emitiendo un fotón dispersado. Si la molécula cae hasta el estado fundamental, que es lo más probable, el fotón dispersado tendrá la misma energía que el fotón incidente (dispersión Rayleigh). Una pequeña proporción de moléculas caen a un nivel excitado de energía, emitiendo un fotón con menor energía que el fotón incidente (dispersión Stokes). Si la molécula está inicialmente en un estado excitado, puede absorber la energía del fotón volviendo entonces al nivel fundamental, emitiendo un fotón con una energía $h v_{m}$ mayor que la del fotón incidente (dispersión anti-Stokes).

La espectroscopia Raman es un instrumento importante para la caracterización de materiales ya que diferentes estructuras moleculares dan lugar a distintos espectros Raman.

En el intervalo del espectro comprendido entre 100 y $1200 \mathrm{~cm}^{-1}$ aparecen las bandas más interesantes para la determinación de las estructuras de los óxidos de vanadio y molibdeno. Así, las bandas asociadas a las vibraciones de tensión correspondientes al enlace $M=O(M=M o, V)$ terminal aparecen entre 770 y 1050 $\mathrm{cm}^{-1}$, las de $M-O-M$ entre 500 y $800 \mathrm{~cm}^{-1}$ y las asociadas a las vibraciones de flexión, por debajo de los $400 \mathrm{~cm}^{-1}$ [20].

Los espectros Raman (en Transformada de Fourier) se obtuvieron mediante un espectrofotómetro Renishaw system 1000, equipado con un microscopio Olympus. Las muestras se excitaron con un láser de Argón ionizado (Espectra Physics 171), emitiendo radiación discreta a $785 \mathrm{~nm}$ (correspondiente a la luz verde visible en el espectro electromagnético) con una potencia de $2.5 \mathrm{~mW}$. Adicionalmente, se adquirieron espectros de algunos de los sólidos con la radiación de $514 \mathrm{~nm}$. Para cada muestra se adquieren varios espectros Raman en diferentes puntos, para determinar el grado de homogeneidad de la misma.

\subsubsection{Espectroscopia Fotoelectrónica de rayos X (XPS)}

Entre las técnicas de caracterización de superficie la espectroscopia fotoelectrónica de rayos X (XPS), también conocida como espectroscopia de electrones para el análisis químico (ESCA), es la más utilizada. Es una técnica de caracterización superficial no destructiva que permite obtener información, tanto cualitativa como cuantitativa, de las especies químicas en superficie con una capacidad de penetración hasta unos $6 \mathrm{~nm}$.

En XPS, se produce la irradiación de la superficie de una muestra con un haz de rayos $\mathrm{X}$ monocromático (líneas $\mathrm{K} \alpha_{1,2}$ de $\mathrm{Mg}$ o Al que tienen energías de 1253.6 y $1486 \mathrm{eV}$ ). Como consecuencia de la absorción de los fotones de rayos $\mathrm{X}$ por la 
muestra se produce una transferencia de energía del fotón a los electrones de las capas internas de los átomos de la superficie, dando como resultado la emisión de un haz de electrones que pueden ser analizados y separados en función de su energía. La energía de los fotoelectrones está relacionada con el entorno atómico y molecular de donde son generados [21]. De este modo, conociendo la energía del fotón irradiado y la energía cinética del electrón emitido, se puede calcular la energía de enlace (energía de ligadura) de dicho electrón, la cual es característica del átomo y del orbital en el que se encontraba el electrón emitido:

$$
E_{B}=h v-E_{K}-W
$$

donde $h v$ es la energía del fotón; $E_{K}$, la energía cinética del fotoelectrón emitido; $W$, la función de trabajo del espectrómetro y; $E_{B}$, la energía de ligadura (parámetro que identifica al electrón de forma específica, en términos del elemento y nivel atómico). El equipo XPS procesa la señal y se obtiene un espectro donde se representa directamente la velocidad de recuento de electrones (electrones/s) frente a su energía de enlace.

Así, la aplicación fundamental del XPS es el estudio de la superficie de una muestra. Este estudio permite detectar los elementos presentes en la superficie y cuantificarlos, pero también se puede obtener los estados de oxidación y entornos de coordinación de los elementos presentes en la superficie.

Los análisis de XPS se han llevado a cabo en un instrumento de la marca SPECS, usando un ánodo de aluminio como fuente de rayos $X\left(A I K_{\alpha}=1486.6\right.$ $\mathrm{eV})$. Para realizar el análisis, el portamuestras con una pastilla de la muestra, usando aproximadamente entre 30 y $60 \mathrm{mg}$ de muestra, se introduce en el equipo de medida, donde permanece hasta alcanzar un vacío del orden de $10^{-7} \mathrm{mbar}$. Después, la muestra se dirige a la línea de transferencia desde donde se puede distribuir a tres posibles cámaras: pre-cámara, cámara de reacción y cámara de análisis. En la pre-cámara se calienta la muestra a vacío para eliminar agua y otros compuestos lábiles y volátiles (posibles impurezas); la cámara de reacción, permite la introducción de gases para que reaccionen con la muestra a temperatura controlada; $y$, en la cámara de análisis se hace primeramente un espectro en el rango de energías de enlace entre 1400 y $0 \mathrm{eV}$, y luego se analizan en detalle las zonas de energía correspondientes a los átomos que más interesen, mediante acumulaciones de espectros centradas en una determinada región del espectro. La energía de ligadura $\left(\mathrm{E}_{\mathrm{B}}\right)$ se determina con una precisión de $\pm 0.1 \mathrm{eV}$ y se regula mediante la señal $\mathrm{C} 1 \mathrm{~s}$ del carbono como referencia (284.6 $\mathrm{eV})$. Los análisis de los espectros se han realizado empleando el software CASA. 


\subsubsection{Microscopía electrónica de barrido (SEM) y microanálisis de rayos $X(E D X)$}

En la química catalítica es muy importante el conocimiento detallado de la naturaleza física de las superficies de los sólidos. El método clásico para obtener tal información fue la microscopía óptica. Sin embargo, la resolución de un microscopio está limitada por la longitud de onda que emplea al irradiar la muestra para su visualización. En el caso de un microscopio óptico, donde se emplea luz visible $(400-700 \mathrm{~nm})$, el límite de resolución está alrededor de $550 \mathrm{~nm}$ aproximadamente [1]. El desarrollo de la microscopía electrónica ofrece mejores oportunidades. El uso de haces de electrones acelerados permite obtener longitudes de onda menores con las que irradiar, reduciendo así los límites de resolución y aumentando la resolución máxima que se puede alcanzar teóricamente $(0.1 \mathrm{~nm})$.

Así, el uso de la microscopía electrónica de barrido (scanning electron microscopy, SEM) permite la observación y caracterización de materiales a una escala nano $(\mathrm{nm})$ y micrométrica $(\mu \mathrm{m})$. A partir de la obtención de micro-imágenes tridimensionales de las muestras se pueden estudiar las características morfológicas y topográficas de los sólidos microscópicos que componen la muestra.

En un microscopio electrónico de barrido se barre mediante un rastreo programado la superficie del sólido con un haz de electrones de energía elevada $y$, como consecuencia de ello, se producen en la superficie diversos tipos de señales. Estas señales incluyen electrones retrodispersados, secundarios y Auger; fotones debido a la fluorescencia de rayos $\mathrm{X}$ y otros fotones de diversas energías. La microscopía electrónica de barrido se fundamenta en las señales de los electrones retrodisperdados y secundarios [22].

El número de electrones retrodispersados dependerá del tipo de núcleo con el que interaccionan, permitiendo así obtener información sobre la composición elemental del material, mediante imágenes en las que se combinan escalas de grises donde las zonas más claras corresponden a la presencia de elementos más pesados, y las zonas oscuras a elementos más ligeros.

Tanto los electrones incidentes como los electrones retrodispersados pueden interaccionar con los electrones que forman parte de los orbitales externos de los átomos de la muestra y expulsarlos, generando lo que se conoce como haces de electrones secundarios, que salen en todas direcciones y permiten obtener información sobre la morfología y la superficie de la muestra bajo estudio, ya que poseen una energía muy baja y sólo pueden alcanzar la lente aquellos que estén próximos a la superficie del material. 
La espectroscopía de dispersión de energía de rayos X (EDS o EDX) es una técnica de microanálisis químico utilizado en conjunto con la microscopía electrónica de barrido (SEM). La técnica EDS detecta los rayos $X$ emitidos por la muestra durante el bombardeo de un haz de electrones sobre dicha muestra, determinando la composición elemental del volumen analizado[22]. Cuando la muestra es bombardeada por el haz de electrones de alta energía, procedente de la fuente, arranca electrones de capas internas (niveles $\mathrm{K}$ y $\mathrm{L}$ son los más utilizados, debido a su mayor energía) de los átomos de la superficie de la muestra. Esto, genera átomos excitados (ionizados) donde un electrón de un orbital de mayor energía ocupa el lugar del electrón expulsado y que, al volver a su estado fundamental emiten radiación de rayos $X$ para equilibrar la diferencia de energía. La energía de estos rayos $X$ es característica de cada átomo, lo que permite, mediante el empleo de un detector adecuado, la determinación cualitativa (medida de la $\lambda$ emitida) y cuantitativa (intensidad de energía de una determinada $\lambda$, por segundo) de los elementos que componen una muestra.

En nuestro caso, las imágenes se han obtenido fundamentalmente mediante el uso de electrones secundarios, empleando un microscopio electrónico de barrido JEOL JSM 6300 LINK ISIS, equipado con un emisor termo-iónico convencional, trabajando a $20 \mathrm{kV}$ y colocando la muestra a una distancia de 7 ó 15 $\mathrm{mm}$ de la lente del microscopio.

Además, el microscopio SEM utilizado tiene incorporado un sistema de análisis por dispersión de energías de rayos X (EDX), mediante el cual se pueden realizar análisis cualitativos y cuantitativos de los elementos que componen las muestras, previa visualización y selección "in situ" de la zona de análisis (extensa o puntual) en una micro-imágen de SEM. Se utilizó un sistema de microanálisis Oxford LINK ISIS System con el software SEMQUANT incorporado para el procesado de los datos, el cual introduce la corrección ZAF. El detector se calibró con un patrón de $\mathrm{Cu}$ a un voltaje de $20 \mathrm{kV}, 100 \mathrm{~s}$ de adquisición, 3s de procesado para cada adquisición, y $7 \mathrm{~mm}$ de distancia de la muestra a la lente.

La muestra ha de ser fijada y deshidratada antes de introducirla en la cámara de vacío de microscopio SEM. La muestra se prepara mediante una cinta adhesiva de doble cara sobre un porta-muestras de carbono donde se sitúa la muestra, de forma que se obtenga una película de sólido lo más fina posible donde las partículas están fijas y no se muevan cuando se hagan los barridos para obtener las imágenes en el microscopio. Antes de introducir la muestra en el microscopio se realiza un recubrimiento de oro, para la obtención de imágenes, o carbono, si se va a realizar además microanálisis. 


\subsubsection{Técnicas de temperatura programada}

El comportamiento de reducción, oxidación, descomposición, desorción o reacción superficial de una especie adsorbida se puede estudiar mediante técnicas de temperatura programada. Las muestras se someten a una rampa térmica bajo una atmósfera controlada mientras se detectan las especies emitidas o consumidas por los procesos que tienen lugar. En la presente tesis se ha empleado la reducción (TPR- $\mathrm{H}_{2}$ ), la desoción de amoníaco $\left(T P D-\mathrm{NH}_{3}\right)$ o el intercambio isótopico de oxígeno $\left({ }^{18} \mathrm{O}_{2}\right)$ a temperatura programada.

\subsubsection{Reducción a temperatura programada (TPR- $\left.H_{2}\right)$}

La reducción a temperatura programada $\left(T P R-\mathrm{H}_{2}\right)$ se suele emplear para el estudio de la reductibilidad de óxidos metálicos puros o soportados en otros materiales.

Los experimentos de TPR- $\mathrm{H}_{2}$ consisten en una reacción de reducción mediante un agente reductor, normalmente una mezcla gaseosa diluida de hidrógeno (en helio). Durante la reacción de reducción se produce un consumo de $\mathrm{H}_{2}$, que modifica la conductividad térmica del agente reductor (mezcla de $\mathrm{H}_{2}$ y $\mathrm{He}$ ). La variación de la conductividad térmica durante el experimento se registra en un detector de conductividad térmica. Su representación en función del tiempo y la temperatura da lugar a un perfil característico, que refleja la reducibilidad de los metales presentes en el material analizado. La cantidad de $\mathrm{H}_{2}$ consumida durante la reducción se determina a partir del área generada de la curva de reducción y un calibrado previo ( $\mathrm{mL} \mathrm{H}_{2}$ /número de cuentas) del detector de conductividad térmica, que se realiza utilizando un óxido metálico de referencia ( $\mathrm{CuO}, \mathrm{NiO}$, etc).

Los análisis TPR- $\mathrm{H}_{2}$ se han llevado a cabo en un equipo ThermoFinnigan TPDRO1110 empleando un detector de conductividad térmica (TCD). Aproximadamente $50 \mathrm{mg}$ de muestra se cargaron en un reactor de cuarzo de lecho fijo en forma de $U$. Las muestras se tratan previamente en flujo de $\operatorname{Ar}$ a temperatura ambiente durante $30 \mathrm{~min}$. Posteriormente, se introduce un flujo de 50 $\mathrm{mL} /$ min de una mezcla $\mathrm{H}_{2} / \mathrm{Ar}\left(5 \% \mathrm{H}_{2}\right.$ en volumen), y se incrementa la temperatura desde temperatura ambiente hasta $1250 \mathrm{~K}$ con una rampa de $10 \mathrm{~K} / \mathrm{min}$.

\subsubsection{Desorción de amoníaco a temperatura programada (TPD-NH3)}

La desorción a temperatura programada (TPD) de una molécula básica como el amoníaco (TPD- $\mathrm{NH}_{3}$ ) es uno de los métodos más comúnmente utilizado en catálisis para medir la acidez superficial de un material.

En general, un experimento TPD está basado en la quimisorción de un gas sobre un sólido y la posterior desorción del gas mediante un aumento progresivo 
de la temperatura. En un primer paso, se adsorbe el gas sobre la superficie de un material a una temperatura dada, la fracción absorbida reversiblemente se evacúa de modo que únicamente permanece el gas quimisorbido. Después, se calienta la muestra, aumentando la temperatura con el tiempo. Durante la etapa de calentamiento, la cantidad de especies desorbidas que pasan a fase gas son monitorizadas con diferentes tipos de detectores, el de conductividad térmica y el espectrofotómetro de masas son los más utilizados.

Los experimentos de TPD se pueden usar con fines cualitativos $y / 0$ cuantitativos. En el análisis cualitativo se puede obtener información sobre las características de las especies de adsorción y sus estabilidades relativas; entendiendo como especie de adsorción al conjunto de la molécula adsorbida y el centro donde se adsorbe. Por lo tanto, existirán distintos tipos de especies de adsorción si el sólido presenta centros de adsorción no equivalentes, puesto que las moléculas del gas son iguales. Cada pico de desorción observado en un diagrama de TPD se atribuye aun a especie de adsorción diferente, siendo generalmente aceptado que cuanto mayor es la temperatura que corresponde al máximo de un pico de adsorción, mayor es la estabilidad de las especies que dan lugar a ese pico.

Por otro lado, conociendo el número total de moléculas quimisorbidas se puede cuantificar el número de centros de adsorción por unidad de masa del catalizador, o por unidad de área (si se conoce ésta). Además, si existe más de un tipo de centro de adsorción y la resolución es buena, se puede determinar la cantidad relativa de cada uno mediante el cálculo de las áreas de sus picos correspondientes.

La molécula de $\mathrm{NH}_{3}$ se puede comportar como una base de Lewis compartiendo los dos electrones solitarios del nitrógeno, y como una base de Bronsted aceptando un protón. Por esta razón, los experimentos de TPD- $\mathrm{NH}_{3}$ tienen la finalidad de estudiar comparativamente las características ácidas de la superficie de los catalizadores. Así, se puede determinar el número de centros ácidos (Brönsted y Lewis) por el área de los picos, mientras que los diferentes tipos de centros ácidos (y su fortaleza relativa) se determinan de acuerdo con la temperatura del máximo de adsorción: a mayor temperatura mayor fortaleza ácida.

Los experimentos TPD- $\mathrm{NH}_{3}$ se llevaron a cabo en un aparato de la marca Micromeritics TPD/2900. La muestra se pre-trata en flujo de argón a $450^{\circ} \mathrm{C}$ durante $1 \mathrm{~h}$, para eliminar cualquier contaminación de la superficie $\mathrm{y} / \mathrm{o}$ especies volátiles ocluidas que pudieran desprenderse posteriormente durante la desorción, interfiriendo en el análisis. Después, se introduce una corriente de amoníaco y, mediante un sistema de pulsos, se quimisorbe el amoníaco sobre la muestra a una temperatura de $100^{\circ} \mathrm{C}$ hasta que se alcanza el equilibrio, es decir, hasta que la 
cantidad de $\mathrm{NH}_{3}$ adsorbida irreversiblemente (a esa temperatura) permanece constante. Entonces, se hace pasar una corriente de He de $100 \mathrm{ml} / \mathrm{min}$, se aumenta progresivamente la temperatura hasta llegar a los $500^{\circ} \mathrm{C}$, usando una rampa de calentamiento de $10^{\circ} \mathrm{C} / \mathrm{min}$. La desorción de amoníaco se monitoriza mediante un detector de conductividad térmica (TCD) y un espectrómetro de masas.

Tanto el volumen adsorbido como el desorbido se miden en condiciones estándar de presión y temperatura. Es importante indicar la posibilidad de que ambos volúmenes no coincidan, ya que durante la desorción a alta temperatura el $\mathrm{NH}_{3}$ adsorbido puede reaccionar químicamente con átomos de la superficie dando lugar a otras especies que también desorban. Además, la temperatura final de desorción $\left(500^{\circ} \mathrm{C}\right)$ es superior a la del pre-tratamiento de la muestra $\left(450^{\circ} \mathrm{C}\right)$, pudiéndose incorporar también a la fase gas especies (presentes inicialmente 0 productos de una reacción) que no se desprendieron durante el pre-tratamiento.

\subsubsection{Intercambio isotópico de oxígeno}

El intercambio isotópico de oxígeno ${ }^{18} \mathrm{O}_{2}$ a temperatura programada se emplea normalmente en catálisis para obtener información de la naturaleza y reactividad de los oxígenos presentes en la superficie de óxidos metálicos. De esta forma, se puede determinar si las especies oxígeno presentes participan en las reacciones de oxidación [23-25].

Los experimentos de intercambio isotópico de oxígeno a temperatura programada se han realizado empleando un reactor de cuarzo equipado con controladores de flujo y un horno eléctrico. La salida del reactor se conecta mediante un sistema capilar a un espectrómetro de masas Omnistar Balzers para analizar la composición de los gases de salida. Los perfiles de concentración se obtienen mediante la adquisición de las señales con las siguientes relaciones masa/carga $(\mathrm{m} / \mathrm{z}): 32\left(16 \mathrm{O}_{2}\right), 34\left({ }^{18} \mathrm{O}^{16} \mathrm{O}\right)$ y $36\left({ }^{18} \mathrm{O}_{2}\right)$. Antes de cada experimento, la muestra (40 mg) se pre-trata a $250^{\circ} \mathrm{C}$ en una mezcla $20 \% \mathrm{O}_{2}$ /argón durante $2 \mathrm{~h}$, seguido de $1 \mathrm{~h}$ con flujo de argón a la misma temperatura y, posteriormente, se enfría a temperatura ambiente en flujo de argón. Para los experimentos de intercambio isotópico de oxígeno, el catalizador se somete a un flujo ${ }^{18} \mathrm{O}_{2} /$ argón $\left(15 \mathrm{~mL} / \mathrm{min}\right.$ ) y la temperatura se eleva de $25^{\circ} \mathrm{C}$ a $420^{\circ} \mathrm{C}$ con una velocidad de $10^{\circ} \mathrm{C} / \mathrm{min}$. El sistema se mantiene isotérmicamente a $420^{\circ} \mathrm{C}$ durante $20 \mathrm{~min}$ en la mezcla de ${ }^{18} \mathrm{O}_{2}$. 


\subsection{Ensayos catalíticos en la oxidación parcial de propano a ácido acrílico}

\subsubsection{Sistema de reacción}

El sistema de reacción empleado ha sido en todo momento el esquematizado en la Figura 3.1.

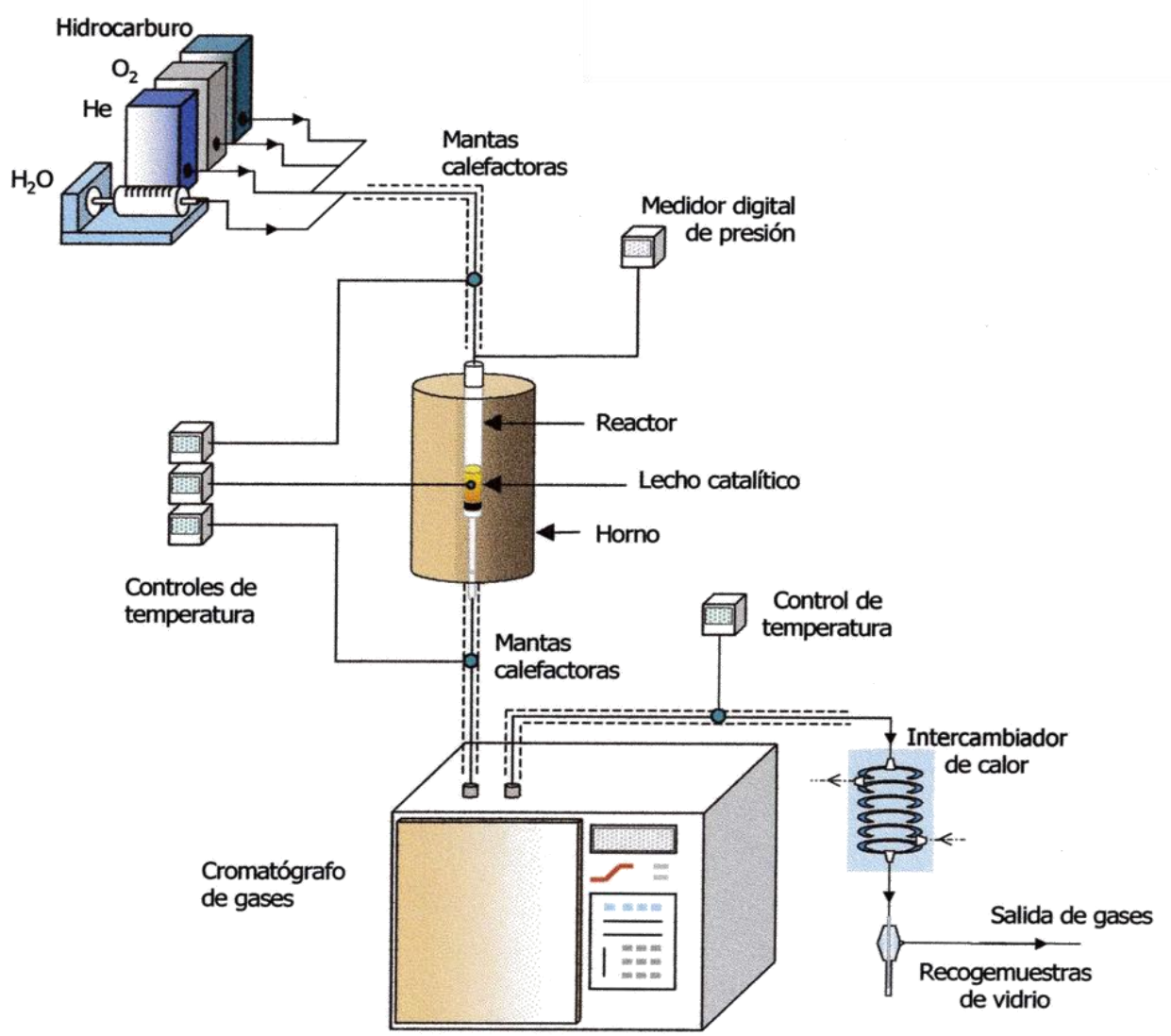

Figura 3.1. Sistema de reacción utilizado en el estudio catalítico.

En general, se hace pasar una alimentación con un caudal determinado (generalmente entre $25-50 \mathrm{ml} / \mathrm{min}$ ) por un reactor donde se sitúa el catalizador $(0.5$ - 1g) y se lleva a cabo la reacción, la cual es seguida on line por un cromatógrafo de gases. 
El reactor utilizado es de cuarzo de lecho fijo con una longitud de $330 \mathrm{~mm}$ y un diámetro interno de $10 \mathrm{~mm}$ (externo de $12 \mathrm{~mm}$ ), que está equipado con un termopar coaxial con el fin de controlar el perfil de temperaturas a lo largo del reactor. En el interior del reactor, se sitúa una placa porosa sobre la que se dispone el catalizador que permite el paso de los gases de la alimentación pero no del catalizador. Al reactor lo recubre un horno que dispone de una resistencia que es la encargada de suministrar el calor para regular la temperatura a la que se van a llevar a cabo las reacciones.

Los gases de reacción (helio, oxígeno y propano) provienen de balas a presión, mientras que el agua se suministra al sistema por medio de una bomba perfusora, con una relación $\mathrm{C}_{3} \mathrm{H}_{8} / \mathrm{O}_{2} / \mathrm{H}_{2} \mathrm{O} / \mathrm{He}$ de $4 / 8 / 30 / 58 \%$. Para poder alimentar el agua en fase gas, antes de llegar al reactor, se colocó un precalentador a $180^{\circ} \mathrm{C}$. Una vez que los productos de reacción han salido del reactor y para evitar la condensación del agua y de otros compuestos con alta temperatura de ebullición, como el ácido acrílico (P. eb. $141^{\circ} \mathrm{C}$ ), la conducción que llega hasta el cromatógrafo se calefactó a $180^{\circ} \mathrm{C}$.

Los catalizadores se prensaron y tamizaron, de modo que el tamaño de partícula se situara entre 0.25 y $0.60 \mathrm{~mm}$, a fin de evitar problemas de difusión de gases y de sobrepresión en las líneas.

\subsubsection{Descripción de un experimento}

Los ensayos catalíticos se llevaron a cabo a presión atmosférica y en un rango de temperaturas comprendido entre 340 y $420 \stackrel{\circ}{\circ} \mathrm{C}$. A continuación se muestran de forma esquemática los pasos seguidos para la realización de un ensayo catalítico:

1) Se carga el reactor con la cantidad de catalizador deseada, se introduce en el horno y se conecta al sistema.

2) Se ajustan los caudales de los gases que se van a alimentar (propano, oxígeno y helio) y se hacen pasar por el sistema.

3) Se conectan tanto el precalentador $\left(180^{\circ} \mathrm{C}\right)$ como las líneas de conducción después del reactor $\left(180-200^{\circ} \mathrm{C}\right)$.

4) Se enciende el horno y se programa para que alcance una temperatura de $200^{\circ} \mathrm{C}$ con una velocidad de calentamiento moderada.

5) Si se alimenta agua en el experimento, nos cercioramos de que tanto el horno como el precalentador y las líneas de conducción han alcanzado una temperatura superior a los $120{ }^{\circ} \mathrm{C}$ (para evitar condensaciones). Una vez alcanzada esta 
temperatura podemos conectar la bomba perfusora, en la que se encuentra acoplada una jeringa de vidrio (vol. $10 \mathrm{ml}$ ) con su salida conectada a la conducción principal.

6) Se debe esperar a que el caudal de agua sea constante. En estudios preliminares se ha determinado que esto ocurre cuando se han alimentado $0.2 \mathrm{ml}$ de agua líquida.

7) Una vez el flujo de agua es constante, se realiza el primer ensayo con una temperatura en el interior del reactor de $200^{\circ} \mathrm{C}$. El resultado de este análisis nos servirá de blanco para el resto de los cálculos, ya que a esta temperatura no se ha obtenido reacción para ninguno de los catalizadores estudiados.

8) Se incrementa lentamente la temperatura del horno hasta alcanzar la temperatura de reacción deseada en el lecho catalítico. Una vez alcanzada la temperatura requerida, se deja al menos 1 hora para que el sistema se estabilice y alcance el estado estacionario.

9) Se analiza la corriente gaseosa que sale del reactor mediante cromatografía degases. Al menos dos veces para cada temperatura de reacción.

10) Se repiten los pasos 8 y 9 para cada una de las temperaturas a las que se desea estudiar la reacción.

\subsubsection{Análisis de los productos de reacción}

El análisis de los reactivos sin reaccionar y de los productos se llevó a cabo con un cromatógrafo de gases HP 6890, equipado con un detector de conductividad térmica (TCD). El aparato dispone de dos columnas cromatográficas para la separación de los compuestos que aparecen en la reacción. Las columnas utilizadas son:

- Tamiz molecular 5A (3.0 m de largo y 1/8" de diámetro externo), que separa el $\mathrm{O}_{2}$ y el $\mathrm{CO}$

- Porapak QS (3.0 m de largo y 1/8" de diámetro externo), que separa los alcanos, las olefinas y los compuestos oxigenados.

En todo momento, el gas portador, que arrastra la muestra a través de las columnas, ha sido He y su caudal se ha mantenido constante en $30 \mathrm{~mL} / \mathrm{min}$. La temperatura del detector y del inyector se fijó en $250^{\circ} \mathrm{C}$. Para una mejor separación de los compuestos, se ha establecido una rampa de temperaturas en el horno del cromatógrafo.

La separación por cromatografía de gases se fundamenta en la diferente velocidad de difusión de los distintos compuestos gaseosos de una mezcla a 
través de la columna cromatográfica. Por lo tanto, si se consigue una correcta separación, cada compuesto saldrá de la/s columna/s a un tiempo determinado, denominado tiempo de retención. El tiempo de retención es específico para cada compuesto químico (para unas condiciones de análisis determinadas). Así, mediante el empleo de patrones podemos identificar cada uno de los compuestos de la muestra a analizar en función de su tiempo de retención. Una vez el compuesto ha salido de la/s columna/s, se detecta en el TCD por diferencia de conductividad térmica, emitiendo una señal que es proporcional a la cantidad de dicho componente en la muestra.

Para relacionar la concentración de un componente en la muestra analizada con el área bajo su correspondiente pico cromatográfico, se necesita un factor de corrección o factor de respuesta:

$$
\mathrm{C}_{\mathrm{i}}=\mathrm{A}_{\mathrm{i}} / \mathrm{F}_{\mathrm{i}}
$$

donde $C_{i}$ es la concentración del compuesto i; $A_{i}$ es el área encerrada bajo el pico correspondiente al compuesto i; y $F_{i}$ es el factor de respuesta del compuesto i.

Los factores de respuesta no son siempre los mismos, siendo diferentes para cada especie; por ello, se define el factor de respuesta absoluto de i respecto del componente j como el cociente entre el factor de respuesta absoluto de i y el factor de respuesta absoluto de $\mathrm{j}$.

$$
\mathrm{F}_{\mathrm{ij}}=\mathrm{F}_{\mathrm{i}} / \mathrm{F}_{\mathrm{j}}
$$

Los factores de respuesta dependen también del detector utilizado, sin embargo, son prácticamente independientes del tipo y caudal del gas portador, de la temperatura, de la presión y de la concentración del producto.

\subsubsection{Cálculo de conversión, selectividad y rendimiento}

Se define conversión de un compuesto j, como el número de moles del compuesto j reaccionados, por cada mol de dicho componentes presentes inicialmente.

$$
\mathrm{X}_{\mathrm{j}}=\frac{\sum_{\text {productos }} \mathrm{A}_{\mathrm{i}} / \mathrm{F}_{\mathrm{ij}} \cdot \omega_{\mathrm{i}} / \omega_{\mathrm{j}}}{\mathrm{A}_{\mathrm{j}}+\sum_{\text {productos }} \mathrm{A}_{\mathrm{i}} / \mathrm{F}_{\mathrm{ij}} \cdot \omega_{\mathrm{i}} / \omega_{\mathrm{j}}}
$$

Donde:

j se refiere al reactivo; i denota al producto de reacción.

$A_{i}$ es el área encerrada bajo el pico correspondiente al compuesto i.

$X_{j}$ es la conversión del reactivo $j$.

$\omega_{\mathrm{i}}$ es el número de átomos de carbono que hay en la fórmula molecular de i. 
Se define selectividad a un producto i respecto del reactivo j, como la proporción del reactivo j reaccionado, que se ha convertido en el producto i.

$$
S_{i j}=\frac{A_{i} / F_{i j} \cdot \omega_{i} / \omega_{j}}{\sum_{\text {productos }} A_{i} / F_{i j} \cdot \omega_{i} / \omega_{j}}
$$

Donde: $\mathrm{S}_{\mathrm{ij}}$ es la selectividad al producto i respecto del reactivo $\mathrm{j}$.

Se define rendimiento a un producto i respecto del reactivo j, como la proporción inicial del reactivo j, que se ha convertido en el producto i. Puede calcularse multiplicando la conversión del compuesto i por la selectividad al producto i respecto del reactivo j.

$$
\mathrm{R}_{\mathrm{ij}}=\frac{\mathrm{A}_{\mathrm{i}} / \mathrm{F}_{\mathrm{ij}} \cdot \omega_{\mathrm{i}} / \omega_{\mathrm{j}}}{\mathrm{A}_{\mathrm{j}}+\sum_{\text {productos }} \mathrm{A}_{\mathrm{i}} / \mathrm{F}_{\mathrm{ij}} \cdot \omega_{\mathrm{i}} / \omega_{\mathrm{j}}}
$$

donde $R_{i j}$ es el rendimiento al producto i respecto del reactivo $j$.

En este estudio, la conversión, las selectividades y los rendimientos se refieren al propano.

Otro concepto importante es el tiempo de contacto $(\mathrm{W} / \mathrm{F})$, que da una idea de cuánto tiempo tarda el alimento en atravesar el lecho catalítico. Aquí, se ha definido W/F como el cociente entre la masa del catalizador (en gramos) y el caudal molar del hidrocarburo en la mezcla reactante (en moles/h). En condiciones habituales de trabajo, la conversión de reactivo aumentará cuando lo haga el tiempo de contacto.

\subsection{Ensayos catalíticos en la oxidación parcial de propileno a ácido acrílico}

La oxidación parcial de propeno a ácido acrílico se ha llevado a cabo en mismo sistema de reacción empleado para la oxidación de propano (Figura 3.1). En este caso, se ha sustituido la bala de propano por una bala de propileno (o en su caso, una mezcla propileno/oxígeno/helio en $2 / 8 / 90 \%$ ). En todo momento, la alimentación se mantuvo con una relación $\mathrm{C}_{3} \mathrm{H}_{6} / \mathrm{O}_{2} / \mathrm{H}_{2} \mathrm{O} / \mathrm{He}$ de 1.7/6.8/15/76.5\%.

Debido a la reactividad de la olefina, en este caso, se empleó 0.025-0.05 g de catalizador diluido con gránulos de $\mathrm{SiC}$ (tamaño de partícula mayor de $0.8 \mathrm{~mm}$ ) hasta $1 \mathrm{~g}$. El caudal empleado, generalmente entre $25-50 \mathrm{ml} / \mathrm{min}$, se ha ajustado para un tiempo de contacto, W/F, de 75 ó $150 \mathrm{~g}_{\mathrm{cat}} \mathrm{h} \mathrm{mol}_{\mathrm{C} 3 \mathrm{H}}{ }^{-1}$. Los ensayos catalíticos se llevaron a cabo a presión atmosférica y en un rango de temperaturas comprendido entre 340 y $420^{\circ} \mathrm{C}$. El análisis de los reactivos productos se llevó a cabo con el mismo cromatógrafo de gases HP 6890, empleado en la oxidación de propano (apartado 3.4.3). 


\subsection{Ensayos catalíticos en la oxidación de metanol}

El sistema de reacción empleado en la oxidación de metanol es muy similar al esquematizado en la Figura 3.1. En este caso, el metanol, al ser líquido, se suministra al sistema por medio de una bomba perfusora, mientras que el resto de la alimentación (oxígeno y nitrógeno) se suministran mediante una bala de presión, con una relación $\mathrm{CH}_{3} \mathrm{OH} / \mathrm{O}_{2} / \mathrm{N}_{2}$ de $6 / 13 / 81 \%$

La cantidad de catalizador empleado en este caso es $100 \mathrm{mg}$ (tamaño de partícula $0.25-0.60 \mathrm{~mm}$ ) diluido con $100 \mathrm{mg}$ de $\mathrm{SiC}$ (tamaño de partícula mayor de $0.8 \mathrm{~mm}$ ). Generalmente, se ha empleado $100 \mathrm{ml} / \mathrm{min}$, para un tiempo de contacto, $\mathrm{W} / \mathrm{F}$, de $7 \mathrm{~g}_{\mathrm{cat}} \mathrm{h} \mathrm{mol}_{\mathrm{CH} 3 \mathrm{OH}^{-1}}$. Los ensayos catalíticos se llevaron a cabo a presión atmosférica y en un rango de temperaturas comprendido entre 230 y $320 \stackrel{\circ}{\circ}$.

En este caso, el análisis de los reactivos y de los productos obtenidos se han llevado a cabo en un cromatógrafo de gases AGILENT 7890A, equipado también con un detector de conductividad térmica (TCD). Las columnas empleadas para la separación de los compuestos son específicas para los productos obtenidos en la oxidación de metanol:

- Tamiz molecular HP Q 5Å, $30 \mathrm{~m}, 0.53 \mathrm{~mm}$ y $25 \mu \mathrm{m}$, que separa el $\mathrm{O}_{2}, \mathrm{~N}_{2}$ y CO.

- RESTEK $\mathrm{Rt}^{\circledR}-\mathrm{U}-\mathrm{BOND}, 30 \mathrm{~m}, 0.53 \mathrm{~mm}$ DI, $20 \mu \mathrm{m}$ df, que separa el formaldehido, dimetiléter, metanol, formiato de metilo, dimetoximetano, $\mathrm{CO}_{2}$ y $\mathrm{H}_{2} \mathrm{O}$.

Los cálculos de conversión y selectividad se han realizado de acuerdo con las ecuaciones mostradas en el apartado 3.4.4. 


\section{Bibliografía}

[1] D. A. Skoog, F. J. Holler, T. A. Nieman, Principios de análisis intrumental, 2001.

[2] S. Brunauer, P. H. Emmett, E. Teller, Journal of the American Chemical Society 60 (1938) 309-319.

[3] M. Faraldos, C. Goberna, (Editoras), Técnicas de análisis y caracterización de materiales, 2002.

[4] L. B. McCusker, R. B. Von Dreele, D. E. Cox, D. Louer, P. Scardi, Journal of Applied Crystallography 32 (1999) 36-50.

[5] P. Van Der Voort, M. G. White, M. B. Mitchell, A. A. Verberckmoes, E. F. Vansant, Spectrochimica Acta Part A: Molecular and Biomolecular Spectroscopy 53 (1997) 2181-2187.

[6] B. Imelik, J. C. Vedrine, Catalyst Characterization: Physical Techniques for Solids Materials, 1994.

[7] S. Gontier, A. Tuel, Microporous Materials 5 (1995) 161-171.

[8] M. Dieterle, G. Weinberg, G. Mestl, Physical Chemistry Chemical Physics 4 (2002) 812-821.

[9] J. Ryczkowski, Catalysis Today 68 (2001) 263-381.

[10] I. E. Wachs, Catalysis Today 27 (1996) 437-455.

[11] J. C. Lavalley, Catalysis Today 27 (1996) 377-401.

[12] A. A. Tsyganenko, D. V. Pozdnyakov, V. N. Filimonov, Journal of Molecular Structure 29 (1975) 299-318.

[13] G. Busca, Catalysis Today 27 (1996) 457-496.

[14] A. Badri, C. Binet, J.-C. Lavalley, Journal of the Chemical Society, Faraday Transactions 93 (1997) 1159-1168.

[15] J. A. Anderson, C. H. Rochester, Journal of the Chemical Society, Faraday Transactions 1: Physical Chemistry in Condensed Phases 85 (1989) 11291138.

[16] G. Busca, Catalysis Today 27 (1996) 323-352.

[17] M. P. Fuller, P. R. Griffiths, Analytical Chemistry 50 (1978) 1906-1910.

[18] T. A. Ntho, J. A. Anderson, M. S. Scurrell, Journal of Catalysis 261 (2009) 94-100.

[19] A. Iglesias-Juez, A. B. Hungría, A. Martínez-Arias, J. A. Anderson, M. Fernández-García, Catalysis Today 143 (2009) 195-202.

[20] M. D. Argyle, K. Chen, A. T. Bell, E. Iglesia, Journal of Catalysis 208 (2002) 139-149.

[21] J. C. Vickerman, I. Gilmore, Surface Analysis: The principal techniques, 2009.

[22] J. Goldtein, D. E. Newbury, D. C. Joy, C. E. Lyman, P. Echlin, E. Lifshin, L. Sawyer, J. R. Michael, Scanning Electron Microscopy and X-ray Microanalysis, Vol. 1, 2003.

[23] G. W. Keulks, Journal of Catalysis 19 (1970) 232-235.

[24] R. D. Wragg, P. G. Ashmore, J. A. Hockey, Journal of Catalysis 22 (1971) 49-53.

[25] Y. Moro-oka, W. Ueda, K.-H. Lee, Journal of Molecular Catalysis A: Chemical 199 (2003) 139-148. 



\section{4}
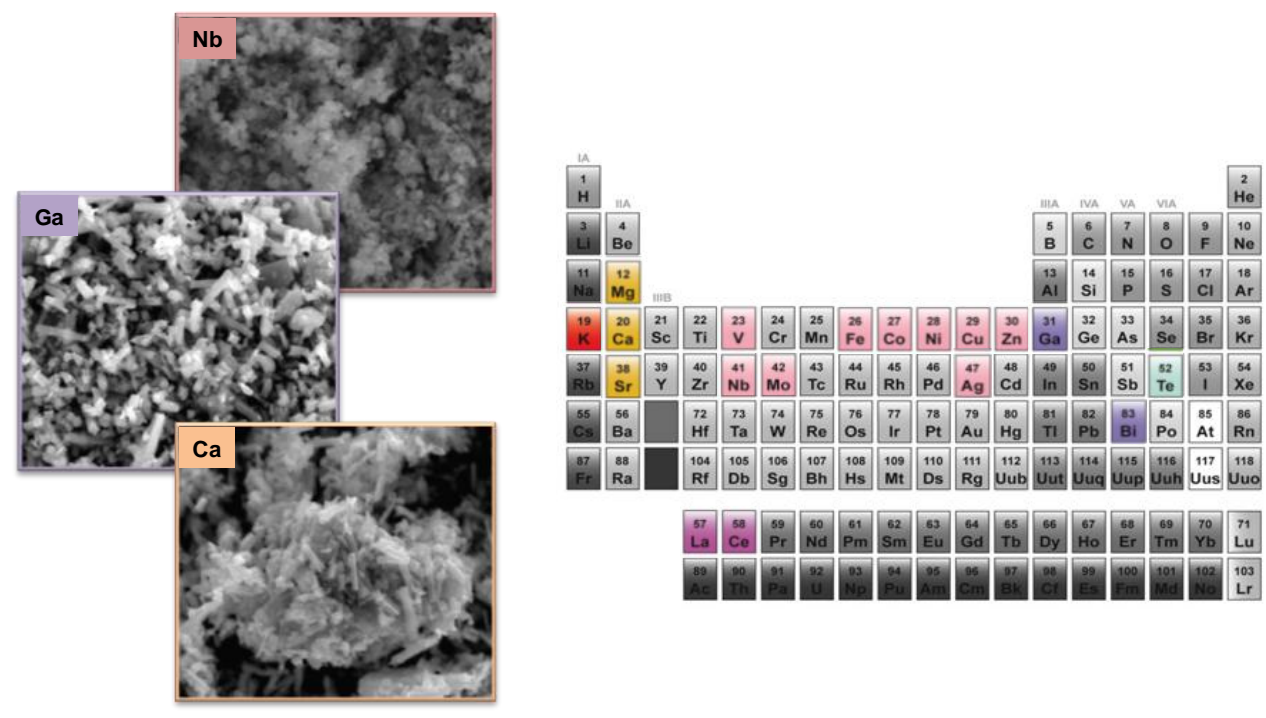

\section{Óxidos Mixtos Mo-V-Te}

promovidos con metales 



\begin{abstract}
$\operatorname{MoVTe}-X(X=\mathrm{Ag}, \mathrm{K}, \mathrm{Mg}, \mathrm{Ca}, \mathrm{Sr}, \mathrm{Fe}, \mathrm{Co}, \mathrm{Ni}, \mathrm{Cu}, \mathrm{Ga}, \mathrm{La}, \mathrm{Bi}, \mathrm{Ce}$ and $\mathrm{Nb}$ ) mixed oxides catalysts have been prepared hydrothermally with a Mo/V/Te/X molar ratio of $1 / 0.50 / 0.17 / 0.04$ in order to study their influence on the nature of crystalline phases and the catalytic behavior in the partial propane oxidation to acrylic acid. In general, the incorporation of a fourth element changes both the distribution of the crystalline phases and the catalytic properties of the MoVTeO system. Only in the case of $\mathrm{Ca}$-, $\mathrm{Ga}$ - or $\mathrm{Nb}$-promoted catalysts, a considerable increase in the propane conversion (Nb-containing catalysts), in the selectivity of acrylic acid (Gacontaining catalysts) or both parameters (Ca-containing catalysts) have been observed. The optimum X/Mo ratio in the synthesis gel was been studied for Ca-, Ga- and Nb-promoted catalysts. Ca-promoted MoVTe catalysts increase both the propane conversion and the selectivity to acrylic acid with an optimum $\mathrm{Ca} / \mathrm{Mo}$ of 0.04. However, it is not clear that $\mathrm{Ca}^{2+}$ cations were incorporated into $\mathrm{Te}_{2} \mathrm{M}_{20} \mathrm{O}_{57}$ phase. $\mathrm{Nb}$-containing catalysts increase propane conversion at low Nb/Mo ratio in the synthesis gel, while a higher $\mathrm{Nb}$ content results in an increase in the selectivity to acrylic acid (the most selective catalyst was $\mathrm{Nb} / \mathrm{Mo}=0.17$ ). Ga-containing catalysts significantly increase the selectivity to acrylic acid at low propane conversion; although at high propane conversion the selectivity depend on the catalyst composition. The higher selectivity to acrylic acid has been related to changes on the surface of the M1 phase by the incorporation of $\mathrm{Ga}$ into the octahedral network of the M1 phase, which could also imply new gallium active sites. On the other hand, high selectivity to acrylic acid at high propane conversion is observed over catalysts with $\mathrm{Ga} /(\mathrm{V}+\mathrm{Ga})$ of 0.25 . In this case, presence of extraframework Ga species on the catalyst surface was determined by XPS, which could be related with the differences observed in the catalytic behavior.
\end{abstract}




\section{Resumen}

Los óxidos mixtos MoVTe-X ( $\mathrm{X}=\mathrm{Ag}, \mathrm{K}, \mathrm{Mg}, \mathrm{Ca}, \mathrm{Sr}, \mathrm{Fe}, \mathrm{Co}, \mathrm{Ni}, \mathrm{Cu}, \mathrm{Ga}, \mathrm{La}$, $\mathrm{Bi}$, Ce y Nb) se han preparado por el método hidrotermal, con una relación molar $\mathrm{Mo} / \mathrm{V} / \mathrm{Te} / \mathrm{X}$ de 1/0.50/0.17/0.04, con el fin de estudiar su influencia en la naturaleza de las fases cristalinas y en el comportamiento catalítico en la oxidación parcial de propano a ácido acrílico. En general, la incorporación de un cuarto elemento en el sistema MoVTe puede cambiar la distribución de fases cristalinas y las propiedades catalíticas de los catalizadores. Solamente en el caso de los catalizadores promovidos con $\mathrm{Ca}, \mathrm{Ga}$ o $\mathrm{Nb}$ se ha observado un considerable aumento de la conversión de propano (catalizadores con $\mathrm{Nb}$ ), de la selectividad a ácido acrílico (catalizadores con $\mathrm{Ga}$ ) o de ambos parámetros (catalizadores con Ca). La relación óptima X/Mo en el gel de síntesis se ha estudiado para los catalizadores promovidos con Ca, Ga y Nb. Los catalizadores MoVTe promovidos con Ca aumentan tanto la conversión de propano como la selectividad a ácido acrílico (con una relación $\mathrm{Ca} / \mathrm{Mo}$ de 0.04), si bien no está clara la incorporación de cationes $\mathrm{Ca}^{2+}$ en la fase $\mathrm{Te}_{2} \mathrm{M}_{20} \mathrm{O}_{57}$. Los catalizadores con $\mathrm{Nb}$ aumentan la conversión de propano a baja relación Nb/Mo en el gel de síntesis, mientras que mayores relaciones $\mathrm{Nb} / \mathrm{Mo}$ aumentan la selectividad a ácido acrílico (siendo el más selectivo el catalizador con $\mathrm{Nb} / \mathrm{Mo}=0.17$ ). Los catalizadores promovidos con Ga aumentan significativamente la selectividad a ácido acrílico a baja conversión de propano, aunque a alta conversión de propano la selectividad depende de la composición del catalizador. La mayor selectividad a ácido acrílico observada en los catalizadores con $\mathrm{Ga}$ se ha relacionado a los cambios producidos en la superficie por la incorporación de Ga en la estructura de la fase M1, lo que implicaría la presencia de nuevos centros activos de galio. Por otro lado, una mayor selectividad a alta conversión de propano se ha observado con catalizadores con una relación $\mathrm{Ga} /(V+G a)$ de 0.25. En este caso, se ha determinado por XPS la presencia de especies de Ga extrared en la superficie del catalizador que podrían estar relacionadas con las diferencias observadas en el comportamiento catalítico. 


\subsection{Antecedentes}

Los óxidos metálicos mixtos $\mathrm{MoVTe}(\mathrm{Sb}) \mathrm{Nb}$ han demostrado ser un sistema catalítico eficaz en la amoxidación/oxidación de propano a ácido acrílico y acrilonitrilo [1-4], y en la deshidrogenación oxidativa de etano a eteno [5-6], mostrando valores de conversión y selectividad altos.

El comportamiento catalítico de este tipo de sistemas $\mathrm{MoVTe}(\mathrm{Nb}) \mathrm{O}$ se ha relacionado con la presencia de la fase $\mathrm{Te}_{2} \mathrm{M}_{20} \mathrm{O}_{57}$ (donde $M=\mathrm{Mo}, \mathrm{V}, \mathrm{Nb}$ ), también denominada fase M1. Sin embargo, las propiedades catalíticas no parecen estar relacionadas sólo con la fase M1 sino que también dependen otros factores, tales como la composición química del material (especialmente de la presencia o ausencia de niobio en el catalizador [7-10]), así como de otras características de la superficie del catalizador [11]. En este sentido, los catalizadores basados en óxidos metálicos mixtos de Mo-V-Te (sin Nb) son capaces de mostrar una actividad y selectividad considerable durante la oxidación de propano a ácido acrílico. Sin embargo, la presencia de niobio parece ser determinante a la hora de obtener una selectividad a ácido acrílico mayor [4, 12-21].

De lo publicado hasta el momento, la incorporación de oxalato de niobio en la síntesis parece favorecer la formación de la fase M1, sugiriendo que el niobio puede tener un papel estructural. Pero, también, su incorporación favorece una disminución drástica de centros ácidos Brönsted y Lewis en la superficie de los catalizadores [22-23], los cuales parecen ser los responsables de la oxidación no selectiva, aumentando la selectividad a ácido acrílico.

Un efecto similar se observa en el sistema Mo-V-Sb-O con la incorporación de potasio, favoreciendo un aumento de la selectividad a ácido acrílico, probablemente como consecuencia de la desaparición de centros ácidos Brönsted de la superficie del catalizador. Este efecto se observa cuando el potasio se incorpora bien por impregnación en la superficie del catalizador activado [24-25], o bien, mediante la incorporación de una sal de potasio en el gel de síntesis del método hidrotermal [26].

En vista a estos resultados, cabe pensar que el empleo de promotores en la síntesis de óxidos mixtos MoVTe-X-(Nb) (X= Te o $\mathrm{Sb}$ ) es una forma de mejorar las propiedades catalíticas de estos materiales en la oxidación de propano a ácido acrílico. La incorporación de promotores puede modificar la acidez superficial de los materiales (empleando metales con propiedades ácido-base adecuadas); o favorecer la sustitución parcial o total de alguno de los elementos que forman la fase activa, modificando su estructura. Además, el empleo de metales con propiedades redox, pueden conformar nuevos centros activos durante la oxidación selectiva del alcano, modificando la actividad catalítica. 
En este sentido, varios autores han estudiado la incorporación de diversos promotores metálicos en los catalizadores formados por óxidos mixtos multicomponentes Mo-V-X-(Nb) (X = Te ó $\mathrm{Sb}$ ) para la oxidación de propano a ácido acrílico [24-41].

En general, se han estudiado diferentes elementos químicos como promotores. Para ello, se ha empleado el método de impregnación sobre la fase M1, o bien, por incorporación del elemento químico en el gel de síntesis de los materiales $\mathrm{MoVTe}(\mathrm{Sb}) \mathrm{NbO}$. La incorporación del metal promotor mediante impregnación en el material activado modifica las propiedades superficiales del catalizador, lo que puede cambiar la actividad y selectividad catalítica de los materiales. Por otro lado, la incorporación de otros cationes en el gel de síntesis puede afectar también a la distribución de las fases cristalinas y, por tanto, a sus propiedades catalíticas.

Entre los elementos químicos estudiados por impregnación de los catalizadores MoVTeNb se encuentran Pd, W, Ru y Au [27-29]. La presencia de Pd y W en la superficie del catalizador parece aumentar ligeramente la actividad catalítica dependiendo de la cantidad de metal incorporado [27-28]. Sin embargo, los materiales con $\mathrm{Ru}$ o Au son menos activos y selectivos que el material sin dopar debido a la formación de nanopartículas de $\mathrm{Au}$ y de $\mathrm{RuO}_{2}$ en la superficie del catalizador, inactivas en la amoxidación de propano [29].

La incorporación de promotores a la fase M1 de los catalizadores MoVTeNb mediante su incorporación en el gel de síntesis se ha estudiado para elementos químicos tales como: W, P, B, Cu, Ti, Sn, Ge, Re o Mn [30-31]. La incorporación de $\mathrm{Re}$ o $\mathrm{Mn}$ da lugar a la aparición de otras fases cristalinas como la fase M2, $\mathrm{MoO}_{3}$ y $\mathrm{Mo}_{5} \mathrm{O}_{14}$, en lugar de la fase activa $\mathrm{M} 1$. En algunos casos no se observa incorporación del metal en la fase M1, como en el caso del Ge. Sin embargo, en otros, la incorporación de $\mathrm{W}, \mathrm{Ti}$ o $\mathrm{Sn}$ produce un efecto negativo en las propiedades de la fase M1 [30]. Por último, en el caso del uso de P, B y Cu [31], además de conservarse la fase M1, se produce una ligera mejoría en la actividad del catalizador.

En el caso de catalizadores con antimonio, se ha estudiado la incorporación de metales alcalinos [25-26], alcalinotérreos [32], y tierras raras como La, Ce, Nd y $\mathrm{Sm}$ [33], siendo el potasio el promotor más efectivo hasta el momento. Los metales alcalinos son los que muestran mejores resultados en el comportamiento catalítico de los materiales, aumentando la selectividad a ácido acrílico en el caso de la incorporación de $\mathrm{Na}, \mathrm{K}$ y $\mathrm{Rb}$, en el caso del Li la selectividad a ácido acrílico disminuye, mientras que los catalizadores preparados con Cs no son activos en la oxidación de propano [25-26]. 
Por otro lado, también se ha estudiado la sustitución parcial de algunos elementos que conforman la estructura de la fase M1. Así, se han preparado óxidos mixtos Mo-V-M ( $\mathrm{M}=\mathrm{Te}, \mathrm{Sb}, \mathrm{Bi}, \mathrm{Fe}, \mathrm{W}, \mathrm{Ga})$ con el fin de obtener la fase $\mathrm{M} 1$, aunque sólo con Te ó Sb se obtiene un fase M1 cristalina y selectiva [34-35]. Un estudio realizado por Hibst y col. [36] presenta la síntesis de materiales con estructura similar a la fase M1 pero empleando cationes de Cs en lugar de Te o $\mathrm{Sb}$. Al igual que los cationes de $\mathrm{Te}$ y $\mathrm{Sb}$, el Cs se localizaría principalmente en los canales hexagonales de la fase M1, además de poder ocupar los canales heptagonales que normalmente se encuentran vacíos en catalizadores activos y selectivos. Sin embargo, la fase M1 obtenida con Cs no es activa en la oxidación de propano, posiblemente debido a la ocupación de los canales heptagonales.

Además, se ha estudiado la sustitución parcial de ciertos elementos químicos en la fase $\mathrm{M} 2, \mathrm{Te}_{0.33} \mathrm{MO}_{3.33}(M=\mathrm{Mo}, \mathrm{V}, \mathrm{Nb})$, la cual es activa en la amoxidación/oxidación de propileno. Así, se ha logrado la sustitución de Mo por W; $\mathrm{V}$ por $\mathrm{Ti}, \mathrm{Nb}$ o $\mathrm{Fe}$; y Te por $\mathrm{Ce}$ en la fase M2 de los catalizadores MoVTeNb [3739], conservándose la estructura de la fase cristalina. Los resultados en la amoxidación de propileno revelan que las sustituciones en la estructura de la fase M2 de Mo por W y Te por Ce dan lugar a un aumento de la actividad acompañado por un aumento de la selectividad a acrilonitrilo a expensas de acroleína [38].

Sin embargo, existen pocos resultados del empleo de promotores en el sistema MoVTeO ( $\sin \mathrm{Nb}$ ), donde la incorporación de un cuarto metal, como el $\mathrm{Nb}$, puede dar lugar a efectos importantes sobre las propiedades estructurales y catalíticas de los materiales. La incorporación de Fe en la fase M1 es posible siempre y cuando se emplee un precursor ferroso en la preparación del catalizador [40]. Al contrario que el niobio, la presencia de hierro no aumenta las propiedades catalíticas de los materiales. Así mismo, la incorporación de metales como $\mathrm{Ce}, \mathrm{Cu}$ - Co en el sistema MoVTeO da lugar a catalizadores muy poco activos en la oxidación de propano a ácido acrílico, debido a la ausencia de fase M1 [41].

Por tanto, sería interesante conocer el efecto de la incorporación de diferentes metales en el sistema catalítico MoVTeO y su influencia sobre la naturaleza de las fases cristalinas presentes en el catalizador y, también, sobre las propiedades catalíticas en la oxidación selectiva de propano a ácido acrílico.

Para ello, se han seleccionado diversos cationes metálicos para su incorporación al sistema MoVTeO que clasificaremos, según su estado de oxidación, en: monovalentes $(\mathrm{K}, \mathrm{Ag}$ ), divalentes (alcalinotérreos: $\mathrm{Mg}, \mathrm{Ca}, \mathrm{Sr}$; y metales de transición: $\mathrm{Fe}, \mathrm{Co}, \mathrm{Ni}, \mathrm{Cu}$ ), trivalentes ( $\mathrm{Ga}, \mathrm{Bi}, \mathrm{La}, \mathrm{Ce})$, y Nb (V). Los elementos se han seleccionado en función de su tamaño y sus propiedades ácidas y/o redox. 
Los catalizadores Mo-V-Te-X $\left(\mathrm{X}=\mathrm{Ag}^{+}, \mathrm{K}^{+}, \mathrm{Mg}^{2+}, \mathrm{Ca}^{2+}, \mathrm{Sr}^{2+}, \mathrm{Fe}^{2+}, \mathrm{Co}^{2+}, \mathrm{Ni}^{2+}\right.$, $\mathrm{Cu}^{2+}, \mathrm{Ga}^{3+}, \mathrm{La}^{3+}, \mathrm{Bi}^{3+}, \mathrm{Ce}^{3+} \mathrm{y} \mathrm{Nb}^{5+}$ ) se prepararon mediante el método hidrotermal, empleando un gel de síntesis acuoso compuesto de heptamolibdato amónico, óxido de teluro, sulfato de vanadilo y el sulfato correspondiente al catión $\mathrm{X}$ (salvo en caso de $\mathrm{Ca}$ y $\mathrm{Nb}$ donde se han empleado carbonato y oxalato, respectivamente), con una composición molar Mo/V/Te/X de 1/0.50/0.17/x ( $\mathrm{x}=0 \mathrm{a}$ $0.21)$. Las características del procedimiento seguido se pueden ver con detalle en la sección 2.1. Los catalizadores finalmente obtenidos se han nombrado como Te$\mathbf{X} \boldsymbol{x}$, donde " $\boldsymbol{X}$ " se sustituye por el metal incorporado y " $\boldsymbol{x}$ " es 2, 4, 6, 8, 12, 17 ó 21 según la relación atómica $X /$ Mo empleada en el gel de síntesis $(0.02,0.04,0.06$, $0.08,0.12,0.17$ ó 0.21 , respectivamente). Con fines comparativos, los resultados obtenidos se contrastarán con los del catalizador MoVTeO sin promotor, Te-600.

\subsection{Estudio preliminar sobre la incorporación de un metal en catalizadores Mo-V-Te-O}

\subsubsection{Caracterización físico-química de los materiales}

En la Tabla 4.1 se muestran las características más representativas de los catalizadores preparados con una relación atómica Mo/V/Te/X de 1/0.50/0.17/0.04 en el gel de síntesis y activados a $600^{\circ} \mathrm{C}$ en flujo de $\mathrm{N}_{2}$.

Tabla 4.1. Características generales de los catalizadores MoVTeX preparados con una relación $\mathrm{X} / \mathrm{Mo}=0.04$ y activados a $600^{\circ} \mathrm{C} / \mathrm{N}_{2}$.

\begin{tabular}{|c|c|c|c|}
\hline Muestra $^{a}$ & $\begin{array}{l}\mathrm{S}_{\mathrm{BET}} \\
\left(\mathrm{m}^{2} \mathrm{~g}^{-1}\right)\end{array}$ & $\begin{array}{l}\text { Composición } \\
\text { Mo/V/Te/X }\end{array}$ & Fases Cristalinas $^{c}$ \\
\hline Te-600 & 5.9 & $1 / 0.46 / 0.17 / 0.00$ & $\mathrm{M} 1, \mathrm{M} 2, \mathrm{TeMo}_{5} \mathrm{O}_{16}, \mathrm{MoO}_{3}, \mathrm{Mo}_{0.97} \mathrm{~V}_{0.95} \mathrm{O}_{5}$ \\
\hline Te-K4 & 11.1 & $1 / 0.45 / 0.13 / 0.01$ & $\mathrm{M} 1, \mathrm{M} 2, \mathrm{TeMo}_{5} \mathrm{O}_{16}, \mathrm{MoO}_{3}, \mathrm{Mo}_{0.97} \mathrm{~V}_{0.95} \mathrm{O}_{5}$ \\
\hline Te-Ag4 & nd & $1 / 0.48 / 0.15 / 0.02$ & $\mathrm{M} 1, \mathrm{M} 2, \mathrm{VOMoO}_{4}, \mathrm{TeMo}_{5} \mathrm{O}_{16}, \mathrm{MoO}_{3}$ \\
\hline Te-Mg4 & nd & $1 / 0.39 / 0.15 / 0.06$ & $\mathrm{M} 1, \mathrm{M} 2, \mathrm{VOMoO}_{4}, \mathrm{TeMo}_{5} \mathrm{O}_{16}, \mathrm{MoO}_{3}$ \\
\hline Te-Ca4 & 9.9 & $1 / 0.46 / 0.12 / 0.01$ & $\mathrm{M} 1, \mathrm{M} 2, \mathrm{TeMo}_{5} \mathrm{O}_{16}, \mathrm{Mo}_{0.97} \mathrm{~V}_{0.95} \mathrm{O}_{5}$ \\
\hline Te-Sr4 & nd & $1 / 0.40 / 0.12 / 0.00$ & $\mathrm{M} 1, \mathrm{M} 2, \mathrm{TeMo}_{5} \mathrm{O}_{16}$ \\
\hline Te-Fe4 & 7.6 & $1 / 0.46 / 0.26 / 0.05$ & $\mathrm{M} 1, \mathrm{M} 2, \mathrm{TeMo}_{5} \mathrm{O}_{16}, \mathrm{Mo}_{0.97} \mathrm{~V}_{0.95} \mathrm{O}_{5}$ \\
\hline Te-Co4 & nd & $1 / 0.40 / 0.15 / 0.02$ & $\mathrm{M} 1, \mathrm{M} 2, \mathrm{TeMo}_{5} \mathrm{O}_{16}$ \\
\hline Te-Ni4 & 14.3 & $1 / 0.44 / 0.08 / 0.01$ & $\mathrm{M} 1, \mathrm{M} 2, \mathrm{TeMo}_{5} \mathrm{O}_{16}, \mathrm{MoO}_{3}, \mathrm{Mo}_{0.97} \mathrm{~V}_{0.95} \mathrm{O}_{5}$ \\
\hline Te-Cu4 & nd & $1 / 0.47 / 0.16 / 0.01$ & $\mathrm{M} 2, \mathrm{VOMoO}_{4}, \mathrm{TeMo}_{5} \mathrm{O}_{16}, \mathrm{MoO}_{3}$ \\
\hline Te-Ga4 & 6.0 & $1 / 0.43 / 0.16 / 0.03$ & $\mathrm{M} 1, \mathrm{M} 2, \mathrm{TeMo}_{5} \mathrm{O}_{16}, \mathrm{MoO}_{3}, \mathrm{VOMoO}_{4}$ \\
\hline Te-Bi4 & nd & $1 / 0.46 / 0.16 / 0.05$ & $\mathrm{M} 1, \mathrm{M} 2, \mathrm{TeMo}_{5} \mathrm{O}_{16}, \mathrm{VOMoO}_{4}$ \\
\hline Te-La4 & nd & $1 / 0.48 / 0.13 / 0.00$ & $\mathrm{M} 1, \mathrm{M} 2, \mathrm{TeMo}_{5} \mathrm{O}_{16}, \mathrm{MoO}_{3}, \mathrm{Mo}_{0.97} \mathrm{~V}_{0.95} \mathrm{O}_{5}$ \\
\hline Te-Ce4 & 10.7 & $1 / 0.50 / 0.16 / 0.01$ & $\mathrm{M} 1, \mathrm{M} 2, \mathrm{TeMo}_{5} \mathrm{O}_{16}, \mathrm{MoO}_{3}, \mathrm{Mo}_{0.97} \mathrm{~V}_{0.95} \mathrm{O}_{5}$ \\
\hline Te-Nb4 & 22.3 & $1 / 0.37 / 0.14 / 0.04$ & $\mathrm{M} 1, \mathrm{M} 2, \mathrm{Mo}_{0.97} \mathrm{~V}_{0.95} \mathrm{O}_{5}$ \\
\hline
\end{tabular}

${ }^{a}$ Muestras preparadas con una relación atómica Mo/V/Te/X en el gel de síntesis de 1/0.50/0.17/0.04 y activadas a $600^{\circ} \mathrm{C}$ en flujo de $\mathrm{N}_{2}$.

${ }^{\mathrm{b}}$ Composición química de los catalizadores activados determinada por AES-ICP;

${ }^{\mathrm{C}}$ Fases cristalinas determinadas por DRX: $\mathrm{M} 1=\mathrm{TeM}_{20} \mathrm{O}_{57} ; \mathrm{M} 2=\mathrm{Te}_{0.33} \mathrm{MO}_{3.33}(M=\mathrm{Mo}, \mathrm{V}) ; \mathrm{TeMo}_{5} \mathrm{O}_{16}$ [JCPDS: 31-874]; VOMoO $_{4}$ [JCPDS: 18-582]; $\mathrm{MoO}_{3}$ ortorrómbica [JCPDS: 05-508]; $\mathrm{Mo}_{0.97} \mathrm{~V}_{0.95} \mathrm{O}_{5}$ [JCPDS:77-649]. 
En general, este tipo de materiales presentan áreas superficiales bajas (para el catalizador sin metal Te-600 corresponde a $5.9 \mathrm{~m}^{2} \mathrm{~g}^{-1}$ ) entre 5 y $14 \mathrm{~m}^{2} \mathrm{~g}^{-1}$ dependiendo del catión incorporado. Debemos destacar el caso del catalizador con $\mathrm{Nb}$ que muestra un incremento notable del área superficial del catalizador $\left(22.3 \mathrm{~m}^{2} \mathrm{~g}^{-1}\right)$.

Los resultados de análisis químico de los catalizadores activados, determinado por AES-ICP, muestran poca variación en el contenido de Mo, V y Te. Sólo en el caso de los catalizadores con Ni ó Fe se observa una incorporación de teluro menor o mayor, respectivamente. Sin embargo, existe una fuerte dependencia entre el tipo de metal incorporado en la síntesis y la relación atómica $\mathrm{X} / \mathrm{Mo}$ final del catalizador. Los metales $\mathrm{Mg}$, $\mathrm{Fe}, \mathrm{Bi}$ y $\mathrm{Nb}$ presentan una incorporación total, sin cambios en la relación atómica inicial del gel de síntesis. En cambio, en el caso de los elementos Sr o La, estos no están presentes en el catalizador activado por lo que se deduce que no se produce una incorporación de estos metales durante la síntesis hidrotermal.

En la Figura 4.1 se muestran los difractogramas de rayos $X$ obtenidos para el catalizador MoVTeO sin promotor, antes (a) y después (b) del tratamiento térmico a $600^{\circ} \mathrm{C}$. En el catalizador MoVTeO antes de la activación (Figura 4.1, a), se observa principalmente la presencia de reflexiones a $2 \theta=6.7,7.9,8.9,22.2,27.1$, 29.3, 30.5 y $35.3^{\circ}$, correspondientes a la fase M1 [21].

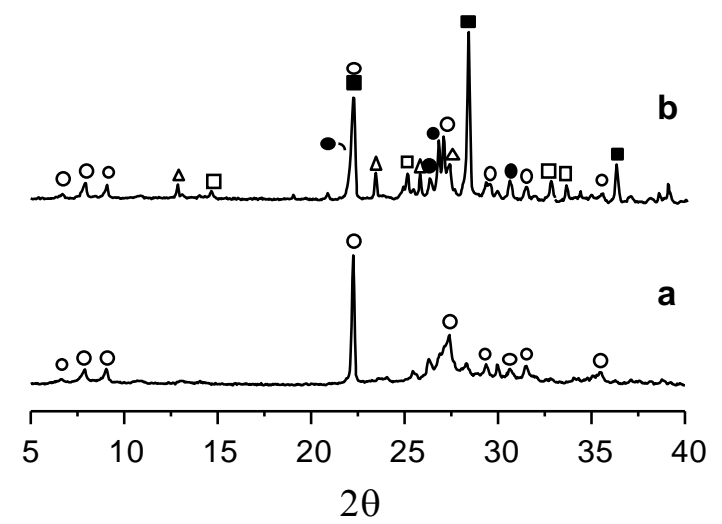

Figura 4.1. Difractogramas del óxido mixto MoVTe sin promotor antes (a) y después (b) del tratamiento térmico a $600^{\circ} \mathrm{C}$. Símbolos: (-) $\mathrm{Te}_{0.33} \mathrm{MO}_{3.33}$ (fase $\mathrm{M} 2$ ), (०) $\mathrm{Te}_{2} \mathrm{M}_{20} \mathrm{O}_{57}$ (fase M1), $(\bullet) \mathrm{TeMo}_{5} \mathrm{O}_{16},(\triangle) \mathrm{MoO}_{3}$-ortorrómbica, ( $\left.\square\right) \mathrm{Mo}_{0.97} \mathrm{~V}_{0.95} \mathrm{O}_{5}$.

Por otro lado, el catalizador activado (Figura 4.1, b) muestra la aparición de picos a $2 \theta=22.2,28.2$, y 36.2 correspondientes a la fase $\mathrm{Te}_{0.33} \mathrm{Mo}_{3.33}$ [21], también denominada fase M2. Además de éstos picos de difracción aparecen otros picos de menor intensidad correspondientes a las fases cristalinas $\mathrm{TeMo}_{5} \mathrm{O}_{16}(2 \theta=21.7$, 24.6, 26.2, 26.7 y $\left.30.5^{\circ}\right)$ [JCPDS 31-0874]; $\mathrm{MoO}_{3}$ ortorrómbica $(2 \theta=12.8,23.4$, 
25.7 y $\left.27.3^{\circ}\right)$ [JCPDS 35-609] y $\mathrm{Mo}_{0.97} \mathrm{~V}_{0.95} \mathrm{O}_{5}(2 \theta=14.6,21.9,25.0,29.5,32.7$ y 33.4) [JCPDS: 77-0649]. La presencia de estas fases sugiere que durante el tratamiento térmico tiene lugar una descomposición parcial de la fase M1 y/o alguna fase amorfa presente en el material sin activar, como se observa en trabajos anteriores [42].

En general, los materiales promovidos antes de la activación (difractogramas no mostrados), presentan una distribución muy similar al sistema MoVTeO (Figura 4.1, a), observándose principalmente la presencia de reflexiones correspondientes a la fase M1, independientemente del metal incorporado. Sin embargo, en el caso del catalizador con $\mathrm{Mg}$, aparece además una nueva fase cristalina diferente con picos a $2 \theta=8.2,16.4,26.7$ y $28.6^{\circ}$ correspondiente a la formación de un óxido de vanadio y magnesio $\mathrm{MgV}_{6} \mathrm{O}_{16}$ [JCPDS: 46-281]. En el difractograma correspondiente al precursor con $\mathrm{Nb}$, se observa la presencia de una fase poco cristalina. Si bien, es conocido que la presencia de oxalato en los sistemas con $\mathrm{Nb}$, da lugar a una fase de baja cristalinidad en los materiales frescos [43], caracterizado por la presencia de un pico a $2 \theta=22.2$ y una banda ancha a $2 \theta=27.1$, precursor de la fase ortorrómbica.

Los difractogramas de rayos $\mathrm{X}$ de los catalizadores promovidos con metales activados a $600^{\circ} \mathrm{C}$ se muestran en la Figura 4.2. De acuerdo con estos resultados, los catalizadores promovidos con metales muestran también una descomposición parcial de la fase M1 durante el tratamiento térmico, con la aparición de nuevas fases como la M2, $\mathrm{TeMo}_{5} \mathrm{O}_{16} \circ \mathrm{MoO}_{3}$. Sin embargo, se observa una distribución de fases cristalinas diferente dependiendo del tipo de metal incorporado (Tabla $4.1 \mathrm{y}$ Figura 4.2). De ese modo, la naturaleza y el tipo de metal incorporado tienen un fuerte efecto en la estabilización de la fase M1.

Así, la incorporación de $\mathrm{K}, \mathrm{Ca}, \mathrm{Fe}, \mathrm{Ni}$ y Ce presenta principalmente la fase M1 con una intensidad menor de los picos relacionados con la fase $\mathrm{M} 2$ y $\mathrm{TeMo}_{5} \mathrm{O}_{16}$ que en el catalizador sin promotor, lo que podría indicar una mayor estabilización de la fase $\mathrm{Te}_{2} \mathrm{M}_{20} \mathrm{O}_{57}$ con la presencia de estos metales. En el caso del catalizador con $\mathrm{Nb}$ se observa solamente la presencia de $\mathrm{M} 1$ y $\mathrm{M} 2$, sugiriendo que el $\mathrm{Nb}$ estabiliza la fase M1 aún incorporado en poca cantidad ( $\mathrm{Nb} / \mathrm{Mo}=0.04)$.

Sin embargo, la incorporación de $\mathrm{Ag}, \mathrm{Mg}$ y $\mathrm{Cu}$ tiene un efecto contrario, dando lugar mayoritariamente a las fases $\mathrm{M} 2$ y $\mathrm{TeMo}_{5} \mathrm{O}_{16}$, además de la formación de una nueva fase cristalina $\mathrm{VOMoO}_{4}$ [JCPDS 18-852], con picos a $2 \theta=19.0$, $20.8,24.9$ y $27.1^{\circ}$, indicando una descomposición prácticamente total de la fase M1, cuya presencia es minoritaria pues se observa únicamente dos picos de baja intensidad a $2 \theta=7.9$ y 8.9 , característicos de la M1. 

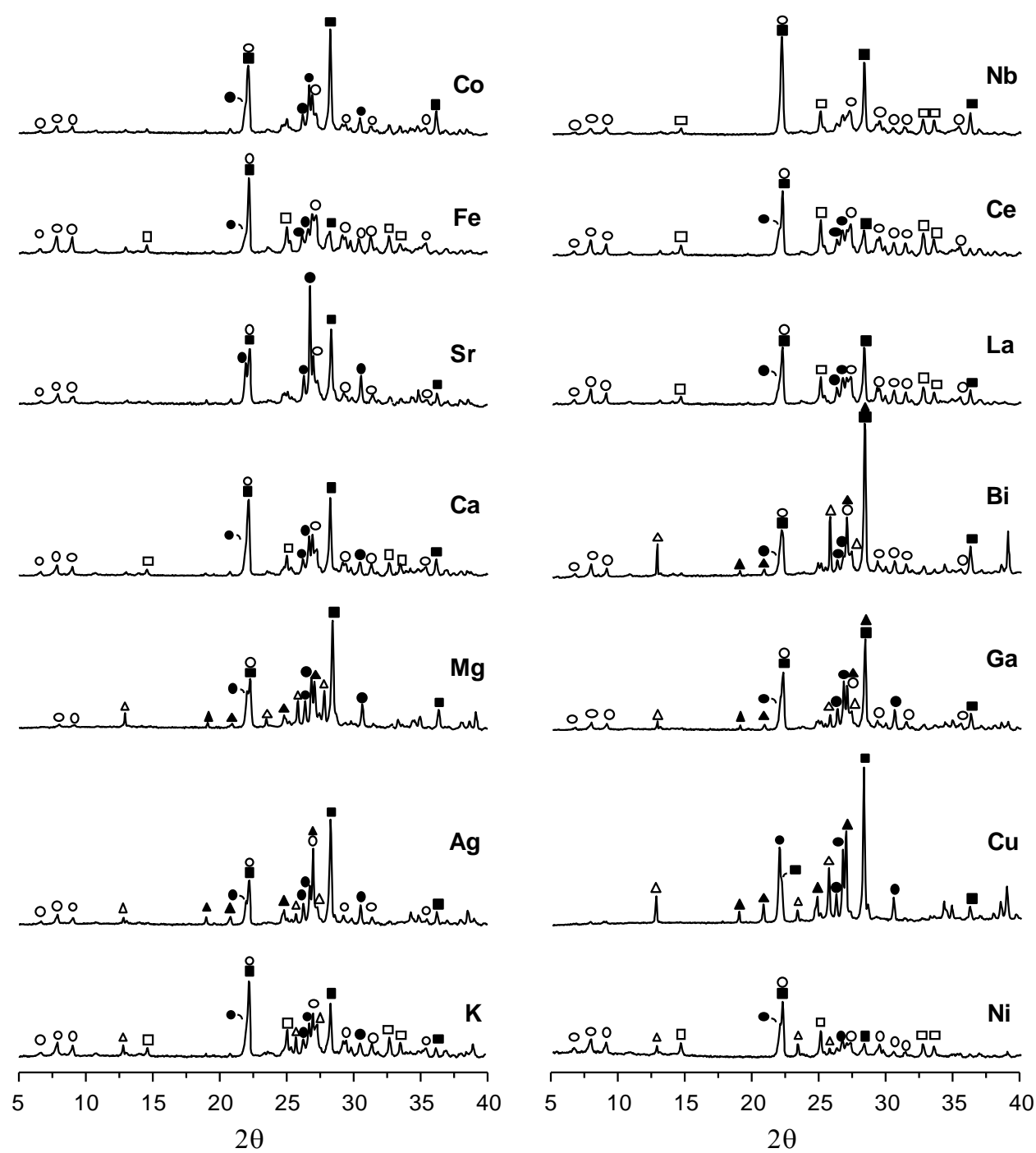

Figura 4.2. Difractogramas de los materiales Te-X4 después del tratamiento térmico a

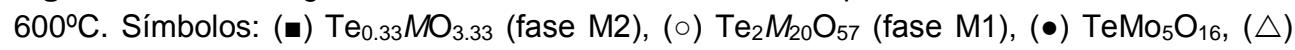
$\mathrm{MoO}_{3}$-ortorrómbica, ( $\left.\mathbf{\Delta}\right) \mathrm{VOMoO}_{4}$, (口) $\mathrm{Mo}_{0.97} \mathrm{~V}_{0.95} \mathrm{O}_{5}$.

\subsubsection{Resultados catalíticos para la Oxidación parcial de Propano}

La Figura 4.5 muestra los resultados de conversión de propano y selectividad a ácido acrílico (para una conversión de propano del 20\%) obtenidos en la oxidación de propano con catalizadores MoVTeX preparados con una relación atómica $\mathrm{Mo} / \mathrm{V} / \mathrm{Te} / \mathrm{X}$ de $1 / 0.50 / 0.17 / 0.04$ y activados a $600^{\circ} \mathrm{C}$ en flujo de $\mathrm{N}_{2}$. En la misma figura se ha incluido como referencia los datos obtenidos para el material MoVTe sin promotor, Te-600. 
En estos resultados se puede observar claramente que, si bien la mayoría de los catalizadores estudiados muestran ser activos en la oxidación de propano a ácido acrílico, la naturaleza del metal incorporado tiene una gran influencia en el comportamiento catalítico de estos materiales.

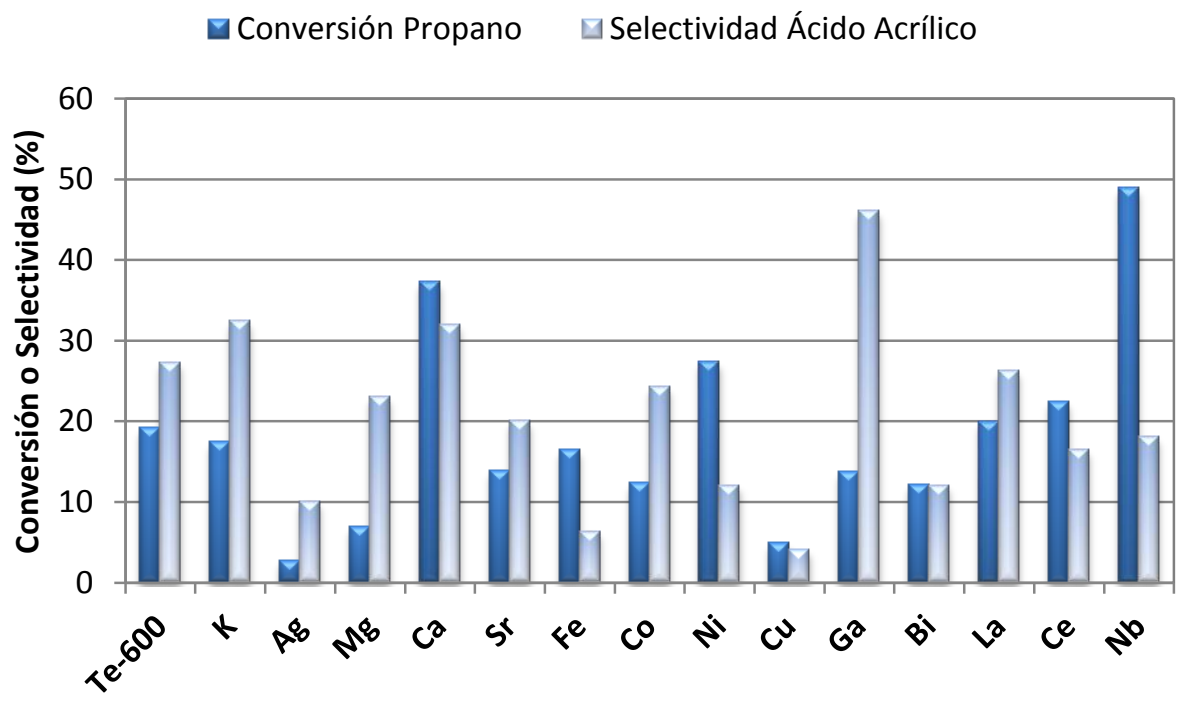

Figura 4.3. Conversión de propano obtenida durante la oxidación de propano a $380^{\circ} \mathrm{C}$, tiempo de contacto, $\mathrm{W} / \mathrm{F}=200 \mathrm{~g}_{\mathrm{cat}} \mathrm{h} \mathrm{mol}^{-1}$ сзн8, y selectividad a ácido acrílico (a una isoconversión de propano del 20\%) con catalizadores Te-X4.

En general, la incorporación de un metal al sistema MoVTe modifica las propiedades catalíticas del catalizador, aunque sólo, en algunos casos, existe una mejora en la actividad y/o en la selectividad a ácido acrílico.

Así, excepto en el caso de los catalizadores con $\mathrm{Ni}, \mathrm{Ca} \circ \mathrm{Nb}$, para los que se observa un incremento claro de la actividad catalítica, en el resto de catalizadores se observa una conversión de propano similar (en el caso de los materiales con $\mathrm{Ce}, \mathrm{La}, \mathrm{K} \circ \mathrm{Fe}$ ) o inferior ( $\mathrm{Ag}, \mathrm{Mg}, \mathrm{Cu}, \mathrm{Sr}$, Co o $\mathrm{Bi}$ ) a la observada para el catalizador sin promotor, Te-600. En el caso del catalizador con $\mathrm{Ga}$, se observa una menor conversión de propano pero una selectividad a ácido acrílico mayor.

Por otro lado, la selectividad a ácido acrílico para el $20 \%$ de conversión de propano muestra que también depende del metal incorporado. Así, la incorporación de $\mathrm{Cu}, \mathrm{Fe}, \mathrm{Ag}$ y $\mathrm{Mg}$ disminuye radicalmente la selectividad, mientras que con $\mathrm{K}$, Ca y, en especial con $\mathrm{Ga}$, se observa un aumento considerable de la selectividad a ácido acrílico. 


\subsubsection{Discusión de los resultados}

En vista a los resultados obtenidos se puede concluir que la incorporación de un cuarto catión metálico en el sistema $\mathrm{MoVTeO}$, incluso en pequeñas cantidades, relación $\mathrm{X} / \mathrm{Mo}=0.04$ en el gel de síntesis, tiene una influencia importante tanto en la distribución de las fases cristalinas como en el comportamiento catalítico de los materiales.

En general, la actividad catalítica de estos sistemas está relacionada con la presencia de la fase $\mathrm{Te}_{2} \mathrm{M}_{20} \mathrm{O}_{57}$ (fase M1), activa en la oxidación de propano. De esta forma, la incorporación de $\mathrm{Ce}, \mathrm{Ni}$ o $\mathrm{Ca}$ favorece una mayor actividad que el catalizador sin promotor (Figura 4.3), debido a la mayor presencia de fase M1 en su composición. Por otro lado, en el caso de los catalizadores con $\mathrm{Ag}, \mathrm{Mg}$ o Cu se observa poca actividad catalítica (Figura 4.3), posiblemente debido a que la fase M1 está presente aunque de forma minoritaria. También los catalizadores con Co, $\mathrm{Bi}$ y $\mathrm{Sr}$, que tienen una baja actividad catalítica, se puede relacionar con la baja presencia de la fase M1 (y la mayor formación de las fases cristalinas M2 y $\left.\mathrm{TeMo}_{5} \mathrm{O}_{16}\right)$.

En el caso de la incorporación de K, se observa una influencia positiva al producir un aumento en la selectividad a ácido acrílico, en comparación con el catalizador sin metal Te-600, durante la oxidación de propano. Como se ha mencionado anteriormente, la incorporación de potasio en los catalizadores basados en óxidos mixtos MoVSbO favorece la eliminación de los centros Brönsted en la superficie del catalizador, favoreciendo la formación selectiva a ácido acrílico con el consecuente aumento en la selectividad del mismo [24-26]. Sin embargo, el incremento de selectividad observado al incorporar potasio es menor en materiales con teluro que el observado en materiales con antimonio. Esto se debe posiblemente a la menor acidez superficial que presentan, en general, los catalizadores con Te respecto a los correspondientes con Sb [22-23].

En la incorporación de metales alcalinotérreos cabe esperar un comportamiento similar al encontrado con metales alcalinos, debido a que estos también pueden disminuir el número de centros ácidos presentes en la superficie de los materiales. Sin embargo, estudios anteriores realizados en catalizadores MoVSbO promovidos con metales alcalinotérreos muestran que sólo los materiales con $\mathrm{Mg}$ son activos en la oxidación de propano [32], debido a que mantiene la fase M1 en el material activado. No obstante, un efecto importante en la síntesis de estos materiales es la sal empleada como precursor del metal. La incorporación de metales mediante el empleo de la correspondiente sal de nitrato durante la síntesis hidrotermal da lugar a la formación mayoritaria de $\mathrm{MoO}_{3}$ hexagonal y presencia minoritaria de la fase $\mathrm{M} 1$ en el material sin activar. Durante el tratamiento térmico a $600^{\circ} \mathrm{C}$ se produce la desaparición de la fase M1 y/o la 
formación de otras fases como $\mathrm{MoO}_{3}$ ortorrómbica, $\mathrm{VOMo}_{4}$ y fase $\mathrm{M} 2$ (inactivas en la oxidación de propano). Por esta razón, para este estudio se han empleado principalmente los correspondientes sulfatos de los metales estudiados, el cual no parece influir en la naturaleza de las fases cristalinas formadas durante el tratamiento térmico de estos materiales. Así, en nuestro caso, se observa la formación de la fase M1 en todos los catalizadores promovidos por metales alcalinotérreos, que se mantiene después del tratamiento térmico, aún siendo minoritaria en el material con Mg. Sin embargo, sólo en el caso de la incorporación de $\mathrm{Ca}$ se observa un aumento en la actividad y selectividad a ácido acrílico durante la oxidación de propano.

La incorporación de metales de transición divalentes $(\mathrm{Fe}, \mathrm{Co}, \mathrm{Ni}$ y $\mathrm{Cu}$ ) tiene una gran influencia en la formación y estabilidad de la fase M1 y, por consiguiente, en la actividad catalítica de los materiales. Así, los metales de transición $\mathrm{Fe}$, Co y $\mathrm{Ni}$ favorecen una mayor estabilidad de la fase M1 (Figura 4.2), siendo activos en la oxidación de propano (Figura 4.3). Por el contrario, la presencia de Cu favorece una descomposición prácticamente total de la fase M1, disminuyendo la actividad catalítica en la oxidación de propano. Sin embargo, la selectividad a ácido acrílico no está solamente relacionada con la mayor o menor presencia de fase M1. Si bien, la incorporación de $\mathrm{Fe}$ y Ni parece estabilizar la fase M1, la selectividad a ácido acrílico (a una conversión de $20 \%$ ) es menor que en catalizador sin promotor (Figura 4.3), sugiriendo que la presencia de estos metales en la fase cristalina M1 podría variar el número de centros selectivos en la superficie del catalizador. De hecho, la composición de Te en estos materiales (Tabla 4.1) es diferente al catalizador sin promotor, aumentando en el caso de Fe y disminuyendo en el caso del Ni. Por otra parte, la presencia de Fe en la fase M1 puede influir negativamente en las propiedades catalíticas de los materiales basados en óxidos mixtos [40].

La incorporación de bismuto en la fase M1 tiene un efecto negativo tanto en la conversión como en la selectividad a ácido acrílico. El bismuto, que se incorpora totalmente en la síntesis hidrotermal, puede sustituir al teluro en los canales hexagonales de la estructura de la fase M1 dado que tanto su tamaño como sus propiedades químicas son similares al teluro. Sin embargo, su incorporación parece desestabilizar la estructura durante el tratamiento térmico a $600^{\circ} \mathrm{C}$, favoreciendo la formación de la fase M2.

El comportamiento catalítico del catalizador con La se explica por la no incorporación de éste al catalizador activado, como muestran los resultados de análisis químico (Tabla 4.1). Por ello, presenta unos resultados de conversión de propano y selectividad a ácido acrílico prácticamente idénticos al sistema catalítico sin promotor Te-600. 
La incorporación de Ce parece estabilizar la fase M1, siendo esta fase mayoritaria en el material activado, aumentando ligeramente la actividad catalítica en comparación con el catalizador sin metal (sin embargo, es menos selectivo a ácido acrílico). En cambio, la incorporación de Ga tiene un efecto contrario. Si bien la actividad catalítica es menor que el catalizador sin promotor, la selectividad a ácido acrílico se ve considerablemente incrementada por la presencia de Ga. Así, el catalizador promovido con $\mathrm{Ga}, \mathrm{Te}-\mathrm{Ga} 4$, ha resultado ser el catalizador más selectivo a ácido acrílico.

En el caso del catalizador con $\mathrm{Nb}$, este sólo presenta las fases M1 y M2, sugiriendo que la presencia de niobio en pequeñas cantidades estabiliza la fase M1. Además, los resultados catalíticos muestran un alto valor de conversión de propano, siendo el catalizador más activo para la oxidación de propano a ácido acrílico de los estudiados. Sin embargo, no es un catalizador muy selectivo, efecto contrario al normalmente observado con la incorporación de niobio para relaciones $\mathrm{Nb} / \mathrm{Mo}$ del gel de síntesis mayores [44].

En resumen, la naturaleza del metal incorporado en el gel de síntesis tiene una gran influencia en los resultados catalíticos para la oxidación de propano a ácido acrílico. Aunque gran parte de los metales estudiados tienen un efecto negativo en la actividad y selectividad a ácido acrílico, también se han encontrado metales que mejoran la eficacia del catalizador. Así, la incorporación de $\mathrm{Nb}$ incrementa la actividad del catalizador, mientras que, la incorporación de $\mathrm{Ca}$ y $\mathrm{Ga}$ aumenta la selectividad a ácido acrílico. Además, la presencia de Ca también mejora la conversión de propano. Estos metales representan unos promotores interesantes para aumentar la eficacia de los catalizadores Mo-V-Te-O, y serán estudiados en el apartado siguiente.

\subsection{Efecto de la incorporación de $\mathrm{Ca}, \mathrm{Ga}$ y $\mathrm{Nb}$ en catalizadores Mo-V-Te-O}

En vista de los resultados obtenidos con los catalizadores MoVTeX en el apartado anterior, los materiales de mayor interés son los obtenidos por incorporación de $\mathrm{Ca}, \mathrm{Ga}$ y $\mathrm{Nb}$, dado que mejoran los resultados catalíticos obtenidos con el material sin promotor, Te-600.

Por este motivo, se ha llevado a cabo un estudio más detallado de estos materiales promovidos con $\mathrm{Ca}$, Ga y $\mathrm{Nb}$. Para ello, se han caracterizado por diversas técnicas de caracterización a fin de comprender las mejoras catalíticas influenciadas por la presencia de estos metales. Además, se ha estudiado el efecto de la relación $\mathrm{X} / \mathrm{Mo}(\mathrm{X}=\mathrm{Ca}, \mathrm{Ga} \circ \mathrm{Nb})$, con el fin de determinar la relación óptima en el gel de síntesis para cada promotor. 


\subsubsection{Caracterización físico-química de los materiales promovidos con $\mathrm{Ca}, \mathrm{Ga}$ o $\mathrm{Nb}$}

La síntesis de los materiales promovidos con $\mathrm{Ca}, \mathrm{Ga} \circ \mathrm{Nb}$ se ha llevado a cabo variando la relación Ca/Mo (0.02 a 0.06), Ga/Mo (0.04 a 0.12) o Nb/Mo (0.04 a 0.21) en el gel de síntesis. En la Tabla 4.2 se muestran las características de estos catalizadores. Además, se ha estudiado la incorporación de dos promotores ( $\mathrm{Ca}, \mathrm{Ga}$ y/o Nb) en el catalizador MoVTeO.

Tabla 4.2. Características de los catalizadores $\mathrm{Te}-\mathbf{X} \boldsymbol{x}(\mathrm{X}=\mathrm{Ca}, \mathrm{Ga} \circ \mathrm{Nb})$ preparados con diferente relación X/Mo y Te-X4Y4 (X e Y = Ca, Ga o Nb) activados a 600ㄷ en flujo de $\mathrm{N}_{2}$.

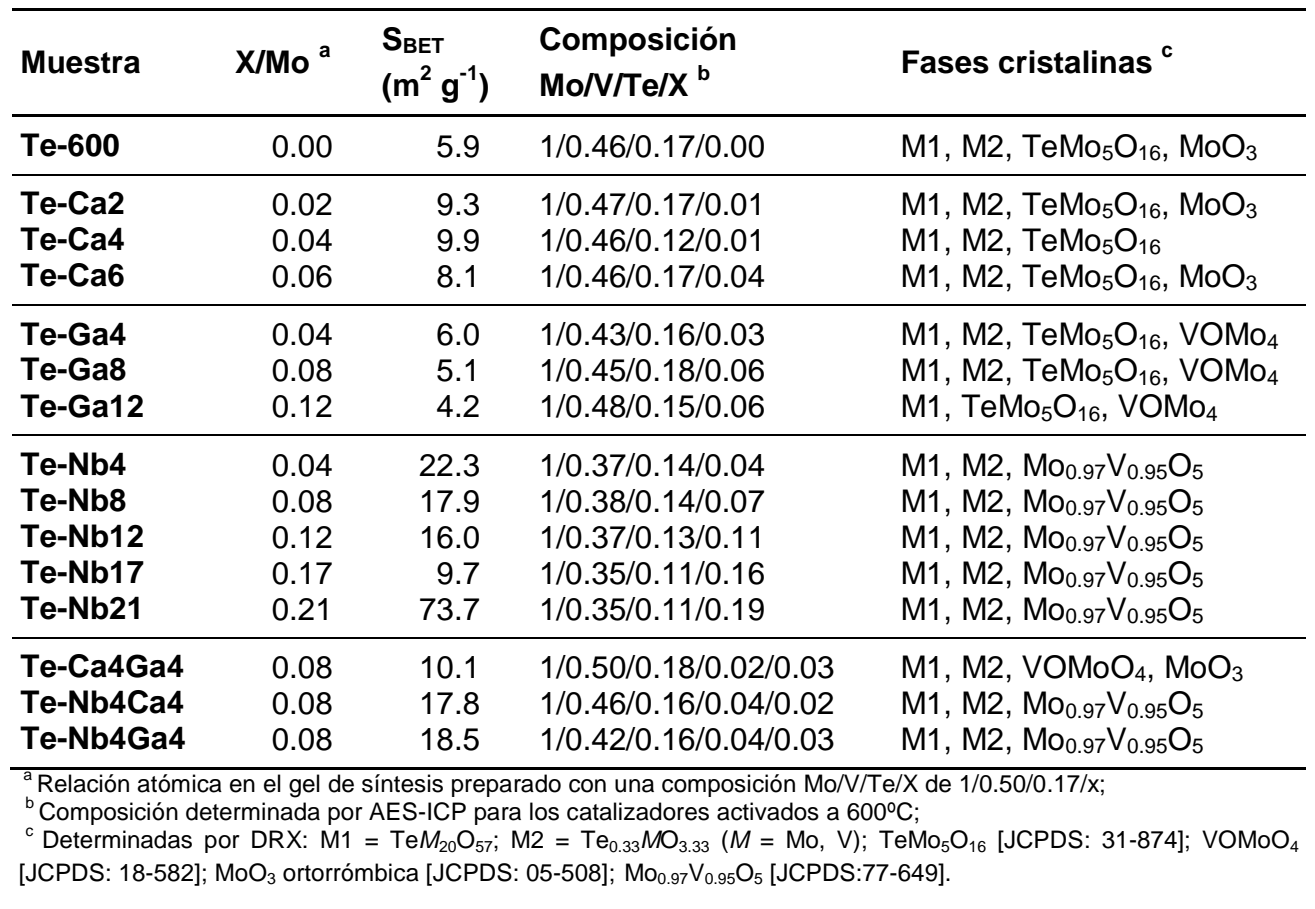

En los resultados de análisis químico se observa que la composición final del catalizador activado depende del metal incorporado $(\mathrm{Ca}, \mathrm{Ga} \circ \mathrm{Nb})$ y de la relación inicial del gel de síntesis. Así, para una misma relación X/Mo la cantidad de metal incorporado es mayor en el caso del galio que en el calcio. Para las muestras con $\mathrm{Ca}$, se debe señalar que si bien se parte de una relación atómica $\mathrm{Ca} / \mathrm{Mo}$ en el gel de síntesis de 0.02 ó 0.04 se produce la misma incorporación de $\mathrm{Ca}$ en el catalizador final $(\mathrm{Ca} / \mathrm{Mo}=0.01)$. Así mismo, aunque se aumentó la relación $\mathrm{Ga} / \mathrm{Mo}$ de 0.08 a 0.12 la composición final máxima de galio fue la misma $(\mathrm{Ga} / \mathrm{Mo}=0.06)$. La incorporación de $\mathrm{Nb}$ en el catalizador activado es prácticamente total, obteniendo la misma relación $\mathrm{Nb} / \mathrm{Mo}$ en el material activado que en el gel de síntesis. En general, estos materiales muestran poca variación en la composición 
de $\mathrm{V}$ y Te, aunque para la muestra Te-Ca4 y las muestras con niobio se observa una concentración de teluro y/o vanadio algo menor.

En relación con el área superficial de estos materiales, se observa que los catalizadores promovidos presentan un área superficial mayor que el catalizador sin promotor, Te-600, y que el valor de $\mathrm{S}_{\mathrm{BET}}$ disminuye ligeramente al aumentar la relación X/Mo en el gel de síntesis (Tabla 4.2). Para los catalizadores promovidos con $\mathrm{Nb}$ este efecto es más acusado, disminuyendo considerablemente el área superficial a medida que se aumenta el contenido de $\mathrm{Nb}$ en el gel de síntesis. Sólo en el caso del catalizador con una relación $\mathrm{Nb} / \mathrm{Mo}=0.21$, se observó un área superficial significativamente alta.

Respecto a la naturaleza de las fases cristalinas de estos materiales, en las Figuras 4.4-4.5 se muestran los difractogramas de rayos $X$ para los catalizadores estudiados después del tratamiento térmico a $600^{\circ} \mathrm{C}$. Además, con fines comparativos, en la Figura 4.5 se han incluido los difractogramas de los catalizadores promovidos con dos metales ( $\mathrm{Ca}, \mathrm{Ga}$ y/o $\mathrm{Nb}$ )
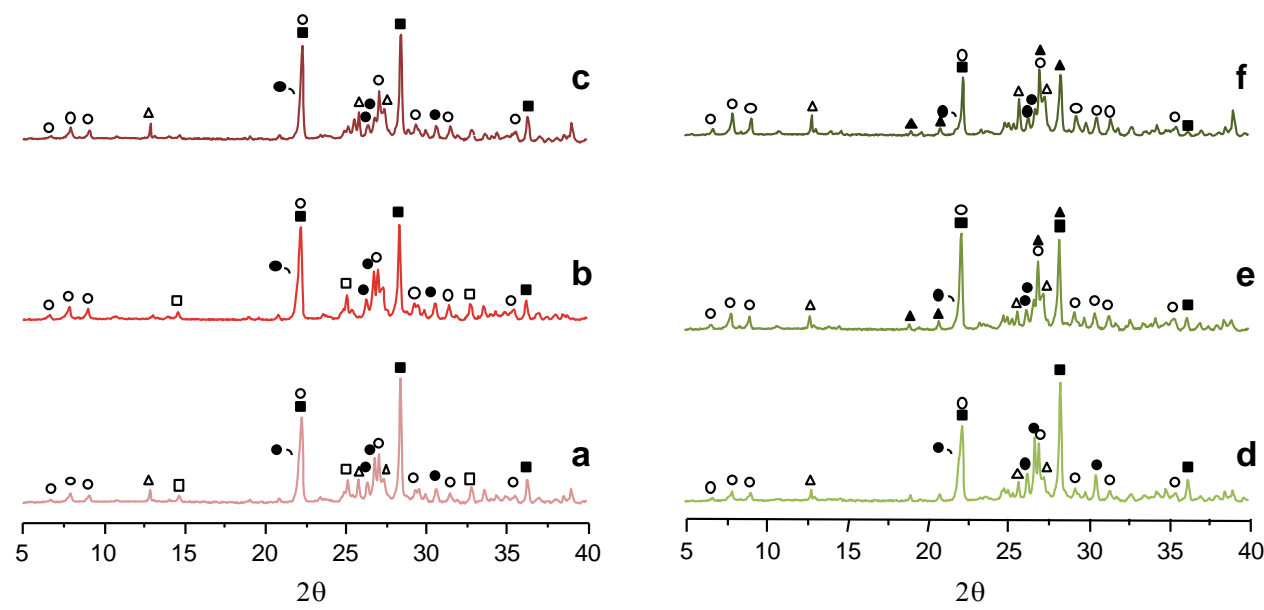

Figura 4.4. Difractogramas de los catalizadores $\operatorname{MoVTe}-\mathrm{X}(\mathrm{X}=\mathbf{C a} \circ \mathbf{G a})$ preparados con diferente relación X/Mo y activados a $600^{\circ} \mathrm{C} / \mathrm{N}_{2}$ : a) Te-Ca2; b) Te-Ca4; c) Te-Ca6; d) TeGa4; e) Te-Ga8; f) Te-Ga12. Símbolos: (ロ) $\mathrm{Te}_{0.33} \mathrm{MO}_{3.33}$ (fase M2), (०) $\mathrm{Te}_{2} \mathrm{M}_{20} \mathrm{O}_{57}$ (fase M1), $(\bullet) \mathrm{TeMo}_{5} \mathrm{O}_{16},(\triangle) \mathrm{MoO}_{3}$-ortorrómbica, (口) $\mathrm{Mo}_{0.97} \mathrm{~V}_{0.95} \mathrm{O}_{5}$.

Los catalizadores con incorporación de $\mathrm{Ca} \circ \mathrm{Ga}$, antes de ser activados (difractogramas no mostrados), muestran principalmente la presencia de la fase M1, al igual que el sistema MoVTe sin metal, independientemente de la cantidad de calcio o galio incorporado en el gel de síntesis. Por otro lado, los catalizadores preparados con niobio muestran un precursor amorfo igual al observado en estudios anteriores [43]. En el caso de la muestra Te-Nb21, es importante señalar la presencia de teluro metálico (observado a simple vista y confirmado por DRX) en el precursor antes de llevar a cabo la activación del material. Esta reducción de 
teluro se puede deber al exceso de oxalato presente durante la síntesis hidrotermal.

Cuando los precursores son sometidos al tratamiento térmico a $600^{\circ} \mathrm{C}$ los resultados de difracción de rayos $X$ (Figura 4.4) muestran la aparición de nuevas fases cristalinas: fase $\mathrm{M} 2, \mathrm{TeMo}_{5} \mathrm{O}_{16}, \mathrm{MoO}_{3}$ y $\mathrm{Mo}_{0.97} \mathrm{~V}_{0.95} \mathrm{O}_{5}$. La distribución de fases cristalinas es similar en todos los casos, variando únicamente la intensidad de los picos correspondientes a algunas fases e indicando una mayor o menor presencia de éstas. Al aumentar la relación $\mathrm{Ca} / \mathrm{Mo}$ del gel de síntesis (Figura 4.4, izda.) se observa una menor presencia de la fase $\mathrm{M} 2_{2}$ y $\mathrm{TeMo}_{5} \mathrm{O}_{16}$, en comparación con el catalizador sin promotor (Te-600) (Figura 4.1).

En el caso de las muestras con galio (Figura 4.4, dcha.), la incorporación de $\mathrm{Ga}$ favorece una menor presencia tanto de la fase $\mathrm{M} 2$ como de $\mathrm{TeMo}_{5} \mathrm{O}_{16}$, lo que sugiere que la descomposición de la fase M1 es menor al aumentar la cantidad de $\mathrm{Ga}$. Así, al igual que el $\mathrm{Ca}$, la incorporación de $\mathrm{Ga}$ en estos materiales parece estabilizar la fase M1.
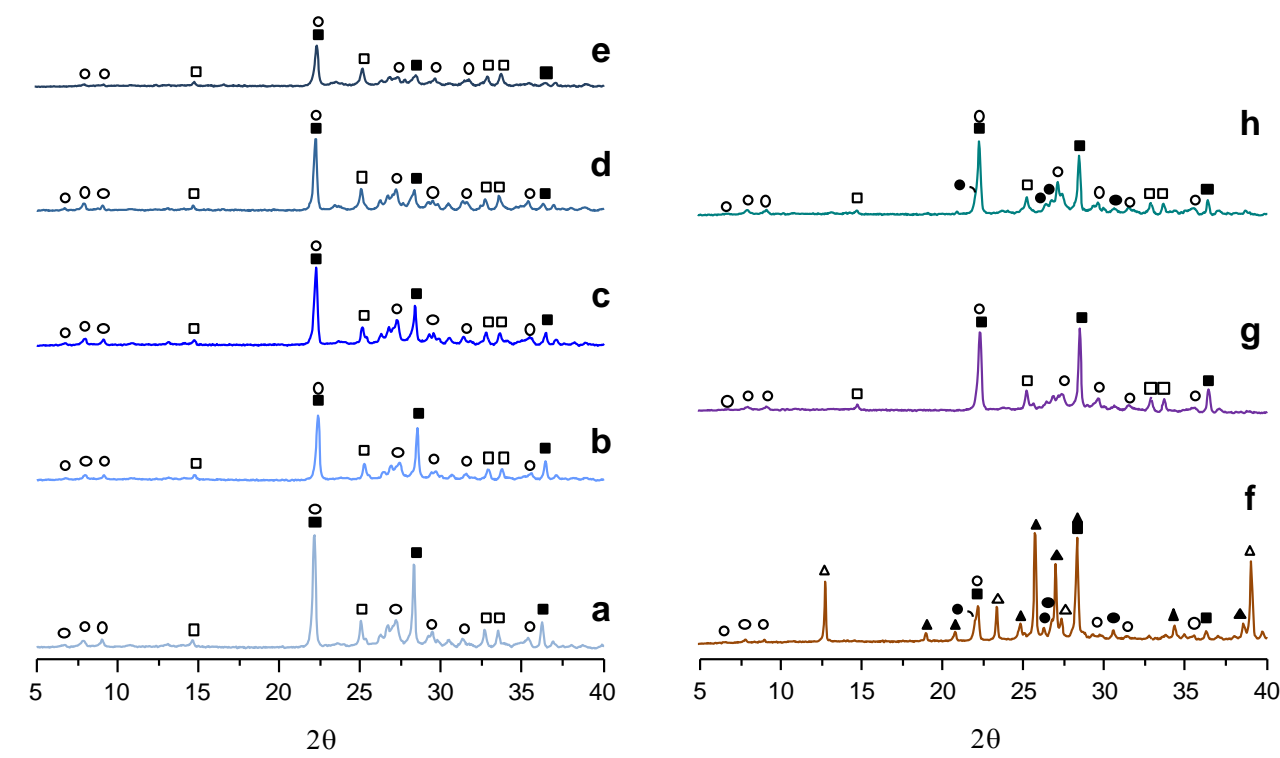

Figura 4.5. Difractogramas de los catalizadores MoVTe-Nb preparados con diferente relación Nb/Mo y MoVTe-XY (X e Y = Ca, Ga o Nb) activados a 600ㄷ: a) Te-Nb4; b) TeNb8; c) Te-Nb12; d) Te-Nb17; e) Te-Nb21; f) Te-Ca4Ga4; g) Te-Nb4Ca4 y h) Te-Nb4Ga4.

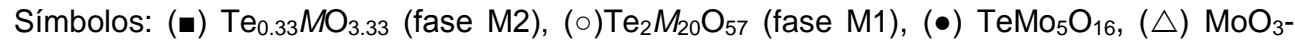

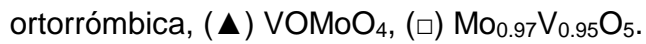

En la Figura 4.5 se pueden observar los difractogramas de rayos $X$ de los catalizadores activados con diferente relación Nb/Mo. Al aumentar la cantidad de niobio incorporado a la fase M1 se obtiene una menor presencia de fase M2. Así, con relaciones $\mathrm{Nb} / \mathrm{Mo}$ altas $(0.17-0.21)$ se observa mayoritariamente la fase $\mathrm{M} 1$. 
Es conocido que la presencia de $\mathrm{Nb}$ en el gel de síntesis estabiliza la fase $\mathrm{M} 1$, observándose únicamente la presencia de la fase M1 en el catalizador activado [45-46].

En el caso de los catalizadores Mo-V-Te promovidos con dos metales (Ca, $\mathrm{Ga} \circ \mathrm{Nb}$ ), se observan principalmente la fase $\mathrm{M} 1$ en el precursor sin activar. Una vez tratados a $600^{\circ} \mathrm{C} / \mathrm{N}_{2}$ la presencia de $\mathrm{Nb}$ parece favorecer una mayor estabilidad de la fase M1 durante el tratamiento térmico (Figura 4.5, $\mathbf{g}$ y $\mathbf{h}$ ). Sin embargo, al incorporar $\mathrm{Ca}$ y $\mathrm{Ga}$ al sistema MoVTe se observa menor presencia de la fase M1 con la formación de otras fases cristalinas.

Si bien la distribución de fases cristalinas obtenida por DRX está relacionada con la estabilidad de la fase M1, lo cual podría explicar en parte el comportamiento catalítico de algunos materiales estudiados (Figura 4.5), no es suficiente para entender la influencia de la incorporación de un metal (como $\mathrm{Ca}, \mathrm{Ga}$ o $\mathrm{Nb}$ ) en el comportamiento catalítico de los materiales. Por eso, se han utilizado otras técnicas en la caracterización con el fin de elucidar el cambio producido en los materiales al incorporar el promotor.

La morfología, la forma y el tamaño de los cristales que componen los catalizadores activados se ha estudiado por microscopía electrónica de barrido (SEM), además, se ha determinado la composición química local y global, mediante análisis EDX. Los resultados obtenidos para los catalizadores activados a $600^{\circ} \mathrm{C}$ con una relación $\mathrm{X} / \mathrm{Mo}=0.04(\mathrm{X}=\mathrm{Ca}, \mathrm{Ga} \circ \mathrm{Nb})$ en el gel de síntesis se muestran en la Figura 4.6 y en la Tabla 4.3.

Las imágenes SEM muestran una morfología similar entre las muestras con $\mathrm{Ca} \circ \mathrm{Ga}$ y el catalizador sin promotor. En todos los casos, se observan cristales en forma de agujas con los bordes estriados que crecen en la dirección paralela al eje de crecimiento [001], igual a la morfología encontrada en este tipo de catalizadores para la fase activa $\mathrm{Te}_{2} M_{20} \mathrm{O}_{57}(M=\mathrm{Mo}, \mathrm{V}$ o Nb) [34, 43, 47].

Se puede observar además que en los catalizadores con $\mathrm{Ca} \circ \mathrm{Ga}$, el tamaño de cristal de las partículas asociadas a la fase $\mathrm{Te}_{2} \mathrm{M}_{20} \mathrm{O}_{57}$ es menor que en el catalizador sin promotor, observándose una modificación de la longitud de los cristales (Figura 4.6, b y c). Así, la incorporación de Ca o Ga en el gel de síntesis, retrasaría el crecimiento del cristal durante la síntesis hidrotermal, favoreciendo cristales de menor tamaño.

En el caso del catalizador con $\mathrm{Nb}$, la incorporación de $\mathrm{Nb}$ en la estructura del catalizador reduce drásticamente el tamaño del cristal, observándose cristales mucho más pequeños, aglomerados en forma de racimo, similares a los encontrados en catalizadores MoVTeNb con mayor relación Nb/Mo [43]. En este sentido, se ha propuesto que tanto los iones $\mathrm{Nb}^{5+}$ como los iones oxalato (sal 
empleada como precursor de niobio) retardan el crecimiento cristalino durante la síntesis hidrotermal [14, 19, 43]. Este hecho podría explicar el aumento de la superficie específica que tiene lugar por la incorporación de Nb (Tabla 4.1).
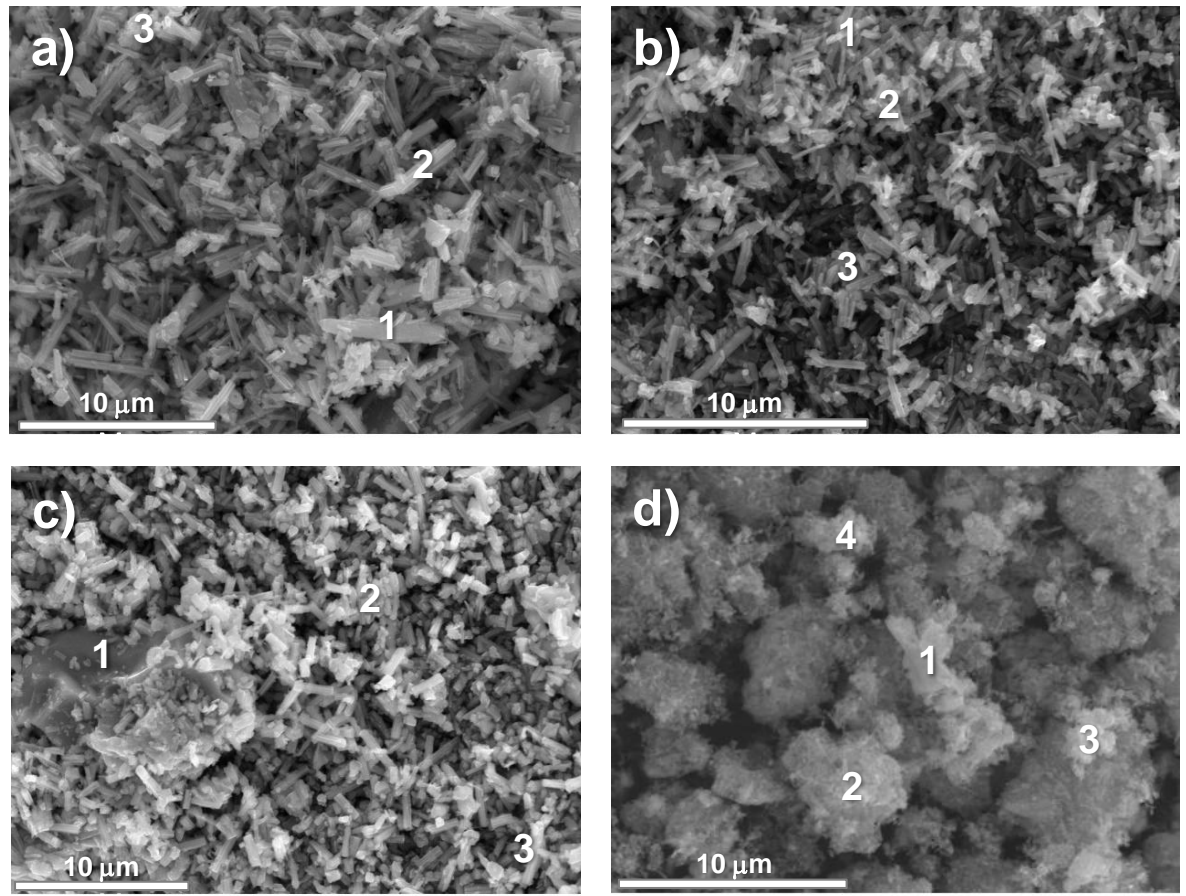

Figura 4.6. Imágenes SEM de los catalizadores MoVTeX activados: a) Te-600; b) Te-Ca4; c) Te-Ga4; d) Te-Nb4. Los números corresponden a las partículas analizadas por EDX (ver Tabla 4.3).

La composición química total obtenida por EDX a partir de las imágenes de los materiales activados que se muestran en la Tabla 4.3 concuerda relativamente bien con la composición global de los mismos materiales determinada por AESICP (Tabla 4.1). Por lo tanto, se puede considerar que las imágenes de SEM expuestas son suficientemente representativas de la totalidad de cada uno de los materiales analizados.

Por otro lado, se ha determinado la composición local de algunas partículas por EDX (Tabla 4.3) mostrando algunas diferencias en la composición de los cristales. En este punto, cabe señalar que en la muestra Te-600 se observa la presencia de grandes cristales, cuya composición corresponde a la fase $\mathrm{MoO}_{3}$ (observada en los resultados de DRX), y que no se encuentran en las muestras con $\mathrm{Ca}, \mathrm{Ga}$ o $\mathrm{Nb}$. 
Tabla 4.3. Análisis EDX de los catalizadores MoVTe y $\operatorname{MoVTeX}(X=\mathbf{C a}, \mathbf{G a} \circ \mathbf{N b})$ preparados con una relación $\mathrm{X} / \mathrm{Mo}=0.04$ y activados a $600^{\circ} \mathrm{C}$.

\begin{tabular}{|c|c|c|c|}
\hline Muestra & $\begin{array}{c}\text { Composición Total } \\
M o / V / T e / X^{a}\end{array}$ & Partícula $^{\text {b }}$ & $\begin{array}{c}\text { Composición } \\
\text { Local Mo/V/Te/X a }\end{array}$ \\
\hline Te-600 & $1 / 0.52 / 0.13 / 0.00$ & $\begin{array}{l}1 \\
2 \\
3\end{array}$ & $\begin{array}{l}1 / 0.39 / 0.26 / 0.00 \\
1 / 0.43 / 0.12 / 0.00 \\
1 / 0.47 / 0.16 / 0.00\end{array}$ \\
\hline Te-Ca4 & $1 / 0.46 / 0.10 / 0.01$ & $\begin{array}{l}1 \\
2 \\
3\end{array}$ & $\begin{array}{l}1 / 0.44 / 0.14 / 0.01 \\
1 / 0.42 / 0.10 / 0.00 \\
1 / 0.44 / 0.40 / 0.01\end{array}$ \\
\hline Te-Ga4 & $1 / 0.44 / 0.15 / 0.03$ & $\begin{array}{l}1 \\
2 \\
3\end{array}$ & $\begin{array}{l}1 / 0.17 / 0.19 / 0.01 \\
1 / 0.42 / 0.12 / 0.01 \\
1 / 0.41 / 0.12 / 0.02\end{array}$ \\
\hline Te-Nb4 & $1 / 0.38 / 0.11 / 0.02$ & $\begin{array}{c}1 \\
2 \text { y } 3 \\
4\end{array}$ & $\begin{array}{l}1 / 0.37 / 0.19 / 0.02 \\
1 / 0.37 / 0.08 / 0.04 \\
1 / 0.36 / 0.13 / 0.02\end{array}$ \\
\hline
\end{tabular}

En general, se ha encontrado que las partículas presentan una composición con una relación Te/Mo y V/Mo variable (0.12-0.26 y 0.17-0.47, respectivamente) aunque dentro del rango correspondiente a las fases $\mathrm{Te}_{0.33} M_{3.33}$ y $\mathrm{Te}_{2} \mathrm{M}_{20} \mathrm{O}_{57}(\mathrm{M}$ $=\mathrm{Mo}, \mathrm{V})$. Así, tanto la incorporación de Ca como de Ga da lugar a cristales con una composición química muy similar a la composición teórica de la fase M1, $\mathrm{Te}_{2} \mathrm{M}_{20} \mathrm{O}_{57}$ (Partículas 1 y 2 en Te-Ca4; Partículas 2 y 3 en Te-Ga4), aunque también se observe cristales con morfología diferente y con una relación Te/M similar a la de la fase M2 (Partícula 3 en Te-Ca4; Partícula 1 en Te-Ga4).

A fin de determinar el contenido y localización del metal incorporado, Ca o $\mathrm{Ga}$, se ha realizado un mapeo de la zona estudiada. En ambos casos, se determina que tanto el $\mathrm{Ca}$ como el Ga están presentes en el catalizador de forma homogénea, sin grandes localizaciones o vacíos de metal. En el caso de la incorporación de $\mathrm{Ca}$, el análisis de la composición de las partículas con morfología y composición similar a la fase M1 (Partículas 1 y 2 Tabla 4.3) muestra la existencia de cristales con y sin calcio. Sin embargo, la composición de $\mathrm{Ca}$ observada, $0.1 \%$ en peso de $\mathrm{Ca}$ en el material, entra dentro de los límites de detección de la técnica para este elemento, por lo que no se puede asegurar la incorporación de $\mathrm{Ca}$. Por otro lado, la incorporación de Ga en el gel de síntesis conlleva partículas con una composición de Ga bastante homogénea (Tabla 4.3), con presencia tanto en cristales de fase M1 como de fase M2.

En el caso del catalizador con $\mathrm{Nb}$ (Te-Nb4) la estequiometria de los cristales observada por microscopia indica que corresponden a la estequiometria descrita para la fase M1. Sin embargo, se observan diferencias en la composición química 
de teluro y niobio dependiendo del cristal analizado. Así, en algunos casos (Partículas 2 y 3, Te-Nb4, Tabla 4.3) se observa una mayor cantidad de Nb con un menor contenido de teluro. En otros casos (Partículas 1 y 4, Te-Nb4) el contenido de teluro es mayor, mientras que la cantidad de $\mathrm{Nb}$ incorporado es menor (Nb/Mo $=0.02$ ).

La Figura 4.7 muestra los espectros FT-IR (A), en la zona 1700-300 $\mathrm{cm}^{-1}, \mathrm{y}$ los espectros Raman (B) del catalizador MoVTeO sin metal (Te-600) y de los catalizadores Te-X4 (X = Ca, Ga ○ Nb). En los materiales obtenidos directamente de síntesis se puede observar una banda de absorción a $1402 \mathrm{~cm}^{-1}$ que corresponde a la vibración de deformación de los iones $\mathrm{NH}_{4}{ }^{+}$(además de otra banda ancha a $\sim 3145 \mathrm{~cm}^{-1}$ característica de la vibración de tensión de estos iones [48]). Durante la activación a $600^{\circ} \mathrm{C}$ se produce la eliminación de los iones amonio cuyas bandas de absorción no aparecen en el espectro de los materiales activados. Por otro lado, también se observan las bandas de absorción típicas de los modos de vibración de los iones $\mathrm{OH}^{-}$a $\sim 3145\left(v_{\mathrm{OH}}\right)$ y $1620 \mathrm{~cm}^{-1}\left(\delta_{\mathrm{OH}}\right)$ [48], estas bandas también se han observado en los catalizadores activados (no presentadas en la figura). En el caso del material con $\mathrm{Ca}$, se observa una banda adicional a $1385 \mathrm{~cm}^{-1}$ que no se observa en el resto de materiales. Esta banda puede asignarse a la presencia del ion carbonato en la muestra (sal de calcio empleada durante la síntesis), cuyas bandas características aparecen a 1600 y $1385 \mathrm{~cm}^{-1}$ [49], y desaparecen durante el tratamiento térmico a $600^{\circ} \mathrm{C}$.

El espectro FTIR de los materiales activados muestra bandas a 918, 870, 805, 715, 650 y $602 \mathrm{~cm}^{-1}$ (Figura 4.7, A). Estudios anteriores [50] muestran que estas bandas son características de la fase $M 1$. La banda a $918 \mathrm{~cm}^{-1}$ está relacionada con el enlace $M-O_{t}(M=M o, V)\left(O_{t}\right.$, oxígeno terminal), mientras que las bandas a $870,805,715$ y $650 \mathrm{~cm}^{-1}$ probablemente estén relacionadas con las vibraciones antisimétricas del enlace puente Mo-O-X $(X=M o, T e)$ [50]. Además, en los espectros IR aparecen otras bandas de absorción a 970, 890, 750, 560, 455 $\mathrm{cm}^{-1}$ (Figura 4.7, A). Anteriormente, se ha sugerido que la fase M2 se caracteriza por la presencia de una fase intensa a $924 \mathrm{~cm}^{-1}$, dos bandas anchas a 750 y 560 $\mathrm{cm}^{-1}$, y una banda intensa a $455 \mathrm{~cm}^{-1}$ [50]. La banda a $924 \mathrm{~cm}^{-1}$ (al igual que la banda a $918 \mathrm{~cm}^{-1}$ de la fase $\left.M 1\right)$ corresponde al enlace $M-O_{t}(M=M o, V)\left(O_{t}\right.$, oxígeno terminal). La banda a $750 \mathrm{~cm}^{-1}$ puede asignarse a la vibración de tensión asimétrica de los enlaces $\mathrm{Mo}_{\mathrm{O}} \mathrm{O}_{\mathrm{b}}\left(\mathrm{O}_{\mathrm{b}}\right.$, oxígeno no coordinado al Te en los canales hexagonales), mientras que la banda a $455 \mathrm{~cm}^{-1}$ está relacionada con la tensión asimétrica del enlace $\mathrm{M}-\mathrm{O}_{\mathrm{a}}-\mathrm{M}(\mathrm{M}=\mathrm{Mo}, \mathrm{V}),\left(\mathrm{O}_{\mathrm{a}}\right.$, oxígeno coordinado al Te en los canales hexagonales) [50]. 

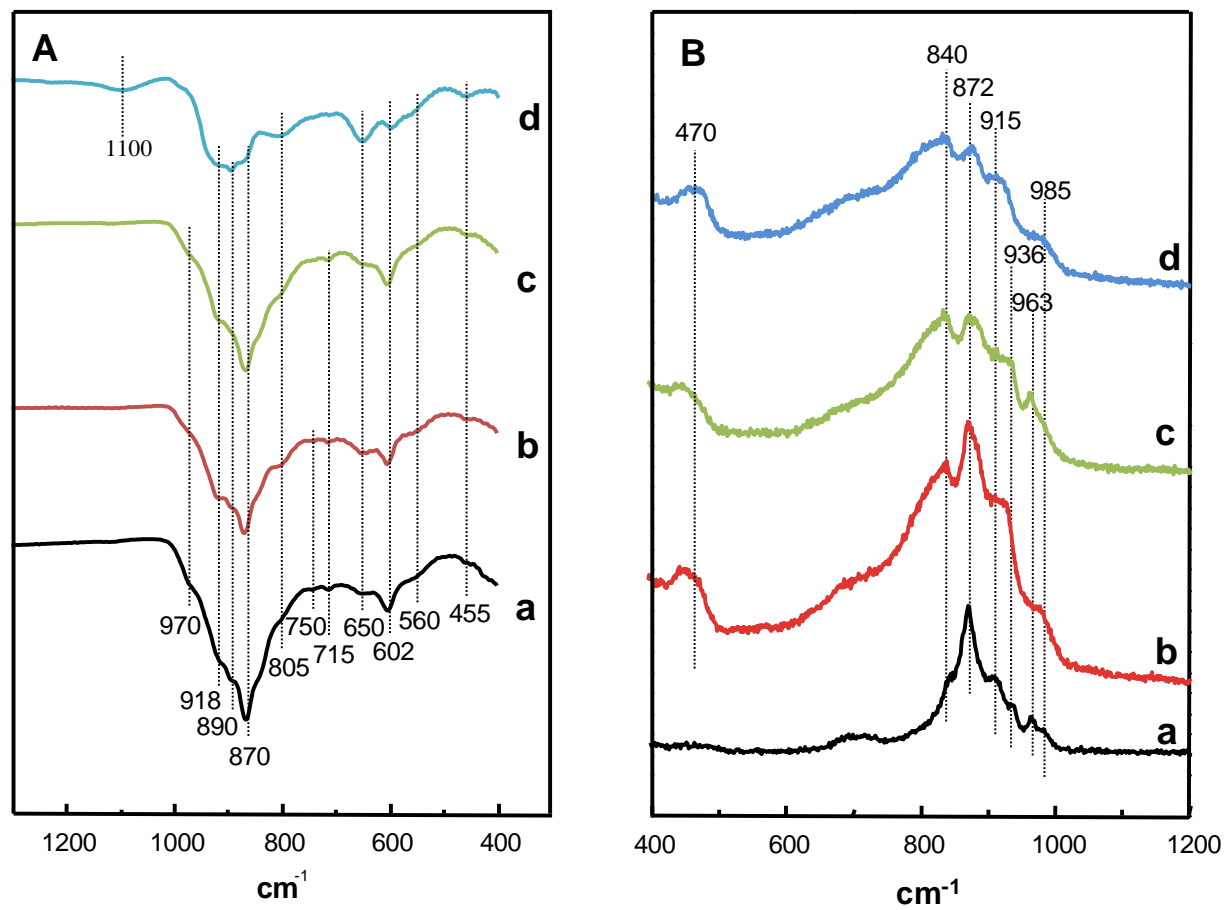

Figura 4.7. Espectros FT-IR (A) y Raman (B) de los óxidos mixtos MoVTe-X: a) Te-600; b) Te-Ca4; c) Te-Ga4; d) Te-Nb4.

Por otro lado, la presencia de $\mathrm{TeMo}_{5} \mathrm{O}_{16}$ se caracteriza por la aparición de bandas de absorción a 920, 802, 704 y $640 \mathrm{~cm}^{-1}$ con un hombro a $765 \mathrm{~cm}^{-1}$, coincidiendo con las bandas de la fase $\mathrm{M} 1$ por lo que no se descarta su presencia, mientras que la fase $\alpha-\mathrm{TeMo}_{4} \mathrm{O}_{13}$ se caracteriza por la presencia de dos bandas a 928 y $952 \mathrm{~cm}^{-1}$ con dos hombros a 890 y $980 \mathrm{~cm}^{-1}$ [51-52]. En este sentido, las dos bandas observadas a 970 y $890 \mathrm{~cm}^{-1}$ (Figura 4.7, A) en los catalizadores activados sugieren la presencia de $\alpha-\mathrm{TeMo}_{4} \mathrm{O}_{13}$.

Los espectros Raman de los materiales MoVTeO (Te-600) y Te-X4 (X = Ca, $\mathrm{Ga} \circ \mathrm{Nb}$ ) (Figura 4.7, B), presentan bandas a 989, 930, 872, 835 y $453 \mathrm{~cm}^{-1}$, similares a las encontradas para los materiales MoVTe [53-54]. Las bandas a mayores frecuencias $\left(970-990 \mathrm{~cm}^{-1}\right)$ pueden asignarse a los modos de vibración de tensión de los enlaces terminales $\mathrm{Mo}=\mathrm{O}$ y $\mathrm{V}=\mathrm{O}$, mientras que las bandas que aparecen en la región Raman a 770-880 $\mathrm{cm}^{-1}$ corresponden a los modos de tensión asimétrica de los enlaces puentes $\mathrm{M}-\mathrm{O}-\mathrm{M}(\mathrm{M}=\mathrm{Mo}, \mathrm{V})$, cuyo modo de tensión simétrica aparece a bajas frecuencias (sobre $\left.470 \mathrm{~cm}^{-1}\right)$ [55-56].

El catalizador Te-600 presenta una intensa banda de absorción a $872 \mathrm{~cm}^{-1}$ con dos hombros anchos a 840 y $915 \mathrm{~cm}^{-1}$, además de varias bandas débiles a 936, 963 y $985 \mathrm{~cm}^{-1}$, similar al obtenido por otros autores para este tipo de 
catalizadores [53, 56-57]. Al incorporar Ca o Ga en el sistema MoVTe, la banda a $872 \mathrm{~cm}^{-1}$ disminuye su intensidad relativa, definiéndose más claramente la banda a $840 \mathrm{~cm}^{-1}$. Además, la banda a $915 \mathrm{~cm}^{-1}$ se desplaza a $936 \mathrm{~cm}^{-1}$. En el caso de $\mathrm{Nb}$, el espectro Raman es similar al observado en estudios anteriores para los catalizadores MoVTeNb [43, 53, 56] con bandas a 840, 875, 820 y $985 \mathrm{~cm}^{-1}$ de menor intensidad que en el material sin $\mathrm{Nb}$ (Te-600). Además, aparece una banda ancha a $470 \mathrm{~cm}^{-1}$ que está relacionada con la presencia de la fase $\mathrm{Te}_{2} \mathrm{M}_{20} \mathrm{O}_{57}$ (fase M1) [56].

Con el fin de conocer el número y fortaleza de los centros ácidos presentes en los catalizadores estudiados se ha empleado la desorción de amoníaco a temperatura programada (TPD- $\mathrm{NH}_{3}$ ). Los espectros TPD- $\mathrm{NH}_{3}$ obtenidos para los catalizadores promovidos con $\mathrm{Ca}, \mathrm{Ga} \circ \mathrm{Nb}$, o promovidos con dos metales se muestran en la Figura 4.8. Así mismo, en la Tabla 4.4 se muestra la cantidad de amoníaco absorbida durante los experimentos de TPD- $\mathrm{NH}_{3}$ (medida en condiciones estándar), por unidad de masa o por unidad de área de cada catalizador, así como las temperaturas de los máximos de desorción de $\mathrm{NH}_{3}$ (obtenidas a partir de las curvas normalizadas de la Figura 4.8).

Tabla 4.4. Resultados $\mathrm{TPD}-\mathrm{NH}_{3}$ de los catalizadores $\operatorname{MoVTeX}(\mathrm{X}=\mathbf{C a}, \mathbf{G a} \circ \mathbf{N b})$ preparados con diferente relación X/Mo en el gel de síntesis y catalizadores MoVTeXY (X e $\mathrm{Y}=\mathrm{Ca}, \mathrm{Ga}$ y/o Nb)

\begin{tabular}{|c|c|c|c|}
\hline \multirow{2}{*}{ Catalizador } & \multicolumn{2}{|c|}{ Centros ácidos } & \multirow{2}{*}{$\mathrm{T}_{\text {máx }}\left({ }^{\circ} \mathrm{C}\right)^{\mathrm{c}}$} \\
\hline & $(\mu \mathrm{mol} / \mathrm{g})^{\mathrm{a}}$ & $\left(\mu \mathrm{mol} / \mathrm{m}^{2}\right)^{b}$ & \\
\hline Te-600 & 55.5 & 9.4 & 176.9 \\
\hline Te-Ca2 & 73.0 & 7.8 & 176.0 \\
\hline Te-Ca4 & 121.2 & 12.2 & 178.7 \\
\hline Te-Ca6 & 55.3 & 6.8 & 175.6 \\
\hline Te-Ga4 & 40.1 & 6.7 & 171.8 \\
\hline Te-Ga8 & 33.6 & 6.6 & 183.8 \\
\hline Te-Ga12 & 18.4 & 4.4 & 171.2 \\
\hline Te-Nb4 & 209.5 & 9.4 & 179.5 \\
\hline Te-Nb8 & 164.4 & 9.2 & 177.0 \\
\hline Te-Nb12 & 152.7 & 9.5 & 176.6 \\
\hline Te-Nb17 & 57.0 & 5.9 & 181.8 \\
\hline Te-Nb21 & 57.9 & 0.3 & 210.6 \\
\hline Te-Ca4Ga4 & 57.9 & 5.7 & 162.2 \\
\hline Te-Nb4Ca4 & 144.4 & 8.1 & 197.1 \\
\hline Te-Nb4Ga4 & 120.8 & 6.5 & 171.9 \\
\hline
\end{tabular}


En general, estos resultados indican que la naturaleza y la composición de los metales incorporados en el sistema MoVTeO influyen en el número de centros ácidos presentes en la superficie de los materiales. El sistema MoVTe (Te-600) presenta un número bajo de centros ácidos, mientras que la incorporación de un promotor aumenta, o disminuye, el número de centros ácidos presentes en la superficie del catalizador.

La incorporación de calcio al sistema MoVTe $(\mathrm{Ca} / \mathrm{Mo}=0.02$ ó 0.04$)$, da lugar a un aumento del número de centros ácidos, mientras que al aumentar la cantidad de $\mathrm{Ca}$ incorporado el volumen de amoníaco adsorbido es similar al catalizador sin calcio. Así, la adsorción de amoníaco por unidad de masa aumenta siguiendo la tendencia Te-600 $\approx$ Te-Ca6 $<$ Te-Ca2 $<$ Te-Ca4.

Por otro lado, todos los materiales con Ga presentan un número de centros ácidos más bajo respecto al catalizador sin promotor (Te-600), siendo menor a medida que se aumenta la cantidad de Ga en la síntesis hidrotermal.
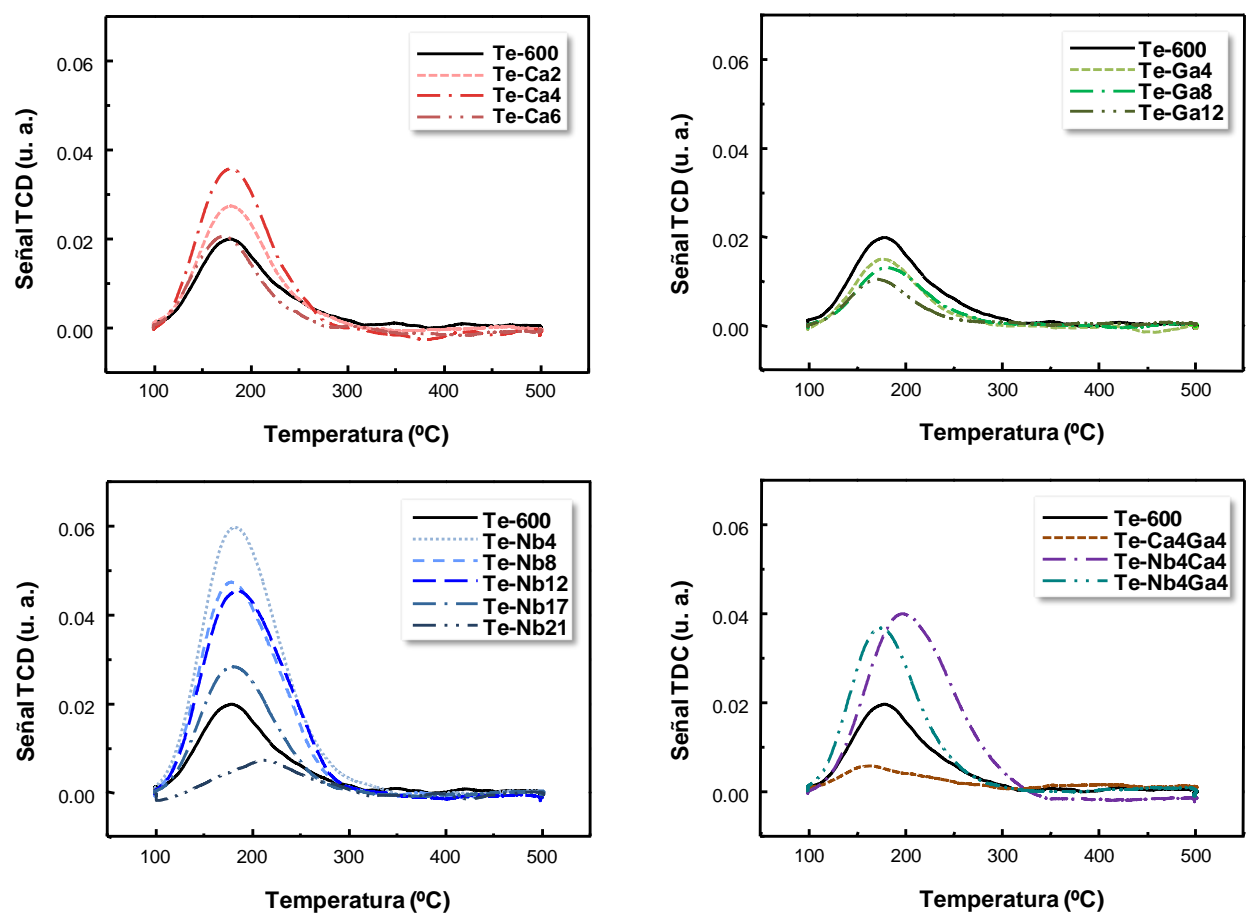

Figura 4.8. Espectro TPD-NH $\mathrm{NH}_{3}$ las muestras Te-Cax, $x=2,4$ ó 6, (arriba izda.); Te-Gax, $x=4,8$ ó 12, (arriba dcha.); Te-Nbx, $x=4,8,12,17$ ó 21, (abajo izda.); y Te-X4Y4, X e Y = $\mathrm{Ca}, \mathrm{Ga}$ o $\mathrm{Nb}$, (abajo dcha.).

Sin embargo, la incorporación de niobio aumenta el número de centros ácidos en la superficie de los catalizadores, si bien, este efecto es menos importante a medida que se aumenta la relación Nb/Mo. Por último, la incorporación conjunta 
de Ca y Ga da lugar a un material con una baja concentración de centros ácidos, mientras que los materiales con $\mathrm{Nb}$ presentan un aumento considerable del número de centros ácidos.

Aunque se observan cambios en el número de centros ácidos en la superficie del catalizador al incorporar un promotor al sistema MoVTeO, el tipo de centros ácidos parece ser el mismo en todos los casos, siendo la fortaleza ácida de dichos centros similar a la encontrada en el catalizador sin promotor.

Además, se han estudiado los estados de oxidación de los elementos en la superficie de los catalizadores Te-Ca4, Te-Ga8 y TeNb-17 empleando espectroscopía fotoelectrónica de Rayos-X (XPS) (Tabla 4.5). En todos los catalizadores estudiados, el espectro del nivel Mo $3 \mathrm{~d}$ se observa la presencia de dos componentes, con energías de enlace a 232.8 y $233.8 \mathrm{eV}$, asociadas a $\mathrm{Mo}^{6+}$ en entornos de coordinación diferentes [11].

Los espectros del nivel fundamental $2 \mathrm{p}_{3 / 2}$ del $\mathrm{V}$ para estos materiales se ajustan principalmente para dos componentes a 516.7 y $517.7 \mathrm{eV}$, las cuales están asociadas a especies $V^{4+}$ y $V^{5+}$, respectivamente [50, 58-59]. La relación atómica $\mathrm{V}^{5+} /\left(\mathrm{V}^{4+}+\mathrm{V}^{5+}\right)$ aumenta al incorporar un metal promotor al catalizador, especielmente en el caso del catalizador con Ga (Tabla 4.5).

Tabla 4.5. Resultados XPS de los catalizadores MoVTeX (X = Ca, Ga o Nb).

\begin{tabular}{|c|c|c|c|c|}
\hline \multirow{2}{*}{ Muestra } & \multicolumn{4}{|c|}{ Composición superficial $^{a}$} \\
\hline & $\mathrm{Mo} / \mathrm{V} / \mathrm{Te} / \mathrm{X} / \mathrm{O}$ & $\mathrm{Mo}_{A}{ }^{6+} / \mathrm{Mo}_{\text {total }}{ }^{\mathrm{b}}$ & $\mathrm{V}^{5+} / \mathrm{V}_{\text {total }}{ }^{\mathrm{c}}$ & $\mathrm{Te}^{6+} / \mathrm{Te}_{\text {total }}{ }^{\mathrm{d}}$ \\
\hline Te-600 & $1 / 0.25 / 0.16 / 0.00 / 5.22$ & 72.2 & 20.4 & 23.3 \\
\hline Te-Ca4 & $1 / 0.27 / 0.09 / 0.00 / 3.33$ & 79.8 & 28.5 & 13.4 \\
\hline Te-Ga8 & $1 / 0.27 / 0.16 / 0.05 / 4.07$ & 85.6 & 38.3 & 0 \\
\hline Te-Nb17 & $1 / 0.10 / 0.29 / 0.25 / 3.52$ & 89.4 & 32.8 & 0 \\
\hline
\end{tabular}

${ }^{\mathrm{a}}$ Composición superficial determinada por XPS; ${ }^{\circ} \mathrm{Mo}_{\mathrm{A}}{ }^{6+}(\mathrm{BE}=232.8 \mathrm{eV}), \mathrm{Mo}_{\mathrm{B}}{ }^{6+}(\mathrm{BE}=233.8 \mathrm{eV})$;

${ }^{\mathrm{c}} \mathrm{V}^{5+}(\mathrm{BE}=517.67 \mathrm{eV}), \mathrm{V}^{4+}(\mathrm{BE}=516.65 \mathrm{eV}) ;{ }^{\mathrm{d}} \mathrm{Te}^{6+}(\mathrm{BE}=577.7 \mathrm{eV}), \mathrm{Te}^{4+}(\mathrm{BE}=576.4 \mathrm{eV})$;

${ }^{e} \mathrm{O}_{\mathrm{A}}(\mathrm{BE}=530.6 \mathrm{eV}), \mathrm{O}_{\mathrm{B}}(\mathrm{BE}=532.3 \mathrm{eV})$.

Las mayores diferencias de composición superficial entre los catalizadores corresponden al espectro del nivel fundamental $3 \mathrm{~d}_{5 / 2}$ del Te. En el catalizador $\sin$ promotor, el espectro Te $3 d_{5 / 2}$ muestra dos componentes a 577.7 y $576.4 \mathrm{eV}$, asociados a la presencia de especies $\mathrm{Te}^{6+}$ y $\mathrm{Te}^{4+}$, respectivamente [60]. Ambos estados de oxidación están presentes en la superficie del catalizador con $\mathrm{Ca}$, aunque muestra una menor proporción de $\mathrm{Te}^{6+}$. Sin embargo, en los catalizadores promovidos con $\mathrm{Ga} \circ \mathrm{Nb}$ el espectro $\mathrm{Te} 3 \mathrm{~d}_{5 / 2}$ se observa una sola componente relacionada con la presencia de cationes $\mathrm{Te}^{4+}$ (Tabla 4.5). 


\subsubsection{Resultados catalíticos para la Oxidación de Propano con catalizadores promovidos con $\mathrm{Ca}, \mathrm{Ga}$ o $\mathrm{Nb}$}

En la Tabla 4.6 se presentan comparativamente los resultados catalíticos durante la oxidación de propano con catalizadores MoVTe-X $(X=\mathrm{Ca}, \mathrm{Ga} \circ \mathrm{Nb})$ preparados con diferente relación X/Mo en el gel de síntesis, así como para el catalizador Te-600. Los principales productos obtenidos en la reacción son el

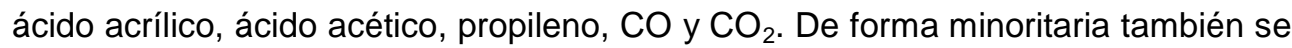
observan acetona y acroleína.

Tabla 4.6. Oxidación de propano con catalizadores Te-600, Te-Xx y Te-X4Y4 (X e Y = Ca, $\mathrm{Ga} \circ \mathrm{Nb})^{\mathrm{a}}$.

\begin{tabular}{|c|c|c|c|c|c|c|}
\hline \multirow{2}{*}{ Catalizador } & \multirow{2}{*}{ Conv.(\%) } & \multicolumn{5}{|c|}{ 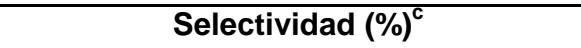 } \\
\hline & & AA & $\mathrm{C}_{3} \mathrm{H}_{6}$ & HAc & $\mathrm{CO}$ & $\mathrm{CO}_{2}$ \\
\hline Te-600 & 19 & 25 & 13 & 15 & 21 & 25 \\
\hline Te-Ca2 & 28 & 37 & 8 & 11 & 20 & 24 \\
\hline Te-Ca4 & 37 & 37 & 6 & 14 & 19 & 24 \\
\hline Te-Ca6 & 26 & 17 & 9 & 13 & 27 & 33 \\
\hline Te-Ga4 & 14 & 47 & 17 & 6 & 15 & 15 \\
\hline Te-Ga8 & 14 & 50 & 17 & 6 & 13 & 13 \\
\hline Te-Ga12 & 9 & 42 & 28 & 5 & 12 & 12 \\
\hline Te-Nb4 & 49 & 23 & 3 & 15 & 25 & 35 \\
\hline Te-Nb8 & 45 & 32 & 4 & 11 & 25 & 29 \\
\hline Te-Nb12 & 42 & 42 & 4 & 9 & 21 & 22 \\
\hline Te-Nb17 & 21 & 55 & 13 & 5 & 13 & 13 \\
\hline Te-Nb21 & 8 & 25 & 26 & 6 & 23 & 18 \\
\hline Te-Ca4Ga4 & 7 & 39 & 36 & 3 & 11 & 9 \\
\hline Te-Nb4Ca4 & 50 & 23 & 3 & 13 & 27 & 33 \\
\hline Te-Nb4Ga4 & 26 & 50 & 8 & 9 & 16 & 15 \\
\hline
\end{tabular}

Los resultados de la Tabla 4.6 sugieren que la selectividad a ácido acrílico depende de la naturaleza y la composición del metal incorporado. En general, la incorporación de $\mathrm{Ca}$ o Ga mejora la selectividad a ácido acrílico (con un máximo de $50 \%$ para el catalizador Te-Ga8). En el caso de $\mathrm{Nb}$, la selectividad a ácido acrílico aumenta al aumentar la relación $\mathrm{Nb} / \mathrm{Mo}$ en el gel de síntesis. Por otro lado, se observa una reducción importante en la formación de $\mathrm{CO}$ y $\mathrm{CO}_{2}$, cuyas selectividades siguen una tendencia opuesta a la observada para la selectividad a ácido acrílico. 
La Figura 4.9 muestra la variación de la selectividad a ácido acrílico con la conversión de propano durante la oxidación de propano con catalizadores MoVTe$\mathrm{X}(\mathrm{X}=\mathbf{C a}, \mathbf{G a} \circ \mathbf{N b})$ preparados con diferente relación X/Mo. En este punto, se debe señalar que el ácido acrílico es un producto secundario, y, por tanto, la curva de la selectividad frente a conversión da una idea sobre la velocidad de formación de ácido acrílico (a baja conversión de propano) y la estabilidad del ácido acrílico (a alta conversión de propano).
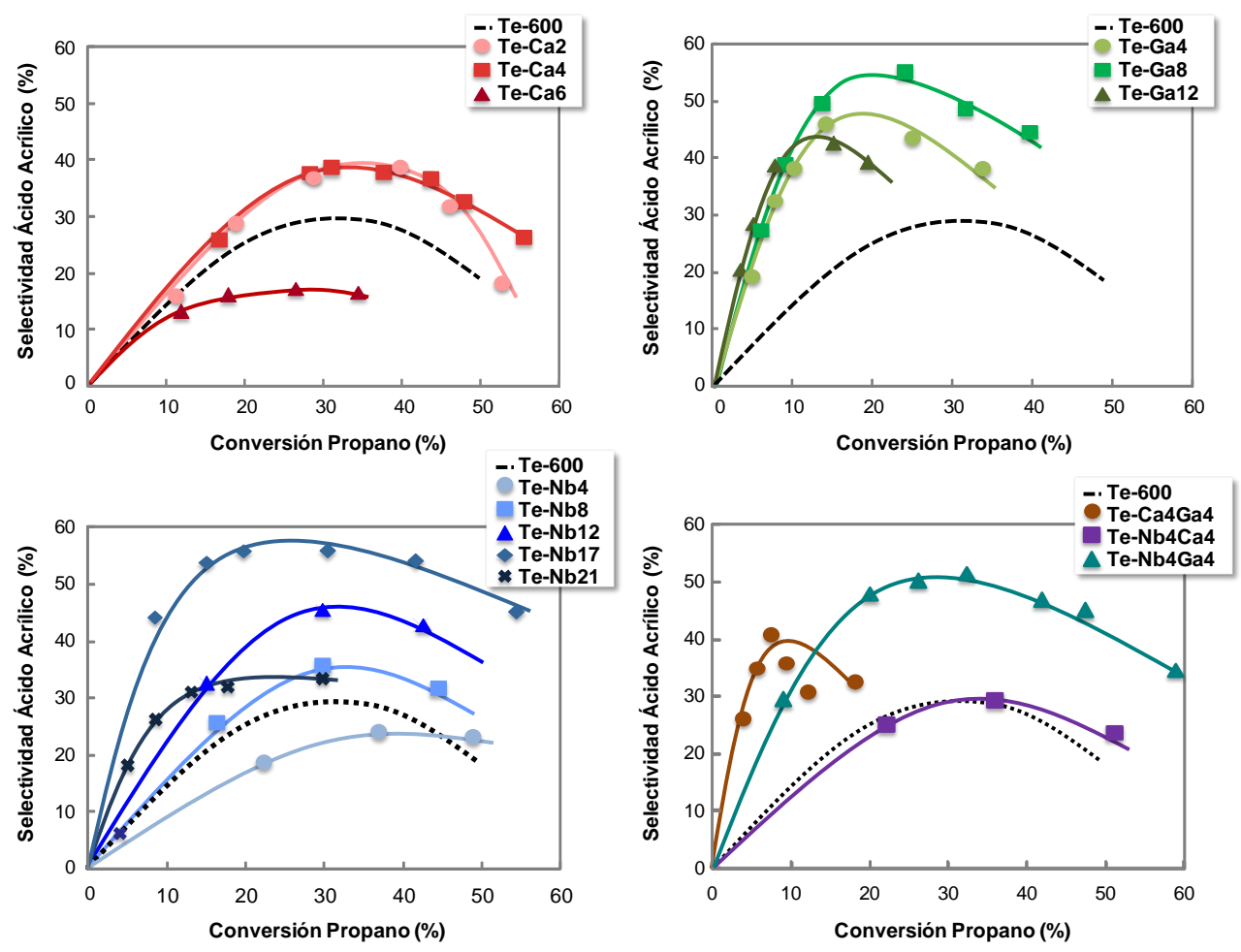

Figura 4.9. Variación de la selectividad a acido acrílico con la conversión de propano durante la oxidación de propano con catalizadores MoVTe-X (X = Ca, Ga o Nb) con distinta relación X/Mo; y catalizadores MoVTe-XY (X e Y = Ca, Ga o Nb).

En este caso, los catalizadores con Ca presentan una velocidad inicial de formación de ácido acrílico similar al catalizador sin promotor. Sin embargo, la selectividad a ácido acrílico para una conversión del $40 \%$ sugiere que el ácido acrílico se descompone más lentamente en el catalizador con $\mathrm{Ca}$ que en el catalizador sin promotor.

En el caso de los catalizadores con $\mathrm{Ga}$, el comportamiento catalítico es diferente. Así, en todos los casos, se observa una mayor formación de ácido acrílico a baja conversión de propano, lo que sugiere que existe una rápida transformación de propileno a ácido acrílico. Sin embargo, el máximo de 
selectividad a ácido acrílico cambia con el contenido de Ga. Así, la máxima selectividad se observa para una conversión de propano del 10\% en el catalizador Te-Ga12; mientras que en el catalizador Te-Ga8, la selectividad máxima se observa para una conversión de propano del $20 \%$. Esto sugiere que la concentración de $\mathrm{Ga}$ tiene un efecto claro en la estabilidad del ácido acrílico, siendo mayor en el caso del catalizador Te-Ga8.

En el caso de los catalizadores con $\mathrm{Nb}$ se observa un mecanismo promotor similar al del $\mathrm{Ca}$, a baja relación $\mathrm{Nb} / \mathrm{Mo}$ en el gel de síntesis, mientras que la curva de selectividad a ácido acrílico para materiales con relaciones $\mathrm{Nb} / \mathrm{Mo}$ mayores (0.12-0.17) muestra un comportamiento similar a los catalizadores con Ga. Así, el catalizador MoVTeNb preparado con una relación $\mathrm{Nb} / \mathrm{Mo}=0.17$ en el gel de síntesis ha demostrado ser el catalizador más efectivo, siendo la relación empleada normalmente en este tipo de materiales [19-20, 42-43].

Por otra parte, los resultados catalíticos de los catalizadores con dos promotores no parecen mostrar un efecto sinérgico, y los resultados de selectividad a ácido acrílico fueron inferiores a los obtenidos con los materiales con $\mathrm{Ca}, \mathrm{Ga}$ o $\mathrm{Nb}$. Sin embargo, cabe señalar el comportamiento catalítico del catalizador Te-Ga4Nb4, similar al observado en materiales con niobio para relaciones $\mathrm{Nb} / \mathrm{Mo}$ mayores $(0.12-0.17)$.

\subsubsection{Estudio mediante microscopía de alta resolución (HREM) de los catalizadores promovidos con Ca ó Ga}

Los catalizadores MoVTeO más efectivos, aquellos promovidos con $\mathrm{Ca}$ ó $\mathrm{Ga}$, es decir, los preparados con una relación $\mathrm{Ca} / \mathrm{Mo}=0.04(\mathrm{Te}-\mathrm{Ca} 4) \circ \mathrm{Ga} / \mathrm{Mo}=0.08$ (Te-Ga8), se han analizado mediante microscopía de alta resolución (HREM), a fin de caracterizar la incorporación de $\mathrm{Ca}$ o $\mathrm{Ga}$ en los materiales. En el caso de la muestra Te-Ca4, no se han encontrado evidencias de la incorporación de Ca en el material, por lo que nos centraremos en más detalle en los resultados obtenidos en el caso del catalizador promovido con $\mathrm{Ga}$ (Te-Ga8).

El análisis por HREM de la muestra Te-Ga8 indica principalmente la presencia de la fase $\mathrm{M} 1, \mathrm{Te}_{2} \mathrm{M}_{20} \mathrm{O}_{57}(\mathrm{M}=\mathrm{Mo}, \mathrm{V})$, junto con la presencia minoritaria de cristales de $\mathrm{VOMoO}_{4}$. Cabe destacar que después de un examen exhaustivo de la muestra sólo se ha encontrado algún cristal aislado de fase $\mathrm{M} 2, \mathrm{Te}_{0.33} \mathrm{Mo}_{3.33}(\mathrm{M}$ $=\mathrm{Mo}, \mathrm{V})$, por lo que si esta fase está presente en la composición cristalina del material debe estar en una proporción mínima. Estos resultados están de acuerdo con los resultados observados por DRX.

Un aspecto importante de los cristales de la fase $\mathrm{M} 1$ se refiere a su morfología, presentando una forma característica tipo bastón (o aguja) con 
longitudes variables entre 0.5 y $2 \mu \mathrm{m}$. Esta morfología se asocia a su crecimiento preferencial a lo largo de los planos $a b o$ ac de la estructura. Las imágenes como las mostradas en las Figura 4. 10 (a) y (b) se encuentran habitualmente para esta fase cristalina. La Figura 4.10 (a) corresponde a la proyección [010], mientras que la micrografía de la Figura 4.10 (b) corresponde al eje de zona [011]. Puede observarse que la dirección preferente de crecimiento del cristal es paralela al eje $c$ de la estructura.
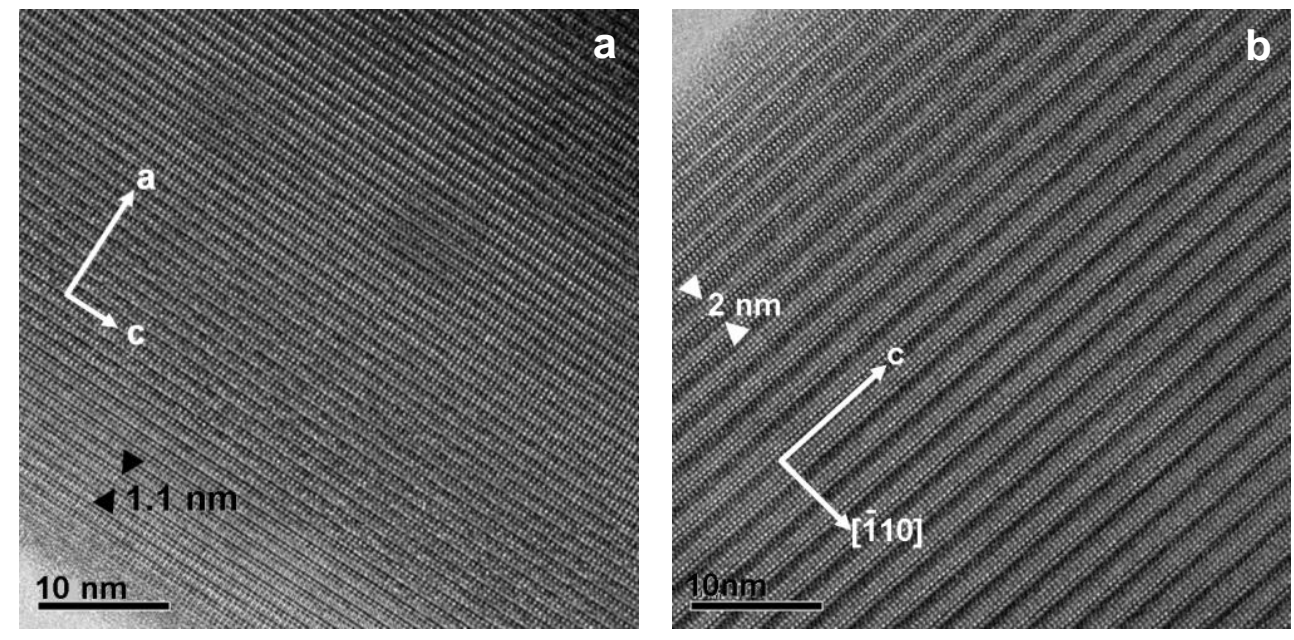

Figura 4.10. Micrografías HREM de un cristal de la fase $\mathrm{Te}_{2} \mathrm{M}_{20} \mathrm{O}_{57}$ tomadas a lo largo de los ejes de zona (a) [010] y (b) [011].

El análisis químico de los cristales se ha llevado a cabo mediante microanálisis EDS con rayos $X$. Los resultados de microanálisis XEDS efectuado cristal a cristal muestran que no tiene lugar la formación de ninguna fase secundaria constituida por galio como elemento mayoritario. Entre las fases cristalinas presentes en el catalizador Te-Ga8, el galio introducido en el gel de síntesis se incorpora únicamente a los cristales de la fase $\mathrm{M} 1$, observándose cristales de la fase M1 con un 2.8 - 4\% de Ga (porcentaje atómico). La composición atómica de la fase $\mathrm{M} 1$ es prácticamente constante y corresponde a una estequiometria aproximada $\mathrm{Te}_{0.5}\left(\mathrm{Mo}_{0.65} \mathrm{~V}_{0.24} \mathrm{Ga}_{0.02}\right)_{5} \mathrm{O}_{14}$.

La capacidad del galio (III) para adoptar coordinación tetraédrica [61] y octaédrica [62] facilita su incorporación al esqueleto estructural de la fase M1. El tamaño de las especies $\mathrm{Ga}^{3+}$ en coordinación tetraédrica $(62 \mathrm{pm})$ u octaédrica (76 $\mathrm{pm})$ es adecuado para sustituir al $\mathrm{Mo}^{6+}(73 \mathrm{pm})$ o a especies vanadio, tales como $\mathrm{V}^{5+}(68 \mathrm{pm}) \circ \mathrm{V}^{4+}(72 \mathrm{pm})$; y demasiado pequeño para competir con el teluro $\mathrm{y}$ situarse en los túneles hexagonales. Por otro lado, la flexibilidad composicional de la estructura de la fase M1 [63] hace posible que su incorporación pueda ir 
acompañada de una reducción parcial del contenido de oxígeno sin que se desmorone la base de la estructura. Todos estos hechos, permiten asumir la incorporación de galio (III) en la estructura de la fase M1 por sustitución parcial de las especies $\mathrm{V}^{\mathrm{n+}} / \mathrm{Mo}^{\mathrm{n+}}$.

\subsubsection{Discusión de los resultados}

\subsubsection{Efecto de Ca como promotor}

La incorporación de $\mathrm{Ca}$ al sistema catalítico MoVTeO aumenta la actividad catalítica y selectividad a ácido acrílico durante la oxidación de propano en comparación con el catalizador sin metal, Te-600 (Figura 4.4). Sin embargo, la actividad catalítica específica (teniendo en cuenta el área superficial de los materiales) no se ve afectada por la presencia de Ca. Por otro lado, el efecto observado en la selectividad a ácido acrílico depende de la composición de Ca en el catalizador, observándose un máximo de selectividad a ácido acrílico para una relación $\mathrm{Ca} / \mathrm{Mo}$ de 0.04 (Figura 4.9). Con relaciones $\mathrm{Ca} / \mathrm{Mo}$ mayores en el gel de síntesis se produce una pérdida de selectividad a ácido acrílico.

Los resultados de caracterización por DRX, FT-IR y Raman sugieren que la incorporación de calcio podría favorecer una menor descomposición de la fase M1 durante el tratamiento térmico, en comparación con el catalizador sin promotor. No obstante, los resultados de composición química del material activado, determinados por ICP-AES (Tabla 4.2), muestran una baja incorporación de $\mathrm{Ca}$ cuando la relación atómica $\mathrm{Ca} / \mathrm{Mo}$ en el gel de síntesis es 0.02 ó 0.04 . Sin embargo, el microanálisis efectuado mediante microscopía de alta resolución descarta la incorporación de Ca en los materiales. Del mismo modo, el análisis de la composición superficial del catalizador Te-Ca4 por XPS muestra la ausencia de calcio en la superficie (Tabla 4.5). En este sentido, no se puede asegurar la incorporación de $\mathrm{Ca}$ en la fase M1 de estos materiales.

Además, la incorporación de cationes de metal alcalinotérreos, como el calcio, debería favorecer la eliminación de centros ácidos (Brönsted o Lewis), cuya presencia favorece la formación de ácido acético y óxidos de carbono [22]. Sin embargo, los resultados de TPD- $\mathrm{NH}_{3}$ (Tabla 4.4 y Figura 4.8) muestran un mayor número de de centros ácidos en la superficie de los catalizadores Te-Ca2 y TeCa4, en comparación con el catalizador sin promotor Te-600.

En este sentido, se puede observar que existe una relación directa entre el número de centros ácidos por unidad de superficie (Tabla 4.4) y la conversión de propano observada en la oxidación selectiva de propano (Tabla 4.6). Así mismo, la selectividad a ácido acrílico también se podría ver inicialmente favorecida por un mayor número de centros ácidos. Esto puede ser debido a que la presencia de 
centros ácidos podría favorecer la desorción del ácido acrílico durante la reacción, evitando reacciones consecutivas y favoreciendo una mayor selectividad a ácido acrílico. De hecho, en la Figura 4.9 se observa que los catalizadores con $\mathrm{Ca}$ la descomposición del ácido acrílico (a altas conversiones de propano) es menor que en el catalizador sin promotor.

Por otro lado, puede existir una influencia del anión de la sal empleada para la incorporación de $\mathrm{Ca}$ en la síntesis hidrotermal. En el caso de $\mathrm{Ca}$ se ha empleado carbonato cálcico, cuya presencia se ha determinado por FT-IR en el material precursor antes de la activación. La presencia de especies carbonato durante el tratamiento térmico podría influir tanto en la descomposición parcial de la fase M1 como en el número de centros ácidos en la superficie del catalizador. Aunque no se ha incluido en el apartado de resultados, la incorporación de calcio se ha estudiado empleando diferentes sales de calcio en la síntesis hidrotermal, obteniendo los mejores resultados con carbonato cálcico. El empleo de sulfato cálcico da lugar a una mayor presencia de las fases cristalinas $\mathrm{MoO}_{3}$ y $\mathrm{M} 2$ en el catalizador activado, con un comportamiento catalítico muy similar al catalizador sin metal (Te-600) aumentando ligeramente la selectividad a ácido acrílico.

En el caso del catalizador preparado con una relación atómica $\mathrm{Ca} / \mathrm{Mo}=0.06$ en el gel de síntesis, los análisis químicos sugieren la incorporación de Ca en el material $(\mathrm{Ca} / \mathrm{Mo}=0.04$ en el catalizador activado, Tabla 4.2). Sin embargo, los resultados catalíticos muestran una menor conversión y selectividad a ácido acrílico que el catalizador sin promotor (Figura 4.9). Si se produce una incorporación de calcio en la fase $\mathrm{M} 1$, los cationes $\mathrm{Ca}^{2+}$ podrían incorporarse en los canales hexagonales de la fase cristalina en sustitución parcial del $\mathrm{Te}^{4+}$, o bien en los canales heptagonales donde supuestamente se encuentran localizados los centros activos para la oxidación de propano [16, 18, 64]. En ambos casos, la incorporación de calcio en la fase M1 daría lugar a la pérdida de centros activos en la oxidación de propano, disminuyendo sus propiedades catalíticas.

\subsubsection{Efecto de Nb como promotor}

Los resultados de caracterización (DRX, FT-IR y Raman) indican que la incorporación de $\mathrm{Nb}$ en la síntesis estabiliza la presencia de la fase $\mathrm{M} 1$, en comparación con el catalizador sin niobio, Te-600. En efecto, en los catalizadores con $\mathrm{Nb}$ se observan principalmente las fases cristalinas M1 y M2, mientras que en el catalizador sin promotor aparecen otras fases cristalinas durante el tratamiento térmico. Este efecto se produce aunque se haya incorporado niobio en pequeñas cantidades (como en el caso del catalizador Te-Nb4). Además, a medida que se aumenta la relación atómica $\mathrm{Nb} / \mathrm{Mo}$ se observa una menor formación de la fase M2, presentando principalmente fase M1 (Figura 4.5). 
La incorporación de $\mathrm{Nb}$ en los catalizadores MoVTeO tiene un efecto positivo en las propiedades catalíticas, aún cuando se incorpora en pequeñas cantidades en el gel de síntesis. Así, con una baja relación $\mathrm{Nb} / \mathrm{Mo}$ se favorece un aumento de la actividad catalítica de los materiales (catalizador Te-Nb4, Tabla 4.6). Con relaciones $\mathrm{Nb} / \mathrm{Mo}$ mayores se observa un aumento destacable de la selectividad a ácido acrílico. De esta forma, al aumentar la relación atómica Nb/Mo en el gel de síntesis se observa un máximo en el rendimiento a ácido acrílico para una relación $\mathrm{Nb} / \mathrm{Mo}=0.17$ (Figura 4.13).

Sin embargo, el comportamiento catalítico durante la oxidación de propano de los catalizadores con niobio se puede relacionar no sólo con la presencia de la fase M1, sino también con el área superficial y el número de centros ácidos que presentan estos materiales. Así, la incorporación de cantidades pequeñas de niobio (Te-Nb4) da lugar a un aumento del área superficial y una mayor estabilidad de la fase M1 (aunque con presencia de fase M2) en comparación con el catalizador sin $\mathrm{Nb}, \mathrm{Te}-600$. Esto le confiere una mayor actividad catalítica, además de un aumento del número de centros ácidos, favoreciendo las reacciones de oxidación no selectiva (formación de ácido acético y óxidos de carbono) (Tabla 4.6). Al aumentar la cantidad de niobio incorporado al material se observa una disminución del área superficial, obteniendo una conversión de propano menor.

El aumento de selectividad a ácido acrílico encontrado en catalizadores con niobio es similar al observado anteriormente [19-20, 22-23, 45-46, 65], en los que la presencia de $\mathrm{Nb}$ suprime la combustión de ácido acrílico, mejorando la selectividad a ácido acrílico [14]. Así mismo, la incorporación de niobio en el gel de síntesis favorece una disminución del número de centros ácidos Brönsted y Lewis, los cuales están relacionados con la formación de óxidos de carbono por reacciones paralelas y consecutivas [22-23].

Por otro lado, se observa una morfología diferente entre los catalizadores con niobio en comparación con el catalizador sin niobio (Figura 4.6, d). Así, el tamaño de partícula de la fase M1 es menor que en los catalizadores sin Nb. Esto se debe a la presencia de niobio ( $y$ de aniones oxalato) durante la síntesis hidrotermal de los materiales, que podría ralentizar la cristalización impidiendo la formación de agujas largas en el eje [011] de las partícula [66]. A medida que se aumenta la relación atómica $\mathrm{Nb} / \mathrm{Mo}$ se aumenta también la concentración de iones oxalato presentes en la síntesis hidrotermal, favoreciendo un estado de oxidación medio del catalizador menor, lo que favorece una mayor selectividad a ácido acrílico. En este sentido, se observa un máximo para el catalizador preparado con una relación atómica $\mathrm{Nb} / \mathrm{Mo}=0.17$.

Sin embargo, la selectividad a ácido acrílico obtenida durante la oxidación de propano con catalizadores con niobio es ligeramente menor a los resultados 
publicados para relaciones en el gel de síntesis similares, $\mathrm{Nb} / \mathrm{Mo}=0.12$ ó 0.17 [20, $42-43,67]$. Este hecho puede deberse al empleo de óxido de teluro (IV) en la síntesis hidrotermal, habitual en la en la síntesis de materiales MoVTeO [42, 44, 68-70], en lugar de un precursor de $\mathrm{Te}^{6+}$ (como ácido telúrico), que normalmente se emplea en la síntesis de catalizadores con niobio. En este sentido, es conocido que para la preparación de materiales con o sin niobio, el empleo de diferentes fuentes de Te favorece la formación de materiales con diferentes estructuras cristalinas y, por lo tanto, diferentes comportamientos catalíticos [44, 68, 71-72]. No obstante, cabe señalar que, en nuestro caso, se obtiene un aumento significativo tanto de la actividad catalítica como de la selectividad a ácido acrílico. Así, los resultados obtenidos durante este estudio con catalizadores preparados con $\mathrm{Te}^{4+}$ y una relación $\mathrm{Nb} / \mathrm{Mo}$ de 0.17 , son superiores a los resultados publicados anteriormente de catalizadores MoVTeNb preparados con $\mathrm{Te}^{4+}[44]$.

En la síntesis de catalizadores MoVTeNbO empleando un reactivo de $\mathrm{Te}^{6+}$ hay que tener en cuenta que los iones oxalato presentes en la síntesis de los materiales MoVTeNb son capaces de reducir el $\mathrm{Te}^{6+}$ proporcionando el $\mathrm{Te}^{4+}$ necesario para la formación de la estructura M1 [12, 44, 68]. Sin embargo, en la síntesis hidrotermal donde se emplea un reactivo de $\mathrm{Te}^{4+}$, la incorporación de $\mathrm{Nb}$ (como oxalato de niobio) favorece la presencia de iones oxalato en el gel de síntesis lo que puede favorecer una mayor reducción de otras especies, en especial: $\mathrm{Te}^{4+}$ a $\mathrm{Te}^{0}\left(\mathrm{E}_{0}=+0.57 \mathrm{eV}\right) \mathrm{y} / \mathrm{o} \mathrm{Mo}{ }^{6+} \mathrm{a} \mathrm{Mo}^{5+}\left(\mathrm{E}_{0}=+0.43 \mathrm{eV}\right)$. Es importante señalar que, según un estudio de nuestro grupo recientemente publicado [73], la presencia de altos contenidos de oxalato favorece la reducción excesiva de $T e^{6+} 0$ $\mathrm{Te}^{4+}$ a teluro metálico $\left(\mathrm{Te}^{0}\right)$, lo que provoca pérdidas considerables de teluro en el sólido durante la etapa de activación térmica, y la consiguiente formación de fases amorfas pobres en teluro. Así, el exceso de oxalato en la síntesis del catalizador preparado con una relación atómica $\mathrm{Nb} / \mathrm{Mo}=0.21$ reduce el $\mathrm{Te}^{4+}$ a $\mathrm{Te}^{0}$ (presente en el material sin activar) dando lugar a una menor formación de la fase M1 que conlleva a una baja actividad catalítica durante la oxidación de propano.

\subsubsection{Efecto de Ga como promotor}

En la Figura 4.11 se muestra la variación de la actividad catalítica y de la selectividad a ácido acrílico (a una conversión de propano del $20 \%$ ) con la relación Ga/Mo en el gel de síntesis obtenida durante la oxidación de propano con catalizadores MoVTeO promovidos con galio.

En todos los casos, se observa que la actividad catalítica en los catalizadores con $\mathrm{Ga}$ disminuye a medida que aumenta la relación Ga/Mo. Sin embargo, la selectividad a ácido acrílico aumenta inicialmente con el contenido de $\mathrm{Ga}$ en el gel de síntesis, presentando un máximo de selectividad a ácido acrílico para el catalizador preparado con una relación atómica Ga/Mo de 0.08 (Figura 4.11). Con mayores cantidades de $\mathrm{Ga}$, la selectividad a ácido acrílico disminuye. 


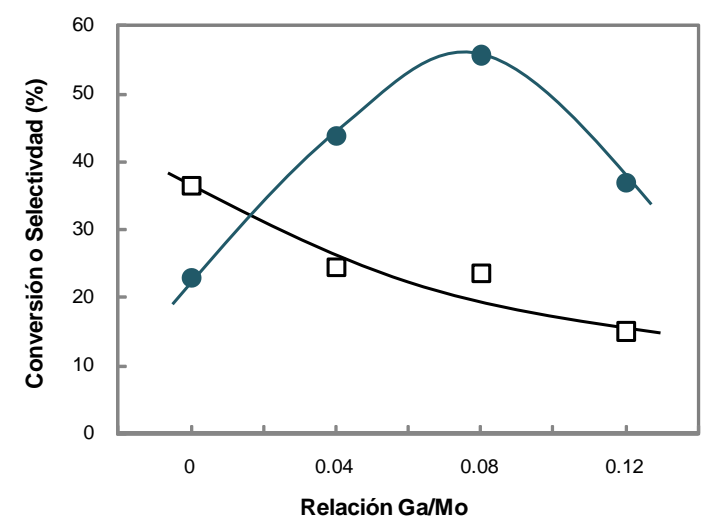

Figura 4.11. Variación de la conversión de propano ( $\square$ ) y la selectividad a ácido acrílico (•) obtenida durante la oxidación de propano con catalizadores MoVTeGaO con diferente relación $\mathrm{Ga} / \mathrm{Mo}$. Conversión de propano obtenida a $380^{\circ} \mathrm{C}$ y tiempo de contacto $400 \mathrm{~g}$ cat $\mathrm{h}$ mol ${ }_{\text {сзн }}{ }^{-1}$; selectividad a ácido acrílico para una conversión de propano de $20 \%$.

La modificación del comportamiento catalítico de estos materiales debería estar directamente relacionada con la incorporación de galio a la fase M1. De acuerdo con los resultados de HREM, la incorporación de Ga en la fase M1 es posible, siendo la única fase cristalina en la que se incorpora y observándose cristales de la fase M1 con y sin Ga. Por otro lado, en los resultados de caracterización por DRX, FT-IR, Raman o HREM de los catalizadores MoVTeGa, no se evidencia la presencia de óxido de galio en la superficie de los materiales. Así mismo, no se ha encontrad evidencia de la formación de otras fases cristalinas constituidas principalmente por galio en los microanálisis por XEDS.

Así, la presencia de Ga en la fase M1 podría influir en las propiedades físicoquímicas de dicha fase. En este sentido, la fase M1 con Ga presenta una mayor estabilidad durante el tratamiento térmico (Figura 4.4), un menor tamaño de cristal (Figura 4.6), una menor cantidad de centros ácidos (Tabla 4.4) y cambios más significativos en los estados de oxidación de los elementos presentes en la superficie del catalizador (Tabla 4.5). Resulta interesante resaltar las diferencias encontradas en composición superficial, obtenidas por XPS, para el catalizador con $\mathrm{Ga}$ y el catalizador sin promotor (Tabla 4.5). En este sentido, el catalizador con Ga presenta únicamente especies $\mathrm{Te}^{4+}$ en su superficie, además de un mayor contenido de $\mathrm{V}^{5+}$. Estos cambios observados en la composición y en el estado de oxidación de los elementos de la superficie del catalizador son muy similares a los observados en catalizadores con $\mathrm{Nb}$ [11]. Estas diferencias sugieren que la incorporación de Ga en el gel de síntesis puede producir (como ocurre en el caso de $\mathrm{Nb}$ ) cambios en las características superficiales de los catalizadores que serían responsables de los cambios observados en las propiedades catalíticas de estos materiales. 
Sin embargo, estos cambios no pueden explicar, por sí solos, las propiedades catalíticas observadas con los catalizadores promovidos con galio. La incorporación de galio al catalizador favorece una mayor formación de ácido acrílico (a baja conversión de propano) seguido de una pérdida de selectividad a ácido acrílico (a altas conversiones de propano) (Figura 4.9). Este hecho sugiere que el Ga incorporado en la fase M1 podría participar como un centro activo en la oxidación selectiva de propano, modificando el mecanismo de reacción, favoreciendo la oxidación de propileno a ácido acrílico y la descomposición de ácido acrílico $\left(\mathrm{a} \mathrm{CO}\right.$ y $\left.\mathrm{CO}_{2}\right)$ a mayor conversión de propano.

En la literatura se pueden encontrar catalizadores promovidos con $\mathrm{Ga}$ donde el Ga actúa como un centro activo en determinadas reacciones. Este es el caso de zeolitas promovidas con $\mathrm{Ga}$, como es la zeolita Ga-ZSM-5, empleada en la deshidrogenación o aromatización de alcanos ligeros [74-79]. Es generalmente aceptado que el papel de los centros de galio en las reacciones de deshidrogenación (o aromatización) es la activación del enlace C-H del alcano [7576]. Sin embargo, el galio también puede favorecer la activación de las olefinas y productos de reacción intermedios, mejorando las propiedades catalíticas en la reacción de aromatización [77-79].

En nuestro caso, no se observa un incremento de la actividad catalítica con los catalizadores promovidos con $\mathrm{Ga}$, lo que sugiere que las especies de $\mathrm{Ga}$ no participarían directamente en la activación del enlace $\mathrm{C}-\mathrm{H}$ de propano. Por otro lado, es conocido que la primera etapa de la oxidación de propano es la formación de propileno por deshidrogenación oxidativa. La activación de propileno formado podría también tener lugar en los centros de galio de la fase M1, favoreciéndose la posterior oxidación parcial de propileno a ácido acrílico. Sin embargo, el Ga incorporado en la fase M1 también sería capaz de activar el ácido acrílico (a altas conversiones de propano) favoreciendo su oxidación total (a $\mathrm{CO}$ y $\mathrm{CO}_{2}$ ), y disminuyendo su selectividad.

Aún así, el galio parece ser un promotor interesante para los catalizadores del tipo MoVTeO. En efecto, los catalizadores con galio alcanzan selectividades a ácido acrílico relativamente altas (del 55\% para una conversión de propano del $25 \%$ con el catalizador Te-Ga8) que sólo se habían descrito anteriormente con los catalizadores MoVTeNbO.

Una posible mejora de este catalizador es la incorporación de $\mathrm{Ca}$ ó $\mathrm{Nb}$ que parecen estabilizar al ácido acrílico a altas conversiones de propano (Figura 4.9). Sin embargo, la incorporación de Ca y Ga en el sistema MoVTeO (Te-Ca4Ga4), da lugar a un catalizador menos efectivo que el catalizador promovido sólo con galio. Así, se observa una menor actividad catalítica en comparación con el catalizador sin metal o los respectivos catalizadores Te-Ca4 y Te-Ga4. Respecto a 
la selectividad a ácido acrílico, el comportamiento es muy similar al observado con catalizadores con Ga pero alcanzando el máximo de selectividad a menor conversión de propano (conversión menor al 10\%) (Figura 4.9).

Por otro lado, la incorporación de $\mathrm{Ga}$ y $\mathrm{Nb}$ (Te-Ga4Nb4) tiene un efecto positivo en las propiedades catalíticas para la oxidación de propano. En este sentido, la presencia de Ga parece favorecer altos valores de selectividad a ácido acrílico a bajas conversiones de propano, mientras que el $\mathrm{Nb}$ estabiliza el ácido acrílico a altas conversiones de propano, llegando a altos valores de selectividad (55\% de selectividad a ácido acrílico para una conversión de propano del 30\%). Este comportamiento catalítico es intermedio al encontrado con catalizadores MoVTeNb con una relación $\mathrm{Nb} / \mathrm{Mo}$ en el gel de síntesis de 0.12 y 0.17 . Así, con una baja composición de $\mathrm{Ga}$ y $\mathrm{Nb},(\mathrm{Ga}+\mathrm{Nb}) / \mathrm{Mo}=0.08$, se obtiene una mayor eficacia catalítica que con composiciones de $\mathrm{Nb}$ mayores en el gel de síntesis, sugiriendo que también es interesante el empleo de $\mathrm{Ga}$ como promotor en óxidos metálicos mixtos MoVTeNb.

\subsection{Catalizadores MoVTeGaO con diferente relación $\mathrm{Ga} /(\mathrm{Ga}+\mathrm{V})$}

Los resultados obtenidos por microscopía de alta resolución (HREM) del catalizador Te-Ga8 sugieren que el Ga podría estar sustituyendo al vanadio en los octaedros de la estructura de la fase M1. En este sentido, se pensó en la síntesis de nuevos materiales MoVTeGaO para estudiar la posible sustitución de vanadio por galio. Para ello, se ha realizado la síntesis de estos materiales variando la composición del gel de síntesis con una relación $\mathrm{Ga} /(\mathrm{V}+\mathrm{Ga})=0.50$ ó 0.25 , manteniendo constante la relación $(\mathrm{Ga}+\mathrm{V}) / \mathrm{Mo}=0.50$. Los catalizadores así obtenidos se han denominado Te-Ga25 y Te-Ga50, dependiendo de que la relación $\mathrm{Ga} /(\mathrm{V}+\mathrm{Ga})$ sea 0.25 ó 0.50 , respectivamente.

Por otro lado, se ha estudiado la sustitución de Te por Ga con la preparación del catalizador MoVGa (Ga-500), con una relación en el gel de síntesis Mo/V/Ga de $1 / 0.50 / 0.17$. En este caso, el precursor se ha activado a $500^{\circ} \mathrm{C}$, de acuerdo con la publicación precedente [35] de este tipo de materiales.

\subsubsection{Resultados catalíticos de los catalizadores MoVTeGaO y MoVGaO}

En la Tabla 4.7 se muestran los resultados catalíticos obtenidos durante la oxidación de propano a $380 \stackrel{\circ}{\circ}$ y un tiempo de contacto, W/F, de $200 \mathrm{~g}_{\text {cat }} \mathrm{h}$ $\left(\text { mol }_{\text {сзнв }}\right)^{-1}$ sobre los catalizadores MoVTeGaO. De forma comparativa, se han incluido los materiales MoVTeO (Te-600) y MoVGaO (Ga-500). 
Tabla 4.7. Oxidación de propano con catalizadores MoVTeO, MoVTeGaO y MoVGaO .

\begin{tabular}{|c|c|c|c|c|c|c|}
\hline \multirow{2}{*}{ Catalizador } & \multirow{2}{*}{ Conv.(\%) } & \multicolumn{5}{|c|}{ Selectividad (\%) $^{c}$} \\
\hline & & AA & $\mathrm{C}_{3} \mathrm{H}_{6}$ & HAc & $\mathrm{CO}$ & $\mathrm{CO}_{2}$ \\
\hline Te-600 & 19 & 25 & 13 & 15 & 21 & 25 \\
\hline Te-Ga25 & 13 & 45 & 15 & 8 & 17 & 13 \\
\hline Te-Ga50 & 1 & 0 & 67 & 0 & 7 & 23 \\
\hline Ga-500 & 50 & 0 & 2 & 5 & 57 & 36 \\
\hline
\end{tabular}

Los resultados catalíticos muestran que sólo el catalizador Te-Ga25, con una relación $\mathrm{Ga} /(\mathrm{V}+\mathrm{Ga})$ de 0.25 , es activo y selectivo en la oxidación selectiva de propano a ácido acrílico, aumentando considerablemente la selectividad a ácido acrílico en comparación con el catalizador sin promotor (Te-600). Sin embargo, al aumentar la relación $\mathrm{Ga} /(\mathrm{V}+\mathrm{Ga})$ en el gel de síntesis a 0.50 (catalizador Te-Ga50) las propiedades catalíticas cambian drásticamente, siendo inactivo en la oxidación de propano. Por otro lado, el catalizador sin Te (catalizador Ga-500) es activo en la oxidación de propano pero se obtiene mayoritariamente productos de oxidación total $\left(\mathrm{CO}\right.$ y $\left.\mathrm{CO}_{2}\right)$.

En la Figura 4.12 se presenta la variación de la selectividad a ácido acrílico con la conversión de propano para los catalizadores Te-Ga25 (con una relación en el gel de síntesis $\mathrm{Ga} /(\mathrm{V}+\mathrm{Ga})=0.25$ ), Te-600 (el catalizador $\sin \mathrm{Ga}$ ) y Ga-500 (el catalizador sin Te), así como el catalizador Te-Ga8 (el catalizador más efectivo promovido con galio).

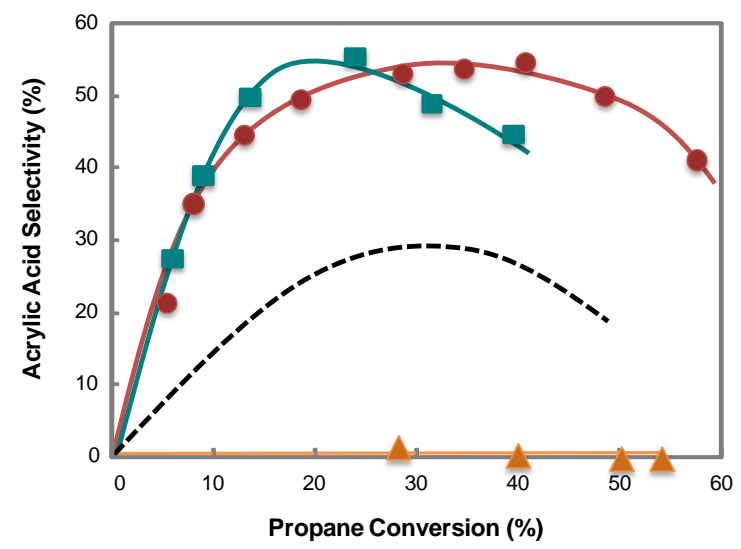

Figura 4.12. Variación de la selectividad a acido acrílico con la conversión de propano durante la oxidación de propano con catalizadores MoVTeGaO: Te-600 (...); Te-Ga8 (घ); Te-Ga25 (•); Ga-500 ( $\triangle$ ). 
Los catalizadores con Ga presentan mayor selectividad a ácido acrílico que el catalizador sin Ga (Te-600). En todos los casos, los catalizadores MoVTeGa favorecen una mayor formación de ácido acrílico a bajas conversiones de propano. Sin embargo, se han observado diferencias en el comportamiento catalítico a mayor conversión de propano. Así, se puede observar que la descomposición de ácido acrílico depende de la relación $\mathrm{Ga} /(\mathrm{V}+\mathrm{Ga})$ en el gel de síntesis.

Cuando se sustituye parcialmente el vanadio por galio en el gel de síntesis, alcanzando una relación $\mathrm{Ga} /(\mathrm{V}+\mathrm{Ga})=0.25$ (catalizador Te-Ga25), se observa también una selectividad a ácido acrílico mayor, incluso a conversiones de propano altas, lo que indicaría una mayor estabilidad de ácido acrílico a altas conversiones de propano. De esta forma, el catalizador Te-Ga25 presenta una selectividad a ácido acrílico de $55 \%$ a una conversión de propano del $40 \%$, resultados casi comparables a los obtenidos con catalizadores MoVTeNbO.

Esta diferencia en el comportamiento catalítico sugiere que el galio incorporado en el catalizador Te-Ga25 podría intervenir en el mecanismo de reacción de la oxidación de propano de forma diferente a la observada en los otros catalizadores con $\mathrm{Ga}$.

\subsubsection{Caracterización físico-química de los catalizadores MoVTeGaO y MoVGaO}

Las características físico-químicas de estos materiales se muestran en la Tabla 4.8. De forma comparativa, se han incluido los catalizadores MoVTeO y MoVGaO. En todos los casos, los análisis químicos de los materiales MoVTeGa indican una buena incorporación de galio en las muestras. Por otro lado, las muestras activadas presentan áreas superficiales dentro del rango observado anteriormente para los catalizadores promovidos con $\mathrm{Ga}$, excepto en el caso del catalizador MoVGa que presenta una mayor área superficial.

Tabla 4.8. Características de los catalizadores MoVTeGaO y MoVGaO.

\begin{tabular}{|c|c|c|c|c|c|}
\hline Muestra & $\mathrm{Ga} / \mathrm{Mo}^{\mathrm{a}}$ & $\mathrm{Ga} /(\mathrm{V}+\mathrm{Ga})^{\mathrm{a}}$ & $\begin{array}{l}\mathrm{S}_{\mathrm{BET}} \\
\left(\mathrm{m}^{2} \mathrm{~g}^{-1}\right)\end{array}$ & $\begin{array}{l}\text { Composición } \\
\mathrm{Mo} / \mathrm{V} / \mathrm{Te} / \mathrm{Ga}^{\mathrm{c}}\end{array}$ & Fases cristalinas $^{d}$ \\
\hline Te-600 & 0.00 & 0.00 & 5.9 & $1 / 0.46 / 0.17 / 0.00$ & $\mathrm{M} 1, \mathrm{M} 2, \mathrm{TeMo}_{5} \mathrm{O}_{16}, \mathrm{MoO}_{3}$ \\
\hline $\begin{array}{l}\text { Te-Ga25 } \\
\text { Te-Ga50 }\end{array}$ & $\begin{array}{l}0.15 \\
0.25\end{array}$ & $\begin{array}{l}0.25 \\
0.50\end{array}$ & $\begin{array}{l}4.4 \\
4.8\end{array}$ & $\begin{array}{l}1 / 0.40 / 0.13 / 0.10 \\
1 / 0.20 / 0.19 / 0.07\end{array}$ & $\begin{array}{l}\mathrm{M} 1, \mathrm{M} 2 \\
\mathrm{M} 2, \mathrm{TeMo}_{5} \mathrm{O}_{16}, \mathrm{MoO}_{3}, \mathrm{M}_{5} \mathrm{O}_{14}\end{array}$ \\
\hline Ga-500 b & 0.17 & 0.25 & 8.8 & $1 / 0.46 / 0.00 / 0.07$ & Baja cristalinidad \\
\hline
\end{tabular}


En los difractogramas de rayos $X$ de los materiales antes del tratamiento térmico (no mostrados), se observa principalmente la fase M1 en el material TeGa25, al igual que en el catalizador sin galio (Figura 4.1, a). Sin embargo, en el caso del material preparado con una relación molar $\mathrm{Ga} /(\mathrm{V}+\mathrm{Ga})=0.5$ (muestra TeGa50) se observa otra serie de reflexiones a $2 \theta=8.24,22.31,22.69,26.7,28.04$, $28.68,29.10$ y $37.68^{\circ}$, que pueden indicar la presencia de un heteropolicompuesto con una estructura tipo Anderson [80].

En la Figura 4.13.A se muestran los difractogramas DRX de las muestras activadas a $600^{\circ} \mathrm{C}$. El catalizador preparado con una relación $\mathrm{Ga} /(\mathrm{V}+\mathrm{Ga})$ menor (Te-Ga25) conserva mayoritariamente la presencia de fase M1, con formación de la fase M2 durante el tratamiento térmico.

Una relación $\mathrm{Ga} /(\mathrm{V}+\mathrm{Ga})$ mayor $(\mathrm{Te}-\mathrm{Ga} 50)$ da lugar a la presencia de otras fases cristalinas como $\mathrm{M} 2, \mathrm{TeMo}_{5} \mathrm{O}_{16}, \mathrm{MoO}_{3}$, sin formación de la fase M1 (Figura 4.13.A, b). La ausencia de fase M1 en el material Te-Ga50 explica la inactividad observada en este catalizador para la oxidación de propano.

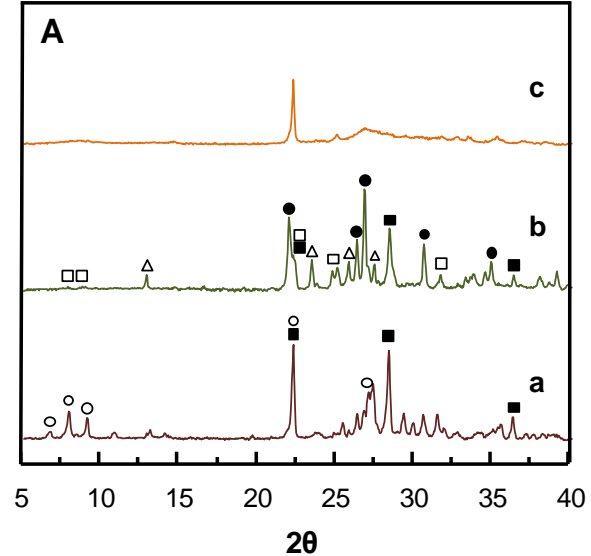

Figura 4.13. (A) Difractogramas DRX $y$

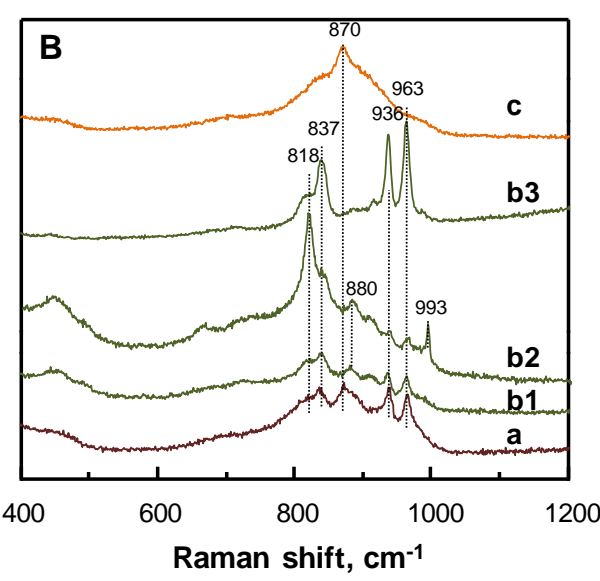

(B) espectros Raman de los materiales

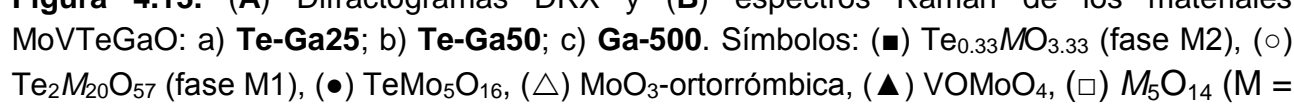
Mo, V). b1, b2 y b3 indican espectros Raman de diferentes partículas en la misma muestra.

Por otro lado, en el catalizador MoVGa se observa un material amorfo laminar, con un pico de difracción a $2 \theta=22.2^{\circ}(4 \AA)$, similar al observado en trabajos anteriores [34-35].

Los espectros Raman de los catalizadores MoVTeGaO preparados con diferente relación $\mathrm{Ga} /(\mathrm{V}+\mathrm{Ga})$ se muestran en la Figura 4.13.B. A modo de comparación, se ha incluido el espectro Raman del catalizador MoVGaO, el cual es muy similar al observado para el catalizador MoVTe sin Ga (Figura 4.7). La 
muestra Te-Ga25 presenta una composición homogénea con espectros Raman prácticamente idénticos en diferentes puntos de la muestra, caracterizados por la presencia de bandas a 840 y $870 \mathrm{~cm}^{-1}$ y similares a los observados para los catalizadores promovidos con Ga (Figura 4.7). Sin embargo, a diferencia de los espectros observados anteriormente, el catalizador Te-Ga25 muestra bandas más definidas a 936 y $963 \mathrm{~cm}^{-1}$.

En el caso del catalizador Te-Ga50 (con una relación $\mathrm{Ga} /(\mathrm{V}+\mathrm{Ga})=0.5$ ), se observa una composición heterogénea con espectros Raman diferentes en los puntos seleccionados de la muestra (Figura 4.13.B, espectro b1-b3), debido a la presencia de diferentes fases cristalinas tal y como se observa por DRX (Figura 4.13.A). En primer lugar, se observa un espectro Raman muy similar al observado para el catalizador Te-Ga25 (Figura 4.13.B, espectro b1), donde la banda a 870 $\mathrm{cm}^{-1}$ se desplaza a $880 \mathrm{~cm}^{-1}$. El espectro b2 presenta bandas adicionales a $818 \mathrm{y}$ $992 \mathrm{~cm}^{-1}$, que se pueden relacionar con la presencia de $\mathrm{TeMo}_{5} \mathrm{O}_{16}$ [81]. Sin embargo, también existe un nuevo espectro Raman con bandas intensas a 813, 837, 936, $963 \mathrm{~cm}^{-1}$ y bandas débiles alrededor a $915 \mathrm{~cm}^{-1}$ (Figura 4.13.B, espectro b3). Las bandas a 818,837 y $915 \mathrm{~cm}^{-1}$ se puede asignar a la presencia de la fase cristalina $\mathrm{M}_{5} \mathrm{O}_{14}(M=\mathrm{Mo}, \mathrm{V})$ [82-83]. Las bandas Raman a 963 y $936 \mathrm{~cm}^{-1} \mathrm{se}$ pueden asignar a la vibracione del enlace terminal $\mathrm{Mo}=\mathrm{O}[82,84]$, que son más difíciles de relacionar con una fase cristalina en particular. Sin embargo, en bibliografía se ha observado que el complejo tipo Keggin $\left[\mathrm{GaMo}_{12} \mathrm{O}_{40}\right]^{\mathrm{n}-}$ se caracteriza por la presencia de cuatro bandas a 963, 936, 872 y $642 \mathrm{~cm}^{-1}$ [85]. Esto sugiere que las bandas observadas en ambos catalizadores (Te-Ga25 y Te-Ga50) a at 963 y $936 \mathrm{~cm}^{-1}$, se podrían relacionar con la presencia de galio en los materiales. En ningún caso se han observado las bandas características del óxido de galio $\left(\mathrm{Ga}_{2} \mathrm{O}_{3}\right)$ a $766,653,416$ y $346 \mathrm{~cm}^{-1}[78]$.

A fin de entender el comportamiento catalítico de los catalizadores MoVTeGa y las diferencias catalíticas observadas entre ellos, dependiendo de la cantidad de vanadio y galio empleada en la síntesis de estos materiales, se ha llevado a cabo su caracterización por XPS y HREM.

El estudio por HREM del catalizador MoVTeGaO preparado con una relación $\mathrm{Ga} /(\mathrm{V}+\mathrm{Ga})=0.25(\mathrm{Te}-\mathrm{Ga25})$ indica, principalmente, la presencia de la fase $\mathrm{M} 1$, $\mathrm{Te}_{2} M_{20} \mathrm{O}_{57}(M=\mathrm{Mo}, \mathrm{V})$. Además, se ha observado la presencia minoritaria de cristales correspondientes a la fase $\mathrm{M} 2, \mathrm{Te}_{0.33} \mathrm{MO}_{3.33}(M=\mathrm{Mo}, \mathrm{V})$, de acuerdo con los resultados observados por DRX.

En este caso, el análisis químico mediante microanálisis XEDS (cristal a cristal) tampoco revela la presencia de una fase secundaria formada principalmente por Ga. En comparación con el catalizador Te-Ga8, la composición atómica de la fase $\mathrm{M} 1$ es prácticamente constante independientemente de la 
relación $\mathrm{Ga} / \mathrm{Mo}$ en el gel de síntesis $(2.5-5 \%)$ y corresponde a la estequiometria $\mathrm{Te}_{0.5}\left(\mathrm{Mo}_{0.65} \mathrm{~V}_{0.24} \mathrm{Ga}_{0.02}\right)_{5} \mathrm{O}_{14}$ observada anteriormente.

Por otro lado, en la Tabla 4.9 se muestran los resultados XPS para el catalizador Te-Ga25. A modo de comparación, se han incluido los catalizadores MoVTe (Te-600), MoVGa (Ga-500) y el catalizador promovido con Ga (Te-Ga8).

En la composición superficial determinada por XPS se observa una menor composición de vanadio en la superficie de los materiales con galio. Además, se observa un enriquecimiento de teluro en la superficie del catalizador Te-Ga25. Por otro lado, también se observan diferencias en el estado de oxidación de algunos elementos en comparación con el catalizador sin galio (Te-600) y el catalizador promovido con galio (Te-Ga8, Tabla 4.9).

Así, en el catalizador Te-Ga25 el espectro Mo 3d se ajusta a tres componentes, con energías de enlace 233.7, 232.7 y $231.7 \mathrm{eV}$, asociadas con la presencia de especies $\mathrm{Mo}^{6+}$ en diferentes entornos de coordinación [11] y especies $\mathrm{Mo}^{5+}(\mathrm{BE}=231.7 \mathrm{eV})$ [86]. Estos resultados difieren de los obtenidos para los catalizadores Te-600 y Te-Ga8 (Tabla 4.9) en los que en ningún caso se observa la contribución de especies $\mathrm{Mo}^{5+}$.

Tabla 4.9. Resultados XPS de los catalizadores MoVTe, MoVTeGa y MoVGa.

\begin{tabular}{|c|c|c|c|c|c|}
\hline \multirow{2}{*}{ Muestra } & \multicolumn{5}{|c|}{ Composición superficial $^{a}$} \\
\hline & $\mathrm{Mo} / \mathrm{V} / \mathrm{Te} / \mathrm{Ga} / \mathrm{O}$ & $\mathrm{Mo}^{5+} / \mathrm{Mo}_{\text {total }}{ }^{\mathrm{b}}$ & $\mathrm{V}^{5+} / \mathrm{V}_{\text {total }}{ }^{\mathrm{c}}$ & $\mathrm{Te}^{6+} / \mathrm{Te}_{\text {total }}{ }^{\mathrm{d}}$ & $\mathrm{Ga}_{\mathrm{B}}{ }^{3+} / \mathrm{Ga}_{\text {total }}{ }^{\mathrm{e}}$ \\
\hline Te-600 & $1 / 0.25 / 0.16 / 0.00 / 5.22$ & 0 & 20.4 & 23.3 & - \\
\hline Te-Ga8 & $1 / 0.27 / 0.16 / 0.05 / 4.07$ & 0 & 38.2 & 0 & 0 \\
\hline Te-Ga25 & $1 / 0.20 / 0.27 / 0.17 / 5.10$ & 17.1 & 25.2 & 14.9 & 32.1 \\
\hline Ga-500 & $1 / 0.30 / 0.00 / 0.05 / 4.62$ & 14.7 & 31.1 & - & 0 \\
\hline
\end{tabular}

Por otro lado, el espectro Te 3d del catalizador Te-Ga25 muestra la presencia de especies $\mathrm{Te}^{4+}$ y $\mathrm{Te}^{6+}$ en su superficie, con una menor relación $\mathrm{Te}^{6+} / \mathrm{Te}_{\text {total }}$ que el catalizador Te-600, mientras que el catalizador promovido con Ga, Te-Ga8, muestra solamente la presencia de especies $\mathrm{Te}^{4+}$ (Tabla 4.9).

La mayor diferencia de composición superficial encontrada, entre los catalizadores con galio, por ejemplo entre el catalizador Te-Ga8 y el catalizador Te-Ga25, corresponde al espectro del nivel fundamental $2 p_{3 / 2}$ del Ga. En el primer caso, el catalizador Te-Ga8 presenta un espectro de $\mathrm{Ga} 2 \mathrm{p}_{3 / 2}$ que se ajusta a una sola componente a $1118.4 \mathrm{eV}$, la cual está relacionada con la presencia de cationes $\mathrm{Ga}^{3+}$ [87]. Sin embargo, en el catalizador Te-Ga25, aparece una nueva 
componente a $1120.2 \mathrm{eV}$ debido posiblemente a la presencia de especies $\mathrm{Ga}^{3+}$ en un entorno de coordinación diferente.

\subsubsection{Discusión de los resultados}

La relación $\mathrm{Ga} /(\mathrm{V}+\mathrm{Ga})$ en el gel de síntesis influye en la distribución de fases cristalinas de los catalizadores, y con ello, en sus propiedades catalíticas en la oxidación de propano a ácido acrílico. Así, la fase M1 es la fase mayoritaria para una relación $\mathrm{Ga} /(\mathrm{V}+\mathrm{Ga})=0.25$, mientras que relaciones mayores (catalizador TeGa50) da lugar a la formación de otras fases no deseadas, como la fase M2, $\mathrm{TeMo}_{5} \mathrm{O}_{16}, \mathrm{MoO}_{3}$ y $\mathrm{M}_{5} \mathrm{O}_{14}(M=\mathrm{Mo}, \mathrm{V})$ (inactivas en la oxidación de propano).

El catalizador Te-Ga25 es activo y selectivo en la oxidación de propano a ácido acrílico debido a la presencia de la fase M1. Los resultados de conversión y selectividad muestran que la presencia de $\mathrm{Ga}$ en el catalizador aumenta considerablemente la selectividad a ácido acrílico. En este sentido, se ha observado un aumento en la selectividad a ácido acrílico a bajas conversiones de propano como en el caso de los catalizadores promovidos con Ga (Te-Ga4-12). Por el contrario, la estabilidad del ácido acrílico a mayores conversiones de propano es mayor, disminuyendo la selectividad a ácido acrílico a conversiones de propano mayores de $50 \%$.

Sin embargo, ambos catalizadores MoVTeGa (Te-Ga8 y Te-Ga25) muestran la incorporación de Ga en la estructura de la fase M1, con un porcentaje atómico similar $(2.5-5 \%)$, mientras que en los análisis de la composición de la superficie por XPS se observa una relación Ga/Mo mayor en el catalizador Te-Ga25 (Ga/Mo $=0.17$, Tabla 4.9). Estos resultados sugieren que el $\mathrm{Ga}$ podría localizarse principalmente en la superficie del material. Además, el espectro del nivel Ga $2 \mathrm{p}_{3 / 2}$ de el catalizador Te-Ga25 está formado por dos componentes que indican la presencia de dos tipos de especies de Ga en la superficie, las cuales de podrían relacionar con las especies galio en la estructura de la fase M1 y especies galio extrared presentes en la superficie del material. En este sentido, las diferencias en el comportamiento catalítico observadas con los catalizadores MoVTeGa (Te-Ga8 y Te-Ga25) puede deberse a la presencia de galio en la superficie del material.

En un principio, los centros de galio fuera de la estructura cristalina (extrared) se podrían relacionar con la formación de óxido de galio en la superficie de los materiales altamente dispersado y no detectado por DRX. Sin embargo, mediante espectroscopia Raman (técnica más sensible) no se observa la presencia de óxido de galio, cuyas bandas son características y no se solapan con las bandas de la fase M1. En cambio, el espectro Raman del catalizador Te-Ga25 presenta bandas a 963 y $936 \mathrm{~cm}^{-1}$ que podrían relacionarse con la presencia de galio en la superficie de los materiales. 
Así bien, parece existir una relación entre las propiedades catalíticas del catalizador Te-Ga25 y los cambios observados en sus propiedades superficiales, principalmente a la presencia de más de una especies de galio en la superficie. En este sentido, la presencia de especies galio extrared en la superficie del catalizador podría estar relacionado con el comportamiento catalítico diferente observado en este catalizador a altas conversiones de propano.

En este sentido, cabe señalar que los catalizadores estudiados se han preparado mediante la incorporación de Ga en el gel de síntesis hidrotermal. Una posibilidad para estudiar la influencia de las especies de Ga en la superficie sería la incorporación de $\mathrm{Ga}$ mediante impregnación en el material activado térmicamente. De esta forma sólo se modificarían las propiedades superficiales del catalizador y se podría estudiar el efecto del Ga en estas propiedades.

\subsection{Conclusiones}

En el presente trabajo se ha estudiado la influencia de la incorporación de un catión X (X = Ag, K, Mg, Ca, Sr, Fe, Co, Ni, Cu, Ga, Bi, La o Nb) en el sistema MoVTeO en la naturaleza de las fases cristalinas y el comportamiento catalítico de estos materiales en la oxidación selectiva de propano a ácido acrílico.

En general, la incorporación de un catión en el gel de síntesis afecta principalmente a la formación de la fase M1, pero también a la estabilidad durante el tratamiento térmico a $600^{\circ} \mathrm{C} / \mathrm{N}_{2}$. En ese sentido, dependiendo del tipo de metal incorporado se observa una mayor o menor descomposición de dicha fase. Por otra parte, los resultados catalíticos obtenidos muestran que la incorporación de un metal tiene, en general, un efecto negativo en la efectividad del catalizador, excepto en el caso de la incorporación de metales como $\mathrm{Ni}$, $\mathrm{Ca}$ ó $\mathrm{Nb}$ en el que se observa un aumento considerable de la conversión de propano. Además, la incorporación de K, Ca o Ga mejora la selectividad a ácido acrílico

Cabe destacar el efecto producido por estos metales, sobretodo en el caso de catalizadores con $\mathrm{Ca}, \mathrm{Ga}$ o $\mathrm{Nb}$, donde se observa un aumento considerable de la conversión de propano (caso del $\mathrm{Nb}$ ), de la selectividad a ácido acrílico (caso del $\mathrm{Ga}$ ) o de ambos parámetros (caso del $\mathrm{Ca}$ ) indicando la posibilidad de ser utilizados como promotores para mejorar la eficacia de los catalizadores MoVTeO.

En este sentido, variando la relación X/Mo en el gel de síntesis $(X=\mathrm{Ca}$, Ga o $\mathrm{Nb}$ ), se puede alcanzar un aumento importante en la conversión de propano y/o selectividad a ácido acrílico, aunque la relación X/Mo óptima varia con el catión: 0.04 para los catalizadores con $\mathrm{Ca}, 0.08$ para los catalizadores con $\mathrm{Ga}$, y 0.17 para los catalizadores con $\mathrm{Nb}$. 
La incorporación de $\mathrm{Ca}$ en el sistema MoVTe da lugar a un aumento de la selectividad a ácido acrílico y de la conversión de propano (aunque sin cambios aparentes en la actividad específica) de los materiales, si bien no está claro que se haya producido una incorporación de cationes $\mathrm{Ca}^{2+}$ en la fase activa, $\mathrm{Te}_{2} \mathrm{M}_{20} \mathrm{O}_{57}$.

La incorporación de $\mathrm{Nb}$ durante la síntesis hidrotermal de óxidos metálicos mixtos MoVTe tiene un efecto claro estabilizando la fase M1 durante el tratamiento térmico. Como consecuencia, los catalizadores con $\mathrm{Nb}$ muestran una menor formación de productos no deseados (como ácido acético u óxidos de carbono). Lógicamente, este efecto depende de la concentración del niobio en el gel de síntesis, siendo el efecto más importante a medida que aumenta la relación atómica $\mathrm{Nb} / \mathrm{Mo}$ en el gel de síntesis.

Los resultados catalíticos de los catalizadores con $\mathrm{Ga}$ han mostrados que éstos son menos activos y más selectivos a ácido acrílico en comparación con el catalizador sin metal, Te-600, alcanzando selectividades sólo observadas en catalizadores MoVTeNbO. La incorporación de Ga a la fase M1 se ha confirmado por HREM de los catalizadores Te-Ga8 y Te-Ga25, donde la concentración de galio en el cristal no depende de la composición inicial del gel. Por otro lado, es de destacar el hecho de que los catalizadores MoVTeGaO favorecen la formación de ácido acrílico a conversiones de propano menores a las observadas con los otros catalizadores. Sin embargo, a altas conversiones de propano, la selectividad a ácido acrílico disminuye rápidamente, favoreciéndose la selectividad a óxidos de carbono. Por tanto, los centros de Ga en la fase M1 de estos catalizadores favorecen la formación, pero también la descomposición, del ácido acrílico.

Por último, se han preparado catalizadores MoVTeGa variando la relación $\mathrm{Ga} /(\mathrm{V}+\mathrm{Ga})$ en el gel de síntesis. La composición de fases cristalinas depende de la relación $\mathrm{Ga} /(\mathrm{V}+\mathrm{Ga})$. Así, únicamente la fase $\mathrm{M} 1$ está presente principalmente en la composición del catalizador Te-Ga25, con una relación $\mathrm{Ga} /(\mathrm{V}+\mathrm{Ga})=0.25$. Los resultados catalíticos muestran un catalizador muy selectivo a ácido acrílico con una menor degradación de ácido acrílico a altas conversiones de propano que los catalizadores promovidos con galio (Te-Ga4-12), alcanzando selectividades a ácido acrílico de 55\% para una conversión de propano del 40\%. Estas diferencias en el comportamiento catalítico entre los catalizadores con Ga pueden estar relacionadas con la presencia de especies $G a$ extrared en la superficie del catalizador, tal y como se ha determinado por XPS.

Por lo tanto, la incorporación de Ga en la fase M1 da lugar a un considerable aumento de la selectividad a ácido acrílico, alcanzando resultados comparables a los catalizadores MoVTeNbO. Esto sugiere que la optimización en la incorporación de Ga podría suponer mejoras importantes en el comportamiento catalítico de estos materiales. 


\section{Conclusions}

In this work, the incorporation of metal $X(X=A g, K, M g, C a, S r, F e, C o, N i$, $\mathrm{Cu}, \mathrm{Ga}, \mathrm{Bi}, \mathrm{La} \circ \mathrm{Nb}$ ) into the catalytic system MoVTeO has prepared by hydrothermal synthesis. The nature of crystalline phases and the catalytic behavior have been studied.

In general, both the formation and the stability of M1 phase during the heattreatment a $600^{\circ} \mathrm{C} / \mathrm{N}_{2}$ were affected by the metal incorporated into synthesis gel. In this way, higher or lower M1 phase decomposition during the heat-treatment have been observed depending on nature of metal incorporated. On the other hand, in general, the catalytic results show a negative effect in the catalysts effectiveness. Except in the case of $\mathrm{Ni}$-, $\mathrm{Ca}$-, or $\mathrm{Nb}$-promoted catalysts a higher propane conversion was observed. Also, the selectivity to acrylic acid was increased in the case of K-, Ca- or Ga-containing catalysts.

Should be noted the effect produced by these metals, especially in the case of $\mathrm{Ca}-$, Ga- or Nb-promoted catalysts, where a considerable increase in the propane conversion (Nb-containing catalysts), in the selectivity of acrylic acid (Gacontaining catalysts) or both parameters (Ca-containing catalysts). These results suggest the possibility to be used as promoters to improve the effectiveness of MoVTe catalysts.

Thus, a significant increase of catalytic activity and/or selectivity to acrylic acid can be obtained varying the X/Mo ratio in the synthesis gel. Although, the optimum X/Mo ratio varies with the cation: 0.04 for Ca-promoted catalysts, 0.08 for Gacontaining catalysts and 0.12 for $\mathrm{Nb}$-promoted catalysts.

Ca-incorporated MoVTe catalysts increase both the selectivity to acrylic acid and the propane conversion (although without changes in the specific catalytic activity), while it is not clear that $\mathrm{Ca}^{2+}$ cations were incorporated into $\mathrm{Te}_{2} \mathrm{M}_{20} \mathrm{O}_{57}$ phase.

The incorporation of $\mathrm{Nb}$ into the hydrothermal synthesis gel has a clear effect in the stability of M1 phase during the heat-treatment a high temperature. As consequence, $\mathrm{Nb}$-containing catalysts show less formation of non desired products (as acetic acid or carbon oxides). This effect depends on the amount of niobium in the synthesis gel, increasing with the atomic $\mathrm{Nb} / \mathrm{Mo}$ ratio in the synthesis gel.

Ga-promoted MoVTe catalysts have shown less active and more selective than metal-free catalysts (Te-600), with selectivity to acrylic acid only observed in the case of MoVTeNbO catalysts. The incorporation of $\mathrm{Ga}$ into the framework of M1 phase has been confirmed by HREM. Ga-containing catalysts favor the formation to acrylic acid at low propane conversion. However, at high propane 
conversion a decrease in the selectivity to acrylic acid (favoring the selectivity to carbon oxides) has been observed. Therefore, both the formation and the decomposition of acrylic acid are influenced by Ga sites.

Finally, MoVTeGa catalysts were prepared varying the $\mathrm{Ga} /(\mathrm{V}+\mathrm{Ga})$ ratio in the synthesis gel. The crystalline phase composition of materials depends on the $\mathrm{Ga} /(\mathrm{V}+\mathrm{Ga})$ ratio. Thus, only $\mathrm{M} 1$ phase is mainly present in Te-Ga25 catalyst $(\mathrm{Ga} /(\mathrm{V}+\mathrm{Ga})=0.25)$. The catalytic results show a very selective catalyst with less degradation of acrylic acid at high propane conversion than Ga-promoted catalysts (Te-Ga4-12). Selectivity to acrylic acid of $55 \%$ at propane conversion of $40 \%$ has been achieved. These differences observed in the catalytic behavior between Gacontaining catalysts could be related with the presence of extraframework $\mathrm{Ga}$ species on the catalyst surface, as determined by XPS.

Accordingly the results, the incorporation of $\mathrm{Ga}$ into M1 phase structure results in an important increase in the selectivity to acrylic acid, only observed with MoVTeNbO catalysts. This suggests that the optimization in the incorporation of Ga could improve the catalytic behavior of these materials. 


\section{Bibliografía}

[1] T. Ushikubo, K. Oshima, A. Kayo, T. Umezawa, K. Kiyono, T. Sawaki, EP Patent 0529853 A2 (1992) assigned to Mitsubishi.

[2] T. Ushikubo, H. Nakamura, Y. Koyasu, S. Wajiki, US Patent 5380933 (1995) assigned to Mitsubushi.

[3] T. Ushikubo, K. Oshima, A. Kayou, M. Hatano, X. Can Li and Qin, in Studies in Surface Science and Catalysis, Volume 112, Elsevier, (1997), 473-480.

[4] H. Tsuji, Y. Koyasu, Journal of the American Chemical Society 124 (2002) 5608-5609.

[5] J. M. López Nieto, P. Botella, M. I. Vazquez, A. Dejoz, Chemical Communications (2002) 1906-1907.

[6] P. Botella, E. García-González, A. Dejoz, J. M. López Nieto, M. I. Vázquez, J. González-Calbet, Journal of Catalysis 225 (2004) 428-438.

[7] M. Baca, M. Aouine, J. L. Dubois, J. M. M. Millet, Journal of Catalysis 233 (2005) 234-241.

[8] W. Ueda, D. Vitry, T. Kato, N. Watanabe, Y. Endo, Research on Chemical Intermediates 32 (2006) 217-233.

[9] W. Ueda, D. Vitry, T. Katou, Catalysis Today 99 (2005) 43-49.

[10] D. Vitry, J.-L. Dubois, W. Ueda, Journal of Molecular Catalysis A: Chemical 220 (2004) 67-76.

[11] P. Concepción, S. Hernández, J. M. López Nieto, Applied Catalysis A: General 391 (2011) 92-101.

[12] J. M. M. Millet, H. Roussel, A. Pigamo, J. L. Dubois, J. C. Jumas, Applied Catalysis A: General 232 (2002) 77-92.

[13] D. Vitry, Y. Morikawa, J. L. Dubois, W. Ueda, Topics in Catalysis 23 (2003) 47-53.

[14] D. Vitry, Y. Morikawa, J. L. Dubois, W. Ueda, Applied Catalysis A: General 251 (2003) 411-424.

[15] R. K. Grasselli, J. D. Burrington, D. J. Buttrey, P. DeSanto, C. G. Lugmair, A. F. Volpe, T. Weingand, Topics in Catalysis 23 (2003) 5-22.

[16] P. Botella, E. García-González, J. M. López Nieto, J. M. González-Calbet, Solid State Sciences 7 (2005) 507-519.

[17] M. Baca, A. Pigamo, J. L. Dubois, J. M. M. Millet, Topics in Catalysis 23 (2003) 39-46.

[18] R. K. Grasselli, Catalysis Today 99 (2005) 23-31.

[19] P. Botella, J. M. López Nieto, B. Solsona, A. Mifsud, F. Márquez, Journal of Catalysis 209 (2002) 445-455.

[20] P. Botella, B. Solsona, A. Martinez-Arias, J. M. López Nieto, Catalysis Letters 74 (2001) 149-154.

[21] J. M. Oliver, J. M. López Nieto, P. Botella, Catalysis Today 96 (2004) 241249.

[22] P. Concepción, P. Botella, J. M. López Nieto, Applied Catalysis A: General 278 (2004) 45-56.

[23] M. Baca, A. Pigamo, J. L. Dubois, J. M. M. Millet, Catalysis Communications 6 (2005) 215-220.

[24] T. Blasco, P. Botella, P. Concepción, J. M. López Nieto, A. Martinez-Arias, C. Prieto, Journal of Catalysis 228 (2004) 362-373. 
[25] F. Ivars, B. Solsona, P. Botella, M. D. Soriano, J. M. López Nieto, Catalysis Today 141 (2009) 294-299.

[26] F. Ivars, B. Solsona, M. Soriano, J. M. López Nieto, Topics in Catalysis 50 (2008) 74-81.

[27] S. S. Kum, B. Y. Jo, S. H. Moon, Applied Catalysis A: General 365 (2009) 79-87.

[28] B. Y. Jo, S. S. Kum, S. H. Moon, Applied Catalysis A: General 378 (2010) 76-82.

[29] P. Biswas, J. Woo, V. V. Guliants, Catalysis Communications 12 (2010) 58-63.

[30] B. Deniau, J. M. M. Millet, S. Loridant, N. Christin, J. L. Dubois, Journal of Catalysis 260 (2008) 30-36.

[31] R. Grasselli, C. Lugmair, A. Volpe, Topics in Catalysis 50 (2008) 66-73.

[32] C. S. Chaudhari, S. S. Sable, H. Gurav, A. A. Kelkar, V. H. Rane, Journal of Natural Gas Chemistry 19 (2010) 593-599.

[33] V. H. Rane, U. Rodemerck, M. Baerns, Journal of Chemical Technology \& Biotechnology 81 (2006) 381-386.

[34] W. Ueda, K. Oshihara, Applied Catalysis A: General 200 (2000) 135-143.

[35] N. R. Shiju, V. V. Guliants, Catalysis Communications 9 (2008) 2253-2256.

[36] H. Hibst, F. Rosowski, G. Cox, Catalysis Today 117 (2006) 234-241.

[37] J. Holmberg, S. Hansen, R. Grasselli, A. Andersson, Topics in Catalysis 38 (2006) 17-29.

[38] J. Holmberg, J. B. Wagner, R. Häggblad, S. Hansen, L. R. Wallenberg, A. Andersson, Catalysis Today 128 (2007) 153-160.

[39] R. Häggblad, J. Wagner, B. Deniau, J.-M. Millet, J. Holmberg, R. Grasselli, S. Hansen, A. Andersson, Topics in Catalysis 50 (2008) 52-65.

[40] N. R. Shiju, V. V. Guliants, Am. Chem. Soc. Div. Pet. Chem. 52 (2007).

[41] K. S. Oh, S. I. Woo, Catalysis Today 137 (2008) 61-70.

[42] P. Korovchenko, N. Shiju, A. Dozier, U. Graham, M. Guerrero-Pérez, V. Guliants, Topics in Catalysis 50 (2008) 43-51.

[43] F. Ivars, P. Botella, A. Dejoz, J. M. López Nieto, P. Concepción, M. Vázquez, Topics in Catalysis 38 (2006) 59-67.

[44] P. Botella, P. Concepción, J. M. López Nieto, Y. Moreno, Catalysis Today 99 (2005) $51-57$.

[45] J. Holmberg, R. K. Grasselli, A. Andersson, Topics in Catalysis 23 (2003) 55-63.

[46] W. Ueda, D. Vitry, T. Katou, Catalysis Today 96 (2004) 235-240.

[47] P. DeSanto, D. J. Buttrey, R. K. Grasselli, C. G. Lugmair, A. F. Volpe, B. H. Toby, T. Vogt, Topics in Catalysis 23 (2003) 23-38.

[48] L. Huo, H. Zhao, F. Mauvy, S. Fourcade, C. Labrugere, M. Pouchard, J.-C. Grenier, Solid State Sciences 6 (2004) 679-688.

[49] K. D. Dobson, A. J. McQuillan, Langmuir 13 (1997) 3392-3396.

[50] F. Ivars, B. Solsona, E. Rodríguez-Castellón, J. M. López Nieto, Journal of Catalysis 262 (2009) 35-43.

[51] J. C. J. Bart, G. Petrini, N. Giordano, Z. anorg. allg. Chem 413 (1975) 180192.

[52] P. Botella, J. M. López Nieto, B. Solsona, Journal of Molecular Catalysis A: Chemical 184 (2002) 335-347. 
[53] G. Y. Popova, T. V. Andrushkevich, Y. A. Chesalov, L. M. Plyasova, L. S. Dovlitova, E. V. Ischenko, G. I. Aleshina, M. I. Khramov, Catalysis Today In Press, Corrected Proof.

[54] G. Y. Popova, T. V. Andrushkevich, L. S. Dovlitova, G. A. Aleshina, Y. A. Chesalov, A. V. Ishenko, E. V. Ishenko, L. M. Plyasova, V. V. Malakhov, M. I. Khramov, Applied Catalysis A: General 353 (2009) 249-257.

[55] I. E. Wachs, J. M. Jehng, W. Ueda, The Journal of Physical Chemistry $B$ 109 (2005) 2275-2284.

[56] B. Solsona, M. I. Vázquez, F. Ivars, A. Dejoz, P. Concepción, J. M. López Nieto, Journal of Catalysis 252 (2007) 271-280.

[57] X. Yang, W. Zhang, R. Feng, W. Ji, C.-T. Au, Catalysis Letters 124 (2008) 288-296.

[58] V. Bondarenka, S. Grebinskij, S. Kačiulis, G. Mattogno, S. Mickevičius, Journal of Electron Spectroscopy and Related Phenomena 107 (2000) 253-259.

[59] V. Nivoix, B. Gillot, Materials Chemistry and Physics 63 (2000) 24-29.

[60] H. Hayashi, N. Shigemoto, S. Sugiyama, N. Masaoka, K. Saitoh, Catalysis Letters 19 (1993) 273-277.

[61] R. M. Yeh, J. Xu, G. Seeber, K. N. Raymond, Inorganic Chemistry 44 (2005) 6228-6239.

[62] L. Melo, Y. Díaz, M. Mediavilla, A. Albornoz, J. L. Brito, Catalysis Letters 97 (2004) 105-109.

[63] P. DeSanto, D. J. Buttrey, R. K. Grasselli, C. G. Lugmair, A. F. Volpe, B. H. Toby, T. Vogt, Zeitschrift Fur Kristallographie 219 (2004) 152-165.

[64] R. K. Grasselli, D. J. Buttrey, P. DeSanto, J. D. Burrington, C. G. Lugmair, A. F. Volpe, T. Weingand, Catalysis Today 91-92 (2004) 251-258.

[65] H. Tsuji, K. Oshima, Y. Koyasu, Chemistry of Materials 15 (2003) 21122114.

[66] A. Celaya Sanfiz, T. Hansen, F. Girgsdies, O. Timpe, E. Rödel, T. Ressler, A. Trunschke, R. Schlögl, Topics in Catalysis 50 (2008) 19-32.

[67] P. Botella, J. M. López Nieto, B. Solsona, Catalysis Letters 78 (2002) 383387.

[68] J. M. López Nieto, P. Botella, B. Solsona, J. M. Oliver, Catalysis Today 81 (2003) 87-94.

[69] V. V. Guliants, R. Bhandari, J. N. Al-Saeedi, V. K. Vasudevan, R. S. Soman, O. Guerrero-Pérez, M. A. Bañares, Applied Catalysis A: General 274 (2004) 123-132.

[70] W. Ueda, K. Oshihara, D. Vitry, T. Hisano, Y. Kayashima, Catalysis Surveys from Japan 6 (2002) 33-44.

[71] X. Tu, N. Furuta, Y. Sumida, M. Takahashi, H. Niiduma, Catalysis Today 117 (2006) 259-264.

[72] R. M. Feng, X. J. Yang, W. J. Ji, H. Y. Zhu, X. D. Gu, Y. Chen, S. Han, H. Hibst, Journal of Molecular Catalysis A: Chemical 267 (2007) 245-254.

[73] F. Ivars, B. Solsona, S. Hernández, J. M. López Nieto, Catalysis Today 149 (2010) 260-266.

[74] G. J. Buckles, G. J. Hutchings, Catalysis Today 31 (1996) 233-246.

[75] J. L. G. Fierro, Metal oxides: chemistry and applications, Taylor \& Francis, (2006).

[76] P. Qiu, J. Lunsford, M. Rosynek, Catalysis Letters 52 (1998) 37-42. 
[77] P. Mériaudeau, C. Naccache, Catalysis Today 31 (1996) 265-273.

[78] V. Cortés Corberán, R. X. Valenzuela, B. Sulikowski, M. Derewiński, Z. Olejniczak, J. Kryściak, Catalysis Today 32 (1996) 193-204.

[79] Y.-T. Cheng, J. Jae, J. Shi, W. Fan, G. W. Huber, Angewandte Chemie International Edition 51 (2012) 1387-1390.

[80] I. Ramli, P. Botella, F. Ivars, W. Pei Meng, S. M. M. Zawawi, H. A. Ahangar, S. Hernández, J. M. López Nieto, Journal of Molecular Catalysis A: Chemical 342-343 (2011) 50-57.

[81] I. L. Botto, C. I. Cabello, H. J. Thomas, Materials Chemistry and Physics $47(1997) 37-45$.

[82] M. Dieterle, G. Mestl, Physical Chemistry Chemical Physics 4 (2002) 822826.

[83] G. Mestl, Journal of Raman Spectroscopy 33 (2002) 333-347.

[84] H. Tian, I. E. Wachs, L. E. Briand, The Journal of Physical Chemistry $B$ 109 (2005) 23491-23499.

[85] S. Himeno, I. Kitazumi, K. i. Sano, Analytical Sciences 15 (1999) 35-40.

[86] S. Damyanova, L. Petrov, M. A. Centeno, P. Grange, Applied Catalysis A: General 224 (2002) 271-284.

[87] F. Scharmann, G. Cherkashinin, V. Breternitz, C. Knedlik, G. Hartung, T. Weber, J. A. Schaefer, Surface and Interface Analysis 36 (2004) 981-985. 


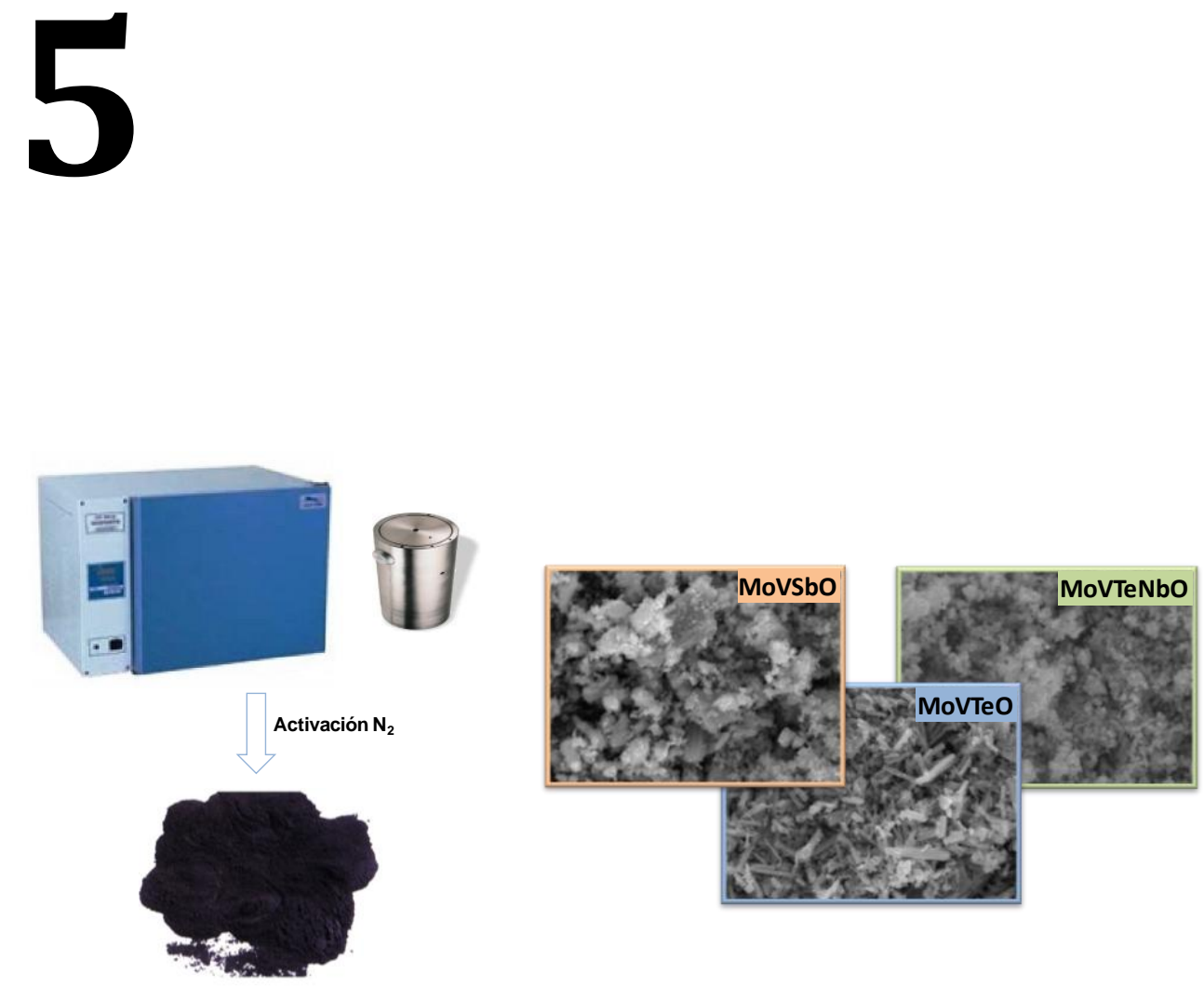

\section{Estudio sobre la preparación de óxidos mixtos MoVSbO, MoVTeO y MoVTeNbO}





\begin{abstract}
MoVSbO, MoVTeO and MoVTeNbO catalysts have been prepared by hydrothermal synthesis, characterized (by XRD, Raman, IR, XPS and $\mathrm{NH}_{3}-\mathrm{TPD}$ ) and tested in the partial oxidation of propane to acrylic acid. Two important parameters on the preparation of these metal mixed oxides have been studied: i) the hydrothermal synthesis temperature; and ii) the catalysts activation temperature. The catalysts have been prepared hydrothermally at 100-200ㄷ range temperature. In general, the hydrothermal synthesis temperature mainly affects to M1 phase formation, then, a higher M1 phase amount is observed when increasing synthesis temperature. In the case of Nb-free catalysts (MoVSbO and $\mathrm{MoVTeO}$ ) after heat-treatment a $600^{\circ} \mathrm{C}$, an increase of $\mathrm{M} 2$ phase and the formation of other phases (as $\mathrm{TeMo}_{5} \mathrm{O}_{16}$ or $\mathrm{Sb}_{2} \mathrm{Mo}_{10} \mathrm{O}_{31}$ ) have observed, due to the minority presence of other crystalline phases and/or amorphous solid in the precursor (MoVSbO catalysts) or a decomposition of the M1 phase during the heattreatmente (MoVTeO catalysts). Nb-containing MoVTe favors a higher thermal stability of M1 phase and an improvement in the catalytic properties of the materials for the partial propane oxidation to acrylic acid. On the other hand, the catalysts prepared hydrothermally have been heat-treated at 500,550 or $600^{\circ} \mathrm{C}$ in a $\mathrm{N}_{2}$ atmosphere. The heat-treatment has different influence on the formation and stability of M1, the surface characteristics of catalysts and the catalytic behavior of MoVSbO, MoVTeO and MoVTeNbO catalysts. The more selective catalyst was the MoVTeNbO sample heat-treated at $600^{\circ} \mathrm{C}$, which present a very low number of acid sites and it is characterized by the presence of only a type of $\mathrm{Mo}^{6+}$ species and the absence of $\mathrm{Te}^{6+}$ species (only $\mathrm{Te}^{4+}$ is observed) on the catalyst surface.
\end{abstract}




\section{Resumen}

Los catalizadores MoVSbO, MoVTeO y MoVTeNbO se han preparado por el método hidrotermal, caracterizado (por DRX, Raman, IR, XPS y TPD-NH $\mathrm{H}_{3}$ y probado en la oxidación parcial de propano a ácido acrílico. En particular, se han estudiado dos parámetros importantes en la preparación de estos óxidos mixtos: i) la temperatura de la síntesis hidrotermal; y ii) la temperatura de activación térmica de los materiales. Los catalizadores se han preparado por el método hidrotermal en el intervalo de temperaturas $100-200^{\circ} \mathrm{C}$. En general, la temperatura de síntesis hidrotermal afecta principalmente a la formación de la fase M1. Así, al aumentar la temperatura de síntesis se observa mayor cantidad de fase M1. En el caso de los materiales sin niobio (MoVSbO y MoVTeO) activados a $600^{\circ} \mathrm{C}$, se observa un aumento de la fase M2 y la formación de otras fases (como $\mathrm{TeMo}_{5} \mathrm{O}_{16} \mathrm{O}$ $\mathrm{Sb}_{2} \mathrm{Mo}_{10} \mathrm{O}_{31}$ ) debido a la presencia minoritaria de otras fases cristalinas y/o sólido amorfo en los precursores (catalizadores MoVSbO) o la descomposición de la fase M1 durante el tratamiento térmico (catalizadores MoVTeO). La presencia de Nb en los catalizadores MoVTe favorece una mayor estabilidad de la fase M1 y una mejora en las propiedades catalíticas de los materiales durante la oxidación parcial de propano a ácido acrílico. Por otra parte, los catalizadores preparados por el método hidrotermal se han activado a 500, 550 ó $600^{\circ} \mathrm{C}$ en corriente de $\mathrm{N}_{2}$. El tratamiento térmico influye de forma distinta en la formación y estabilidad de la fase $\mathrm{M1}$, las características superficiales de los catalizadores, y en el comportamiento catalítico de los materiales MoVSbO, MoVTeO y MoVTeNbO. El catalizador MoVTeNbO activado a $600^{\circ} \mathrm{C}$ es el catalizador más selectivo, y se caracteriza por un menor número de centros ácidos, la presencia de una sola especie de $\mathrm{Mo}^{6+}$ y la ausencia de especies $\mathrm{Te}^{6+}$ (observándose sólo $\mathrm{Te}^{4+}$ ) en la superficie del catalizador. 


\subsection{Antecedentes}

La presencia de la fase cristalina denominada como fase M1 ha resultado ser la clave para entender el comportamiento catalítico de los óxidos mixtos multicomponentes $\mathrm{MoVTe}(\mathrm{Sb}) \mathrm{NbO}$, que muestran una alta actividad y selectividad tanto para la amoxidación/oxidación de propano a acrilonitrilo y ácido acrílico [1-4] como para la deshidrogenación oxidativa de etano a etileno [5-6]. En efecto, la fase activa $\mathrm{M} 1$ se encuentra presente en los óxidos mixtos multicomponentes con antimonio, con estequiometria $(\mathrm{SbO})_{2} \mathrm{M}_{20} \mathrm{O}_{56}(M=\mathrm{Mo}, \mathrm{V})$, o con teluro, con estequiometria $\mathrm{Te}_{2} \mathrm{M}_{20} \mathrm{O}_{57}(M=\mathrm{Mo}, \mathrm{V}, \mathrm{Nb})$. Sin embargo, aunque los catalizadores sin niobio (los sistemas catalíticos MoVTeO y MoVSbO) son relativamente activos y selectivos en la oxidación parcial de propano a ácido acrílico [7-13], los materiales que contienen niobio muestran, hasta el momento, los mejores resultados catalíticos [1-6, 13-15].

Estos catalizadores, con o sin niobio, pueden presentar otras fases critalinas además de la fase $M 1$. Este es el caso de la denominada fase $M 2,\left(\mathrm{X}_{2} \mathrm{O}\right) M_{6} \mathrm{O}_{18}(\mathrm{X}$ $=\mathrm{Te}, \mathrm{Sb} ; M=\mathrm{Mo}, \mathrm{V}, \mathrm{Nb}$ ), $\mathrm{TeMo}_{5} \mathrm{O}_{16}$ (o su equivalente con antimonio, $\mathrm{Sb}_{2} \mathrm{Mo}_{10} \mathrm{O}_{31}$ ), $\mathrm{MoO}_{3} \circ\left(\mathrm{Mo}_{0.93} \mathrm{~V}_{0.07}\right)_{5} \mathrm{O}_{14}$ (o su equivalente con $\mathrm{Mo}$ y $\mathrm{Nb}$ ) que son inactivas en la oxidación de propano, pero cuya proporción depende fuertemente de las condiciones y el método de síntesis empleado [3-4, 13-27]. Ahora bien, si el comportamiento catalítico de estos materiales está fuertemente relacionado con la presencia de la fase M1 [28-30], la presencia de la fase M2, en algunos casos, puede tener un efecto sinérgico [28, 31-32], debido a que la fase M2 es activa y selectiva para la oxidación de propileno a ácido acrílico [33].

Por otra parte, los métodos más empleados en la preparación de este tipo de catalizadores son la síntesis por co-precipitación (también conocida como método slurry) y la síntesis hidrotermal, aunque recientemente se ha sugerido la posibilidad de llevar a cabo la síntesis de algunos de estos materiales poniendo a reflujo la disolución acuosa con los diferentes elemento químicos [34].

En general, las fases cristalinas M1 y M2 se pueden obtener directamente por síntesis hidrotermal en materiales sin niobio [10-13, 35]. En el caso de los materiales con niobio, el precursor que se obtiene tanto por síntesis hidrotermal $[10-13,35]$ como por coprecipitación $[1-4,13]$ es un material amorfo, el cual se transforma en material cristalino tras la activación térmica en corriente de $\mathrm{N}_{2}$ a alta temperatura. A modo de resumen, podemos señalar que los procedimientos de síntesis incluyen una serie de etapas comunes: i) preparación del gel de síntesis; ii) obtención de un precursor sólido (por precipitación o cristalización); y iii) activación térmica del precursor para obtener el catalizador final. Sin embargo, tanto la distribución de fases cristalinas que componen el catalizador, como la composición química de cada fase, pueden variar dependiendo del método de 
preparación empleado, de las condiciones de síntesis y del procedimiento de activación, y con ello sus propiedades catalíticas. Por tanto, todos estos aspectos se deben tener en cuenta a la hora de sintetizar estos materiales para la obtención de la estructura cristalina tipo M1.

La preparación del gel de síntesis consiste en obtener una mezcla, en las condiciones adecuadas (concentración, $\mathrm{pH}$, temperatura, etc.), de las diferentes disoluciones acuosas de las sales de cada uno de los elementos metálicos que se pretende formen parte del catalizador. Es la etapa más delicada de la síntesis de este tipo de catalizadores, independientemente del método de síntesis empleado, pues la variación de las condiciones del gel de síntesis puede conducir a la formación de fases cristalinas no deseadas. Así, la mayor o menor presencia de la fase M1 en la composición final del catalizador se ve fuertemente influenciada por las condiciones del gel síntesis, como es la composición o concentración de los metales [13, 15, 25-27], el pH [22-24], la naturaleza de las sales metálicas empleadas [19-21], la presencia de oxoácidos [16-18] y/o agentes reductores [4]. Recientemente, se ha propuesto el empleo de ultrasonidos [36-38] como sistema de pre-tratamiento para mejorar la dispersión, solubilidad y homogeneidad de los reactivos en el gel de síntesis, aunque no se observan mejoras apreciables en las propiedades catalíticas de los catalizadores finales.

Las condiciones óptimas del gel de síntesis para la formación de la fase activa, fase $\mathrm{M} 1$, varían ligeramente dependiendo del método de síntesis empleado. En este sentido, la sal empleada como precursor de vanadio en el gel de síntesis es diferente para cada método: sulfato de vanadilo $\left(\mathrm{V}^{4+}\right)$ para el método hidrotermal, y metavanadato amónico $\left(\mathrm{V}^{5+}\right)$ en el caso de la síntesis slurry [39]. Sin embargo, si para el método de co-precipitación las condiciones óptimas son relativamente bien conocidas, hasta el momento se ha prestado una menor atención a la influencia de las condiciones de síntesis para el método hidrotermal.

Durante la síntesis hidrotermal, los reajustes estructurales de los elementos que componen el gel de síntesis tienen lugar en el autoclave, un sistema cerrado que permite tener una atmósfera controlada para la formación de especies en estados de oxidación concretos, pero que dificulta un control más exhaustivo del medio de reacción. Aunque la síntesis puede ser optimizada mediante un ajuste adecuado de las propiedades del gel de síntesis, se deben tener en cuenta otros factores que pueden tener una influencia decisiva en la fase y composición química de los catalizadores finales, como es la temperatura a la que se lleva a cabo la síntesis, el material de que está compuesto el contenedor del gel de síntesis, la agitación (o la ausencia de agitación), y el método de enfriamiento del autoclave [40]. 
Independientemente del método de síntesis empleado, los catalizadores activos y selectivos se obtienen sólo cuando los precursores son sometidos a un tratamiento térmico a alta temperatura [1-45], generalmente a $600^{\circ} \mathrm{C}$ bajo atmósfera inerte (normalmente $\mathrm{N}_{2}$ ). Esta etapa resulta imprescindible para obtener catalizadores que muestren rendimientos a ácido acrílico durante la oxidación de propano [11, 13], y las condiciones en las que tiene lugar (temperatura, velocidad de calentamiento, naturaleza y flujo del gas de arrastre, etc.) afectan de manera importante sobre las características y propiedades del catalizador final.

Sin embargo, no existe una explicación clara acerca de los cambios producidos en el catalizador durante el tratamiento térmico a altas temperaturas. Así, algunos autores asocian la formación de otras fases no deseadas, como la fase M2 [13], u otros óxidos mixtos de molibdeno [41], a reacciones en estado sólido que tienen lugar durante el proceso de activación a alta temperatura del precursor. Ueda y col. [42] han observado cambios tanto en el comportamiento catalítico como en las características en la superficie de los materiales MoVTeO que dependen del método de activación de los catalizadores. Schlögl y col. [40] observan un crecimiento anisotrópico de las agujas de la M1 durante el tratamiento térmico. Por consiguiente, durante la activación del catalizador, se podrían producir cambios en la superficie del catalizador especialmente en los materiales con niobio. En ese sentido, se ha propuesto que la incorporación de niobio en el gel de síntesis (y, en algunos casos en la estructura del catalizador), favorece una disminución del número de centros ácidos en el catalizador [43], al mismo tiempo que parece estabilizar la estructura cristalina de la fase M1 [44], lo que favorecería una menor degradación de ácido acrílico a óxidos de carbono [45].

Si bien la fase M1 puede obtenerse directamente por síntesis hidrotermal, su posterior activación a alta temperatura puede dar lugar a la formación de otras fases cristalinas que en ocasiones presentan tamaños de cristal lo suficientemente pequeños para no ser detectadas por DRX, pero sí por microscopía de alta resolución [6,39]. Por este motivo, algunos investigadores han empleado métodos post-síntesis a los materiales activados térmicamente, con el fin de eliminar las fases cristalinas no deseadas [29, 31, 33, 46], lo que, en general, favorece un aumento considerable de la selectividad ( $\mathrm{y}$ en algunos casos de la actividad catalítica) a productos de oxidación parcial.

El presente capítulo, se centra en la síntesis, caracterización y comportamiento catalítico de los catalizadores MoV-X-(Nb), X = Te ó Sb, preparados por el método hidrotermal. En particular se va a llevar a cabo un estudio comparativo de la influencia de la temperatura de síntesis hidrotermal en la formación de la fase M1, parámetro poco estudiado hasta el momento. Además, se va a estudiar el efecto de la temperatura de activación en estos materiales, a 
fin de entender mejor el comportamiento catalítico de los catalizadores dependiendo de su composición y la temperatura de activación.

\subsection{Influencia de la temperatura de síntesis}

\subsubsection{Consideraciones generales}

En este apartado se va a estudiar la influencia de la temperatura de síntesis hidrotermal en la formación de la fase M1 de los catalizadores MoV-X-( $\mathrm{Nb}) \mathrm{O}(\mathrm{X}=$ $\mathrm{Te}$ o Sb), y en su comportamiento catalítico, dependiendo de la composición de los materiales. El intervalo de temperaturas estudiado varía entre 100 y $200^{\circ} \mathrm{C}$, a modo de comparación se incluye la síntesis a $175^{\circ} \mathrm{C}$, temperatura normalmente empleada en la síntesis hidrotermal de este tipo de catalizadores [13, 19-20, 29, 46].

Para este estudio, se han preparado materiales Mo-V-Sb-O, Mo-V-Te-O y Mo-V-Te-Nb-O, por el método hidrotermal a diferentes temperaturas de síntesis: $100,135,150,175$ y $200^{\circ} \mathrm{C}$. En todos los casos, la síntesis se ha llevado a cabo tal y como se indica en el apartado 3.1, empleando heptamolibdato amónico y sulfato de vanadilo, así como bromuro de antimonio (para materiales MoVSbO), óxido de teluro (para materiales MoVTeO), y ácido telúrico y oxalato de niobio (para materiales MoVTeNbO). Por otro lado, el gel de síntesis se ha preparado con una relación molar específica para cada sistema catalítico: $\mathrm{Mo} / \mathrm{V} / \mathrm{Sb}=$ $1 / 0.25 / 0.15 ; \mathrm{Mo} / \mathrm{V} / \mathrm{Te}=1 / 0.50 / 0.17, \mathrm{Mo} / \mathrm{V} / \mathrm{Te} / \mathrm{Nb}=1 / 0.25 / 0.17 / 0.17$. En todos los casos, los precursores resultantes de la síntesis hidrotermal se han tratado térmicamente a $600^{\circ} \mathrm{C}$ durante $2 \mathrm{~h}$ en flujo de $\mathrm{N}_{2}$. Los catalizadores obtenidos se han nombrado Sb-T, Te-T y TeNb-T, según la composición, donde $\boldsymbol{T}$ es la temperatura de síntesis hidrotermal $(\mathbf{T}=100,135,150,175$ ó 200ㅜㄱ). Estos materiales se han caracterizado antes y después del tratamiento térmico a $600^{\circ} \mathrm{C}$ en flujo de $\mathrm{N}_{2}$ con el fin de evaluar la formación de las diferentes fases cristalinas.

\subsubsection{Caracterización de los precursores de síntesis}

En la Tabla 5.1 se muestran las características (composición y fases cristalinas) de los precursores obtenidos directamente por síntesis hidrotermal, antes de la activación, a diferente temperatura de síntesis. En general, se puede observar cambios en la formación de las fases cristalinas y en la composición del sólido precursor con la temperatura de síntesis, algo diferentes dependiendo de la composición del catalizador: antimonio, teluro, o teluro y niobio.

En el caso de los materiales con antimonio, la composición del sólido es similar a la composición del gel de síntesis (Mo/V/Sb de 1/0.25/0.15), la cual apenas varia con la temperatura de síntesis. 
Tabla 5.1. Características de los precursores MoVSbO, MoVTeO y MoVTeNbO preparados por el método hidrotermal a diferente temperatura de síntesis.

\begin{tabular}{|c|c|c|c|}
\hline Muestra $^{a}$ & Temp. de Síntesis & $\begin{array}{l}\text { Composición } \\
\text { Mo/V/X/Nb }\end{array}$ & Fases Cristalinas $^{c}$ \\
\hline $\begin{array}{l}\mathrm{Sb}-100 \\
\mathrm{Sb}-135 \\
\mathrm{Sb}-150 \\
\mathrm{Sb}-175 \\
\mathrm{Sb}-200\end{array}$ & $\begin{array}{l}100^{\circ} \mathrm{C} \\
135^{\circ} \mathrm{C} \\
150^{\circ} \mathrm{C} \\
175^{\circ} \mathrm{C} \\
200^{\circ} \mathrm{C}\end{array}$ & $\begin{array}{l}1 / 0.23 / 0.16 / 0 \\
1 / 0.24 / 0.18 / 0 \\
1 / 0.27 / 0.15 / 0 \\
1 / 0.28 / 0.16 / 0 \\
1 / 0.24 / 0.17 / 0\end{array}$ & $\begin{array}{l}\mathrm{M} 1, \mathrm{M} 2, \mathrm{MoO}_{3}-\mathrm{h} \\
\mathrm{M} 1, \mathrm{M} 2, \mathrm{MoO}_{3}-\mathrm{h} \\
\mathrm{M} 1, \mathrm{M} 2, \mathrm{MoO}_{3}-\mathrm{h} \\
\mathrm{M} 1, \mathrm{M} 2 \\
\mathrm{M} 1, \mathrm{M} 2\end{array}$ \\
\hline $\begin{array}{l}\text { Te-100 } \\
\text { Te-135 } \\
\text { Te-150 } \\
\text { Te-175 } \\
\text { Te-200 }\end{array}$ & $\begin{array}{l}100^{\circ} \mathrm{C} \\
135^{\circ} \mathrm{C} \\
150^{\circ} \mathrm{C} \\
175^{\circ} \mathrm{C} \\
200^{\circ} \mathrm{C}\end{array}$ & $\begin{array}{l}1 / 0.35 / 0.09 / 0 \\
1 / 0.42 / 0.06 / 0 \\
1 / 0.44 / 0.06 / 0 \\
1 / 0.46 / 0.09 / 0 \\
1 / 0.48 / 0.12 / 0\end{array}$ & $\begin{array}{l}\mathrm{A}, \mathrm{TeO}_{2} \\
\mathrm{M} 1, \mathrm{TeO}_{2} \\
\mathrm{M} 1, \mathrm{TeO}_{2} \\
\mathrm{M} 1 \\
\mathrm{M} 1\end{array}$ \\
\hline $\begin{array}{l}\text { TeNb-100 } \\
\text { TeNb-135 } \\
\text { TeNb-150 } \\
\text { TeNb-175 } \\
\text { TeNb-200 }\end{array}$ & $\begin{array}{l}100^{\circ} \mathrm{C} \\
135^{\circ} \mathrm{C} \\
150^{\circ} \mathrm{C} \\
175^{\circ} \mathrm{C} \\
200^{\circ} \mathrm{C}\end{array}$ & $\begin{array}{l}1 / 0.08 / 0.20 / 0.13 \\
1 / 0.11 / 0.23 / 0.21 \\
1 / 0.17 / 0.21 / 0.22 \\
1 / 0.24 / 0.25 / 0.25 \\
1 / 0.28 / 0.52 / 0.43\end{array}$ & $\begin{array}{l}\mathrm{Nb}_{2} \mathrm{O}_{5}, \mathrm{TeO}_{2} \\
\mathrm{~A} \\
\mathrm{~A} \\
\mathrm{~A} \\
\mathrm{~A}, \mathrm{Te}\end{array}$ \\
\hline
\end{tabular}

${ }^{a}$ Precursores obtenidos con una relación en el gel de síntesis Mo/V/Sb de 1/0.25/0.15; Mo/V/Te de 1/0.50/0.17; y $\mathrm{Mo} / \mathrm{V} / \mathrm{Te} / \mathrm{Nb}$ de $1 / 0.25 / 0.17 / 0.17 ;{ }^{\mathrm{b}}$ Composición química de los precursores determinada por EDX ( $\mathrm{X}=\mathrm{Te}$ ó $\mathrm{Sb}$ );

${ }^{\circ}$ Fases cristalinas mayoritarias determinadas por DRX: $\mathrm{M} 1=(\mathrm{XO})_{2} M_{20} \mathrm{O}_{56} ; \mathrm{M} 2=\left(\mathrm{X}_{2} \mathrm{O}\right) M_{6} \mathrm{O}_{18}(\mathrm{X}=\mathrm{Sb}$ ó Te; $M=\mathrm{Mo}, \mathrm{V}$ $\mathrm{y} / \mathrm{O} \mathrm{Nb}$ ); $\mathrm{MoO}_{3}$ hexagonal [JCPDS: 21-569]; $\mathrm{TeO}_{2}$ [JCPDS: 65-3825]; $\mathrm{Nb}_{2} \mathrm{O}_{5}$ [JCPDS: 27-1312]; Te [JCPDS: 36-1452] ; $A=$ amorfo.

En el caso de los materiales con Te, no se observa variación de la relación Te/Mo con la temperatura de síntesis, aunque si aumenta el contenido de vanadio en el sólido al aumentar la temperatura de síntesis. En todo caso, los contenidos de teluro fueron inferiores a los del gel de síntesis $(\mathrm{Mo} / \mathrm{V} / \mathrm{Te}=1 / 0.50 / 0.17)$. Mientras que, en el caso de los materiales MoVTeNbO, el contenido de vanadio, teluro y niobio aumentan significativamente con la temperatura de síntesis.

En la Figura 5.1, se muestran los resultados de DRX para los materiales preparados con diferente temperatura de síntesis hidrotermal, donde se puede observar que la distribución de fases cristalinas presentes en los materiales sintetizados depende de la composición.

En el difractograma de rayos $X$ de la muestra con antimonio (Fig. 5.1, A) preparada a $100^{\circ} \mathrm{C}$ se observa la presencia de reflexiones a $2 \theta=22.1,28.3,36.2$ y $45^{\circ}$ correspondientes a la fase $\mathrm{M} 2$ con antimonio, $\left(\mathrm{Sb}_{2} \mathrm{O}\right) \mathrm{M}_{6} \mathrm{O}_{18}(\mathrm{M}=\mathrm{Mo}, \mathrm{V})$ [46], y $\mathrm{MoO}_{3}$ hexagonal $(2 \theta=9.7,25.8,29.4$ y 35.5ㅇ. [JCPDS: $\left.21-569]\right)$, sugiriendo que la formación de la fase M2 se ve favorecida en estos materiales incluso a baja temperatura de síntesis. Al aumentar la temperatura de la síntesis hidrotermal, se observa la aparición de la fase $\mathrm{M} 1,2 \theta=6.7,7.9,8.9,22.2,27.1,29.3,30.5$ y 35.3으. $(\mathrm{SbO})_{2} \mathrm{M}_{20} \mathrm{O}_{56}$ [46], disminuyendo la presencia de $\mathrm{MoO}_{3}$ hexagonal. A alta temperatura (Sb-175 y Sb-200) se observan principalmente las fases M1 y M2. 


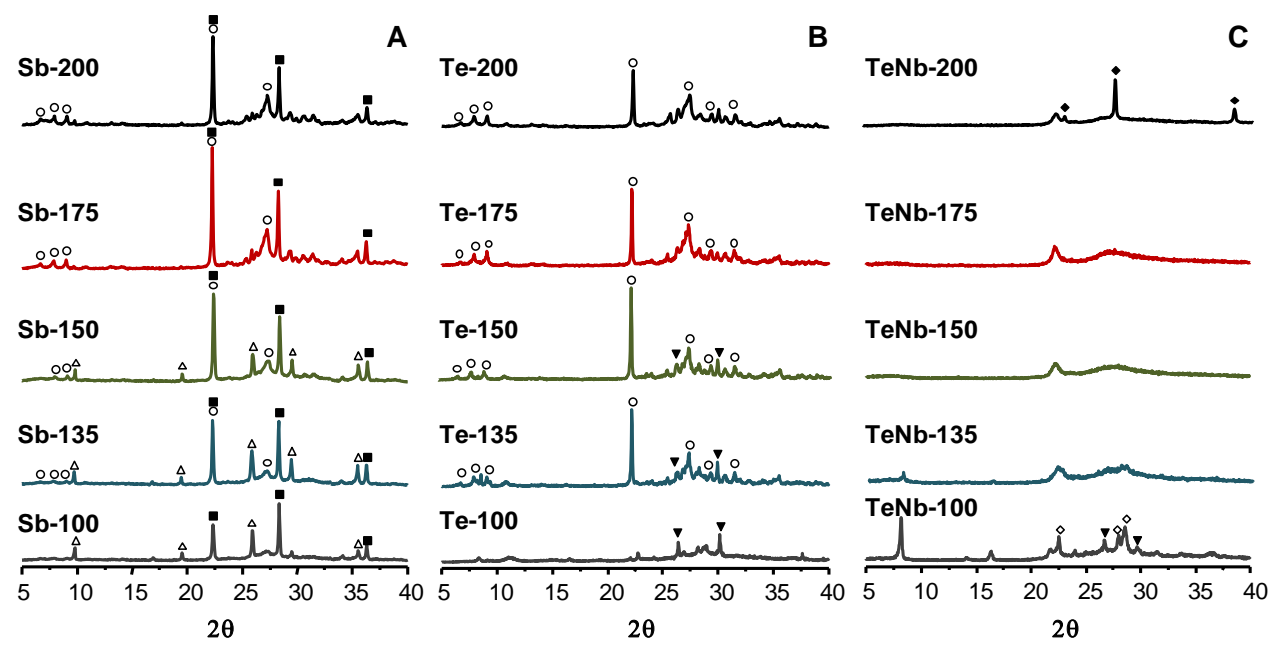

Figura 5.1. Difractogramas de rayos $X$ de los precursores MoVSbO (A), MoVTeO (B) y MoVTeNbO (C) preparados por el método hidrotermal a diferente temperatura de síntesis

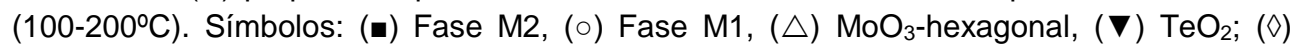
$\mathrm{Nb}_{2} \mathrm{O}_{5} ;(\diamond) \mathrm{Te}$.

En los precursores de los materiales MoVTeO, la fase M1 es mayoritaria en el intervalo de temperaturas de síntesis de 135-200C (Figura 5.1, B). Sin embargo, en el DRX de la muestra preparada a $100^{\circ} \mathrm{C}$ (Te-100) se observa la presencia de un material amorfo y $\mathrm{TeO}_{2}$. Los resultados de la composición de este material determinada por EDX (Tabla 5.1) muestra una baja relación Te/Mo, por lo que cabría pensar que casi todo el teluro está formando $\mathrm{TeO}_{2}$. Estos resultados sugieren que es necesaria una mayor temperatura de síntesis para la formación de la fase $\mathrm{M} 1$. Por otro lado la presencia de $\mathrm{TeO}_{2}$ es minoritaria a mayores temperaturas de síntesis, hasta $150^{\circ} \mathrm{C}$, indicando que los átomos de teluro se incorporan a las fases cristalinas, en especial a la fase M1.

En el caso de los precursores de los catalizadores MoVTeNbO (Figura 5.1, C), los DRX sugieren la presencia de un material amorfo, el cual es característico de los materiales con niobio, debido a la presencia de aniones oxalato en el gel de síntesis [13, 17, 40]. Únicamente a baja temperatura de síntesis (TeNb-100) se observa la presencia de $\mathrm{TeO}_{2}$ y $\mathrm{Nb}_{2} \mathrm{O}_{5}$, además de un pico a 8.3ำ correspondiente a $\left(\mathrm{NH}_{4}\right)_{8}\left(\mathrm{~V}_{19} \mathrm{O}_{41}(\mathrm{OH})_{9}\left(\mathrm{H}_{2} \mathrm{O}\right)_{11}\right.$ [40], indicando que es necesaria una temperatura de síntesis mayor para la formación del precursor de la fase M1. En el precursor preparado a $200^{\circ} \mathrm{C}$ (TeNb-200) se observa la presencia de Te metálico, debido posiblemente a la reducción del teluro por los iones oxalato durante la síntesis hidrotermal.

Así, los materiales MoVSb muestran principalmente la formación de las fases M1 y M2, mientras que los materiales MoVTe con teluro dan lugar a la fase M1 (y 
$\mathrm{TeO}_{2}$ ). Posiblemente, esta diferencia en la composición cristalina se debe a la menor incorporación de Te en el sólido. En el caso de los materiales MoVTeNbO, se observa sólo la presencia de un sólido amorfo (caracterizado por la presencia de un pico a $2 \theta=22.0$ ). Además, se puede observar una influencia de la temperatura de síntesis sobre la formación de las fases cristalinas dependiendo de la composición de los materiales.

Por otro lado, para los materiales MoVSbO y MoVTeO, se ha realizado una cuantificación de las fases cristalinas presentes en los precursores antes de la activación mediante el empleo del método de refinamiento de Rietveld [47]. Los resultados se muestran en la Figura 5.2. Cabe señalar que los cálculos se han realizado con un patrón interno $\left(20 \%\right.$ de $\left.\mathrm{V}_{2} \mathrm{O}_{5}\right)$ para tener en cuenta la presencia de sólido amorfo en los materiales.
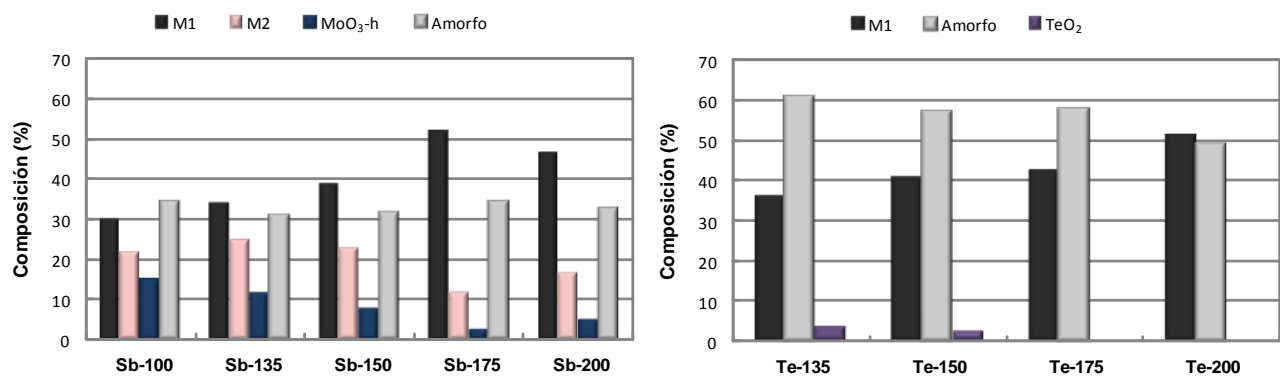

Figura 5.2. Composición de fases cristalinas de los precursores MoVSbO y MoVTeO, antes de la activación, preparados a diferente temperatura de síntesis.

Tanto en los materiales con antimonio como con teluro, la cantidad de fase M1 formada aumenta al aumentar la temperatura de síntesis hidrotermal. En los materiales con antimonio (Figura 5.2, izda.) la presencia de fase $\mathrm{M} 2$ y $\mathrm{MoO}_{3}$ hexagonal disminuye al aumentar la temperatura de síntesis. En los materiales con teluro (Figura 5.2, dcha.) se observa la presencia minoritaria de $\mathrm{TeO}_{2}$ (aproximadamente un $3 \%$ ) en los materiales preparados a 135 y $150^{\circ} \mathrm{C}$, que desaparece a mayores temperaturas de síntesis.

Por otro lado, la cantidad de sólido amorfo presente en los precursores con antimonio es muy similar (aproximadamente un 25\%), independiente de la temperatura de síntesis. Sin embargo, la cantidad de sólido amorfo presente en los materiales con teluro es mayor (60\% en el material Te-135) y disminuye con la temperatura de síntesis.

En la Figura 5.3 se muestran las micrografías SEM obtenidas para los precursores sin activar (MoVSbO, MoVTe y MoVTeNb). Se puede apreciar claramente el efecto de la temperatura de la síntesis en el tamaño de los cristales que componen los materiales. 
$100^{\circ} \mathrm{C}$

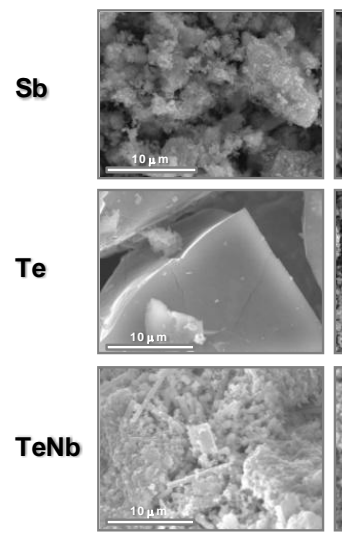

$135 \circ \mathrm{C}$
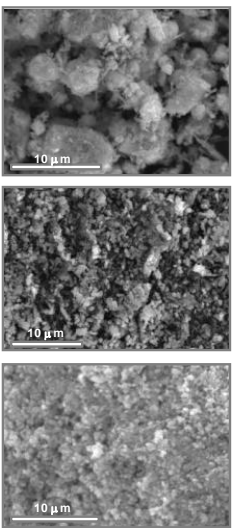

$150^{\circ} \mathrm{C}$
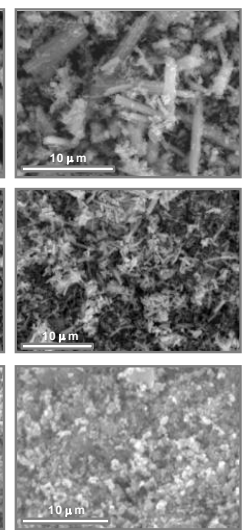

$175^{\circ} \mathrm{C}$
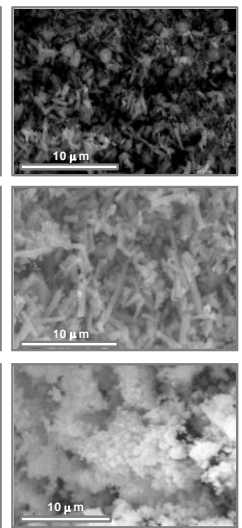

$200^{\circ} \mathrm{C}$

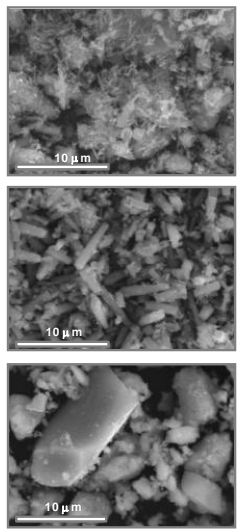

Figura 5.3. Micrografías SEM de los precursores sin activar MoVSbO (serie Sb), MoVTe (serie Te), y MoVTeNbO (serie TeNb) preparados a diferente tempertura de síntesis hidrotermal (en $\left.{ }^{\circ} \mathrm{C}\right)$.

La morfología de los cristales presentes en los materiales es similar a la observada para este tipo de óxidos mixtos, dependiendo de la composición. Así, los materiales MoVSbO y MoVTe, sin niobio, presentan principalmente cristales alargado con los bordes estriados que corresponden a cristales de la fase M1. En el caso de los materiales con antimonio, también se observan cristales de mayor tamaño en forma de placa correspondientes a la fase M2. En el caso del catalizador con $\mathrm{Nb}$, se observan cristales mucho más pequeños, los cuales corresponderían al material amorfo, tal y como se observa por DRX.

Por otro lado, el tamaño de cristal observado por microscopía de barrido está influenciado por la temperatura de síntesis a la que se han preparado los materiales. En este sentido, se puede observar que aunque el tamaño de cristal a baja temperatura $\left(100^{\circ} \mathrm{C}\right)$ es mucho mayor que para el resto de temperaturas, los cristales observados corresponden a otras fases no deseadas formadas durante la síntesis (Figura 5.1). Sin embargo, en los catalizadores con teluro (MoVTeO y MoVTeNb), se observa un aumento claro del tamaño de cristal con la temperatura de síntesis en el intervalo de temperatura entre 135 y $200^{\circ} \mathrm{C}$, lo que sugiere que son necesarias mayores temperaturas de síntesis para la formación y cristalización de la fase M1. En ese sentido, cabe destacar el precursor TeNb-200 donde se observan cristales de gran tamaño (mayor al observado en la micrografía) con estequiometria correspondiente a la fase M1.

En el caso de los materiales con antimonio, se observa un efecto contrario en el tamaño de los cristales correspondientes a la fase M1, siendo menor el tamaño de cristal a medida que se aumenta la temperatura de síntesis. A bajas temperaturas la fase mayoritaria es la fase M2 (Sb-100 y Sb-135). Al aumentar la 
temperatura de síntesis se observa una mayor presencia de fase M1 (con presencia de fase M2 también) y un aumento de la cristalización de la misma. Sin embargo, al comparar las imágenes SEM de los precursores preparados en el intervalo $150-200^{\circ} \mathrm{C}$, se puede observar que los cristales de la fase M1 presentan menor tamaño de cristal, al aumentar la temperatura de síntesis.

\subsubsection{Caracterización de los materiales activados térmicamente}

En la Tabla 5.2 se presentan algunas características de los catalizadores MoVSbO, MoVTeO y MoVTeNbO activados a $600^{\circ} \mathrm{C} / \mathrm{N}_{2}$, preparados con diferente temperatura de síntesis hidrotermal. En general, todos ellos presentan áreas superficiales relativamente bajas, por debajo de los $12 \mathrm{~m}^{2} \mathrm{~g}^{-1}$.

Tabla 5.2. Características de los catalizadores del tipo MoVSbO, MoVTeO y MoVTeNbO, preparados a diferentes temperaturas de síntesis (Tabla 5.1) y tratados térmicamente a $600^{\circ} \mathrm{C}$

\begin{tabular}{|c|c|c|c|c|}
\hline \multirow{2}{*}{ Muestra } & \multirow{2}{*}{$\begin{array}{c}S_{\mathrm{BET}} \\
\left(\mathrm{m}^{2} \mathrm{~g}^{-1}\right)\end{array}$} & \multicolumn{2}{|l|}{ TPD- $\mathrm{NH}_{3}$} & \multirow{2}{*}{ Fases Cristalinas $^{c}$} \\
\hline & & $\left(\mu \mathrm{mol}_{\mathrm{NH} 3} \mathrm{~g}^{-1}\right)^{\mathrm{a}}$ & $\mathrm{T}_{\text {máx }}\left({ }^{\mathrm{o}} \mathrm{C}\right)^{\mathrm{b}}$ & \\
\hline Sb-100a & 4.5 & 53.8 & 193.6 & $\mathrm{M} 1, \mathrm{M} 2, \mathrm{Sb}_{2} \mathrm{Mo}_{10} \mathrm{O}_{31}$ \\
\hline Sb-135a & 6.1 & 45.1 & 183.9 & $\mathrm{M} 1, \mathrm{M} 2, \mathrm{Sb}_{2} \mathrm{Mo}_{10} \mathrm{O}_{31}$ \\
\hline Sb-150a & 8.8 & 63.7 & 191.5 & M1, M2 \\
\hline Sb-175a & 12.0 & 92.6 & 192.7 & M1, M2 \\
\hline Sb-200a & 7.9 & 50.7 & 178.1 & M1, M2 \\
\hline Te-100a & n.d & n.d & - & $\mathrm{TeMo}_{5} \mathrm{O}_{16}, \mathrm{Mo}_{0.97} \mathrm{~V}_{0.95} \mathrm{O}_{5}$ \\
\hline Te-135a & 8.4 & 70.6 & 164.8 & $\mathrm{M} 1, \mathrm{M} 2, \mathrm{TeMo}_{5} \mathrm{O}_{16}, \mathrm{Mo}_{0.97} \mathrm{~V}_{0.95} \mathrm{O}_{5}$ \\
\hline Te-150a & 9.4 & 77.4 & 171.3 & $\mathrm{M} 1, \mathrm{M} 2, \mathrm{TeMO}_{5} \mathrm{O}_{16}, \mathrm{MoO}_{3}$ \\
\hline Te-175a & 5.9 & 55.5 & 176.9 & $\mathrm{M} 1, \mathrm{M} 2, \mathrm{TeMo}_{5} \mathrm{O}_{16}, \mathrm{MoO}_{3}$ \\
\hline Te-200a & 3.8 & 46.7 & 182.7 & $\mathrm{M} 1, \mathrm{M} 2, \mathrm{TeMo}_{5} \mathrm{O}_{16}$ \\
\hline TeNb-100a & n.d & n.d & - & $\mathrm{TeMo}_{5} \mathrm{O}_{16}$ \\
\hline TeNb-135a & 3.1 & 49.9 & 170.8 & $\mathrm{M} 1, \mathrm{TeMo}_{5} \mathrm{O}_{16}$ \\
\hline TeNb-150a & 4.3 & 22.3 & 177.1 & M1 \\
\hline TeNb-175a & 7.9 & 53.4 & 193.1 & M1 \\
\hline TeNb-200a & 11.8 & 34.9 & 186.7 & A \\
\hline
\end{tabular}

${ }^{\mathrm{a}}$ Cantidad de amoníaco quimisorbida a $100^{\circ} \mathrm{C}$ durante el experimento $\mathrm{TPD}-\mathrm{NH}_{3}$, por gramo del catalizador (medido en condiciones standard de presión y temperatura);

${ }^{\mathrm{b}} \mathrm{T}_{\text {máx }}$, temperatura del máximo de desorción.

${ }^{c}$ Fases cristalinas mayoritarias determinadas por DRX: $\mathrm{M} 1=(\mathrm{XO})_{2} M_{20} \mathrm{O}_{56} ; \mathrm{M} 2=\left(\mathrm{X}_{2} \mathrm{O}\right) M_{6} \mathrm{O}_{18}(\mathrm{X}=\mathrm{Sb}$ ó Te; $M=\mathrm{Mo}, \mathrm{V}$ $\mathrm{y} / \mathrm{o} \mathrm{Nb}$ ); $\mathrm{Sb}_{2} \mathrm{Mo}_{10} \mathrm{O}_{31}$ [JCPDS: 33-105]; $\mathrm{TeMo}_{5} \mathrm{O}_{16}$ [JCPDS: 31-0874]; $\mathrm{Mo}_{0.97} \mathrm{~V}_{0.95} \mathrm{O}_{5}$ [JCPDS: 77-649]; $\mathrm{MoO}_{3}-\mathrm{o}$ [JCPDS: 05-508]; A = amorfo;

El área superficial en los materiales con antimonio o con niobio aumenta al aumentar la temperatura de síntesis, mientras que los materiales con teluro sin niobio (MoVTeO) presentan un área superficial menor a medida que aumenta la temperatura de síntesis. 
En la Figura 5.4 se muestran los difractogramas de rayos $X$ (DRX) de los catalizadores activados a $600^{\circ} \mathrm{C} / \mathrm{N}_{2}$. En general, en los materiales sin niobio (MoVSbO y MoVTeO), se observa una descomposición parcial de la fase M1, presente en los materiales sin activar (Figura 5.1), al ser tratados a $600^{\circ} \mathrm{C}$ (en $\mathrm{N}_{2}$ ). En general, el tratamiento térmico favorece la formación de la fase M2 (o un aumento en la intensidad de las reflexiones características de la fase $\mathrm{M} 2$, en el caso de los materiales con antimonio), así como de las fases $\mathrm{TeMo}_{5} \mathrm{O}_{16} \mathrm{O}$ $\mathrm{Sb}_{2} \mathrm{Mo}_{10} \mathrm{O}_{31}$.

Sin embargo, en los catalizadores MoVTeNbO, se observa mayoritariamente la presencia de la fase $\mathrm{M} 1$, al menos en los catalizadores que fueron preparados a temperaturas de síntesis entre 135 y $175^{\circ} \mathrm{C}$.

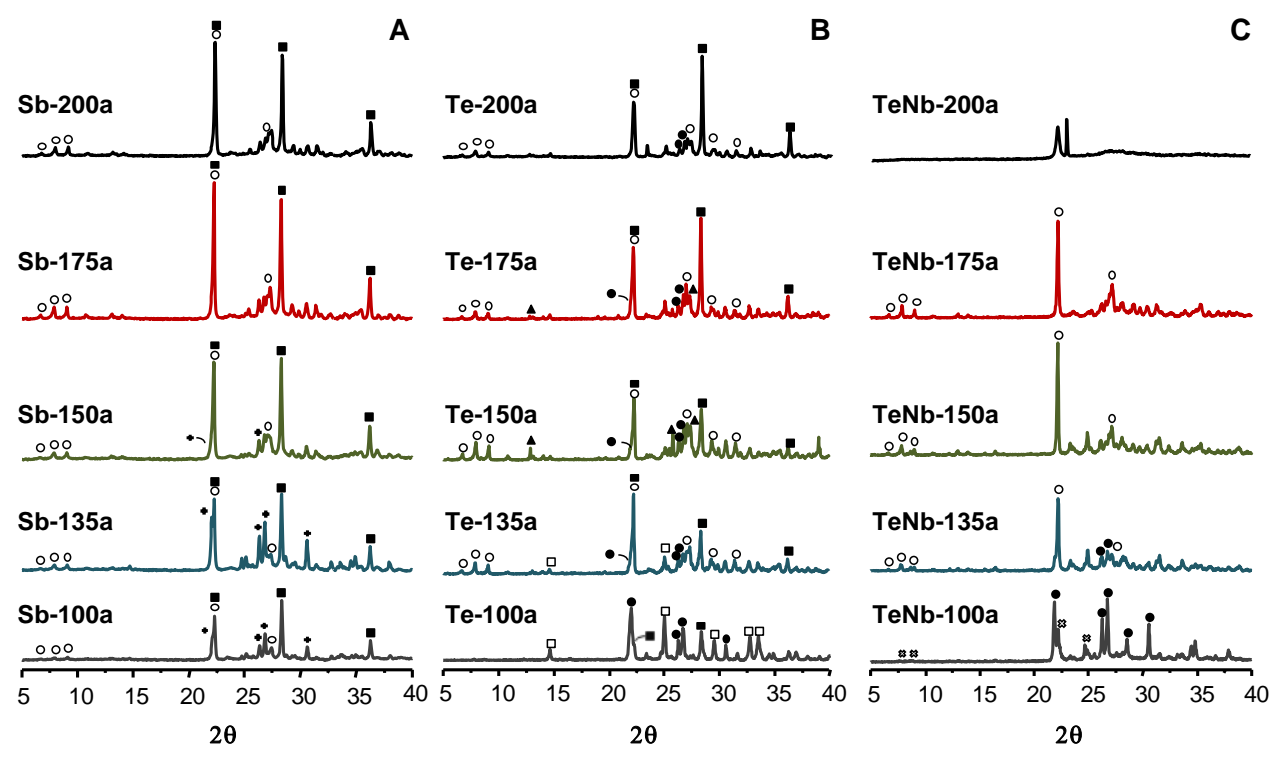

Figura 5.4. Difractogramas de rayos $X$ de los catalizadores MoVSbO (A), MoVTeO (B) y MoVTeNbO (C) preparados por el método hidrotermal a diferente temperatura de síntesis $\left(100-200^{\circ} \mathrm{C}\right)$ y activados térmicamente a $600^{\circ} \mathrm{C} / \mathrm{N}_{2}$. Símbolos: (๘) Fase M2, (०) Fase M1, (†) $\mathrm{Sb}_{2} \mathrm{Mo}_{10} \mathrm{O}_{31},(\bullet) \mathrm{TeMo}_{5} \mathrm{O}_{16},(\boldsymbol{\Delta}) \mathrm{MoO}_{3}$-ortorrómbica, (口) $\mathrm{Mo}_{0.97} \mathrm{~V}_{0.95} \mathrm{O}_{5},(\mathfrak{x})\left(\mathrm{V}_{0.07} \mathrm{Mo}_{0.93}\right)_{5} \mathrm{O}_{14}$.

En la Figura 5.5 se muestra la cuantificación de fases cristalinas presentes en los catalizadores activados. En este caso, no se ha tenido en cuenta la posibilidad de la presencia de sólidos amorfos en los catalizadores. En general, se puede observar que la cantidad de fases cristalinas presente depende de la composición de los materiales y la temperatura de síntesis a la que se han preparado. Además de las fases $\mathrm{M} 1, \mathrm{M} 2$ y $\mathrm{Sb}_{2} \mathrm{Mo}_{10} \mathrm{O}_{31}$ (o su equivalente $\mathrm{TeMo}_{5} \mathrm{O}_{16}$ ) mostradas en la Figura 5.4, se observa la presencia minoritaria de $\mathrm{MoO}_{3}$ ortorrómbica y $\quad\left(\mathrm{Mo}_{0.97} \mathrm{~V}_{0.95}\right) \mathrm{O}_{5}$ (en los materiales sin niobio) o 
$\left(\mathrm{Mo}_{0.97} \mathrm{~V}_{0.03}\right)_{5} \mathrm{O}_{14}$ (en los materiales con niobio), cuya presencia disminuye al aumentar la temperatura de síntesis hidrotermal.

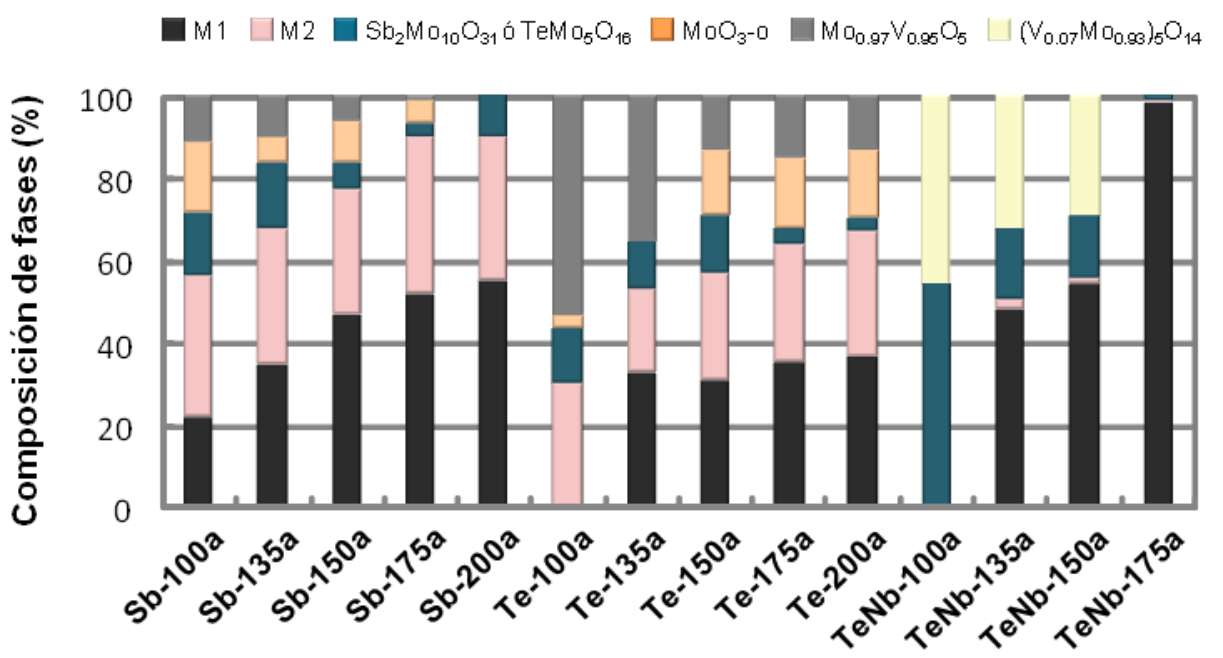

Figura 5.5. Composición de fases cristalinas de los catalizadores MoVSbO, MoVTeO y MoVTeNbO activados a $600^{\circ} \mathrm{C}$ preparados a diferente temperatura de síntesis.

Por otro lado, en el caso de los catalizadores MoVTeO sin niobio (Figura 5.4, B), la descomposición parcial de la fase M1 (presente mayoritariamente en el material sin activar, Fig. 5.1), está relacionada con la temperatura de síntesis a la que fueron preparados estos materiales. Así, a medida que aumenta la temperatura de síntesis se observa un aumento en la intensidad de los picos correspondientes a la fase $\mathrm{M} 2$ (además de otras fases como $\mathrm{TeMo}_{5} \mathrm{O}_{16}$ y $\mathrm{MoO}_{3}$ ). Estos resultados sugieren que la temperatura de síntesis no sólo influye en la formación de la fase M1 sino también en su estabilidad durante el tratamiento térmico de activación de los materiales. En este sentido, debemos resaltar que, de acuerdo con los resultados de la Tabla 5.1, el contenido de vanadio y (en menor medida de teluro) aumenta con el incremento de la temperatura de síntesis. Por tanto, una mayor incorporación de vanadio podría no ser beneficiosa para la estabilidad térmica de la fase M1.

Por último, los catalizadores con niobio, materiales MoVTeNbO tratados térmicamente a $600^{\circ} \mathrm{C}$, presentan mayoritariamente la fase $\mathrm{M} 1$ cuando los materiales fueron preparados en el intervalo de temperatura de síntesis de 135 a 175ㄷ (Figura 5.4, C). Sin embargo, el catalizador obtenido a partir del material preparado a una temperatura de síntesis de $100^{\circ} \mathrm{C}$, presenta mayoritariamente la fase $\mathrm{TeMo}_{5} \mathrm{O}_{16}$. Por otra parte, en el catalizador TeNb-200a se observa la presencia de un material amorfo similar al encontrado en el material sin activar (TeNb-200), presumiblemente debido al colapso de la estructura M1. 
Por otro lado, el estudio por microscopía de barrido (SEM) de los catalizadores activados a $600^{\circ} \mathrm{C}$ se muestran en la Figura 5.6, mientras que en la Tabla 5.3 se presentan los resultados de los análisis EDX de dichos cristales.

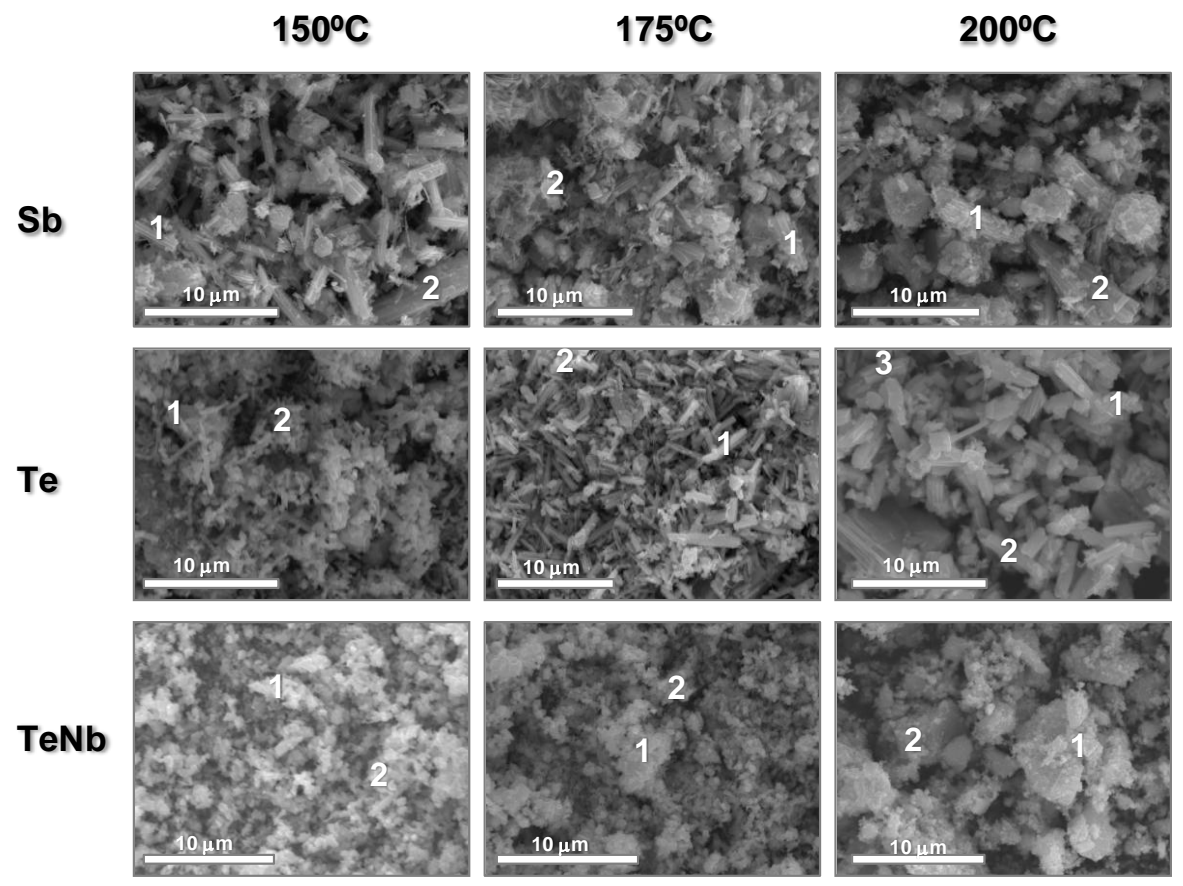

Figura 5.6. Micrografías SEM de los catalizadores MoVSbO, MoVTeO y MoVTeNbO preparados en intervalo de temperaturas de síntesis $150-200^{\circ} \mathrm{C}$ y activado a $600^{\circ} \mathrm{C} / \mathrm{N}_{2}$.

Si se compara cada una de estas micrografías con las obtenidas para el correspondiente material sin activar (Figura 5.3), no se aprecian cambios morfológicos importantes, salvo ligeras diferencias en el tamaño de los cristales de la fase M1 dependiendo de la composición de los mismos. Así, en general, se observa un ligero aumento del tamaño medio de los cristales, especialmente los relacionados con la fase M1, lo que está de acuerdo con los resultados de DRX que muestran un aumento de la cristalinidad tras la activación térmica a alta temperatura. Sin embargo, en el caso de los materiales MoVTeO se puede apreciar que además de cristales de la fase M1 de menor tamaño que en los materiales sin activar, aumenta la presencia de cristales con forma de placa (característicos de la fase M2).

Por otro lado, si tenemos en cuenta la temperatura de síntesis a la que se han preparado los catalizadores, se observa una tendencia en el tamaño de cristal de la fase M1 similar a la encontrada en los materiales sin activar: al aumentar la 
temperatura de síntesis se produce un aumento del tamaño de cristal de la fase M1.

En este punto se debe indicar que las micrografías de los precursores, antes de la activación, se han realizado en los materiales directamente de síntesis sin molturar. En cambio, en el caso de los materiales activados, los precursores obtenidos se han molturado antes de someterlos al tratamiento térmico, con lo que los tamaños de partícula podrían haber variado.

Por otro lado, la composición de los catalizadores activados a $600^{\circ} \mathrm{C}$ (Tabla 5.3) es muy similar a la encontrada en los materiales antes de la activación térmica (Tabla 5.1), si bien en los materiales con teluro (con o sin niobio) se ha observado un ligero aumento de las relaciones V/Mo, Te/Mo y Nb/Mo con el aumento de la temperatura de síntesis (Tabla 5.3).

Tabla 5.3. Análisis EDX de los catalizadores MoVSbO, MoVTeO y MoVTeNbO preparados en el intervalo de temperatura de síntesis $150-200^{\circ} \mathrm{C}$ y activados a $600^{\circ} \mathrm{C} / \mathrm{N}_{2}$.

\begin{tabular}{lll}
\hline \multirow{2}{*}{ Muestra } & \multicolumn{2}{l}{ Composición, Mo/V/X/Nb } \\
\cline { 2 - 3 } & Total $^{\text {a }}$ & Local $^{\mathbf{b}}$ \\
\hline Sb-150a & $1 / 0.28 / 0.15 / 0$ & $1 / 0.25-0.26 / 0.09 / 0.10 / 0$ \\
Sb-175a & $1 / 0.28 / 0.16 / 0$ & $1 / 0.23-0.24 / 0.08-0.11 / 0$ \\
Sb-200a & $1 / 0.25 / 0.16 / 0$ & $1 / 0.24-0.26 / 0.08-0.09 / 0$ \\
\hline Te-150a & $1 / 0.55 / 0.11 / 0$ & $1 / 0.46-0.49 / 0.07-0.09 / 0$ \\
Te-175a & $1 / 0.46 / 0.13 / 0$ & $1 / 0.43-0.47 / 0.12-0.16 / 0$ \\
Te-200a & $1 / 0.49 / 0.16 / 0$ & $1 / 0.37-0.44 / 0.12-0.15 / 0$ \\
\hline TeNb-150a & $1 / 0.18 / 0.16 / 0.22$ & $1 / 0.14-0.16 / 0.04-0.10 / 0.22-0.23$ \\
TeNb-175a & $1 / 0.22 / 0.16 / 0.23$ & $1 / 0.19-0.21 / 0.15-0.17 / 0.22-0.23$ \\
TeNb-200a & $1 / 0.28 / 0.18 / 0.43$ & $1 / 0.24-0.35 / 0.13-0.16 / 0.37-0.45$ \\
\hline${ }^{a}$ Análisis químico determinado por EDX; \\
${ }^{b}$ Análisis químico de las partículas indicadas en las imágenes de SEM (ver Figura 5.4).
\end{tabular}

Sin embargo, si se tiene en cuenta la composición local de los cristales de la fase $M 1$ (con una relación teórica $X / M=0.1$; donde $X=T$ é $S b$ y $M=M o, V$ ó $\mathrm{Nb}$ ), la composición de estos cristales permanece constante en los materiales MoVSbO, independientemente de la temperatura de síntesis a la que se han preparado, mientras que en los materiales con teluro se observan diferencias significativas en el contenido de teluro en función de la temperatura de síntesis (Tabla 5.3). Así, los materiales con y sin niobio preparados a $150^{\circ} \mathrm{C}$ presentan una relación Te/Mo menor que la encontrada para los catalizadores preparados a 175ㄷ․ Además, la composición local de los materiales con niobio, MoVTeNbO, muestran una variación de la relación molar V/Mo y Nb/Mo en función de la temperatura de síntesis.

Por otro lado, en la muestra MoVTeNb preparada a $200^{\circ} \mathrm{C}$ y activada a $600^{\circ} \mathrm{C}, \mathrm{TeNb}-200 \mathrm{a}$, se observa la presencia de cristales grandes, con una relación 
$\mathrm{Mo} / \mathrm{V} / \mathrm{Nb}$ de $1 / 0.5 / 1$ (sin teluro), que debe corresponder a la fase cristalina aún no determinada que se observa por DRX, además del material amorfo (Figura 5.4).

Por otro lado, y con el fin de analizar posibles cambios en la densidad de centros ácidos de estos materiales, se ha llevado a cabo un estudio de desorción de amoníaco a temperatura programada (TPD- $\mathrm{NH}_{3}$ ). En la Figura 5.7 se muestran las curvas de desorción normalizadas obtenidas experimentalmente para los diferentes catalizadores, mientras que en la Tabla $\mathbf{5 . 2}$ se presentan los resultados de las medidas de TPD- $\mathrm{NH}_{3}$ : la cantidad de amoníaco quimisorbido a $100^{\circ} \mathrm{C}$ y la temperatura del máximo de desorción.
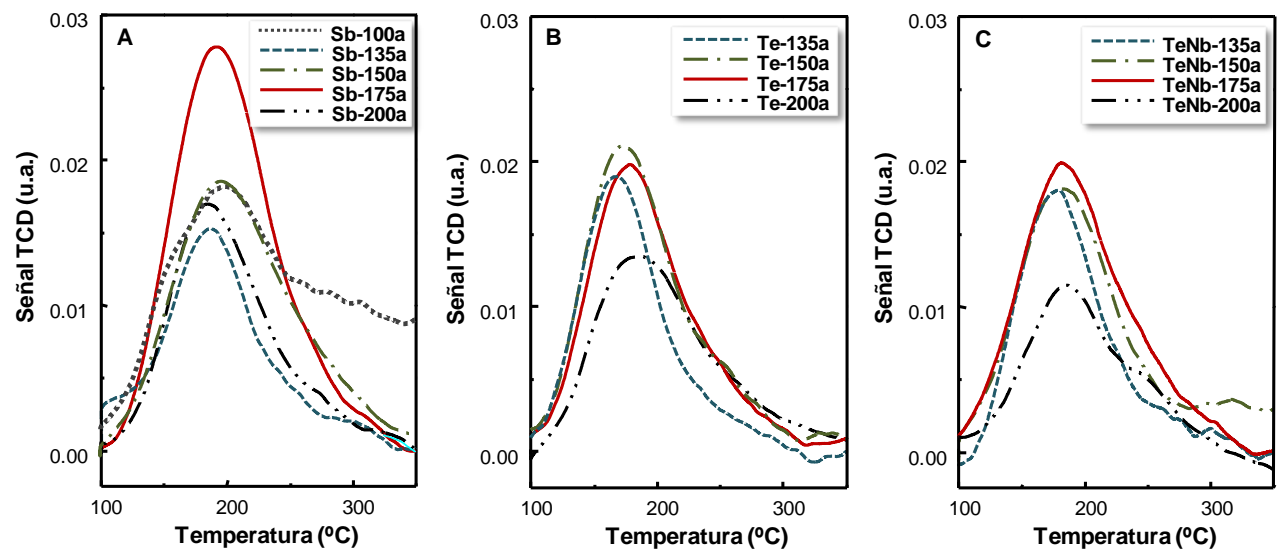

Figura 5.7. Espectros TPD-NH $\mathrm{NH}_{3}$ de los sistemas (A) MoVSb; (B) MoVTe y (C) MoVTeNb preparados a diferente temperatura de síntesis y activados a $600^{\circ} \mathrm{C} / \mathrm{N}_{2}$.

En el caso de los materiales con antimonio, MoVSbO, el número y la naturaleza de centros ácidos cambia con la temperatura de síntesis, mientras que en los catalizadores con teluro, tanto MoVTeO como MoVTeNbO, no se observan variaciones significativas (salvo en el caso de los catalizadores preparados a 200드, Te-200a y TeNb-200a, materiales que no son de interés dado que no presentan la fase M1).

Resultados anteriores sugieren que los materiales con antimonio presentan un número de centros ácidos mayor que los correspondientes materiales con teluro $[43,48]$. Sin embargo, si se observan las curvas presentadas en la Figura 5.7 se puede ver que esta mayor densidad de centros ácidos solamente se produce en los materiales preparados a $175^{\circ} \mathrm{C}$ (temperatura normalmente empleada en la síntesis hidrotermal). Al disminuir o aumentar la temperatura de la síntesis hidrotermal se observa una disminución del número de centro ácidos presentes en la superficie del catalizador, con valores para el material con antimonio muy similares a los observados en los materiales con teluro. Por otro lado, si se tiene en cuenta el área superficial de los materiales, se puede concluir 
que, en realidad, no existe variación del número de centros ácidos por superficie, siendo aproximadamente $7 \mu \mathrm{mol}_{\mathrm{NH} 3} \mathrm{~m}^{-2}$ independientemente de la temperatura de síntesis. La única excepción se presenta en el catalizador preparado a $100^{\circ} \mathrm{C}$ (en el que se observa una adsorción de amoníaco de $12 \mu \mathrm{mol}_{\mathrm{NH} 3} \mathrm{~m}^{-2}$ ). En cambio, la temperatura del máximo de desorción en materiales con antimonio es mayor que en catalizadores con teluro, indicando una fortaleza ácida ligeramente mayor.

En el caso de los materiales con teluro (Figura 5.7, B y C), en el intervalo de temperaturas de síntesis entre $135-175^{\circ} \mathrm{C}$, no se observa variación del número de centros ácidos presentes en la superficie del catalizador, independientemente de la presencia o ausencia de niobio en el catalizador. Solamente, en el caso de los materiales con teluro preparados a $200^{\circ} \mathrm{C}$ se observa una disminución del número de centros ácidos y un ligero aumento de la temperatura del máximo de adsorción lo que sugiere una fortaleza ácida ligeramente mayor.

\subsubsection{Resultados catalíticos para la oxidación de propano}

En las Figura 5.8 se muestra la variación de la conversión de propano a $380^{\circ} \mathrm{C}$ (Fig. 5.8 A) y de la selectividad a ácido acrílico (a una conversión de propano de 20\%) (Fig. 5.8 B), durante la oxidación de propano sobre los catalizadores MoVSbO, MoVTeO y MoVTeNbO, preparados a diferentes temperaturas de síntesis (y activados a $600^{\circ} \mathrm{C}$ ). Los catalizadores con teluro $\mathrm{MoVTe}(\mathrm{Nb}) \mathrm{O}$ preparados a baja temperatura de síntesis $\left(100^{\circ} \mathrm{C}\right)$ son prácticamente inactivos para la oxidación de propano (Figura 5.8, A), independientemente de la presencia o ausencia de niobio, mientras que el correspondiente catalizador con antimonio, Sb-100a, ha mostrado ser activo en la oxidación de propano. Estas diferencias de actividad se pueden explicar en función de la ausencia (materiales con Te) o presencia (materiales con Sb) de la fase M1 en los catalizadores (Figura 5.4).

A mayores temperaturas de síntesis, se favorece la obtención de catalizadores activos para la oxidación de propano, aumentando la actividad a medida que aumenta la temperatura de síntesis, siendo los catalizadores más activos aquellos preparados a $175^{\circ} \mathrm{C}$ (los materiales obtenidos a $200^{\circ} \mathrm{C}$ presenta muy baja actividad debido a la casi ausencia de la fase M1) (Figura 5.8, A).

Por otro lado, la temperatura de síntesis también tiene una fuerte influencia en la selectividad a ácido acrílico (Figura 5.8, B), tendencia similar a la observada para la actividad catalítica. Así, los catalizadores más selectivos son los materiales con niobio preparados en el intervalo de temperaturas de síntesis entre 150-175드 (alcanzando selectividades a ácido acrílico del 70\%). 

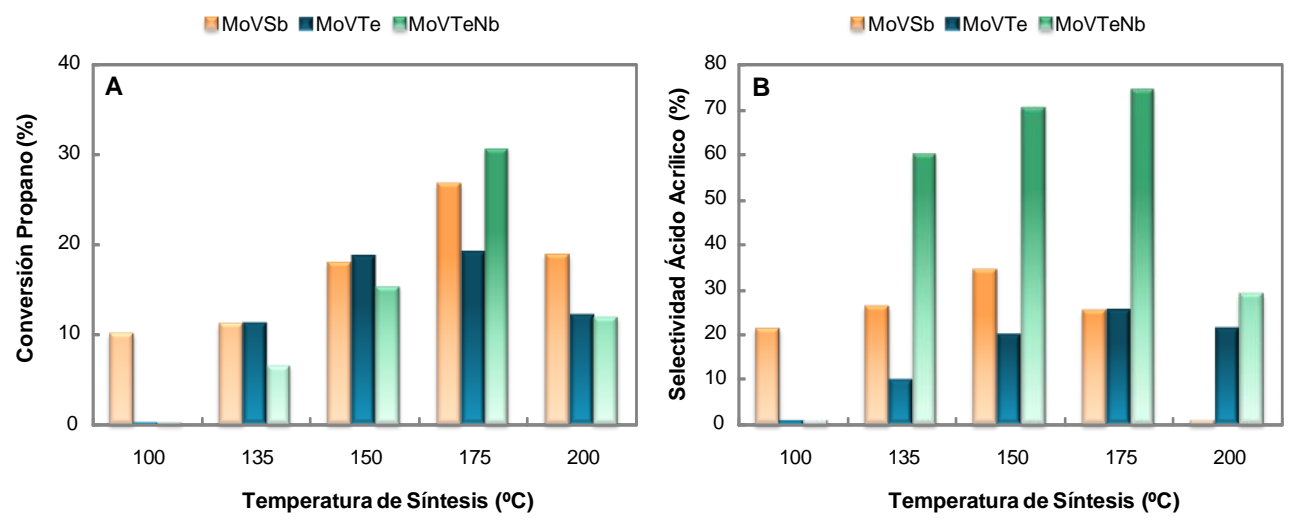

Figura 5.8. Variación de la conversión de propano (A) y de la selectividad a ácido acrílico (B) (a una conversión de propano de 20\%) con la temperatura empleada en la síntesis hidrotermal de los catalizadores. Condiciones de reacción: tiempo de contacto, W/F, de 200 $\mathrm{g}_{\text {cat }} \mathrm{h}\left(\mathrm{mol}_{\mathrm{C} 3 \mathrm{H} 8}\right)^{-1} ; \mathrm{T}=380^{\circ} \mathrm{C}$; relación molar $\mathrm{C}_{3} \mathrm{H}_{8} / \mathrm{O}_{2} / \mathrm{H}_{2} \mathrm{O} / \mathrm{He}$ de $4 / 8 / 30 / 58$.

Sin embargo, en los catalizadores preparados sin niobio, las selectividades a ácido acrílico fueron inferiores al 30\%. Cabe destacar que en el caso de los materiales con antimonio, MoVSbO, el catalizador preparado a baja temperatura ha demostrado ser selectivo a ácido acrílico durante la oxidación de propano, mientras que el más selectivo fue aquel preparado a una temperatura de síntesis de $150^{\circ} \mathrm{C}$.

\subsection{Influencia de la temperatura de activación}

\subsubsection{Consideraciones generales}

En el presente apartado se estudiará la influencia de la temperatura de activación térmica en las propiedades catalíticas de los catalizadores MoVSbO, MoVTeO y MoVTeNbO. Para este estudio, los precursores de los catalizadores se han preparado por el método hidrotermal, al igual que los materiales descritos en el apartado 5.2.1, a una temperatura de síntesis de $175^{\circ} \mathrm{C}$. Los precursores obtenidos en la síntesis hidrotermal (antes de la activación térmica) se denominaran como Sb-as, Te-as y TeNb-as (para los materiales MoVSbO, MoVTeO o MoVTeNbO, respectivamente), mientras que los materiales tratados térmicamente (durante $2 \mathrm{~h}$, en flujo de $\mathrm{N}_{2}$, en el intervalo $500-600^{\circ} \mathrm{C}$ ) se han denominado como Sb-Tx, Te-Tx y TeNb-Tx, donde $\mathbf{T x}$ es la temperatura de activación de los catalizadores ( $\mathbf{T x}=500,550$ ó $600^{\circ} \mathrm{C}$ ). Las características de los catalizadores se muestran en la Tabla 5.5. 


\subsubsection{Resultados catalíticos para la Oxidación Parcial de Propano}

En la Tabla 5.4 se muestran los resultados catalíticos en la oxidación parcial de propano a $400^{\circ} \mathrm{C}$ para los catalizadores MoVSb, MoVTeO y MoVTeNbO activados térmicamente a diferentes temperaturas. Los productos principalmente observados son propileno, ácido acrílico, ácido acético y óxidos de carbono (CO y $\mathrm{CO}_{2}$ ), con trazas de acetona.

Tabla 5.4. Resultados catalíticos en la oxidación parcial de propano sobre catalizadores $\operatorname{MoVX}(\mathrm{Nb}) \mathrm{O}\left(\mathrm{X}=\mathrm{Te}\right.$ o Sb) a $400^{\circ} \mathrm{C}$.

\begin{tabular}{|c|c|c|c|c|c|c|c|}
\hline \multirow{2}{*}{ Catalizador } & \multirow{2}{*}{$\begin{array}{l}\text { Temperatura } \\
\text { de Activación }\end{array}$} & \multirow{2}{*}{$\begin{array}{l}\text { Conv. } \\
(\%)^{a}\end{array}$} & \multicolumn{5}{|c|}{ Selectividad (\%) } \\
\hline & & & AA & $\mathrm{C}_{3} \mathrm{H}_{6}$ & HAC & $\mathrm{CO}$ & $\mathrm{CO}_{2}$ \\
\hline Sb-as & - & 29.8 & 1 & 3 & 4 & 56 & 36 \\
\hline Sb-T500 & $500^{\circ} \mathrm{C} / \mathrm{N}_{2}$ & 38.1 & 1 & 4 & 7 & 50 & 38 \\
\hline Sb-T550 & $550^{\circ} \mathrm{C} / \mathrm{N}_{2}$ & 31.4 & 6 & 6 & 13 & 43 & 32 \\
\hline Sb-T600 & $600^{\circ} \mathrm{C} / \mathrm{N}_{2}$ & 20.5 & 35 & 13 & 13 & 22 & 17 \\
\hline Te-as & - & $48.1^{\mathrm{C}}$ & $\mathrm{t}$ & 2 & $\mathrm{t}$ & 48 & 47 \\
\hline Te-T500 & $500^{\circ} \mathrm{C} / \mathrm{N}_{2}$ & $49.8^{d}$ & 2 & 3 & 10 & 38 & 47 \\
\hline Te-T550 & $550^{\circ} \mathrm{C} / \mathrm{N}_{2}$ & 45.2 & 5 & 3 & 8 & 38 & 45 \\
\hline Te-T600 & $600^{\circ} \mathrm{C} / \mathrm{N}_{2}$ & 27.6 & 27 & 9 & 12 & 24 & 28 \\
\hline TeNb-as & - & $23.3^{c}$ & 1 & 6 & 2 & 44 & 46 \\
\hline TeNb-T500 & $500^{\circ} \mathrm{C} / \mathrm{N}_{2}$ & 19.4 & 12 & 9 & 3 & 38 & 38 \\
\hline TeNb-T550 & $550^{\circ} \mathrm{C} / \mathrm{N}_{2}$ & 42.4 & 73 & 5 & 3 & 9 & 10 \\
\hline TeNb-T600 & $600^{\circ} \mathrm{C} / \mathrm{N}_{2}$ & 44.2 & 74 & 5 & 3 & 10 & 8 \\
\hline TeNb-T650 & $650^{\circ} \mathrm{C} / \mathrm{N}_{2}$ & 14.5 & 64 & 17 & 2 & 10 & 7 \\
\hline
\end{tabular}

${ }^{\text {a }}$ Conversión de propano a $400^{\circ} \mathrm{C}$ y tiempo de contacto, W/F, de $200 \mathrm{~g}_{\mathrm{cat}} \mathrm{h}$ mol $\mathrm{C}_{\mathrm{HH}} 8^{-1}$.

${ }^{\mathrm{b}}$ Selectividad a Ácido Acrílico (AA); Propeno $\left(\mathrm{C}_{3} \mathrm{H}_{6}\right)$; Ácido Acético $(\mathrm{HAc})$; y Óxidos de carbono $\left(\mathrm{CO}_{\text {y }} \mathrm{CO}_{2}\right)$. Acetona se observa con una selectividad igual o menor que $1 \%$.

${ }^{\mathrm{C}}$ Activados en condiciones de reacción a $400^{\circ} \mathrm{C}$, después de 180 (Te-as) y $300 \mathrm{~min}$ (Sb-as, TeNb-as).

${ }^{\mathrm{d}} \mathrm{A}$ una temperatura de reacción de $380^{\circ} \mathrm{C}$.

En general, en los catalizadores sin niobio (es decir, MoVSbO y MoVTeO), la conversión de propano disminuye al aumentar la temperatura de activación térmica, mientras que para los catalizadores con niobio (MoVTeNbO) se observa una tendencia opuesta, aumentando la conversión de propano al aumentar la temperatura de activación.

Por otro lado, también se observa una variación en la selectividad a ácido acrílico dependiendo de la temperatura de activación del catalizador. Así, los catalizadores MoVTeO y MoVSbO activados a 500 o $550^{\circ} \mathrm{C}$ son muy poco selectivos a ácido acrílico. Sólo los catalizadores tratados térmicamente a $600^{\circ} \mathrm{C}$ mostraron un aumento significativo de la selectividad a ácido acrílico (con una reducción importante en la formación de $\mathrm{CO}$ y $\mathrm{CO}_{2}$ ). Por otra parte, no se 
observan cambios significativos en la selectividad a ácido acético, por lo que, no existe una influencia importante con la temperatura de calcinación.

En el caso de los catalizadores con niobio, la selectividad a ácido acrílico también aumenta con la temperatura de activación térmica, siendo la selectividad muy superior a la observada con los catalizadores sin niobio.

En la Figura 5.9 se muestra la variación de la selectividad a ácido acrílico con la temperatura de activación a una conversión de propano del 30\% para los sistemas catalíticos MoVSbO, MoVTeO y MoVTeNbO. En general, la selectividad a ácido acrílico aumenta al aumentar la temperatura de activación, sin embargo, los óxidos mixtos sin niobio (MoVSbO y MoVTeO) muestran selectividades a ácido acrílico menores que los materiales MoVTeNbO.

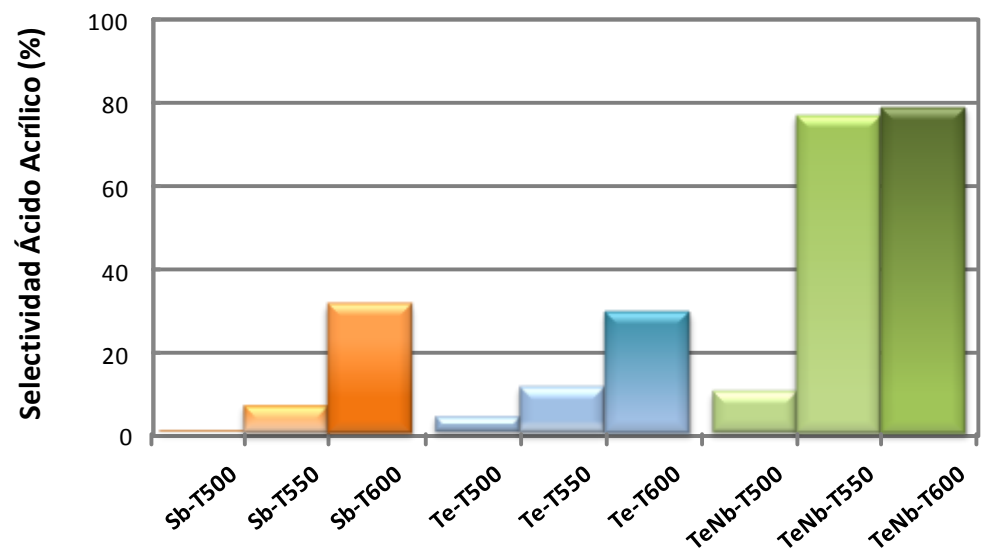

Figura 5.9. Selectividad a ácido acrílico (para una conversión de propano del 30\%) en la oxidación de propano para catalizadores MoVSb, MoVTe y MoVTeNb obtenidos a diferentes temperaturas de activación.

Cabe destacar que las muestras TeNb-T550 y TeNb-T600 son las más selectivas presentando selectividades a ácido acrílico a una conversión del $30 \%$ de 76 y $78 \%$, respectivamente, muy superior a la alcanzada con los catalizadores sin niobio. Por otro lado, los precursores activados a $400^{\circ} \mathrm{C}$ en condiciones de reacción (muestras Sb-as, Te-as y TeNb-as en la Tabla 5.4), resultaron ser activos en la oxidación de propano pero no selectivos para la formación de ácido acrílico. En este caso, no se han observado cambios aparentes en el comportamiento catalítico con el tiempo de reacción. 


\subsubsection{Caracterización de los catalizadores}

Con el fin de entender la variación del comportamiento catalítico de estos catalizadores, se ha estudiado la caracterización de las muestras tratadas térmicamente. Además, para completar el estudio, se han incluido tanto las muestras tratadas a $650^{\circ} \mathrm{C}$ (Sb-T650, Te-T650 y TeNb-T650) como las muestras sin activación térmica. Las características de los catalizadores se muestran en la Tabla 5.5.

Tabla 5.5. Características de los materiales MoVSbO, MoVTeO y MoVTeNbO activados a diferente temperatura.

\begin{tabular}{|c|c|c|c|c|}
\hline Catalizador & Temp. Act. $\left({ }^{\circ} \mathrm{C}\right)^{\mathrm{a}}$ & $\begin{array}{l}\text { Composición } \\
\text { Mo/V/X/Nb }\end{array}$ & $\begin{array}{l}\mathrm{S}_{\mathrm{BET}} \\
\left(\mathrm{m}^{2} \mathrm{~g}^{-1}\right)\end{array}$ & Fases Cristalinas $^{c}$ \\
\hline $\begin{array}{l}\text { Sb-as } \\
\text { Sb-T500 } \\
\text { Sb-T550 } \\
\text { Sb-T600 } \\
\text { Sb-T650 }\end{array}$ & $\begin{array}{l}- \\
500 \\
550 \\
600 \\
650\end{array}$ & $\begin{array}{l}1 / 0.24 / 0.13 / 0 \\
1 / 0.24 / 0.13 / 0 \\
1 / 0.25 / 0.16 / 0 \\
1 / 0.24 / 0.15 / 0 \\
1 / 0.45 / 0.11 / 0\end{array}$ & $\begin{array}{r}\text { n.d. } \\
13.6 \\
12.7 \\
9.3 \\
\text { n.d. }\end{array}$ & $\begin{array}{l}\mathrm{M} 1, \mathrm{M} 2 \\
\mathrm{M} 1, \mathrm{M} 2 \\
\mathrm{M} 1, \mathrm{M} 2 \\
\mathrm{M} 1, \mathrm{M} 2, \mathrm{Sb}_{2} \mathrm{Mo}_{10} \mathrm{O}_{31} \\
\mathrm{Sb}_{2} \mathrm{Mo}_{10} \mathrm{O}_{31}, \mathrm{MoO}_{3}\end{array}$ \\
\hline $\begin{array}{l}\text { Te-as } \\
\text { Te-T500 } \\
\text { Te-T550 } \\
\text { Te-T600 } \\
\text { Te-T650 }\end{array}$ & $\begin{array}{c}- \\
500 \\
550 \\
600 \\
650\end{array}$ & $\begin{array}{l}1 / 0.47 / 0.18 / 0 \\
1 / 0.48 / 0.15 / 0 \\
1 / 0.50 / 0.15 / 0 \\
1 / 0.46 / 0.13 / 0 \\
1 / 0.67 / 0.06 / 0\end{array}$ & $\begin{array}{r}\text { n.d. } \\
16.3 \\
15.7 \\
5.9 \\
\text { n.d. }\end{array}$ & $\begin{array}{l}\mathrm{M} 1 \\
\mathrm{M} 1 \\
\mathrm{M} 1 \\
\mathrm{M} 1, \mathrm{M} 2, \mathrm{MoO}_{3}, \mathrm{TeMo}_{5} \mathrm{O}_{16} \\
\mathrm{VOMoO}_{4}, \mathrm{MoO}_{3}\end{array}$ \\
\hline $\begin{array}{l}\text { TeNb-as } \\
\text { TeNb-T500 } \\
\text { TeNb-T550 } \\
\text { TeNb-T600 } \\
\text { TeNb-T650 }\end{array}$ & $\begin{array}{l}- \\
500 \\
550 \\
600 \\
650\end{array}$ & $\begin{array}{l}1 / 0.24 / 0.25 / 0.25 \\
1 / 0.21 / 0.22 / 0.22 \\
1 / 0.23 / 0.21 / 0.22 \\
1 / 0.22 / 0.16 / 0.23 \\
1 / 0.25 / 0.17 / 0.22\end{array}$ & $\begin{array}{r}\text { n.d. } \\
19.5 \\
11.7 \\
7.0 \\
3.0\end{array}$ & $\begin{array}{l}A \\
A \\
M 1 \\
M 1 \\
M 1\end{array}$ \\
\hline
\end{tabular}

a En todos los casos la activación se llevó a cabo en corriente de $\mathrm{N}_{2}$; Los materiales Sb-a, Te-as y TeNb-as corresponden a los sólidos obtenidos hidrotermalmente. ${ }^{b}$ Composición química de los catalizadores activados determinada por $\operatorname{EDX}(\mathrm{X}=\mathrm{Te}$ ó $\mathrm{Sb}) .{ }^{\mathrm{C}}$ Fases cristalinas mayoritarias determinadas por DRX: $\mathrm{M} 1=(\mathrm{XO})_{2} \mathrm{M}_{20} \mathrm{O}_{56} ; \mathrm{M} 2=$ $\left(\mathrm{X}_{2} \mathrm{O}\right) M_{6} \mathrm{O}_{18}\left(\mathrm{X}=\mathrm{Sb}\right.$ ó Te; $M=\mathrm{Mo}, \mathrm{V}$ y/o Nb); $\mathrm{Sb}_{2} \mathrm{Mo}_{10} \mathrm{O}_{31}$ [JCPDS: 33-105]; $\mathrm{TeMo}_{5} \mathrm{O}_{16}$ [JCPDS: 31-0874]; VOMoO [JCPDS: 18-582]; $\mathrm{MoO}_{3}$ ortorrómbica [JCPDS: 05-508]; $\mathrm{A}=$ amorfo.

En general, los catalizadores muestran áreas superficiales bajas, que disminuyen al aumentar la temperatura de activación térmica. Por otro lado, en los catalizadores con teluro, se puede observar una pérdida de teluro durante la etapa de activación, dado que la concentración de teluro en los materiales activados térmicamente es menor que en el material sin activar $[13,17,26]$. Esto se debe al hecho de que algo de teluro se puede reducir a teluro metálico y al bajo punto de fusión del mismo $\left(450^{\circ} \mathrm{C}\right)$ [26]. Esta pérdida de teluro es aún más acusada en el material activado a $650^{\circ} \mathrm{C}$. Sin embargo, los catalizadores con antimonio no muestran variación en la composición con la temperatura de activación, aunque se observa un aumento en la relación atómica $\mathrm{V} / \mathrm{Mo}$ en la muestra activada a $650^{\circ} \mathrm{C}$. 
Los difractogramas de rayos $\mathrm{X}$ de las muestras antes de activar y activadas a diferente temperatura se muestran en las Figura 5.10. En general, en los catalizadores con $\mathrm{Sb}$ (MoVSbO) se observan principalmente las fases cristalinas M1 y M2. En este sentido, el precursor sin activar muestra reflexiones a $2 \theta=6.7$, $7.9,8.9,22.2,27.1,29.3,30.5$ y $35.3^{\circ}$, correspondientes a la fase M1 con antimonio, $(\mathrm{SbO})_{2} \mathrm{M}_{20} \mathrm{O}_{56}$ [46], así como de reflexiones a $2 \theta=22.1,28.3,36.2$ y $45^{\circ}$, las cuales corresponden a la fase $\mathrm{M} 2,\left(\mathrm{Sb}_{2} \mathrm{O}\right) M_{6} \mathrm{O}_{18}(M=\mathrm{Mo}, \mathrm{V})$ [46] (Figura 5.10, Sb-as).

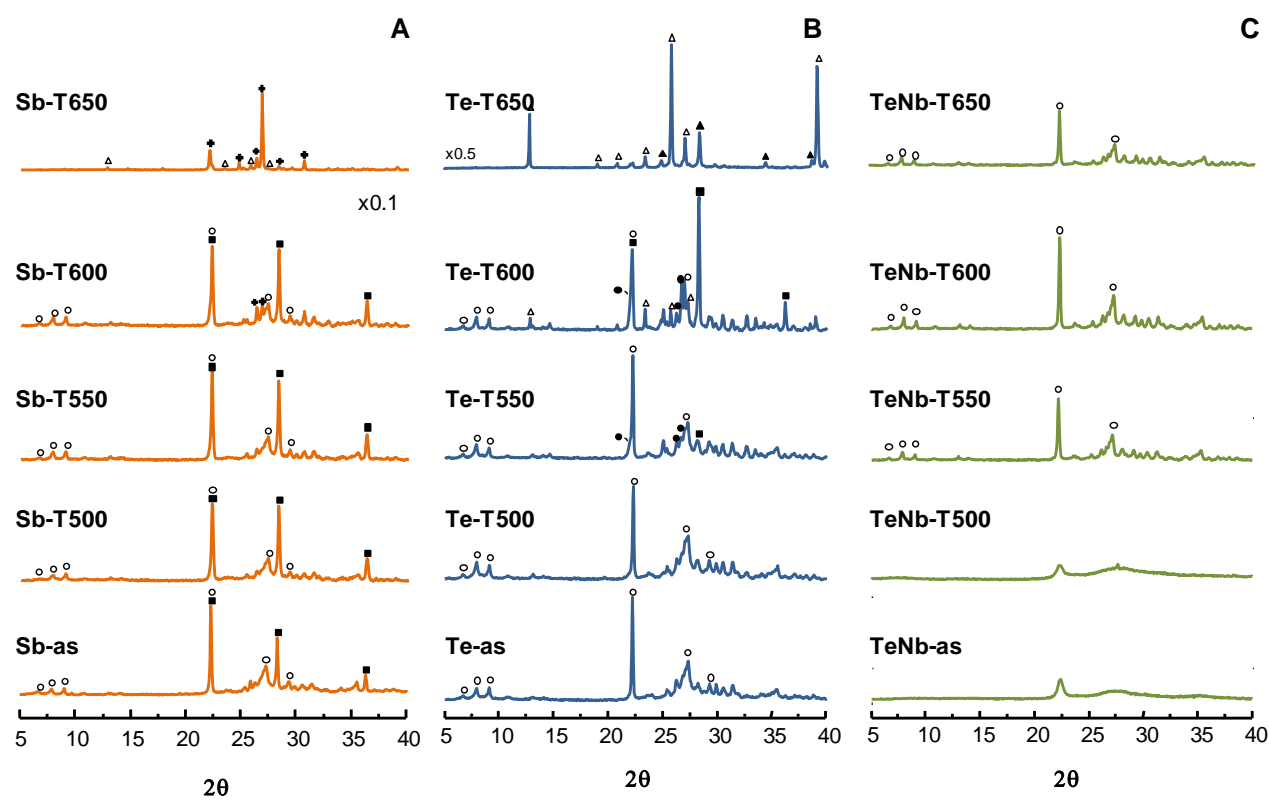

Figura 5.10. Difractogramas de rayos $X$ de los catalizadores MoVSbO (A), MoVTe (B) y MoVTeNb (C) antes y después de la activación en el intervalo de temperatura 500-650․ $\mathrm{C}$. Símbolos: (•) Fase M2, (०) Fase M1, (†) $\mathrm{Sb}_{2} \mathrm{Mo}_{10} \mathrm{O}_{31},(\bullet) \mathrm{TeMo}_{5} \mathrm{O}_{16},(\triangle) \mathrm{MoO}_{3}-\mathrm{o},(\boldsymbol{\Delta})$ $\mathrm{VOMOO}_{4}$.

Al someter este precursor a un tratamiento térmico a $500^{\circ} \mathrm{C}$ se observa un aumento de la cristalinidad de la muestra, además de un aumento en las intensidades relativas de los picos correspondientes a la fase M2 (Figura 5.10, Sb-T500). En este sentido, tanto la fase M1 como la fase M2 están presentes en los materiales activados en el intervalo de temperaturas entre 500-600 $\mathrm{C}$ (Figura 5.10, A), con unas intensidades relativas muy similares. Aunque, al activar la muestra a $650^{\circ} \mathrm{C}$ se favorece una descomposición prácticamente total de ambas fases, apareciendo nuevas fases cristalinas, tales como $\mathrm{Sb}_{2} \mathrm{Mo}_{10} \mathrm{O}_{31}$ y $\mathrm{MoO}_{3}$ (Figura 5.10, Sb-T650).

En el caso de los difractogramas de los catalizadores MoVTeO, sin $\mathrm{Nb}$ (Figura 5.10, B), se observa una descomposición gradual de la fase M1 con la 
temperatura de activación térmica. Así, mientras que la muestra sin activar (Te-as) y las muestras activadas a 500 o $550^{\circ} \mathrm{C}$ muestran la presencia mayoritaria de la fase M1, el difractograma del catalizador activado a $600^{\circ} \mathrm{C}$ (Te-T600) sugiere la presencia de otras fases cristalinas $\left(\mathrm{TeMo}_{5} \mathrm{O}_{16}\right.$ y fase $\left.\mathrm{M} 2\right)$ además de la fase M1.

En el caso de la serie de catalizadores MoVTeNbO, se observa un material amorfo con un pico de difracción a $2 \theta=222^{\circ}(\mathrm{d}=4 \AA$ ) tanto en la muestra sin activar, TeNb-as (Figura 5.10, C) como en el catalizador activado a $500^{\circ} \mathrm{C}$ (Figura 5.10, TeNb-T500). Sin embargo, la fase M1 se encuentra de forma mayoritaria en las muestras activadas a 550 o $600^{\circ} \mathrm{C}$ (Figura 5.10, C).

Las imágenes SEM de los catalizadores MoVTeO sin tratar térmicamente o tratados a 500 y $600^{\circ} \mathrm{C}$ presentan cristales con forma alargada, sin una orientación particular, con longitudes sobre 2-10 $\mu \mathrm{m}$ (Figura 5.11), característicos de la fase M1. En el caso de los catalizadores con Nb, las micrografías SEM muestran la presencia de pequeños cristales alargados y con forma de placa de pequeño diámetro (aproximadamente 1 $\mu \mathrm{m}$ ) (Figura 5.11), presentando una gran homogeneidad en la composición (determinada por EDX).
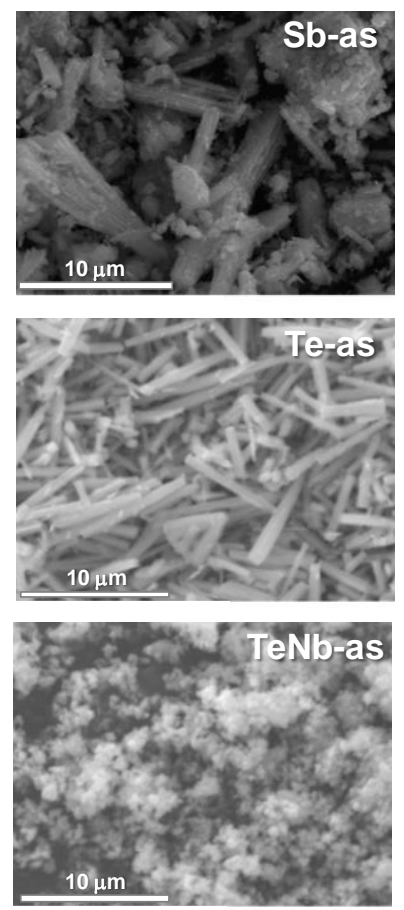
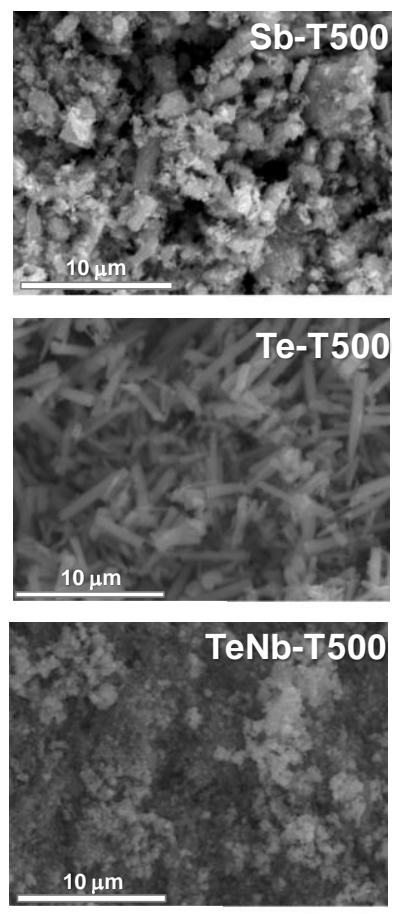
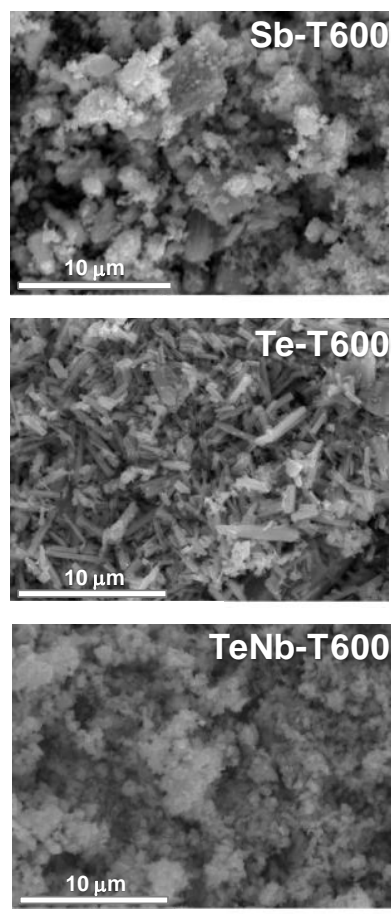

Figura 5.11. Micrografías SEM de las muestras MoVSbO, MoVTeO y MoVTeNbO antes de la activación y activadas a 500 y $600^{\circ} \mathrm{C}$. 
En el precursor de antimonio (Figura 5.11, Sb-as) los cristales de la fase M1 se encuentran más agregados formando superestructuras tridimensionales de mayor sección que en los materiales con teluro. En este sentido, se ha sugerido que el diámetro de los cristales de la fase M1 varía en función del heteroátomo introducido, junto con Mo y $\mathrm{V}$, en el gel de síntesis [11]. Además, independientemente de la temperatura de activación, se observan otros cristales con forma de placa, de contorno irregular, que corresponden a la fase $M 2$, de acuerdo con el análisis EDX y los resultados de DRX (Figura 5.10, A), lo que está de acuerdo con estudios previos de TEM [46].

En la Figura 5.12 se muestra los espectros infrarrojos de los catalizadores en la región de baja frecuencia $\left(1100-400 \mathrm{~cm}^{-1}\right)$. En general, todos los catalizadores sin niobio, MoVSb y MoVTe (Figura 5.12, espectros a - h), presentan bandas a $924,870,802,715,650,600$ y $460 \mathrm{~cm}^{-1}$, aunque con diferente intensidad.

De acuerdo con estudios anteriores [12, 46], las bandas observadas en los espectros de la Figura $\mathbf{5 . 1 2}$ se pueden asociar con la presencia de las fases M1 y $M 2$, existiendo una cierta equivalencia entre las bandas que presentan ambas fases en materiales con teluro y materiales con antimonio. Así, las bandas a 918 , $870,807,650$ y $605 \mathrm{~cm}^{-1}$ se pueden relacionar con la presencia de la fase $\mathrm{M} 1$, $(\mathrm{XO})_{2} \mathrm{M}_{20} \mathrm{O}_{56}$, mientras que las bandas a 924,750 y $450 \mathrm{~cm}^{-1}$ están relacionadas por la presencia de la fase $\mathrm{M} 2,\left(\mathrm{X}_{2} \mathrm{O}\right) M_{6} \mathrm{O}_{18}(\mathrm{X}=\mathrm{Sb}$ ó Te; $M=\mathrm{Mo}, \mathrm{V})$. De acuerdo con los resultados de la Fig. 5.12, podemos concluir que, en el caso del catalizador MoVSb sin activar, se observan principalmente las bandas características de la fase M1 (Figura 5.12, espectros a), mientras que, en los materiales activados térmicamente se aprecian además las bandas propias de la fase M2 (Figura 5.12, espectros b-d), confirmándose los resultados de DRX.

Así mismo, la muestra MoVTeO sin activar muestra bandas a 918, 870, 807, 715, 650 y $605 \mathrm{~cm}^{-1}$ (Figura 5.12, espectro e), que pueden relacionarse con la presencia de la fase M1 [46]. Un espectro similar se ha observado en las muestras tratadas térmicamente a 500 (Figura 5.12, espectro f) o $550^{\circ} \mathrm{C}$ (Figura 5.12, espectro g), aunque con bandas adicionales a 924 y $895 \mathrm{~cm}^{-1}$ (relacionadas con la fase $\mathrm{TeMo}_{5} \mathrm{O}_{16}$ [49]), y a 990 y $820 \mathrm{~cm}^{-1}$ (relacionadas con $\mathrm{MoO}_{3}$ [49]). Por consiguiente, se puede concluir que la fase $\mathrm{M} 1$ junto con $\mathrm{MoO}_{3}$ y $\mathrm{TeMo}_{5} \mathrm{O}_{16}$ está presentes en la muestra tratada térmicamente, aunque la presencia de la fase M2 no se puede descartar completamente. 

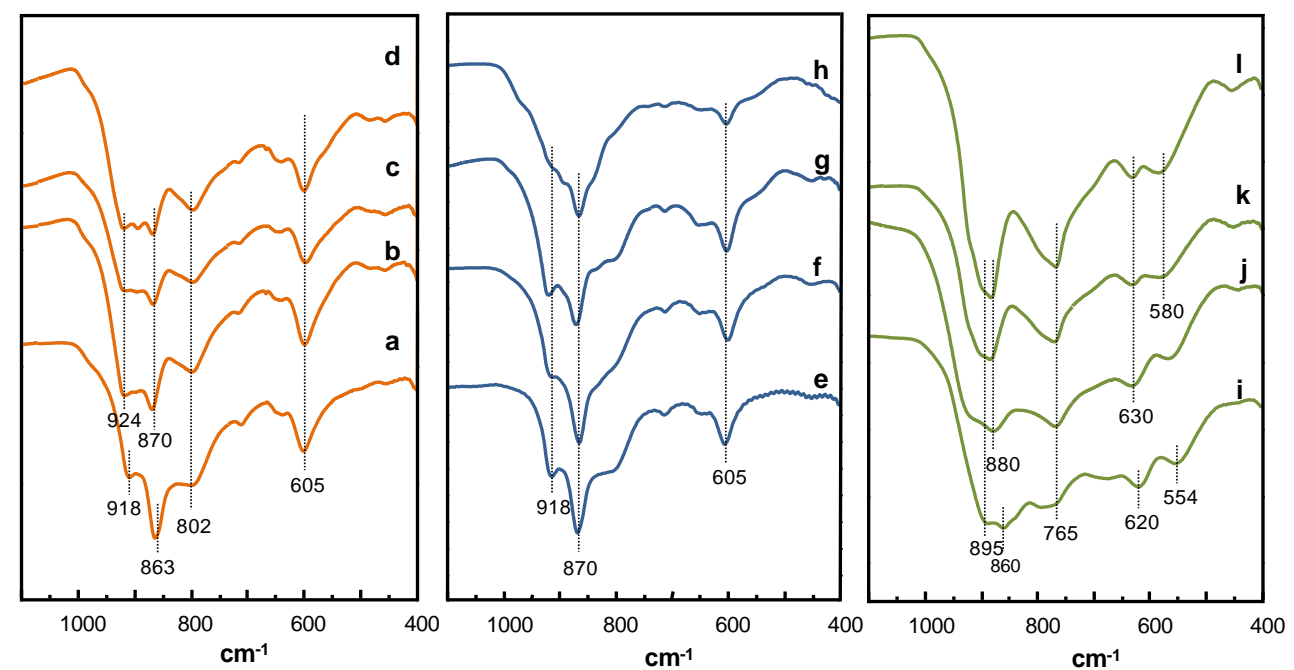

Figura 5.12. Espectros FTIR de los catalizadores MoVSbO, MoVTeO y MoVTeNbO: a) Sbas; b) Sb-T500; c) Sb-T550; d) Sb-T600; e) Te-as; f) Te-T500; g) Te-T550; h) Te-T600; i) TeNb-as; j) TeNb-T500; k) TeNb-T550; I) TeNb-T600.

En el caso de las muestras con niobio, MoVTeNbO, se observan diferencias importantes dependiendo de la temperatura de activación del catalizador. Así, se observan bandas a $895,860,765,620$ y $554 \mathrm{~cm}^{-1}$ en la muestra sin activar (Figura 5.12, espectro i), mientras que se pueden observar bandas a $895,880,765,630$, 580 y $455 \mathrm{~cm}^{-1}$ en las muestras tratadas térmicamente (Figura 5.12, espectros j I). En este sentido, la fase M1 se observa mayoritariamente en los catalizadores activados a 550 y $600^{\circ} \mathrm{C}$ (aunque la fase M2 se observa también, aunque de forma minoritaria, en ambos catalizadores). Por otra parte, tanto en la muestra sin activar como en la muestra activada a $500^{\circ} \mathrm{C}$, se observan bandas adicionales que deberían estar relacionadas con el material amorfo descrito a partir de los difractogramas de rayos $X$ (Figura 5.10, C). Además, si bien la fase M2 no se observa por DRX, los resultados de infrarrojo sugieren la presencia de pequeños cristales de esta fase en los catalizadores activado térmicamente.

En la Figura 5.13 se muestran los espectros Raman de los catalizadores MoVSbO, MoVTeO y MoVTeNbO. Los catalizadores sin niobio, MoVSbO y MoVTeO, exhiben una banda Raman intensa a $874 \mathrm{~cm}^{-1}$ con un hombro ancho a baja frecuencia (en la región Raman $770-840 \mathrm{~cm}^{-1}$ ) y otro hombro más débil a frecuencias más altas (alrededor de $970 \mathrm{~cm}^{-1}$ ), junto con otras bandas a menor frecuencia $\left(437\right.$ y $470 \mathrm{~cm}^{-1}$ ). Este espectro es similar al encontrado por otros autores [3, 30, 50-53]. De acuerdo con éstos, el hombro a $970-980 \mathrm{~cm}^{-1}$ puede asignarse a la vibración de tensión de los enlaces terminales $\mathrm{Mo}=\mathrm{O}$ y $\mathrm{V}=\mathrm{O}$ [54], mientras que las bandas a $770-880 \mathrm{~cm}^{-1}$ y a aprox. $470 \mathrm{~cm}^{-1}$ pueden relacionarse a los modos de tensión asimétrico y simétrico, respectivamente, de enlaces puentes 
Me-O-Me. En el caso de la muestra de teluro tratada térmicamente a $600^{\circ} \mathrm{C}$, TeT600, se puede observar una banda adicional a $964 \mathrm{~cm}^{-1}$ que puede relacionarse con la presencia de $\mathrm{TeMo}_{5} \mathrm{O}_{16}[30]$.
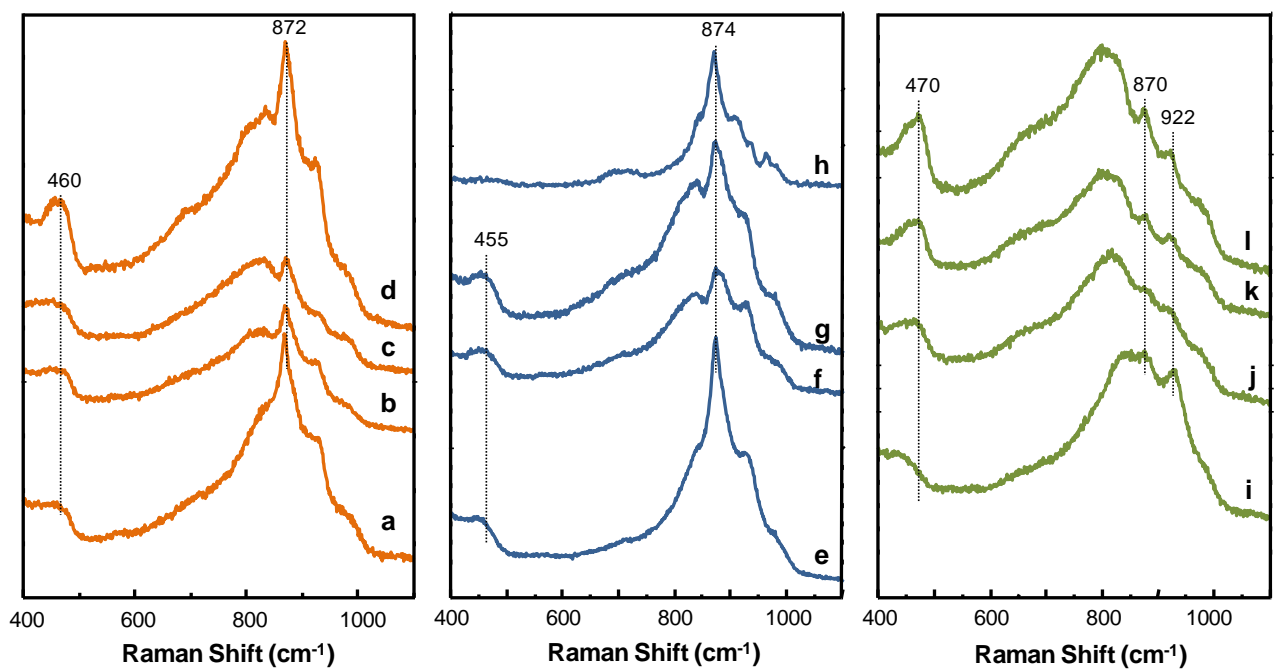

Figura 5.13. Espectros Raman de los catalizadores MoVSbO, MoVTeO y MoVTeNbO: a) Sb-as; b) Sb-T500; c) Sb-T500; d) Sb-T600; e) Te-as; f) Te-T500; g) Te-T550; h) Te-T600; i) TeNb-as; j) TeNb-T500; k) TeNb-T550; l) TeNb-T600.

En los catalizadores MoVTeNbO se observan diferencias significativas (Figura 5.13, espectros i - I). Así, se observa claramente una banda ancha a 840 $\mathrm{cm}^{-1}$ (para la muestra sin activar, Figura 5.13, espectro i), la cual se desplaza a $800-817 \mathrm{~cm}^{-1}$ (para las muestras activadas térmicamente, Figura 5.13 , espectros j - I). Este espectro es similar al encontrado por otros autores [38]. La banda ancha a $817 \mathrm{~cm}^{-1}$ junto con la banda a $650 \mathrm{~cm}^{-1}$ se puede asignar a la formación de enlaces $\mathrm{Nb}-\mathrm{O}-\mathrm{Nb}$ [55], mientras que la vibración simétrica de octaedros $\mathrm{NbO}_{6}$ aislados se han asignado a $907 \mathrm{~cm}^{-1}$. También se observan bandas a 470, 870, 922 y $982 \mathrm{~cm}^{-1}$ asignadas a los modos de tensión del puente Me-O-Me y del enlace $\mathrm{Me}=\mathrm{O}$.

Un aspecto importante para explicar las propiedades catalíticas de estos materiales es el relacionado con la presencia de centros ácidos en la superficie del catalizador. Por eso, los materiales activados a 500 y $600{ }^{\circ} \mathrm{C}$ se han estudiado empleando la desorción de amoníaco a temperatura programada (TPD-NH $\mathrm{N}_{3}$ ). Los resultados de TPD- $\mathrm{NH}_{3}$ se muestran en la Figura 5.14. En todos los casos se observa que al aumentar la temperatura de activación se favorece un descenso en el número de centros ácidos, y la fortaleza de dichos centros, presentes en la superficie del catalizador. 

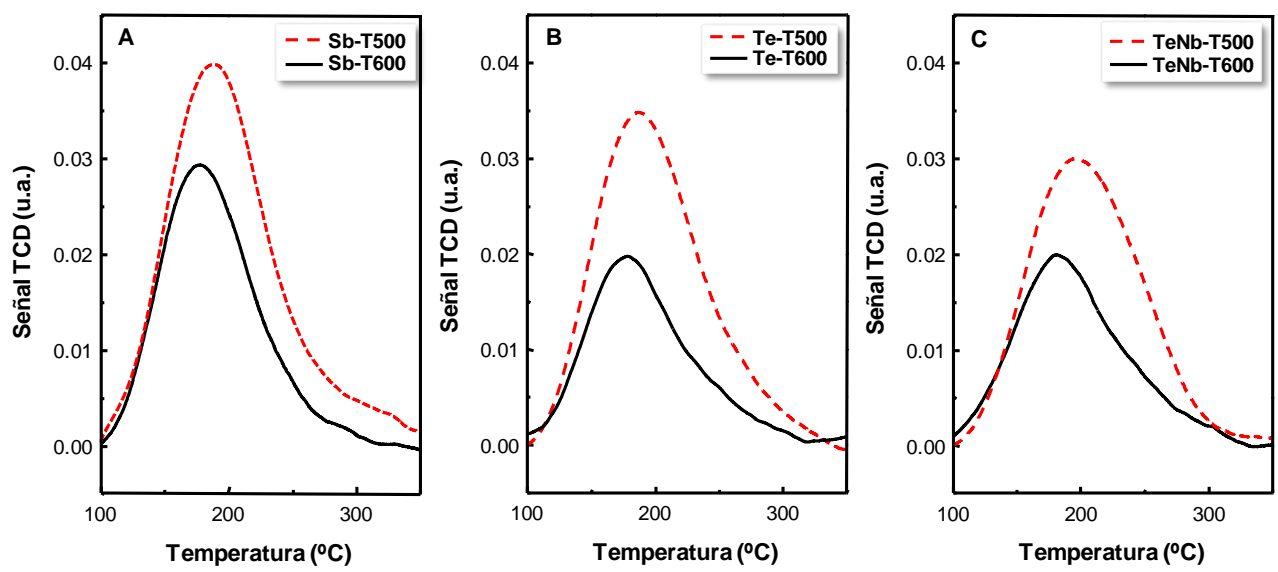

Figura 5.14. Espectros TPD-NH $\mathrm{NH}_{3}$ de los sistemas (A) MoVSb; (B) MoVTe y (C) MoVTeNb activados a 500 y $600^{\circ} \mathrm{C}$ bajo flujo de $\mathrm{N}_{2}$.

Por otro lado, también se observa una dependencia del número de centros ácidos presentes en la superficie del catalizador con la composición de los catalizadores. Así, los materiales MoVSbO presentan una concentración de centros ácidos mayor que los catalizadores con teluro, mientras que la presencia de niobio favorece la obtención de materiales con una presencia de centros ácidos menor (Figura 5.14).

Si bien se muestran únicamente los resultados de adsorción de amoníaco a temperatura programa de los catalizadores activados a 500 y $600^{\circ} \mathrm{C}$, se debe señalar que, en todos los casos, los materiales activados a $550^{\circ} \mathrm{C}$ muestran una concentración de centros ácidos intermedia entre la observada en el catalizador calcinado a $500^{\circ} \mathrm{C}$ y la observada en los catalizadores activados a $600^{\circ} \mathrm{C}$, y por tanto, podemos concluir que un aumento en la temperatura de activación térmica favorece un descenso de la concentración de centros ácidos.

En las Tabla 5.6 se resumen los resultados de XPS de los catalizadores MoVSbO, mientras que en la Figura 5.15 se muestran los espectros XPS de los niveles $\vee 2 p 3 / 2$ y Sb $3 d 3 / 2$ de los catalizadores activados a 500 y $600^{\circ} \mathrm{C}$.

Tabla 5.6. Resultados XPS de los catalizadores MoVSbO.

\begin{tabular}{llcccc}
\hline \multirow{2}{*}{ Muestra } & \multicolumn{4}{l}{ Composición superficial ${ }^{\mathrm{a}}$} \\
\cline { 2 - 6 } & $\mathrm{Mo} / \mathrm{V} / \mathrm{Sb} / \mathrm{O}$ & $\mathrm{Mo}^{6+}{ }^{6+} / \mathrm{Mo}_{\text {total }}{ }^{\mathrm{b}}$ & $\mathrm{V}^{5+} / \mathrm{V}_{\text {total }}{ }^{\mathrm{c}}$ & $\mathrm{Sb}^{5+} / \mathrm{Sb}_{\text {total }}{ }^{\mathrm{d}}$ & $\mathrm{O}_{\mathrm{B}} / \mathrm{O}_{\text {total }}{ }^{\mathrm{e}}$ \\
\hline Sb-T500 & $1 / 0.17 / 0.13 / 3.48$ & 100 & 16.1 & 26.3 & 0 \\
Sb-T600 & $1 / 0.17 / 0.13 / 3.47$ & 100 & 20.3 & 42.1 & 0 \\
\hline
\end{tabular}

${ }^{a}$ Composición superficial determinada por XPS; ${ }^{b} \mathrm{Mo}_{A}{ }^{6+}(\mathrm{BE}=232.8 \mathrm{eV}), \mathrm{Mo}_{\mathrm{B}}{ }^{6+}(\mathrm{BE}=233.8 \mathrm{eV})$;

${ }^{c} \mathrm{~V}^{5+}(\mathrm{BE}=517.6 \mathrm{eV}), \mathrm{V}^{4+}(\mathrm{BE}=516.5 \mathrm{eV}) ;{ }^{\mathrm{d}} \mathrm{Sb}^{5+}(\mathrm{BE}=540.5 \mathrm{eV}), \mathrm{Sb}^{3+}(\mathrm{BE}=539.6 \mathrm{eV})$;

${ }^{\mathrm{e}} \mathrm{O}_{\mathrm{A}}(\mathrm{BE}=530.6 \mathrm{eV}), \mathrm{O}_{B}(\mathrm{BE}=532.3 \mathrm{eV})$. 

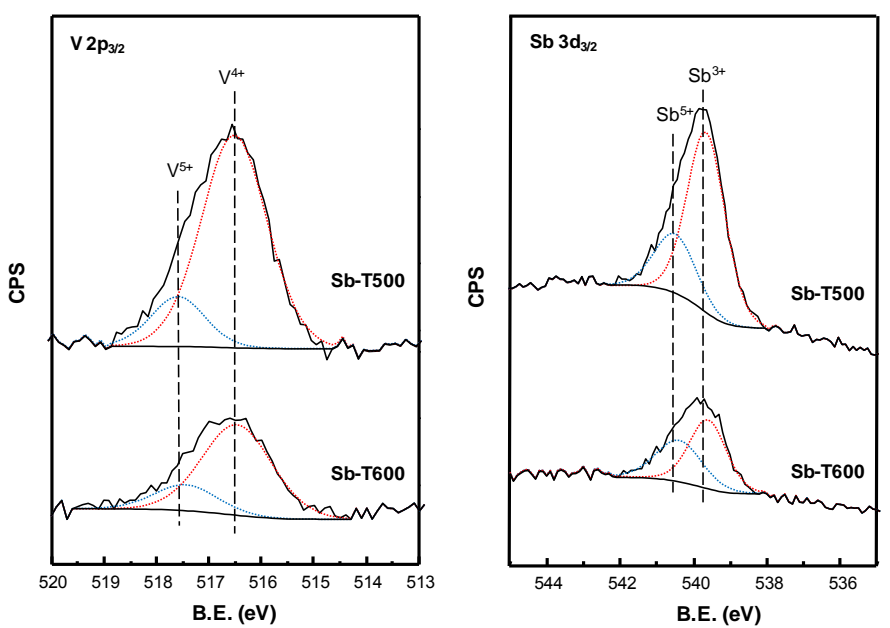

Figura 5.15. Espectros XPS de los niveles: (a) $\vee 2 p_{3 / 2}$, y (b) $S b 3 d_{3 / 2}$ de los catalizadores MoVSbO activados a 500 (Sb-T500) y 600ㄷ (Sb-T600). (Línea sólida) Datos observados; (Línea punteada) Picos deconvolucionados. CPS: cuentas por segundo.

De acuerdo con los resultados XPS, se observa en todos los casos una concentración de vanadio en la superficie inferior a los valores obtenidos por EDX. Los espectros de $V 2 p_{3 / 2}$ de estos catalizadores (Figura 5.15 y Tabla 5.6) están formados por la contribución de dos componentes a $517.6 \mathrm{eV}$ y $516.5 \mathrm{eV}$ relacionadas con la presencia de los estados de oxidación $\mathrm{V}^{5+}$ y $\mathrm{V}^{4+}$, respectivamente [46, 56-57]. En la muestra tratada térmicamente a alta temperatura $\left(600^{\circ} \mathrm{C}\right)$, se puede observar un ligero aumento en la concentración de cationes $\mathrm{V}^{5+}$ (Tabla 5.6).

Por otro lado, los espectros XPS de $\mathrm{Sb} 3 \mathrm{~d}_{3 / 2}$ para los mismos catalizadores (Figura 5.15) muestran dos componentes, a 539.6 y $540.5 \mathrm{eV}$, asociadas a los estados de oxidación $\mathrm{Sb}^{3+}$ y $\mathrm{Sb}^{5+}$, respectivamente [8, 46, 51]. Cabe de señalar que el catalizador activado a $600^{\circ} \mathrm{C}$ presenta una proporción de cationes $\mathrm{Sb}^{5+}$ mayor que el catalizador activado a menor temperatura.

En la Tabla 5.7 se muestran los resultados de XPS para los catalizadores $\operatorname{MoVTe}(\mathrm{Nb}) \mathrm{O}$, mientras que en la Figura 5.16 se muestran los espectros Mo $3 \mathrm{~d}_{5 / 2}$ y $3 d_{3 / 2}$ (Figura 5.16, a), Te $3 d_{5 / 2}$ (Figura 5.16, b) y $O_{1 s}$ (Figura 5.16, c) de los catalizadores Te-T500 y TeNb-T600 (los cuales, de acuerdo con los resultados de DRX muestran, de forma mayoritaria, la fase M1). 
Tabla 5.7. Resultados XPS de los catalizadores MoVTeO y MoVTeNbO.

\begin{tabular}{|c|c|c|c|c|c|}
\hline \multirow[t]{2}{*}{ Muestra } & \multicolumn{5}{|c|}{ Composición superficial $^{\text {a }}$} \\
\hline & $\mathrm{Mo} / \mathrm{V} / \mathrm{Te} / \mathrm{Nb} / \mathrm{O}$ & $\mathrm{Mo}_{\mathrm{A}}{ }^{6+} / \mathrm{Mo}_{\text {total }}{ }^{\mathrm{b}}$ & $\mathrm{V}^{5+} / \mathrm{V}_{\text {total }}{ }^{\mathrm{c}}$ & $\mathrm{Te}^{6+} / \mathrm{Te}_{\text {total }}{ }^{\mathrm{d}}$ & $\mathrm{O}_{\mathrm{B}} / \mathrm{O}_{\text {total }}{ }^{\mathrm{e}}$ \\
\hline Te-T500 & $1 / 0.30 / 0.14 / 0.0 / 4.04$ & 88.5 & 25.8 & 21.6 & 21.2 \\
\hline Te-T600 & $1 / 0.25 / 0.16 / 0.0 / 5.22$ & 72.2 & 20.4 & 23.3 & 20.5 \\
\hline TeNb-T500 & $1 / 0.12 / 0.28 / 0.21 / 4.23$ & 93.0 & 38.1 & 17.1 & 16.5 \\
\hline TeNb-T600 & 1/0.10/0.29/0.25/3.52 & 100 & 28.9 & 0 & 14.2 \\
\hline
\end{tabular}

El espectro XPS del nivel Mo 3d de los catalizadores muestra que la energía de enlace de Mo $3 d_{5 / 2}$ cambia dependiendo de la composición y el tratamiento térmico de los catalizadores (Figura 5.16, a). Así, mientras que en los catalizadores con teluro (series Te y TeNb), se observan dos tipos de especies $\mathrm{Mo}^{6+}, \mathrm{Mo}_{\mathrm{A}}{ }^{6+}(\mathrm{BE}=232.8 \mathrm{eV}) \mathrm{y} \mathrm{Mo}_{\mathrm{B}}{ }^{6+}(\mathrm{BE}=233.8 \mathrm{eV})$, en diferentes entornos de coordinación, en las muestras con niobio activadas por encima de los $550^{\circ} \mathrm{C}$ (como TeNb-T600, Figura 5.16, a), donde sólo se observa un tipo de especies $\mathrm{Mo}\left(\mathrm{Mo}_{\mathrm{A}}{ }^{6+}\right)$. Es importante resaltar las diferencias respecto a los catalizadores con antimonio, en los que tan sólo se ha observado la contribución de una única componente a $232.8 \mathrm{eV}$ (Fig. 5.15). Por otro lado, podemos concluir que, en ninguna caso, se ha observado la presencia de especies $\mathrm{Mo}^{5+}$, con BE a $231.7 \mathrm{eV}$ [58].

Por otro lado, los espectros XPS de los catalizadores con teluro sugieren que la energía de enlace de $\mathrm{Te} 3 \mathrm{~d}_{5 / 2}$ cambia de 577.9 a $576.4 \mathrm{eV}$ (Tabla 5.6). Dado que la energía de enlace correspondiente a cationes $\mathrm{Te}^{4+}$ es $576.2 \mathrm{eV}$, mientras que la energía de enlace correspondiente a cationes $\mathrm{Te}^{6+}$, como en $\mathrm{H}_{6} \mathrm{TeO}_{6}$, se observa a $577.3 \mathrm{eV}$ [59], podemos concluir que estos catalizadores presentan cambios en el estado de oxidación de teluro superficial: $\mathrm{Te}^{6+}$ y $T \mathrm{e}^{4+}$ en la muestra Te-T500, pero sólo $\mathrm{Te}^{4+}$ en la muestra TeNb-T600 (Figura 5.16, b). Sin embargo, en ningún caso, se ha observado la presencia de $\mathrm{Te}^{0}(\mathrm{BE}$ a $573.0 \mathrm{eV})$.

El espectro del nivel $\mathrm{Nb} 3 \mathrm{~d}$ de los catalizadores con niobio (serie TeNb) presenta una única componente asignada a especies $\mathrm{Nb}^{5+}(\mathrm{BE}=207.0 \mathrm{eV})$. Además, el espectro $V 2 p_{3 / 2}$ muestra la presencia de dos componentes a $516.6 \mathrm{eV}$ $\left(\mathrm{V}^{4+}\right)$ y $517.67 \mathrm{eV}\left(\mathrm{V}^{5+}\right)$, al igual que los catalizadores con antimonio (Tabla 5.7). En todos los catalizadores se observa principalmente especies de $\mathrm{V}^{4+}$ (desde un 60 a un $80 \%$ dependiendo de la composición y la temperatura de activación). Al contrario que en los catalizadores con antimonio (Tabla 5.6), el tratamiento térmico de los materiales con teluro favorece un ligero descenso en la concentración de $\mathrm{V}^{5+}$ superficial en todas las muestras, aunque superior en la muestra activada a $600^{\circ} \mathrm{C}$ (Tabla 5.7). 

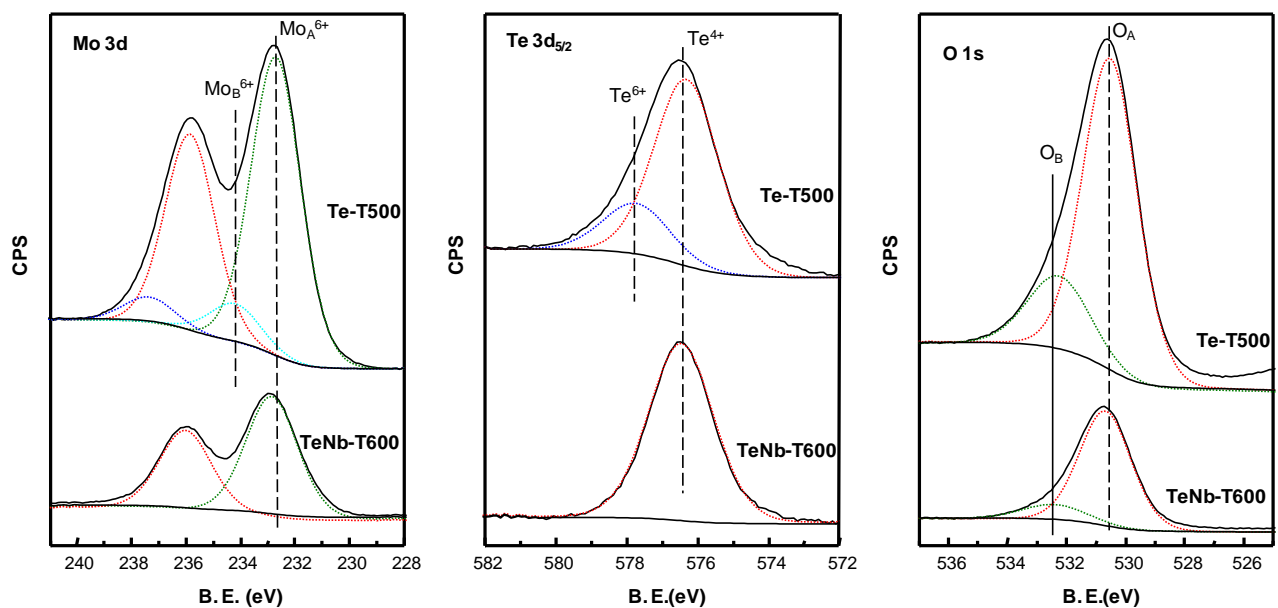

Figura 5.16. Espectros XPS de los niveles: (a) Mo $3 d_{5 / 2}$ y $3 d_{3 / 2}$, (b) Te $3 d_{5 / 2}$, y (c) $O_{1 \text { s }}$ de los catalizadores MoVTeO (Te-T500) y MoVTeNbO (TeNb-T600). (Línea sólida) Datos observados; (Línea punteada) Picos deconvolucionados. CPS: cuentas por segundo.

Por otro lado, dos tipos de oxígeno superficial con BE a 530.6 eV y 532.3 eV se observan en todas las muestras con teluro (Figura 5.16, c; Tabla 5.7), que se pueden asignar a especies oxígeno con diferentes propiedades electrofílicas. La relación $\mathrm{O}_{B} /\left(\mathrm{O}_{A}+\mathrm{O}_{B}\right)$ en los catalizadores con niobio es menor que la observada en los catalizadores MoVTe sin niobio (y disminuye al aumentar la temperatura de activación).

Sin embargo, las diferencias observadas en la composición superficial y el estado de oxidación de los elementos, debe interpretarse con precaución en aquellas muestras que presentan diferentes fases cristalinas $\mathrm{y} / 0$ materiales amorfos, como las muestras Te-T600 y TeNb-T500.

Así, en la muestra Te-T600, se observa una mayor proporción de especies $\mathrm{Mo}_{\mathrm{B}}{ }^{6+}$ y un enriquecimiento de $\mathrm{Te}^{6+}$ (Tabla 5.7) lo que parece estar relacionado con la presencia de las fases cristalinas $\mathrm{MoO}_{3}$ y $\mathrm{TeMo}_{5} \mathrm{O}_{16}$. Por otro lado, la presencia de una fase amorfa en la muestra TeNb-T500 parece modificar la composición superficial tal y como se desprende de los resultados de la Tabla 5.7. Sin embargo, las diferencias observadas por XPS en la composición superficial de las muestras Te-T500 y TeNb-T600 no pueden explicarse ni por la presencia de cristalinas diferentes y/o la presencia de fases amorfas, dado que los resultados de DRX, IR y Raman sugieren que la fase M1 es mayoritaria (aunque algo de fase M2 puede estar presente de forma minoritaria).

Como se ha indicado anteriormente, la muestra TeNb-T600 presenta sólo un tipo de especies de molibdeno superficiales $\left(\mathrm{Mo}_{\mathrm{A}}{ }^{6+}\right)$ y un solo tipo de especies de teluro superficiales $\left(\mathrm{Te}^{4+}\right)$, así como una menor concentración de especies oxígeno superficial, aparentemente con mayor basicidad (Figura 5.16), por lo que estas 
diferencias podrían explicar parcialmente el diferente comportamiento catalítico observado para estos catalizadores.

\subsection{Discusión de los resultados}

\subsubsection{Influencia de la temperatura de síntesis hidrotermal}

Los resultados de caracterización de los materiales antes y después de la activación a $600^{\circ} \mathrm{C}$ (apartado 5.2) sugieren que la temperatura de síntesis hidrotermal influye notablemente en la distribución y estabilidad de las fases cristalinas (y más concretamente en la formación y estabilidad de la fase M1), y por tanto, y en el comportamiento catalítico de estos materiales. Aunque, la influencia de la temperatura de síntesis depende además de los elementos químicos incorporados.

En general, los materiales MoVSbO muestran la presencia mayoritaria de la fases M1 y M2 incluso a baja temperaturas de síntesis, tanto antes (Figura 5.1) como después del tratamiento térmico a $600^{\circ} \mathrm{C}$ (Figura 5.4). Además, a baja temperaturas de síntesis, $100-150^{\circ} \mathrm{C}$, se observan la presencia de $\mathrm{MoO}_{3}$ hexagonal en los precursores y de $\mathrm{Sb}_{2} \mathrm{Mo}_{10} \mathrm{O}_{31}$ en los catalizadores activados. Sin embargo, en los materiales activados térmicamente, también se observa una descomposición parcial de la fase M1 (favoreciendo una presencia mayor de la fase M2) lo que sugiere que el tratamiento térmico facilita cierta descomposición de la fase M1 (Figura 5.4).

En los materiales con teluro, MoVTe (preparados con $\mathrm{TeO}_{2}$ como compuesto de teluro de partida), se observa que la composición de los catalizadores varía dependiendo de la temperatura de síntesis hidrotermal (Tabla 5.1), lo que sugiere que la temperatura de síntesis influye en la incorporación de Te en los materiales sólidos y, por tanto en la formación de la fase M1. En efecto, en la síntesis realizada a $100^{\circ} \mathrm{C}$ se observa la presencia de un material amorfo y $\mathrm{TeO}_{2} \sin$ reaccionar (Figura 5.1), que durante el tratamiento térmico facilita la formación de las fases $\mathrm{TeMo}_{5} \mathrm{O}_{16}$ y $\mathrm{Mo}_{0.97} \mathrm{~V}_{0.95} \mathrm{O}_{5}$ (Figura 5.4). Mientras que, al aumentar la temperatura de síntesis, aumenta la incorporación de $\mathrm{Te}$ y $\mathrm{V}$ en los materiales, favoreciendo la formación de la fase M1. Una vez sometidos al tratamiento térmico a $600^{\circ} \mathrm{C}$, se observa una descomposición parcial de la fase M1 (favoreciéndose la formación de la fase $\mathrm{M} 2$ y $\mathrm{TeMo}_{5} \mathrm{O}_{16}$ ) la cual depende de la temperatura de síntesis. Esto sugiere que la estabilidad térmica de la fase M1 estaría también influenciada por la temperatura de síntesis (y quizás por la composición del sólido).

La incorporación de $\mathrm{Nb}$ en los materiales con teluro da lugar a un precursor amorfo (Figura 5.1) que al someterlo al tratamiento térmico a $600^{\circ} \mathrm{C}$ se obtiene la formación principalmente la fase M1 (Figura 5.4). Se ha sugerido que la presencia 
de niobio estabiliza la estructura cristalina durante el tratamiento térmico [44]. Sin embargo, dependiendo de la temperatura de síntesis a la que se han preparado los materiales se observa una variación en la composición final de los catalizadores (Tabla 5.1 y 5.4), en la relación V/Mo, Te/Mo y Nb/Mo, lo que influirá no sólo en la formación del precursor de la fase M1, sino también en la estabilidad de la fase M1.

En este sentido, debemos tener en cuenta la cuantificación de las fases cristalinas presentes en los materiales (Figuras 5.2 y 5.5). En general, la cantidad de fase M1 presente en los materiales depende de la temperatura de síntesis, siendo mayor a mayores temperaturas de síntesis, en todos los casos. Estos resultados se pueden relacionar con los resultados determinados por SEM (Figura 5.3 y 5.6), donde en los materiales preparados a alta temperatura $\left(175-200^{\circ} \mathrm{C}\right)$ se observa principalmente fase M1 con mayor tamaño de cristal que los preparados a menor temperatura. En el caso de los materiales con antimonio (Figura 5.2) se observa además una influencia en la formación de la fase M2, la cual está favorecida a menor temperatura de síntesis.

Por otro lado, la comparación entre la cuantificación de fases cristalinas presentes en los precursores antes y después de la activación (Figuras 5.2 y 5.5), muestra que se produce una descomposición parcial de la fase M1 durante el tratamiento térmico a alta temperatura, disminuyendo la cantidad de fase $\mathrm{M} 1 \mathrm{y}$ favoreciendo la formación de la fase $\mathrm{M} 2$ y $\mathrm{TeMo}_{5} \mathrm{O}_{16}$ (Figura 5.5) únicamente en el caso de los materiales con teluro (serie Te). Así, se ha observado que el aumento de la temperatura de síntesis empleada en la síntesis hidrotermal favorece una mayor descomposición de la fase M1 durante el tratamiento térmico, En este sentido, el material preparado a $135^{\circ} \mathrm{C}$ (Te-135) no muestra descomposición de fase M1, mientras que el material a $200^{\circ} \mathrm{C}$ muestra el mayor porcentaje de descomposición (Te-200). En este sentido, parece que la estabilidad de la fase M1 con teluro estaría relacionada con la temperatura de síntesis hidrotermal a la que se han preparado los materiales, y que la presencia de niobio (serie $\mathbf{T e N b}$ ) estabiliza la fase M1 independientemente de la temperatura de síntesis.

Sin embargo, en los materiales con antimonio no se observa una descomposición de la fase M1 durante el tratamiento térmico, ya que la cantidad de fase M1 presente en los materiales antes o después de la activación es muy similar (Figuras 5.2 y 5.5). Si bien, en los materiales activados se observa la presencia de la fase $\mathrm{Sb}_{2} \mathrm{Mo}_{10} \mathrm{O}_{31}$, además de un aumento de la cantidad de fase M2, por lo que su formación puede deberse a la presencia de otras fases en los materiales sin activar (tanto sólidos amorfos, como $\mathrm{MoO}_{3}$ hexagonal) debido a reacciones en estado sólido que pueden darse durante el tratamiento térmico a $600^{\circ} \mathrm{C}[42]$. 
Así mismo, la influencia de la temperatura de síntesis hidrotermal en la distribución de fases cristalinas (y en especial a la formación de la fase M1) se refleja en los resultados catalíticos obtenidos para la oxidación de propano. En el caso de los catalizadores MoVSbO, se observa un máximo de conversión de propano para el material preparado a $175^{\circ} \mathrm{C}$, mientras que en la selectividad a ácido acrílico el máximo corresponde al material preparado a 150ㄷ (Figura 5.8). Mientras que en el caso de los catalizadores con teluro, con o sin niobio, se alcanza un máximo de conversión y selectividad a ácido acrílico con los materiales obtenidos a $175^{\circ} \mathrm{C}$, si bien la selectividad a ácido acrílico obtenida con los catalizadores MoVTeNbO es mayor que con los catalizadores sin niobio.

Por tanto, podemos concluir que, existe un paralelismo entre la actividad catalítica de los materiales y la cantidad de fase M1 presente en el catalizador (Figura 5.5). Del mismo modo, la selectividad a ácido acrílico se ve favorecida al aumentar la cantidad de fase M1 en el catalizador. Ahora bien, si estos factores parecen evidentes en el caso de los materiales MoVSbO y MoVTeNbO, en los catalizadores MoVTeO, hay que considerar otros factores. En efecto, además de la presencia de fase activa M1, cuya cantidad es similar en los catalizadores activados, se debe tener en cuenta la descomposición de la fase M1 durante el tratamiento térmico a $600^{\circ} \mathrm{C}$. Así, se observa una dependencia del rendimiento a ácido acrílico con el porcentaje de descomposición de la fase M1, tal y como se muestra en la Figura 5.17.

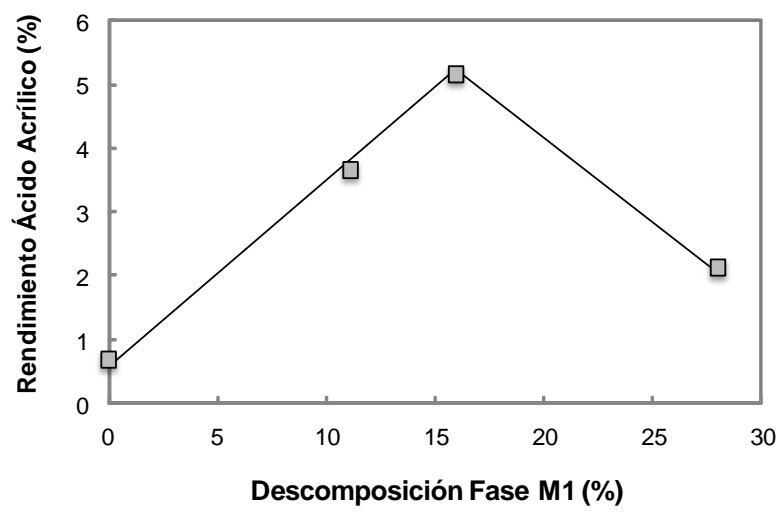

Figura 5.17. Variación del rendimiento a ácido acrílico con la descomposición de la fase M1 durante el tratamiento térmico observada en catalizadores MoVTeO preparados con diferente temperatura de síntesis.

En este sentido, la descomposición inicial de la fase M1 durante el tratamiento térmico favorece un incremento tanto de la conversión como de la selectividad a ácido acrílico durante la oxidación de propano, observándose un máximo de conversión y selectividad para, aproximadamente, un $15 \%$ de 
descomposición de la fase M1, obtenida para el catalizador Te-175a. Durante el tratamiento térmico, se puede producir una modificación de las propiedades superficiales, mejorando las propiedades catalíticas de la fase M1. Sin embargo, una mayor descomposición de la fase M1 (Te-200a), dando lugar a una mayor presencia de fases cristalinas no activas en la oxidación de propano, tiene un efecto negativo en las propiedades catalíticas.

\subsubsection{Influencia de la temperatura de activación térmica}

De acuerdo con los resultados de caracterización (DRX, FTIR y Raman) la influencia de la temperatura de activación del catalizador sobre las propiedades físico-química depende de la composición de los precursores.

En los catalizadores con teluro, pero sin niobio, la fase M1 se forma durante la síntesis hidrotermal (Te-as) y aparece como mayoritaria en los catalizadores tratados térmicamente a 500 o $550^{\circ} \mathrm{C}$. Mientras que, a temperaturas de activación de $600^{\circ} \mathrm{C}$, se favorece su descomposición parcial con la formación de otras fases: $\mathrm{TeMo}_{5} \mathrm{O}_{16}$ y $\mathrm{MoO}_{3}(\mathrm{Te}-\mathrm{T} 600)$.

En los catalizadores con antimonio, pero sin niobio, el precursor obtenido durante la síntesis hidrotermal (Sb-as) presenta las fases cristalinas M1 y M2, si bien la contribución de la fase M2 aumenta con el tratamiento de activación térmica, independientemente de la temperatura final de activación (500-600ㅜㄷ).

Sin embargo, los catalizadores con teluro y niobio, tienen un comportamiento diferente. Así, los DRX del precursor sin activar (TeNb-as) sugiere la presencia de un material amorfo, material que se observa también en la muestra tratada térmicamente a $500^{\circ} \mathrm{C}$ (TeNb-T500). Sin embargo, este material amorfo se transforma, selectivamente, en fase $\mathrm{M} 1$ en las muestras tratadas térmicamente a temperaturas de activación superiores a 5500 (TeNb-T550 y TeNb-T600).

También, cuando se comparan los resultados catalíticos para la oxidación de propano con catalizadores MoVSbO, MoVTeO y MoVTeNbO (Tabla 5.4), se puede concluir que la temperatura de activación del catalizador tiene una influencia importante en el comportamiento catalítico de estos materiales. Así, los materiales activados a $600^{\circ} \mathrm{C}$ son los que presentan mayor selectividad a ácido acrílico, aunque los catalizadores con niobio han sido los materiales más selectivos, lo que está de acuerdo con resultados previos [1-6, 12-13, 28, 31, 36, 39, 43, 60-61]. Sin embargo, no sucede lo mismo con la actividad catalítica de estos materiales.

En la Figura 5.18 se muestra la variación de la actividad catalítica (Figura 5.18, a) y la actividad catalítica específica (Figura 5.18, b) con la temperatura de activación para los tres tipo de catalizadores (MoVSbO, MoVTeO, MoVTeNbO). La actividad catalítica para la oxidación de propano en catalizadores sin niobio, 
MoVTe o MoVSbO, disminuye al aumentar la temperatura de activación (Figura 5.18, a), mientras que en los catalizadores MoVTeNbO se observa la tendencia opuesta. Este hecho puede directamente explicarse por la mayor 0 menor presencia de la fase M1, por lo que podemos concluir que el comportamiento catalítico, y más específicamente la conversión de propano, está relacionado con la presencia de la fase M1.
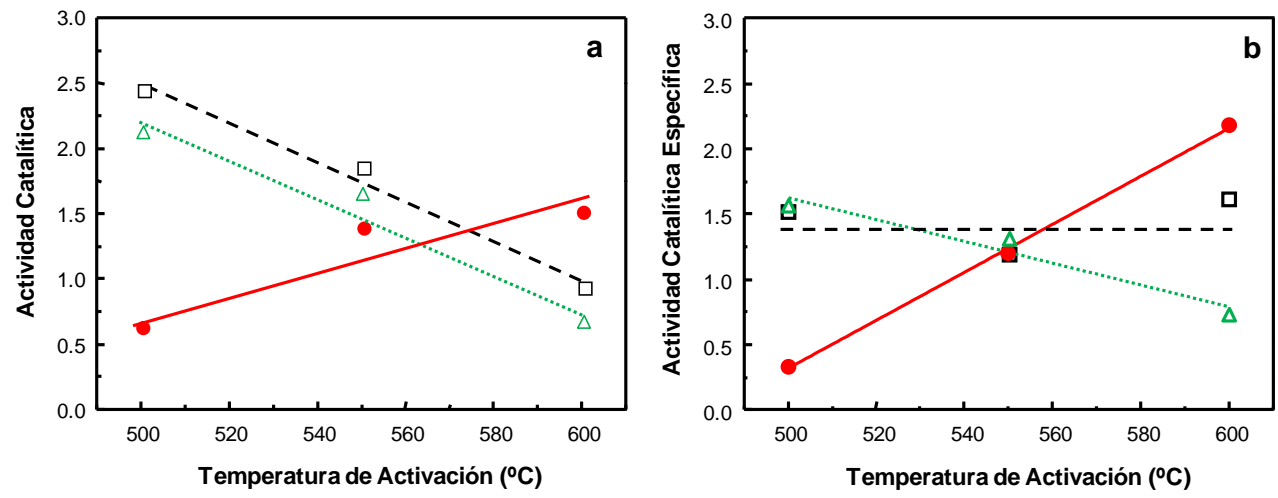

Figura 5.18. (a) Actividad catalítica $\left(10^{-3} \mathrm{~mol}_{\mathrm{c} 3 \mathrm{H} 8} \mathrm{~h}^{-1} \mathrm{~g}^{-1}\right)$ y (b) Actividad catalítica específica (en $10^{-4}$ mol $_{\text {СзH8 }} \mathrm{h}^{-1} \mathrm{~m}^{-2}$ ) de los catalizadores MoVSbO $(\Delta)$, MoVTeO (口) y MoVTeNbO $(\bullet)$ tratados térmicamente a 500,550 y $600^{\circ} \mathrm{C}$ ( $2 \mathrm{~h}$ en flujo de $\mathrm{N}_{2}$ ). Condiciones de reacción: temperatura de reacción: $380^{\circ} \mathrm{C}$; tiempo de contacto, W/F, de $200 \mathrm{~g}_{\text {cat }} \mathrm{h}\left(\mathrm{mol}_{\mathrm{c} 3 \mathrm{H} 8}\right)^{-1} \mathrm{y}$ relación molar propano/oxígeno/agua/helio de 4/8/30/58 (Flujo total de $50 \mathrm{ml} \mathrm{min}^{-1}$ ).

Sin embargo, cuando se considera la actividad catalítica específica (es decir la actividad catalítica por área superficial del catalizador) (Figura 5.18, b), se puede observar que no existe una tendencia clara, y que en cada caso, la temperatura de calcinación tiene una influencia diferente. Este hecho se puede explicar, al menos parcialmente, si consideramos que la descomposición parcial de la fase M1, y la formación de otras fases cristalinas, puede modificar el área superficial efectiva de la fase $\mathrm{M} 1$ en estos catalizadores. En efecto, la presencia de pequeños cristales de $\mathrm{MoO}_{3}$ y $\mathrm{TeMo}_{5} \mathrm{O}_{16}$ puede enmascarar el área real de la fase M1, aumentando el área superficial de los catalizadores y disminuyendo la actividad catalítica específica. Este hecho se ha observado recientemente en catalizadores con fase M1 pura preparados por un método post-síntesis [29, 46].

Por otro lado, las mayores diferencias observadas en el comportamiento catalítico de estos materiales están relacionadas con la formación de ácido acrílico. En efecto, de acuerdo con los resultados mostrados en la Tabla 5.4, la fase $\mathrm{M} 1$ en los catalizadores MoVTeO y MoVSbO presenta selectividades a ácido acrílico bajas, mientras que la fase M1 en catalizadores MoVTeNbO es muy activa y selectiva en la oxidación parcial de propano a ácido acrílico. Por tanto, el comportamiento catalítico no puede explicarse sólo en términos de la 
presencia/ausencia de la fase M1, sino como consecuencia de modificaciones en la superficie de los catalizadores durante la etapa de activación.

Se ha propuesto que los catalizadores con y sin niobio presentan una morfología completamente diferente [12-13]. Esto es, en parte, como consecuencia de la presencia de aniones oxalato que modifican el estado de oxidación de cada elemento en la superficie del catalizador [12,14] pero, además, previene la formación de agujas largas durante la síntesis hidrotermal, ralentizando la cristalización en el eje [001] de las partículas [40]. Sin embargo, el factor más importante a ser considerado es el hecho que la incorporación de niobio en la estructura de la fase M1 facilita una disminución del número de centros ácidos en este tipo de catalizadores [43], lo que facilita cambios significativos en el mecanismo de reacción $[9,43,62]$. Por otro lado, la presencia de niobio en la estructura de la fase M1 aumenta la estabilidad de la estructura [44], y podría facilitar una menor degradación de ácido acrílico a óxidos de carbono [45].

De hecho, es conocido que no sólo los catalizadores MoVTeO [10-12] sino que también los catalizadores MoVSbO [9, 11, 62-63], muestran una selectividad a ácido acrílico baja, aunque la selectividad se pueda aumentar usando un método post-síntesis $[9,46]$. Y se ha observado que esta baja selectividad a ácido acrílico en los sistemas catalíticos sin niobio (MoVTeO y MoVSbO) esta de alguna manera relacionada con la mayor presencia de centros ácidos (en especial de centros Brönsted) [9, 43, 46, 63].

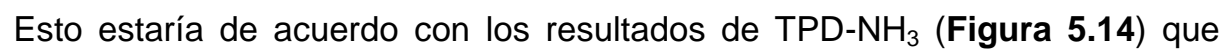
indican que la existencia del mayor número de centros ácidos se produce en los materiales tratados a $500^{\circ} \mathrm{C}$, pero que disminuyen drásticamente al activar los catalizadores a $600^{\circ} \mathrm{C}$.

En el caso de los materiales sin niobio, la acidez observada en los catalizadores activados a $500^{\circ} \mathrm{C}$ debe estar directamente relacionada con la fase M1 (mayoritaria según los resultados de DRX), mientras que el aumento de la temperatura de activación facilita la descomposición parcial de la fase M1 y la formación de fases cristalinas como $\mathrm{MoO}_{3}, \mathrm{TeMo}_{5} \mathrm{O}_{16}$ favoreciendo la contaminación de la superficie del catalizador (lo que favorecería una disminución importante del número de centros ácidos).

En el caso de los catalizadores MoVTeNbO activados a $500^{\circ} \mathrm{C}$, la presencia de centros ácidos debe estar relacionada con la presencia del material amorfo, los cuales desaparecen durante la transformación del material amorfo en fase M1 al aumentar la temperatura de activación.

Así pues, además de la existencia de la fase M1, existen otros factores que deben ser considerados para explicar los cambios observados en la formación de 
ácido acrílico con estos catalizadores. En este sentido, se han observado diferencias importantes cuando se compara las características superficiales de los catalizadores (Tabla 5.6), en especial: la naturaleza de las especies $\mathrm{Mo}^{6+}$, la presencia o ausencia de $\mathrm{Te}^{6+}$ y la naturaleza de las especies oxígeno en la superficie del catalizador. En este sentido, el catalizador más selectivo (TeNbT600) muestra la ausencia de una segunda especie de $\mathrm{Mo}^{6+}$, observada en los catalizadores $\sin \mathrm{Nb}\left(\mathrm{Mo}_{\mathrm{B}}{ }^{6+}, \mathrm{BE}=233.8 \mathrm{eV}\right)$ y que puede estar relacionada con la formación de otras fases cristalinas como $\mathrm{MoO}_{3} \circ \mathrm{TeMo}_{5} \mathrm{O}_{16}$. Además, la ausencia de $\mathrm{Te}^{6+}$ debe estar también relacionada con la presencia mayoritaria de la fase $\mathrm{M} 1$ y/o la incorporación de $\mathrm{Nb}^{5+}$ en la estructura de la fase $\mathrm{M} 1$.

En este sentido, durante el tratamiento térmico a alta temperatura se produce una reorganización de los elementos en la superficie del sólido, modificando el número de centros ácidos y el estado de oxidación de algunos elementos, en especial Mo, $\mathrm{V}$ y $\mathrm{Te}$, lo que favorece cambios significativos en las propiedades catalíticas de la fase activa M1.

\subsection{Conclusiones}

En este capítulo se ha estudiado la influencia de dos parámetros importantes en la preparación de óxidos mixtos con Mo y V: la temperatura de la síntesis hidrotermal y la temperatura de activación térmica de los materiales. En general, se ha observado que la temperatura de síntesis hidrotermal afecta principalmente a la formación de la fase activa M1, mientras que la temperatura de activación influye en las características superficiales del catalizador lo que tiene una gran influencia en las propiedades catalíticas de los materiales.

Los materiales MoVSbO, MoVTeO y MoVTeNbO preparados hidrotermalmente en el intervalo de $100-200^{\circ} \mathrm{C}$ muestran diferencias importantes en la distribución de las fases cristalinas dependiendo de la temperatura de síntesis y de la composición de los catalizadores.

En los materiales con antimonio se observa la formación de las fases M1 y M2 en los materiales de síntesis (incluso antes de la activación térmica final), aunque la formación de la fase M2 está más favorecida a temperaturas de síntesis bajas (la presencia de fase M1 aumenta a mayores temperaturas de síntesis). Sin embargo, los resultados de los materiales después de la activación final a $600^{\circ} \mathrm{C}$ sugieren que la presencia en los precursores de otras fases cristalinas minoritarias y/o de sólidos amorfos favorece un aumento de la fase M2 y la formación de otras fases (como $\mathrm{Sb}_{2} \mathrm{Mo}_{10} \mathrm{O}_{31}$ ) en los materiales activados. Estos cambios observados con la temperatura de síntesis afecta a las propiedades catalíticas, observándose un máximo en la actividad catalítica en el catalizador obtenido por activación a $600^{\circ} \mathrm{C}$ de un sólido sintetizado a $175^{\circ} \mathrm{C}$ (Sb-175a), y un máximo de selectividad a 
ácido acrílico para el catalizador obtenido por activación a $600^{\circ} \mathrm{C}$ de un sólido sintetizado a $150^{\circ} \mathrm{C}$ (Sb-150a).

En los materiales con teluro sin niobio, MoVTeO, se ha observado que la temperatura de síntesis hidrotermal influye, no sólo en la formación de la fase M1 sino también en la estabilidad de la fase M1 frente al tratamiento térmico a $600^{\circ} \mathrm{C}$. Así, los materiales preparados a mayores temperaturas de síntesis (Te-175, Te200) muestran la mayor presencia de fase $M 1$ en los precursores, sin embargo, al someterlos a la activación se observa una descomposición de la fase M1, con formación de $\mathrm{M} 2$ y $\mathrm{TeMo}_{5} \mathrm{O}_{16}$, mayor que en los materiales preparados a baja temperatura. Sin embargo, los resultados catalíticos sugieren que una pequeña descomposición de la fase M1 puede favorecer una mayor selectividad a ácido acrílico, siendo el catalizador Te-175a el más efectivo.

La presencia de niobio en los materiales con teluro, da lugar a la formación de un sólido amorfo en la síntesis hidrotermal, el cual se transforma principalmente a la fase M1 durante el tratamiento térmico. Además, la presencia de niobio favorece una mayor estabilidad térmica de la fase $\mathrm{M} 1$, ya que la descomposición de esta fase es mucho menor que la observada con los materiales sin niobio. Como resultado, se observa que en los catalizadores activados térmicamente la presencia de fase $\mathrm{M} 1$ en los materiales con niobio es mayor que en los catalizadores sin niobio. Además, la presencia de niobio parece favorecer una mejora en las propiedades catalíticas de los materiales dando lugar a una mayor selectividad a ácido acrílico durante la oxidación de propano.

Por otra parte, los materiales sintetizados hidrotermalmente se transforman de forma diferente cuando los sólidos son finalmente activados térmicamente, dependiendo de la temperatura de activación.

En el caso de los materiales MoVTeO, los materiales de síntesis presentan inicialmente la fase M1. Los resultados de caracterización de los catalizadores activados térmicamente (entre 500 y $600^{\circ} \mathrm{C}$ ) muestran que la fase $\mathrm{M} 1$ sigue siendo mayoritaria cuando la activación se lleva a cabo a temperaturas inferiores a $550^{\circ} \mathrm{C}$, pero se descompone parcialmente (con la formación de $\mathrm{MoO}_{3}$ y $\mathrm{TeMo}_{5} \mathrm{O}_{16}$ ) cuando la activación se lleva a cabo a $600^{\circ} \mathrm{C}$. Por otro lado, los resultados catalíticos para la oxidación de propano indican que la actividad catalítica disminuye y la selectividad a ácido acrílico aumenta al aumentar la temperatura de activación térmica de los catalizadores. Así, solamente después de una descomposición parcial de la fase M1, y probablemente con alguna contaminación en la superficie del catalizador, es posible lograr alguna una mejora en la selectividad a ácido acrílico.

Los catalizadores con antimonio, MoVSbO, presentan mayoritariamente las fases cristalinas M1 y M2 (cuya relación depende de la temperatura de activación). 
Sin embargo, en el material activado a $600^{\circ} \mathrm{C}$ se observa cierta modificación de ambas fases cristalinas con la aparición de otras fases $\left(\right.$ como $\left.\mathrm{Sb}_{2} \mathrm{Mo}_{10} \mathrm{O}_{31}\right)$. Por otra parte, el aumento de la temperatura de activación de los catalizadores favorece una disminución en la actividad catalítica y un aumento en la selectividad a ácido acrílico, aunque la selectividad a ácido acrílico obtenida es menor que su homólogo con teluro.

En el caso de los catalizadores MoVTeNbO, el material de síntesis no muestra fases cristalinas (aunque los resultados de DRX muestran la presencia de un sólido amorfo con cierto ordenamineto). Este sólido se transforma selectivamente en fase $\mathrm{M} 1$ a alta temperatura de activación superior a $550^{\circ} \mathrm{C}$. Además, tanto la actividad catalítica como la selectividad a ácido acrílico aumentan al aumentar la temperatura de activación. Así, la fase M1 con niobio, con cationes niobio incorporados en la estructura [28, 39, 43, 60-61], es la fase cristalina activa y selectiva para la oxidación parcial de propano.

La caracterización de los materiales por XPS y TPD- $\mathrm{NH}_{3}$ sugiere que el tratamiento térmico al que son sometidos los materiales puede producir cambios en las características superficiales de los catalizadores, que se pueden relacionar con el diferente comportamiento catalítico observado. Así, la menor acidez encontrada en los catalizadores con $\mathrm{Nb}$ y el cambio observado en la composición y estado de oxidación de los elementos en la superficie del catalizador, presencia únicamente de especies $\mathrm{Te}^{4+}$ y de un tipo de especies $\mathrm{Mo}^{6+}$ (ligadas a la fase M1) (Tabla 5.6), puede explicar la eficacia catalítica observada en catalizadores MoVTeNbO activados en el intervalo de temperaturas 550-600 ${ }^{\circ} \mathrm{C}$. Sin embargo, sólo un estudio más profundo de las características de la superficie de estos materiales puede ayudarnos a entender su relación con la efectividad catalítica en la oxidación parcial de propano.

\section{Conclusions}

The influence of two important parameters on the preparation of Mo and $\mathrm{V}$ based mixed oxides has been studied: the hydrothermal synthesis temperature and the catalysts activation temperature. In general, the hydrothermal synthesis temperature mainly affects to $\mathrm{M} 1$ phase formation, while the catalysts activation temperature has an influence in the catalysts surface properties and, thus, on their catalytic behavior.

MoVSbO, MoVTe and MoVTeNb prepared at $100-200^{\circ} \mathrm{C}$ temperature range show important differences in the crystalline phase distribution depending on the synthesis temperature and catalysts composition.

Sb-containing catalysts present M1 and M2 formation even before heattreatment. M1 phase amount increased at high temperature, while M2 phase is 
favored at low synthesis temperature. However, after heat-treatment a $600^{\circ} \mathrm{C}$, an increase of $\mathrm{M} 2$ phase and the formation of other phases $\left(\right.$ as $\left.\mathrm{Sb}_{2} \mathrm{Mo}_{10} \mathrm{O}_{31}\right)$ have observed, due to the minority presence of other crystalline phases and/or amorphous solid in the precursor. These changes observed with the synthesis temperature affect to catalytic properties, being the most active catalysts that prepared at $175^{\circ} \mathrm{C}(\mathbf{S b}-\mathbf{1 7 5 a})$ and the most selective to acrylic acid than prepared at $150^{\circ} \mathrm{C}(\mathbf{S b}-150 a)$.

The synthesis temperature in $\mathrm{Nb}$-free MoVTeO catalysts has an influence not only on $\mathrm{M} 1$ phase formation, but also on $\mathrm{M} 1$ phase stability during heat-treatment at $600^{\circ} \mathrm{C}$. Thus, samples prepared at high temperature (Te-175, Te-200) show higher present of $\mathrm{M} 1$ phase in the precursor but also a higher decomposition of the $\mathrm{M} 1$ phase ( $\mathrm{M} 2$ phase and $\mathrm{TeMo}_{5} \mathrm{O}_{16}$ formation) during the heat-treatment than materials prepared at low temperature. However, the catalytic results suggest than a small decomposition of M1 phase can favor a higher selectivity to acrylic acid, being Te-175a catalysts the most effective.

$\mathrm{Nb}$-containing MoVTeO catalysts show an amorphous solid in the hydrothermal synthesis, which is transformed mainly to M1 phase during heattreatment. Moreover, the presence of niobium favors a higher thermal stability of M1 phase due to the decomposition of this phase is lower than $\mathrm{Nb}$-free catalysts. As results, the amount of $\mathrm{M} 1$ phase in $\mathrm{Nb}$-containing catalysts is higher than $\mathrm{Nb}$ free catalysts. In addition, niobium seems to favor an improvement in the catalytic properties of the materials, resulting in a higher selectivity to acrylic acid in the propane oxidation.

On the other hand, the precursors obtained by hydrothermal synthesis are transformed in a different way during the activation, depending on the catalysts activation temperature.

In the case of MoVTeO catalysts, which present M1 phase in the precursor material obtained by hydrothermal synthesis, M1 phase is mainly observed at low catalyst activation temperatures ( 500 and $550^{\circ} \mathrm{C}$ ), while a partial decomposition of $\mathrm{M} 1$ phase into $\mathrm{M} 2, \mathrm{MoO}_{3}$ and $\mathrm{TeMo}_{5} \mathrm{O}_{16}$ in the sample heat-treated at $600^{\circ} \mathrm{C}$. On the other hand, the catalytic activity for propane oxidation decreases and the selectivity to acrylic acid increases when increasing the catalyst activation temperature. Accordingly, the catalytic results can be explained by considering the $\mathrm{M} 1$ phase in Mo-V-Te catalysts as very active but unselective for the partial oxidation of propane to acrylic acid. However, some improvement in the selectivity to acrylic acid for samples heat-treated at $600^{\circ} \mathrm{C}$, in which a partial decomposition of M1 phase is observed. Maybe some contamination of the catalyst surface can provide some modification of non-selective sites in these catalysts and improve the selectivity to acrylic acid. 
MoVSbO catalysts present mainly M1 and M2 phase (which relation depends on the activation temperature). However, some modification of both crystalline phases with the formation of other phases $\left(\mathrm{as} \mathrm{Sb}_{2} \mathrm{Mo}_{10} \mathrm{O}_{31}\right)$ is observed in the sample heat-treated at $600^{\circ} \mathrm{C}$. On the other hand, the catalytic activity decreases and the selectivity to acrylic acid increases when increasing the activation temperature. Although, the selectivity to acrylic acid obtained is lower than Tecontaining catalysts.

In the case of MoVTeNbO catalysts, the presence of amorphous phases at low catalyst activation temperatures and M1 phase at high activation temperatures has been observed. Since both the catalytic activity for propane oxidation and the selectivity to acrylic acid increase when increasing the catalyst activation temperature, it can be concluded that $\mathrm{Nb}$-containing $\mathrm{M} 1$ phase, with $\mathrm{Nb}$ cations incorporated in the framework, could be proposed as active and selective for partial oxidation of propane.

The characterization of materials by XPS and $\mathrm{NH}_{3}$-TPD suggests that the catalytic behavior of these materials could be more easily explained by considering the characteristics of the surface of the catalysts, which change in a different manner depending on the catalyst composition and activation temperature. Thus, in addition to the positive effect of the presence of $\mathrm{Nb}$ on the stability of M1 phase, the elimination of the acid character of catalysts, the presence of some element in a lower oxidation state (especially the presence of $\mathrm{Te}^{4+}$ and the elimination of $\mathrm{Te}^{6+}$ ) and a better homogeneous distribution of molybdenum cations (the presence of $\mathrm{Mo}_{A}{ }^{6+}$ species as indicated in Table 5.6) can explain the high selectivity to acrylic acid of $\mathrm{Nb}$-containing $\mathrm{MoVTeO}$ catalysts heat-treated at $550-600^{\circ} \mathrm{C}$ temperature range. However, only a deeper study of the surface characteristics of these materials can help us to understand their relation with the catalytic effectiveness in the partial oxidation of propane. 


\section{Bibliografía}

[1] T. Ushikubo, I. Sawaki, K.Oshima, K. Inumaru, S. Kovayakawa, K. Kiyono, EP 0603836 (1993)

[2] T. Ushikubo, H. Nakamura, Y. Koyasu, S. Wajiki, US Patent 5380933 (1995) assigned to Mitsubushi.

[3] T. Ushikubo, K. Oshima, A. Kayou, M. Hatano, X. Can Li and Qin, in Studies in Surface Science and Catalysis, Volume 112, Elsevier, (1997), 473-480.

[4] H. Tsuji, Y. Koyasu, Journal of the American Chemical Society 124 (2002) 5608-5609.

[5] J. M. López Nieto, P. Botella, M. I. Vazquez, A. Dejoz, Chemical Communications (2002) 1906-1907.

[6] P. Botella, E. García-González, A. Dejoz, J. M. López Nieto, M. I. Vázquez, J. González-Calbet, Journal of Catalysis 225 (2004) 428-438.

[7] W. Ueda, K. Oshihara, D. Vitry, T. Hisano, Y. Kayashima, Catalysis Surveys from Japan 6 (2002) 33-44.

[8] J. M. M. Millet, M. Baca, A. Pigamo, D. Vitry, W. Ueda, J. L. Dubois, Applied Catalysis A: General 244 (2003) 359-370.

[9] T. Blasco, P. Botella, P. Concepción, J. M. López Nieto, A. Martinez-Arias, C. Prieto, Journal of Catalysis 228 (2004) 362-373.

[10] J. N. Al-Saeedi, V. K. Vasudevan, V. V. Guliants, Catalysis Communications 4 (2003) 537-542.

[11] W. Ueda, K. Oshihara, Applied Catalysis A: General 200 (2000) 135-143.

[12] P. Botella, J. M. López Nieto, B. Solsona, Catalysis Letters 78 (2002) 383387.

[13] D. Vitry, Y. Morikawa, J. L. Dubois, W. Ueda, Applied Catalysis A: General 251 (2003) 411-424.

[14] P. Botella, B. Solsona, A. Martinez-Arias, J. M. López Nieto, Catalysis Letters 74 (2001) 149-154.

[15] P. Botella, J. M. López Nieto, B. Solsona, A. Mifsud, F. Márquez, Journal of Catalysis 209 (2002) 445-455.

[16] H. Tsuji, K. Oshima, Y. Koyasu, Chemistry of Materials 15 (2003) 21122114.

[17] F. Ivars, P. Botella, A. Dejoz, J. M. López Nieto, P. Concepción, M. Vázquez, Topics in Catalysis 38 (2006) 59-67.

[18] G. Y. Popova, T. V. Andrushkevich, G. I. Aleshina, L. M. Plyasova, M. I. Khramov, Applied Catalysis A: General 328 (2007) 195-200.

[19] J. M. López Nieto, P. Botella, B. Solsona, J. M. Oliver, Catalysis Today 81 (2003) 87-94.

[20] P. Botella, P. Concepción, J. M. López Nieto, Y. Moreno, Catalysis Today 99 (2005) 51-57.

[21] X. Tu, N. Furuta, Y. Sumida, M. Takahashi, H. Niiduma, Catalysis Today 117 (2006) 259-264.

[22] J. M. Oliver, J. M. López Nieto, P. Botella, A. Mifsud, Applied Catalysis A: General 257 (2004) 67-76.

[23] Y. Zhu, W. Lu, H. Li, H. Wan, Journal of Catalysis 246 (2007) 382-389. 
[24] E. V. Ischenko, T. V. Andrushkevich, G. Y. Popova, V. M. Bondareva, Y. A. Chesalov, T. Y. Kardash, L. M. Plyasova, L. S. Dovlitova, A. V. Ischenko, Studies in Surface Science and Catalysis Volume 175 (2010) 479-482.

[25] B. Solsona, J. M. López Nieto, J. M. Oliver, J. P. Gumbau, Catalysis Today 91-92 (2004) 247-250.

[26] F. Ivars, B. Solsona, S. Hernández, J. M. López Nieto, Catalysis Today 149 (2010) 260-266.

[27] F. N. Naraschewski, C. Praveen Kumar, A. Jentys, J. A. Lercher, Applied Catalysis A: General 391 (2011) 63-69.

[28] R. Grasselli, D. Buttrey, J. Burrington, A. Andersson, J. Holmberg, W. Ueda, J. Kubo, C. Lugmair, A. Volpe, Topics in Catalysis 38 (2006) 7-16.

[29] B. Deniau, G. Bergeret, B. Jouguet, J. Dubois, J. Millet, Topics in Catalysis 50 (2008) 33-42.

[30] B. Solsona, M. I. Vázquez, F. Ivars, A. Dejoz, P. Concepción, J. M. López Nieto, Journal of Catalysis 252 (2007) 271-280.

[31] M. Baca, M. Aouine, J. L. Dubois, J. M. M. Millet, Journal of Catalysis 233 (2005) 234-241.

[32] V. Guliants, H. Brongersma, A. Knoester, A. Gaffney, S. Han, Topics in Catalysis 38 (2006) 41-50.

[33] M. Baca, J. M. M. Millet, Applied Catalysis A: General 279 (2005) 67-77.

[34] I. Ramli, P. Botella, F. Ivars, W. Pei Meng, S. M. M. Zawawi, H. A. Ahangar, S. Hernández, J. M. López Nieto, Journal of Molecular Catalysis A: Chemical 342-343 (2011) 50-57.

[35] D. Vitry, Y. Morikawa, J. L. Dubois, W. Ueda, Topics in Catalysis 23 (2003) 47-53.

[36] R. M. Feng, X. J. Yang, W. J. Ji, H. Y. Zhu, X. D. Gu, Y. Chen, S. Han, H. Hibst, Journal of Molecular Catalysis A: Chemical 267 (2007) 245-254.

[37] L. Espinal, K. A. Malinger, A. E. Espinal, A. M. Gaffney, S. L. Suib, Advanced Functional Materials 17 (2007) 2572-2579.

[38] X. J. Yang, R. M. Feng, W. J. Ji, C. T. Au, Journal of Catalysis 253 (2008) 57-65.

[39] P. Botella, E. García-González, J. M. López Nieto, J. M. González-Calbet, Solid State Sciences 7 (2005) 507-519.

[40] A. Celaya Sanfiz, T. Hansen, F. Girgsdies, O. Timpe, E. Rödel, T. Ressler, A. Trunschke, R. Schlögl, Topics in Catalysis 50 (2008) 19-32.

[41] P. Beato, A. Blume, F. Girgsdies, R. E. Jentoft, R. Schlögl, O. Timpe, A. Trunschke, G. Weinberg, Q. Basher, F. A. Hamid, S. B. A. Hamid, E. Omar, L. Mohd Salim, Applied Catalysis A: General 307 (2006) 137-147.

[42] K. Oshihara, T. Hisano, W. Ueda, Topics in Catalysis 15 (2001) 153-160.

[43] M. Baca, A. Pigamo, J. L. Dubois, J. M. M. Millet, Catalysis Communications 6 (2005) 215-220.

[44] P. Korovchenko, N. Shiju, A. Dozier, U. Graham, M. Guerrero-Pérez, V. Guliants, Topics in Catalysis 50 (2008) 43-51.

[45] W. Ueda, D. Vitry, T. Katou, Catalysis Today 99 (2005) 43-49.

[46] F. Ivars, B. Solsona, E. Rodríguez-Castellón, J. M. López Nieto, Journal of Catalysis 262 (2009) 35-43.

[47] L. B. McCusker, R. B. Von Dreele, D. E. Cox, D. Louer, P. Scardi, Journal of Applied Crystallography 32 (1999) 36-50. 
[48] P. Concepción, P. Botella, J. M. López Nieto, Applied Catalysis A: General 278 (2004) 45-56.

[49] J. C. J. Bart, F. Cariati, A. Sgamellotti, Inorganica Chimica Acta 36 (1979) 105-112.

[50] M. O. Guerrero-Pérez, J. N. Al-Saeedi, V. V. Guliants, M. A. Bañares, Applied Catalysis A: General 260 (2004) 93-99.

[51] P. Botella, A. Dejoz, J. M. López Nieto, P. Concepción, M. I. Vázquez, Applied Catalysis A: General 298 (2006) 16-23.

[52] I. E. Wachs, J. M. Jehng, W. Ueda, The Journal of Physical Chemistry $B$ 109 (2005) 2275-2284.

[53] X. Yang, W. Zhang, R. Feng, W. Ji, C. T. Au, Catalysis Letters 124 (2008) 288-296.

[54] H. Knoezinger, H. Jeziorowski, The Journal of Physical Chemistry 82 (1978) 2002-2005.

[55] L. Koudelka, J. Pospišil, P. Mošner, L. Montagne, L. Delevoye, Journal of Non-Crystalline Solids 354 (2008) 129-133.

[56] V. Bondarenka, S. Grebinskij, S. Kačiulis, G. Mattogno, S. Mickevičius, Journal of Electron Spectroscopy and Related Phenomena 107 (2000) 253-259.

[57] V. Nivoix, B. Gillot, Materials Chemistry and Physics 63 (2000) 24-29.

[58] S. Damyanova, L. Petrov, M. A. Centeno, P. Grange, Applied Catalysis A: General 224 (2002) 271-284.

[59] H. Hayashi, N. Shigemoto, S. Sugiyama, N. Masaoka, K. Saitoh, Catalysis Letters 19 (1993) 273-277.

[60] J. M. M. Millet, H. Roussel, A. Pigamo, J. L. Dubois, J. C. Jumas, Applied Catalysis A: General 232 (2002) 77-92.

[61] H. Murayama, D. Vitry, W. Ueda, G. Fuchs, M. Anne, J. L. Dubois, Applied Catalysis A: General 318 (2007) 137-142.

[62] W. Ueda, Y. Endo, N. Watanabe, Topics in Catalysis 38 (2006) 261-268.

[63] F. Ivars, B. Solsona, P. Botella, M. D. Soriano, J. M. López Nieto, Catalysis Today 141 (2009) 294-299. 


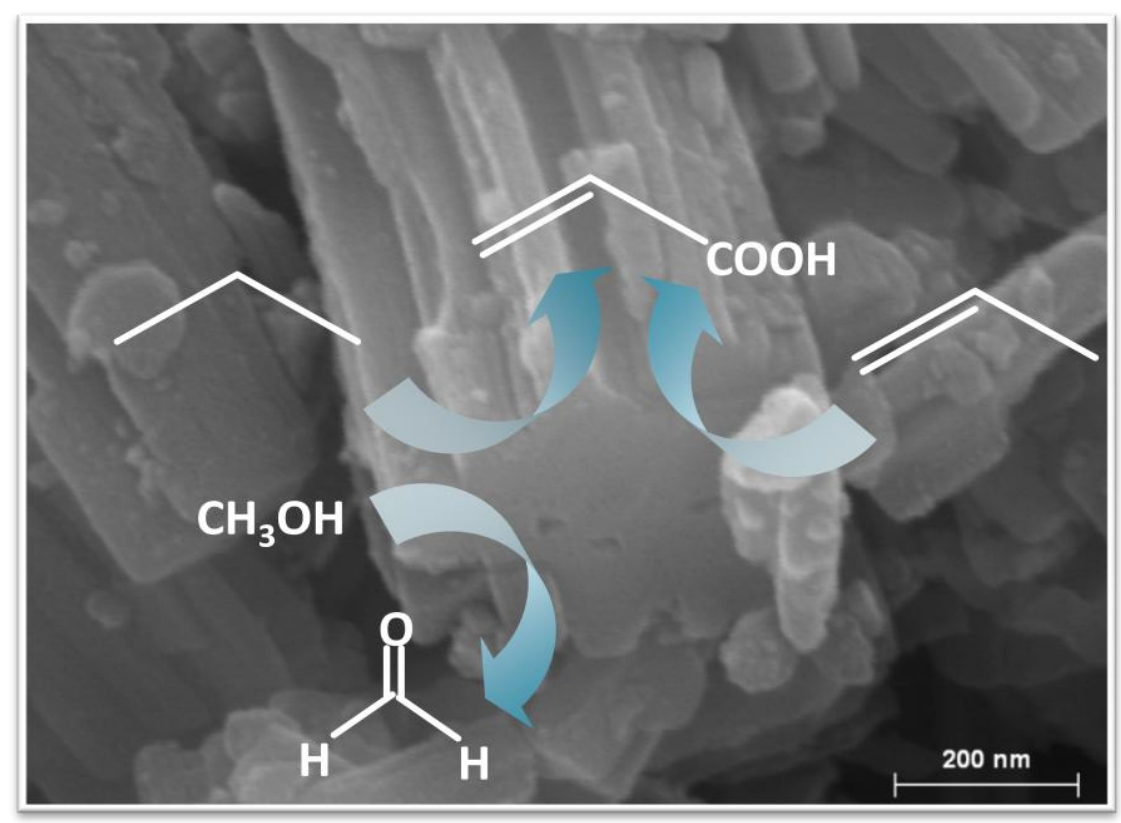

\section{óxidos Mixtos \\ MoVSb0, MoVTe0 y MoVTeNb activados a 500 y $600^{\circ} \mathrm{C}$}





\begin{abstract}
A comparative study on the partial oxidation of propane, propylene and methanol over MoVSbO, MoVTeO and MoVTeNbO heat-treated at 500 and $600^{\circ} \mathrm{C}$ is presented. In general, these catalysts are active and selective in all the reactions studied. However, differences in the catalytic behavior have been observed depending on the catalyst composition and catalysts activation temperature. $\mathrm{Nb}$ free MoVSbO and MoVTeO catalysts heat-treated a $600^{\circ} \mathrm{C}$ present a similar catalytic behavior in all the reactions studied, suggesting similar redox and acid sites in both catalysts. $\mathrm{Nb}$-free catalysts heat-treated at $500^{\circ} \mathrm{C}$ are very active but selective to carbon oxides in the partial oxidation of propane and propylene, while are selective to formaldehide in the methanol oxidation. Nb-containing catalyst heat-treated at $500^{\circ} \mathrm{C}$ is active and selective in the oxidation of propylene, but in the partial oxidation of propane it shows a low activity and selectivity to acrylic acid. The most active and selective catalysts is MoVTeNbO sample heat-treated at $600^{\circ} \mathrm{C}$. These differences observed in the oxidation of propane over MoVTeNbO catalysts could be related to the modification of actives sites for the alkane oxidation during the heat-treatment. The comparative study by other surface characterization techniques, as infrared spectroscopy of adsorbed probe molecules and ${ }^{18} \mathrm{O}_{2}$ isotopic exchange, of MoVSbO, MoVTeO and MoVTeNbO catalysts suggests that the catalytic behavior of these materials could be more easily explained by considering the characteristics of the surface of the catalysts, which change in a different manner depending on the catalyst composition and activation temperature. Thus, the presence of acid sites, the nature and oxidation state of the elements on the surface, the mobility of surface oxygen species and the adsorption of the intermediates species could be related to the catalytic properties of materials.
\end{abstract}




\section{Resumen}

Se ha realizado un estudio comparativo del comportamiento catalítico, durante la oxidación de propano, propeno y metanol de los óxidos mixtos $\mathrm{MoVSbO}, \mathrm{MoVTeO}$ y MoVTeNbO activados a 500 y $600^{\circ} \mathrm{C}$. En general, estos catalizadores son activos y selectivos en las reacciones estudiadas. Sin embargo, se han observado diferencias en el comportamiento catalítico dependiendo de la composición y de la temperatura de activación de los catalizadores. Los catalizadores MoVSbO y MoVTeO sin niobio activados a $600^{\circ} \mathrm{C}$ presentan un comportamiento similar en todas las reacciones estudiadas, sugiriendo la presencia de centros redox y ácidos similares en ambos catalizadores. Los catalizadores sin niobio activados a $500^{\circ} \mathrm{C}$ son muy activos pero selectivo a óxidos de carbono en la oxidación parcial de propano y propileno, mientras que son selectivos a formaldehído en la oxidación de metanol. El catalizador MoVTeNbO activado a $500^{\circ} \mathrm{C}$ es activo y selectivo en la oxidación de propileno, pero en la oxidación parcial de propano muestra baja actividad y selectividad a ácido acrílico. Estas diferencias observadas en la oxidación de propano sobre catalizadores MoVTeNbO pueden estar relacionadas con la modificación de los centros activos para la activación del alcano durante el tratamiento térmico. El estudio comparativo mediante otras técnicas de caracterización superficial, como la adsorción de moléculas sonda por espectroscopia IR y el intercambio isotópico ${ }^{18} \mathrm{O}_{2}$, de los catalizadores MoVSbO, MoVTeO y MoVTeNbO sugiere que el comportamiento catalíticos de estos materiales puede explicarse considerando las características de la superficie de los catalizadores, la cual cambia de forma diferente dependiendo de la composición y de la temperatura de activación de los catalizadores. Así, la presencia de centros ácidos, la naturaleza y estado de oxidación de los elementos en la superficie, la movilidad de las especies oxígeno en la superficie y la adsorción de los intermedios de reacción está directamente relacionada con las propiedades catalíticas de los materiales. 


\subsection{Antecedentes}

Como se ha visto en el capítulo anterior, durante la etapa de activación se pueden producir cambios en las propiedades superficiales de los catalizadores, dando lugar a comportamientos catalíticos diferentes. Así, se ha observado que la presencia de la fase $\mathrm{M} 1$ en los óxidos mixtos $\mathrm{MoVTe}(\mathrm{Sb}) \mathrm{NbO}$ da lugar a un catalizador activo en la oxidación de propano. Sin embargo, la selectividad a ácido acrílico depende, además, de las propiedades superficiales (número de centros ácidos o estado de oxidación de los elementos) en la superficie de dichos materiales.

El estado de oxidación de los diferentes elementos catiónicos en el bulk de los catalizadores MoVTeNbO se han estudiado por XANES [1-3] y, en el caso del $\mathrm{Te}$ o Sb, también por espectroscopia Mösbauer [1]. En este sentido, se ha sugerido que los cationes teluro no tienen únicamente un papel estructural en los catalizadores sino que actúan también como almacenamiento de oxígeno estructural en los canales hexagonales [4].

Por otro lado, algunos de los resultados de XPS de estos materiales sugieren ciertas diferencias entre el interior (bulk) y la superficie del catalizador [1, 4-6], aunque en algunos casos la modificación en el estado de oxidación de los elementos en la superficie del material podría estar relacionada sólo con el procedimiento de activación de los materiales [7-8]. Sin embargo, se podrían producir cambios más importantes en la superficie de los catalizadores, en especial en la primera monocapa, que sería difícil de observar por XPS. Así, se ha sugerido que la zona dinámica de este tipo de catalizadores podría limitarse a un espesor de, aproximadamente, $1 \mathrm{~nm}$ [9]. Por consiguiente, se deberían utilizar otras técnicas de caracterización para determinar, más adecuadamente, los cambios producidos en la superficie de los catalizadores.

La espectroscopia de reacción superficial a temperatura programada (temperature programmed surface reaction, TPSR) de metanol se ha empleado en la determinación de la naturaleza de los centros activos en la superficie de los catalizadores MoVTeNbO [10], concluyendo que los cationes $\mathrm{V}^{5+}$ (redox) y $\mathrm{Mo}^{6+}$ (ácido) son los centros activos en la superficie, mientras que los cationes $\mathrm{Nb}^{5+}$ y $\mathrm{Te}^{4+}$ podrían ser considerados como promotores. Además, se ha observado que en el caso de catalizadores del tipo MoVO ó MoVTeO solamente se producía la formación de formaldehído, mientras que en los catalizadores MoVTeNbO se producía tanto formaldehído (posiblemente en centros $\mathrm{VO}_{\mathrm{x}}$ ) como dimetiléter (posiblemente en centros $\mathrm{MoO}_{\mathrm{x}}$ ). Así, se puede concluir que dependiendo de la composición de los catalizadores se producen modificaciones en las características de los centros redox y de los centros ácidos. 
Guliants y col. [11] estudiaron el papel de los cationes superficiales en la oxidación de propano con catalizadores basados en óxidos mixtos MoVMe (Me = $\mathrm{Te}, \mathrm{Nb}$ y $\mathrm{Sb}$ ), y que presentan la fase ortorrómbica M1, empleando espectrometría de esparcimiento de iones de baja energía (Low-energy ion scattering, LEIS) sugiriendo que los cationes $\mathrm{Nb}$ estaban localizados preferiblemente en la superficie más externa, mientras que la concentración de Te o Sb en la zona más cercana a la superficie disminuye gradualmente a medida que se adentra al interior de la partícula (es decir hacía el bulk). Más recientemente, este grupo ha empleado estudios de quimisorción y de reacción superficial de metanol y alcohol alílico en combinación con LEIS para investigar la composición superficial y la naturaleza química de la fase activa en este tipo de catalizadores [11]. De acuerdo con estos autores, las especies de metanol se absorben preferentemente en los centros superficiales $\mathrm{VO}_{\mathrm{x}}$ y $\mathrm{MoO}_{\mathrm{x}}$. Además, concluyen que la superficie de los catalizadores muestran un contenido de $\mathrm{V}$ y Mo menor (así como un enriquecimiento de $\mathrm{Nb}$ y $\mathrm{Te}$ ) con respecto a la composición bajo la superficie o del bulk, sugiriendo que el bulk de los catalizadores actúa como un soporte.

En el presente capítulo se realizará un estudio comparativo sobre el comportamiento catalítico para la oxidación de propano, propileno y metanol de los catalizadores MoVSbO, MoVTeO y MoVTeNbO activados a 500 y $600^{\circ} \mathrm{C}$. Además, se han estudiado las características superficiales de estos materiales por adsorción de moléculas sonda en el infrarrojo e intercambio isotópico de ${ }^{18} \mathrm{O}_{2}$.

\subsection{Estudio comparativo de la oxidación selectiva de propano, propeno y metanol}

\subsubsection{Consideraciones Generales}

Los óxidos mixtos MoVTe(Sb)NbO han demostrado ser un sistema catalítico eficaz en la amoxidación/oxidación de propano a acrilonitrilo/ácido acrílico. Sin embargo, es importante señalar que la distribución de productos en la oxidación selectiva de propano depende de la composición del catalizador. En este sentido, se ha observado que los materiales MoVTeNbO muestran principalmente la formación de ácido acrílico, mientras que los catalizadores sin niobio, MoVTeO o MoVSbO, favorecen no sólo la formación de ácido acrílico, sino también la formación de ácido acético y una mayor producción de óxidos de carbono.

Por otra parte, en todos los casos estudiados, se observa también la formación de propileno a bajas conversiones de propano, aunque la selectividad a propileno disminuye a medida que se aumenta la conversión de propano (condiciones en la que se observa un aumento de la selectividad a productos de oxidación parcial y óxidos de carbono). En vista a estos resultados, está 
generalmente aceptado que la deshidrogenación oxidativa de propano a propileno es la primera etapa en la oxidación de propano a ácido acrílico con catalizadores $\mathrm{MoVTe}(\mathrm{Sb}) \mathrm{NbO}$ (Esquema 6.1) [1, 12-17]. El propileno formado en esta etapa puede transformarse a ácido acrílico, ácido acético u óxidos de carbono, dependiendo de las características del catalizador. Por ello, el propileno es un producto primario e inestable durante la oxidación de propano, mientras que el ácido acético y ácido acrílico son productos secundarios (e inestables, dado que a altas conversiones se transforman en óxidos de carbono). Por otra parte, los óxidos de carbono se forman tanto por reacciones paralelas como consecutivas de los productos primarios y secundarios.

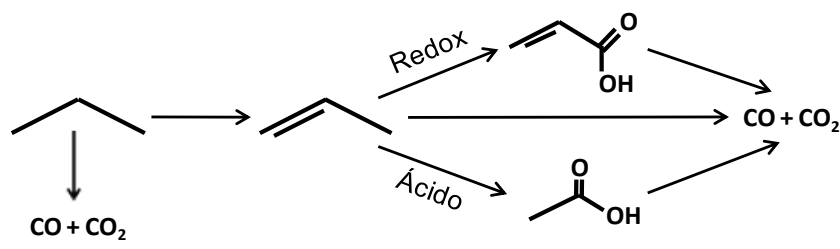

Esquema 6.1. Mecanismo de reacción para la oxidación selectiva de propano con óxidos mixtos $\mathrm{MoVTe}(\mathrm{Sb}) \mathrm{NbO}$.

La activación oxidativa del alcano debe tener lugar por la abstracción de un hidrógeno del propano mediante un mecanismo concertado sobre un par ácidobase, un centro Lewis $\left(\mathrm{V}^{5+}\right)$ y un oxígeno básico $\left(\mathrm{O}^{2-}\right)$, para la formación de propileno. De esta forma, las especies $\mathrm{V}^{5+}$ octaédricas en los pares $\mathrm{V}-\mathrm{O}-\mathrm{Mo}^{\mathrm{n+}}$ serían las especies activas en la activación oxidativa de propano con este tipo de catalizadores [1, 12-20].

La oxidación de propileno (alimentado directamente en el reactor $u$ obtenido a partir de propano) puede dar lugar a la formación de ácido acrílico, ácido acético y/o óxidos de carbono dependiendo de las características de los centros presentes en los catalizadores. En todos los casos, el ácido acrílico se forma por un mecanismo redox, con la participación de centros $\mathrm{Te}^{4+} \mathrm{o} \mathrm{Sb}^{3+}$ (responsables de la abstracción del hidrógeno $\alpha$ del propileno) y especies $\mathrm{Mo}^{6+}$ (responsables de la inserción de oxígeno) [16-20]. Sin embargo, la presencia de centros ácidos Brönsted favorecerá la formación de acetona que, tras una reacción de oxidación se transformará en ácido acético [17]. Por otra parte, la presencia de centros ácidos Lewis y centros Brónsted puede también favorecer la formación de un intermedio adsorbido (isopropóxido) que podría conducir a la formación de los óxidos de carbono [17].

En este sentido, debido al paralelismo entre los productos oxigenados observado en la oxidación de propano y propileno, se han llevado a cabo un estudio en paralelo sobre la oxidación selectiva de propileno con catalizadores $\mathrm{MoVTe}(\mathrm{Sb}) \mathrm{NbO}$ activados a 500 y $600^{\circ} \mathrm{C}$, con el fin de comprender mejor las 
diferencias catalíticas observadas con estos catalizadores durante la oxidación parcial de propano.

Por otro lado, es conocido que la transformación de metanol en presencia de oxígeno puede dar lugar a varios productos dependiendo del catalizador empleado, temperatura de reacción, conversión y presión parcial de los reactivos [21]. En el Esquema 6.2 se describen las diferentes vías que pueden desarrollarse durante la transformación catalítica del metanol en fase gaseosa. Así, en presencia de un catalizador con propiedades redox, el principal producto que se obtiene es el formaldehido $\left(\mathrm{CH}_{2} \mathrm{O}\right)$. Sin embargo, cuando se trata de un catalizador ácido, el producto principal es el dimetiléter $\left(\mathrm{CH}_{3} \mathrm{OCH}_{3}\right)$. Otros productos como el formiato de metilo $\left(\mathrm{HCOOCH}_{3}\right)$, dimetoximetano $\left(\left(\mathrm{CH}_{3} \mathrm{O}\right)_{2} \mathrm{CH}_{2}\right)$ y óxidos de carbono también pueden formarse durante la oxidación de metanol en función de las características redox y/o ácidas del catalizador. Sin embargo, la formación de ácido fórmico $(\mathrm{HCOOH})$ raramente se observa [22-23], dado que este producto se considera un intermedio en la formación del formiato de metilo [24] u óxidos de carbono.

Por tanto, estas reacciones pueden clasificarse en dos rutas principales: i) reacciones de oxidación (necesitan aporte de oxígeno molecular o del propio catalizador; y ii) reacciones de deshidratación. De acuerdo con este esquema, todos los productos obtenidos durante la transformación de metanol, a excepción de dimetiléter, necesitan al menos una etapa de oxidación.

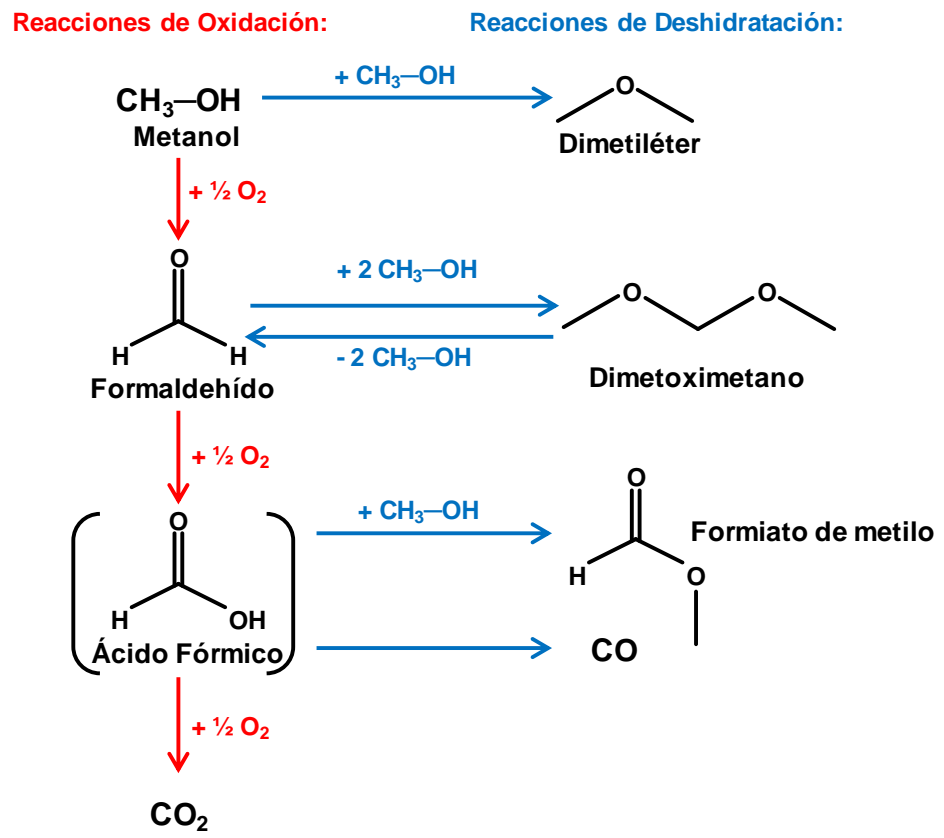

Esquema 6.2. Transformación catalítica de metanol en presencia de oxígeno [21]. 
Por otra parte, del estudio del mecanismo de la reacción con diferentes sistemas catalíticos [21], se concluye que la primera etapa es la formación del grupo metoxi por la adsorción disociativa del metanol sobre un par ácido-base de la superficie del catalizador. La transformación de los grupos metoxi adsorbidos depende de las características redox o ácidas de los centros activos del catalizador. Así, los productos obtenidos dependen de la propiedades específicas del catalizador: i) acidez (Lewis o Brönsted), ii) características redox, iii) diferente configuración de los átomos superficiales del catalizador (sensibilidad de la estructura) [21].

En este sentido, si en la superficie del catalizador están presentes centros ácidos fuertes y centros básicos muy débiles, se formará solamente dimetiléter [25-26]. La formación selectiva de formaldehído requiere centros ácidos y básicos débiles, que limiten la abstracción de hidrógeno, favoreciendo la desorción de formaldehido. En centros con mayor fortaleza ácida, el tiempo de residencia de formaldehido es mayor, pudiendo reaccionar con grupos metoxi adsorbidos para formar dimetoximetano [21]. Si ambos centros ácidos y básicos son más fuertes que aquellos necesarios para la formación de dimetoximetano, entonces las especies dioximetilenos se oxidarán para formar especies formiato, las cuales rápidamente reaccionan con metanol para formar formiato de metilo o productos de combustión (óxidos de carbono) [22, 24]. Al aumentar la conversión de metanol, se favorecen las reacciones consecutivas, observándose principalmente la formación de óxidos de carbono, productos más favorecidos termodinámicamente.

Dada la versatilidad del metanol, se ha llevado a cabo un estudio comparativo de la transformación selectiva de metanol, en presencia de oxígeno, con el fin de evaluar, en condiciones de reacción la formación de productos por un mecanismo redox y/o ácido. En este caso, la transformación de metanol en presencia de oxígeno se va a emplear como una reacción test para la caracterización de estos materiales con el fin de determinar las propiedades químicas de los centros activos en la superficie del catalizador.

Por tanto, en este apartado se va a llevar a cabo el estudio comparativo del comportamiento catalítico, durante la oxidación de propano, propeno y metanol, de algunos óxidos mixtos estudiados en el capítulo anterior, concretamente los óxidos mixtos MoVSbO, MoVTeO y MoVTeNbO activados a 500 y $600^{\circ} \mathrm{C}$.

En la Tabla 6.1 se resumen las características de los catalizadores estudiados (apartado 5.3). Se incluyen además los valores de conversión de propano y la selectividad a ácido acrílico que se obtuvieron para la oxidación de propano a $400^{\circ} \mathrm{C}$ y un tiempo de contacto, W/F, de $200 \mathrm{~g}_{\mathrm{cat}} \mathrm{h}\left(\mathrm{mol}_{\mathrm{C} 3 \mathrm{H} 8}\right)^{-1}$. 
Tabla 6.1. Características y resultados catalíticos en la oxidación parcial de propano de los catalizadores MoVX(Nb)O (X = Te o Sb) estudiados.

\begin{tabular}{lcccl}
\hline Catalizador & $\begin{array}{c}\text { Temperatura } \\
\text { de Activación }\end{array}$ & Conv.(\%) $^{\mathbf{a}}$ & $\mathbf{S}_{\mathrm{AA}}(\%)^{\mathbf{b}}$ & Fases Cristalinas $^{\mathbf{c}}$ \\
\hline $\mathrm{Sb}-500$ & $500^{\circ} \mathrm{C} / \mathrm{N}_{2}$ & 38.1 & 1 & $\mathrm{M} 1, \mathrm{M} 2$ \\
$\mathrm{Sb}-600$ & $600^{\circ} \mathrm{C} / \mathrm{N}_{2}$ & 20.5 & 35 & $\mathrm{M} 1, \mathrm{M} 2, \mathrm{Sb}_{2} \mathrm{Mo}_{10} \mathrm{O}_{31}$ \\
\hline Te-500 & $500^{\circ} \mathrm{C} / \mathrm{N}_{2}$ & $49.8^{\mathrm{d}}$ & 2 & $\mathrm{M} 1$ \\
Te-600 & $600^{\circ} \mathrm{C} / \mathrm{N}_{2}$ & 27.6 & 27 & $\mathrm{M} 1, \mathrm{M} 2, \mathrm{MoO}_{3}, \mathrm{TeMO}_{5} \mathrm{O}_{16}$ \\
\hline TeNb-500 & $500^{\circ} \mathrm{C} / \mathrm{N}_{2}$ & 19.4 & 12 & $\mathrm{~A}$ \\
TeNb-600 & $600^{\circ} \mathrm{C} / \mathrm{N}_{2}$ & 38.1 & 81 & $\mathrm{M} 1$ \\
\hline
\end{tabular}

${ }^{\mathrm{a}}$ Conversión de propano a $400^{\circ} \mathrm{C}$ y tiempo de contacto, W/F, de $200 \mathrm{~g}_{\text {cat }} \mathrm{h}$ mol $\mathrm{C} 3 \mathrm{H} 8^{-1}$;

${ }^{\mathrm{b}}$ Selectividad a Ácido Acrílico (AA);

${ }^{\mathrm{C}}$ Fases cristalinas mayoritarias determinadas por DRX: $\mathrm{M} 1=(\mathrm{XO}){ }_{2} M_{20} \mathrm{O}_{56} ; \mathrm{M} 2=\left(\mathrm{X}{ }_{2} \mathrm{O}\right) M_{6} \mathrm{O}_{18}(\mathrm{X}=\mathrm{Sb}$ ó Te; $M=\mathrm{Mo}, \mathrm{V}$ y/o Nb); $\mathrm{TeMo}_{5} \mathrm{O}_{16}$ [JCPDS: 31-0874]; $\mathrm{MoO}_{3}$ ortorrómbica [JCPDS: 05-508]; $\mathrm{A}$ = amorfo;

${ }^{\mathrm{d}} \mathrm{A}$ una temperatura de reacción de $380^{\circ} \mathrm{C}$.

\subsubsection{Resultados catalíticos para la oxidación selectiva de propano a ácido acrílico}

En la Figura 6.1 se representa la variación de la conversión de propano con la temperatura de reacción (Figura 6.1, A) y la variación de la selectividad a ácido acrílico con la conversión de propano (Figura 6.1, B), obtenidas durante la oxidación de propano con catalizadores Mo-V-X-(Nb) $(\mathbf{X}=\mathrm{Te}$ ó $\mathrm{Sb})$ activados a 500 y $600^{\circ} \mathrm{C}$.
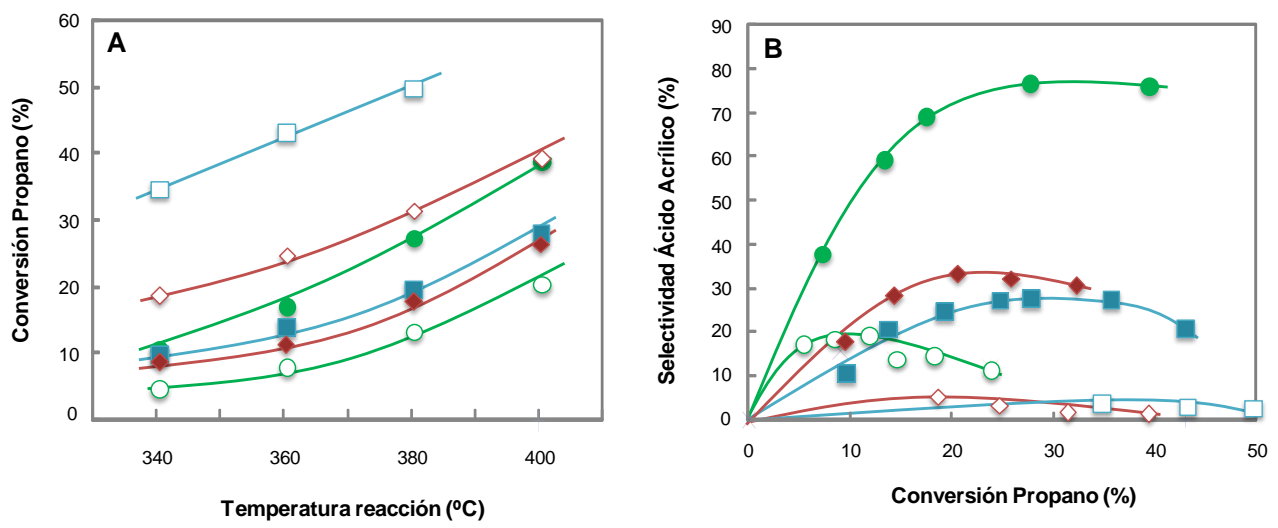

Figura 6.1 A) Variación de la conversión de propano con la temperatura de reacción (a un tiempo de contacto, W/F, de $200 \mathrm{~g}_{\mathrm{cat}} \mathrm{h} \mathrm{mol}_{\mathrm{C} 3 \mathrm{H}}{ }^{-1}$ ); y B) Variación de la selectividad a ácido acrílico con la conversión de propano durante la oxidación de propano con catalizadores

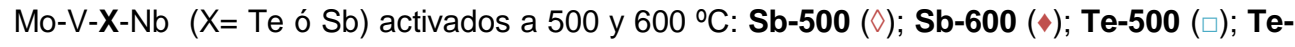
600 (घ); TeNb-500 (०); y TeNb-600 (•). 
En general, se observa que los materiales activados a $500^{\circ} \mathrm{C}$ son más activos en la oxidación de propano que los catalizadores activados a $600^{\circ} \mathrm{C}$ (Figura 6.1, A), excepto en el caso del sistema catalítico con niobio, MoVTeNbO, donde el catalizador TeNb-600 es el más activo.

Por otra parte, existe una gran diferencia en la selectividad a ácido acrílico. Así, los materiales activados a $500^{\circ} \mathrm{C}$ presentan una selectividad a ácido acrílico muy baja, mientras que en los materiales activados a $600^{\circ} \mathrm{C}$, se observa un aumento significativo (Figura 6.1, B). Sin embargo, la presencia de niobio parece favorecer considerablemente la selectividad a ácido acrílico, siendo el catalizador TeNb-600 el más selectivo, llegando a duplicar la selectividad obtenida sobre el catalizador $\sin \mathrm{Nb}(\mathrm{Te}-600)$.

En este sentido, y con el fin de conocer la influencia de algunos parámetros de reacción, se realizó un estudio con los catalizadores Sb-600 y TeNb-600. Para ello, se conectó un espectrómetro de masas a la salida del reactor para analizar los principales productos obtenidos durante la oxidación selectiva de propano, pero también para llevar a cabo un seguimiento instantáneo de la influencia de las condiciones de reacción en el comportamiento catalítico de estos materiales. Más específicamente, nos ha permitido conocer el efecto de la presencia/ausencia de agua 0 de oxígeno en la alimentación del reactor. En la Figura 6.2, se muestran los resultados obtenidos por espectrometría de masas para $\mathrm{CO}, \mathrm{CO}_{2}$, ácido acético (HAC) y ácido acrílico (AA), mientras en la Tabla 6.2, se muestran los resultados catalíticos obtenidos para los principales productos de reacción bajo las mismas condiciones de reacción, pero obtenidos tras un periodo de estabilización de 1 hora (para cada etapa en estudio).
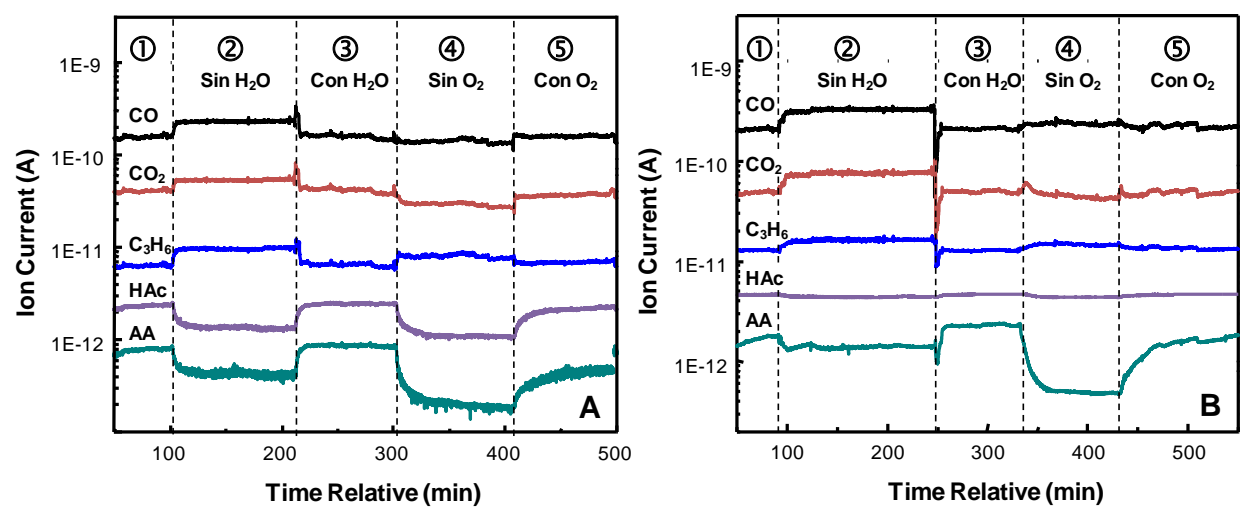

Figura 6.2. Perfiles de los principales productos de oxidación observados durante la oxidación de propano con catalizadores: A) Sb-600; y B) TeNb-600. Los números indican los análisis mostrados en la Tabla 6.2. Condiciones de reacción: $400^{\circ} \mathrm{C}$; tiempo de contacto, $\mathrm{W} / \mathrm{F}=200 \mathrm{~g}_{\text {cat }} \mathrm{h} \mathrm{mol}_{\mathrm{C} 3 \mathrm{H} 8}{ }^{-1}$; flujo total $50 \mathrm{~mL} / \mathrm{min}$. 
Cuando se elimina el agua (etapa 2), el efecto observado en la mezcla de reacción en ambos catalizadores es muy similar. Así, la ausencia de agua conlleva una disminución drástica e inmediata de los productos de oxidación selectiva (ácido acrílico y ácido acético), aumentando los productos de oxidación total ( $\mathrm{CO}$ y $\mathrm{CO}_{2}$ ) y propileno (Figura 6.2). En los resultados catalíticos obtenidos por cromatografía, tras un periodo de estabilización de 1 hora (Tabla 6.2, etapa 2), se observa una disminución de la conversión de propano, lo que explicaría el aumento de la selectividad a propileno y óxidos de carbono, y una disminución drástica de la selectividad a ácido acético (HAc) y, en especial, de ácido acrílico (AA), respecto a los resultados en las condiciones usuales de reacción (Tabla 6.2, etapa 1).

Cuando se vuelve a introducir agua en la alimentación del reactor (Figura 6.2, etapa 3) se observa una rápida recuperación tanto en el catalizador con antimonio, como en el material con teluro y niobio. Así, a los pocos minutos, se observa un aumento de ácido acético y ácido acrílico, además de una disminución de propileno y óxidos de carbono, alcanzando una conversión de propano y selectividades a los principales productos de oxidación similares a los observados en la etapa 1.

Tabla 6.2. Resultados catalíticos en la oxidación parcial de propano sobre catalizadores MoVSbO y MoVTeNb a $400^{\circ} \mathrm{C}$ en las condiciones mostradas en la Figura 6.2.

\begin{tabular}{|c|c|c|c|c|c|c|c|}
\hline \multirow{2}{*}{ Catalizador } & \multirow{2}{*}{ Etapa $^{a}$} & \multirow{2}{*}{ Conv.(\%) ${ }^{b}$} & \multicolumn{5}{|c|}{ Selectividad (\%) ${ }^{\mathrm{C}}$} \\
\hline & & & $\overline{A A}$ & $\mathrm{C}_{3} \mathrm{H}_{6}$ & $\mathrm{HAC}$ & $\mathrm{CO}$ & $\mathrm{CO}_{2}$ \\
\hline \multirow{5}{*}{ Sb-600 } & 1 & 27.6 & 33 & 10 & 12 & 25 & 19 \\
\hline & 2 & 19.3 & 14 & 17 & 3 & 40 & 26 \\
\hline & 3 & 24.2 & 30 & 12 & 11 & 26 & 20 \\
\hline & $4^{\mathrm{d}}$ & 0.2 & 0 & 35 & 0 & 9 & 29 \\
\hline & $5^{\mathrm{e}}$ & 17.3 & 17 & 17 & 15 & 30 & 20 \\
\hline \multirow{5}{*}{ TeNb-600 } & 1 & 38.1 & 81 & 5 & 2 & 7 & 5 \\
\hline & 2 & 24.2 & 59 & 11 & 0 & 16 & 14 \\
\hline & 3 & 37.4 & 80 & 6 & 2 & 7 & 5 \\
\hline & $4^{d}$ & 0.2 & 7 & 9 & 0 & 22 & 41 \\
\hline & $5^{\mathrm{e}}$ & 27.6 & 72 & 8 & 3 & 10 & 8 \\
\hline
\end{tabular}

${ }^{a}$ Condiciones de reacción indicadas en la Figura 6.2.

${ }^{\mathrm{b}}$ Conversión de propano a $400^{\circ} \mathrm{C}$ y tiempo de contacto, W/F, de $200 \mathrm{~g}_{\mathrm{cat}} \mathrm{h} \mathrm{mol}_{\mathrm{C} 3 \mathrm{H} 8}{ }^{-1}$

${ }^{c}$ Selectividad a Ácido Acrílico (AA); Propeno $\left(\mathrm{C}_{3} \mathrm{H}_{6}\right)$; Ácido Acético (HAc); y Óxidos de carbono $\left(\mathrm{CO}\right.$ y $\left.\mathrm{CO}_{2}\right)$. Acetona se observa con una selectividad igual o menor que $1 \%$.

${ }^{\mathrm{d}}$ Análisis realizado después de $1.5 \mathrm{~h}$ en ausencia de oxígeno.

e Análisis realizado después de $2 \mathrm{~h}$ con oxígeno.

Estos resultados están de acuerdo con resultados anteriores [27-28], y sugieren que el agua tiene un papel importante en la reacción de oxidación selectiva de propano. Así, en ausencia de agua la reacción estaría limitada por la activación del propano, observándose una menor actividad catalítica. Además, la 
presencia de vapor de agua favorecería la desorción de productos oxigenados a la fase gas, impidiendo la oxidación consecutiva del ácido acrílico a óxidos de carbono y aumentando así su selectividad.

Por otro lado, durante la oxidación de propano en condiciones anaeróbicas (Figura 6.2, etapa 4) se observa una lenta disminución de la conversión de propano hasta la pérdida total de actividad (Tabla 6.2, etapa 4). Una vez restablecido el oxígeno (después de 1.5h sin oxígeno) la conversión de propano aumenta lentamente (Figura 6.2, etapa 5). Sin embargo, no se alcanzan los valores de conversión de propano y selectividad a ácido acrílico obtenidos anteriormente, incluso después de haber tratado el catalizador durante $2 \mathrm{~h}$ con oxígeno (Tabla 6.2, etapa 5).

En condiciones anaeróbicas, la oxidación de propano puede seguir teniendo lugar por el oxígeno superficial del catalizador. Sin embargo, la ausencia de oxígeno molecular impide la reoxidación del catalizador, por lo que finalmente los centros activos ya no son capaces de activar al alcano. Al alimentar de nuevo oxígeno se debería esperar la reoxidación de la superficie del catalizador y, por tanto, una completa recuperación de sus propiedades catalíticas. No obstante, se observa una pérdida de actividad, debida posiblemente a modificaciones irreversibles en la superficie del catalizador. Cabe señalar que en el caso del catalizador con antimonio (Sb-600) se observa también una selectividad a ácido acrílico menor que la que cabría esperar a esa conversión de propano (Figura 6.1). En este sentido, se puede concluir que al someter al catalizador MoVSb a las diferentes etapas estudiadas, se producen cambios en la actividad y selectividad, es decir, se está modificando el número de los centros activos, pero también el número de centros selectivos. Sin embargo, en el catalizador con MoVTeNb sólo se produce un ligero descenso en el número de centros activos, pero la selectividad a ácido acrílico no se modifica. Por tanto el catalizador MoVTeNbO parece ser más estable que el catalizador MoVSbO.

Por ello, y con el fin de confirmar estos resultados, se han caracterizado los catalizadores usados después de la reacción mediante DRX y XPS. Los resultados de DRX se muestran en la Figura 6.3, mientras que la composición superficial determinada por XPS se presenta en la Tabla 6.3.

En el caso del catalizador TeNb-600 no se observan diferencias en los difractogramas de rayos $X$ tanto antes como después de la reacción (Figura 6.3, c y d), por lo que podemos concluir que no se producen cambios estructurales durante en estudio en condiciones de reacción anaeróbicas. En cambio, el catalizador Sb-600 muestra modificaciones en la distribución de fases cristalinas, aumentando la presencia de $\mathrm{Sb}_{2} \mathrm{Mo}_{10} \mathrm{O}_{31}$ (Figura 6.3, b), concretamente el pico a $2 \theta=26.7^{\circ}$ correspondiente al plano $\left(\begin{array}{lll}6 & 0 & 0\end{array}\right)$. 

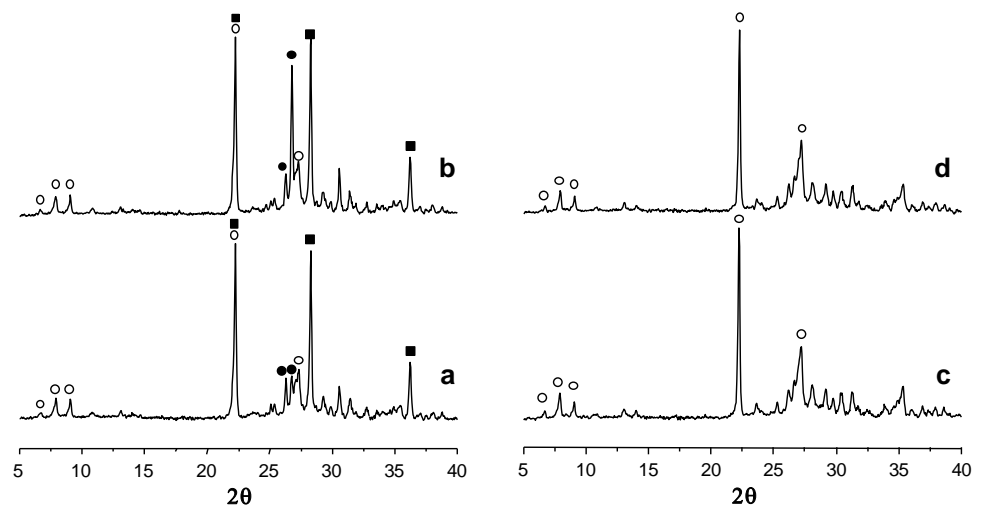

Figura 6.3. Difractogramas de los catalizadores Sb-600 (a, b) y TeNb-600 (c, d) frescos (a, c) y usados en la oxidación de propano en condiciones anaeróbicas (b, d). a) Sb-600; b) Sb-600-U; c) TeNb-600; d) TeNb-600-U.

Por otro lado, de acuerdo con los resultados mostrados en la Tabla 6.3, por XPS se observan también diferencias significativas en la composición superficial y en el estado de oxidación de los elementes de la superficie del catalizador, antes y después de reacción, dependiendo de la composición del catalizador. Así, en el catalizador con antimonio (Sb-600-U), cabe señalar la aparición de una nueva componente en el espectro Mo $3 \mathrm{~d}$ a $233.8 \mathrm{eV}$, relacionada con la especie $\mathrm{Mo}^{6+}$ en un entorno de coordinación diferente $\left(\mathrm{Mo}_{\mathrm{B}}{ }^{6+}\right)$. La presencia de especies $\mathrm{Mo}_{\mathrm{B}}{ }^{6+}$ puede relacionarse con el aumento de la presencia de la fase cristalina $\mathrm{Sb}_{2} \mathrm{Mo}_{10} \mathrm{O}_{31}$. Sin embargo, no se observan diferencias significativas en los estados de oxidación de vanadio o de antimonio en el material fresco o usado (Tabla 6.3).

Tabla 6.3. Resultados XPS de los catalizadores Sb-600 y TeNb-600 frescos y usados en la oxidación de propano en condiciones anaeróbicas.

\begin{tabular}{|c|c|c|c|c|}
\hline \multirow{3}{*}{$\begin{array}{l}\text { Muestra } \\
\text { Sb-600 }\end{array}$} & \multicolumn{4}{|c|}{ Composición superficial } \\
\hline & \multirow{2}{*}{$\begin{array}{l}\mathrm{Mo} / \mathrm{V} / \mathrm{X} / \mathrm{NbO}^{\mathrm{a}} \\
1 / 0.15 / 0.09 / 0.00 / 3.34\end{array}$} & \multicolumn{3}{|c|}{$\mathrm{Mo}_{\mathrm{A}}{ }^{6+} / \mathrm{Mo}_{\text {total }}{ }^{\mathrm{b}} \mathrm{V}^{5+} / \mathrm{V}_{\text {total }}{ }^{\mathrm{c}} \mathrm{Sb}^{5+} / \mathrm{Sb}_{\text {total }}{ }^{\mathrm{d}}$} \\
\hline & & 100 & 20.3 & 24.2 \\
\hline Sb-600-U & $1 / 0.17 / 0.09 / 0.00 / 3.61$ & 61.2 & 22.5 & 28.5 \\
\hline TeNb-600 & $1 / 0.10 / 0.29 / 0.25 / 3.52$ & 100 & 28.9 & - \\
\hline TeNb-600-U & $1 / 0.12 / 0.37 / 0.14 / 3.49$ & 100 & 42.6 & - \\
\hline
\end{tabular}

En cambio, en el catalizador con niobio, TeNb-600, se observan mayores diferencias, aunque no se observa la presencia de nuevas especies de Mo. En primer lugar, se observa un enriquecimiento de Te en la superficie del catalizador, aunque no existe un cambio en el estado de oxidación del teluro. Así, tanto en el catalizador fresco como el usado, el espectro $T e 3 d_{5 / 2}$ se ajusta a una sola 
componente a $576.4 \mathrm{eV}$, relacionada con la presencia de cationes $\mathrm{Te}^{4+}$. Además, se observa una disminución de la cantidad de niobio presente en la superficie del catalizador usado en comparación con el catalizador fresco. Por último, en la muestra usada en condiciones anaeróbicas (TeNb-600-U) se observa una oxidación parcial de los cationes $\mathrm{V}^{4+}$ aumentando la cantidad de especies $\mathrm{V}^{5+}$ (Tabla 6.3).

\subsubsection{Resultados catalíticos para la oxidación selectiva de propileno a ácido acrílico}

En la Tabla 6.4 se muestran los resultados catalíticos obtenidos durante la oxidación de propileno con los catalizadores $\operatorname{MoVX}(\mathrm{Nb}) \mathrm{O}(\mathrm{X}=\mathrm{Te} \circ \mathrm{Sb})$ activados a 500 y $600^{\circ} \mathrm{C}$. Los principales productos de reacción obtenidos son ácido acrílico (AA), ácido acético ( $\mathrm{HAc}$ ), acetona, $\mathrm{CO}$ y $\mathrm{CO}_{2}$. Aunque también se identifican trazas de acroleína y acetaldehído (selectividad < 1\%) durante el análisis por cromatografía de gases. Cabe destacar que, a diferencia de lo observado durante la oxidación de propano, en la oxidación de propeno se observa claramente la formación de acetona, especialmente a baja conversión de propileno.

Tabla 6.4. Resultados catalíticos en la oxidación parcial de propileno sobre catalizadores MoV-X-(Nb)O (X = Te ó Sb) a 400ㄷ․

\begin{tabular}{|c|c|c|c|c|c|c|c|}
\hline \multirow{2}{*}{ Catalizador } & \multirow{2}{*}{ Conv.(\%) ${ }^{a}$} & \multicolumn{5}{|c|}{ 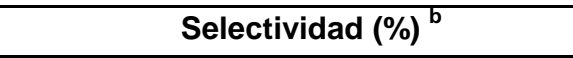 } & \multirow{2}{*}{$Y_{A A}{ }^{c}$} \\
\hline & & AA & HAc & Acet & $\mathrm{CO}$ & $\mathrm{CO}_{2}$ & \\
\hline Sb-500 & 72.9 & 12 & 14 & 2 & 53 & 20 & 8.6 \\
\hline Sb-600 & 35.9 & 49 & 13 & 14 & 17 & 7 & 17.7 \\
\hline Te-500 & 91.0 & 10 & 11 & 1 & 55 & 24 & 8.8 \\
\hline Te-600 & 62.1 & 45 & 7 & 4 & 29 & 15 & 27.8 \\
\hline TeNb-500 & 84.7 & 56 & 3 & 0 & 28 & 12 & 47.4 \\
\hline TeNb-600 & 74.1 & 88 & 3 & 1 & 6 & 2 & 65.2 \\
\hline
\end{tabular}

${ }^{\mathrm{a}}$ Conversión de propileno a $400^{\circ} \mathrm{C}$ y tiempo de contacto, W/F, de $75 \mathrm{~g}_{\mathrm{cat}} \mathrm{h} \mathrm{mol} \mathrm{C} 3 \mathrm{H} 6^{-1}$.

${ }^{\mathrm{b}}$ Selectividad a Ácido Acrílico (AA); Ácido Acético (HAc); Acetona (Acet); y óxidos de carbono (CO y $\mathrm{CO}_{2}$ ); Acroleína se observa con una selectividad igual o menor que $1 \%$.

${ }^{\mathrm{C}}$ Rendimiento a ácido acrílico $\left(\mathrm{Y}_{\mathrm{AA}}\right)$.

La actividad catalítica durante la oxidación de propeno es mucho mayor que la observada para propano, dada la mayor reactividad de la olefina. Sin embargo, en ambos casos se observa una tendencia similar. En la Figura 6.4 (A) se representa la variación de la conversión de propeno con la temperatura de reacción obtenida durante la oxidación selectiva de propileno.

En efecto, la conversión de propileno también es mayor en los catalizadores activados a $500^{\circ} \mathrm{C}$ que en los activados a $600^{\circ} \mathrm{C}$, aunque las diferencias de actividad entre ellos son más evidentes que para el caso del propano (Figura 6.4, 
A). Cabe señalar que, en la oxidación de propileno el catalizador TeNb-500 es más activo que el activado a $600^{\circ} \mathrm{C}$, al contrario que lo observado para la oxidación de propano (Figura 6.1, A).

Por otra parte, durante la oxidación de propileno se obtienen selectividades a ácido acrílico más altas que durante la oxidación de propano sobre los mismos catalizadores. En la Figura 6.4 (B) se presenta la variación de la selectividad a ácido acrílico con la conversión de propeno durante la oxidación de propileno.

En este caso, la selectividad a ácido acrílico también depende tanto de la composición del catalizador como de la temperatura de activación, siguiendo una tendencia similar a la observada durante la oxidación de propano. En general, los catalizadores activados a $600^{\circ} \mathrm{C}$ muestran una selectividad a ácido acrílico mayor que los activados a $500^{\circ} \mathrm{C}$.
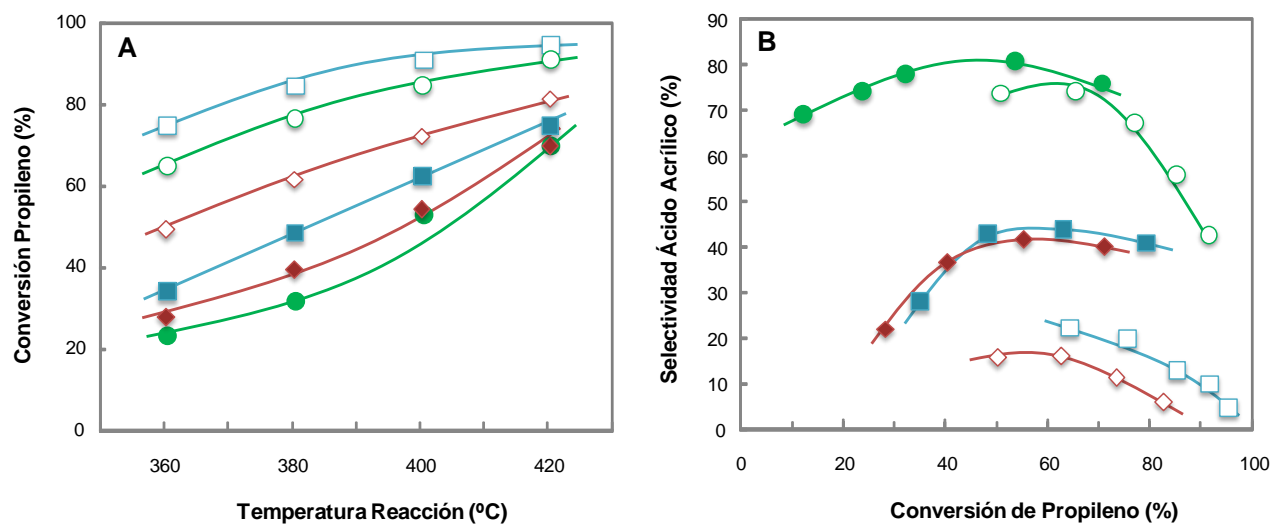

Figura 6.4. A) Variación de la conversión de propileno con la temperatura de reacción (a un tiempo de contacto, $\mathrm{W} / \mathrm{F}$, de $75 \mathrm{~g}_{\text {cat }} \mathrm{h} \mathrm{mol}_{\mathrm{C} 3 \mathrm{H} 6}{ }^{-1}$ ); y B) Variación de la selectividad a ácido acrílico con la conversión de propeno durante la oxidación de propileno con catalizadores

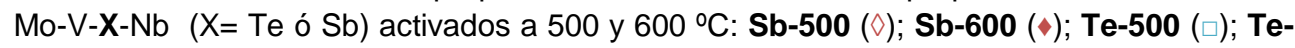
600 (घ); TeNb-500 (०); y TeNb-600 (•).

Así, los catalizadores MoVTeO, sin Nb, son menos selectivos a ácido acrílico que los correspondientes catalizadores MoVTeNbO. En el caso de los catalizadores sin niobio, la muestra con Te activada a $600^{\circ} \mathrm{C}$ (Te-600) es más selectiva a ácido acrílico en la oxidación parcial de propeno, mostrando una selectividad a ácido acrílico muy similar a su homólogo con antimonio (Sb-600). Cabe destacar que las muestras TeNb-500 y TeNb-600 son las más selectivas, mostrando selectividades a ácido acrílico muy similares, al contrario que en la oxidación de propano, donde el catalizador TeNb-500 es poco selectivo a ácido acrílico. 
Por otra parte, la forma de las curvas de selectividad a ácido acrílico de la Figura 6.1 (oxidación de propano) es diferente a las de la Figura 6.4 (oxidación de propeno). Dado que se observa una alta selectividad inicial (a bajas conversiones de propeno) a ácido acrílico que va disminuyendo según aumenta la conversión de propeno, se puede concluir que el ácido acrílico en la reacción de oxidación de propeno puede considerarse como un producto de reacción primario e inestable, cuya descomposición a altas conversiones de propeno es inferior a la que se observa durante la oxidación de propano (Figura 6.1, B).

Del mismo modo que con propano, se ha llevado a cabo un estudio de la oxidación de propileno por espectrometría de masas variando las condiciones de reacción, sin agua y bajo condiciones anaeróbicas, con los catalizadores $\mathbf{S b - 6 0 0 ~ y ~}$ TeNb-600. Los resultados se muestran en la Figura 6.5, mientras que la conversión y selectividad a los principales productos de oxidación se presentan en la Tabla 6.5.
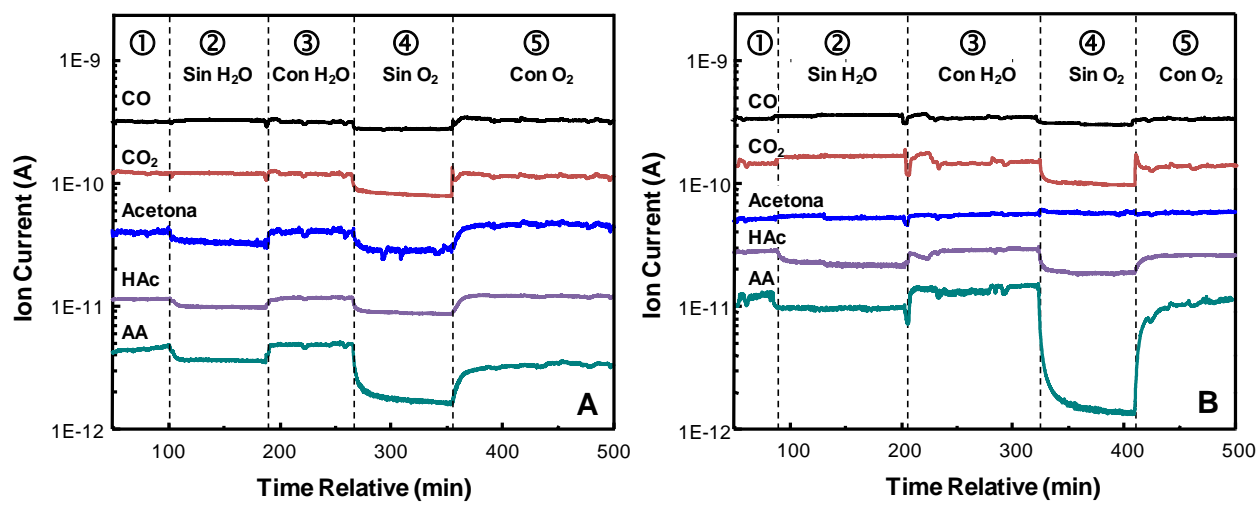

Figura 6.5. Perfiles de los principales productos de oxidación observados durante la oxidación de propeno con catalizadores: A) Sb-600; y B) TeNb-600. Los números indican los análisis mostrados en la Tabla 6.5. Condiciones de reacción: $400^{\circ} \mathrm{C}$; tiempo de contacto, $\mathrm{W} / \mathrm{F}=75 \mathrm{~g}_{\text {cat }} \mathrm{h}$ mol $_{\mathrm{C} 3 \mathrm{H}^{-1}}$; flujo total $50 \mathrm{~mL} / \mathrm{min}$.

En el caso de la oxidación de propileno en ausencia de agua, se observa también una disminución de los productos de oxidación selectiva (acetona, ácido acético y ácido acrílico), aumentando los productos de oxidación total $\left(\mathrm{CO}\right.$ y $\left.\mathrm{CO}_{2}\right)$ (Figura 6.5, etapa 2). Así, se observa una disminución de la conversión de propileno (Tabla 6.5, etapa 2), aumentando la selectividad a óxidos de carbono y disminuyendo la selectividad a ácido acético y acetona. 
Tabla 6.5. Resultados catalíticos en la oxidación parcial de propileno sobre catalizadores MoVSbO y MoVTeNb a $400^{\circ} \mathrm{C}$ en las condiciones mostradas en la Figura 6.5.

\begin{tabular}{|c|c|c|c|c|c|c|c|}
\hline \multirow{2}{*}{ Catalizador } & \multirow{2}{*}{ Etapa $^{a}$} & \multirow{2}{*}{ Conv.(\%) } & \multicolumn{5}{|c|}{ Selectividad (\%) $^{c}$} \\
\hline & & & $\mathrm{AA}$ & Acet & $\mathrm{HAc}$ & $\mathrm{CO}$ & $\mathrm{CO}_{2}$ \\
\hline \multirow{5}{*}{ Sb-600 } & 1 & 35.9 & 49 & 14 & 13 & 17 & 7 \\
\hline & 2 & 24.8 & 53 & 4 & 7 & 25 & 10 \\
\hline & 3 & 34.6 & 50 & 13 & 14 & 17 & 6 \\
\hline & $4^{d}$ & 0.4 & 0 & 91 & 0 & 2 & 5 \\
\hline & $5^{\mathrm{e}}$ & 28.1 & 28 & 20 & 19 & 25 & 8 \\
\hline \multirow{5}{*}{ TeNb-600 } & 1 & 74.1 & 88 & 1 & 3 & 6 & 2 \\
\hline & 2 & 57.2 & 80 & 1 & 1 & 12 & 6 \\
\hline & 3 & 72.2 & 87 & 1 & 3 & 6 & 3 \\
\hline & $4^{d}$ & 0.8 & 0 & 83 & 0 & 5 & 7 \\
\hline & $5^{e}$ & 58.7 & 85 & 1 & 3 & 8 & 3 \\
\hline \multicolumn{8}{|c|}{ 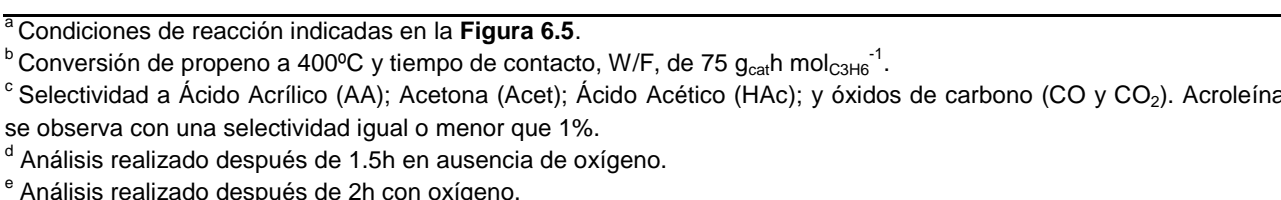 } \\
\hline
\end{tabular}

Sin embargo, la selectividad a ácido acrílico apenas se ve afectada en el caso del catalizador Sb-600, o disminuye ligeramente en TeNb-600. En cuanto se vuelve a introducir agua en la alimentación del reactor (Figura 6.5, 3) se observa una rápida recuperación tanto de la conversión de propileno como de las selectividades a los principales productos de oxidación, iguales a los observados antes de la eliminación de agua de la alimentación. Estos resultados sugieren que el agua favorece una mayor conversión de propeno, sin embargo, no influye en la selectividad a ácido acrílico de la misma forma que en la oxidación de propano.

Por otro lado, en condiciones anaeróbicas (Figura 6.5, etapa 3) se observa el mismo comportamiento que en la oxidación propano, disminuyendo lentamente la conversión de propileno hasta la inactividad (Tabla 6.5, etapa 4). Una vez restablecido el oxígeno aumenta la conversión de propileno. Sin embargo, los resultados muestran que no se produce una recuperación total de las propiedades catalíticas, mostrando una conversión de propano y selectividad a ácido acrílico menores (Tabla 6.5, etapa 5). Cabe señalar que después de 6 horas con oxígeno los resultados no alcanzan los valores iniciales de conversión de propileno y selectividad a ácido acrílico. Al igual que con propano, durante la oxidación de propileno en condiciones anaeróbicas se deben haber modificado las propiedades catalíticas de los materiales.

La caracterización de los materiales por DRX se muestra en la Figura 6.6, mientras que los resultados XPS se presentan en la Tabla 6.6. Al igual que durante la oxidación de propano, el catalizador con antimonio usado en 
condiciones anaeróbicas muestra un aumento de la presencia de las reflexiones de la fase cristalina $\mathrm{Sb}_{2} \mathrm{Mo}_{10} \mathrm{O}_{31}$ (Figura 6.6, b). En cambio, el catalizador con niobio usado después de reacción en condiciones anaeróbicas no muestra diferencias en comparación con el catalizador fresco.
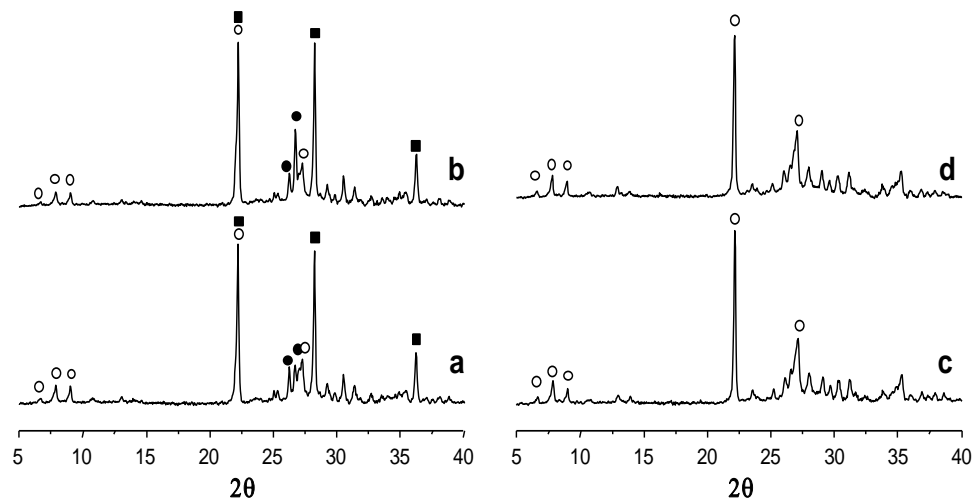

Figura 6.6. Difractogramas de los catalizadores Sb-600 (a, b) y TeNb-600 (c, d) frescos (a, c) y usados en la oxidación de propileno en condiciones anaeróbicas (b, d). a) Sb-600; b) Sb-600-U; c) TeNb-600; d) TeNb-600-U.

Los resultados XPS de los catalizadores usados se muestran en la Tabla 6.6, observándose diferencias en la composición superficial y en el estado de oxidación de los elementos de la superficie del catalizador usado en condiciones anaeróbicas, dependiendo de la composición del catalizador. Así, el catalizador con antimonio sometido a 1.5h sin oxígeno (Sb-600-U), muestra una reducción parcial de las especies $\mathrm{V}^{5+}$, además de una oxidación de las especies $\mathrm{Sb}^{3+}$ en la superficie. Cabe señalar, que en el caso de la oxidación de propileno el espectro Mo $3 \mathrm{~d}$ de los catalizadores usados se ajusta a una sola componente, a $232.8 \mathrm{eV}$ $\left(\mathrm{Mo}^{6+}\right)$.

Tabla 6.6. Resultados XPS de los catalizadores Sb-600 y TeNb-600 frescos y usados en la oxidación de propeno en condiciones anaeróbicas.

\begin{tabular}{|c|c|c|c|c|}
\hline \multirow{2}{*}{ Muestra } & \multicolumn{4}{|c|}{ Composición superficial } \\
\hline & $\mathrm{Mo} / \mathrm{V} / \mathrm{X} / \mathrm{NbO}^{\mathrm{a}}$ & $\mathrm{Mo}_{A}{ }^{6+} / \mathrm{Mo}_{\text {total }}{ }^{\mathrm{b}}$ & $\mathrm{V}^{5+} / \mathrm{V}_{\text {total }}{ }^{\mathrm{c}}$ & $\mathrm{Sb}^{5+} / \mathrm{Sb}_{\text {total }} \mathrm{d}^{\mathrm{d}}$ \\
\hline Sb-600 & $1 / 0.15 / 0.09 / 0.00 / 3.34$ & 100 & 20.3 & 24.2 \\
\hline Sb-600-U & $1 / 0.17 / 0.09 / 0.00 / 3.21$ & 100 & 17.5 & 32.0 \\
\hline TeNb-600 & 1/0.10/0.29/0.25/3.52 & 100 & 28.9 & - \\
\hline TeNb-600-U & $1 / 0.12 / 0.30 / 0.26 / 3.58$ & 100 & 26.6 & - \\
\hline
\end{tabular}

Por otro lado, no se observan diferencias en la composición superficial ni en los estados de oxidación de los elementos de la superficie del catalizadores con 
niobio fresco (TeNb-600) y usado (TeNb-600-U) en la oxidación de propileno en condiciones anaeróbicas.

\subsubsection{Resultados catalíticos para la oxidación de metanol}

Los resultados catalíticos obtenidos durante la oxidación de metanol con los catalizadores MoV-X-(Nb)O (X = Te o Sb) activados a 500 y $600^{\circ} \mathrm{C}$ se muestran en la Tabla 6.7. Los principales productos de reacción obtenidos son formaldehido $\left(\mathrm{CH}_{2} \mathrm{O}\right)$, dimetiléter (DME), formiato de metilo $(\mathrm{FM})$, dimetóximetano (DMM), $\mathrm{CO}$ y $\mathrm{CO}_{2}$.

En general, los catalizadores basados en óxidos mixtos MoVTe(Sb)NbO muestran ser activos en la oxidación de metanol, alcanzando conversiones mayores de $50 \%$ (Tabla 6.7). Sin embargo, la actividad catalítica depende de la composición y de la temperatura de activación de los catalizadores. En la Figura 6.7 se representa la variación de la conversión de metanol con la temperatura de reacción obtenida durante la oxidación selectiva de metanol para los materiales activados a 500 (Figura 6.7, A) y $600^{\circ} \mathrm{C}$ (Figura 6.7, B).

Tabla 6.7. Resultados catalíticos de la transformación de metanol en presencia de oxígeno sobre catalizadores MoV-X-(Nb)O (X = Te ó Sb) a 230 y $265^{\circ} \mathrm{C}$.

\begin{tabular}{|c|c|c|c|c|c|c|c|c|}
\hline \multirow{2}{*}{ Catalizador } & \multirow{2}{*}{$\mathbf{T}(\stackrel{\circ}{ } \mathbf{C})$} & \multirow{2}{*}{ Conv.(\%) ${ }^{a}$} & \multicolumn{5}{|c|}{ Selectividad (\%) } & \multirow[b]{2}{*}{$\mathrm{CO}_{2}$} \\
\hline & & & $\mathrm{CH}_{2} \mathrm{O}$ & DME & FM & DMM & $\mathrm{CO}$ & \\
\hline \multirow{2}{*}{ Sb-500 } & 230 & 18.7 & 59 & 13 & 12 & 4 & 12 & 1 \\
\hline & 265 & 60.0 & 38 & 1 & 1 & 0 & 59 & 1 \\
\hline \multirow{2}{*}{ Sb-600 } & 230 & 6.7 & 48 & 17 & 16 & 15 & 3 & 1 \\
\hline & 265 & 32.2 & 75 & 3 & 4 & 1 & 17 & 1 \\
\hline \multirow{2}{*}{ Te-500 } & 230 & 18.4 & 62 & 8 & 8 & 14 & 6 & 2 \\
\hline & 265 & 68.8 & 36 & 1 & 1 & 0 & 62 & 1 \\
\hline \multirow{2}{*}{ Te-600 } & 230 & 9.2 & 53 & 9 & 8 & 27 & 2 & 1 \\
\hline & 265 & 29.2 & 80 & 4 & 5 & 3 & 7 & 1 \\
\hline \multirow{2}{*}{ TeNb-500 } & 230 & 19.2 & 45 & 24 & 21 & 8 & 2 & 1 \\
\hline & 265 & 49.6 & 78 & 3 & 3 & 1 & 14 & 1 \\
\hline \multirow{2}{*}{ TeNb-600 } & 230 & 8.2 & 75 & 6 & 4 & 13 & 2 & 1 \\
\hline & 265 & 24.9 & 81 & 5 & 5 & 3 & 5 & 1 \\
\hline
\end{tabular}

En todos los casos, los catalizadores activados a $500^{\circ} \mathrm{C}$ (Figura 6.7, A) son más activos en la oxidación de metanol que los materiales activados a $600^{\circ} \mathrm{C}$ (Figura 6.7, B). Además, los materiales sin niobio (bien con antimonio o con 
teluro) han mostrado una actividad muy similar, pero superior a la observada en el caso de los catalizadores con niobio. En este sentido, el catalizador TeNb-600 es el menos activo de los catalizadores estudiados (Figura 6.7, B).
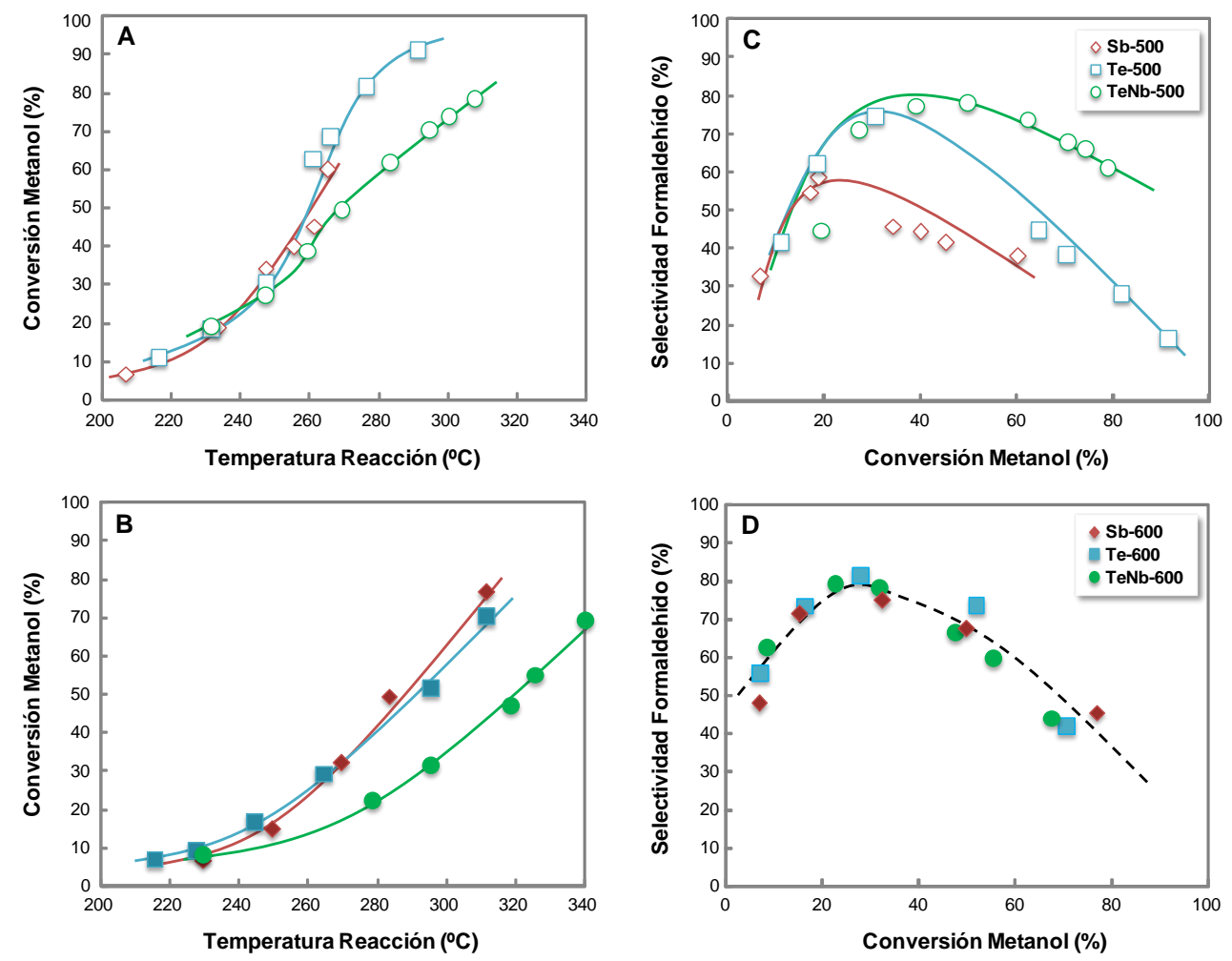

Figura 6.7. (A y B) Variación de la conversión de metanol con la temperatura de reacción (a un tiempo de contacto, W/F, de $\left.7 \mathrm{~g}_{\mathrm{cat}} \mathrm{h} \mathrm{mol}_{\mathrm{CH}_{3} \mathrm{OH}^{-1}}\right)$; ( $\mathbf{C}$ y D) Variación de la selectividad a formaldehído con la conversión de metanol durante la oxidación de metanol con catalizadores Mo-V-X-Nb (X= Te ó Sb) activados a 500 (A y C) o $600{ }^{\circ} \mathrm{C}$ (B y D): Sb-500 $(\diamond)$; Sb-600 (४); Te-500 ( $\square)$; Te-600 (घ); TeNb-500 ( $)$; y TeNb-600 (•).

Por otra parte, estos catalizadores son relativamente selectivos para la formación de formaldehído, siendo éste el principal producto observado durante la oxidación de metanol en todos los casos estudiados (Tabla 6.7). Sin embargo, cabe señalar que la selectividad a formaldehido depende de la composición y de la temperatura de activación del catalizador. Así, para los catalizadores activados a $500^{\circ} \mathrm{C}$ (Figura 6.7, C), la selectividad disminuye de acuerdo con: TeNb-500 > Te$500>$ Sb-500. En los catalizadores activados a $600^{\circ} \mathrm{C}$ no se observan variaciones significativas (Figura 6.7, D).

Sin embargo, además de la selectividad a formaldehido, es interesante comparar la distribución de productos obtenidos con la conversión de metanol observada durante la oxidación de metanol (Figura 6.8). Con el fin de facilitar la 
comparación se han dividido los productos en tres grupos: formaldehído, productos de deshidratación y $\mathrm{CO}_{x}$.
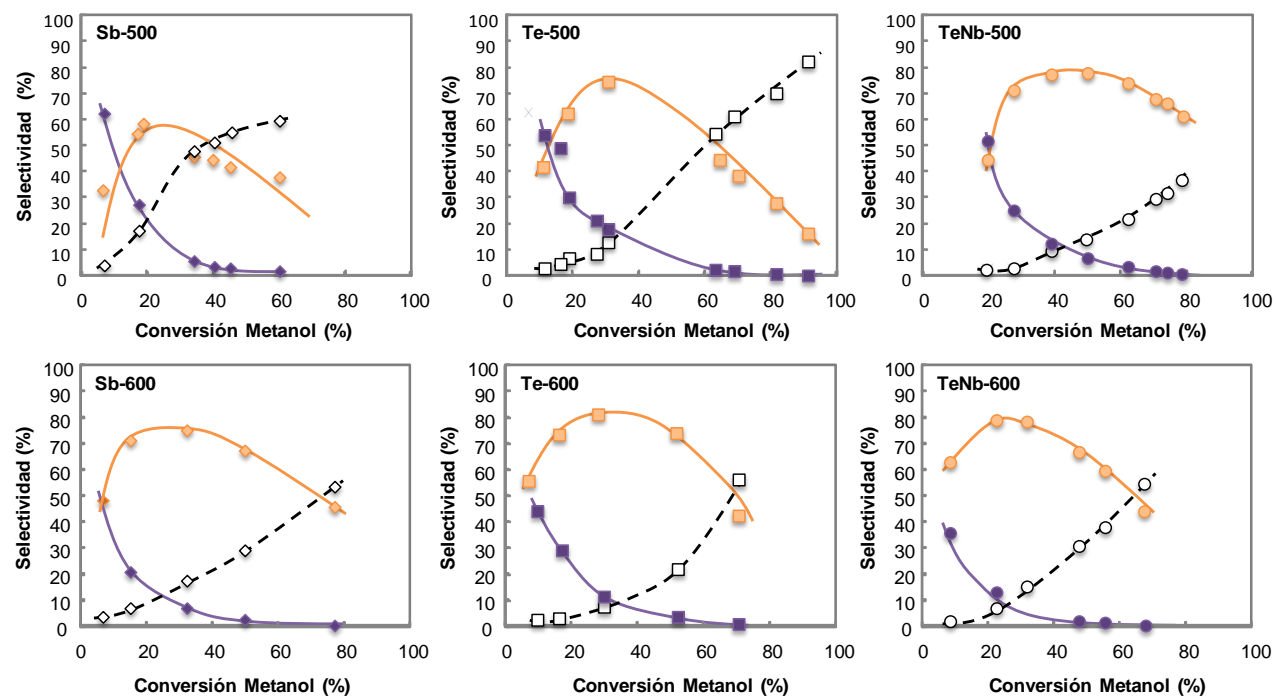

Figura 6.8. Variación de la selectividad a los productos principales de reacción con la conversión de metanol durante la oxidación de metanol con catalizadores Mo-V-X-Nb (X= Te ó Sb) activados a 500 y $600^{\circ} \mathrm{C}$. Selectividad a formaldehído (naranja), productos de deshidrogenación: DME, FM, DMM (morado) y $\mathrm{CO}_{x}$ (negro con línea discontinua).

En este sentido, a baja conversión de metanol (Figura 6.8), se observa la formación de productos de deshidratación, mayoritariamente dimetiléter, y en menor medida formiato de metilo o dimetoximetano. La selectividad a estos productos de deshidratación es mayor en los catalizadores activados a $500^{\circ} \mathrm{C}$, lo que sugiere una mayor presencia de centros de ácidos en estos materiales respecto a los materiales activados a $600^{\circ} \mathrm{C}$, lo que está de acuerdo con los resultados obtenidos por TPD-NH $\mathrm{NH}_{3}$ (apartado 5.3.3) donde los materiales activados a $500^{\circ} \mathrm{C}$ muestran una mayor acidez que los activados a $600^{\circ} \mathrm{C}$ (Figura 5.15).

Al aumentar la conversión de metanol, las selectividades a dimetiléter, formiato de metilo o dimetoximetano disminuyen (observándose selectividades menores al $5 \%$ en todos los casos) aumentando la selectividad a formaldehido (Tabla 6.7). Sin embargo, a altas conversiones de metanol (superiores al 60\%) se observa una disminución de la selectividad a formaldehído con la formación creciente de óxidos de carbono (Figura 6.8), principalmente CO (debido a la descomposición de formaldehído en estas condiciones).

El comportamiento catalítico de los catalizadores $\mathrm{MoVTe}(\mathrm{Sb}) \mathrm{Nb}$ activados a $600^{\circ} \mathrm{C}$ en la oxidación de metanol es muy similar (Figura 6.7, D), presentando altas selectividades a formaldehído, con un máximo de selectividad obtenido para 
una conversiones de metanol del $30 \%$. Debido a la baja actividad de estos materiales, para aumentar la conversión de metanol es necesario aumentar la temperatura de reacción, favoreciendo, en estas condiciones, la descomposición de formaldehído a óxidos de carbono.

En el caso de los catalizadores activados a $500^{\circ} \mathrm{C}$ se observan diferencias en su comportamiento catalítico dependiendo de la composición. Así, el material con antimonio activado a $500^{\circ} \mathrm{C}(\mathbf{S b}-\mathbf{5 0 0})$ es muy activo en la oxidación de metanol pero poco selectivo a formaldehído, formando principalmente monóxido de carbono a conversiones mayores del $20 \%$. Sin embargo, los catalizadores con teluro activados a $500^{\circ} \mathrm{C}(\mathrm{Te}-500$ y TeNb-500) muestran mayor selectividad a formaldehído que el catalizador con antimonio (Sb-500), alcanzando selectividades a formaldehído de $80 \%$ (similares a las obtenidas con los materiales activados a $600^{\circ} \mathrm{C}$ ). En el caso del catalizador TeNb-500 se observa una mayor estabilidad en la selectividad a formaldehído, en comparación con el resto de catalizadores, disminuyendo a conversiones de metanol superiores al $60 \%$. Esto sugiere que el catalizador con niobio activado a $500^{\circ} \mathrm{C}(\mathrm{TeNb}-500)$ tiene un efecto claro en la estabilidad del formaldehído.

\subsubsection{Discusión de los resultados}

Los óxidos mixtos MoVTe(Sb)NbO han demostrado ser activos y selectivos en la oxidación de propano, propileno y metanol. En el caso de la oxidación de propano y propeno el principal producto de oxidación es ácido acrílico, mientras que en el caso de la oxidación de metanol se observa principalmente la formación de formaldehído. En la Figura 6.9 se resumen los resultados de conversión y selectividad a los productos de oxidación (a una conversión de 30\%) obtenidos durante la oxidación de propano, propileno y metanol.

En todos los casos, se ha observado una tendencia en la conversión muy similar en cada una de las reacciones (Figura 6.9). En general, la actividad catalítica de los materiales depende de la composición y la temperatura de activación. En este sentido, se observa que los catalizadores activados a $500^{\circ} \mathrm{C}$ muestran una mayor actividad que los catalizadores activados a $600^{\circ} \mathrm{C}$, excepto para la oxidación de propano sobre catalizadores MoVTeNb en el que el catalizador tratado a $600^{\circ} \mathrm{C}$ (y que presenta fase M1) es más activo que el catalizador activado a $500^{\circ} \mathrm{C}$ (que presenta una fase amorfa en el DRX) (Tabla 6.1). Dado que los catalizadores sin niobio tratados térmicamente a $500^{\circ} \mathrm{C}$ presentan sólo la fase $M 1$, mientras que en los tratados a $600^{\circ} \mathrm{C}$ se observó una cierta descomposición de la fase M1, podemos concluir que la fase M1 es activa en la activación de las tres moléculas estudiadas. Sin embargo las diferencias entre la oxidación de propileno y metanol y la oxidación de propano con 
catalizadores MoVTeNbO sugiere que la fase amorfa (observada en el catalizador TeNb-500) es también activa en la oxidación de propileno y metanol.
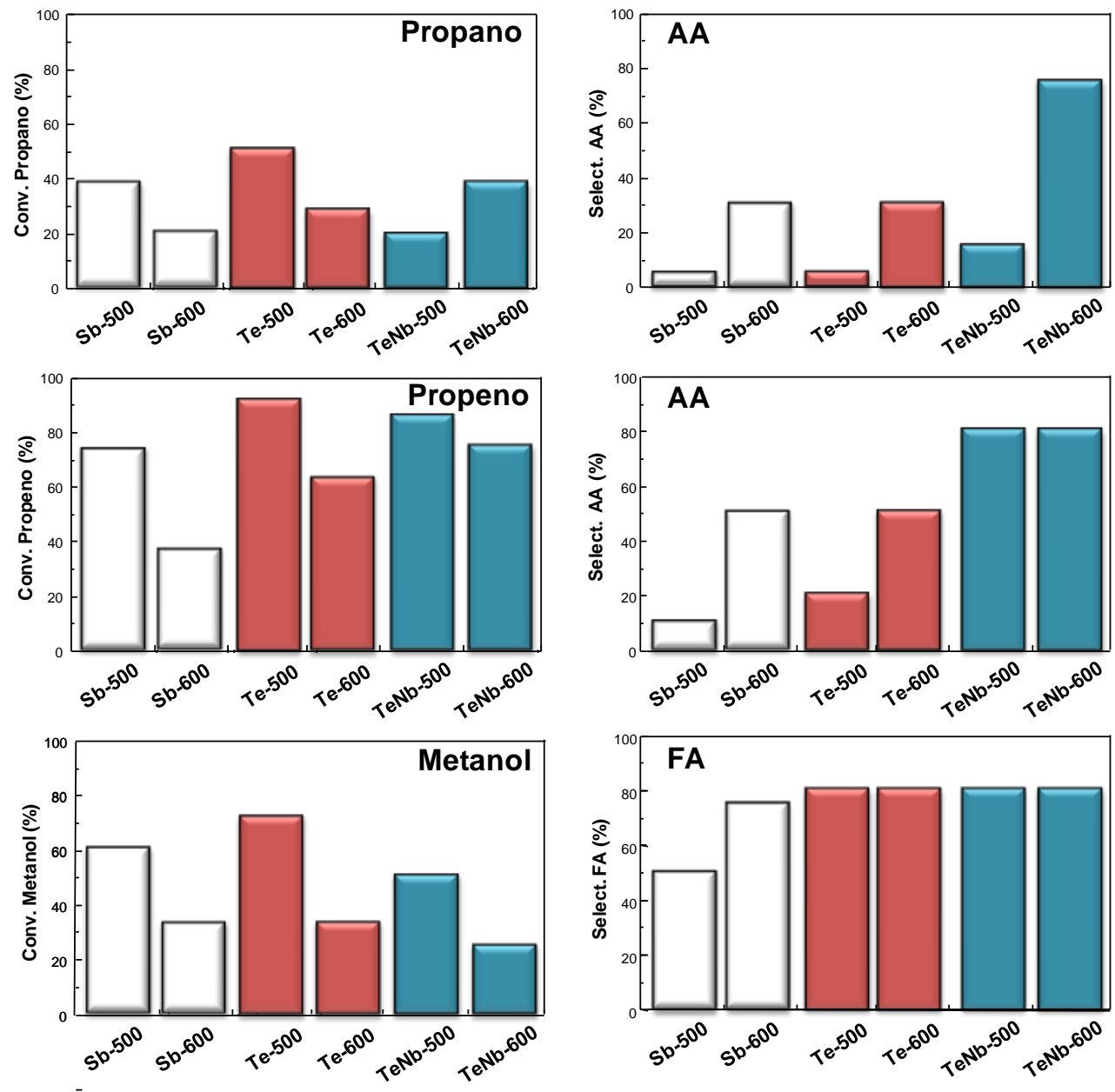

Figura 6.9. Conversión (izda.) y máxima selectividad al producto principal de oxidación parcial (dcha.) obtenidos durante la oxidación de propano, propileno a ácido acrílico (AA) o metanol a formaldehido (FA) con catalizadores MoVTe(Sb) $\mathrm{Nb}$ activados a $500^{\circ} \mathrm{C}$ y $600^{\circ} \mathrm{C}$. Condiciones de reacción en las Tablas 6.1, 6.4 y 6.7.

Sin embargo, el comportamiento de estos materiales en la selectividad a los diferentes productos de oxidación parcial es diferente dependiendo de las características de las fases cristalinas del catalizador.

Cabe señalar que, en todos los casos, la selectividad muestra un máximo para una conversión del 20-40\% (en el caso de la oxidación de propano) (Fig. 6.1, B), del 30-50\% (en la oxidación de metanol) (Fig. 6.7, B), o del 50-70\% (en el caso 
de la oxidación de propileno) (Fig. 6.4, B). Esto indica que en todos los casos, el principal producto de oxidación parcial es inestable y se transforma, a altas conversiones de hidrocarburo, en óxidos de carbono.

En este punto, es importante señalar que tanto la fase cristalina $T e_{0.33} M_{3.33}$ $\left(M=\mathrm{Mo}, \mathrm{V}, \mathrm{Nb}\right.$ ) (denominada fase $\mathrm{M} 2$ ) [29-33], así como la fase $\mathrm{TeMo}_{5} \mathrm{O}_{16}$ [34] o la fase equivalente de antimonio, $\mathrm{Sb}_{2} \mathrm{Mo}_{10} \mathrm{O}_{31}$ [35] son activas y selectivas en la oxidación de propileno. Sin embargo, la distribución de productos puede variar con la composición del catalizador. Así, materiales con fase M2 pura sin niobio, MoVTeO, muestran alta selectividad a acroleína [29-31]. Por lo que en el estudio de la oxidación de propileno se debe tener en cuenta la presencia de otras fases cristalinas, mientras que estas fases no son activas en la oxidación de propano.

Por otra parte, es conocido que no sólo el $\mathrm{MoO}_{3}$, sino también óxidos mixtos de Mo y Te [36-37] o Mo y Sb [38-40] son activos y selectivos en la oxidación de metanol a formaldehido. Además, la fase $\mathrm{Sb}_{2} \mathrm{Mo}_{10} \mathrm{O}_{31}$ es activa también en la oxidación oxidación de etanol [41]. Por lo que, en los materiales sin niobio tratados a $600^{\circ} \mathrm{C}$, en los que se observa este tipo de fases cristalinas, se debería observar una mejora en la selectividad a formaldehido.

En el caso de los catalizadores con antimonio y teluro sin niobio activados a $600^{\circ} \mathrm{C}$, Te-600 y Sb-600, se observa un comportamiento catalítico muy similar en las tres reacciones estudiadas (Figuras 6.1, 6.4 y 6.7). Ambos catalizadores son activos en la oxidación de propano y propileno pero alcanzan bajas selectividades a ácido acrílico, observándose también la presencia de ácido acético y óxidos de carbono (Tabla 6.1 y 6.4). Estos materiales se caracterizan por la presencia de un mayor número de centros ácidos, en comparación con los materiales con niobio (Figura 5.15). La presencia de centros ácidos favorece la reacción ácida frente a la reacción redox, facilitando la formación de ácido acético y óxidos de carbono (a altas conversiones de propano). Así, la presencia de centros ácidos facilita la aparición de reacciones paralelas y consecutivas con un descenso importante en la selectividad a ácido acrílico. En la oxidación de metanol, se obtiene principalmente formaldehído con una selectividad muy similar en ambos catalizadores, indicando la presencia de centros redox similares en ambos catalizadores.

Los materiales sin niobio activados a 500ㄷ (Te-500 y Sb-500) presentan un mayor número de centros ácidos que los materiales activados a $600^{\circ} \mathrm{C}$ (Figura 5.15). La mayor presencia de centros ácidos repercute en la actividad de los catalizadores, siendo los más activos en las tres reacciones estudiadas (Figura 6.9), y en la distribución de los productos de oxidación, mostrando principalmente la formación de óxidos de carbono en la oxidación de propano y propileno (Tabla 5.4 y 6.4). Sin embargo, la actividad catalítica también depende de la composición 
de los materiales, siendo el catalizador Te-500 más activo en la oxidación de propano, debido a que presenta principalmente la fase M1 (Tabla 6.1). En la oxidación de metanol, se observan además diferencias en la selectividad a formaldehído, donde el catalizador Sb-500 es poco selectivo, probablemente debido a la mayor presencia de centros ácidos que favorece la formación de dimetileter (a bajas conversiones de metanol) y óxidos de carbono (a altas conversiones de metanol).

Por otro lado, los catalizadores con niobio muestran un comportamiento catalítico diferente. Las diferencias entre los catalizadores con niobio o sin niobio se deben tanto a las diferencias en las propiedades redox ( $y$ el estado de oxidación medio del catalizador) como a la diferente naturaleza ácida de los catalizadores. Así, se puede explicar la mayor selectividad a ácido acrílico tanto en la oxidación de propano como en la oxidación de propileno.

El catalizador TeNb-500 que se compone por un sólido amorfo es muy activo en la oxidación de propileno (alcanzando conversiones de propileno de 90\%) e igual de selectivo que el catalizador activado a $600^{\circ} \mathrm{C}$. Estos resultados sugieren que el catalizar activado a $500^{\circ} \mathrm{C}$ presenta los mismos centros capaces de oxidar selectivamente al propeno que la muestra activada a $600^{\circ} \mathrm{C}$. Sin embargo, es poco activo en la oxidación de propano, indicando que durante el tratamiento térmico se modifican las propiedades superficiales del material MoVTeNbO, concretamente los centros activos capaces de activar al propano. Este hecho podría estar relacionado con las diferencias observadas por XPS en los estados de oxidación de los elementos de la superficie de los materiales (Tabla 5.7).

\subsection{Técnicas de caracterización superficiales}

Como hemos visto en el capítulo anterior, durante el tratamiento de activación térmica de los catalizadores a alta temperatura, se observa una reorganización de las fases cristalinas, pero también de la superficie. Así, de acuerdo con los resultados de TPD- $\mathrm{NH}_{3}$ y XPS, el tratamiento térmico favorece una disminución del número de centros ácidos así como cambios en los estados de oxidación de algunos elementos.

Sin embargo, el uso de la espectroscopia XPS facilita el análisis de unas 50 capas de la superficie del catalizador. Por tanto, la información obtenida no está estrictamente relacionada con la primera monocapa de la superficie del catalizador. Con el fin de evaluar los cambios en la superficie del catalizador se han empleado otras técnicas de caracterización tales como el intercambio isotópico de oxígeno, la adsorción de metanol por FTIR, o la adsorción de amoníaco por DRIFT. 


\subsubsection{Intercambio isotópico de oxígeno ${ }^{18} \mathrm{O}_{2}$}

Con el fin de obtener información adicional sobre la naturaleza y/o reactividad de las especies oxígeno que participan en la oxidación de propano se ha estudiado el intercambio isotópico de oxígeno $c{ }^{18} \mathrm{O}_{2}$. El intercambio isotópico de oxígeno es un método empleado frecuentemente para el estudio de la participación de oxígeno de los catalizadores en reacciones de oxidación [42-46]. En la Figura 6.10 se muestra los perfiles obtenidos durante el intercambio de oxígeno a temperatura programada en el intervalo de temperaturas $25-420^{\circ} \mathrm{C}$ de los catalizadores $\mathrm{MoVTe}(\mathrm{Nb}) \mathrm{O}$ activados a 500 y $600^{\circ} \mathrm{C}$.

En todos los casos, se observa consumo de ${ }^{18} \mathrm{O}_{2}$ y liberación de ${ }^{16} \mathrm{O}_{2}$ y ${ }^{16} \mathrm{O}^{18} \mathrm{O}$. La temperatura a la que se inicia el consumo de ${ }^{18} \mathrm{O}_{2}$ es menor en las muestras activadas a $500^{\circ} \mathrm{C}$. Así, se observa a $310^{\circ} \mathrm{C}$ para la muestra Te-500, $333^{\circ} \mathrm{C}$ para $\mathrm{TeNb}-500,382^{\circ} \mathrm{C}$ para Te-600 $\circ 399^{\circ} \mathrm{C}$ para TeNb-600. Estos resultados sugieren una mayor movilidad de oxígeno en las muestras activadas a $500^{\circ} \mathrm{C}$, es decir Te-500 y TeNb-500, de acuerdo con la baja selectividad a ácido acrílico observada durante la oxidación de propano (Tablas 5.4 y 6.1).
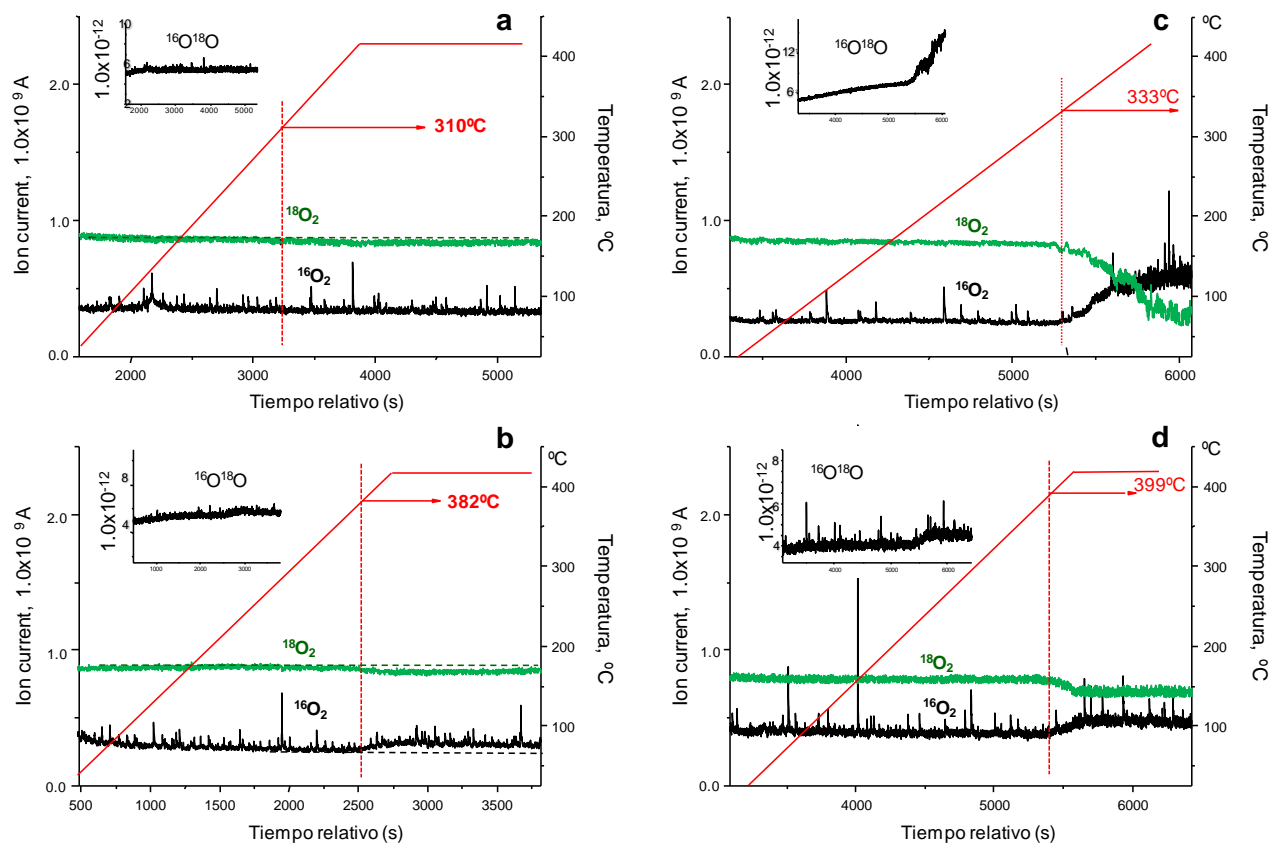

Figura 6.10. Intercambio isotópico de oxígeno a temperatura programada en catalizadores MoVTe(Nb)O: a) Te-500; b) Te-600; c) TeNb-500; y d) TeNb-600. 
Por otro lado, la cantidad de oxígeno intercambiado disminuye siguiendo la tendencia (Figura 6.10): $0.269 \times 10^{-10} \mathrm{~A} / \mathrm{m}^{2}(\mathrm{TeNb}-500)>0.140 \times 10^{-10} \mathrm{~A} / \mathrm{m}^{2}$ (TeNb600) $>0.053 \times 10^{-10} \mathrm{~A} / \mathrm{m}^{2}(\mathrm{Te}-600)>0.016 \times 10^{-10} \mathrm{~A} / \mathrm{m}^{2}$ (TeNb-500). En consecuencia, la cantidad de oxígeno intercambiado es mayor en los catalizadores con $\mathrm{Nb}$ que los correspondientes catalizadores sin niobio.

\subsubsection{Adsorción de metanol por espectroscopia FTIR}

Con el fin de estudiar la naturaleza de los centros ácidos Lewis localizados en la superficie de los catalizadores, se ha llevado a cabo un estudio de la adsorción de metanol en la superficie del catalizador, empleando para ello la espectroscopia FTIR. Es conocido que la adsorción de metanol a temperatura ambiente en los óxidos mixtos puede ser molecular (adsorción física) o disociativa. La adsorción disociativa de metanol implica la presencia de pares ácido/base Lewis en la superficie del óxido metálico, con la formación de grupos metal-metoxi $\left(\mathrm{M}-\mathrm{OCH}_{3}\right)$ y grupos hidroxilo $(\mathrm{OH})$ en la superficie. Se ha demostrado que el modo $v(\mathrm{OC})$ de los grupos metoxi $\left(-\mathrm{OCH}_{3}\right)$ en la superficie depende de las caracteristicas del centro de adsorción catiónico [47]. Así, se puede obtener información importante de la frecuencia de vibración $v(\mathrm{OC})$ de dichas especies adsorbidas. Por otro lado, las especies metoxi en la superficie pueden ser susceptibles de oxidaciones adicionales con la producción de productos oxigenados (formaldehido y formiato de metilo), que nos pueden dar una mayor información del entorno de los centros activos.

En la Figura 6.11 se muestra el espectro IR, en la región $2000-1000 \mathrm{~cm}^{-1}$, de metanol adsorbido en los catalizadores $\mathrm{MoV}-\mathrm{X}-(\mathrm{Nb}) \mathrm{O}$ (X = Te ó $\mathrm{Sb})$. En las muestra activadas a $500^{\circ} \mathrm{C}$ de los catalizadores (con o sin $\mathrm{Nb}$ ) se observa una banda ancha de adsorción en el rango 1182-1041 $\mathrm{cm}^{-1}$ (Figura 6.11, a y c), mientras que en todos los casos, se observan bandas IR a baja frecuencia (1031, 1091 y $1006 \mathrm{~cm}^{-1}$ ). Las bandas IR a alta frecuencia (máximo a 1148 y $1078 \mathrm{~cm}-1$ ) se pueden asignar la frecuencia de vibración del enlace $O-C$ de las especies metal-metoxi, mientras que las bandas IR a baja frecuencia pueden ser asignadas a las especies débilmente adsorbidas de metanol (metanol en fase gas muestra bandas IR a 1058, 1034 y $1014 \mathrm{~cm}^{-1}$ ).

Así, la disociación de metanol con la formación de las especies metal-metoxi se observa principalmente en las muestras activadas a $500^{\circ} \mathrm{C}$ (Figura 6.11, a, c y e). Esto sugiere la presencia de cierto tipo de pares Lewis ácido/base en las muestras activadas a $500^{\circ} \mathrm{C}$, las cuales parecen estar ausentes en las muestras activadas a mayor temperatura, $600^{\circ} \mathrm{C}$ (Figura 6.11, b, d y f). Por otro lado, bandas IR a $1453 \mathrm{~cm}^{-1}$ debido a la vibración $\delta\left(\mathrm{CH}_{3}\right)$ de las especies de metanol adsorbidas y a $1361 \mathrm{~cm}^{-1}$ debido al modo de vibración de los $\mathrm{OH}$ también se observan en todas las muestras. Bandas adicionales a 1564,1607 y $1355 \mathrm{~cm}^{-1}$ 
debido a las especies formiato y $1710\left(1774 \mathrm{~cm}^{-1}\right)$ debido al formiato a metilo se observan en las muestras activadas a $500^{\circ} \mathrm{C}$, revelando un alta reactividad de las especies metoxi adsorbidas hacía productos de oxidación.

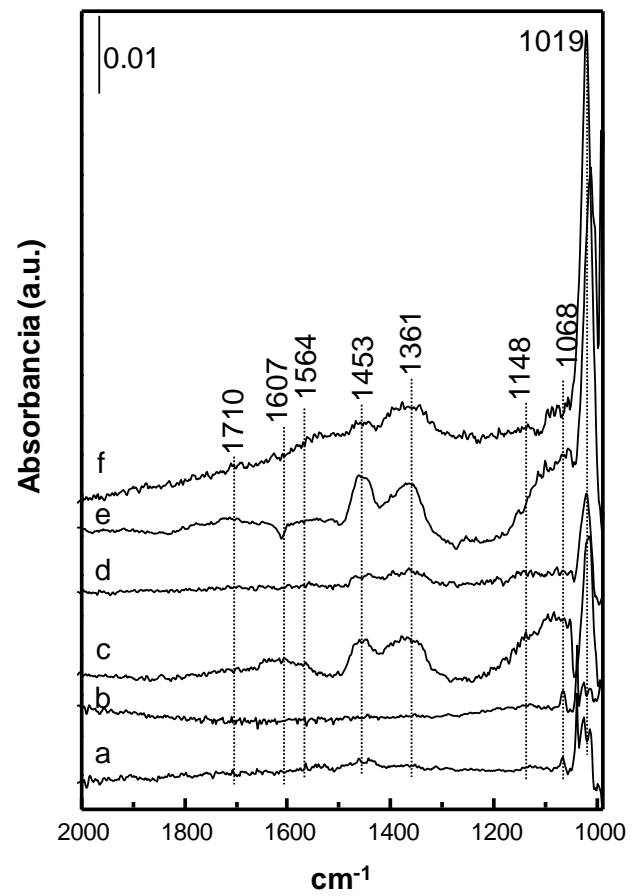

Figura 6.11. Espectro FTIR de la adsorción de metanol a $25^{\circ} \mathrm{C}$ sobre catalizadores $\operatorname{MoVX}(\mathrm{Nb}) \mathrm{O}$ (X = Te o Sb): a) Sb-500; b) Sb-600; c) Te-500; d) Te-600; e) TeNb-500; y f) TeNb-600.

Conclusiones similares se obtienen a partir del estudio de la región IR relacionada con bandas $v(\mathrm{CH})$. Aunque, en esta región, no se observa bandas IR en las muestras activadas a $600^{\circ} \mathrm{C}$, tanto en los catalizadores con niobio o sin niobio activados a $500^{\circ} \mathrm{C}$, se observan bandas IR a 2653 y $2845 \mathrm{~cm}^{-1}$ (debido a las especies metoxi superficiales disociadas), y a 1926 y $1832 \mathrm{~cm}^{-1}$ (asociadas a especies formiato). La ausencia de bandas IR en esta región para las muestras activadas a $600^{\circ} \mathrm{C}$ se debe a la baja concentración de especies adsorbidas en la superficie de estas muestras.

Así, se puede concluir que existe una reactividad diferente (debido a cambios en la naturaleza de la superficie de los catalizadores) en función de las condiciones del tratamiento térmico. Estos resultados están de acuerdo con los resultados obtenidos mediante TPD- $\mathrm{NH}_{3}$ (Figura 5.15), en los que se deduce que las muestras activadas a $500^{\circ} \mathrm{C}$ muestran una concentración de centros ácidos mayor que las muestras tratadas térmicamente a $600^{\circ} \mathrm{C}$. 


\subsubsection{Adsorción de moléculas sonda $\left(\mathrm{NH}_{3}\right.$ y acroleína) por espectroscopia DRIFT}

Por otra parte, se ha realizado un estudio de la adsorción de amoníaco y acroleína empleando para ello la espectroscopia de reflectancia difusa en el infrarrojo (DRIFTS), para completar la caracterización superficial de los catalizadores estudiados. Así, mientras la adsorción de amoníaco aporta información de la naturaleza y tipo de centros ácidos presentes en la superficie de los materiales, los resultados de adsorción de acroleína puede dar una idea de la posible formación de acrilatos y los modos de adsorción de este intermedio de reacción en la superficie de los catalizadores.

\subsubsection{Adsorción de amoníaco}

En primer lugar, se procedió a la adsorción de amoníaco para obtener información de la naturaleza de los centros ácidos o básicos presentes en la superficie del catalizador. El amoníaco es una molécula sonda muy empleada para la determinación de la naturaleza de los centros ácidos de la superficie del material. Así, por espectroscopia infrarroja se puede diferenciar entre la adsorción de amoníaco sobre centros ácidos Lewis o Brönsted.

La molécula de amoníaco se puede adsorber en la superficie de los óxidos metálicos de diferente forma, dependiendo del tipo de centro, tal y como se indica en el Esquema 6.3:

I) Mediante un enlace de hidrógeno a través de uno de sus átomos de hidrógeno con un oxígeno de la superficie (o al oxígeno de un grupo hidroxilo de la superficie).

II) Mediante un enlace de hidrógeno a través del átomo de nitrógeno con el hidrógeno de un grupo hidroxilo de la superficie (centros ácidos Brönsted). Si se produce la transferencia completa del protón se observa la formación de iones amonio $\mathrm{NH}_{4}^{+}$adsorbidos.

III) Mediante coordinación con un átomo metálico deficiente en electrones (centros ácidos Lewis).

IV) Disociación del amoníaco con la formación de especies $\mathrm{NH}_{2}$ y $\mathrm{OH}$ en la superficie.

De esta forma, se pueden distinguir entre los diferentes tipos de centros presentes en la superficie del catalizador. La formación de especies adsorbidas tipo I implica un centro básico, mientras que la disociación del amoníaco (tipo IV) implica la presencia de un par ácido-base. 


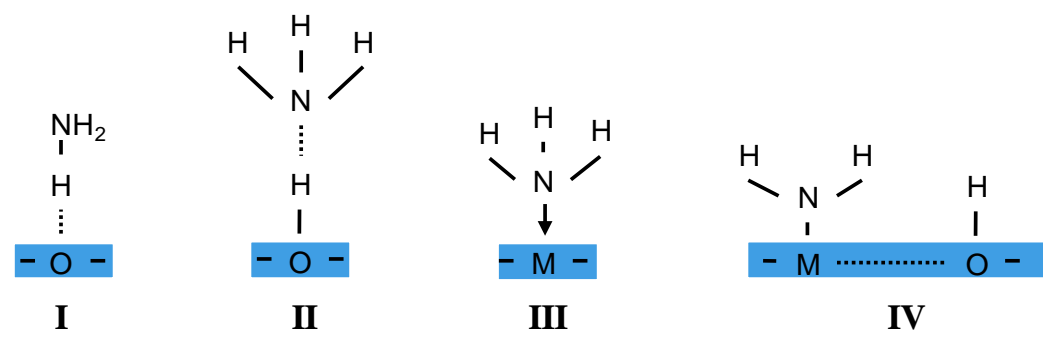

Esquema 6.3. Modos de adsorción de la molécula de amoníaco.

Las bandas de adsorción del amoníaco en fase gas se observan a 3444 y $1628 \mathrm{~cm}^{-1}$, mientras que la quimisorción de amoníaco da lugar a bandas a 1625 $\mathrm{cm}^{-1}$ (en centros Brönsted), a $1400 \mathrm{~cm}^{-1}$ (asociadas a los iones amonio), a 16301615 y $1350-1235 \mathrm{~cm}^{-1}$ (cuando la adsorción se produce en centros Lewis) o a $1580-1505 \mathrm{~cm}^{-1}$ (en el caso de la formación de especies $\mathrm{NH}_{2}$ por disociación del amoníaco) [48].

En la Figura 6.12 se muestra los espectros DRIFTS resultantes de la adsorción de amoníaco para los catalizadores activados a 500 o $600^{\circ} \mathrm{C}$. En todos los casos, se observan principalmente dos bandas de adsorción del amoníaco a $1557 \mathrm{~cm}^{-1}$ (relacionada con las especies $\mathrm{NH}_{2}$ producidas por la disociación del amoníaco), y la banda a $1420 \mathrm{~cm}^{-1}$ (asignada a la vibración de deformación asimétrica de los iones amonio, $\mathrm{NH}_{4}{ }^{+}$). Esto confirma la presencia tanto de centros ácidos Brönsted en la superficie del catalizador como de centros ácido-base, los cuales son capaces de disociar al amoníaco adsorbido.
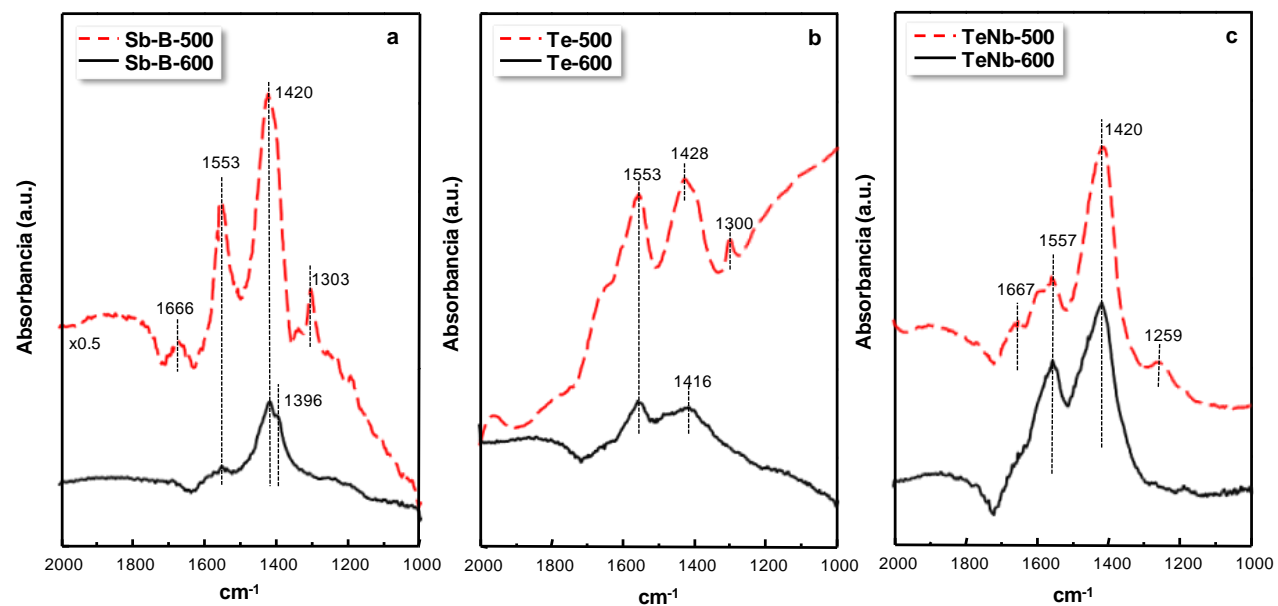

Figura 6.12. Espectros DRIFTS de la adsorción de $\mathrm{NH}_{3}$ sobre catalizadores: a) MoVSbO activados a 500 (Sb-500) y $600^{\circ} \mathrm{C}$ (Sb-600); b) MoVTeO activados a 500 (Te-500) y 600 (Te-600); y c) MoVTeNbO activados a 500 (TeNb-500) y 600드 (TeNb-600). 
En el caso de los catalizadores MoVSbO tratados térmicamente a $500^{\circ} \mathrm{C}$ (Figura 6.12, a), aparecen otras bandas de adsorción de amoníaco a 1666 y 1303 $\mathrm{cm}^{-1}$ que deben estar relacionadas con la presencia de centros ácidos Lewis, en los que la molécula de amoníaco se puede coordinar con el metal deficiente de electrones. Sin embargo, en el catalizador activado a $600^{\circ} \mathrm{C}$, las bandas de adsorción asociadas a la disociación de amoníaco y a la presencia de iones amonio son menos intensas. Así, los catalizadores tratados térmicamente a $500^{\circ} \mathrm{C}$ presentan mayor acidez que los activados a mayor temperatura de activación, de tal modo que al aumentar la temperatura de activación se observa la desaparición de los centros ácidos Lewis y la disminución de la concentración de centros ácidos Brönsted.

En el caso de los materiales MoVTe con o sin $\mathrm{Nb}$ tratados térmicamente a 500 y $600^{\circ} \mathrm{C}$ se observa también una disminución de la acidez en la superficie del catalizador al aumentar la temperatura de activación. Así, los materiales tratados a $500^{\circ} \mathrm{C}$ presentan, en ambos casos, bandas de adsorción a 1259 y $1300 \mathrm{~cm}^{-1}$ (propias de los centros ácidos Lewis), los cuales desaparecen al aumentar la temperatura de activación, disminuyendo, así mismo, la intensidad de las bandas propias de especies $\mathrm{NH}_{2}$ e iones amonio.

Estos resultados, que están de acuerdo con los resultados de TPD- $\mathrm{NH}_{3}$, pueden explicar los resultados catalíticos obtenidos en la oxidación de propano a ácido acrílico sobre el catalizador tratado térmicamente a $600^{\circ} \mathrm{C}$ (Figura 6.1 y Tabla 6.1).

\subsubsection{Adsorción de acroleína}

La adsorción de acroleína en óxidos metálicos multicomponentes basados en Mo y $\mathrm{V}$ ha sido estudiada para la determinación del mecanismo de reacción de su oxidación a ácido acrílico [49]. La acroleína se puede adsorber en la superficie del óxido de diferentes formas dependiendo de los centros activos presentes en la superficie. En la Tabla 6.9 se muestran las diferentes estructuras que puede formar la acroleína adsorbida y la posición de las bandas más características. La molécula de acroleína puede adsorberse mediante la coordinación con un metal, mediante un enlace de hidrógeno entre el oxígeno de la acroleína y un grupo hidroxilo superficial, o reaccionar con el oxígeno para formar especies acrilato.

La vibración del enlace $\mathrm{C}=\mathrm{O}$ cuando la acroleína está adsorbida tiene lugar a menor frecuencia en comparación con la fase gaseosa debido a que el oxígeno del grupo carbonilo está involucrado en la adsorción. Por ello, la vibración $v(\mathrm{C}=\mathrm{O})$ es característica de cada modo de adsorción. 
En este sentido, se ha llevado a cabo la adsorción de acroleína con el fin de determinar la formación de los acrilatos y los modos de adsorción de la acroleína en la superficie de los catalizadores.

Tabla 6.8. Modos de adsorción de la acroleína según Krauß et al [49].

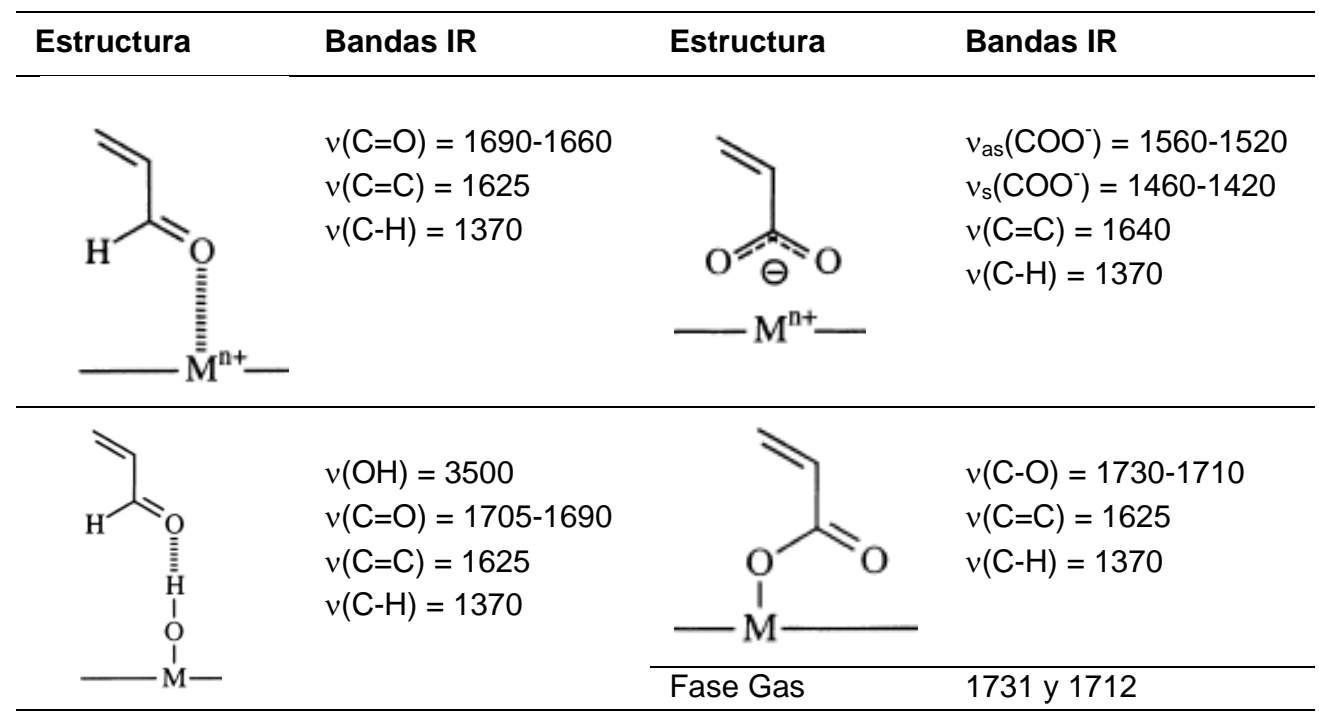

Cuando se absorbe la molécula de acroleína se observan las bandas propias de la molécula en fase gas: 1731 y $1712 \mathrm{~cm}^{-1}$, además, de las bandas correspondientes a las vibraciones simétricas y antisimétricas de los enlaces carboxilo y $\mathrm{C}-\mathrm{H}$. En la Figura $\mathbf{6 . 1 3}$ se muestran los resultados de la adsorción de acroleína para los catalizadores MoVTe(Nb)O activados a 500 y $600^{\circ} \mathrm{C}$, tras la evacuación de acroleína bajo flujo de nitrógeno.

En nuestro caso, se observa principalmente una banda ancha de adsorción a $1725 \mathrm{~cm}^{-1}$ que puede indicar tanto la adsorción de la acroleína como la formación de especies acrilato en la superficie de los materiales (debido a la proximidad de las bandas). Además de esta banda, se observan bandas adicionales a 1552 y $1454 \mathrm{~cm}^{-1}$, en todas las muestras estudiadas, que confirman la formación de especies acrilato. No es de extrañar que se formen este tipo de especies pues la formación de acrilatos es necesaria para la oxidación de acroleína a ácido acrílico, paso intermedio en la oxidación parcial de propano o propileno. Adicionalmente, se observan bandas a $1701 \mathrm{~cm}-1$ características de la vibración $v(\mathrm{C}=\mathrm{O})$ de la molécula de acroleína que pueden estar relacionadas con la absorción por puente de hidrógeno con un grupos hidróxilos en la superficie de los materiales. Esta banda se observa principalmente en los catalizadores activados a $500^{\circ} \mathrm{C}$. 

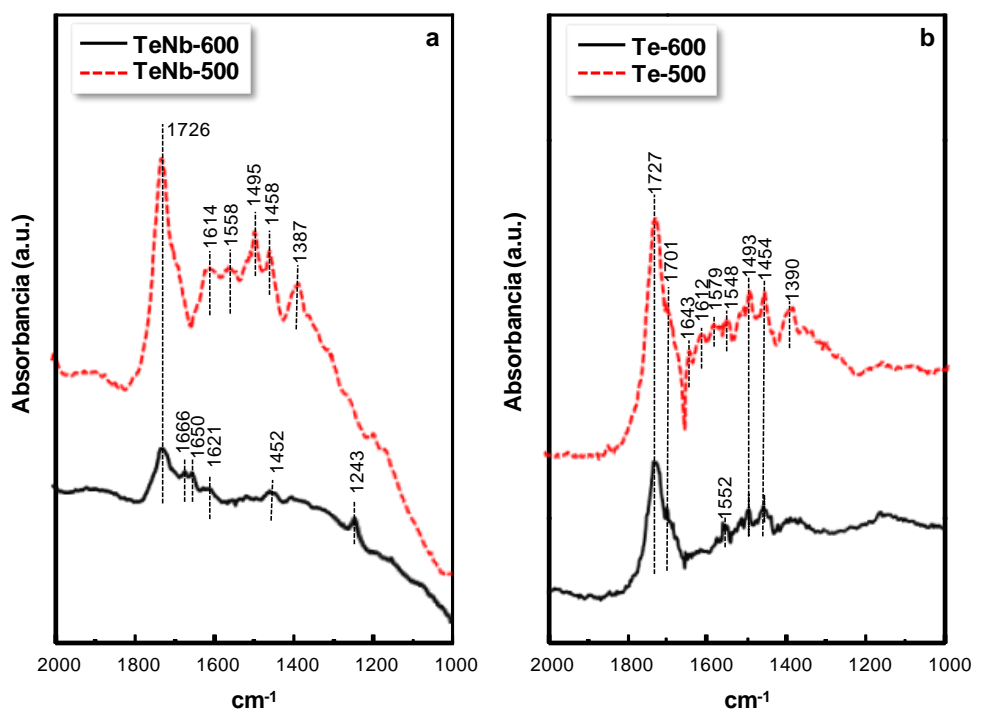

Figura 6.13. Espectros DRIFTS de la adsorción de acroleína sobre catalizadores a) MoVTeNb activados a 500 (TeNb-500) y 600ㄷ (TeNb-600); y b) MoVTe activados a 500 (Te-500) y $600^{\circ} \mathrm{C}(\mathrm{Te}-600)$.

Por otro lado, los materiales activados a menor temperatura $\left(500^{\circ} \mathrm{C}\right)$ presentan unas bandas de adsorción de acroleína mucho más intensas que los tratados a $600^{\circ} \mathrm{C}$. La mayor cantidad de acroleína adsorbida es debido principalmente a la mayor área superficial que presentan estos materiales (Tabla 5.5) y al mayor número de centros ácidos donde se puede adsorber también acroleína. Sin embargo, una mayor adsorción de acroleína no garantiza una mayor selectividad a ácido acrílico, pudiéndose oxidar completamente a óxidos de carbono, lo que explicaría los resultados catalíticos obtenidos en la oxidación de propano y propileno con estos catalizadores (Tablas 6.1 y 6.4).

\subsubsection{Discusión de los resultados}

En vista a los resultados obtenidos, se puede concluir que la actividad catalítica en la oxidación de propano de los óxidos metálicos multicomponente MoV-X-(Nb) (X = Te ó Sb) está relaciona con las características de la superficie de los materiales. Así, un mayor número de centros ácidos, como la presencia de centros Lewis en los materiales activados a $500^{\circ} \mathrm{C}$, da lugar a catalizadores poco selectivos a ácido acrílico. Sin embargo, el aumento de la temperatura de activación elimina la presencia de estos centros ácidos aumentando la selectividad a ácido acrílico.

En el caso de las muestras MoVTeNbO activas a $500^{\circ} \mathrm{C}$, la presencia de centros ácidos debe estar relacionada con la presencia del material amorfo, mientras que los centros ácidos desaparecen cuando el amorfo se transforma en 
fase M1. De acuerdo con esto, la incorporación de cationes Nb en la fase M1 favorece una fuerte disminución de la acidez de estos catalizadores durante el tratamiento térmico. Este hecho está de acuerdo con resultados anteriores en los que la presencia de $\mathrm{Nb}$ facilita una drástica reducción del número de centros ácidos [16]. Sin embargo, este hecho puede no ser una consecuencia de la presencia de cationes $\mathrm{Nb}$, sino también, por la presencia de aniones oxalato durante la preparación de los materiales. De hecho, se ha observado un aumento en la selectividad a ácido acrílico en catalizadores MoVTeO preparados hidrotermalmente en presencia de aniones oxalato en el gel de síntesis [8, 47].

Además de los cambios observados en el carácter ácido de los catalizadores con el tratamiento térmico, la naturaleza de las especies de oxígeno presentes en la superficie de los catalizadores también cambia como se ha determinado mediante los experimentos de intercambio isotópico de oxígeno (Figura 6.10). De hecho, se ha observado una reactividad diferente en la superficie de los catalizadores después del tratamiento térmico a diferente temperatura. El tratamiento térmico a $500^{\circ} \mathrm{C}$ da lugar a la presencia de centros ácidos Lewis y una mayor movilidad de las especies oxígeno de la superficie, que puede ser responsable de la baja selectividad a productos de oxidación observada con estos catalizadores en la oxidación de propano. La activación a mayores temperaturas sugiere algún "bloqueo" de los centros ácidos Lewis y especies oxígeno más reactivas, favoreciendo una mayor selectividad a productos de oxidación.

Esto sugiere que aunque la presencia de la fase M1 es necesaria para aumentar la conversión de propano, algunas características superficiales deben ser adaptadas con el fin de aumentar la selectividad a ácido acrílico. Así, la eliminación de centros ácidos y una ligera disminución de las especies oxígeno más reactivas en la superficie de los catalizadores parecen tener un efecto positivo en la selectividad a ácido acrílico. En otras palabras, como sugieren otros autores [29-32], solamente la superficie de la fase M1 está directamente involucrada en el comportamiento catalítico: la fase M1 podría actuar como un soporte mientras que modificaciones en la monocapa de estos cristales están directamente involucrados en el comportamiento catalítico. De esta forma, el tratamiento térmico podría optimizar la composición superficial y los estados de oxidación de cada elemento, modificando la naturaleza de las especies oxígeno superficiales. Así, el bulk de los catalizadores podría considerarse como un soporte en el cual la fase M1 fácilmente favorece la distribución adecuada de los centros ácidos en entornos con las apropiadas características químicas, es decir, baja acidez y especies oxígeno superficiales con relativa baja movilidad, en los cuales la participación de especies oxígeno adsorbidas es baja. Si esto es así, está claro que los métodos post-síntesis como se ha sugerido recientemente [22, 33] y/o un adecuado procedimiento de activación puede facilitar un aumento de las propiedades catalíticas de estos catalizadores. 
En este sentido, cabe plantearse dónde se encontrarían los centros ácidos en el cristal de la fase M1. Varios grupos de investigación [50-53] sugieren que los centros activos para la oxidación de propano residen en el plano ab de la fase cristalina M1, es decir, el en plano (001) de las agujas que forman el cristal de la fase M1. Así, Guliants et al [50] muestran que al pasivar toda la superficie de la fase M1 a través de la deposición atómica de capas de alúmina ( $22 \mathrm{~nm}$ ), seguida por la rotura de los cristales de M1 para exponer preferentemente los planos ab de la fase, el comportamiento catalítico es muy similar a la fase M1 sin tratamiento, eliminando únicamente la formación de óxidos de carbono durante la amoxidación de propano. Sin embargo, Schlogl et al [54] realizan un experimento similar, donde la fase M1 se recubre con sílice en lugar de alúmina, llegando a una conclusión opuesta, donde el plano (001) no es el único responsable de la actividad catalítica y selectividad a ácido acrílico en la oxidación parcial de propano de la fase M1.

Si los centros ácidos de la fase M1 se situasen en el plano $a b$, sería en los canales heptagonales vacíos (Figura 6.14), donde supuestamente se encuentran los centros de $\mathrm{V}^{5+}$ capaces de activar al propano $[17,51,53]$. Sin embargo, si este es el caso, cuando se emplea un promotor, como K, al bloquear los centros ácidos se debería observar una drástica disminución de la actividad catalítica, pues se bloquearían los canales heptagonales. De forma similar a cuando se obtiene la fase M1 con exceso de teluro, donde el teluro se sitúa en los canales heptagonales dando lugar a catalizadores poco activos en la oxidación de propano [20]. Sin embargo, en los catalizadores promovidos con potasio, sólo se observa una ligera disminución de la actividad catalítica [55-56].

Otra posibilidad es que los centros ácidos se encuentren en defectos a lo largo del cristal de la fase M1 (Figura 6.14), lo que explicaría la relativamente alta cantidad de potasio necesaria para bloquear los centros ácidos [55-56]. Por microscopía electrónica se ha observado que las caras del cristal a lo largo del eje c de la fase M1 se caracterizan por una morfología escalonada, mientras que por microscopía electrónica de alta resolución (HREM) se observa que la periodicidad del plano $a b$ en el cristal de la fase M1 se rompe en las secciones más delgadas, exponiendo el interior de los canales a largo de los cristales de la fase M1 [57]. De esta forma, los centros activos de la fase M1 capaces de activar al propano podrían estar localizados tanto en el plano $a b$ como a lo largo del eje $c$ (Figura 6.14). 


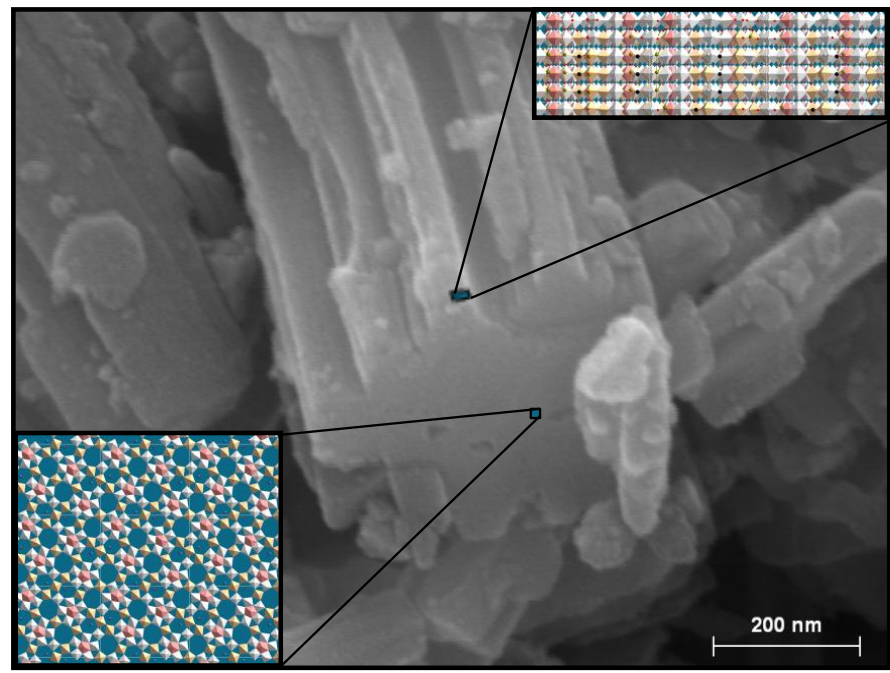

Figura 6.14. Estructura de la fase M1 en el plano $a b$ y a lo largo del eje $c$.

De esta forma, las cadenas $(\mathrm{TeO})_{n}$ que se encuentran en el interior de los canales hexagonales pueden quedar expuestas en la superficie de los catalizadores. Este tipo de terminación a lo largo de los cristales de la fase M1 podría explicar el enriquecimiento de Te observado en la superficie de los materiales por XPS (Tablas 5.4 y 5.7), observado anteriormente por otros autores $[1,20,58]$. Recientemente [59], se ha estudiado teóricamente la adsorción de especies $\mathrm{C}_{3}$ en un modelo de los centros activos del plano ab por DFT (Density Functional Theory), revelando que la activación de propano en las especies $\mathrm{Te}=\mathrm{O}$ está más favorecida que en los grupos $V=O$. En este sentido, la presencia de especies $\mathrm{Te}=\mathrm{O}$ en la terminación de los cristales de la fase M1 podría favorecer la activación de la molécula de propano.

Por otro lado, las cadenas $(\mathrm{TeO})_{n}$ pueden romperse al resultar expuestas en la terminación a lo largo de los cristales de la fase M1, formando especies $\mathrm{Te}-\mathrm{OH}$ [60] que pueden dispersarse en la superficie del material. Estos grupos $\mathrm{Te}-\mathrm{OH}$ podrían corresponder a los centros Brönsted observados por adsorción de $\mathrm{NH}_{3}$ (Figura 6.12).

Sin embargo, la terminación a lo largo de los cristales de la fase M1 puede variar dependiendo de la ocupación del centro catiónico [61], por lo que la composición, el método de síntesis y el tipo de post-tratamiento deben tener una influencia considerable. 


\subsection{Conclusiones}

Los óxidos mixtos MoVTe(Sb)NbO activados a 500 y $600^{\circ} \mathrm{C}$ han demostrado ser activos en la oxidación de propano, propileno y metanol. En el caso de la oxidación de propano y propeno el principal producto de oxidación es ácido acrílico, mientras que en el caso de la oxidación de metanol se observa principalmente la formación de formaldehído.

En general, los catalizadores presentan una tendencia en la actividad catalítica muy similar en las tres reacciones estudiadas. En este sentido, los catalizadores sin niobio (MoVSbO y MoVTeO) son más activos que los materiales con niobio (MoVTeNbO). Además, los materiales activados a 500ㄷ muestran una mayor conversión que los catalizadores activados a $600^{\circ} \mathrm{C}$, excepto en el caso de la oxidación de propano con el catalizador MoVTeNb activado a $500^{\circ} \mathrm{C}$, que es menos activo que el catalizador activado a $600^{\circ} \mathrm{C}$. Los catalizadores estudiados presentan principalmente la fase $\mathrm{M} 1$ en su composición (a excepción del catalizador TeNb-500 que presenta una fase amorfa), por lo que se deduce que la fase M1 es activa en la oxidación de las tres moléculas estudiadas.

Sin embargo, se han observado diferencias en la selectividad al principal producto de oxidación parcial dependiendo de la composición del catalizador, la temperatura de activación y de la reacción de oxidación estudiada.

Los materiales sin niobio activados a 600ㄷ (Sb-600 y Te-600) presentan un comportamiento muy similar en todas las reacciones estudiadas. En ambos casos, además de la fase $M 1$ se observa la presencia de fase $M 2\left(\operatorname{Te}_{0.33} M O_{3.33}\right)$, $\mathrm{TeMo}_{5} \mathrm{O}_{16}$ (o su equivalente con antimonio, $\mathrm{Sb}_{2} \mathrm{Mo}_{10} \mathrm{O}_{31}$ ). Si bien estas fases no son activas en la oxidación de propano, pueden ser activas en la oxidación de propileno y metanol, mostrando una mejoría en la selectividad a ácido acrílico o formaldehído. Sin embargo, la selectividad a ácido acrílico obtenida es menor a la que se observa con materiales con niobio, debido posiblemente a una mayor presencia de centros ácidos que favorecen la formación de ácido acético y óxidos de carbono. Por otro lado, la selectividad a formaldehído en estos material es muy similar, indicando la presencia de centros redox similares en ambos catalizadores.

Los catalizadores sin niobio activados a $500^{\circ} \mathrm{C}$ (Sb-500 y Te-500) muestran un comportamiento diferente dependiendo de la reacción estudiada. En el caso de la oxidación de propano y propileno, son muy activos pero poco selectivos a ácido acrílico, dando principalmente productos de oxidación total $\left(\mathrm{CO}\right.$ y $\left.\mathrm{CO}_{2}\right)$ debido a la mayor acidez superficial que presentan estos materiales. Sin embargo, en la oxidación de propano, el catalizador Te-500 es más activo, debido a que presenta principalmente la fase M1. En la oxidación de metanol, se observan además diferencias en la selectividad a formaldehído, donde el catalizador $\mathbf{S b - 5 0 0}$ es poco selectivo, probablemente debido a la mayor presencia de centros ácidos que 
favorece la formación de productos de deshidratación (a bajas conversiones de metanol) y óxidos de carbono (a altas conversiones de metanol).

Por otro lado, los catalizadores con niobio muestran un comportamiento catalítico diferente, debido a las diferencias observadas en las propiedades superficiales de los materiales (estados de oxidación de los elementos y número de centros ácidos). El catalizador activado a $500^{\circ} \mathrm{C}$ (TeNb-500) es activo y selectivo en la oxidación de propileno (alcanzando una selectividad a ácido acrílico similar al catalizador activado a $600^{\circ} \mathrm{C}$ ), lo que sugiere la presencia de los mismos centros activos y selectivos para la oxidación de propileno. Esto indica que el diferente comportamiento observado en la oxidación de propano se puede deber a la modificación de los centros activos donde tiene lugar la activación del alcano durante el tratamiento térmico.

El estudio comparativo de los catalizadores mediante otras técnicas de caracterización superficial, como la adsorción de moléculas sonda o el intercambio isotópico de ${ }^{18} \mathrm{O}_{2}$, sugiere que el comportamiento catalítico de estos materiales puede explicarse teniendo en cuenta las características superficiales de los catalizadores. En este sentido, el tratamiento térmico a $500^{\circ} \mathrm{C}$ da lugar a la presencia de centros ácidos Lewis, a una mayor movilidad de las especies oxígeno de la superficie y una mayor adsorción de los intermedios de reacción. Estas características superficiales pueden relacionarse con la baja selectividad a productos de oxidación observada con estos catalizadores (observándose principalmente $\mathrm{CO}$ y $\mathrm{CO}_{2}$ en la oxidación de propano y propileno).

Sin embargo, la activación a mayores temperaturas parece modificar las propiedades superficiales disminuyendo el número de centros ácidos (principalmente los centros Lewis en la superficie de los catalizadores) y las especies de oxígeno más reactivas. De esta forma, se favorece una mayor selectividad a productos de oxidación. Así, la presencia de centros ácidos, la naturaleza y estado de oxidación de los elementos en la superficie y la movilidad de las especies oxígeno en la superficie está relacionada con la composición y la temperatura de activación de los materiales, y por tanto, con sus propiedades catalíticas.

En conclusión, la presencia de la fase M1 es necesaria para la activación de la molécula de propano, aunque las propiedades superficiales de dicha fase se deben optimizar con el fin de aumentar la selectividad a ácido acrílico y mejorar la efectividad catalítica de los catalizadores. 


\section{Conclusions}

$\mathrm{MoVTe}(\mathrm{Sb}) \mathrm{NbO}$ mixed oxides activated at 500 and $600^{\circ} \mathrm{C}$ have been shown to be active in the oxidation of propane, propylene and methanol. In the case of the oxidation of propane and propylene, the main oxidation product was acrylic acid, while formaldehide had mainly observed in the oxidation of methanol.

In general, these catalysts present a similar tendency in the catalytic activity in the three reactions studied. Thus, Nb-free catalysts (MoVSbO and MoVTeO) are more active than $\mathrm{Nb}$-containing catalysts (MoVTeNbO). Moreover, catalysts heattreated at $500^{\circ} \mathrm{C}$ shown a higher conversion than catalysts activated at $600^{\circ} \mathrm{C}$, except in the case of the propane oxidation over MoVTeNb catalyst heat-treated a $500^{\circ} \mathrm{C}$ (which is less active than catalyst heat-treated at $600^{\circ} \mathrm{C}$ ). M1 phase is mainly present in the crystalline phase composition of studied catalysts (except in the case of TeNb-500 catalyst, which present an amorphous phase). This fact suggests that M1 phase is active in the oxidation of these three molecules studied.

However, differences in the selectivity to main oxidation product have been observed, depending on the catalyst composition, catalysts activation temperature and the reaction of oxidation studied.

$\mathrm{Nb}$-free catalysts heat-treated a $600^{\circ} \mathrm{C}(\mathrm{Sb}-600$ and Te-600) present a similar catalytic behavior in all the reactions studied. In both cases, other crystalline phases as $\mathrm{M} 2$ phase $\left(\mathrm{Te}_{0.33} \mathrm{MO}_{3.33}\right.$ ), TeMo $\mathrm{O}_{16}$ (or its equivalent, $\mathrm{Sb}_{2} \mathrm{Mo}_{10} \mathrm{O}_{31}$ ) in addition to the $\mathrm{M} 1$ phase are presented. Although these phases are not active in the propane oxidation, these phases can be active in the propylene and methanol oxidation, showing an improvement in the selectivity to acrylic acid or formaldehide. However, the selectivity to acrylic acid is lower than that observed for $\mathrm{Nb}$ containing catalysts, possibly due to an increased of acid sites which favor the formation of acetic acid and carbon oxides. On the other hand, the selectivity to formaldehide obtained over these catalysts is very similar, suggesting similar redox sites in both catalysts.

$\mathrm{Nb}$-free catalysts heat-treated at $500^{\circ} \mathrm{C}(\mathrm{Sb}-500$ y Te-500) show a different catalytic behavior depending on the oxidation reaction studied. In the case of the oxidation of propane and propylene, these catalysts are very active but unselective to acrylic acid (favoring mainly the total oxidation products $\mathrm{CO}$ and $\mathrm{CO}_{2}$ ) due to higher number of acid sites present on the catalytic surface in these materials. However, Te-500 catalyst is more active in the propane oxidation because M1 phase is manly presented. In the methanol oxidation, differences in the selectivity to formaldehide have also observed. Thus, the selectivity to formaldehide is lower over Sb-500 catalysts. This fact can be explained by the superficial acidity observed in this catalysts, which favors the formation of dehydrogenation products (at low methanol conversion) and carbon oxides (at high methanol conversion). 
On the other hand, Nb-containing catalysts show a different catalytic behavior than $\mathrm{Nb}$-free catalysts. These differences observed can be related with the catalysts surface properties (oxidation states of the elements and number of acid sites). MoVTeNbO catalyst heat-treated at $500^{\circ} \mathrm{C}$ ( TeNb-500) is active and selective in the oxidation of propylene, with selectivity to acrylic acid similar to the catalysts heat-treated at $600^{\circ} \mathrm{C}$. This fact suggests that active and selective sites for propene oxidation are presented in both catalysts. In this way, differences observed in the catalytic performance in the oxidation of propane could be related to the modification of actives sites for the alkane oxidation during the heattreatment.

The comparative study by other surface characterization techniques, as infrared spectroscopy of adsorbed probe molecules and ${ }^{18} \mathrm{O}_{2}$ isotopic exchange, of MoVSbO, MoVTeO and MoVTeNbO catalysts suggests that the catalytic behavior of these materials could be more easily explained by considering the characteristics of the surface of the catalysts, which change in a different manner depending on the catalyst composition and activation temperature. Thus, heattreatment at $500^{\circ} \mathrm{C}$ leads to the presence of Lewis acid sites, a higher mobility of surface oxygen species and a higher adsorption of the intermediates species which could be responsible for the low selectivity to acrylic acid observed during the oxidation of propane on this catalyst.

However, a higher activation temperature seems to modify the surface properties, decreasing the amount of acid sites (especially surface Lewis acid sites) and the most reactive oxygen species favoring a higher selectivity to acrylic acid. Thus, the presence of the acid sites on the surface catalysts, the nature and oxidation state of the surface elements, and the mobility of surface oxygen species can be related to the catalysts composition, activation temperature and, therefore, to their catalytic properties.

In conclusion, M1 phase presence is required for the activation of the propane molecule, although the surface properties of this crystalline phase must be optimized in order to increase the selectivity to acrylic acid and enhance the catalytic effectiveness of the catalysts. 


\section{Bibliografía}

[1] J. M. M. Millet, H. Roussel, A. Pigamo, J. L. Dubois, J. C. Jumas, Applied Catalysis A: General 232 (2002) 77-92.

[2] H. Murayama, D. Vitry, W. Ueda, G. Fuchs, M. Anne, J. L. Dubois, Applied Catalysis A: General 318 (2007) 137-142.

[3] N. R. Shiju, A. J. Rondinone, D. R. Mullins, V. Schwartz, S. H. Overbury, V. V. Guliants, Chemistry of Materials 20 (2008) 6611-6616.

[4] M. Baca, J. M. M. Millet, Applied Catalysis A: General 279 (2005) 67-77.

[5] P. Botella, J. M. López Nieto, B. Solsona, A. Mifsud, F. Márquez, Journal of Catalysis 209 (2002) 445-455.

[6] M. Baca, M. Aouine, J. L. Dubois, J. M. M. Millet, Journal of Catalysis 233 (2005) 234-241.

[7] W. Ueda, K. Oshihara, Applied Catalysis A: General 200 (2000) 135-143.

[8] K. Oshihara, T. Hisano, W. Ueda, Topics in Catalysis 15 (2001) 153-160.

[9] A. C. Sanfiz, T. W. Hansen, D. Teschner, P. Schnörch, F. Girgsdies, A. Trunschke, R. Schlögl, M. H. Looi, S. B. A. Hamid, The Journal of Physical Chemistry C 114 (2010) 1912-1921.

[10] I. E. Wachs, J. M. Jehng, W. Ueda, The Journal of Physical Chemistry B 109 (2005) 2275-2284.

[11] V. V. Guliants, R. Bhandari, B. Swaminathan, V. K. Vasudevan, H. H. Brongersma, A. Knoester, A. M. Gaffney, S. Han, The Journal of Physical Chemistry B 109 (2005) 24046-24055.

[12] P. DeSanto, D. J. Buttrey, R. K. Grasselli, C. G. Lugmair, A. F. Volpe, B. H. Toby, T. Vogt, Topics in Catalysis 23 (2003) 23-38.

[13] H. Tsuji, Y. Koyasu, Journal of the American Chemical Society 124 (2002) 5608-5609.

[14] P. Botella, B. Solsona, A. Martinez-Arias, J. M. López Nieto, Catalysis Letters 74 (2001) 149-154.

[15] J. M. M. Millet, M. Baca, A. Pigamo, D. Vitry, W. Ueda, J. L. Dubois, Applied Catalysis A: General 244 (2003) 359-370.

[16] P. Botella, P. Concepción, J. M. López Nieto, B. Solsona, Catalysis Letters 89 (2003) 249-253.

[17] P. Concepción, P. Botella, J. M. López Nieto, Applied Catalysis A: General 278 (2004) 45-56.

[18] R. Schlögl, Topics in Catalysis 54 (2011) 627-638.

[19] R. K. Grasselli, J. D. Burrington, D. J. Buttrey, P. DeSanto, C. G. Lugmair, A. F. Volpe, T. Weingand, Topics in Catalysis 23 (2003) 5-22.

[20] P. Botella, E. García-González, J. M. López Nieto, J. M. González-Calbet, Solid State Sciences 7 (2005) 507-519.

[21] J. M. Tatibouët, Applied Catalysis A: General 148 (1997) 213-252.

[22] G. Busca, Journal of Molecular Catalysis A: Chemical 50 (1989) 241.

[23] M. Ai, Journal of Catalysis 54 (1978) 426.

[24] A. S. Elmi, E. Tronconi, C. Cristiani, J. P. Gomez Martin, P. Forzatti, G. Busca, Industrial \& Engineering Chemistry Research 28 (1989) 387-393.

[25] I. Carrizosa, G. Munuera, S. Castañar, Journal of Catalysis 49 (1977) 265277.

[26] L. M. Gomez Sainero, S. Damyanova, J. L. G. Fierro, Applied Catalysis A: General 208 (2001) 63-75. 
[27] J. C. Védrine, E. K. Novakova, E. G. Derouane, Catalysis Today 81 (2003) 247-262.

[28] M. Estenfelder, H. G. Lintz, B. Stein, J. Gaube, Chemical Engineering and Processing: Process Intensification 37 (1998) 109-114.

[29] P. Botella, J. M. López Nieto, B. Solsona, Catalysis Letters 78 (2002) 383387.

[30] D. Vitry, Y. Morikawa, J. L. Dubois, W. Ueda, Topics in Catalysis 23 (2003) 47-53.

[31] B. Solsona, J. M. López Nieto, J. M. Oliver, J. P. Gumbau, Catalysis Today 91-92 (2004) 247-250.

[32] J. Holmberg, R. K. Grasselli, A. Andersson, Applied Catalysis A: General 270 (2004) $121-134$.

[33] J. Holmberg, S. Hansen, R. Grasselli, A. Andersson, Topics in Catalysis 38 (2006) 17-29.

[34] P. Botella, J. M. López Nieto, B. Solsona, Journal of Molecular Catalysis A: Chemical 184 (2002) 335-347.

[35] J. C. Vedrine, G. Coudurier, M. Forissier, J. C. Volta, Materials Chemistry and Physics 13 (1985) 365-378.

[36] G. Bliznakov, Y. Pesheva, D. Klissuerski, M. Marinov, V. Kozhukharov, Applied Catalysis 29 (1987) 211-218.

[37] H. Hayashi, Catalysis Surveys from Japan 3 (1999) 43-52.

[38] R. Castillo, K. Dewaele, P. Ruiz, B. Delmon, Applied Catalysis A: General 153 (1997) L1-L8.

[39] R. S. Mann, R. A. Diaz-Real, in Studies in Surface Science and Catalysis, Volume 75, Elsevier, (1993), 1991-1994.

[40] R. Díaz, R. S. Mann, Materials Letters 33 (1997) 19-22.

[41] Magdy A. Wassela, N. K. Allahaverdovab, K. Y. Adyamovb, Collect. Czech. Chem. Commun. 57 (1992) 446-449.

[42] G. W. Keulks, Journal of Catalysis 19 (1970) 232-235.

[43] R. D. Wragg, P. G. Ashmore, J. A. Hockey, Journal of Catalysis 22 (1971) 49-53.

[44] Y. Moro-oka, W. Ueda, K.-H. Lee, Journal of Molecular Catalysis A: Chemical 199 (2003) 139-148.

[45] E. Heracleous, A. A. Lemonidou, Journal of Catalysis 237 (2006) 175-189.

[46] J. M. López Nieto, A. Dejoz, M. I. Vazquez, W. O'Leary, J. Cunningham, Catalysis Today 40 (1998) 215-228.

[47] A. Badri, C. Binet, J.-C. Lavalley, Journal of the Chemical Society, Faraday Transactions 93 (1997) 1159-1168.

[48] A. A. Tsyganenko, D. V. Pozdnyakov, V. N. Filimonov, Journal of Molecular Structure 29 (1975) 299-318.

[49] K. Krauß, A. Drochner, M. Fehlings, J. Kunert, H. Vogel, Journal of Molecular Catalysis A: Chemical 162 (2000) 413-422.

[50] N. R. Shiju, X. Liang, A. W. Weimer, C. Liang, S. Dai, V. V. Guliants, Journal of the American Chemical Society 130 (2008) 5850-5851.

[51] R. Grasselli, D. Buttrey, J. Burrington, A. Andersson, J. Holmberg, W. Ueda, J. Kubo, C. Lugmair, A. Volpe, Topics in Catalysis 38 (2006) 7-16.

[52] P. Korovchenko, N. Shiju, A. Dozier, U. Graham, M. Guerrero-Pérez, V. Guliants, Topics in Catalysis 50 (2008) 43-51.

[53] R. Grasselli, C. Lugmair, A. Volpe, Topics in Catalysis 54 (2011) 595-604. 
[54] A. Celaya Sanfiz, T. W. Hansen, A. Sakthivel, A. Trunschke, R. Schlögl, A. Knoester, H. H. Brongersma, M. H. Looi, S. B. A. Hamid, Journal of Catalysis 258 (2008) 35-43.

[55] F. Ivars, B. Solsona, M. Soriano, J. M. López Nieto, Topics in Catalysis 50 (2008) 74-81.

[56] F. Ivars, B. Solsona, P. Botella, M. D. Soriano, J. M. López Nieto, Catalysis Today 141 (2009) 294-299.

[57] W. Zhang, A. Trunschke, R. Schlögl, D. Su, Angewandte Chemie International Edition 49 (2010) 6084-6089.

[58] W. Ueda, D. Vitry, T. Katou, Catalysis Today 96 (2004) 235-240.

[59] K. Muthukumar, J. Yu, Y. Xu, V. Guliants, Topics in Catalysis 54 (2011) 605-613.

[60] M. Hävecker, S. Wrabetz, J. Kröhnert, L. I. Csepei, R. Naumann d'Alnoncourt, Y. V. Kolen'ko, F. Girgsdies, R. Schlögl, A. Trunschke, Journal of Catalysis 285 (2012) 48-60.

[61] W. D. Pyrz, D. A. Blom, N. R. Shiju, V. V. Guliants, T. Vogt, D. J. Buttrey, The Journal of Physical Chemistry C 112 (2008) 10043-10049. 


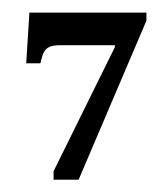

Conclusiones Generales 

A lo largo de la presente tesis doctoral se ha estudiado la preparación, caracterización y comportamiento catalítico en la oxidación parcial de propano a ácido acrílico de los materiales basados en bronces de Mo y $\mathrm{V}$. De los resultados obtenidos se han extraído las siguientes conclusiones:

El comportamiento catalítico de estos materiales está principalmente determinado por la presencia de una estructura cristalina, un óxido de molibdeno no estequiométrico con estructura de bronce ortorrómbico $\left(\mathrm{Te}_{2} \mathrm{M}_{20} \mathrm{O}_{57}\right.$ or $\left.\left(\mathrm{Sb}_{2} \mathrm{O}\right) M_{20} \mathrm{O}_{56}, M=\mathrm{Mo}, \mathrm{V} \mathrm{y} / \mathrm{o} \mathrm{Nb}\right)$ denominado fase $\mathrm{M} 1$. No obstante, las propiedades catalíticas de estos materiales están fuertemente influenciadas por otros factores tales como la composición y las características superficiales de los cristales. Estos factores están estrechamente relacionados con los parámetros de síntesis empleados en la preparación de estos materiales.

En este sentido, la incorporación de un metal (Ag, K, Mg, Ca, Sr, Fe, Co, Ni, $\mathrm{Cu}, \mathrm{Ga}, \mathrm{Bi}, \mathrm{La}$ o $\mathrm{Nb}$ ) en el sistema catalítico MoVTeO ejerce una influencia importante en las propiedades catalíticas de los catalizadores finales. En general, la incorporación de la mayoría de los promotores estudiados tiene un efecto negativo en el comportamiento catalítico. Sin embargo, los catalizadores promovidos con $\mathrm{Ca}, \mathrm{Ga}$ o $\mathrm{Nb}$ mejoran la conversión de propano y/o la selectividad a ácido acrílico, aunque este efecto depende de la cantidad de metal incorporado.

Una baja incorporación de $\mathrm{Ca}$ en el gel de síntesis $(\mathrm{Ca} / \mathrm{Mo}=0.02$ ó 0.04$)$ mejora la conversión de propano y la selectividad a ácido acrílico. Sin embargo, no se ha encontrado evidencia de la incorporación de especies $\mathrm{Ca}^{2+}$ en la fase M1 final. Por otro lado, un aumento de la concentración de calcio en el gel de síntesis $(\mathrm{Ca} / \mathrm{Mo}>0.06)$ favorece una pérdida tanto en la actividad como en la selectividad a ácido acrílico.

La incorporación de niobio en el gel de síntesis favorece la formación de un amorfo, aunque los catalizadores MoVTe con $\mathrm{Nb}$ presentan principalmente la fase M1 después del tratamiento térmico a $600^{\circ} \mathrm{C}$. Se observa además un aumento de la estabilidad de la fase M1 en los materiales con niobio tratados térmicamente. Por otra parte, los catalizadores con $\mathrm{Nb}$ muestran una mayor selectividad a ácido acrílico. Este efecto aumenta inicialmente con la relación $\mathrm{Nb} / \mathrm{Mo}$ en el gel de síntesis, siendo máximo para una relación $\mathrm{Nb} / \mathrm{Mo}=0.17$.

Por otro lado, la incorporación parcial de Ga en la estructura de la fase M1 se ha confirmado mediante el uso de HREM, aunque se observan cambios significativos en las propiedades superficiales de los catalizadores con galio. Además, respecto a los materiales MoVTe, la presencia de galio favorece: una mayor estabilidad de la fase M1 durante el tratamiento térmico y un número de centros ácidos superficiales menor, así como cambios significativos en los estados de oxidación de los elementos de la superficie del catalizador. En este sentido, los 
catalizadores MoVTeO promovidos con $\mathrm{Ga}$ muestran valores de selectividad a ácido acrílico altos a conversiones de propano bajas, resultados que sólo se han observado con catalizadores MoVTeNbO. Sin embargo, la selectividad a ácido acrílico a altas conversiones de propano depende de la relación $\mathrm{Ga} / \mathrm{Mo}$ y $\mathrm{Ga} /(\mathrm{V}+\mathrm{Ga})$. Así, los centros de $\mathrm{Ga}$ influyen tanto la formación como la descomposición de ácido acrílico. El catalizador más efectivo (selectividad a ácido acrílico de $55 \%$ a una conversión de $40 \%$ ) se ha preparado con una relación $\mathrm{Ga} /(\mathrm{V}+\mathrm{Ga})$ de 0.25 en el gel de síntesis. Estos resultados sugieren que los catalizadores MoVTeGa podrían ser un sistema catalítico interesante para la oxidación selectiva de propano a ácido acrílico.

Se ha llevado a cabo un estudio de la influencia de la temperatura de síntesis hidrotermal y de la temperatura de activación térmica del catalizador sobre las propiedades catalíticas y físico-químicas de estos catalizadores. Los resultados obtenidos sugieren que la temperatura de síntesis hidrotermal afecta principalmente a la formación de la fase M1, mientras que la temperatura de activación tiene una influencia en las propiedades superficiales de los catalizadores y, por tanto, en su comportamiento catalítico. La influencia de ambos parámetros dependen, así mismo, de la composición de los catalizadores, principalmente la presencia o ausencia de niobio en los materiales.

En los catalizadores sin niobio, la cantidad de fase M1 antes del tratamiento térmico aumenta al aumentar la temperatura de síntesis, mientras que en los catalizadores con niobio se obtiene una fase amorfa durante la síntesis hidrotermal, independientemente de la temperatura de síntesis.

La síntesis hidrotermal de materiales MoVSbO da lugar a la formación de la fase M1. También se observa la presencia de la fase M2, la cual está más favorecida a baja temperatura de síntesis. Después de tratamiento térmico en nitrógeno, se observa una disminución de la presencia de la fase $\mathrm{M} 1$, un aumento de fase $\mathrm{M} 2$ y la aparición de otras fases (como $\mathrm{MoO}_{3} \circ \mathrm{Sb}_{2} \mathrm{Mo}_{10} \mathrm{O}_{31}$ ) cuya relación depende de la temperatura de activación. Esto se debe a la presencia minoritaria de otras fases cristalinas y/o sólidos amorfos en el precursor. Por otro lado, la actividad catalítica disminuye y la selectividad a ácido acrílico aumenta al aumentar la temperatura de activación. Sin embargo, la selectividad a ácido acrílico obtenida con materiales MoVSbO es menor en comparación con los catalizadores con Te.

En la síntesis hidrotermal de materiales MoVTeO, la temperatura de síntesis tiene una influencia no sólo en la formación de la fase M1, sino también en la estabilidad de la fase M1 durante el tratamiento térmico posterior. En el caso del material preparado hidrotermalmente a $175^{\circ} \mathrm{C}$ presenta principalmente la fase $\mathrm{M} 1$. Esta fase se mantiene tras la activación térmica a 500 o $550^{\circ} \mathrm{C}$. Sin embargo, se 
observa una descomposición parcial de la fase M1 (con la formación de otras fases cristalinas: fase $\mathrm{M} 2, \mathrm{MoO}_{3}$ and $\mathrm{TeMo}_{5} \mathrm{O}_{16}$ ) en la muestra activada a $600^{\circ} \mathrm{C}$. De acuerdo con los resultados catalíticos, la fase M1 de los catalizadores MoVTeO es muy activa pero poco selectiva en la oxidación parcial de propano a ácido acrílico. Sin embargo, la descomposición parcial de la fase M1 (y la contaminación superficial del catalizador) durante la activación térmica $600^{\circ} \mathrm{C}$ favorece una mayor selectividad a ácido acrílico. En efecto, estos cambios se deben posiblemente a cierta contaminación de la superficie catalítica que modifica la concentración y fortaleza de los centros ácidos (no selectivos) en la superficie de estos catalizadores, tal y como se desprende de los resultados de TPD-NH

En la síntesis hidrotermal de materiales MoVTeNbO sólo se obtiene un sólido amorfo que se transforma principalmente en la fase M1 durante el tratamiento térmico a temperaturas de $550 \circ 600^{\circ} \mathrm{C}$. Sin embargo la presencia de la fase M1 en los catalizadores con niobio calcinados a $600^{\circ} \mathrm{C}$ es mayor que la observada en los catalizadores sin niobio, sugiriendo que la presencia de niobio favorece una mayor estabilidad térmica de la fase M1. Dado que tanto la actividad como la selectividad a ácido acrílico aumentan al aumentar la temperatura de activación, se puede concluir que la fase $\mathrm{M} 1$ con niobio, con cationes $\mathrm{Nb}^{5+}$ incorporados en la estructura, es activa y selectiva para la oxidación de propano a ácido acrílico. En efecto, los catalizadores MoVTeNbO preparados a $175^{\circ} \mathrm{C}$ y activados a 550 ó $600^{\circ} \mathrm{C}$ han demostrado ser los catalizadores más efectivos.

De acuerdo con los resultados de la caracterización de los materiales, se puede concluir que el comportamiento catalítico de estos catalizadores puede explicarse teniendo en cuenta las características superficiales de los catalizadores, que cambian de forma diferente dependiendo de la composición y de la temperatura de activación de los catalizadores:

El proceso de activación térmica a $600^{\circ} \mathrm{C}$ (en corriente de nitrógeno) parece modificar, en todos los casos, las propiedades superficiales de todos los materiales estudiados, favoreciendo una mayor selectividad a ácido acrílico. Esto se debe a: i) una disminución del número y fuerza de los centros ácidos superficiales (el tratamiento térmico favorece la eliminación parcial de los centros ácidos Lewis); ii) la modificación de las características redox de los centros activos; y iii) la movilidad de las especies oxígeno de la superficie.

En el caso de materiales MoVTeNbO, además del efecto positivo de la presencia de niobio en la estabilidad de la fase $\mathrm{M} 1$, se observan cambios significativos en el estado de oxidación de algunos elementos (especialmente la presencia mayoritaria de $\mathrm{Te}^{4+}$ y la eliminación total de especies $\mathrm{Te}^{6+}$ ), así como una distribución más homogénea de las especies de molibdeno. Ambos factores 
puede explicar la mayor selectividad a ácido acrílico observada con los catalizadores MoVTeNbO activados a 550 y $600^{\circ} \mathrm{C}$.

Finalmente, del estudio catalítico de las reacciones de oxidación de propano, propileno y metanol con catalizadores MoVSb, MoVTe y MoVTeNb activados a 500 y $600^{\circ} \mathrm{C}$, se puede concluir que la fase $\mathrm{M} 1$ es activa en las tres reacciones estudiadas. Sin embargo, la selectividad al principal producto de oxidación depende de la composición y la temperatura de activación de los catalizadores, lo cual se podría explicar considerando las propiedades ácidas y/o redox de la superficie de los materiales. Así, aunque la fase M1 parece ser la fase activa en la oxidación parcial de alcanos, las propiedades superficiales de esta fase cristalina deben optimizarse con el fin de mejorar la eficacia catalítica de los catalizadores. 


\section{General Remarks}



In the present work, the preparation, characterization and catalytic behavior of materials based on Mo- and V-containing bronzes have been shown. These bronzes have been employed as catalysts in the partial oxidation of propane to acrylic acid. From the results obtained, the following conclusions can be drawn:

The catalytic behavior of the materials is mainly determined by the presence of a crystalline structure, a non-stoichiometric and partially substituted molybdenum oxide with orthorhombic structure, $\left(\mathrm{Te}_{2} \mathrm{M}_{20} \mathrm{O}_{57}\right.$ or $\left(\mathrm{Sb}_{2} \mathrm{O}\right) \mathrm{M}_{20} \mathrm{O}_{56}, M=\mathrm{Mo}, \mathrm{V}$ and/or $\mathrm{Nb})$ named the M1 phase. Nevertheless, the catalytic properties of such materials are strongly influenced by other factors such as the composition and the surface characteristics of the crystals, which are closely related to the synthesis parameters employed in their preparation.

In this way, the incorporation of a metal promoter (such as $\mathrm{Ag}, \mathrm{K}, \mathrm{Mg}, \mathrm{Ca}, \mathrm{Sr}$, $\mathrm{Fe}, \mathrm{Co}, \mathrm{Ni}, \mathrm{Cu}, \mathrm{Ga}, \mathrm{Bi}, \mathrm{La}$ or $\mathrm{Nb}$ ) into the catalytic system MoVTeO exerts an important influence on the properties of the final catalysts. In general, the incorporation of a metal promoter has a negative effect on the catalytic behavior for partial oxidation. However, the incorporation of $\mathrm{Ca}, \mathrm{Ga}$ or $\mathrm{Nb}$ improved the propane conversion and/or the selectivity to acrylic acid compared with non-promoted catalysts. Moreover, the catalytic behavior was shown to depend on the amount of metal incorporated.

The addition of a low amount of calcium into the synthesis gel $(\mathrm{Ca} / \mathrm{Mo}=0.02$ or 0.04$)$ improves the propane conversion and the selectivity to acrylic acid, although $\mathrm{Ca}^{2+}$ species do not seem to be present in the final M1 phase. On the other hand, a loss of activity and selectivity to acrylic acid is observed when the amount of calcium is increased $(\mathrm{Ca} / \mathrm{Mo}>0.06)$.

The addition of niobium into the synthesis gel favors the formation of an amorphous material, which is transformed into the M1 phase after the heattreatment at $600^{\circ} \mathrm{C}$ (in $\mathrm{N}_{2}$ ). The characterization results suggest a positive effect of the presence of $\mathrm{Nb}^{5+}$ species on the stability of the $\mathrm{M} 1$ phase. In addition, Nbcontaining catalysts show higher selectivity to acrylic acid. This effect initially increases with the $\mathrm{Nb} / \mathrm{Mo}$ atomic ratio in the synthesis gel, in which a maximum is observed at a $\mathrm{Nb} / \mathrm{Mo}$ ratio of 0.17 .

The addition of gallium into the synthesis gel favors the formation of the M1 phase. In this case, the incorporation of $\mathrm{Ga}^{3+}$ into the framework of the $\mathrm{M} 1$ phase has been confirmed by HREM, and results in changes of the surface M1 phase properties: higher stability during heat-treatment, low amount of acid sites and changes to the oxidation state of the element on its surface. In this way, Gapromoted MoVTe catalysts show high value of the selectivity to acrylic acid at low propane conversion, only observed with MoVTeNbO catalysts. However, selectivity to acrylic acid at high propane conversion decreases depending on the $\mathrm{Ga} / \mathrm{Mo}$ and 
$\mathrm{Ga} /(\mathrm{V}+\mathrm{Ga})$ atomic ratios. Thus, both the formation and the decomposition of acrylic acid are influenced by $\mathrm{Ga}^{3+}$ sites. The most effective catalyst (selectivity to acrylic acid of $55 \%$ at propane conversion of $40 \%$ has been achieved) that has been prepared with a Ga/ $(\mathrm{V}+\mathrm{Ga})$ ratio of 0.25 in the synthesis gel. These results suggest that the MoVTeGa catalyst could be an interesting catalytic system for the selective oxidation of propane to acrylic acid.

On the other hand, the influence of both the hydrothermal synthesis temperature and the catalysts activation temperature on catalytic behavior and physico-chemical characteristics of the catalysts have also been studied. In general, the hydrothermal synthesis temperature mainly affects the M1 phase formation, while the catalysts activation temperature has an influence in the catalysts surface properties and, thus, on their catalytic behavior. Both parameters depend also on the catalyst composition, mainly on the presence or absence of niobium in these materials.

In $\mathrm{Nb}$-free catalysts prepared by hydrothermal synthesis, the amount of the M1 phase increases when increasing the synthesis temperature. However, Nbcontaining samples prepared by hydrothermal synthesis, amorphous material are only observed, independent of the hydrothermal synthesis temperature.

In the hydrothermal synthesis of MoVSbO materials, M1 is mainly observed. In addition, the M2 phase is also formed, which is favored at low synthesis temperatures. After heat-treatment, an increased amount of the M2 phase and the formation of other phases $\left(\mathrm{as} \mathrm{Sb}_{2} \mathrm{Mo}_{10} \mathrm{O}_{31}\right)$ have been observed (which relation depends on the activation temperature) due to the presence of other minority crystalline phases and/or amorphous solid in the precursor. On the other hand, the catalytic activity decreases and the selectivity to acrylic acid increases when increasing the activation temperature. Although, the selectivity to acrylic acid obtained is lower than Te-containing catalysts.

In the hydrothermal synthesis of MoVTeO materials, the synthesis temperature has an influence not only on the M1 phase formation, but also on the stability of the M1 phase during heat-treatment at $600^{\circ} \mathrm{C}$. Thus, in the sample prepared at $175^{\circ} \mathrm{C}$, the $\mathrm{M} 1$ phase is mainly present not only in the precursor material but also in the samples heat-treated at 500 and $550^{\circ} \mathrm{C}$. Moreover, a partial decomposition of $\mathrm{M} 1$ phase into $\mathrm{M} 2, \mathrm{MoO}_{3}$ and $\mathrm{TeMo}_{5} \mathrm{O}_{16}$ is observed after the heat-treatment at $600^{\circ} \mathrm{C}$. Accordingly to the catalytic results, the M1 phase in MoVTe catalysts is very active but unselective for the partial oxidation of propane to acrylic acid. However, the decomposition of the M1 phase at $600^{\circ} \mathrm{C}$ favors a higher selectivity to acrylic acid, due to some contamination of the catalyst surface, which could provide some modification of the non-selective sites in these catalysts. 
An amorphous solid is obtained in the hydrothermal synthesis of $\mathrm{Nb}$ containing MoVTe catalysts, which is transformed mainly to the M1 phase during heat-treatment. The amorphous phase is conserved at low catalyst activation temperatures, while at high activation temperatures $\left(550-600^{\circ} \mathrm{C}\right)$ the $\mathrm{M} 1$ phase is observed. The amount of the M1 phase in Nb-containing catalysts is higher than in $\mathrm{Nb}$-free catalysts, suggesting that the presence of niobium favors a higher thermal stability of the M1 phase. Since both the catalytic activity and the selectivity to acrylic acid increase when increasing the catalyst activation temperature, it can be concluded that the $\mathrm{Nb}$-containing $\mathrm{M} 1$ phase, with $\mathrm{Nb}$ cations incorporated in the framework, could be proposed as active and selective for the partial oxidation of propane. As results, $\mathrm{Nb}$-containing catalysts prepared at $175^{\circ} \mathrm{C}$ and heat-treated at 550 or $600^{\circ} \mathrm{C}$ are the most effective for the selective oxidation of propane to acrylic acid. This effect could be a consequence of some contamination of the catalyst surface, which modifies the concentration and strength of acid sites, as deduced from the TPD- $\mathrm{NH}_{3}$ experiments.

According to the catalysts characterization results, it can be concluded that the catalytic behavior of these materials could be more easily explained by considering the characteristics of the surface of the catalysts, which change in a different manner depending on the catalyst composition and activation temperature:

The heat-treatment at $600^{\circ}$ (in nitrogen flow) seems to modify the surface properties favoring a higher selectivity to acrylic acid, especially due to: i) a decrease in the number and strength of acid sites (elimination of Lewis acid sites); ii) the modification of redox features of the active sites; and iii) the mobility of surface oxygen species.

In the case of the MoVTeNbO catalysts, and in addition to the positive effect of the presence of $\mathrm{Nb}^{5+}$ species on the stability of $\mathrm{M} 1$ phase, other changes are also observed: i) the presence of some elements in a lower oxidation state (especially the presence of $\mathrm{Te}^{4+}$ and the elimination of $\mathrm{Te}^{6+}$ ) and ii) a better homogeneous distribution of molybdenum cations. Both aspects can explain the high selectivity to acrylic acid of $\mathrm{Nb}$-containing $\mathrm{MoVTeO}$ catalysts heat-treated in the $550-600^{\circ} \mathrm{C}$ temperature range.

Finally, from the comparative study of partial oxidation reactions of propane, propylene and methanol over MoVSb, MoVTe and MoVTeNb heat-treated at 500 and $600^{\circ} \mathrm{C}$, it can be concluded that the $\mathrm{M} 1$ phase is active in all the reactions studied. Nevertheless, the selectivity to the main oxidation products depend on the catalyst composition and the activation temperature, i.e. the acid and redox properties of the catalyst surface. Thus, the M1 phase is the most active in the partial oxidation of the alkanes, although the surface properties of this crystalline 
phase must be optimized in order to enhance the catalytic effectiveness of the catalysts. 
Anexo I

\author{
Índice de Tablas, \\ Esquemas y Figuras
}



Tabla 1.1 Estado actual de posibles aplicaciones de oxidación selectiva de alcanos ligeros $\left(\mathrm{C}_{1}-\mathrm{C}_{5}\right)$ a procesos industriales.

Catalizadores más representativos de los tres sistemas catalíticos

Tabla 1.2. estudiados en para la oxidación selectiva de propano a ácido acrílico.

Tabla 4.1. Características generales de los catalizadores MoVTeX preparados con una relación $\mathrm{X} / \mathrm{Mo}=0.04$ y activados a $600^{\circ} \mathrm{C} / \mathrm{N}_{2}$.

Características de los catalizadores $\mathrm{Te}-\mathrm{X} x(\mathrm{X}=\mathrm{Ca}, \mathrm{Ga} \circ \mathrm{Nb})$

Tabla 4.2. preparados con diferente relación X/Mo y Te-X4Y4 (X e Y $=\mathrm{Ca}$, Ga 104 o $\mathrm{Nb}$ ) activados a $600^{\circ} \mathrm{C}$ en flujo de $\mathrm{N}_{2}$.

Tabla 4.3. Análisis EDX de los catalizadores MoVTe y MoVTeX (X = Ca, Ga o $\mathrm{Nb})$ preparados con una relación $\mathrm{X} / \mathrm{Mo}=0.04$ y activados a $600^{\circ} \mathrm{C}$.

Resultados TPD-NH $\mathrm{NH}_{3}$ de los catalizadores MoVTeX (X = Ca, Ga o

Tabla 4.4. $\quad \mathrm{Nb}$ ) preparados con diferente relación $\mathrm{X} / \mathrm{Mo}$ en el gel de síntesis y

catalizadores MoVTeXY (X e Y = Ca, Ga y/o Nb).

Tabla 4.5 .

Resultados XPS de los catalizadores MoVTeX (X = Ca, Ga o $\mathrm{Nb})$.

Tabla 4.6. Oxidación de propano con catalizadores Te-600, Te-Xx y Te-X4Y4 (X e $\mathrm{Y}=\mathrm{Ca}, \mathrm{Ga} \circ \mathrm{Nb}$ ).

Tabla 4.7. Oxidación de propano con catalizadores MoVTeO, MoVTeGaO y MoVGaO.

Tabla 4.8. Características de los catalizadores MoVTeGaO y MoVGaO.

Tabla 4.9. Resultados XPS de los catalizadores MoVTe, MoVTeGa y MoVGa.

Características de los precursores MoVSbO, MoVTeO y

Tabla 5.1. MoVTeNbO preparados por el método hidrotermal a diferente temperatura de síntesis.

Características de los catalizadores del tipo MoVSbO, MoVTeO y

Tabla 5.2. MoVTeNbO, preparados a diferentes temperaturas de síntesis (Tabla 5.1) y tratados térmicamente a $600^{\circ} \mathrm{C}$.

\begin{tabular}{ll}
\hline Tabla 5.3. & $\begin{array}{l}\text { Análisis EDX de los catalizadores MoVSbO, MoVTeO y } \\
\text { MoVTeNbO preparados en el intervalo de temperatura de síntesis } \\
150-200^{\circ} \mathrm{C} \text { y activados a } 600^{\circ} \mathrm{C} / \mathrm{N}_{2} .\end{array}$ \\
\hline Tabla 5.4. & $\begin{array}{l}\text { Resultados catalíticos en la oxidación parcial de propano sobre } \\
\text { catalizadores MoVX(Nb)O (X }=\text { Te o } \mathrm{Sb}) \text { a } 400^{\circ} \mathrm{C} .\end{array}$
\end{tabular}

MoVTeNbO preparados en el interva
$150-200^{\circ} \mathrm{C}$ y activados a $600^{\circ} \mathrm{C} / \mathrm{N}_{2}$.

catalizadores $\mathrm{MoVX}(\mathrm{Nb}) \mathrm{O}(\mathrm{X}=\mathrm{Te}$ o $\mathrm{Sb})$ a $400^{\circ} \mathrm{C}$. 
Tabla 5.5 .

Características de los materiales MoVSbO, MoVTeO y MoVTeNbO activados a diferente temperatura.

Tabla 5.6. Resultados XPS de los catalizadores MoVSbO.

Tabla 5.7. Resultados XPS de los catalizadores MoVTeO y MoVTeNbO.

Características y resultados catalíticos en la oxidación parcial de

Tabla 6.1. propano de los catalizadores $\operatorname{MoVX}(\mathrm{Nb}) \mathrm{O}(\mathrm{X}=\mathrm{Te} \quad \mathrm{O} \mathrm{Sb})$ estudiados.

Resultados catalíticos en la oxidación parcial de propano sobre
catalizadores MoVSbO y MoVTeNb a $400^{\circ} \mathrm{C}$ en las condiciones mostradas en la Figura 6.2.

Tabla 6.3 Resultados XPS de los catalizadores Sb-600 y TeNb-600 frescos y usados en la oxidación de propano en condiciones anaeróbicas.

Tabla 6.4. Resultados catalíticos en la oxidación parcial de propileno sobre catalizadores $\mathrm{MoVX}(\mathrm{Nb}) \mathrm{O}(\mathrm{X}=\mathrm{Te}$ o $\mathrm{Sb})$ a $400^{\circ} \mathrm{C}$.

Resultados catalíticos en la oxidación parcial de propileno sobre

Tabla 6.5. catalizadores MoVSbO y MoVTeNb a $400^{\circ} \mathrm{C}$ en las condiciones mostradas en la Figura 6.5.

Resultados XPS de los catalizadores Sb-600 y TeNb-600

Tabla 6.6. frescos y usados en la oxidación de propeno en condiciones anaeróbicas.

Resultados catalíticos en la transformación de metanol en

Tabla 6.7. presencia de oxígeno sobre catalizadores MoVX(Nb)O (X = Te o 206 $\mathrm{Sb)}$ a 230 y $265^{\circ} \mathrm{C}$.

Tabla 6.8. Modos de adsorción de la acroleína según Krauß et al [49].

219

\begin{tabular}{llc}
\hline \multicolumn{1}{c}{ Esquema } & \multicolumn{1}{c}{ Encabezado } & Pág \\
\hline Esquema 1.1 & Mecanismo Mars-Van Krevelen simplificado. & 18 \\
\hline & $\begin{array}{l}\text { Proceso de obtención del anhídrido maleico (AM) a partir de n- } \\
\text { butano en comparación con el antiguo proceso que empleaba } \\
\text { benceno como materia prima. Conversión (X) del alcano, } \\
\text { Esquema 1.2. }\end{array}$ & 30 \\
\hline Esquema 6.1. & $\begin{array}{l}\text { Mecanismo de reacción para la oxidación selectiva de propano } \\
\text { con óxidos mixtos MoVTe(Sb)NbO. }\end{array}$ & 193 \\
\hline Esquema 6.2 & $\begin{array}{l}\text { Transformación catalítica de metanol en presencia de oxígeno. } \\
\text { Esquema 6.3. }\end{array}$ & Modos de adsorción de la molécula de amoníaco. \\
\hline
\end{tabular}




\begin{tabular}{lll}
\hline Figura 1.1 & Empleo de propeno como materia prima. & 7 \\
\hline Figura 1.2. & $\begin{array}{l}\text { Esquema del proceso Sohio para la amoxidación de propileno a } \\
\text { acrilonitrilo }\end{array}$ & 13 \\
\hline Figura 1.3. & Demanda mundial de Ácido Acrílico. Datos 2007. & 15 \\
\hline Figura 1.4. & $\begin{array}{l}\text { Esquema de la oxidación de propano y entalpías estándar de } \\
\text { reacción (KJ/mol), adaptado de [20]. }\end{array}$ & 31 \\
\hline & $\begin{array}{l}\text { Diagrama de composición para el sistema } \mathrm{Mo} / \mathrm{V} / \mathrm{Nb}(+\mathrm{Te} \text { o Sb), } \\
\text { indicando la estequiometria de los compuestos que pueden formar }\end{array}$ & 40 \\
\hline Figura 1.5. & \\
\hline Figura 1.6. & $\begin{array}{l}\text { Estructuras propuestas para las fases } \mathrm{Te}_{2} \mathrm{M}_{20} \mathrm{O}_{57}(\mathrm{M} 1) \mathrm{y} \mathrm{Te}_{0.3} \mathrm{MO}_{3.33} \\
(\mathrm{M} 2) .\end{array}$ & 42
\end{tabular}

Esquema general de los centros activos y las etapas de reacción

Figura 1.7. propuesto para la oxidación de propano a ácido acrílico sobre catalizadores basados en óxidos mixtos de MoV-X con o $\sin \mathrm{Nb}(\mathrm{X}=$ Te ó Sb) [147].

Figura 1.8. Esquema de la distribución de los centros activos [148] 46

Figura 3.1. Sistema de reacción utilizado en el estudio catalítico.

Difractogramas del óxido mixto MoVTe sin promotor antes (a) y

Figura 4.1. después (b) del tratamiento térmico a $600^{\circ} \mathrm{C}$. Símbolos: (a) $\mathrm{Te}_{0.33} \mathrm{MO}_{3.33}$ (fase $\mathrm{M} 2$ ), (०) $\mathrm{Te}_{2} \mathrm{M}_{20} \mathrm{O}_{57}$ (fase M1), (•) $\mathrm{TeMo}_{5} \mathrm{O}_{16},(\triangle)$ $\mathrm{MoO}_{3}$-ortorrómbica, (口) $\mathrm{Mo}_{0.97} \mathrm{~V}_{0.95} \mathrm{O}_{5}$.

Difractogramas de los materiales Te-X después (B) del tratamiento

Figura 4.2. térmico a $600^{\circ} \mathrm{C}$. Símbolos: (-) $\mathrm{Te}_{0.33} \mathrm{MO}_{3.33}$ (fase $\mathrm{M} 2$ ), (०)

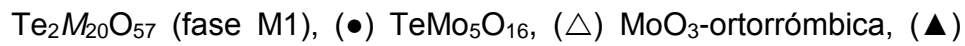
$\mathrm{VOMoO}_{4}$, (口) $\mathrm{Mo}_{0.97} \mathrm{~V}_{0.95} \mathrm{O}_{5}$.

Conversión de propano obtenida durante la oxidación de propano a

$380^{\circ} \mathrm{C}$, tiempo de contacto, $\mathrm{W} / \mathrm{F}=200 \mathrm{~g}_{\mathrm{cat}} \mathrm{h} \mathrm{mol}^{-1} \mathrm{C} 3 \mathrm{H} 8$, y selectividad
Figura 4.3. ádo acrílico (a una isoconversión de propano del 20\%) con catalizadores Te-X4.

Difractogramas de los catalizadores MoVTe-X (X = $\mathrm{Ca} \circ \mathrm{Ga})$ preparados con diferente relación $X /$ Mo y activados a $600^{\circ} \mathrm{C} / \mathrm{N}_{2}$ : a)

Figura 4.4. Te-Ca2; b) Te-Ca4; c) Te-Ca6; d) Te-Ga4; e) Te-Ga8; f) Te-Ga12.

Símbolos: (ロ) $\mathrm{Te}_{0.33} \mathrm{MO}_{3.33}$ (fase $\mathrm{M} 2$ ), (०) $\mathrm{Te}_{2} \mathrm{M}_{20} \mathrm{O}_{57}$ (fase M1), (•) $\mathrm{TeMo}_{5} \mathrm{O}_{16},(\triangle) \mathrm{MoO}_{3}$-ortorrómbica, ( $\left.\square\right) \mathrm{Mo}_{0.97} \mathrm{~V}_{0.95} \mathrm{O}_{5}$. 
Difractogramas de los catalizadores MoVTe-Nb preparados con diferente relación $\mathrm{Nb} / \mathrm{Mo}$ y $\mathrm{MoVTe}-\mathrm{XY}$ ( $\mathrm{X}$ e $\mathrm{Y}=\mathrm{Ca}, \mathrm{Ga} \circ \mathrm{Nb}$ ) activados a $600^{\circ} \mathrm{C}$ bajo $\mathrm{N}_{2}$ : a) Te-Nb4; b) Te-Nb8; c) Te-Nb12; d)

Figura 4.5. Te-Nb17; e) Te-Nb21; f) Te-Ca4Ga4; g) Te-Nb4Ca4 y h) Te-

Nb4Ga4. Símbolos: (ロ) $\mathrm{Te}_{0.33} \mathrm{MO}_{3.33}$ (fase M2), (०) $\mathrm{Te}_{2} \mathrm{M}_{20} \mathrm{O}_{57}$ (fase $\mathrm{M} 1),(\bullet) \mathrm{TeMo}_{5} \mathrm{O}_{16},(\triangle) \mathrm{MoO}_{3}$-ortorrómbica, (ム) $\mathrm{VOMoO}_{4}$, (口) $\mathrm{Mo}_{0.97} \mathrm{~V}_{0.95} \mathrm{O}_{5}$.

Imágenes SEM de los catalizadores MoVTeX activados: a) Te-600;

Figura 4.6. b) Te-Ca4; c) Te-Ga4; d) Te-Nb4. Los números corresponden a las partículas analizadas por EDX (ver Tabla 4.3).

Figura 4.7.

Espectros FT-IR (A) y Raman (B) de los óxidos mixtos MoVTe-X: a) $\mathrm{Te}-600$; b) Te-Ca4; c) Te-Ga4; d) Te-Nb4.

Espectro TPD-NH $\mathrm{NH}_{3}$ de las muestras Te-Cax, $x=2$, 4 ó 6, (arriba

Figura 4.8. izda.); Te-Gax, $x=4$, 8 ó 12, (arriba dcha.); Te-Nbx, $x=4,8,12,17$

ó 21, (abajo izda.); y Te-X4Y4, X e Y = Ca, Ga o Nb, (abajo dcha.).

Variación de la selectividad a acido acrílico con la conversión de

Figura 4.9. propano durante la oxidación de propano con catalizadores MoVTe$\mathrm{X}(\mathrm{X}=\mathrm{Ca}, \mathrm{Ga} \circ \mathrm{Nb})$ con distinta relación $\mathrm{X} / \mathrm{Mo}$; y catalizadores MoVTe-XY (X e Y = Ca, Ga o Nb).

Figura 4.10 . Micrografías HREM de un cristal de la fase $\mathrm{Te}_{2} \mathrm{M}_{20} \mathrm{O}_{57}$ tomadas a lo largo de los ejes de zona (a) [010] y (b) [011].

Variación de la conversión de propano ( $\square$ ) y la selectividad a ácido acrílico $(\bullet)$ obtenida durante la oxidación de propano con

Figura 4.11. catalizadores MoVTeGaO con diferente relación Ga/Mo. Conversión de propano a $380^{\circ} \mathrm{C}$ y tiempo de contacto $400 \mathrm{~g}_{\text {cat }} \mathrm{h} \mathrm{mol}_{\mathrm{C} 3 \mathrm{H} 8}{ }^{-1}$; selectividad a ácido acrílico para conversión de propano de $20 \%$.

Variación de la selectividad a acido acrílico con la conversión de

Figura 4.12. propano durante la oxidación de propano con catalizadores MoVTeGaO: Te-600 (...); Te-Ga8 (®); Te-Ga25 (•); Ga-500 (_).

(A) Difractogramas DRX y (B) espectros Raman de los materiales MoVTeGaO: a) Te-Ga25; b) Te-Ga50; c) Ga-500. Símbolos: (a)

Figura 4.13. $\mathrm{Te}_{0.33} \mathrm{MO}_{3.33}$ (fase M2), (०) $\mathrm{Te}_{2} \mathrm{M}_{20} \mathrm{O}_{57}$ (fase M1), (•) $\mathrm{TeMo}_{5} \mathrm{O}_{16},(\triangle)$ $\mathrm{MoO}_{3}$-ortorrómbica, ( $\boldsymbol{\Delta}$ ) $\mathrm{VOMoO}_{4},(\square) \mathrm{M}_{5} \mathrm{O}_{14}(\mathrm{M}=\mathrm{Mo}, \mathrm{V}) . \mathrm{b} 1, \mathrm{~b} 2$ y b3 indican espectros Raman de diferentes partículas en la misma muestra.

Difractogramas de rayos $X$ de los precursores MoVSbO (A), MoVTeO (B) y MoVTeNbO (C) preparados por el método

Figura 5.1. hidrotermal a diferente temperatura de síntesis (100-200 $\mathrm{C}$ ).

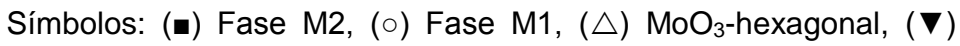
$\mathrm{TeO}_{2} ;(\diamond) \mathrm{Nb}_{2} \mathrm{O}_{5} ;(\bullet) \mathrm{Te}$. 
Composición de fases cristalinas de los precursores MoVSbO y

Figura 5.2. MoVTeO, antes de la activación, preparados a diferente temperatura de síntesis.

Micrografías SEM de los precursores sin activar MoVSbO (serie

Figura 5.3. Sb), MoVTe (serie Te), y MoVTeNbO (serie TeNb) preparados a diferente tempertura de síntesis hidrotermal (en $\left.{ }^{\circ} \mathrm{C}\right)$.

Difractogramas de rayos $X$ de los catalizadores MoVSbO $(A)$, MoVTeO (B) y MoVTeNbO (C) preparados por el método

Figura 5.4. hidrotermal a diferente temperatura de síntesis $\left(100-200^{\circ} \mathrm{C}\right)$ y activados térmicamente a $600^{\circ} \mathrm{C} / \mathrm{N}_{2}$. Símbolos: (a) Fase M2, (o)

Fase $\mathrm{M} 1,(\uparrow) \mathrm{Sb}_{2} \mathrm{Mo}_{10} \mathrm{O}_{31},(\bullet) \mathrm{TeMo}_{5} \mathrm{O}_{16},(\mathbf{\Delta}) \mathrm{MoO}_{3}$-ortorrómbica, () $\mathrm{Mo}_{0.97} \mathrm{~V}_{0.95} \mathrm{O}_{5},(x)\left(\mathrm{V}_{0.07} \mathrm{Mo}_{0.93}\right)_{5} \mathrm{O}_{14}$.

Composición de fases cristalinas de los catalizadores MoVSbO,

Figura 5.5. MoVTeO y MoVTeNbO activados a $600^{\circ} \mathrm{C}$ preparados a diferente temperatura de síntesis.

Micrografías SEM de los catalizadores MoVSbO, MoVTeO y

Figura 5.6. MoVTeNbO preparados en intervalo de temperaturas de síntesis $150-200^{\circ} \mathrm{C}$ y activado a $600^{\circ} \mathrm{C} / \mathrm{N}_{2}$.

Espectros TPD-NH 3 de los sistemas (A) MoVSb; (B) MoVTe y (C)

Figura 5.7. MoVTeNb preparados a diferente temperatura de síntesis y activados a $600^{\circ} \mathrm{C} / \mathrm{N}_{2}$.

Variación de la conversión de propano (A) y de la selectividad a ácido acrílico (B) (a una isoconversión de 20\%) con la temperatura

Figura 5.8. empleada en la síntesis hidrotermal de los catalizadores. Condiciones de reacción: tiempo de contacto, W/F, de $200 \mathrm{~g}_{\text {cat }} \mathrm{h}$ $\left(\text { mol }_{\mathrm{C} 3 \mathrm{H} 8}\right)^{-1} ; \mathrm{T}=380^{\circ} \mathrm{C}$; relación molar $\mathrm{C}_{3} \mathrm{H}_{8} / \mathrm{O}_{2} / \mathrm{H}_{2} \mathrm{O} / \mathrm{He}$ de $4 / 8 / 30 / 58$.

Selectividad a ácido acrílico (para una conversión de propano del

Figura 5.9. $30 \%$ ) en la oxidación de propano para catalizadores MoVSb, MoVTe y MoVTeNb obtenidos a diferentes temperaturas de activación.

Difractogramas de rayos $X$ de los catalizadores $\operatorname{MoVSbO}(A)$, MoVTe (B) y MoVTeNb (C) antes y después de la activación en el

Figura 5.10. intervalo de temperatura 500-650ㄷ. Símbolos: (ロ) Fase M2, (०)

Fase $\mathrm{M} 1,\left(\bullet \mathrm{Sb}_{2} \mathrm{Mo}_{10} \mathrm{O}_{31},(\bullet) \mathrm{TeMo}_{5} \mathrm{O}_{16},(\triangle) \mathrm{MoO}_{3}\right.$-ortorrómbica,

$(\Delta) \mathrm{VOMoO}_{4}$

Figura 5.11

Micrografías SEM de las muestras MoVSbO, MoVTeO y

MoVTeNbO antes de la ctivación y activadas a 500 y $600^{\circ} \mathrm{C}$. 
Espectros FTIR de los catalizadores MoVSbO, MoVTeO y Figura 5.12. MoVTeNbO: a) Sb-as; b) Sb-T500; c) Sb-T550; d) Sb-T600; e) Teas; f) Te-T500; g) Te-T550; h) Te-T600; i) TeNb-as; j) TeNb-T500; k) TeNb-T550; I) TeNb-T600.

Espectros Raman de los catalizadores MoVSbO, MoVTeO y Figura 5.13. MoVTeNbO: a) Sb-as; b) Sb-T500; c) Sb-T500; d) Sb-T600; e) Teas; f) Te-T500; g) Te-T550; h) Te-T600; i) TeNb-as; j) TeNb-T500; k) TeNb-T550; I) TeNb-T600.

$\begin{array}{ll}\text { Figura 5.14. } & \text { Espectros } \mathrm{TPD}^{-\mathrm{NH}_{3}} \text { de los sistemas (A) MoVSb; }(\mathrm{B}) \\ \text { MoVTeNb activados a } 500 \text { y } 600^{\circ} \mathrm{C} \text { bajo flujo de } \mathrm{N}_{2} \text {. }\end{array}$

Espectros XPS de los niveles: (a) $\vee 2 p_{3 / 2}$, y (b) $S b 3 d_{3 / 2}$ de los Figura 5.15. catalizadores MoVSbO activados a 500 (Sb-T500) y $600^{\circ} \mathrm{C}(\mathrm{Sb}-$ T600). (Línea sólida) Datos observados; (Línea punteada) Picos deconvolucionados. CPS: cuentas por segundo.

Espectros XPS de los niveles: (a) Mo $3 d_{5 / 2}$ y $3 d_{3 / 2}$, (b) Te $3 d_{5 / 2}$, y (c) Figura 5.16. $\mathrm{O}_{1 \mathrm{~s}}$ de los catalizadores MoVTeO (Te-T500) y MoVTeNbO (TeNbT600). (Línea sólida) Datos observados; (Línea punteada) Picos deconvolucionados. CPS: cuentas por segundo.

Variación del rendimiento a ácido acrílico con la descomposición de la fase M1 durante el tratamiento térmico observada en Figura 5.17. catalizadores MoVTeO preparados con diferente temperatura de síntesis.

(a) Actividad catalítica $\left(10^{-3} \mathrm{~mol}_{\mathrm{C} 3 \mathrm{H} 8} \mathrm{~h}^{-1} \mathrm{~g}^{-1}\right)$ y (b) Actividad catalítica específica (en $10^{-4} \mathrm{~mol}_{\mathrm{C} 3 \mathrm{H} 8} \mathrm{~h}^{-1} \mathrm{~m}^{-2}$ ) de los catalizadores MoVSbO $(\triangle)$, MoVTeO (口) y MoVTeNbO $(\bullet)$ tratados térmicamente a 500,

Figura 5.18. 550 y $600^{\circ} \mathrm{C}\left(2 \mathrm{~h}\right.$ en flujo de $\left.\mathrm{N}_{2}\right)$. Condiciones de reacción: temperatura de reacción: $380^{\circ} \mathrm{C}$; tiempo de contacto, W/F, de 200 $\mathrm{g}_{\text {cat }} \mathrm{h}\left(\mathrm{mol}_{\mathrm{C} 3 \mathrm{H}}\right)^{-1}$ y relación molar propano/oxígeno/agua/helio de 4/8/30/58 (Flujo total de $50 \mathrm{ml} \mathrm{min}^{-1}$ ).

A) Variación de la conversión de propano con la temperatura de reacción (a un tiempo de contacto, W/F, de $200 \mathrm{~g}_{\text {cat }} \mathrm{h}$ mol $_{\mathrm{C} 3 \mathrm{H} 8}{ }^{-1}$ ); y

Figura 6.1 B) Variación de la selectividad a ácido acrílico con la conversión de propano durante la oxidación de propano con catalizadores Mo-V-X-

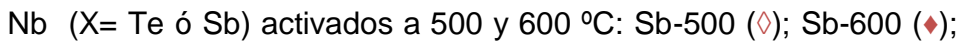
Te-500 ( $\square$ ); Te-600 (๕); TeNb-500 (०); y TeNb-600 (•).

Perfiles de los principales productos de oxidación observados durante la oxidación de propano con catalizadores: A) Sb-600; y B)

Figura 6.2. TeNb-600. Los números indican los análisis mostrados en la Tabla 6.2. Condiciones de reacción: $400^{\circ} \mathrm{C}$; tiempo de contacto, $\mathrm{W} / \mathrm{F}=$ $200 \mathrm{~g}_{\text {cat }}$ h $\mathrm{mol}_{\mathrm{C} 3 \mathrm{H} 8}{ }^{-1}$; flujo total $50 \mathrm{~mL} / \mathrm{min}$. 
Difractogramas de los catalizadores Sb-600 (a, b) y TeNb-600 (c, d)

Figura 6.3. frescos $(a, c)$ y usados en la oxidación de propano en condiciones anaeróbicas (b, d). a) Sb-600; b) Sb-600-U; c) TeNb-600; d) TeNb$600-U$.

A) Variación de la conversión de propano con la temperatura de reacción (a un tiempo de contacto, W/F, de $75 \mathrm{~g}_{\text {cat }} \mathrm{h}$ mol $_{\mathrm{C} 3 \mathrm{H} 6}{ }^{-1}$ ); y B)

Figura 6.4. Variación de la selectividad a ácido acrílico con la conversión de propeno durante la oxidación de propileno con catalizadores Mo-V$\mathrm{X}-\mathrm{Nb} \quad\left(\mathrm{X}=\mathrm{Te}\right.$ ó $\mathrm{Sb}$ ) activados a 500 y $600{ }^{\circ} \mathrm{C}: \mathrm{Sb}-500(\diamond)$; Sb-600

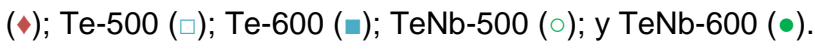

Perfiles de los principales productos de oxidación observados durante la oxidación de propeno con catalizadores: A) Sb-600; y B)

Figura 6.5. TeNb-600. Los números indican los análisis mostrados en la Tabla 6.5. Condiciones de reacción: $400^{\circ} \mathrm{C}$; tiempo de contacto, $\mathrm{W} / \mathrm{F}=75$ $\mathrm{g}_{\text {cat }} \mathrm{h} \mathrm{mol}_{\mathrm{C} 3 \mathrm{H} 6}{ }^{-1}$; flujo total $50 \mathrm{~mL} / \mathrm{min}$.

Difractogramas de los catalizadores Sb-600 (a, b) y TeNb-600 (c, d)

Figura 6.6. frescos $(\mathrm{a}, \mathrm{c})$ y usados en la oxidación de propileno en condiciones anaeróbicas (b, d). a) Sb-600; b) Sb-600-U (1.5h sin oxígeno); c) TeNb-600; d) TeNb-600-U.

Variación de la conversión de metanol con la temperatura de reacción (a un tiempo de contacto, W/F, de $\left.7 \mathrm{~g}_{\text {cat }} \mathrm{h} \mathrm{mol}_{\mathrm{CH} 3 \mathrm{OH}^{-1}}\right)(\mathrm{A}$ y B); Variación de la selectividad a formaldehído con la conversión de

Figura 6.7. metanol $(C$ y $D)$ durante la oxidación de metanol con catalizadores Mo-V-X-Nb (X= Te ó Sb) activados a 500 (A y C) o $600 \stackrel{\circ}{\circ}$ (B y D):

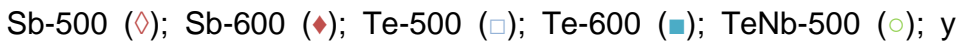
TeNb-600 (•).

Variación de la selectividad a los productos principales de reacción con la conversión de metanol durante la oxidación de metanol con

Figura 6.8. catalizadores Mo-V-X-Nb (X= Te ó Sb) activados a 500 y $600^{\circ} \mathrm{C}$. Selectividad a formaldehído (naranja), productos de deshidrogenación: DME, FM, DMM (morado) y $\mathrm{CO}_{x}$ (negro con línea discontinua).

Conversión (izda.) y máxima selectividad al producto principal de oxidación parcial (dcha.) obtenidos durante la oxidación de propano,

Figura 6.9. propileno a ácido acrílico (AA) o metanol a formaldehido (FA) con catalizadores MoVTe(Sb)Nb activados a $500^{\circ} \mathrm{C}$ y $600^{\circ} \mathrm{C}$. Condiciones de reacción en las Tablas 6.1, 6.4 y 6.7 .

Intercambio isotópico de oxígeno a temperatura programada en

Figura 6.10. catalizadores MoVTe(Nb)O: a) Te-500; b) Te-600; c) TeNb-500; y d) TeNb-600. 
Espectro FTIR de la adsorción de metanol a 25ㅇ sobre

Figura 6.11. catalizadores $\operatorname{MoVX}(\mathrm{Nb}) \mathrm{O}(\mathrm{X}=\mathrm{Te}$ o $\mathrm{Sb}$ ): a) Sb-500; b) Sb-600; c) 215 Te-500; d) Te-600; e) TeNb-500; y f) TeNb-600.

Espectros DRIFTS de la adsorción de $\mathrm{NH}_{3}$ sobre catalizadores: a)

Figura 6.12. MoVSbO activados a 500 (Sb-500) y 600ㄷ (Sb-600); b) MoVTeO activados a 500 (Te-500) y 600 (Te-600); y c) MoVTeNbO activados a $500(\mathrm{TeNb}-500)$ y $600^{\circ} \mathrm{C}(\mathrm{TeNb}-600)$.

Espectros DRIFTS de la adsorción de acroleína sobre catalizadores

Figura 6.13. a) MoVTeNb activados a 500 (TeNb-500) y 600ㄷ (TeNb-600); y b) 220 MoVTe activados a 500 (Te-500) y 600ㄷ (Te-600).

Figura 6.14. Estructura de la fase M1 en el plano ab y a lo largo del eje $c$. 


\section{Anexo II}

\section{Curriculum obtenido durante el período de tesis doctoral}





\section{Proyectos de I+D financiados en convocatorias públicas}

Título del proyecto: Desarrollo de catalizadores basados en oxidos metalicos no estequiométricos de Mo y W con propiedades acidas y/o redox pra procesos de química sostenible (CTQ2009-14495)

Entidad financiadora: MINISTERIO DE CIENCIA E INNOVACION

Duración, desde 01/01/2010 hasta 31/12/2012

\section{Publicaciones, documentos científico y técnicos}

1.- F. Ivars; B. Solsona; S. Hernández; J.M. López Nieto. Influence of gel composition in the synthesis of MoVTeNb catalysts over their catalytic performance in partial propane and propylene oxidation. Catalysis Today 149, (2010) 260 - 266.

2.- P. Concepción; S. Hernández; J. M. López Nieto. On the nature of active sites in MoVTeO and MoVTeNbO catalysts: The influence of catalyst activation temperature. Applied Catalysis A: General 391, (2011) 92 - 101.

3.- I. Ramlia; P. Botella; F. Ivars; W. P. Menga; S. M. M. Zawawia; H. A. Ahangara; S. Hernández; J. M. López Nieto. Reflux method as a novel route for the synthesis of MoVTeNbOx catalysts for selective oxidation of propane to acrylic acid. Journal of Molecular Catalysis A: Chemical 342-343, (2011) 50 - 57.

4.- B. Solsona; P. Concepción; S. Hernández; B. Demicol; J. M. López Nieto. Oxidative dehydrogenation of ethane over $\mathrm{NiO}-\mathrm{CeO}_{2}$ mixed oxides catalysts. Catalysis Today 180, (2012) 51 - 58.

5.- M.O. Guerrero-Pérez; M.J. Valero-Romero; S. Hernández; J.M. López Nieto; J. Rodríguez-Mirasol; T. Cordero. Lignocellulosic-derived mesoporous materials: an answer to manufacturing non-expensive catalysts useful for the bio. Catalysis Today, (2012). In press, http://dx.doi.org/10.1016/j.cattod.2012.03.068.

\section{Contribuciones a Congresos Nacionales e Internacionales}

1.- Autores: F. Ivars; B. Solsona; S. Hernández; J.M. López Nieto. Título: Influencia de la sustitución parcial de $\mathrm{V}$ por $\mathrm{Nb}$ en catalizadores MoVNbTeO sobre el comportamiento catalítico en la oxidación selectiva de propano a ácido acrílico. Tipo de participación: Comunicación oral. Nombre del congreso: SICAT08. Ciudad de realización: Benalmádena, España. Fecha de realización: 06/2008.

2.- Autores: S. Hernández; H. Martínez; F. Ivars; J.M. López Nieto. Título: Influencia del precursor de antimonio en la síntesis hidrotermal de catalizadores Mo-V-Sb. Tipo de participación: Comunicación oral. Nombre del congreso: 
SECAT09. Ciudad de realización: Ciudad Real, España. Fecha de realización: 06/2009.

3.- Autores: S. Hernández; F. Ivars; P. Concepción; J.M. López Nieto. Título: The influence of the nature of promotors on catalytic behavior in selective propane oxidation over MoVTe-X-O mixed oxides. Tipo de participación: Póster. Nombre del congreso: EuropaCatIX. Ciudad de realización: Salamanca, España. Fecha de realización: 09/2009.

4.- Autores: S. Hernández; F. Ivars; J.M. López Nieto. Título: On the effective preparation of MoV-X-O mixed oxides catalysts $(\mathrm{X}=\mathrm{Te}$ or $\mathrm{Sb})$ and their catalytic behavior in selective propane oxidation. Tipo de participación: Póster. Nombre del congreso: 6th World Congress on Oxidation Catalysis. Ciudad de realización: Liylle, Francia. Fecha de realización: 09/2009.

5.- Autores: S. Hernández; F. Ivars; J.M. López Nieto. Título: Influencia del precursor de antimonio en la síntesis hidrotermal de catalizadores Mo-V-Sb. Tipo de participación: Comunicación oral. Nombre del congreso: XXII CICAT. Ciudad de realización: Cón-cón, Chile. Fecha de realización: 09/2010.

6.- Autores: S. Hernández; F. Ivars; J.M. López Nieto. Título: The effect of hydrothermal synthesis temperature of $\operatorname{MoVTe}(\mathrm{Nb})$ mixed oxides on their catalytic behavior in partial propane oxidation. Tipo de participación: Póster. Nombre del congreso: VII International Symposium on Group Five Elements. Ciudad de realización: Rimini, Italia. Fecha de realización: 05/2011.

7.- Autores: M.J. Valero-Romero; S. Hernández; J.M. López Nieto; M.O. GuerreroPérez; J. Rodríguez-Mirasol; T. Cordero. Título: New Zr-V-O carbon-supported catalysts for oxidation reactions: surface active sites and thermal stability. Tipo de participación: Póster. Nombre del congreso: International Conference on Functional Materials: Catalysis, Electrochemistry and Surfactants COST Action D36 Final Workshop. Ciudad de realización: Fuengirola, España. Fecha de realización: 05/2011

8.- Autores: S. Hernández; P. Concepción; F. Ivars; J.M. López Nieto. Título: EI efecto de la temperatura en la síntesis hidrotermal de óxidos mixtos MoVTe(Nb)O. Tipo de participación: Póster. Nombre del congreso: Secat 2011. Ciudad de realización: Zaragoza, España. Fecha de realización: 07/2011

9.- Autores: S. Hernández; F. Ivars; J.M. López Nieto. Título: Influence of Sb source on synthesis of MoVSbO catalysts for propane selective oxidation. Tipo de participación: Póster. Nombre del congreso: EuropaCat X. Ciudad de realización: Glasgow, Reino Unido. Fecha de realización: 09/2011. 
10.- Autores: M. Vassileva; M. Popova; T. Tsoncheva; T. Blasco; M. Dimitrov; S. Hernández; J.M. López Nieto. Título: SBA-15 supported nanosized cerium and copper oxides as catalysts for VOCs elimination. Tipo de participación: Póster. Nombre del congreso: Materials, Methods and Technologies 14th International Symposium. Ciudad de realización: Sunny Beach, Bulgaria. Fecha de realización: 06/2012.

11.- Autores: T. Blasco; M. Popova; M. Dimitrov; S. Hernández; M. Vassileva; T. Tsoncheva; J.M. López Nieto. Título: SBA-15 supported nanosized manganese, cerium and copper oxides as catalysts for VOCs elimination. Tipo de participación: Póster. Nombre del congreso: 15th International Congress on Catalysis 2012. Ciudad de realización: Munich, Alemania. Fecha de realización: 07/2012.

12.- Autores: S. Benomar; R. Issaadi; S. Hernández; T. Blasco; J.M. López Nieto. Título: Catalytic performances of metal anions $\mathrm{MOx}(\mathrm{M}=\mathrm{W}, \mathrm{Cr}, \mathrm{V}, \mathrm{S}, \mathrm{Mo})$ supported on Al2O3-ZrO2 mixed oxides in oxidative dehydrogenation of short chain alkanes. Tipo de participación: Póster. Nombre del congreso: ISCSC2012, International Symposium on Catalysis and Specialty Chemicals. Ciudad de realización: Tlemcen, Argelia. Fecha de realización: 09/2012. 